\title{
COUPLED MECHANICAL AND HYDRAULIC MODELING OF GEOSYNTHETIC-REINFORCED COLUMN- SUPPORTED EMBANKMENTS
}

\author{
By \\ Jie Huang \\ B.S., Wuhan University, Wuhan, China, 2000 \\ M.S., Wuhan University, Wuhan, China, 2003 \\ Submitted to the Department of Civil, Environmental, and Architectural Engineering \\ and the Faculty of the Graduate School of the University of Kansas \\ In partial fulfillment of the requirements for the degree of \\ Doctor of Philosophy \\ $\overline{\text { Dr. Jie Han, Chairperson }}$ \\ Committee members $\quad$ Dr. Caroline R. Bennett \\ Dr. Weizhang Huang \\ Dr. Robert L. Parsons \\ Dr. Francis M. Thomas
}

Date defended: 


\title{
The Dissertation Committee for Jie Huang certifies
}

\section{that this is the approved version of the following dissertation:}

\author{
COUPLED MECHANICAL AND HYDRAULIC MODELING OF \\ GEOSYNTHETIC-REINFORCED COLUMN-SUPPORTED EMBANKMENTS
}

Committee

$\overline{\text { Dr. Jie Han, Chairperson }}$

$\overline{\text { Dr. Caroline R. Bennett }}$

Dr. Weizhang Huang

Dr. Robert L. Parsons

Dr. Francis M. Thomas

Date approved: 


\begin{abstract}
Geosynthetic-reinforced column-supported (GRCS) embankments have been increasingly used worldwide in the past few years. Even though a number of research investigations have been completed on this topic, the behavior of GRCS embankments is not well understood. To improve the understanding of this technology, coupled mechanical and hydraulic numerical analyses were conducted in this study under both two-dimensional (2D) and three-dimensional (3D) conditions to investigate influence of various factors on the performance of GRCS embankments. The selected parameters and their ranges in this study were based on deep-mixed (DM) columns; however, a similar study can be conducted for other types of columns.
\end{abstract}

2D and 3D models were developed based on elasto-plastic constitutive relationships with Mohr-Coulomb failure criteria for DM walls or columns, soft soil, firm soil, and embankment fill. Cable and geogrid elements were selected to simulate geosynthetic reinforcement in 2D and 3D models, respectively. Staged construction was modeled by building the embankment in lifts. The ground water table was assumed at the ground surface. The mechanical model was coupled with the hydraulic model to simulate the generation and dissipation of excess pore water pressure during and after the construction. 
The $2 \mathrm{D}$ and $3 \mathrm{D}$ models were calibrated using a well documented case history with long-term field measurement data and fairly detailed material information to ensure their reasonableness and adequacy. Upon completion of the model calibrations, a 2D baseline case based on a typical configuration of GRCS embankment was analyzed. A 2D parametric study was conducted by changing the parameters individually from the baseline case to investigate the influence of that factor on the performance of the embankment including post-construction settlement, post-construction differential settlement, distortion, tension in geosynthetic, effective stress, stress concentration ratio, excess pore water pressure, and degree of consolidation. The investigated factors include soft soil modulus, soft soil friction angle, soft soil permeability, DM column modulus, DM column spacing, geosynthetic tensile stiffness, and average construction rate.

After the 2D study was completed, the 2D baseline case was converted into a $3 \mathrm{D}$ baseline case based on an area-weighted average approach assuming a square pattern of DM columns. The 3D parametric study was preformed by changing parameters individually from the 3D baseline case to investigate the influence of that specific factor on the performance of the embankment. The factors investigated are the same as those in the 2D parametric study. 
On the basis of the numerical results from the $2 \mathrm{D}$ and $3 \mathrm{D}$ studies, the influence of factors on the performance of the embankment system was rated to provide guidance for practical use. 


\section{ACKNOWLEDGEMENTS}

I would like to express my sincere gratitude and appreciation to Dr. Jie Han, my advisor and committee chair, for his guidance, encourage, inspiration, and support during the course of my doctoral study. It has been an unforgettable experience to work under his supervision.

My thanks also go to my committee members, Profs. Caroline R. Bennett, Weizhang Huang, Robert L. Parsons, and Francis M. Thomas, for their valuable input and suggestions.

I would like to thank my wife, Juan Mao, for her sacrifice and support. Juan took care of me and encouraged me in the vital periods of my doctoral study. In addition, she has brought great joy to my life.

Special thank is given to Dr. Sadik Oztoprak at Istanbul University, Turkey for sharing his research experience on embankments over soft soil and giving insightful suggestions during his visit at the University of Kansas.

Finally, I would like to thank my fellow classmates: Sheryl Gallagher, Rebecca Johnson, Elizabeth Kneebone, Matthew Pierson, Harihar Shiwakoti, Xiaoming Yang, 
and Yuze Zhang, for their help. It has been a great pleasure to discuss and even argue with them. 


\section{TABLE OF CONTENTS}

ABSTRACT

ACKNOWLEDGEMENT $\quad$ v

TABLE OF CONTENTS vii

LIST FIGURES - xii

LIST OF TABLES Xxiv

CHAPTER ONE INTRODUCTION 1

1.1 Background 1

1.2 Column Supported (CS) and Geosynthetic-Reinforced Column-Supported (GRCS)

Embankments 3

1.2.1 History of CS and GRCS Embankments 5

1.2.2 Brief Characterization and Comparison of CS and GRCS Embankments 7

1.3 Purpose and Scope of This Study 11

1.4 Organization of This Dissertation 12

CHAPTER TWO LITERATURE REVIEW 15

2.1 Introduction 15 
4.1.1 2D Dimensions and Properties

4.1.2 2D Modeling Procedure

4.1.3 Results of 2D Baseline Case

92

4.2 2D Parametric Study

4.2.1 Outline of 2D Parametric Study

4.2.2 Settlement

4.2.3 Tension Developed in Geosynthetics

150

4.2.4 Vertical Stress and Stress Concentration Ratio

166

4.2.5 Excess Pore Water Pressure

5.1.1 3D Dimensions and Properties 


\section{CHAPTER SIX COMPARISON OF TWO-DIMENSIONAL AND THREE DIMENSIONAL STUDIES}

6.1 Verification of Simplified Model

6.2 2D and 3D Comparisons

6.2.1 Maximum Settlement and Distortion 
7.3 Future Work

REFERENCES 


\section{LIST OF FIGURES}

Fig. 1-1. Cross-sections of CS and GRCS Embankments 6

Fig. 1-2. Geosynthetic Preventing Slope Lateral Spreading 10

Fig. 2-1. Soil Arching and Tensioned Membrane Effects in GRCS Embankments 17

Fig. 2-2. Terzaghi's Soil Arching Model 21

Fig. 2-3. Soil Arching above Continuous Supports 24

Fig. 2-4. Soil Arches above Column Grid of Square Pattern 26

Fig. 2-5. Finn's Pure Translation and Pure Rotation Models 29

Fig. 2-6. Delmas' and Giroud's Membrane Models 33

Fig. 2-7. Load Carrying Area of Geosynthetics 36

Fig. 2-8. Soil Arching Ratio 45

Fig. 2-9. Tension in Geosynthetic Reinforcement 46

Fig. 3-1. Profile of Sipoo River Bridge Embankment 55

Fig. 3-2. Embankment Cross-section and Column Layout 58

Fig. 3-3. Arrangement of Instrumentations $\quad 59$

Fig. 3-4. Construction Process $\quad 61$

Fig. 3-5. Modeling Procedure $\quad 61$

Fig. 3-6. 2D Numerical Model 64

Fig. 3-7. FLAC Models 66

Fig. 3-8. Settlement Profiles at Different Stages (2D) 68

Fig. 3-9. Settlement versus Time (2D) 69

Fig. 3-10. Settlement Profiles at the Base and on the Crest of the Embankment (2D)

Fig. 3-11. Strain versus Time (2D) 74

Fig. 3-12. Tension Developed in the Geosynthetic Layer with or without Mid-DM Walls 75

$\begin{array}{ll}\text { Fig. 3-13. 3D Numerical Model } & 78\end{array}$ 
Fig. 3-14. FLAC3D Model 79

Fig. 3-15. Settlement Profiles at Different Stages (3D) 80

Fig. 3-16. Settlement versus Time (3D) 82

Fig. 3-17. Settlement Profiles on the Crest and at the Base (3D) 83

Fig. 3-18. Strain versus Time (3D) 85

Fig. 4-1. Two-dimensional Model of the Baseline Case 87

Fig. 4-2. Modeling of Staged Construction 91

Fig. 4-3. Settlement Contour of the 2D Baseline Case 92

Fig. 4-4. Settlement versus Time of the 2D Baseline Case 93

Fig. 4-5. Settlement Profiles of the 2D Baseline Case at Different Time 96

Fig. 4-6. Differential Settlement 97

Fig. 4-7. Tension Distribution of the 2D Baseline Case 98

Fig. 4-8. Tension Profiles of the 2D Baseline Case 99

Fig. 4-9. Post-construction Tension Profiles of the 2D Baseline Case 100

Fig. 4-10. Tension Profiles of the 2D Baseline Case at 30 Years after Service 100

Fig. 4-11. Tension versus Time of the 2D Baseline Case 101

Fig. 4-12. Vertical Effective Stress Contour of the 2D Baseline Case 102

Fig. 4-13. Vertical Stress Distribution of the 2D Baseline Case 103

Fig. 4-14. Additional Vertical Effective Stress versus Time of the 2D Baseline Case

Fig. 4-15. Stress Concentration Ratio Calculation Illustration 106

Fig. 4-16. Stress Concentration Ratio Profiles of the 2D Baseline Case 107

Fig. 4-17. Pore Water Pressure Contour of the 2D Baseline Case 108

Fig. 4-18. Excess Pore Water Pressure at Point $C$ and $D$ versus Time of the $2 D$ Baseline Case 109

Fig. 4-19. Excess Pore Water Pressure at Point D and E versus Time of the 2D Baseline Case 110

Fig. 4-20. Excess Pore Water Pressure versus Depth of the 2D Baseline Case 111

Fig. 4-21. Excess Pore Water Pressure or Additional Vertical Effective Stress versus Time of the 2D Baseline Case 
Fig. 4-22. Settlement Profiles for Various Soil Moduli at 1 Month after Service (2D)

Fig. 4-23. Settlement Profiles for Various Soil Moduli at 30 Years after Service (2D)

Fig. 4-24. Maximum Settlement versus Soil Modulus (2D)

Fig. 4-25. Maximum Differential Settlement versus Soil Modulus (2D)

Fig. 4-26. Maximum Distortion on the Crest versus Soil Modulus (2D)

Fig. 4-27. Settlement Profiles for Various Friction Angles at 1 Month after Service (2D)

Fig. 4-28. Settlement Profiles for Various Friction Angles at 30 Years after Service (2D)

Fig. 4-29. Maximum Settlement versus Friction Angle (2D)

Fig. 4-30. Maximum Differential Settlement versus Friction Angle (2D)

Fig. 4-31. Maximum Distortion on the Crest versus Friction Angle (2D)

Fig. 4-32. Settlement Profiles for Various Permeability at 1 Month after Service (2D)

Fig. 4-33. Settlement Profiles for Various Permeability at 30 Years after Service (2D)

Fig. 4-34. Maximum Settlement versus Soil Permeability (2D) 128

Fig. 4-35. Maximum Differential Settlement versus Soil Permeability (2D) 129

Fig. 4-36. Maximum Distortion on the Crest versus Soil Permeability (2D) 130

Fig. 4-37. Settlement Profiles for Various Column Moduli at 1 Month after Service (2D)

Fig. 4-38. Settlement Profiles for Various Column Moduli at 30 Years after Service (2D)

Fig. 4-39. Maximum Settlement versus Column Modulus (2D)

Fig. 4-40. Maximum Differential Settlement versus Column Modulus (2D)

Fig. 4-41. Maximum Distortion on the Crest versus Column Modulus (2D)

Fig. 4-42. Settlement Profiles for Various Column Spacing at 1 Month after Service (2D)

Fig. 4-43. Settlement Profiles for Various Column Spacing at 30 Years after Service (2D)

Fig. 4-44. Maximum Settlement versus Column Spacing (2D) 139

Fig. 4-45. Maximum Differential Settlement versus Column Spacing (2D) 
Fig. 4-46. Maximum Distortion on the Crest versus Column Spacing (2D)

Fig. 4-47. Settlement Profiles for Various Tensile Stiffness at 1 Month after Service (2D)

Fig. 4-48. Settlement Profiles for Various Tensile Stiffness at 30 Years after Service (2D)

Fig. 4-49. Maximum Settlement versus Tensile Stiffness (2D) 144

Fig. 4-50. Maximum Differential Settlement versus Tensile Stiffness (2D) 144

Fig. 4-51. Maximum Distortion on the Crest versus Tensile Stiffness (2D) 145

Fig. 4-52. Settlement Profiles for Various Average Construction Rates at 1 Month after Service (2D)

Fig. 4-53. Settlement Profiles for Various Average Construction Rates at 30 Years after Service (2D)

Fig. 4-54. Maximum Settlement versus Average Construction Rate (2D)

Fig. 4-55. Maximum Differential Settlement versus Average Construction Rate (2D)

Fig. 4-56. Maximum Distortion on the Crest versus Average Construction Rate (2D)

Fig. 4-57. Tension Profiles for Various Soil Moduli at 1 Month and 30 Years after Service (2D)

Fig. 4-58. Maximum Tension versus Soil Modulus (2D)

Fig. 4-59. Tension Profiles for Various Friction Angles at 1 Month and 30 Years after Service (2D)

Fig. 4-60. Maximum Tension versus Friction Angle (2D)

Fig. 4-61. Tension Profiles for Various Soil Permeability at 1 Month and 30 Years after Service (2D)

Fig. 4-62. Maximum Tension versus Soil Permeability (2D)

Fig. 4-63. Tension Profiles for Various Column Moduli at 1 Month and 30 Years after Service (2D)

Fig. 4-64. Maximum Tension versus Column Modulus (2D)

Fig. 4-65. Tension Profiles for Various Column Spacing at 1 Month and 30 Years after Service (2D)

Fig. 4-66. Maximum Tension versus Column Spacing (2D)

Fig. 4-67. Tension Profiles for Various Tensile Stiffness at 1 Month and 30 Years after Service (2D) 
Fig. 4-68. Maximum Tension versus Tensile Stiffness (2D)

Fig. 4-69. Tension Profiles for Various Average Construction Rates at 1 Month and 30 Years after Service (2D) 164

Fig. 4-70. Maximum Tension versus Average Construction Rate (2D) 165

Fig. 4-71. Additional Vertical Effective Stress Profiles for Various Soil Moduli (2D)

Fig. 4-72. Stress Concentration Ratio Profiles for Various Soil Moduli (2D) 169

Fig. 4-73. Additional Effective Stress Profiles for Various Friction Angles (2D) 170

Fig. 4-74. Stress Concentration Ratio Profiles for Various Friction Angles (2D) 172

Fig. 4-75. Additional Effective Stress Profiles for Various Soil Permeability (2D) 174

Fig. 4-76. Stress Concentration Ratio Profiles for Various Soil Permeability (2D) 175

Fig. 4-77. Additional Vertical Effective Stress Profiles for Various Column Moduli (2D)

Fig. 4-78. Stress Concentration Ratio Profiles for Various Column Moduli (2D) 177

Fig. 4-79. Additional Vertical Effective Stress Profiles for Various Column Spacing (2D)

Fig. 4-80. Stress Concentration Ratio Profiles for Various Column Spacing (2D) 180

Fig. 4-81. Additional Vertical Effective Stress Profiles for Various Tensile Stiffness (2D)

Fig. 4-82. Stress concentration Ratio Profiles for Various Tensile Stiffness (2D) 183

Fig. 4-83. Additional Vertical Effective Stress Profiles for Various Average Construction Rates (2D)

Fig. 4-84. Stress Concentration Ratio Profiles for Various Average Construction Rates (2D)

Fig. 4-85. Excess Pore Water Pressure Distributions for Various Soil Moduli (2D) 189

Fig. 4-86. Degree of Consolidation versus Soil Modulus (2D)

Fig. 4-87. Excess Pore Water Pressure Distributions for Various Friction Angles (2D)

Fig. 4-88. Degree of Consolidation versus Friction Angle (2D)

Fig. 4-89. Excess Pore Water Pressure Distributions for Various Soil Permeability (2D)

Fig. 4-90. Degree of Consolidation versus Soil Permeability (2D)

Fig. 4-91. Excess Pore Water Pressure Distributions for Various Column Moduli (2D) 
Fig. 4-92. Degree of Consolidation versus Column Modulus (2D)

Fig. 4-93. Excess Pore Water Pressure Distributions for Various Column Spacing (2D)

Fig. 4-94. Degree of Consolidation versus Column Spacing (2D)

Fig. 4-95. Excess Pore Water Pressure Distributions for Various Tensile Stiffness (2D)

Fig. 4-96. Degree of Consolidation versus Tensile Stiffness (2D)

Fig. 4-97. Excess Pore Water Pressure Distributions for Various Average Construction Rates (2D)

Fig. 4-98. Degree of Consolidation versus Average Construction Rate (2D)

Fig. 5-1. Three-dimensional Model of the 3D Baseline Case 201

Fig. 5-2. Conversion of Column Modulus 203

Fig. 5-3. Settlement Contour of the 3D Baseline Case 205

Fig. 5-4. Settlement versus Time of the 3D Baseline Case 206

Fig. 5-5. Settlement Profiles of the 3D Baseline Case at Different Time 208

Fig. 5-6. Tension Contours of the 3D Baseline Case 210

Fig. 5-7. Tension Profiles of the 3D Baseline Case 212

Fig. 5-8. Tension versus Time of the 3D Baseline Case 213

Fig. 5-9. Vertical Effective Stress Contour of the 3D Baseline Case 214

Fig. 5-10. Effective Stress Distribution of the 3D Baseline Case 214

Fig. 5-11. Additional Vertical Effective Stress versus Time of the 3D Baseline Case

Fig. 5-12. Stress Concentration Ratio Profiles of the 3D Baseline Case 217

Fig. 5-13. Pore Water Pressure Contour of the 3D Baseline Case 218

Fig. 5-14. Excess Pore Water Pressure at Point C1 and D1 versus Time of the 3D Baseline Case

Fig. 5-15. Excess Pore Water Pressure at Point D1 and E1 versus Time of the 3D Baseline Case

Fig. 5-16. Excess Pore Water Pressure versus Depth of the 3D Baseline Case 221

Fig. 5-17. Excess Pore water Pressure or Additional Vertical Effective Stress versus Time of the 3D Baseline Case 
Fig. 5-18. Settlement Profiles for Various Soil Moduli at 1 Month after Service (3D)

Fig. 5-19. Settlement Profiles for Various Soil Moduli at 4.5 Years after Service (3D)

Fig. 5-20. Maximum Settlement versus Soil Modulus (3D) 230

Fig. 5-21. Maximum Differential Settlement versus Soil Modulus (3D) 230

Fig. 5-22. Maximum Distortion on the Crest versus Soil Modulus (3D) 231

Fig. 5-23. Settlement Profiles for Various Friction Angles at 1 Month after Service (3D)

Fig. 5-24. Settlement Profiles for Various Friction Angles at 4.5 Years after Service (3D)

Fig. 5-25. Maximum Settlement versus Friction Angle (3D) 237

Fig. 5-26. Maximum Differential Settlement versus Friction Angle (3D) 237

Fig. 5-27. Maximum Distortion on the Crest versus Friction Angle (3D) 238

Fig. 5-28. Settlement Profiles for Various Soil Permeability at 1 Month after Service (3D)

Fig. 5-29. Settlement Profiles for Various Soil Permeability at 4.5 Years after Service (3D)

Fig. 5-30. Maximum Settlement versus Soil Permeability (3D)

Fig. 5-31. Maximum Differential Settlement versus Soil Permeability (3D)

Fig. 5-32. Maximum Distortion on the Crest versus Soil Permeability (3D)

Fig. 5-33. Settlement Profiles for Various Column Moduli on at 1 Month after Service (3D)

Fig. 5-34. Settlement Profiles for Various Column Moduli at 4.5 Years after Service (3D)

Fig. 5-35. Maximum Settlement versus Column Modulus (3D)

Fig. 5-36. Maximum Differential Settlement versus Column Modulus (3D)

Fig. 5-37. Maximum Distortion on the Crest versus Column Modulus (3D)

Fig. 5-38. Settlement Profiles for Various Column Spacing on at 1 Month after Service (3D)

Fig. 5-39. Settlement Profiles for Various Column Spacing on at 4.5 Years after Service (3D)

Fig. 5-40. Maximum Settlement versus Column Spacing (3D) 258

Fig. 5-41. Maximum Differential Settlement versus Column Spacing (3D) 259 
Fig. 5-42. Maximum Distortion on the Crest versus Column Spacing (3D)

Fig. 5-43. Settlement Profiles for Various Tensile Stiffness at 1 Month after Service (3D)

Fig. 5-44. Settlement Profiles for Various Tensile Stiffness at 4.5 Years after Service (3D)

Fig. 5-45. Maximum Settlement versus Tensile Stiffness (3D) 265

Fig. 5-46. Maximum Differential Settlement versus Tensile Stiffness (3D) 266

Fig. 5-47. Maximum Distortion on the Crest versus Tensile Stiffness (3D) 266

Fig. 5-48. Settlement Profiles for Various Average Construction Rates at 1 Month after Service (3D)

Fig. 5-49. Settlement Profiles for Various Average Construction Rates at 4.5 Years after Service (3D)

Fig. 5-50. Maximum Settlement versus Average Construction Rate (3D)

Fig. 5-51. Maximum Differential Settlement versus Average Construction Rate (3D)

Fig. 5-52. Maximum Distortion on the Crest versus Average Construction Rate (3D)

Fig. 5-53. Maximum Tension versus Soil Modulus (3D)

Fig. 5-54. Maximum Tension versus Friction Angle (3D)

Fig. 5-55. Maximum Tension versus Soil Permeability (3D)

Fig. 5-56. Maximum Tension versus Column Modulus (3D)

Fig. 5-57. Maximum Tension versus Column Spacing (3D)

Fig. 5-58. Maximum Tension versus Tensile Stiffness (3D)

Fig. 5-59. Maximum Tension versus Average Construction Rate (3D)

Fig. 5-60. Additional Vertical Effective Stress Profiles for Various Soil Moduli at 1 Month after Service (3D)

Fig. 5-61. Additional Vertical Effective Stress Profiles for Various Soil Moduli at 4.5 Years after Service (3D)

Fig. 5-62. Stress Concentration Ratio Profiles for Various Soil Moduli (3D) 285

Fig. 5-63. Additional Vertical Effective Stress Profiles of Various Friction Angles at 1 Month after Service (3D)

Fig. 5-64. Additional Vertical Effective Stress Profiles for Various Friction Angles at 4.5 Years after Service (3D) 
Fig. 5-65. Stress Concentration Ratio Profiles for Various Soil Friction Angles (3D)

Fig. 5-66. Additional Effective Stress Profiles for Various Soil Permeability at 1 Month after Service (3D)

Fig. 5-67. Additional Effective Stress Profiles for Various Soil Permeability at 4.5 Years after Service (3D)

Fig. 5-68. Stress Concentration Ratio Profiles for Various Soil Permeability (3D) 293

Fig. 5-69. Additional Vertical Effective Stress Profiles for Various Column Moduli at 1 Month after Service (3D)

Fig. 5-70. Additional Vertical Effective Stress Profiles for Various Column Moduli at 4.5 Years after Service (3D)

Fig. 5-71. Stress Concentration Ratio Profiles for Various Column Moduli (3D) 297

Fig. 5-72. Additional Vertical Effective Stress Profiles of Various Column Spacing at 1 Month after Service (3D)

Fig. 5-73. Additional Vertical Effective Stress Profiles of Various Column Spacing at 4.5 Years after Service (3D)

Fig. 5-74. Stress Concentration Ratio Profiles for Various Column Spacing (3D) 301

Fig. 5-75. Additional Vertical Effective Stress Profiles for Various Tensile Stiffness at 1 Month after Service (3D)

Fig. 5-76. Additional Vertical Effective Stress Profiles for Various Tensile Stiffness at 4.5 Years after Service (3D)

Fig. 5-77. Stress Concentration Ratio Profiles for Various Tensile Stiffness (3D) 305

Fig. 5-78. Additional Vertical Effective Stress Profiles for Various Average Construction Rates at 1 Month after Service (3D)

Fig. 5-79. Additional Vertical Effective Stress Profiles for Various Average Construction Rates at 4.5 Years after Service (3D)

Fig. 5-80. Stress Concentration Ratio Profiles for Various Average Construction Rates (3D)

Fig. 5-81. Excess Pore Water Pressure Distributions for Various Soil Moduli (3D) 311

Fig. 5-82. Degree of Consolidation versus Soil Modulus (3D)

Fig. 5-83. Excess Pore Water Pressure Distributions for Various Friction Angles (3D)

Fig. 5-84. Degree of Consolidation versus Friction Angle (3D)

Fig. 5-85. Excess Pore Water Pressure Distributions for Various Soil Permeability (3D) 
Fig. 5-86. Degree of Consolidation versus Soil Permeability (3D)

Fig. 5-87. Excess Pore Water Pressure Distributions for Various Column Moduli (3D)

Fig. 5-88. Degree of Consolidation versus Various Column Moduli (3D)

Fig. 5-89. Excess Pore Water Pressure Distributions for Various Column Spacing (3D)

Fig. 5-90. Degree of Consolidation versus Column Spacing (3D)

Fig. 5-91. Excess Pore Water Pressure Distributions for Various Tensile Stiffness (3D)

Fig. 5-92. Degree of Consolidation versus Tensile Stiffness (3D)

Fig. 5-93. Excess Pore Water Pressure Distributions for Various Average Construction Rates (3D)

Fig. 5-94. Degree of Consolidation versus Average Construction Rate (3D)

Fig. 6-1. Comparison of Maximum Settlement

Fig. 6-2. Comparison of Maximum Distortion

Fig. 6-3. Comparison of Maximum Tension

Fig. 6-4. Comparison of Maximum Stress Concentration Ratio

Fig. 6-5. Comparison of Degree of Consolidation

Fig. 6-6. Maximum Settlement versus Soil Modulus under 2D and 3D Conditions 331

Fig. 6-7. Maximum Distortion versus Soil Modulus under 2D and 3D Conditions 332

Fig. 6-8. Maximum Settlement versus Friction Angle under 2D and 3D Conditions

Fig. 6-9. Maximum Distortion versus Friction Angle under 2D and 3D Conditions 334

Fig. 6-10. Maximum Settlement versus Soil Permeability under 2D and 3D Conditions

Fig. 6-11. Maximum Distortion versus Soil Permeability under 2D and 3D Conditions

Fig. 6-12. Maximum Settlement versus Column Modulus under 2D and 3D Conditions

Fig. 6-13. Maximum Distortion versus Column Modulus under 2D and 3D Conditions

Fig. 6-14. Maximum Settlement versus Column Spacing under 2D and 3D Conditions 
Fig. 6-15. Maximum Distortion versus Column Spacing under 2D and 3D Conditions

Fig. 6-16. Maximum Settlement versus Tensile Stiffness under 2D and 3D Conditions

Fig. 6-17. Maximum Distortion versus Tensile Stiffness under 2D and 3D Conditions

Fig. 6-18. Maximum Settlement versus Average Construction Rate under 2D and 3D Conditions

Fig. 6-19. Maximum Distortion versus Average Construction Rate under 2D and 3D Conditions

Fig. 6-20. Maximum Tension versus Soil Modulus under 2D and 3D Conditions 343

Fig. 6-21. Maximum Tension versus Friction Angle under 2D and 3D Conditions 344

Fig. 6-22. Maximum Tension versus Soil Permeability under 2D and 3D Conditions

Fig. 6-23. Maximum Tension versus Column Modulus under 2D and 3D Conditions

Fig. 6-24. Maximum Tension versus Column Spacing under 2D and 3D Conditions

Fig. 6-25. Maximum Tension versus Tensile Stiffness under 2D and 3D Conditions

Fig. 6-26. Maximum Tension versus Average Construction Rate under 2D and 3D Conditions

Fig. 6-27. Maximum Stress Concentration Ratio versus Soil Modulus under 2D and 3D Conditions

Fig. 6-28. Maximum Stress Concentration Ratio versus Friction Angle under 2D and 3D Conditions

Fig. 6-29. Maximum Stress Concentration Ratio versus Soil Permeability under 2D and 3D Conditions

Fig. 6-30. Maximum Stress Concentration Ratio versus Column Modulus under 2D and 3D Conditions

Fig. 6-31. Maximum Stress Concentration Ratio versus Column Spacing under 2D and 3D Conditions

Fig. 6-32. Maximum Stress Concentration Ratio versus Tensile Stiffness under 2D and 3D Conditions

Fig. 6-33. Maximum Stress Concentration Ratio versus Average Construction Rate under 2D and 3D Conditions 
Fig. 6-34. Degree of Consolidation versus Soil Modulus under 2D and 3D Conditions

Fig. 6-35. Degree of Consolidation versus Friction Angle under 2D and 3D Conditions

Fig. 6-36. Degree of Consolidation versus Soil Permeability under 2D and 3D Conditions

Fig. 6-37. Degree of Consolidation versus Column Modulus under 2D and 3D Conditions

Fig. 6-38. Degree of Consolidation versus Column Spacing under 2D and 3D Conditions

Fig. 6-39. Degree of Consolidation versus Tensile Stiffness under 2D and 3D Conditions

Fig. 6-40. Degree of Consolidation versus Average Construction Rate under 2D and 3D Conditions 


\section{LIST OF TABLES}

Table 1-1. Main Advantages and Disadvantages of Embankment Settlement Control Techniques

Table 1-2. Possible Column Types

Table 1-3. Constructed GRCS Embankments

Table 1-4. Guideline for the Design of Necessary Coverage by Pile Caps

Table 2-1. Information of Embankment A and B Used in Comparison

Table 2-2. Finished Study on GRCS Embankments

Table 3-1. Soil Index Properties 56

Table 3-2. Properties of Soft Clay 56

Table 3-3. Construction Information 59

Table 3-4. Material Properties 65

Table 3-5. Maximum Settlements at the Base of the Embankment 71

Table 3-6. Maximum Tension in the Geosynthetic Layer 76

Table 4-1. Properties of Materials in the 2D Baseline Case 88

Table 4-2. Modeling Procedure 90

Table 4-3. Maximum Differential Settlement and Maximum Distortion of the 2D Baseline case $\quad 98$

Table 4-4. Parameters and Variation Used in the 2D Study 113

Table 5-1. Properties of Materials in the 3D Baseline Case 203

Table 5-2. Maximum Differential Settlement and Maximum Distortion of the 3D Baseline Case

Table 5-3. Parameters and Variation Used in the 3D Study

Table 6-1. The Degree of Influence under a 3D Condition 
Table 6-2. The Degree of Influence under a 2D Condition

Table 6-3. The Influence of Factors under a 3D Condition

Table 6-4. The Influence of Factors under a 2D Condition 


\section{CHAPTER ONE}

\section{INTRODUCTION}

\subsection{Background}

As the development of modern society progresses, transportation demand grows dramatically year by year. Numerous embankments have been built to support roadways and railways. Inevitably, soft clays (for example, alluvial soil and peat) and other highly compressible soft soils, which used to be considered technically unsuitable for construction, are encountered. Their adverse features, such as low shear strength, high compressibility and so on, challenge the geotechnical profession (Bell

et al. 1994; Han 1999). They set constraints on design and construction of earth structures, such as the maximum dimension of embankments and the maximum construction rate. To break through these constraints, geotechnical engineers never stop seeking better means technically and economically. In the past several decades, many innovative means have been practiced to control post-construction settlements of embankments built over problematic soils (Hewllet and Randolph 1988; Jones et al. 1994; Magnan 1994). The main techniques used to control embankment settlements are listed and compared in Table 1-1. 
Table 1-1. Main Advantages and Disadvantages of Embankment Settlement Control Techniques (Modified from Magnan 1994)

\begin{tabular}{|c|c|c|}
\hline Technique & Advantage & Disadvantage \\
\hline Preloading & $\begin{array}{l}\text { It is almost the easiest } \\
\text { method among those } \\
\text { techniques. It does not } \\
\text { require extra materials } \\
\text { except for preloading } \\
\text { weight. It is very efficient, if } \\
\text { enough consolidation time } \\
\text { is allowed. }\end{array}$ & $\begin{array}{l}\text { Waiting time for consolidation might be very } \\
\text { long and hard to estimate, so monitoring might } \\
\text { be needed to determine the degree of } \\
\text { consolidation. Sometimes, the transportation and } \\
\text { disposal of the preloading weights could } \\
\text { increase the total cost. }\end{array}$ \\
\hline $\begin{array}{l}\text { Preloading with } \\
\text { vertical drain }\end{array}$ & $\begin{array}{l}\text { Easy to practice and much } \\
\text { faster than preloading. }\end{array}$ & $\begin{array}{l}\text { The cost increases, as either sand well or } \\
\text { fabricated vertical drain is involved. Compared } \\
\text { with sand well, the installation of fabricated } \\
\text { vertical drain is much easier and much faster } \\
\text { than the construction of sand well. Since the } \\
\text { discharge capacity of fabricated vertical drain is } \\
\text { hard to estimate precisely, monitoring may be } \\
\text { needed to determine the degree of consolidation. }\end{array}$ \\
\hline Vacuum preloading & $\begin{array}{l}\text { Compared with the two } \\
\text { preceding preloading } \\
\text { techniques, it saves time and } \\
\text { cost on transporting } \\
\text { preloading weights. }\end{array}$ & $\begin{array}{l}\text { Theoretically speaking, the maximum load that } \\
\text { could be applied is atmospheric pressure. And } \\
\text { efficient pumping equipment and impervious } \\
\text { membrane are vital. Limited experiences are } \\
\text { available. }\end{array}$ \\
\hline $\begin{array}{l}\text { Overexcavation/ } \\
\text { Replacement }\end{array}$ & $\begin{array}{l}\text { A fast and easy to use } \\
\text { method. }\end{array}$ & $\begin{array}{l}\text { The disposal of extracted soil and transportation } \\
\text { of the new fill material increase the cost. It is an } \\
\text { expensive method for a large area and/or deep } \\
\text { excavation. Therefore, it is hardly used on } \\
\text { embankments covering large area. In addition, } \\
\text { some other issues have to taken into } \\
\text { consideration, such as stability of the cut edge, } \\
\text { dewatering if ground water is to be encountered. }\end{array}$ \\
\hline Pile & Fast and effective & Expensive \\
\hline Piled raft & Fast, effective, and reliable & $\begin{array}{l}\text { It is almost the most expensive technique among } \\
\text { those discussed. It is typically used for bridge } \\
\text { approach embankment. }\end{array}$ \\
\hline $\begin{array}{c}\text { Stone column, sand } \\
\text { column, and } \\
\text { rammed aggregate } \\
\text { pier }\end{array}$ & Fast & $\begin{array}{l}\text { They are expensive. And hazardous vibration } \\
\text { could be generated during the construction. } \\
\text { Besides, they could not be used in very soft soil } \\
\text { situation, since stones and sand need some } \\
\text { confinement to sustain their strength. The advent } \\
\text { of encased stone columns and sand columns } \\
\text { seems to help break through this limitation. But } \\
\text { the construction method of encased stone } \\
\text { columns and sand columns has not well } \\
\text { developed. }\end{array}$ \\
\hline $\begin{array}{l}\text { Lightweight } \\
\text { material }\end{array}$ & $\begin{array}{l}\text { Fast and easy to handle. It } \\
\text { has the least disturbance on } \\
\text { in-situ soils. }\end{array}$ & $\begin{array}{l}\text { The lightweight material with reasonable } \\
\text { strength is expensive. Typically, protective } \\
\text { cover is needed. }\end{array}$ \\
\hline
\end{tabular}


Table 1-1. Main Advantages and Disadvantages of Embankment Settlement Control Techniques (continued, Modified from Magnan 1994)

\begin{tabular}{|c|c|l|}
\hline Technique & Advantage & \multicolumn{1}{c|}{ Disadvantage } \\
\hline Jet-grouting & $\begin{array}{c}\text { Fast and reliable method. It is a very popular } \\
\text { ground improvement technique. A lot of } \\
\text { experience could be referred to. }\end{array}$ & Expensive. \\
\hline Electro-osmosis & $\begin{array}{c}\text { Installation is very easy. Besides as } \\
\text { reinforcement, it could also serve as } \\
\text { separation between embankment fill and } \\
\text { foundation soil to avoid the penetration of } \\
\text { granular materials into soft soil. }\end{array}$ & $\begin{array}{l}\text { Very expensive but not } \\
\text { reliable. Destruction of } \\
\text { electrodes, electricity needed. }\end{array}$ \\
\hline $\begin{array}{c}\text { Geosynthetic } \\
\text { reinforcement } \\
\text { stiffer inclusions such as piles, } \\
\text { stone columns. }\end{array}$ \\
$\begin{array}{c}\text { Geosynthetic- } \\
\text { reinforced column- } \\
\text { supported system }\end{array}$ & $\begin{array}{c}\text { Compared with using geosynthetic } \\
\text { reinforcement alone, it is more effective. And } \\
\text { compared with using piles alone, it is more } \\
\text { economical. }\end{array}$ & $\begin{array}{l}\text { Both experiences are limited } \\
\text { and theories have not been } \\
\text { well-established. }\end{array}$ \\
\hline
\end{tabular}

Among the techniques listed in Table 1-1, the geosynthetic-reinforced columnsupported (GRCS) embankment is the focus of this study. Since GRCS originated from column supported (CS) embankments, both CS embankments and GRCS embankments will be briefly reviewed in this chapter.

\subsection{Column Supported (CS) and Geosynthetic-Reinforced Column-Supported}

\section{(GRCS) Embankments}

In this dissertation, the word, 'column', has a very broad meaning, which refers to an inclusion of higher strength and higher stiffness in soft soil. Columns can be conventional piles, columns installed by grouting, compaction, deep-mixing, stone 
columns, aggregate piers, sand columns, and so on. The possible types of columns used in GRCS embankments, together with their typical parameters, are listed in Table 1-2.

Table 1-2. Possible Column Types (Collin 2004)

\begin{tabular}{|c|c|c|c|}
\hline Pile type & $\begin{array}{c}\text { Range of allowable } \\
\text { capacity }(\mathrm{kN})\end{array}$ & Typical length (m) & $\begin{array}{c}\text { Typical column } \\
\text { diameter }(\mathrm{m})\end{array}$ \\
\hline Timber pile & $100-500$ & $5-20$ & $30-55$ \\
\hline Steel H pile & $400-2000$ & $5-30$ & $15-30$ \\
\hline Steel pipe pile & $800-2500$ & $10-40$ & $20-120$ \\
\hline Pre-cast concrete pile & $400-1000$ & $10-15$ & $25-60$ \\
\hline $\begin{array}{c}\text { Cast-in-place concrete } \\
\text { Shell (mandrel driven) }\end{array}$ & $400-1400$ & $3-40$ & $20-45$ \\
\hline $\begin{array}{c}\text { Shell driven without } \\
\text { mandrel }\end{array}$ & $500-1350$ & $5-25$ & $30-45$ \\
\hline CFA & $350-700$ & $5-25$ & $30-60$ \\
\hline Micropile & $300-1000$ & $20-30$ & $15-25$ \\
\hline DMM & $400-1200$ & $10-30$ & $60-300$ \\
\hline Stone column & $100-500$ & $3-10$ & $45-120$ \\
\hline GEC & $300-600$ & $3-10$ & $80-150$ \\
\hline Geopier & $225-650$ & $3-10$ & $60-90$ \\
\hline VCC & $200-600$ & $3-10$ & $45-60$ \\
\hline CSV & $30-60$ & $3-10$ & $12-18$ \\
\hline AU-Geo & $75-150$ & $2-15$ & 15 \\
\hline
\end{tabular}

Note: CFA - continuous flight augered; DMM - deep mixing method; GEC - geotextile encased columns; VCC - vibro concrete columns; CSV—combined soil stabilization; AU-Geo - AU-Geo piling.

Moreover, the embankments, referred here, include roadway embankments, railway embankments, and bridge approach embankments. 


\subsubsection{History of CS and GRCS Embankments}

Columns have been used to improve overall bearing capacity and mitigate postconstruction settlements of various embankments since early 1960s (Magnan 1994). So far, columns have been accepted widely to support road and railway embankments, i.e., column-supported (CS) embankments. After the advent of reliable and durable reinforcement materials - geosynthetics, they were introduced in CS embankments as basal reinforcement to facilitate the load transfer. This category of embankments is called geosynthetic-reinforced column-supported (GRCS) embankments. A typical cross-section of CS and GRCS embankments are presented in Fig. 1-1.

The early documented GRCS embankment was built in Scotland in 1983 as a bridge approach embankment (Reid and Buchanan 1984). A single layer of geomembrane was used in this project. Since then, more GRCS embankments were built in Europe, such as Belgium, Germany, Sweden, Poland, and Netherlands (van Eekelen et al. 2003). The early documented GRCS embankment with multiple layers of geosynthetic reinforcement was built in 1988 to 1989 to support a roadway embankment in London, England (Card and Carter 1995). In 1994, a geosynthetic reinforced column supported platform was built in Philadelphia, PA to support a large diameter storage tank (Collin 2003). After that, a number of GRCS embankments 
were constructed in the U.S., such as the one built in New Jersey to support a light rail (Young et al. 2003).

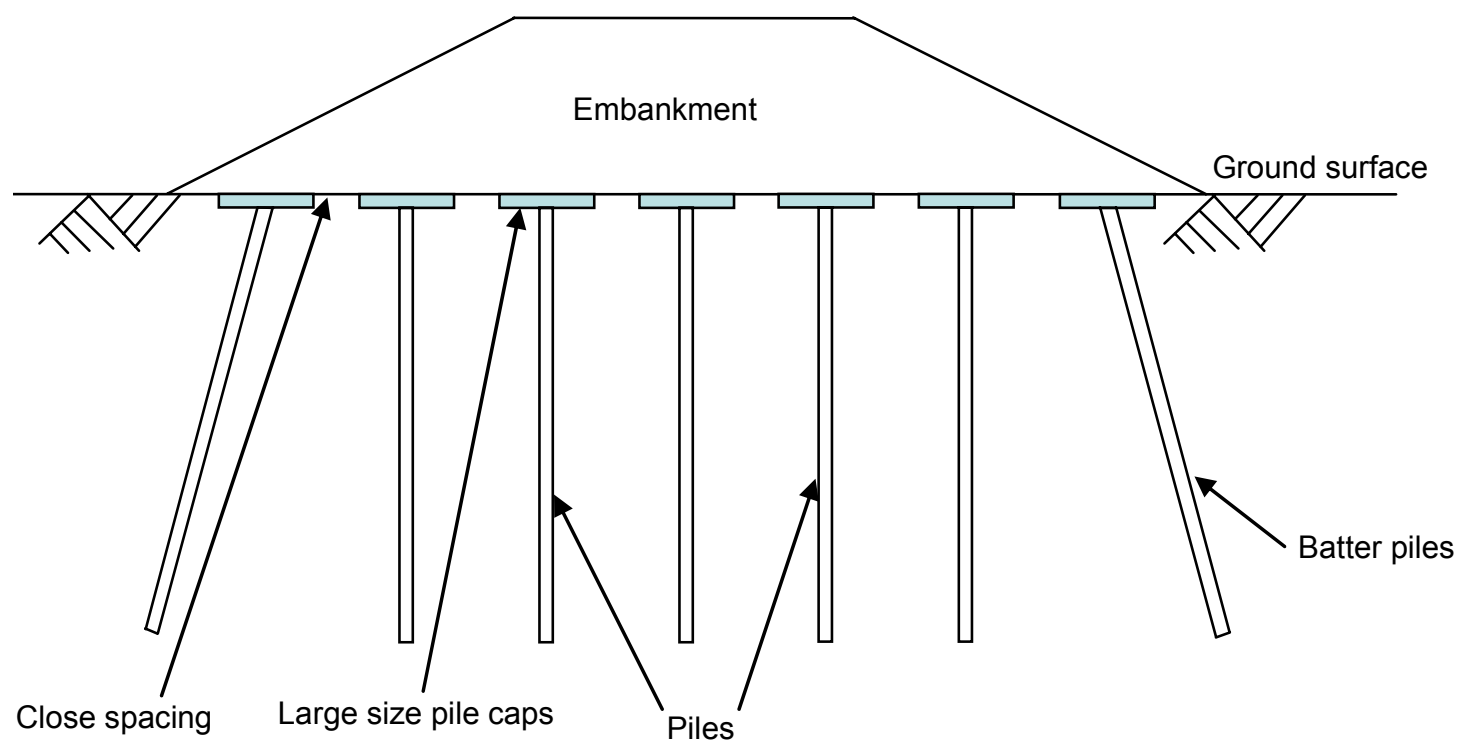

(a) CS embankment cross-section

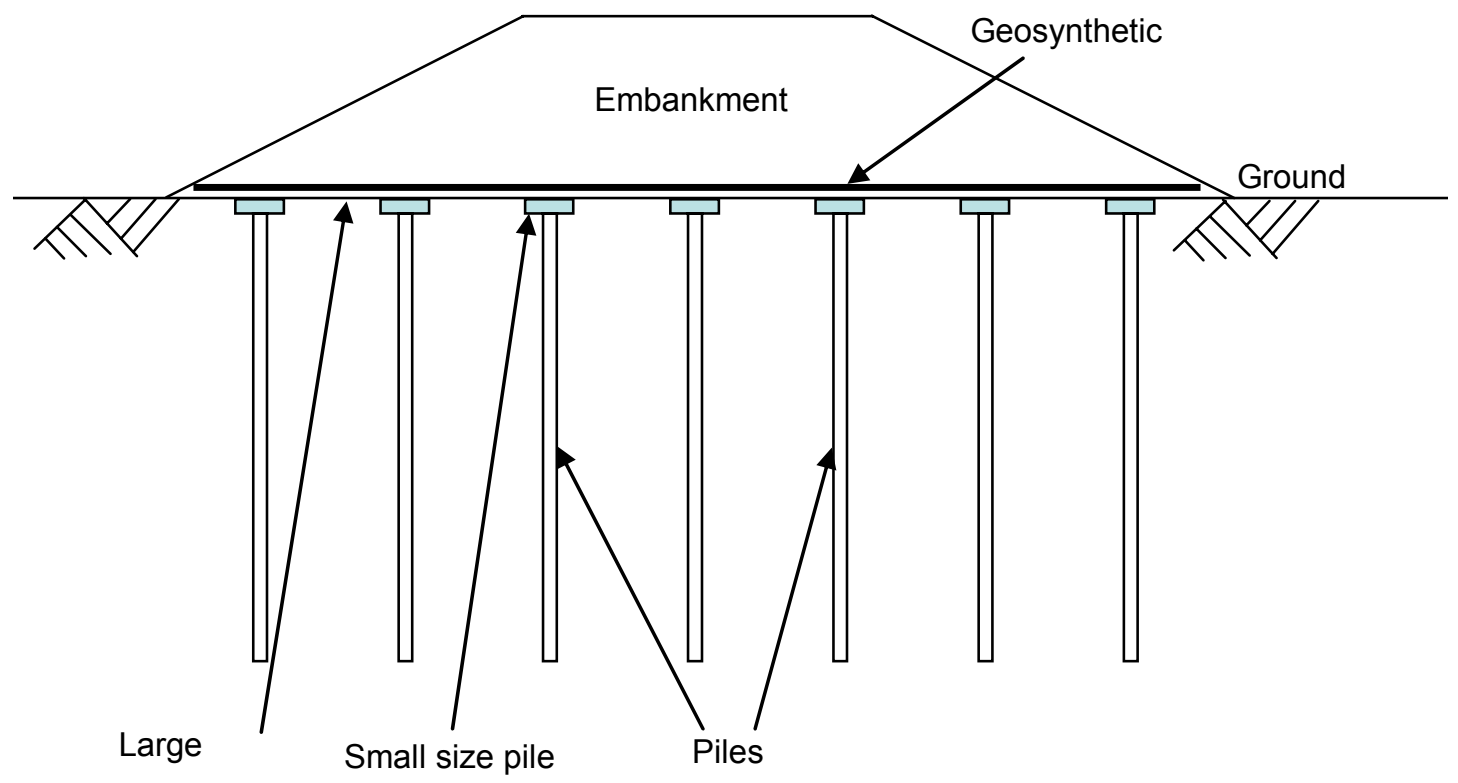

(b) GRCS embankment cross-section

Fig. 1-1. Cross-sections of CS and GRCS Embankments 
In the past few years, GRCS embankments have been increasingly used all over the world, such as southern Asia, England, Sweden, and North America. An inventory of the published case histories is listed in Table 1-3.

\subsubsection{Brief Discussion on CS and GRCS Embankments}

With the inclusion of columns, a large part of load is transferred from soft soil to columns through soil arching induced by differential settlements between columns and soft soil. Soil arching will be discussed in detail with regard to load transfer mechanisms of Chapter Two. The secondary benefit of installation of columns is that they may densify and stiffen surrounding soil, thus reducing differential settlements of the foundation (Hewllet and Randolph 1988).

Generally speaking, it is relatively easier to ensure enough bearing capacity margin as compared with limiting post-construction settlements. To limit the post-construction settlements of CS embankments, columns have to be installed closely or with enlarged heads/caps to increase the percent coverage of caps (Jones et al. 1990) as shown in Fig. 1-1 (a). Table 1-4 presents recommended design guidelines by Rathmayer (1975) who made a recommendation based on data from a research program conducted by Geotechnical Laboratory of the Technical Research Centre of Finland in 1971. 
Table 1-3. Constructed GRCS Embankments (Modified from Han 1999)

\begin{tabular}{|c|c|c|c|c|c|c|}
\hline Application & $\begin{array}{c}\text { Soil } \\
\text { condition }\end{array}$ & $\begin{array}{l}\text { Pile } \\
\text { type }\end{array}$ & $\begin{array}{l}\text { Geosyn.- } \\
\text { type }\end{array}$ & Design parameters & Performance & Reference \\
\hline Railway & Peat & VCC & Fabric & $\begin{array}{c}\mathrm{H}=7.6 \mathrm{~m}, \mathrm{~s}=1.6-2.2 \mathrm{~m} \\
\mathrm{~d}=0.51-0.56 \mathrm{~m}, \mathrm{P}_{\mathrm{c}}=6- \\
8 \%, \mathrm{~N}=1\end{array}$ & $\mathrm{~S}<6 \mathrm{~mm}$. & $\begin{array}{c}\text { Barksd and } \\
\text { Dobson } 1983\end{array}$ \\
\hline $\begin{array}{l}\text { Near bridge } \\
\text { abutment }\end{array}$ & Soft clay & $\begin{array}{l}\text { Concrete } \\
\text { pile }\end{array}$ & $\begin{array}{l}\text { Membrane } \\
\text { (paraweb) }\end{array}$ & $\begin{array}{c}\mathrm{H}=9 \mathrm{~m}, \mathrm{~s}=3.5-4.5 \mathrm{~m} \\
\mathrm{~d}=1.1-1.5 \mathrm{~m}, \mathrm{P}_{\mathrm{c}}=5-14 \% \\
\mathrm{~N}=1\end{array}$ & $\begin{array}{c}\text { No apparent } \\
\text { differential } \\
\text { deformation } \\
\text { adjacent to bridges. }\end{array}$ & $\begin{array}{c}\text { Reid and } \\
\text { Buchanan } \\
1984 .\end{array}$ \\
\hline $\begin{array}{l}\text { Bridge } \\
\text { Approach }\end{array}$ & $\begin{array}{l}\text { Alluvial } \\
\text { silty and } \\
\text { clayey soils }\end{array}$ & $\begin{array}{l}\text { Timber } \\
\text { piles } \\
\text { with } \\
\text { concrete } \\
\text { caps }\end{array}$ & Fabric & $\begin{array}{c}\mathrm{H}=3.5 \mathrm{~m}, \mathrm{~s}=1.5 \mathrm{~m}, \\
\mathrm{~d}=0.8 \mathrm{~m}, \mathrm{P}_{\mathrm{c}}=28.4 \%, \\
\mathrm{~N}=1\end{array}$ & N/A & $\begin{array}{l}\text { Broms and } \\
\text { Wong } 1985\end{array}$ \\
\hline $\begin{array}{l}\text { Bridge } \\
\text { Approach }\end{array}$ & $\begin{array}{l}\text { Loose sand } \\
\text { and marine } \\
\text { clay }\end{array}$ & $\begin{array}{l}\text { Timber } \\
\text { piles } \\
\text { with } \\
\text { concrete } \\
\text { caps } \\
\end{array}$ & Geotextile & $\begin{array}{c}\mathrm{H}=1.5, \mathrm{~s}=1.5 \mathrm{~m}, \\
\mathrm{~d}=0.83 \mathrm{~m}, \mathrm{P}_{\mathrm{c}}=30.6 \%\end{array}$ & N/A & $\begin{array}{l}\text { Broms and } \\
\text { Wong } 1985\end{array}$ \\
\hline Railway & $\begin{array}{l}\text { Very soft } \\
\text { alluvium } \\
\text { and peat }\end{array}$ & $\begin{array}{l}\text { Concrete } \\
\text { pile }\end{array}$ & Geotextile & $\begin{array}{c}\mathrm{H}=3-5 \mathrm{~m}, \mathrm{~s}=2.75 \mathrm{~m} \\
\mathrm{~d}=1.4 \mathrm{~m}, \mathrm{P}_{\mathrm{c}}=20 \%, \mathrm{~N}=1\end{array}$ & $\begin{array}{c}\text { No discernible } \\
\text { differential } \\
\text { settlements between } \\
\text { existing and new } \\
\text { railways }\end{array}$ & $\begin{array}{c}\text { Jones et al. } \\
1990\end{array}$ \\
\hline Roadway & $\begin{array}{l}\text { Soft silty } \\
\text { organic clay } \\
\text { and peat }\end{array}$ & $\begin{array}{l}\text { Concrete } \\
\text { pile }\end{array}$ & Geogrid & $\begin{array}{c}\mathrm{H}=2.5 \sim 3.0 \mathrm{~m}, \mathrm{~s}=3.0 \mathrm{~m} \\
\mathrm{~d}^{\prime}=1.0 \mathrm{~m} \\
\mathrm{P}_{\mathrm{c}}=11 \%, \mathrm{~N}=3\end{array}$ & $\begin{array}{l}\text { After four year of } \\
\text { service, no sign of } \\
\text { excessive } \\
\text { settlements or } \\
\text { distress of surface }\end{array}$ & $\begin{array}{c}\text { Card and Carter } \\
1995\end{array}$ \\
\hline $\begin{array}{l}\text { Highway } \\
\text { and } \\
\text { tramway }\end{array}$ & $\begin{array}{l}\text { Loose fill, } \\
\text { peat and } \\
\text { organic clay }\end{array}$ & VCC & Geogrid & $\begin{array}{c}\mathrm{H} \leq 1.5 \mathrm{~m}, \mathrm{~s}=1.8-2.5 \mathrm{~m}, \\
\mathrm{~d}=0.55 \mathrm{~m}, \mathrm{P}_{\mathrm{c}}=9-17 \%, \\
\mathrm{~N}=2-3\end{array}$ & N/A & $\begin{array}{l}\text { Topolnicki } \\
1996\end{array}$ \\
\hline Railway & $\begin{array}{l}\text { Peat and } \\
\text { soft organic }\end{array}$ & $\begin{array}{l}\text { Driven } \\
\text { pile }\end{array}$ & Geogrid & $\begin{array}{c}\mathrm{H} \geq 2.0 \mathrm{~m}, \mathrm{~s}=1.90 \mathrm{~m} \\
\mathrm{a}=1.1 \mathrm{~m}, \mathrm{P}_{\mathrm{c}}=35 \% \\
\mathrm{~N}=3\end{array}$ & $\begin{array}{c}\mathrm{S}_{\mathrm{c}}=10 \mathrm{~mm}, \mathrm{~S}_{\mathrm{s}}=30- \\
50 \mathrm{~mm}, \mathrm{t}=3 \mathrm{yrs}\end{array}$ & $\begin{array}{l}\text { Brandl et al. } \\
\quad 1997\end{array}$ \\
\hline $\begin{array}{c}\text { Bridge } \\
\text { embankme } \\
n t\end{array}$ & $\begin{array}{l}\text { Organic } \\
\text { clay }\end{array}$ & $\begin{array}{l}\text { Deep- } \\
\text { mixing } \\
\text { columns }\end{array}$ & Geotextile & $\begin{array}{c}\mathrm{H}=1.8 \mathrm{~m}, \mathrm{P}_{\mathrm{c}}=37.5 \% \\
\mathrm{~N}=1\end{array}$ & $\begin{array}{c}\mathrm{S}_{\mathrm{c}}=100 \mathrm{~mm}, \\
\mathrm{~S}_{\mathrm{s}}=120 \mathrm{~mm}, \mathrm{t}>5 \mathrm{yrs} .\end{array}$ & $\begin{array}{c}\text { Forsman et al. } \\
1999\end{array}$ \\
\hline Railway & $\begin{array}{l}\text { Peat and } \\
\text { clay }\end{array}$ & $\begin{array}{l}\text { Concrete } \\
\text { Pile }\end{array}$ & Geogrid & $\begin{array}{c}\mathrm{H}=7.0 \mathrm{~m}, \mathrm{~s}=2.15 \mathrm{~m}, \\
\mathrm{~d}=1.1 \mathrm{~m}, \mathrm{P}_{\mathrm{c}}=26 \%, \mathrm{~N}=2\end{array}$ & $\mathrm{~S}=60 \mathrm{~mm}, \mathrm{t}=3.0 \mathrm{yr}$ & $\begin{array}{c}\text { Rehnman et al. } \\
1999\end{array}$ \\
\hline $\begin{array}{l}\text { Roadway } \\
\text { widening }\end{array}$ & $\begin{array}{l}\text { Soft clay } \\
\text { and organic } \\
\text { silt marsh } \\
\text { deposit } \\
\end{array}$ & $\mathrm{VCC}$ & Geogrid & $\begin{array}{c}\mathrm{H}=1.5 \sim 3.1 \mathrm{~m}, \mathrm{~s}=2.4 \mathrm{~m} \\
\mathrm{~d}=0.6 \mathrm{~m}, \mathrm{Pc}=4 \sim 16 \%\end{array}$ & $\begin{array}{l}\text { No excessive } \\
\text { settlement }\end{array}$ & $\begin{array}{l}\text { Han and Akins } \\
2002\end{array}$ \\
\hline Roadway & $\begin{array}{l}\text { Mainly } \\
\text { peaty and } \\
\text { clayey } \\
\text { material }\end{array}$ & $\begin{array}{l}\text { Driven- } \\
\text { cast-in- } \\
\text { situ pile }\end{array}$ & $\begin{array}{l}\text { Uniaxial } \\
\text { geogrid }\end{array}$ & $\begin{array}{c}\mathrm{H}=9.5 \mathrm{~m}, \mathrm{~s}=2.7 \sim 3.2 \mathrm{~m}, \\
\mathrm{~d}=0.37 \sim 0.425, \\
\mathrm{~d}^{\prime}=0.9 \mathrm{~m}, \mathrm{P}_{\mathrm{c}}=6 \sim 9 \%, \\
\mathrm{~N}=2\end{array}$ & N/A & $\begin{array}{l}\text { Wood et al. } \\
2004\end{array}$ \\
\hline Roadway & $\begin{array}{c}\text { Landfill } \\
\text { material } \\
\text { including } \\
\text { house hold } \\
\text { waste and } \\
\text { rubbish } \\
\end{array}$ & VCC & Geogrid & $\begin{array}{c}\mathrm{H}=2 \mathrm{~m}, \mathrm{~s}=2.1 \mathrm{~m}, \\
\mathrm{~d}=0.6 \mathrm{~m}, \mathrm{~d}^{\prime}=0.8 \mathrm{~m}, \\
\mathrm{P}_{\mathrm{c}}=18 \% \text { (triangular } \\
\text { pattern) } \\
\mathrm{N}=2\end{array}$ & N/A & $\begin{array}{c}\text { Blumel et al. } \\
2004\end{array}$ \\
\hline Roadway & Peat & $\begin{array}{l}\text { Deep } \\
\text { mixing } \\
\text { columns }\end{array}$ & Geogrid & $\begin{array}{c}\mathrm{H}=10 \mathrm{~m}, \mathrm{~s}=0.9 \mathrm{~m} \\
\mathrm{~d}=0.35 \mathrm{~m}, \mathrm{~N}=1\end{array}$ & N/A & $\begin{array}{l}\text { Yan et al. } \\
2005\end{array}$ \\
\hline
\end{tabular}

Note: $\mathrm{H}$ - embankment fill height; $\mathrm{s}$ - pile spacing at centers; a - cap width; $\mathrm{d}$ - pile diameter; $\mathrm{d}^{\prime}$-pile cap diameter, $\mathrm{P}_{\mathrm{c}}$ - percent coverage of pile caps; $\mathrm{N}$ - number of geosynthetics; $\mathrm{S}$ - overall settlement; $\mathrm{S}_{\mathrm{c}}$ - settlement on the caps; $\mathrm{S}_{\mathrm{s}}$ - settlement between caps; $\mathrm{t}$ - time; VCC - vibro-concrete column. 
Table 1-4. Guideline for the Design of Necessary Coverage by Pile Caps

(Rathmayer 1975)

\begin{tabular}{c|cc}
\hline Height of embankment, $H$ & \multicolumn{2}{|c}{ Coverage by pile caps, \% } \\
\cline { 2 - 3 }$(\mathrm{m})$ & Crushed-rock fill & Gravel fill \\
\hline $1.5 \sim 2.0$ & $50 \sim 70$ & $>70$ \\
$2.0 \sim 2.5$ & $40 \sim 50$ & $55 \sim 70$ \\
$2.5 \sim 3.0$ & $30 \sim 40$ & $45 \sim 55$ \\
$3.0 \sim 3.5$ & $30 \sim 40$ & $40 \sim 45$ \\
$3.5 \sim 4.0$ & $>30$ & $>40$ \\
\hline
\end{tabular}

Table 1-4 shows that even when very high quality fill material is used, coverage has to be higher than $30 \%$ to ensure adequate performance. In addition, inclined columns are always needed to counteract the horizontal thrust of the embankment fill as shown in Fig. 1-1 (Jones et al. 1990) because in-situ soil is usually too soft to help vertical columns take any bending load (Broms and Wong 1985). To avoid differential settlements at the base of the embankment and tilt of pile caps being reflected to the surface of the embankment, a minimum thickness of embankment fill is required for a column supported embankment.

To create a more economical embankment system, basal reinforcement has been introduced into CS embankments. The reinforcement can be rigid or flexible (Han 1999). Rigid reinforcement, such as metal strips, bars, or even concrete beams or slabs, are effective in transferring load by their flexural resistance; however, they are expensive and prone to corrode (Magan 1994; Han 1999). Flexible reinforcement, i.e., geosynthetics, can provide a better solution in terms of economy and durability. 
Geosynthetics transfer load by their tensile resistance, which will be addressed later in this section.

In addition, geosynthetic reinforcement is able to effectively counteract the thrust from the embankment as shown in Fig. 1-2. This benefit has been demonstrated by numerical analyses and tests (Chen et al. 2005). As a consequence, inclined columns are often excluded under GRCS embankments.

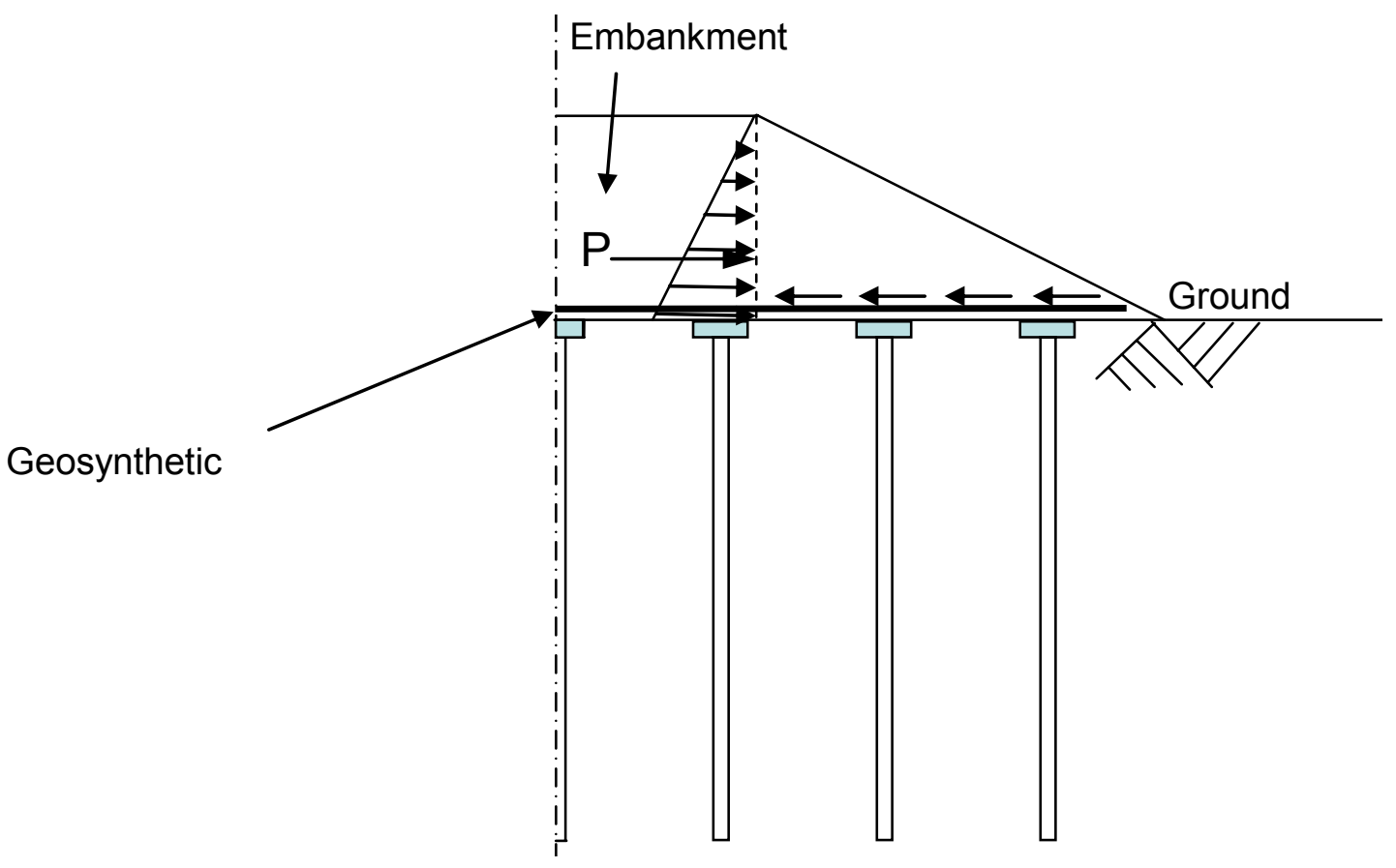

Fig. 1-2. Geosynthetic Preventing Slope Lateral Spreading

In summary, GRCS embankments have demonstrated a number of advantages over CS embankments as follows: 
(1). Columns with larger spacing and smaller heads could be used, which reduces the cost of piling (Jones et al. 1990);

(2). The use of geosynthetic layer can reduce primary settlements and long-term secondary settlements (Bell et al. 1994). As a result, it is not necessary to build GRCS embankments as thick as CS embankments to prevent the differential settlements at the base being reflected to the crest (Broms and Wong 1985);

(3). The construction disturbance of GRCS embankments is less than that of CS embankments, which could reduce settlements induced by disturbance (Miura and Madhav 1994);

(4). Geosynthetic reinforcement is able to counteract thrust from the embankment, which eliminates the need for inclined columns;

(5). Geosynthetics play a very important role in increasing the factor of safety against deep-seated failure of embankment slopes (Han 2003).

\subsection{Purpose and Scope of This Study}

As a relatively new technology, the load transfer mechanisms in the GRCS embankments have not been well understood and the post-construction behavior of the GRCS embankments has not been well investigated. The primary purpose of this study is to investigate the load transfer mechanisms and the post-construction behavior of the GRCS embankments considering a number of key influence factors, 
including soft soil modulus, soft soil friction angle, soft soil permeability, column modulus, column spacing, geosynthetic tensile stiffness and construction rate. The investigated post-construction behavior includes post-construction settlement, tension in geosynthetic, stress transfer, and consolidation. To meet the objective of this study, a mechanical model was coupled with a hydraulic model in 2D and 3D numerical analyses to consider the consolidation of the GRCS embankment. The behavior of the GRCS embankments was framed in a time domain. The factors were rated based on their degree of influence on the performance of the GRCS embankments to provide guidance for practical use.

The secondary purpose of this study is to evaluate the validity of an approach analyzing a 3D problem by a converted $2 \mathrm{D}$ model. In practice, columns are often installed in a square pattern, which is a three-dimensional problem. Since 3D dimensional modeling is much more complicated and time-consuming than $2 \mathrm{D}$ dimensional modeling, researchers often simplify a 3D problem into a $2 \mathrm{D}$ problem according to an area-weighted area conversion. This simplification should be justified by comparing the results of the $3 \mathrm{D}$ case with those of the converted 2D case.

\subsection{Organization of This Dissertation}

Including this chapter, the whole dissertation is divided into seven chapters. 
Chapter Two: Literature Review. In this chapter, load transfer mechanisms were reviewed, typical design methodologies were compared, and past research activities and findings were summarized, and their limitations were identified.

Chapter Three: Model Calibrations. In this chapter, a selected case was used to calibrate 2D and 3D numerical models to ensure the reasonableness and adequacy of these models. The numerical results were compared with field settlement and geosynthetic strain measurements.

Chapter Four: Two-dimensional Parametric Study. The selected baseline was presented and discussed in details. The 2D parametric study results were presented in terms of the influence of factors on total settlement, differential settlement, distortion, tension in geosynthetic, effective vertical stress, stress concentration ratio, excess pore water pressure, and degree of consolidation. The investigated influence factors include soft soil modulus, soft soil friction angle, soft soil permeability, DM column modulus, column spacing, geosynthetic tensile stiffness, and construction rate.

Chapter Five: Three-dimensional Parametric Study. The strategy of converting a 2D case into a corresponding 3D case was stated. The 3D parametric study was conducted. The parametric study results are presented in terms of the influence factors on total settlement, differential settlement, distortion, tension in geosynthetic, 
effective vertical stress, stress concentration ratio, excess pore water pressure, and degree of consolidation.

Chapter Six: Comparison of Two-dimensional and Three-dimensional Studies. The results from the $2 \mathrm{D}$ cases were compared with those of the corresponding $3 \mathrm{D}$ cases to evaluate the validity of simplifying a $3 \mathrm{D}$ case to a $2 \mathrm{D}$ case by the area weighted average conversion. The influence of the investigated factors on maximum settlement, maximum distortion, maximum tension in geosynthetic, maximum stress concentration ratio, and degree of consolidation was rated.

Chapter Seven: Conclusions and Recommendations. The results of this study were summarized and recommendations for future research were presented. 


\section{CHAPTER TWO}

\section{LITERATURE REVIEW}

\subsection{Introduction}

The objective of this study requires an overview of existing knowledge on GRCS embankments. The literature review is presented in this chapter in three sections: load transfer mechanisms of GRCS embankments, current design methodologies for GRCS embankments, and current research status. In the section concerning load transfer mechanisms, soil arching and tensioned membrane theories are presented and compared. In the section concerning current design methodologies for GRCS embankments, British, Swedish, and German design methodologies are presented and compared and the deviations among them are identified. In the section concerning current research status, past research activities and findings on GRCS embankments are tabulated.

\subsection{Load Transfer Mechanisms of GRCS Embankments}

The principle of the load transfer platform in GRCS embankments is to transfer the load from soft soil to relatively stiffer columns through soil arching and tensioned 
membrane effects. These two effects are presented in a plane strain condition in Fig. 2.1. Provided the foundation soil is homogenous and no columns exist, the fill above the foundation soil should settle evenly. Under this condition, the vertical stress at the base of the fill is the product of the unit weight of the fill and the depth (i.e., $\left.\sigma_{z}=\gamma \times z\right)$. However, when the columns are included, the fill above the foundation soil tends to settle relative to the stationary surrounding fill above the columns. The surrounding fill has a tendency to resist the downward movement of the fill while the downward movement of the fill attempts to drag the surrounding fill. Consequently, this relative movement induces friction between the moving and stationary fill materials. The induced friction transfers some load from the potentially moving fill to the stationary fill. Because the weight of the fill is unchanged all the time, the vertical stress under the moving fill is less than the overburden stress. On the other hand, the vertical stress under the stationary fill is higher than the overburden stress. A system of shear stresses, induced by relative displacement within soil mass, is the mechanism through which load is transferred from one location to another. This phenomenon is called soil arching. At the same time, as the soil mass moves downward, the geosynthetic sheet bridging over the span of two columns is stretched. As a result, a tension, T, develops within the geosynthetic sheet tangentially. The vertical component of the tension has the effect of holding the downward moving soil mass. However, the vertical component of the tension also has the effect of applying additional load on the columns. Through the tension developed in a deformed sheet, the applied load is transferred from the foundation soil to the columns. This is called 
the tensioned membrane effect. The combined effect of soil arching and tensioned membrane is the mechanism of the load transfer platform in GRCS embankments.

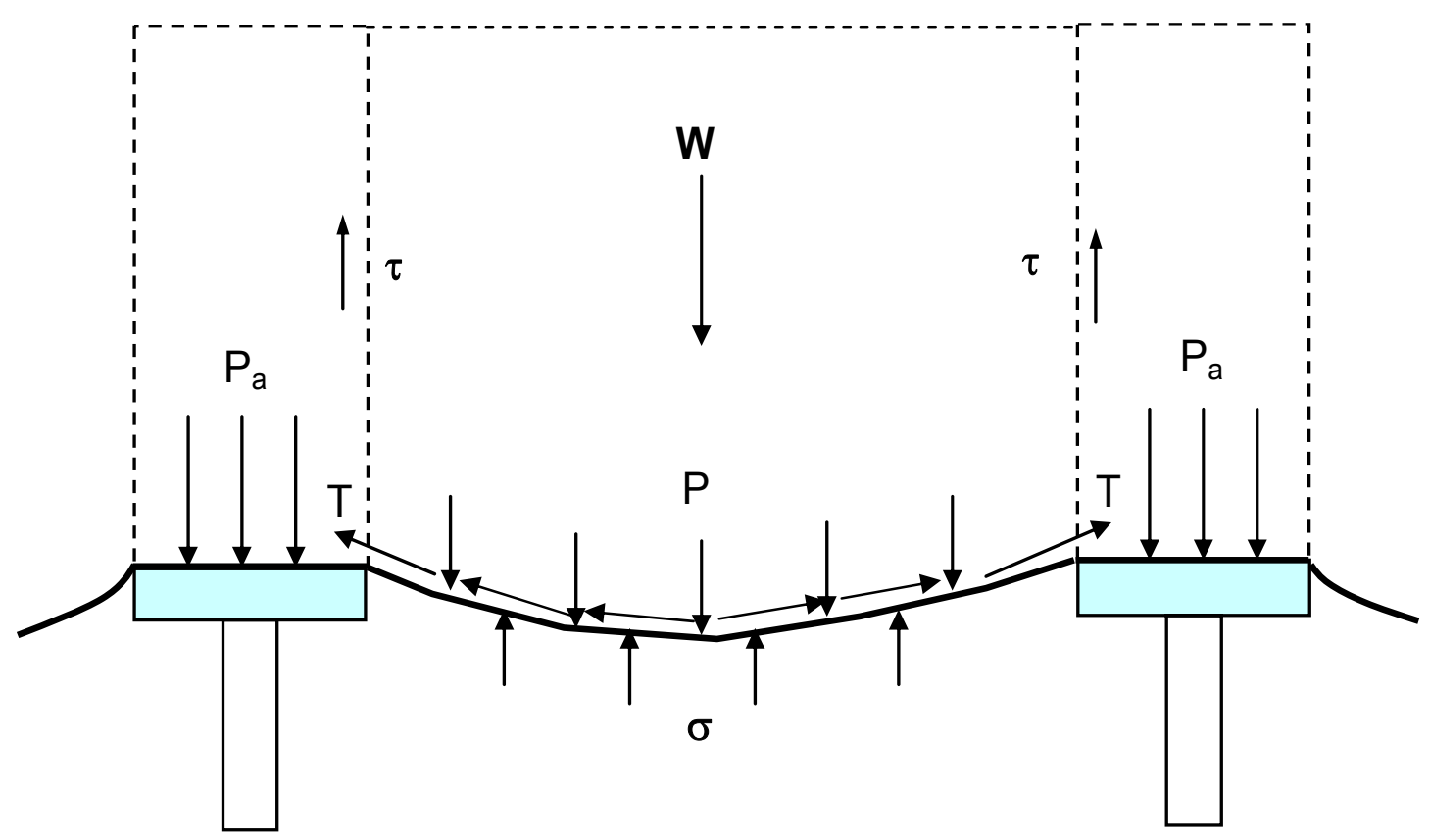

Fig. 2-1. Soil Arching and Tensioned Membrane Effects in GRCS Embankments (Han 1999)

\subsubsection{Soil Arching Theories}

Soil arching is one of the most common phenomena existing in the field (Terzaghi 1943), which was defined by McNulty (1965) as "the ability of a material to transfer loads from one location to another in response to a relative displacement between the locations". Soil arching is commonly evaluated by an index, the soil arching ratio, $\rho$, 
which reflects the degree of load transferred. It is the ratio of the average vertical stress above the foundation soil between supports to the overburden stress plus the surcharge if the load is in a large area:

$$
\rho=\frac{\sigma_{s}}{\gamma H+q}
$$

where $\sigma_{\mathrm{s}}$ - the average vertical stress over the foundation soil;

$\gamma$ - the unit weight of the embankment fill;

$\mathrm{H}$ - the height of the embankment fill;

$\mathrm{q}$ - the surcharge on the crest of the embankment.

When $\sigma_{\mathrm{s}}$ is equal to zero, i.e., all the loads are taken by the stiffer supports (columns), the soil arching ratio is equal to zero. This situation is ideal and only happens when a void exist under the fill. When $\sigma_{\mathrm{s}}$ is equal to $(\gamma \mathrm{H}+\mathrm{q})$, i.e., all the loads are taken by the foundation fill, the soil arching ratio is unity. This situation occurs for a uniform foundation. As long as stiffness difference exists between the foundation soil and the supports, some load must be transferred from the soil to the supports. In this case, the soil arching ratio is between zero and unity, i.e., $0<\rho<1$.

Since the late $19^{\text {th }}$ century, soil arching phenomena were investigated and different theories were proposed (Janssen 1895; Terzaghi 1936; Finn 1963; Hewllet and 
Randolph 1988; Low et al. 1994). The methods used to describe the soil arching effect can be divided into two categories: limit equilibrium (Agaiby and Jones 1995) and continuum mechanics based theories (Finn 1963). The representative methods of these theories are briefly discussed herein.

Limit equilibrium methods are always appealing to engineers due to their simplicity. Limit equilibrium methods assume a failure state with certain shapes and ranges of slip surfaces and make problems easily solved (Agaiby and Jones 1995). The main difference among all the limit equilibrium methods for soil arching is the assumed shape of soil arching, such as a flat arch acting like a lintel and a curved shape like an arch, a ring or a dome (Getzler et al. 1968; Handy 1985; Hewllet and Randolph 1988).

\section{Terzaghi’s Soil Arching Theory}

After performing a series of trapdoor tests, Terzaghi (1943) proposed a theoretical model to describe the soil arching phenomenon and provided an equation to calculate vertical stress above a yield trapdoor. Terzaghi's model is similar to that adopted by Janssen (1895) to investigate the pressure in silos. As shown in Fig. 2-2 (a), Terzaghi (1943) assumed that soil arching developed when the movement of the soil was restrained by two vertical planes passing through the outer edges of the span and a horizontal plane, above which no relative vertical movement existed. This plane was 
called the equal settlement plane, the location of which was to be determined. The soil mass above the equal settlement plane was treated as surcharge. After examining the vertical force equilibrium of any soil mass within the soil arching range (shown in Fig. 2-2 (b)), Terzaghi (1943) derived the following two equations to calculate the vertical stress, $\sigma_{v}$, and the soil arching ratio, $\rho$ :

$$
\begin{gathered}
\sigma_{v}=\frac{B(\gamma-c / B)}{K \tan \phi}\left(1-e^{-K z \tan \phi / B}\right)+q e^{-K z \tan \phi / B} \\
\rho=\frac{\sigma_{v}}{\gamma H+q}=\frac{B(\gamma-c / B)}{(\gamma H+q) K \tan \phi}\left(1-e^{-K z \tan \phi / B}\right)+\frac{q e^{-K z \tan \phi / B}}{\gamma H+q}
\end{gathered}
$$

where $\sigma_{\mathrm{v}}$ - vertical stress at depth $\mathrm{z}$;

$\mathrm{K}$ - coefficient of lateral earth pressure;

$2 \mathrm{~B}$ - width of the span;

c - cohesion of soil;

$\gamma-$ unit weight of soil;

$\phi-$ friction angle of soil;

$\mathrm{z}$ - depth from the equal strain plane. 


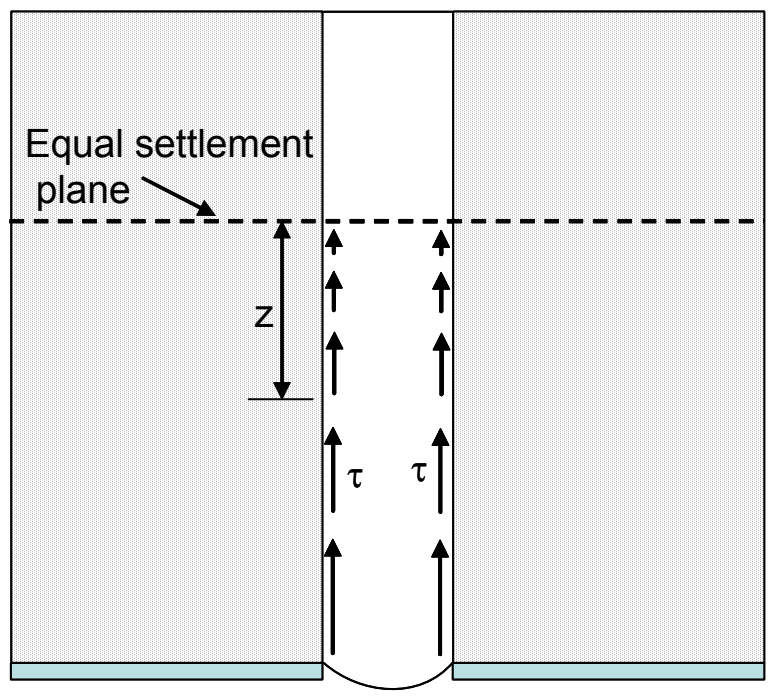

(a) Terzaghi's soil arching model

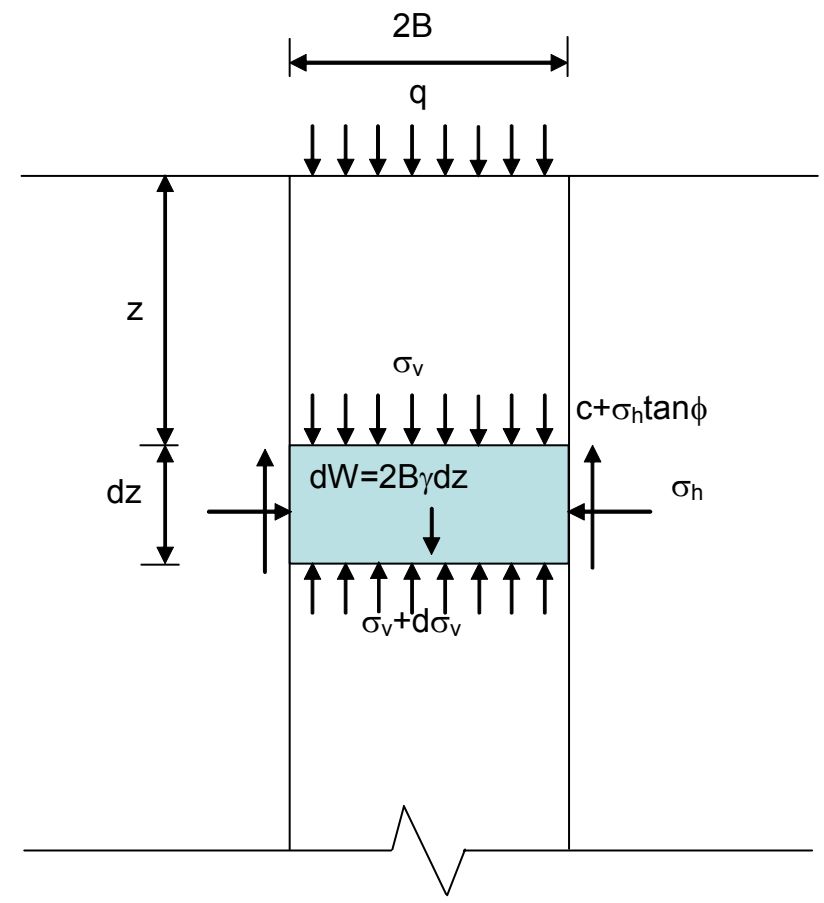

(b) Stress diagram

Fig. 2-2. Terzaghi’s Soil Arching Model 
To adopt the above two equations, the location of the equal settlement plane and the coefficient of lateral earth pressure, K, should be determined first. Terzaghi (1943) suggested that the equal settlement plane was located at a distance of $5 \mathrm{~B}$ above the trapdoor, which was 2.5 times the span. This suggested location of the equal settlement plane was consistent with the experimental results by Spangler and Handy (1982) and the analytical results by Finn (1963) and Mckelvey III (1994). However, different researchers have selected different coefficients of lateral earth pressure, $\mathrm{K}$. Due to the existence of shear stresses, the coefficient of lateral earth pressure, $\mathrm{K}$, would be different from $\mathrm{K}_{\mathrm{o}}$. Terzaghi (1943) suggested that $\mathrm{K}$ should be between 1 and 1.5, however, he did not provide any equation for K. Krynine (1945) and Handy (1985) both proposed equations to calculate K. Giroud (1990) compared the lateral earth pressure coefficient calculated from the equation proposed by Handy with the lateral earth pressure coefficient at rest $(\mathrm{K}=1-\sin \phi$ (Jacky 1944)) and concluded $\mathrm{K}$ as calculated by either Handy or Jacky's equation did not vary significantly with respect to friction angle, $\phi$.

Terzaghi's soil arching theory was derived based on a plane strain assumption. Kezdi (1975) and Chen et al. (2006) obtained the equations applicable to axisymmetric problems, which have similar forms to Terzaghi's.

Getzler et al. (1986) pointed out that inaccuracy would arise if the shape of the shear plane/sliding plane was not properly assumed. Terzaghi's theory is considered over- 
simplified as to the shape for soil arching. Hewllet and Randolph (1988) observed that curved soil arching developed between columns. This phenomenon was also observed by Othman and Pyrah (1996) to trace the particle movement to form soil arching.

\section{Hewllet and Randolph's Soil Arching Theory}

To understand load transfer mechanisms in column supported fill, Hewllet and Randolph (1988) conducted small scale model tests using dry sand. Based on the observed deformations in the fill, they proposed models (shapes and ranges) of soil arching under 2D (two-dimensional) and 3D (three-dimensional) conditions.

\section{Plane Strain Condition}

A plane strain condition may exist when the supports are continuous walls, for example, or when columns are installed tangent or secant to each other (Forsman et al. 1999). For Hewllet and Randolph's 2D model, soil arching was assumed to form above two walls with a semi-cylindrical shape, which was a horizontal vault band similar to masonry arches in cathedrals (Fig. 2-3). 


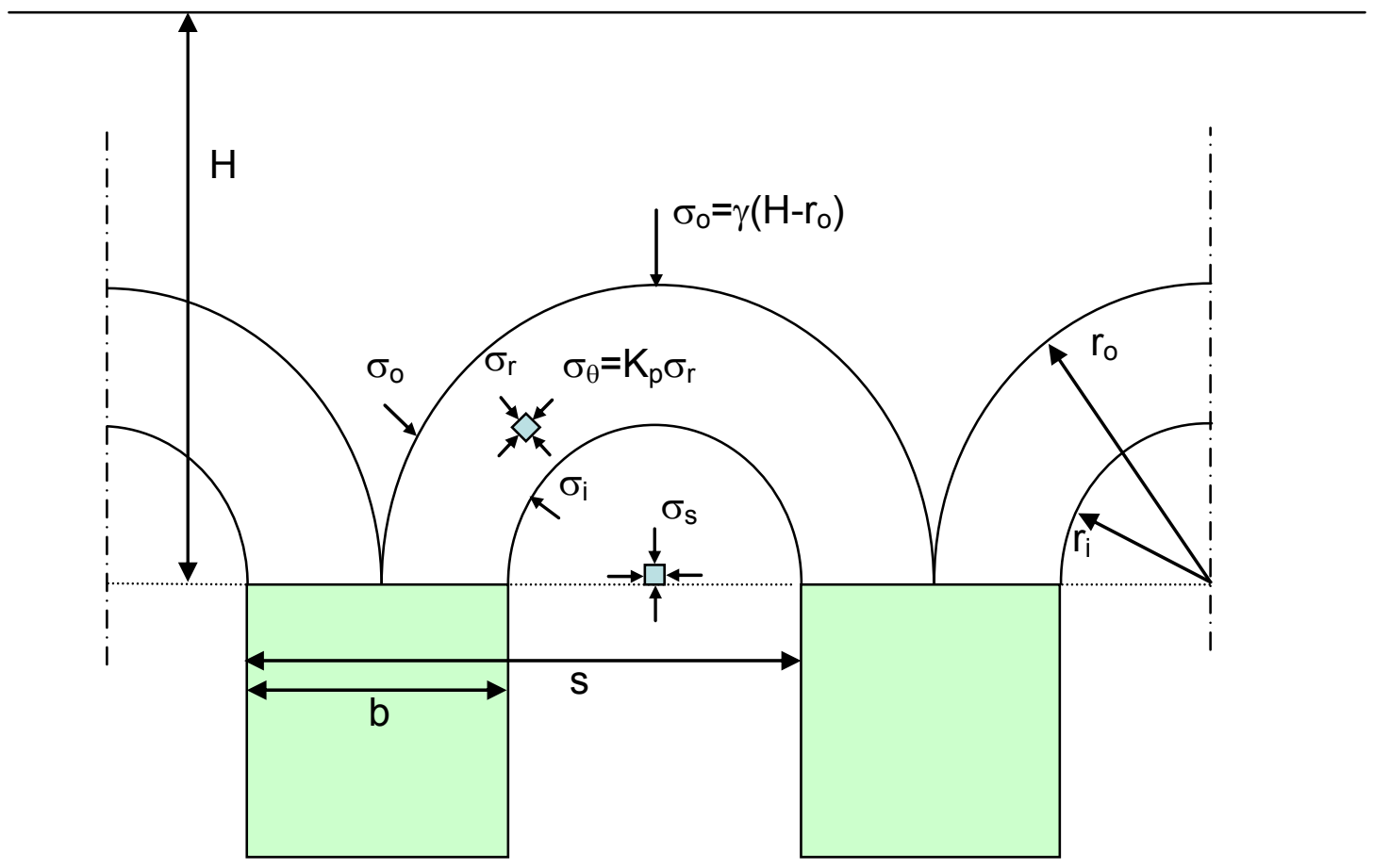

Fig. 2-3. Soil Arching above Continuous Supports (Hewllet and Randolph 1988)

By ignoring soil self weight within the soil arching and assuming that the zone located at the crown first reached limit equilibrium, the differential equation in terms of equilibrium in the radial direction was obtained. The derivations yielded the following solution to the soil arching ratio:

$$
\rho=\frac{\sigma_{i}}{\gamma H}=\frac{1}{H}\left(H-\frac{s}{2}\right)\left(\frac{s-b}{s}\right)^{\left(K_{p}-1\right)}
$$

where $\sigma_{i}$ - the vertical stress in the interior of soil arching, which equals to the radial stress at $\mathrm{r}=(\mathrm{s}-\mathrm{b}) / 2$;

$\mathrm{b}$ - the width of the support; 
$\mathrm{s}$ - the center to center spacing of the neighbored supports;

$\mathrm{K}_{\mathrm{p}}$ - the passive earth pressure coefficient;

$\mathrm{H}$ - the height of the embankment fill.

Low et al. (1994) verified that under a plane strain condition, the critical zone was always located at the crown in theory. They also refined the derivations by including soil weight into the formulae and verified their refined solution by model tests.

Other forms of soil arching under a plane strain condition have also been proposed, such as semi-cylinder (Villard 2000) and catenary (Handy 1985; Harrop-Williams 1989). Details on these soil arching models are referred to these papers.

\section{Square Pattern Condition}

It is more common that columns below embankments are installed in isolated patterns, such as a triangular pattern and a square pattern. Based on the observation of model tests, Hewllet and Randolph (1988) concluded that soil arches forming above columns in a square pattern had the shape of vault as shown in Fig. 2-4. 


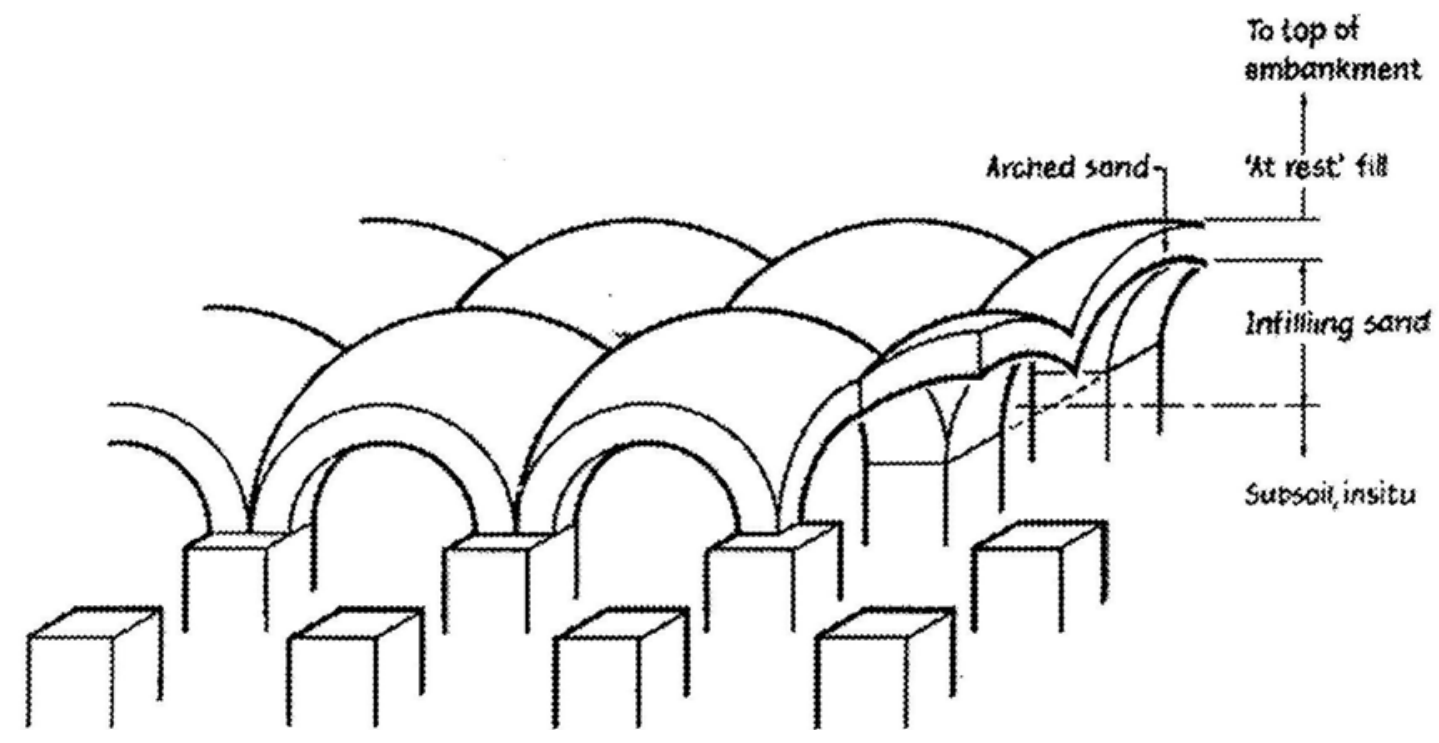

Fig. 2-4. Soil Arches above Column Grid of Square Pattern (Hewllet and Randolph 1988)

Different from the $2 \mathrm{D}$ condition, failure could occur either at the crown or at the contact of the embankment fill and the column heads for a 3D condition. When the height of the embankment fill, $\mathrm{H}$, is relatively low as compared with the center-tocenter span of the columns, s, the failure at the crown governs. However, as the embankment height is increased, the failure at the contact of the embankment fill and the column heads controls. The above statement is consistent with the observation of the penetration of columns into the embankment fill (Broms and Wong 1985).

Therefore, the soil arching ratio, $\rho$, can be expressed in two forms (the failure at the crown and the failure at the contact): 
(a) Failure at the crown

$$
\rho=\frac{1-E}{1-\delta^{2}}=A-A B+C
$$

where $\mathrm{E}-$ efficacy of the columns, $E=1-\left(1-\delta^{2}\right)(A-A B+C)$;

$$
\begin{aligned}
& \delta=b / s \\
& A=(1-\delta)^{2(K p-1)} \\
& B=\frac{s}{\sqrt{2} H}\left(\frac{2 K_{p}-2}{2 K_{p}-3}\right) ; \\
& C=\frac{s-b}{\sqrt{2} H}\left(\frac{2 K_{p}-2}{2 K_{p}-3}\right) .
\end{aligned}
$$

(b) Failure at the contact of the embankment fill and the column heads

$$
\rho=\frac{1-E}{1-\delta^{2}}=\frac{1}{1+\beta} \cdot \frac{1}{1-\delta^{2}}
$$

where $\beta=\frac{2 K_{p}}{K_{p}+1} \cdot \frac{1}{1+\delta} \times\left[(1-\delta)-K_{p}-\left(1+\delta K_{p}\right)\right]$. 
The case with the higher soil arching ratio dominates the actual situation. Chen et al. (2004) suggested that the lateral earth pressure was less than $K_{p}$ before the limit equilibrium state was reached and a reduction coefficient, $\alpha$, should be applied.

Hewllet and Randolph's models are included in the German design methodology for CS and GRCS embankments.

\section{Finn's Theory}

Finn (1963) used continuum mechanics to solve an earth pressure distribution due to soil arching under a 2D condition in terms of displacements (translation and rotation). In his model, the soil does not reach the limit equilibrium state (i.e., soil is in an elastic state) and the movement of the yielding base is either pure translation (Fig. 2.5 (a)) or pure rotation (Fig. 2.5 (b)). Any other forms of movement could be approximated by a combination of pure translation and pure rotation. Finn (1960 and 1963) published analytical solutions for stresses induced by translation and rotation, which are called Finn's boundary value solutions. Finn's solutions were well verified against the existing data. To use Finn's boundary value solutions, it is important to ensure that soil is in an elastic state. However, Finn's solutions contain singularity points $(\mathrm{x}=\mathrm{y}=0 ; \mathrm{x}=\mathrm{b} / \mathrm{x}=-\mathrm{b}, \mathrm{y}=0)$ so that the integration of the stress values on the displaced support becomes impossible. Consequently, Finn's method cannot be used to calculate the soil arching ratio. 


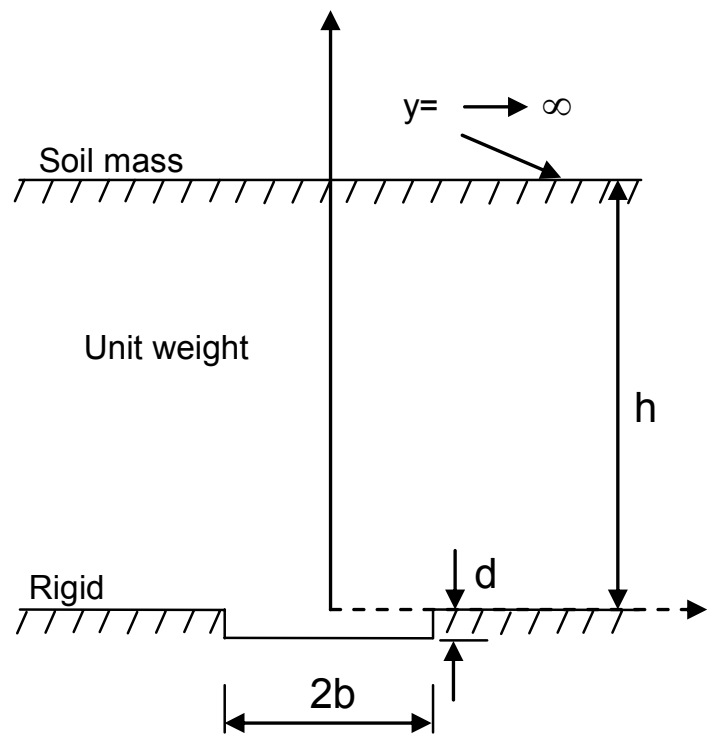

(a)

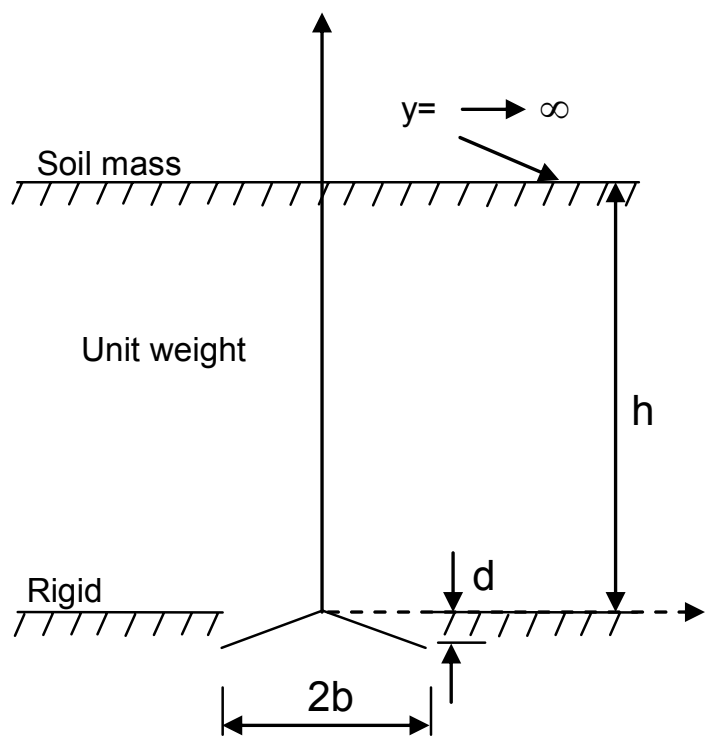

(b)

Fig. 2-5. Finn's Pure Translation and Pure Rotation Models (Finn 1963)

A hypothesis was proposed to limit the maximum stresses at the singularity points to obtain the integration of the induced stresses (Chelapati 1964). However, due to the complexity of the problem, no analytical closed-form solution was obtained. Numerical integration could be an alternative. However, it would likely be too timeconsuming even for a minor case (Getzler et al. 1968), therefore, it is not practical. Another concern of Finn's method is that the soil is treated as a linearly elastic material. In reality, most soils have nonlinear stress-strain relationships. 


\section{Further Discussion on Soil Arching}

Even though the soil arching phenomenon was identified more than a century ago, due to its complexity, no comprehensive soil arching theory has been developed. Ideally, a soil arching theory should be capable of considering the following four factors, which primarily influence the development of soil arching (Terzaghi 1943; Finn 1960; Gelzler et al. 1986): (1) the properties of the support (columns in this study), especially its stiffness; (2) the properties of the soil medium, such as stiffness, friction angle, density, etc.; (3) the geometry of the whole system, for instance, the thickness of the soil medium, the dimension of the span, and the dimension of the support; and (4) the boundary condition including a $2 \mathrm{D}$ or $3 \mathrm{D}$ problem, the surcharge, and the allowable differential settlement.

Terzaghi (1943) assumed absolute rigid supports in his model. This assumption is reasonable when the supports are much stiffer than the soil medium. In real applications, however, some supports, such as stone columns, may not be that much stiffer than the surrounding soil. The assumption of the rigid support may not be valid for this kind of situation.

As demonstrated by all the theories except Finn's, the friction angle of the soil affects the efficiency of the load transfer. As Hewllet and Randolph (1988) pointed out, the soil above the supports may yield first. Therefore, the better the soil, the more the 
load transfer. However, Mckelvey III (1994) pointed out that the available theories neglected classical geotechnical property, such as the change of volume under shear.

The geometry of the whole system has influence on the range and shape of soil arching. For instance, Terzaghi (1943) concluded that the influence of soil arching could extend vertically as high as 5 times of the clear span, while Hewllet and Randolph (1988) found that the influence of soil arching would go to as high as the clear span above the column heads. BS 8006 (BSI 1995) specified that the full soil arching occurred at a height of 1.4 times the clear span.

As discussed earlier, differential settlement induces shear stresses in soil, which is the intrinsic reason for soil arching. There is general agreement that the extent of soil arching depends on the magnitude of differential settlement. The limit equilibrium methods assume that yielding of the soil happens at or above the supports under excessive differential settlement. Therefore, these soil arching theories typically underestimate the soil arching ratio if the differential settlement is not high enough to reach the limit equilibrium state. 


\subsubsection{Tensioned Membrane Theories}

In general, a flexible sheet or membrane used to support a vertical load over a span is referred as the "membrane effect". In geotechnical engineering, geosynthetics are often used as reinforcement to support a vertical load over a span, such as geosynthetics over voids and geosynthetics over columns. Gourc and Villard (2000) defined the "membrane effect" as "the ability of a geosynthetic sheet to be deformed, thereby absorbing forces initially perpendicular to its surface tension."

To quantify the membrane effect, a number of tensioned membrane models have been proposed. Most of them were originally developed for the design of soil-geosynthetic systems over voids (including tension cracks, sinkholes, dissolution cavities, and localized depression). They have also been used in the design of GRCS embankments recently. Among all the methods, Delmas' (Delmas 1979), Giroud et al's (Giroud et al. 1990) and British Standard Method (BSI 1994) are the three most commonly used tensioned membrane theories in geotechnical engineering.

\section{Delmas' Method}

Delmas (1979) published an analytical method to calculate the tension deformation developed in a horizontal sheet above a trench subjected to a uniformly distributed vertical load as shown in Fig. 2-6 (a). 


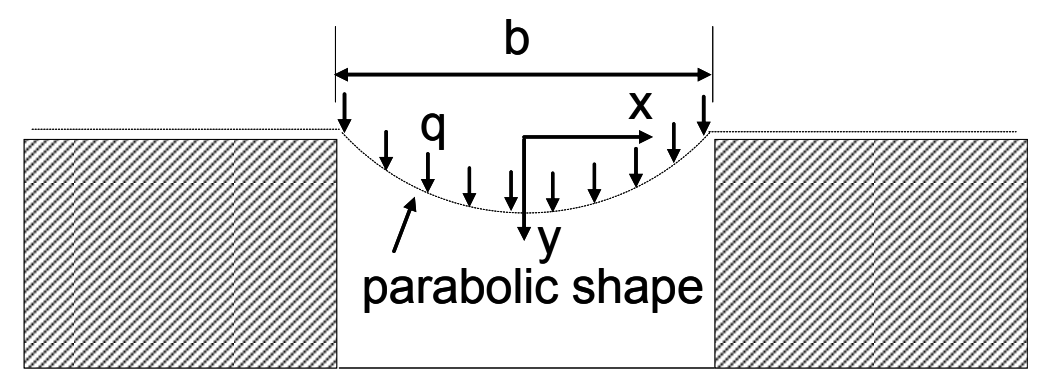

(a) Parabolic deformed layer (Delmas 1979)

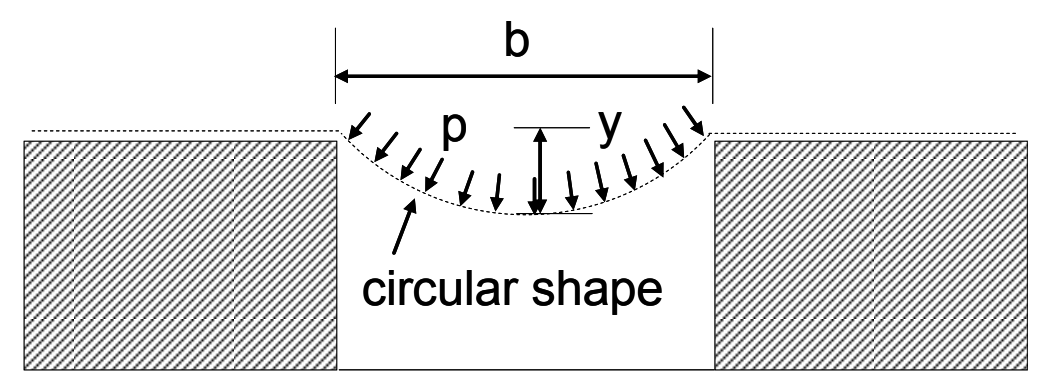

(b) Circular deflected membrane layer (Giroud et al. 1990)

Fig. 2-6. Delmas' and Giroud's Membrane Models

Delmas (1979) assumed that the load remained vertical and the deformed sheet had a parabolic shape, which can be expressed as:

$$
Y(x)=\frac{q b^{2}}{8 T_{0}}-\frac{q x^{2}}{2 T_{0}}
$$

The maximum tension, $\mathrm{T}_{\max }$, and the maximum deformation, $\mathrm{y}_{\max }$, can be calculated as: 


$$
\begin{gathered}
T_{\max }=\frac{\sqrt{4 T_{0}^{2}+q^{2} b^{2}}}{2} \\
y_{\text {max }}=\frac{q L^{2}}{8 T_{0}}
\end{gathered}
$$

where $\mathrm{T}_{0}$ - the horizontal component of $\mathrm{T}_{\max }$, which can be calculated using Eqs. (210) and (2-11).

$$
\begin{gathered}
T_{0}=\frac{q b}{2 \beta} \\
\frac{q L}{J}=\frac{3\left[\beta \sqrt{1+\beta^{2}}+\operatorname{ArgSh}(\beta)-2 \beta\right]}{3+\beta^{2}}
\end{gathered}
$$

\section{Giroud et al's Method}

Giroud et al. (1990) proposed another analytical solution to account for the membrane effect. They assumed that the deformed membrane sheet had a circular shape and the load acted normally to the deformed sheet as shown in Fig. 2-6 (b). They ignored the friction between the soil and the membrane sheet to obtain a uniform strain distribution.

The tension developed in a geosynthetic sheet over a 2D void (i.e., trench) can be expressed in terms of a dimension factor, $\Omega$ : 


$$
T=p b \Omega
$$

where $\mathrm{T}$ - the tension in the membrane;

$\mathrm{p}$ - the pressure normal to the membrane.

The dimension factor, $\Omega$, is a piecewise function, which can be determined using Eqs. (2-13) and (2-14) at a certain strain:

$$
\begin{aligned}
& 1+\varepsilon=2 \Omega \sin ^{-1}\left(\frac{1}{2 \Omega}\right) \quad(y / b \leq 0.5) \\
& 1+\varepsilon=2 \Omega\left[\pi-\sin ^{-1}\left(\frac{1}{2 \Omega}\right)\right] \quad(y / b \geq 0.5)
\end{aligned}
$$

where $\varepsilon$ - the strain in the membrane;

$$
\begin{aligned}
& \mathrm{y} \text { - the maximum deflection; } \\
& \mathrm{b} \text { - the width of the void. }
\end{aligned}
$$

Giroud et al's method has been included in several design methodologies of GRCS embankments.

As to the membrane above a circular void, Giroud et al. (1990) suggested that even though the deflected shape was not a sphere, the diameter, $2 \mathrm{r}$, should be used to 
substitute the width, b, to obtain an approximate solution of the tension, T. Based on Giroud et al's method, the tension developed in the geosynthetic sheet is uniform. However, experimental tests (Fluent et al. 1986; Rogbeck et al. 1998) and numerical analysis (Han and Gabr 2002) have showed that the maximum strain occurred at the edge of the columns.

\section{British Standard Method}

Different from Delmas' (1979) and Giroud et al's (1990) methods, the membrane method included in BS 8006 (BSI 1995) was especially developed to design the GRCS system. It was assumed that the weight of the presumed load is taken by the reinforcement strips between the pile caps (i.e., the hatched area in Fig. 2-7) and the load was distributed horizontally along the bridged span instead of the deformed length, which led to a parabolic deformed shape but not a catenary shape (BSI 1995; Agaiby and Jones 1995).

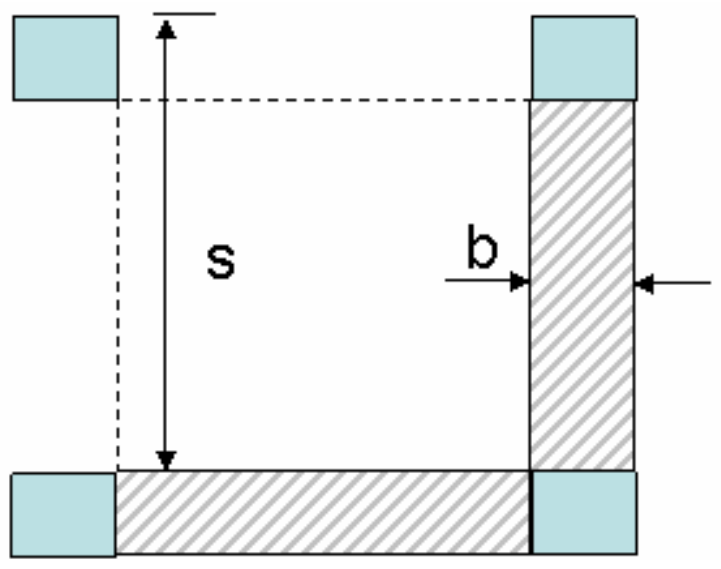

Fig. 2-7. Load Carrying Area of Geosynthetics 
Then the tension developed in the geosynthetic reinforcement could be expressed as:

$$
T=W_{T} \frac{s-b}{2 b} \sqrt{1+\frac{1}{6 \varepsilon}}
$$

where $\mathrm{s}$ and $\mathrm{b}$ - the center to center spacing and the column size, respectively, as shown in Fig. 2-7;

$$
\begin{aligned}
& \mathrm{W}_{\mathrm{T}} \text { - the load to be taken by the geosynthetic; } \\
& \varepsilon-\text { the strain in the geosynthetic. }
\end{aligned}
$$

\section{Further Discussion on Tensioned Membrane Theories}

A common drawback of these membrane theories discussed above is that the compatibility of the tension and the strain developed in the geosynthetic reinforcement is not necessarily satisfied. In addition, these methods neglected the friction and confinement between the soil and the geosynthetic sheet, which is important to the distribution of the tension.

Cautions should be paid when these membrane theories are used to estimate the tension in geosynthetic reinforcement in GRCS embankments. Since these membrane theories were developed based on the assumption that the geosynthetic reinforcement is used to only support the vertical load over a trench or void, they did not account 
for the portion of tension induced by the horizontal movement (such as the lateral movement of the embankment fill) above the geosynthetic sheet. Jones et al. (1994) and Horgan and Sarsby (2002) pointed out that the total tension generated in geosynthetic sheet should be the sum of tension induced by vertical and horizontal movements.

As mentioned earlier, basal reinforcement could have a single layer of geosynthetic or multiple layers of geosynthetics. It has been debated that single-layer base reinforcement may have different load transfer mechanisms from multiple-layer base reinforcement (Collin 2003; Collin 2004; Huang et al. 2005). In the single layer system, the single geosynthetic layer acts as a tensioned membrane. In the multiplelayer system, however, the multiple geosynthetic layers and the fill material form a load transfer platform, which acts similarly as a continuous beam/slab (Collin 2003; Collin 2004; Huang et al. 2005). Obviously, a multiple layer system is more complicated than a single layer system because it has more influence factors, such as the number and spacing of geosynthetic layers. However, this study is only limited to a single layer system, therefore, the discussion on the multiple layer system is beyond the scope of this study. 


\subsection{Current Design Methodologies for GRCS Embankments}

As a result of increased applications of GRCS embankments, a number of design methodologies have been proposed in the past few years. All the design methodologies were developed based on soil arching and tensioned membrane theories. So far, they have considered soil arching and tensioned membrane effects independently. During the design, a soil arching theory is first used to calculate the load or pressure applied on the geosynthetic layer. Based on the assumed or estimated strain level in the geosynthetic layer, the tension in the geosynthetic layer can be calculated using a membrane theory. The commonly cited design methods include the BS8006 Method (BSI 1995), the Swedish Standard Method (Carlson 1987; Rogbeck et al. 1998), and the German Method (Kempfert et al. 2004). These design methodologies are to be briefly reviewed below.

\section{British Design Methodology (BSI 1995)}

In this design methodology, the pressure to be taken by columns is calculated by Eq. (2-16), which is a transform of Martson's theory for positive projecting subsurface:

$$
\frac{p_{c}}{\gamma H}=\left[\frac{C_{c} \cdot b}{H}\right]^{2}
$$


where $\mathrm{C}_{\mathrm{c}}$ - the soil arching coefficient. $C_{c}=1.95 \mathrm{H} / \mathrm{b}-0.18$, for end-bearing piles;

$$
C_{c}=1.5 \mathrm{H} / \mathrm{a}-0.07, \text { for friction and other piles; }
$$

$\mathrm{p}_{\mathrm{c}}$ - the pressure on columns;

$\mathrm{H}$ - the embankment height.

The above formula postulated that the least embankment height would be 1.4 times of the clear spacing in order to fully mobilize the soil arching. In practice, the minimum embankment height would be 0.7 times the clear spacing to mitigate local differential settlements (Svanø et al. 2000).

The weight, $\mathrm{W}_{\mathrm{T}}$, taken by the reinforcement per unit length, would be expressed as:

$$
W_{T}=\frac{s^{2}-b^{2} \frac{p_{c}}{\gamma H}}{s^{2}-b^{2}}\left\{\begin{array}{c}
1.4 s \gamma f_{f s}(s-b), H>1.4(s-b) \\
s\left(\gamma H f_{f s}+f_{q} q\right), 0.7(s-b) \leq H \leq 1.4(s-b)
\end{array}\right\}
$$

where $\mathrm{W}_{\mathrm{T}}$-the distributed vertical load acting on the reinforcement between adjacent pile caps;

$\mathrm{f}_{\mathrm{fs}}$ - the partial load factor for the soil unit weight;

$\mathrm{f}_{\mathrm{q}}$ - the partial load factor for the externally applied load;

$\mathrm{q}$ - the uniformly distributed surcharge. 
On the basis of the calculated load to be taken by the geosynthetic, the tension developed in the reinforcement is calculated using the membrane theory presented in Eq. (2-15). Obviously, there exists a discontinuity if Eq. (2-17) is used to calculate the load taken by the reinforcement (Rogbeck, and Gustavsson, et al. 1998). Consequently, there must be a discontinuity in the calculated tension.

\section{Swedish Design Methodology (Collin 2003)}

For a two-dimensional case, Carlsson's formula was used to calculate the load carried by the geosynthetic as presented in Eq. (2-18).

$$
W_{T}=\frac{(s-b)^{2} \gamma}{4 \tan 15^{0}}
$$

The membrane theory presented in Eq. (2-15) is used to calculate the tension in the geosynthetic layer.

Both British and Swedish design methodologies neglect the subsoil support under the geosynthetic reinforcement. However, numerical results from Jones et al. (1994) showed that subsoil support is significant and could be as high as $80 \%$ of the embankment load for a low embankment supported by widely spaced columns. Rogbeck et al. (1998) also found that the subsoil resistance had noticeable influence 
on the tension developed in the geosynthetic. Fluet et al. (1986) proposed a model called a "fully flexible model", which could consider subsoil resistance. However, they did not provide any guidance on how to estimate the subsoil resistance.

\section{German Design Methodology (Collin 2003)}

The soil arching theory incorporated in the German design methodology is what proposed by Hewlett and Randolph (1988). The vertical stress on the top of the reinforcement is calculated for both two-dimensional and three-dimensional situations. Unlike the British and Swedish design methodologies, the subsoil resistance underneath the reinforcement is taken into consideration in this method. The load taken by the geosynthetic is the difference between the load on the reinforcement and the soil resistance beneath the reinforcement.

By assuming a factor of safety of 2 , the subsoil resistance could be calculated as:

$$
\sigma_{0}=\frac{(2+\pi) C_{u}}{2}
$$

Where $\sigma_{0}-$ the stress on the lower surface of the reinforcement; $c_{u}$ - the undrained shear strength of the subsoil. 
Then the load taken by geosynthetic reinforcement is:

$$
W_{T}=\frac{\left(\sigma_{s}-\sigma_{0}\right)\left(s^{2}-b^{2}\right)}{2(s-b)}
$$

The membrane theory presented in Eq. (2-15) is used to calculate the tension developed in the geosynthetic layer. This design method is very similar to the procedures described by Alzamore et al. (2000).

One of the basic differences from British and Swedish design methodologies is that the German methodology accounts for subsoil resistance. Undoubtedly, the ignorance of the subsoil resistance produces conservative results, which has been verified by Rogbeck et al. (1998). However, whether the partial support of subsoil should be considered is still under debate (Horgan and Sarsby 2002), since the support of subsoil may decrease with the consolidation of soft soil.

\section{Further Discussion on Design Methodologies}

Besides the design methodologies presented above, there are several other design methodologies. The design methodologies are distinguished from each other by the soil arching theory and the membrane theory adopted. Since there are inherent differences among soil arching theories and membrane theories, the consistency of 
these design methodologies became the concern of practitioners. Several comparisons have been done to evaluate the consistency of the design methodologies. However, the investigations are inconclusive because remarkable differences have been found among these design methodologies (Horgan and Sarsby 2002; Naughton and Kempton 2005). Naughton and Kempton (2005) presented an extensive comparison of soil arching ratios and tension in geosynthetic reinforcement obtained from a few available analytical methods and they found large variations. Russell and Pierpoint (1997) also presented a comparison based on two GRCS embankments. The basic information on these two embankments (Embankments A and B) is provided in Table 2-1. The calculated soil arching ratios and tension in the reinforcement using different methods are presented in Figs. 2-8 and 2-9, which show the soil arching ratio could differ by more than three times while the tension could differ by more than two times.

\section{Table 2-1. Information of Embankment A and B Used in Comparison (Russell and Pierpoint 1997)}

\begin{tabular}{|l|c|c|}
\hline \multicolumn{1}{|c|}{ Property } & Embankment A & Embankment B \\
\hline Height $(\mathrm{m})$ & 5.8 & 4.3 \\
\hline Pile cap width $(\mathrm{m})$ & 1.0 & 0.5 \\
\hline Pile spacing $(\mathrm{m})$ & 2.5 & 2.5 \\
\hline Longitude reinforcement stiffness $(\mathrm{kN} / \mathrm{m})$ & 5500 & 294 \\
\hline Transverse reinforcement stiffness $(\mathrm{kN} / \mathrm{m})$ & 9500 & 738 \\
\hline Fill Poisson's ratio & 0.2 & 0.2 \\
\hline Fill stiffness $(\mathrm{MPa})$ & 20 & 40 \\
\hline Average fill density $(\mathrm{kN} / \mathrm{m})$ & 18.2 & 19.0 \\
\hline Fill angle of friction $\left({ }^{\circ}\right)$ & 30 & 40 \\
\hline Fill dilation $\left({ }^{\circ}\right)$ & 0 & 0 \\
\hline Fill cohesion $(\mathrm{kPa})$ & 0 & 10 \\
\hline
\end{tabular}


Soil arching ratio, $\rho$

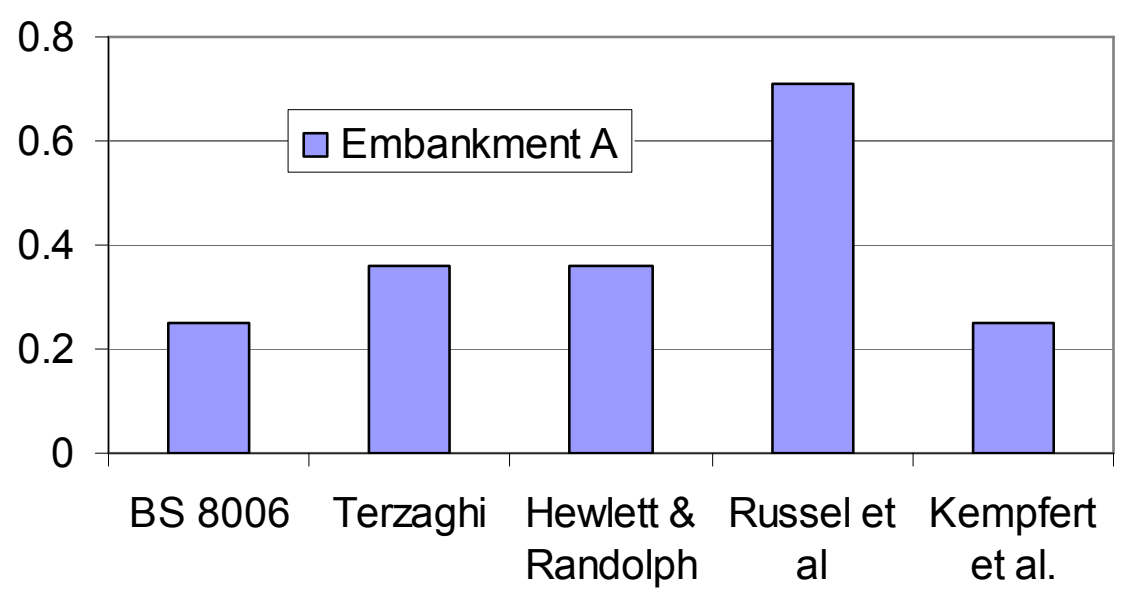

(a) Embankment A

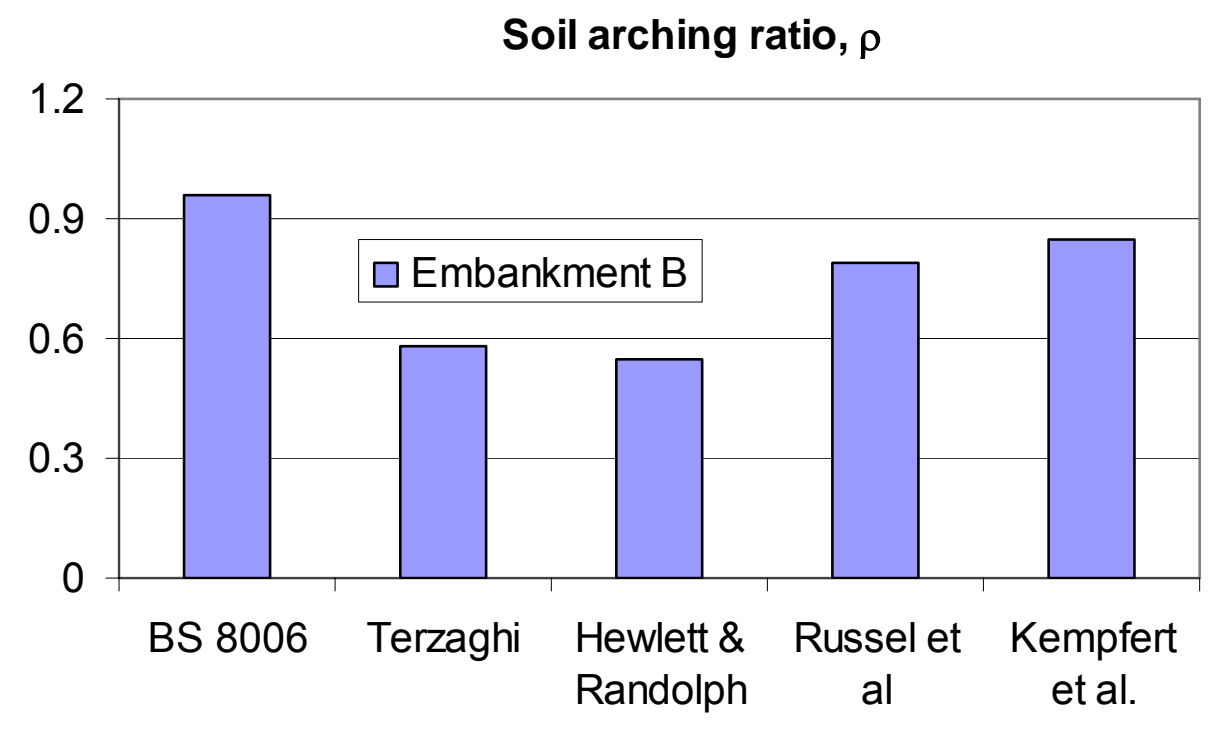

(b) Embankment B

Fig. 2-8. Soil Arching Ratio (Modified from Naughton and Kempton 2005) 
Tension in reinforcement, $T$

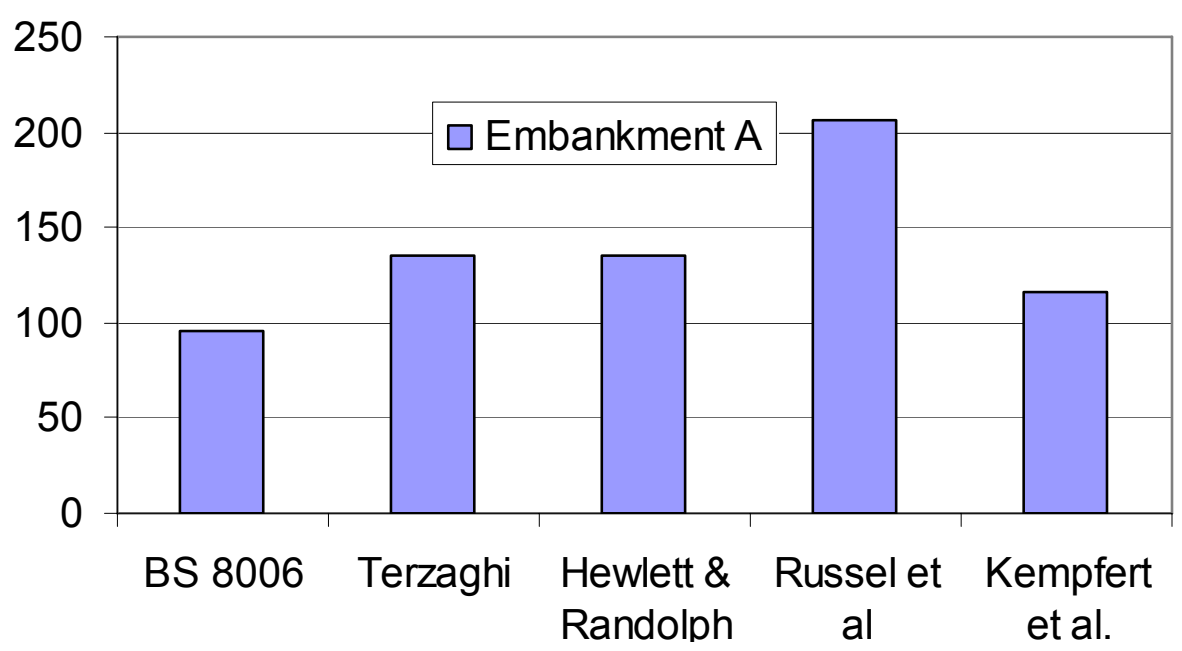

(a) Embankment $\mathrm{A}$

Tension in reinforcement, $\mathrm{T}$

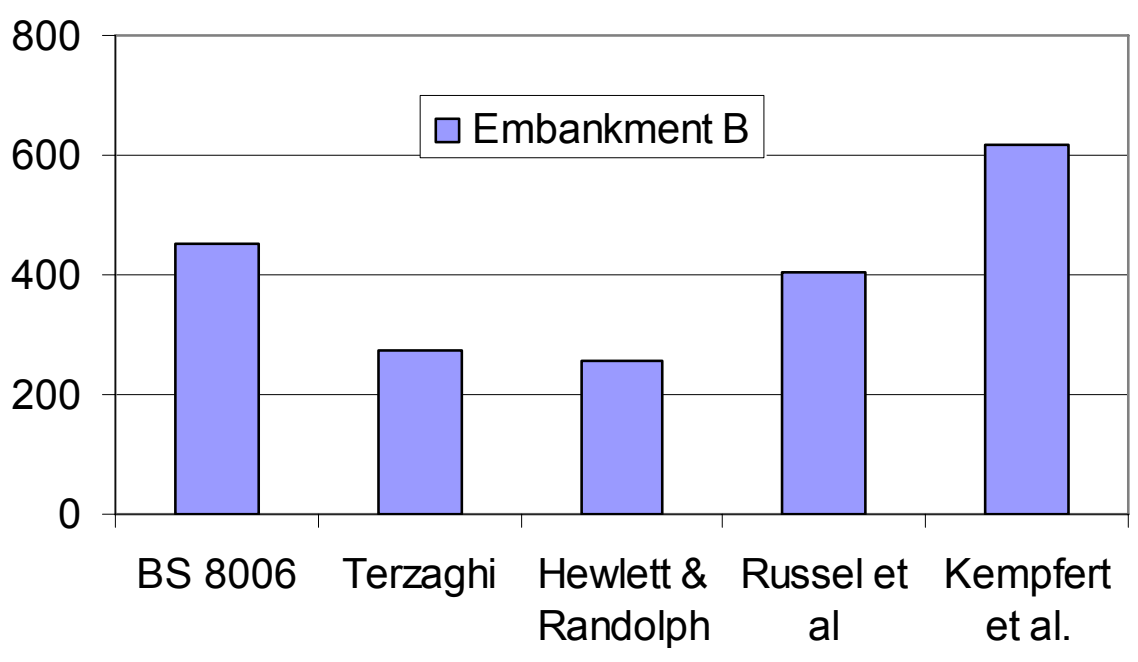

(b) Embankment B

Fig. 2-9. Tension in Geosynthetic Reinforcement (Modified from Naughton and Kempton 2005)

Researchers and designers have felt uncomfortable with these large variations among different design methods, which have brought the uncertainty to the application of 
GRCS embankments. To some extent, this uncertainty obstructs the wide acceptance of GRCS embankments. For example, Collin (2004) suggested GRCS embankments should not be built higher than $10 \mathrm{~m}$.

\subsection{Current Research Status}

In the past few years, a number of studies have been conducted to better understand the mechanisms and behavior of GRCS embankments. These studies include theoretical analyses, numerical modeling, field monitoring, full scale tests, and laboratory tests. A few representative studies are summarized in Table 2-2.

Table 2-2. A Summary of Past Studies on GRCS Embankments

\begin{tabular}{|c|l|c|}
\hline Type & \multicolumn{1}{|c|}{ Brief description } & Reference \\
\hline $\begin{array}{c}\text { Numerical } \\
\text { modeling }\end{array}$ & $\begin{array}{l}\text { A numerical analysis was done to evaluate the } \\
\text { reinforcing effect by varying column spacing, } \\
\text { column modulus, and number of geogrid layers. }\end{array}$ & $\begin{array}{c}\text { Ohkubo et } \\
\text { al. 1996 }\end{array}$ \\
\hline $\begin{array}{c}\text { Experimental } \\
\text { and numerical } \\
\text { study }\end{array}$ & $\begin{array}{l}\text { A physical model with columns in a square pattern } \\
\text { was built in the lab. Influence of various factors } \\
\text { (including properties of columns, properties of } \\
\text { geosynthetic reinforcement, and height of } \\
\text { embankment) on soil arching and surface settlements } \\
\text { was addressed. 2D numerical modeling was also } \\
\text { performed and the results were compared with test } \\
\text { results. }\end{array}$ & $\begin{array}{c}\text { Demerdash } \\
1996\end{array}$ \\
\hline
\end{tabular}


Table 2-2. A Summary of Past Studies on GRCS Embankments (continued)

\begin{tabular}{|c|c|c|}
\hline Type & Brief description & Reference \\
\hline $\begin{array}{l}\text { Long-term } \\
\text { monitoring of } \\
\text { railway widening } \\
\text { project }\end{array}$ & $\begin{array}{l}\text { An old railway was widened to support high speed } \\
\text { trains in Germany in early 1990s. To prevent the } \\
\text { intolerable settlements between old and new } \\
\text { embankments, three layers of geogrid above piles } \\
\text { were used to support the embankments. } \\
\text { Extensometers and strain gauges were installed to } \\
\text { monitor the settlements, tilt of the pile caps, and } \\
\text { strains in geogrid layers. More than 5-year } \\
\text { measurements were recorded and analyzed. }\end{array}$ & $\begin{array}{l}\text { Brandl et } \\
\text { al. } 1997\end{array}$ \\
\hline $\begin{array}{c}\text { Full scale } \\
\text { roadway testing }\end{array}$ & $\begin{array}{l}\text { During the construction, two sections were } \\
\text { instrumented. One section was built as designed } \\
\text { with soil between pile caps while the other section } \\
\text { was built with foam mattresses between pile caps to } \\
\text { simulate a soft subsoil condition. Field } \\
\text { measurements included deformation of geosynthetic } \\
\text { reinforcement, strain in the reinforcement, and } \\
\text { settlement of the embankment. The measurements } \\
\text { were compared with numerical results and British } \\
\text { and Swedish design methods. }\end{array}$ & $\begin{array}{l}\text { Rogbeck et } \\
\text { al. } 1998\end{array}$ \\
\hline $\begin{array}{l}\text { Long-term } \\
\text { monitoring of a } \\
\text { bridge approach } \\
\text { embankment }\end{array}$ & $\begin{array}{l}\text { A bridge approach embankment reinforced by one } \\
\text { layer of geotextile was built over deep mixed } \\
\text { columns in Finland. Instrumentations (including } \\
\text { inclinometers, settlement plates, horizontal } \\
\text { hydrostatic profile gauges, piezometers, and strain } \\
\text { gauges) were installed to track the performance of } \\
\text { the GRCS embankment. More than five year } \\
\text { measurements were recorded. Numerical analysis } \\
\text { was conducted to compare with field } \\
\text { measurements. }\end{array}$ & $\begin{array}{c}\text { Forsman et } \\
\text { al. } 1999\end{array}$ \\
\hline $\begin{array}{l}\text { Test railway } \\
\text { embankment }\end{array}$ & $\begin{array}{l}\text { To verify the design of a GRCS embankment with } \\
\text { multiple layers of geosynthetic, instrumentations } \\
\text { were mounted in two sections to monitor the } \\
\text { deflection and strain of reinforcement sheets } \\
\text { between pile caps. More than three-year field data } \\
\text { were recorded and analyzed. }\end{array}$ & $\begin{array}{l}\text { Rehnman } \\
\text { et al. } 1999\end{array}$ \\
\hline $\begin{array}{l}\text { Numerical } \\
\text { modeling }\end{array}$ & $\begin{array}{l}\text { Two-dimensional numerical modeling was fulfilled } \\
\text { to investigate the influence of various factors } \\
\text { (including height of fill, tensile stiffness of } \\
\text { geosynthetic, and elastic modulus of pile) on } \\
\text { settlement, tension in reinforcement, and soil } \\
\text { arching ratio in a unit cell model. }\end{array}$ & $\begin{array}{c}\text { Han and } \\
\text { Gabr } 2002\end{array}$ \\
\hline
\end{tabular}


Table 2-2. A Summary of Past Studies on GRCS Embankments (continued)

\begin{tabular}{|c|c|c|}
\hline Type & Brief description & Reference \\
\hline $\begin{array}{l}\text { Trial section } \\
\text { of roadway } \\
\text { widening }\end{array}$ & $\begin{array}{l}\text { To confirm the design based on the numerical software- } \\
\text { PLAXIS, a 200m long field trial section was built and } \\
\text { instrumented. During the two months' monitoring, } \\
\text { traffic passed the trial section. Stresses on the piles and } \\
\text { on the soil between piles were measured and analyzed. }\end{array}$ & $\begin{array}{l}\text { Habib et al. } \\
\quad 2002\end{array}$ \\
\hline $\begin{array}{c}\text { Numerical } \\
\text { modeling }\end{array}$ & $\begin{array}{l}\text { Two-dimensional modeling was conducted to } \\
\text { investigate the influence of various factors (including } \\
\text { properties of subsoil, properties of embankment fill, } \\
\text { properties of piles, and properties of geosynthetic) on } \\
\text { settlement, tension in reinforcement, and soil arching } \\
\text { ratio. In addition, slope stability analysis was conducted } \\
\text { using a numerical approach and the results were } \\
\text { compared with the limit equilibrium method. }\end{array}$ & $\begin{array}{c}\text { Han and } \\
\text { Shelth } \\
2003\end{array}$ \\
\hline $\begin{array}{l}\text { Full scale } \\
\text { test }\end{array}$ & $\begin{array}{l}\text { A } 3 \mathrm{~m} \text { (width) } \times 5 \mathrm{~m} \text { (length) test pit was built in Malaysia } \\
\text { to investigate the load transfer mechanism of GRPS } \\
\text { embankments. Steel piles were installed in a triangular } \\
\text { pattern. Two layers of geotextile were placed. Load } \\
\text { cells and Linear Variable Differential Transducers were } \\
\text { mounted to monitor the deflection and the load transfer. } \\
\text { Numerical modeling was conducted for comparison. }\end{array}$ & $\begin{array}{l}\text { Chew et al. } \\
2004\end{array}$ \\
\hline $\begin{array}{l}\text { Analytical } \\
\text { and } \\
\text { numerical } \\
\text { study }\end{array}$ & $\begin{array}{l}\text { Hewllet and Randolph's arching theory was modified to } \\
\text { calculate the tension in geosynthetic. }\end{array}$ & Jia 2004 \\
\hline $\begin{array}{l}\text { Numerical } \\
\text { modeling }\end{array}$ & $\begin{array}{l}\text { Extensive 2D and 3D axisymmetric numerical modeling } \\
\text { was conducted to investigate the influence of various } \\
\text { factors (including height of embankment, properties of } \\
\text { embankment, tensile stiffness of geosynthetic, } \\
\text { properties of pile, properties of subsoil, and even } \\
\text { dilation of embankment fill) on the vertical load } \\
\text { distribution among piles, geosynthetic reinforcement, } \\
\text { and subgrade soil. Based on the findings from } \\
\text { numerical modeling and compatibility analysis, an } \\
\text { iteration approach to calculate the settlements, stresses } \\
\text { on piles and tension in geosynthetic reinforcement was } \\
\text { proposed. }\end{array}$ & $\begin{array}{l}\text { Filz and } \\
\text { Smith } \\
2005\end{array}$ \\
\hline
\end{tabular}


Even though the above studies have greatly improved our knowledge on GRCS embankments, a number of limitations still exist as listed below:

- GRCS embankments are often a three dimensional problem since columns are installed in an isolated pattern, such as a square or triangular pattern. Neither axisymmetric analyses nor plane strain analyses can accurately represent the real situation (Naughton and Kempton 2005).

- Unit-cell modeling cannot include the tension in the geosynthetic reinforcement induced by lateral spreading (Han 2003).

- In most numerical modeling, two extreme states were analyzed: undrained and drained. However, the settlement and tension development after construction are more critical to the performance of the GRCS embankments, which have not been well investigated.

- Laboratory tests have scale effects.

- Full-scale testing and long-term monitoring are ideal for research of GRCS embankments. However, they are very time-consuming and costly. More importantly, they are limited to specific test sites. Parametric studies are difficult to conduct. 
- Little attention has been paid to the post-construction settlements, which are critical to the serviceability of embankments.

To overcome the above limitations, this study was conducted in order to improve the understanding of GRCS embankments. The full-scale embankments were numerically modeled to eliminate the scale effect of unit cell modeling and small scale laboratory tests. The mechanical and hydraulic models were coupled to frame the behavior of GRCS embankments in a time domain to well evaluate the serviceability of the GRCS embankments. The parametric study in $2 \mathrm{D}$ and $3 \mathrm{D}$ analyses investigated the behavior of GRCS embankments under typical conditions in practice. 


\section{CHAPTER THREE \\ MODEL CALIBRATIONS}

\subsection{Introduction}

To ensure the correctness of numerical models, they have to be calibrated against available field data before they can be used for parametric studies. The calibrations discussed below were conducted based on coupled mechanical and hydraulic modeling of GRCS embankments using FLAC 2D and 3D software.

FLAC and FLAC3D are commercial two-dimensional and three-dimensional software, respectively, which were developed by Itasca Consulting Group, Inc. The finite difference software, FLAC (Fast Lagrangian Analysis of Continua) Version 4.0 developed by Itasca Consulting Group, Inc., was adopted in the two-dimensional numerical study. The finite difference software, FLAC3D (Fast Lagrangian Analysis of Continua) Version 3.1, also developed by Itasca Consulting Group, Inc., was adopted in the three-dimensional numerical study.

Since GRCS embankments are usually built over soft soil with a high ground water table, the generation and dissipation of pore water pressure (consolidation) during and after construction are important for the behavior of GRCS embankments. This behavior can be considered as an interaction of mechanical and hydraulic processes in 
a time domain. FLAC and FLAC3D, capable of coupling mechanical and hydraulic processes, were chosen to fulfill this goal. As hydraulic and mechanical modeling is coupled, the mechanical and hydraulic loops are implemented alternately. In the hydraulic loops, saturated transient fluid flow through porous media (soils) is modeled to simulate the generation and dissipation of excess pore water pressures (i.e., consolidation) during and after the construction. On the other hand, in the mechanical loops, the stress and displacement development processes are modeled. The two loops are coupled through the quasi-static Biot theory (Biot 1956). Starting with a hydraulic loop, two variables (i.e., pore water pressure and specific discharge) are evaluated by the transport law (Darcy's law), the fluid mass balance law, and the compatibility law. Then the change of pore water pressure is passed to the mechanical loop to update the effective stress, which is used to check against failure and calculate the volumetric strain based on the selected constitutive model. The calculated volumetric strain is passed back to the hydraulic loop to account for the pore water pressure and the specific discharge in the new hydraulic loop on the basis of the linear quasi-static Biot theory (Itasca 2002), which is formulated in an incremental format. As the two loops are implemented alternately, pore water pressures and volumetric strains are kept exchanging and updating. The modeling of this process may require thousands of cycles, which is terminated as a specified criterion (such as the maximum unbalanced force, the flow time, the stress ratio and so on) is reached. 
There are ten available constitutive models in FLAC and eleven constitutive models in FLAC3D. Any of them can be used in the coupled mechanical and hydraulic modeling to simulate the saturated soil behavior under stresses. In this study, soils and deep mixed columns were modeled as linearly elastic perfectly plastic materials with Mohr-Coulomb failure criteria in the mechanical modeling. The geosynthetic layer was modeled using cable elements in FLAC 2D and geogrid elements in FLAC3D, respectively. The numerical results based on the coupled mechanical and hydraulic modeling are compared with the field measurements and those without the hydraulic modeling.

\subsection{Selected Case Study}

A case history with fairly detailed material properties, necessary construction information, and long-term settlement and tension monitoring data was selected from the published literature (Forsman et al. 1999 and Forsman 2001) for the calibration purposes.

The selected case study is a geosynthetic-reinforced DM column-supported embankment built to support a new bridge approach over Sipoo River, Hertsby, which is located about $30 \mathrm{~km}$ northeast of Helsinki, Finland (Forsman et al. 1999). The foundation soil from the ground surface downward consisted of 1 to $1.5 \mathrm{~m}$ thick 
crust, 10 to $14 \mathrm{~m}$ thick soft clay, 0 to $6 \mathrm{~m}$ thick silt, and 1 to $5 \mathrm{~m}$ thick glacial till. The profile is presented in Fig. 3-1.

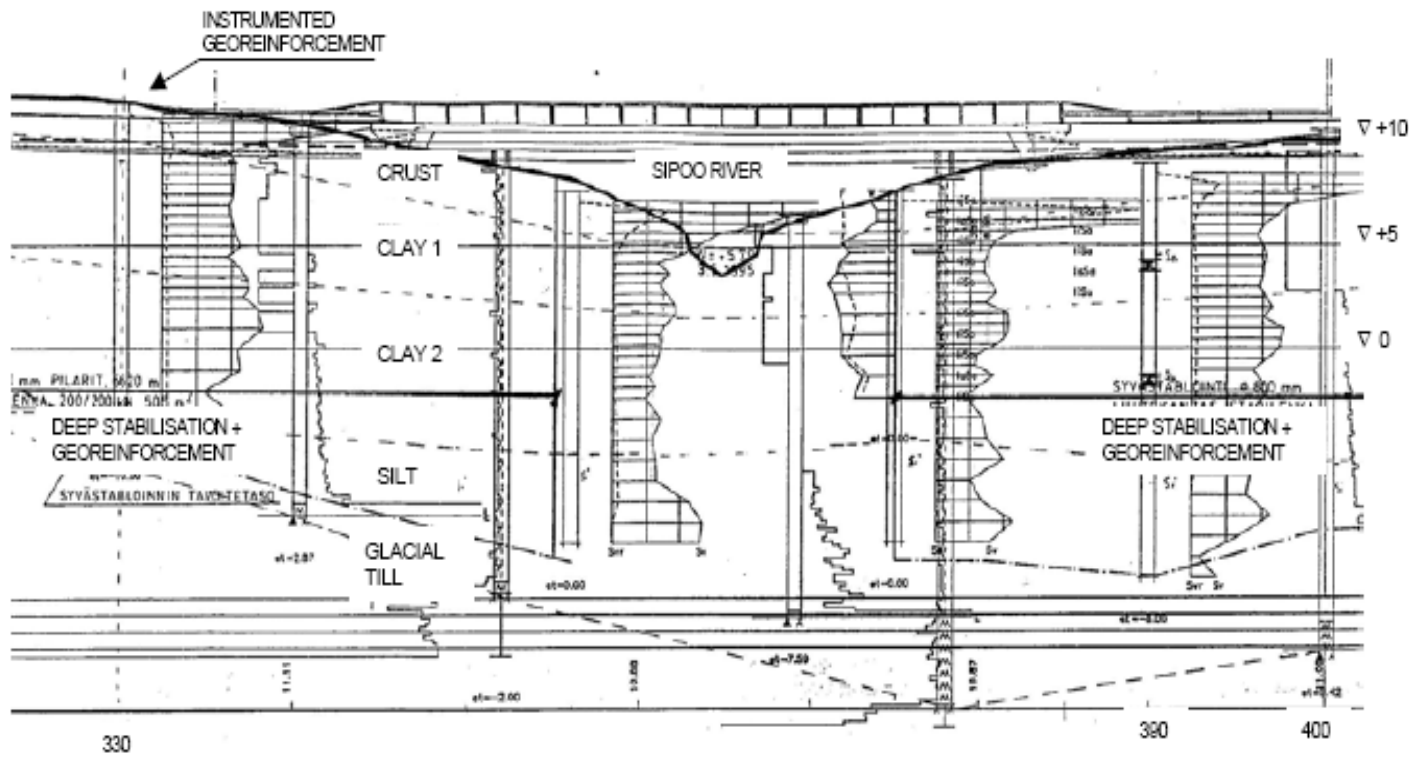

Fig. 3-1. Profile of Sipoo River Bridge Embankment (Forsman et al. 1999)

The index properties of the in-situ soils listed in Table 3-1 were reported by Forsman et al. (1999). Oedometer and CPT tests indicated that the clay layer was normally consolidated. The drained modulus $\mathrm{E}_{\mathrm{d}}$, the undrained modulus $\mathrm{E}_{\mathrm{u}}$, the drained Poisson's ratio $v_{\mathrm{d}}$, the effective friction angle $\phi^{\prime}$, and the effective cohesion $\mathrm{c}^{\prime}$ were determined by triaxial tests, which are listed in Table 3-2. The ground water table was close to the existing ground surface. 
Table 3-1. Soil Index Properties

\begin{tabular}{llll}
\hline Depth $(\mathrm{m})$ & $4.8-5.6$ & $10.5-11.3$ & $15.9-16.3$ \\
\hline Soil type & soft clay & soft clay & silt \\
Organic content $(\%)$ & 0.8 & 0 & 0.7 \\
Unit weight $\left(\mathrm{kN} / \mathrm{m}^{3}\right)$ & $14.6-15.0$ & $14.9-16.6$ & $18.1-18.3$ \\
Water content $(\%)$ & $80-91$ & $58-85$ & $31-41$ \\
Liquidity index $(\%)$ & 91 & 84 & 31 \\
Shear strength $(\mathrm{CPT})(\mathrm{kPa})$ & $6.5-16.1$ & $8.7-15.2$ & 13.9 \\
\hline
\end{tabular}

Table 3-2. Properties of Soft Clay

\begin{tabular}{lllllll}
\hline Depth $(\mathrm{m})$ & $\mathrm{E}_{\mathrm{d}}(\mathrm{kPa})$ & $v_{\mathrm{d}}$ & $\mathrm{E}_{\mathrm{u}}(\mathrm{kPa})$ & $\mathrm{c}_{\mathrm{u}}(\mathrm{kPa})$ & $\phi^{\prime}\left({ }^{\circ}\right)$ & $\mathrm{c}^{\prime}(\mathrm{kPa})$ \\
\hline $4.9-5.7$ & 300 & 0.1 & $3000-6000$ & $12-17$ & 13 & 8 \\
$10.6-11.2$ & 600 & 0.2 & $4000-8000$ & $0-15$ & 13 & 8 \\
\hline
\end{tabular}

The soft clay was considered to be the problematic layer. To minimize the settlements, especially the crest (surface) settlements (also called post-construction settlements), deep mixed (DM) columns were installed to improve the in-situ soils. In addition, a layer of woven geotextile was placed over the DM columns as geosynthetic basal reinforcement with a $0.3 \mathrm{~m}$ thick cushion sand layer below. Each DM column had a diameter of $0.8 \mathrm{~m}$ and undrained shear strength of $150 \mathrm{kPa}$. They were alternately installed into two patterns (walls and isolated columns) parallel to the centerline of the embankment as shown in Fig. 3-2. The isolated columns between DM walls are referred as the mid-columns in this dissertation. The ultimate strength of this geosynthetic reinforcement was $200 \mathrm{kN} / \mathrm{m}$ in both longitudinal and transverse directions. The secant tensile stiffness of this geosynthetic layer was $1790 \mathrm{kN} / \mathrm{m}$ and $2120 \mathrm{kN} / \mathrm{m}$ at strains of $2 \%$ and $6 \%$, respectively. The adjacent geosynthetic sheets 
were jointed together by seams. The soil stabilization was carried out by mixing soil with cement and by-product binder at an amount of $130 \mathrm{~kg} / \mathrm{m}^{3}$ to form DM columns at the beginning of 1996. After the ground improvement, the embankment with 2:1 $(\mathrm{H}: \mathrm{V})$ slopes on both sides was built successively in stages with a $0.50 \mathrm{~m}$ thick sand working platform, a $1.05 \mathrm{~m}$ thick gravel sub-base, a $0.20 \mathrm{~m}$ thick crushed stone base course, and a $0.05 \mathrm{~m}$ thick asphalt layer from 1996 to 1997 . The geosynthetic layer was installed within the working platform and $0.3 \mathrm{~m}$ above the DM column heads. The construction sequence is presented in Table 3-3. The embankment was instrumented with piezometers, inclinometers, settlement plates, horizontal hydrostatic profile gauges, and strain gauges on the geotextile sheet for construction QC/QA and long-tern performance monitoring. However, only some of the settlement and tension data were reported in the publications. The locations of the reported hydrostatic profile gauges, settlement plates, and strain gauges are showed in Fig 3-3. At Station 327.5 and Station 328.2, hydrostatic profile gauges were installed to monitor settlements for transverse settlement profiles. Station 327.5 passes the midspan of the isolated columns, while station 328.2 passes the center of the isolated columns. Settlement plates were mounted at locations of S1, S2, S3, and S4 to monitor the settlements at the DM columns and at the soft soil. Strain gauges were installed to monitor the strains in the geosynthetic sheet in two perpendicular directions (the traffic and transverse directions). Representative points close to Station 330.0 were presented here for comparison. The monitoring started at the same time as the construction began and the data were kept updated up to five years after 
the construction. The measured maximum settlement was approximately $120 \mathrm{~mm}$ (Forsman 2001). Differential settlement between the DM columns and soft soil was observed. The settlements had become relatively stable after two years since the construction. The measured strains in the geotextile in longitudinal and transverse directions of the embankment were 0 to $0.2 \%$ and 0 to $1 \%$, respectively. The tensions in geotextile corresponding to $0.2 \%$ and $1 \%$ strain are $3.6 \mathrm{kN} / \mathrm{m}$ and $18 \mathrm{kN} / \mathrm{m}$, respectively.

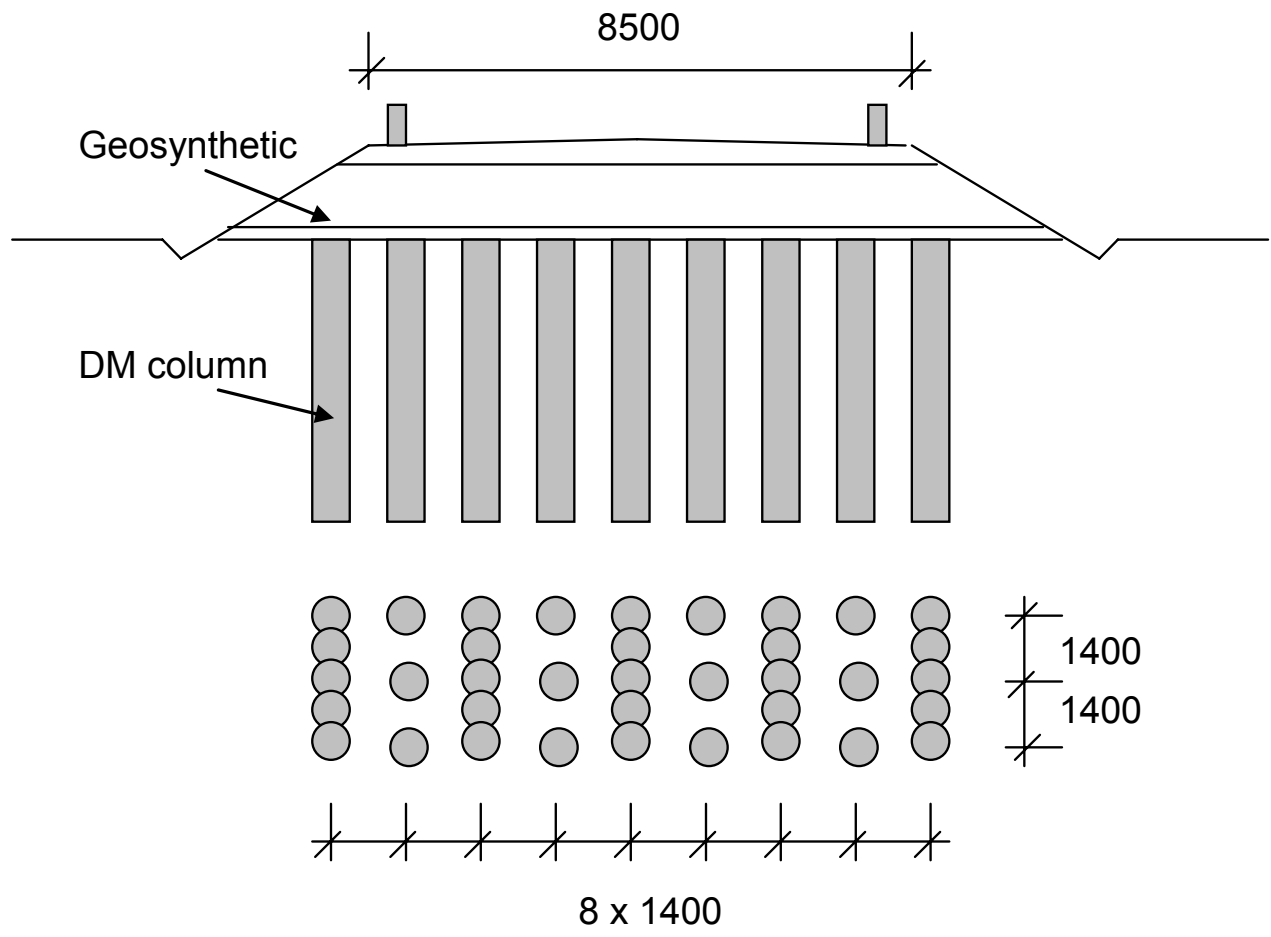

Fig. 3-2. Embankment Cross-section and Column Layout (unit: mm) (Forsman et al. 1999) 
Table 3-3. Construction Information

\begin{tabular}{cccc}
\hline $\begin{array}{c}\text { Stage } \\
\text { No. }\end{array}$ & Material & $\begin{array}{c}\text { Thickness } \\
(\mathrm{m})\end{array}$ & $\begin{array}{c}\text { Duration (mm/yyyy- } \\
\mathrm{mm} / \text { yyyy) }\end{array}$ \\
\hline 1 & Platform fill, sand & 0.6 & $11 / 1996-01 / 1997$ \\
2 & Embankment fill, gravel & 0.9 & $01 / 1997-09 / 1997$ \\
$3^{*}$ & $\begin{array}{c}\text { Embankment fill +asphalt } \\
\text { layer }\end{array}$ & 0.3 & $09 / 1997-03 / 1999$ \\
* Since no information available, it is assumed that traffic starts at this stage.
\end{tabular}

* Since no information available, it is assumed that traffic starts at this stage.

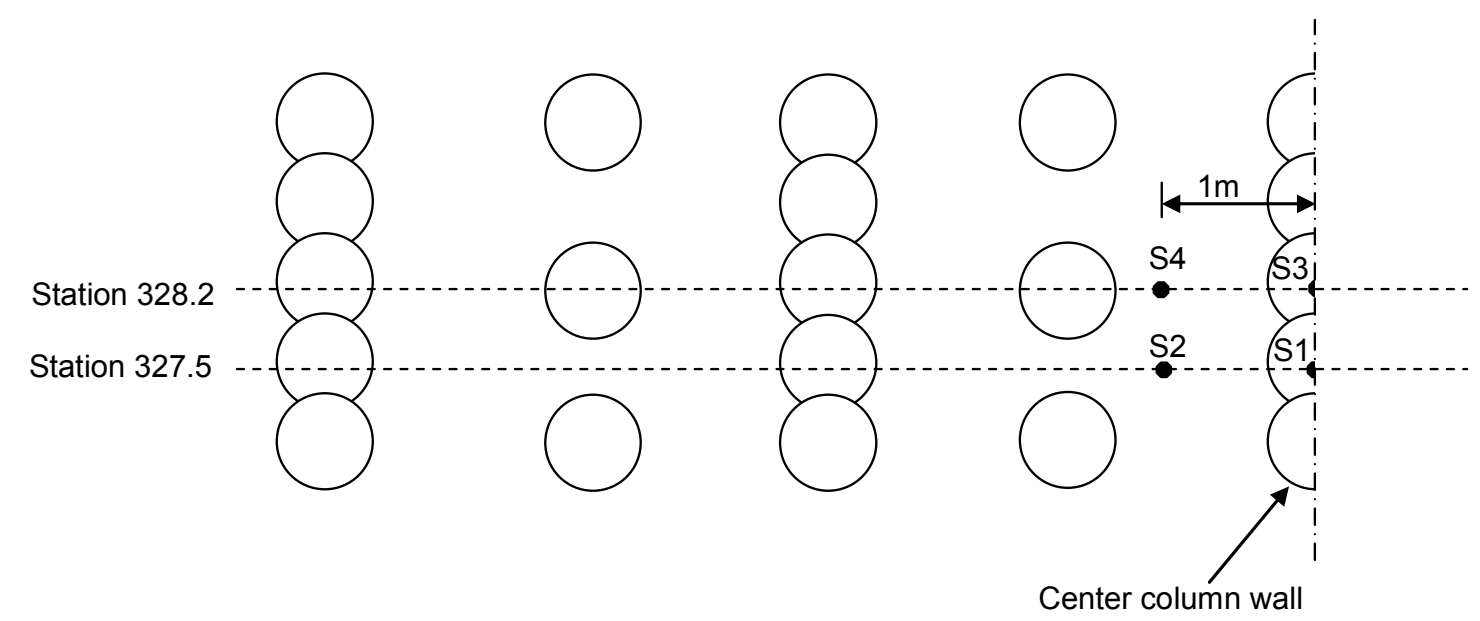

(a) Locations of hydrostatic profile gauges

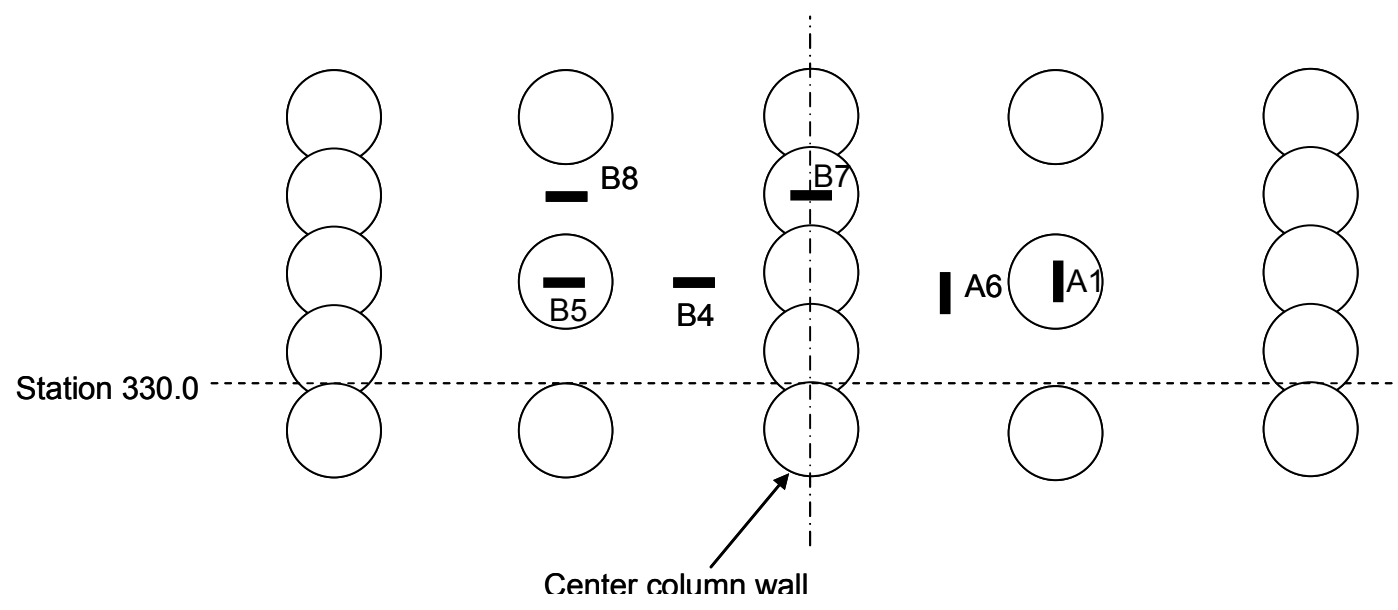

(b) Arrangement of strain gauges

Fig. 3-3. Arrangement of Instrumentations (Forsman 2001) 


\subsection{Numerical Modeling}

To conduct the numerical model calibration, the selected case has to be converted into numerical models. Due to the mid-columns, the selected case is a three-dimensional problem. This case was modeled closely in the 3D calibration, while it was simplified into two plane strain cases in the 2D calibration.

Soil is a stress-path dependant elastic-plastic material. To better simulate the actual performance of the GRCS embankments, the construction procedure should be closely modeled in the numerical analysis. In the actual stage construction, the embankment was built to a pre-determined height for each stage at a certain construction rate, which is typically represented by a linear slope as shown in Fig. 3-

4. After the pre-determined height was reached, the construction was temporarily suspended to allow partial dissipation of excess pore water pressure and soft soil to gain its strength. This time period is represented by a horizontal line in Fig. 3-4. Due to the lack of the detailed construction procedure and the difficulty to simulate the linear increase of the embankment height as shown in Fig. 3-4, the actual construction process was approximated in the numerical model by a simplified construction process as indicated by dash lines. In the simplified construction process, the construction of each stage was completed instantly and then followed by a certain period of waiting time for partial consolidation. The construction of the embankment was modeled in three stages. The duration and the lift thickness of each stage were 
determined based on the reported construction information and are schematically presented in Fig. 3-5. The traffic was simulated by applying a distributed load of $12 \mathrm{kPa}$ on the crest of the embankment, which was assumed starting right after the placement of the asphalt layer in Stage 3, i.e., the traffic loading was included in Stage 3. After the completion of Stage 3 (i.e., 1.5 years after the service), the modeling was extended to the end of the designed service life (30 years assumed in this study) to predict the final crest settlements.

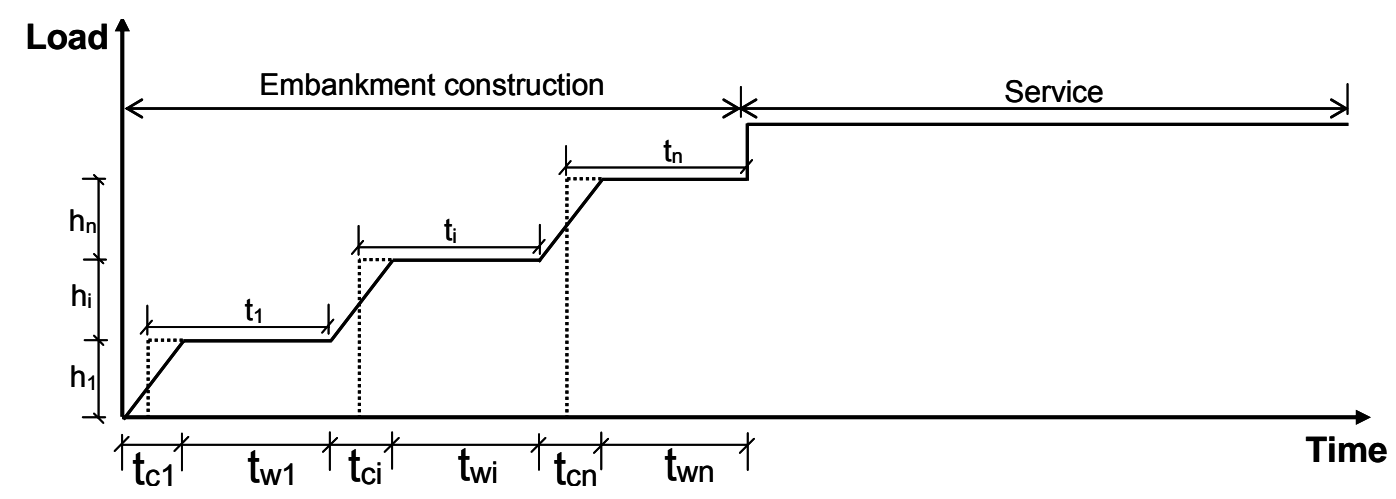

Fig. 3-4. Construction Process

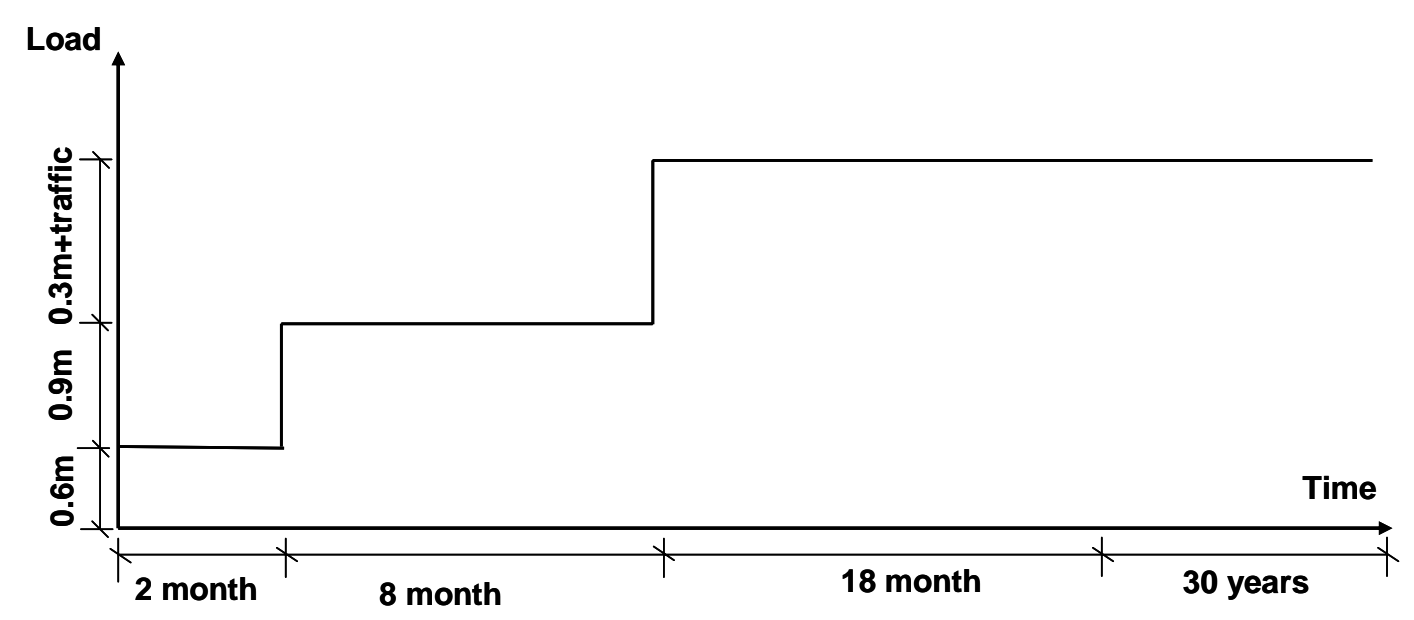

Fig. 3-5. Modeling Procedure 


\subsection{Two-dimensional (2D) Model Calibration}

In the numerical analysis, DM columns, soft soil, firm soil, and embankment fill were modeled as linearly elastic perfectly plastic materials with Mohr-Coulomb failure criteria, i.e., Mohr-Coulomb materials. The geosynthetic reinforcement was modeled as a system of built-in cable elements, which could take axial tensile load only.

\subsubsection{Numerical Modeling}

The two-dimensional (2D) numerical model for this calibration study is presented in

Fig. 3-6. Due to the symmetry of the problem, only half of the section was modeled in the calibration to save the computing time. The DM columns with a wall pattern were represented by two-dimensional DM walls with an effective thickness of $0.7 \mathrm{~m}$. The effective thickness was estimated based on the equivalency of the actual area of a series of DM columns to the area of the wall modeled in the analysis. The wall at the centerline had only half-width, i.e., $0.35 \mathrm{~m}$. The elastic modulus of the DM columns

was estimated based on the typical relationship of $E=100 q_{u}$ (Porbaha 2000 and Bruce 2001), where $\mathrm{q}_{\mathrm{u}}=$ the unconfined compression strength (i.e., $300 \mathrm{kPa}$ in this study). 
The existence of mid-columns made it a three-dimensional problem. To convert the three dimensional problem to a two-dimensional one, two simplified cases were investigated: (1) without the mid-columns (referred as SC1 in this dissertation), i.e., ignore the existence of the mid-columns, which may be the worst situation for design and (2) with the mid-columns (referred as SC2 in this dissertation), but each row of mid-columns and soft soil between were converted to an equivalent DM wall. In the CS2 case, the wall thickness for the mid-columns was taken to be the same as the column walls but the equivalent elastic modulus and the equivalent cohesion of the mid-column walls were determined based on the weighted area average of these properties from the DM columns and the soft soil between as indicated by the dash lines in Fig. 3-6. For instance, the equivalent elastic modulus and cohesion of the middle DM walls are $\mathrm{E}_{\mathrm{eq}}=\mathrm{E}_{\mathrm{c}} \mathrm{a}_{\mathrm{s}}+\mathrm{E}_{\mathrm{s}}\left(1-\mathrm{a}_{\mathrm{s}}\right)$ and $\mathrm{c}_{\mathrm{eq}}=\mathrm{c}_{\mathrm{c}} \mathrm{a}_{\mathrm{s}}+\mathrm{c}_{\mathrm{s}}\left(1-\mathrm{a}_{\mathrm{s}}\right)$, where $\mathrm{E}_{\mathrm{c}}$ and $\mathrm{E}_{\mathrm{s}}$ are the moduli of the mid-DM columns and the soft clay, respectively; $\mathrm{c}_{\mathrm{c}}$, and $\mathrm{c}_{\mathrm{s}}$ are the cohesion of the column and the soft soil, respectively; $\mathrm{a}_{\mathrm{s}}$ is the area replacement ratio, defined as the ratio of the column area to the total area. 


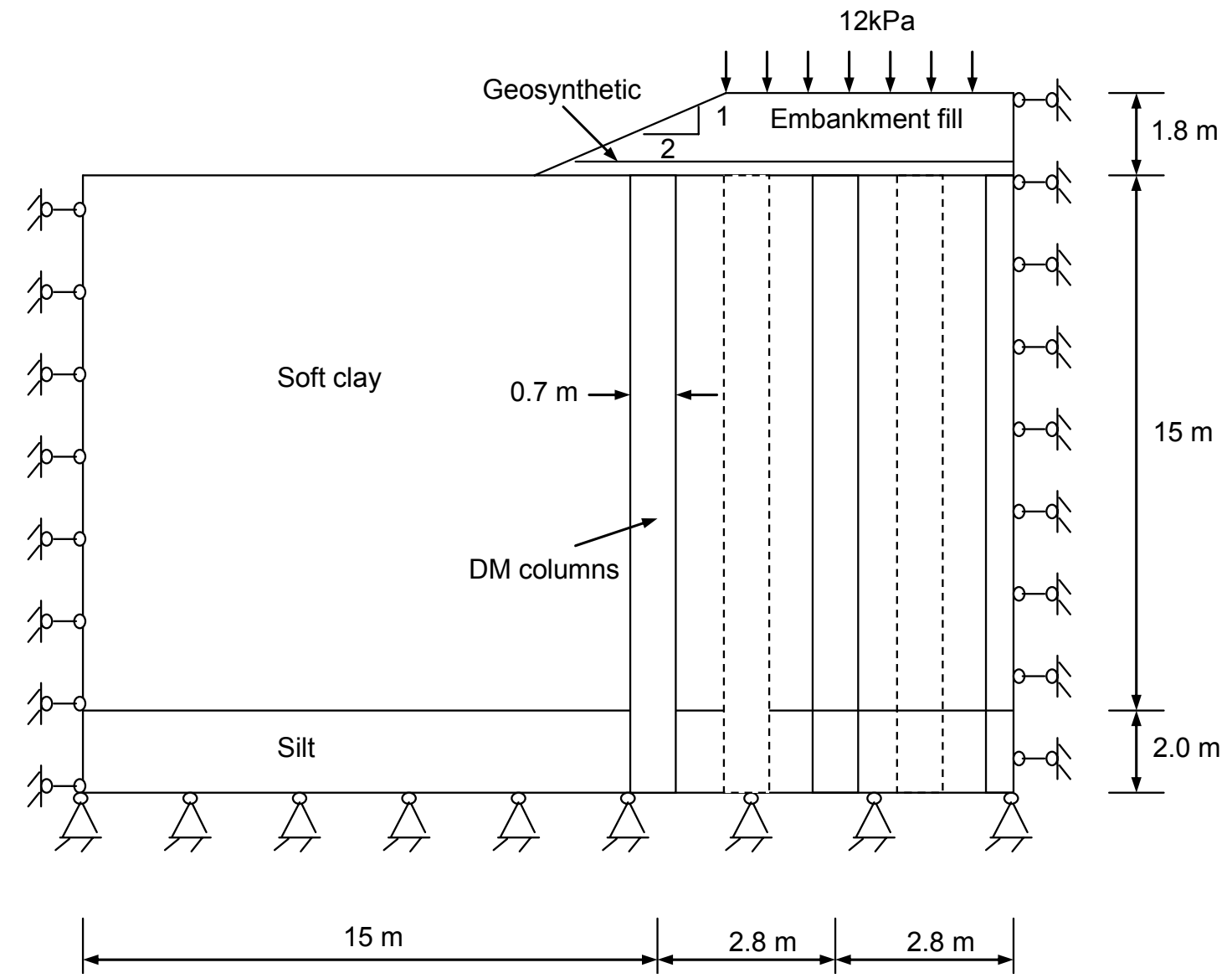

Fig. 3-6. 2D Numerical Model

The DM walls, the converted mid-DM walls, the soft clay, the silt, and the embankment fill were modeled as linearly elastic-perfectly plastic materials with Mohr-Coulomb failure criteria. DM columns extended to the depth of the firm glacial soil. No deformation below the silt layer was assumed. Cable elements incorporated in the software, which can only sustain axial tension, were used to simulate the geotextile layer. The geosynthetic layer was located $0.3 \mathrm{~m}$ above the top of the DM columns. The properties of the DM walls, the converted mid-DM walls, the soft clay, 
the silt, the embankment fill, and the geosynthetic layer are provided in Table 3-4, most of them from Forsman et al. (1999). The properties of the crust at the ground surface were not available and treated as part of the soft clay in the numerical analysis to account for the disturbance of the surface layer during construction.

Table 3-4. Material Properties

\begin{tabular}{|c|c|c|c|c|c|c|c|}
\hline Material & $\begin{array}{c}\mathrm{E} \\
(\mathrm{MPa})\end{array}$ & $v$ & $\begin{array}{c}\gamma \\
\left(\mathrm{kN} / \mathrm{m}^{3}\right)\end{array}$ & $\begin{array}{c}\mathrm{c}^{\prime} \\
(\mathrm{kPa})\end{array}$ & $\begin{array}{l}\phi^{\prime} \\
\left({ }^{0}\right)\end{array}$ & $\begin{array}{c}\mathrm{W} \\
(\%)\end{array}$ & $\begin{array}{c}\mathrm{k} \\
(\mathrm{m} / \mathrm{s})\end{array}$ \\
\hline Soft soil & 0.3 & 0.2 & $10.0 *$ & 8 & 13 & $70 \%$ & $6.342 \times 10^{-11}$ \\
\hline Silt & 1.6 & 0.33 & $15.4^{*}$ & 5 & 20 & $70 \%$ & $6.342 \times 10^{-11}$ \\
\hline $\begin{array}{c}\text { Embankment fill } \\
\text { (base course) }\end{array}$ & 40 & 0.33 & 20 & 5 & 38 & N/A & $\mathrm{N} / \mathrm{A}$ \\
\hline $\begin{array}{c}\text { Platform fill } \\
\text { (sub-base layer) }\end{array}$ & 20 & 0.33 & 20 & 5 & 32 & N/A & N/A \\
\hline DM walls & 30 & 0.3 & 20 & 150 & 0 & $30 \%$ & $6.342 \times 10^{-11}$ \\
\hline $\begin{array}{l}\text { Converted } \\
\text { mid-DM walls }\end{array}$ & 15 & 0.3 & 20 & 79 & 0 & $30 \%$ & $6.342 \times 10^{-11}$ \\
\hline Geotextile & & $\mathrm{J}=$ & $\mathrm{kN} / \mathrm{r}$ & .8 & & $0 \mathrm{k}$ & $/ \mathrm{m}$ \\
\hline
\end{tabular}

Note: $\mathrm{E}=$ elastic modulus, $v=$ Poisson's ratio, $\gamma=$ unit weight, $\mathrm{c}^{\prime}=$ effective cohesion, $\phi^{\prime}=$ effective friction angle, $\mathrm{w}=$ water content, $\mathrm{k}=$ permeability, $\mathrm{J}=$ tensile stiffness of geotextile, $\mathrm{c}_{\mathrm{i}}=$ interaction coefficient between geotextile and sand, and $\mathrm{k}_{\mathrm{s}}=$ interface shear stiffness between geotextile and sand. The unit weight with a symbol '*' is the dry unit weight, which was calculated based on the actual water content and the assumed specific gravity of 2.7. In the modeling of water flow in FLAC, the dry unit weight needs to be assigned to any material below the ground water table.

The FLAC models of these two cases are presented in Fig. 3-7 (a) and (b), respectively. 


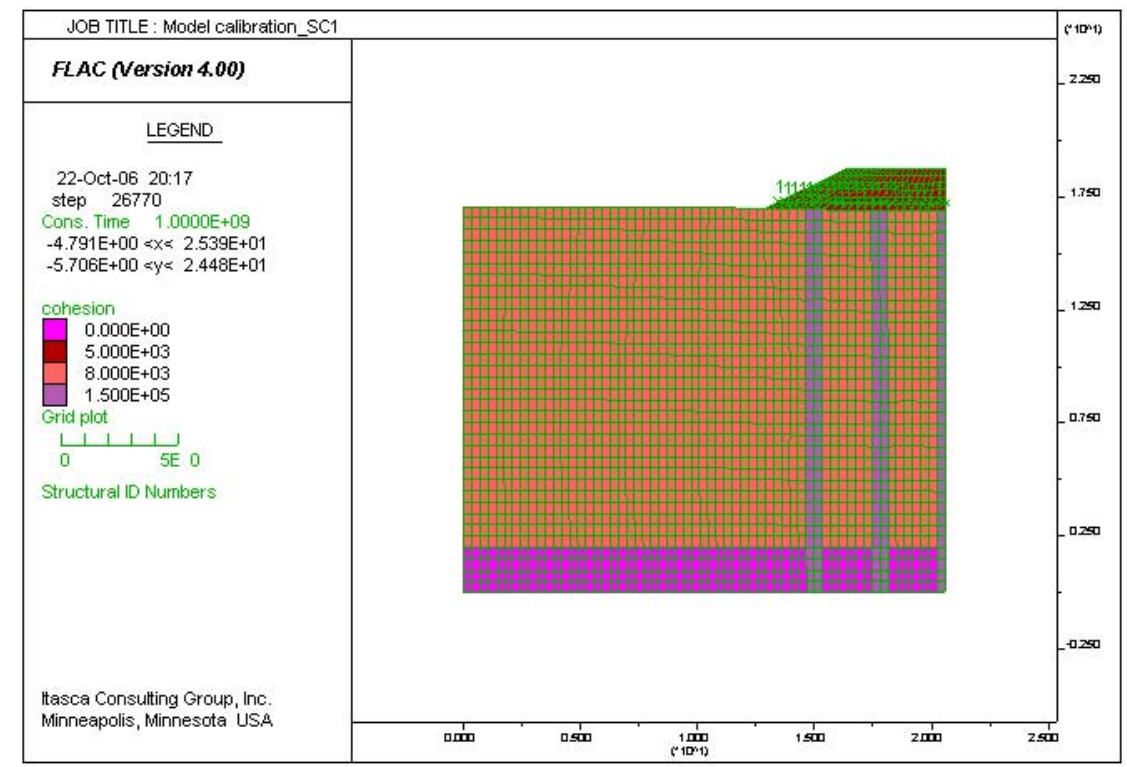

(a) $\mathrm{SC} 1$

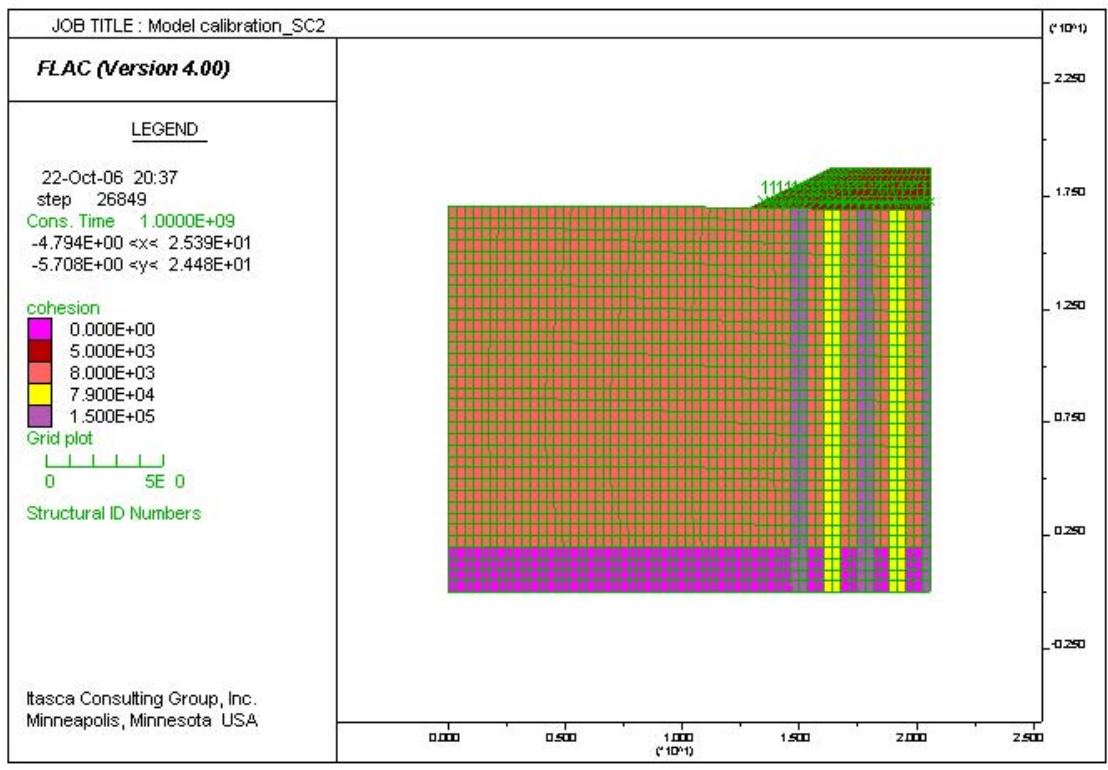

(b) $\mathrm{SC} 2$

Fig. 3-7. FLAC Models 


\subsubsection{Results and Comparison}

In the numerical modeling, pore water pressure, effective stress, settlement, and tension in the geosynthetic layer were recorded. Due to the limited availability of the field measured data, only settlements and strains in the geosynthetic layer at certain locations are compared with the field data.

\section{Settlement}

The settlements at the base of the embankment were monitored by horizontal hydrostatic profile gauges at Station 327.5 and Station 328.2, as shown in Fig. 3-3 (a) (Forsman 2001). Settlements at selected locations (S1, S2, S3, and S4) as shown in Fig. 3-3 (a) were measured by settlement plates and reported from the beginning of the construction. As mentioned in the case description, the measured settlement profiles at Station 327.5 were at the cross-section without isolated columns, while the measured settlement profiles at Station 328.2 were at the cross-section with isolated columns. Therefore, the measured settlement profiles at Station 327.5 and the measured time-settlement curves at S1 and S2 were compared with the numerical results from the $\mathrm{SC1}$ case, while the measured settlement profiles at Station 328.2 and the measured time-settlement curves at S3 and S4 were compared with the numerical results from the SC2 case. 


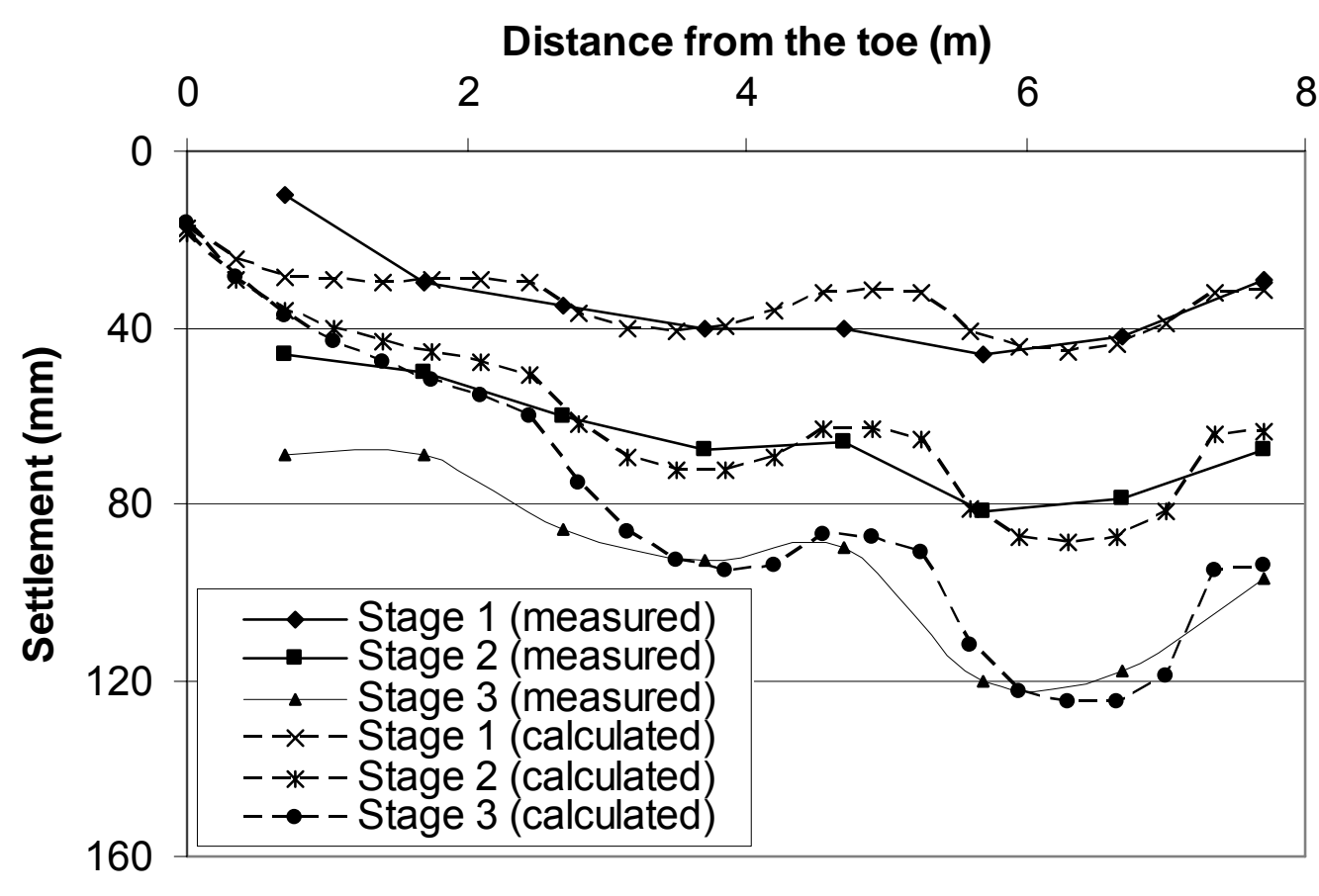

(a) Measured settlement profiles at Station 327.5 and profiles from SC1

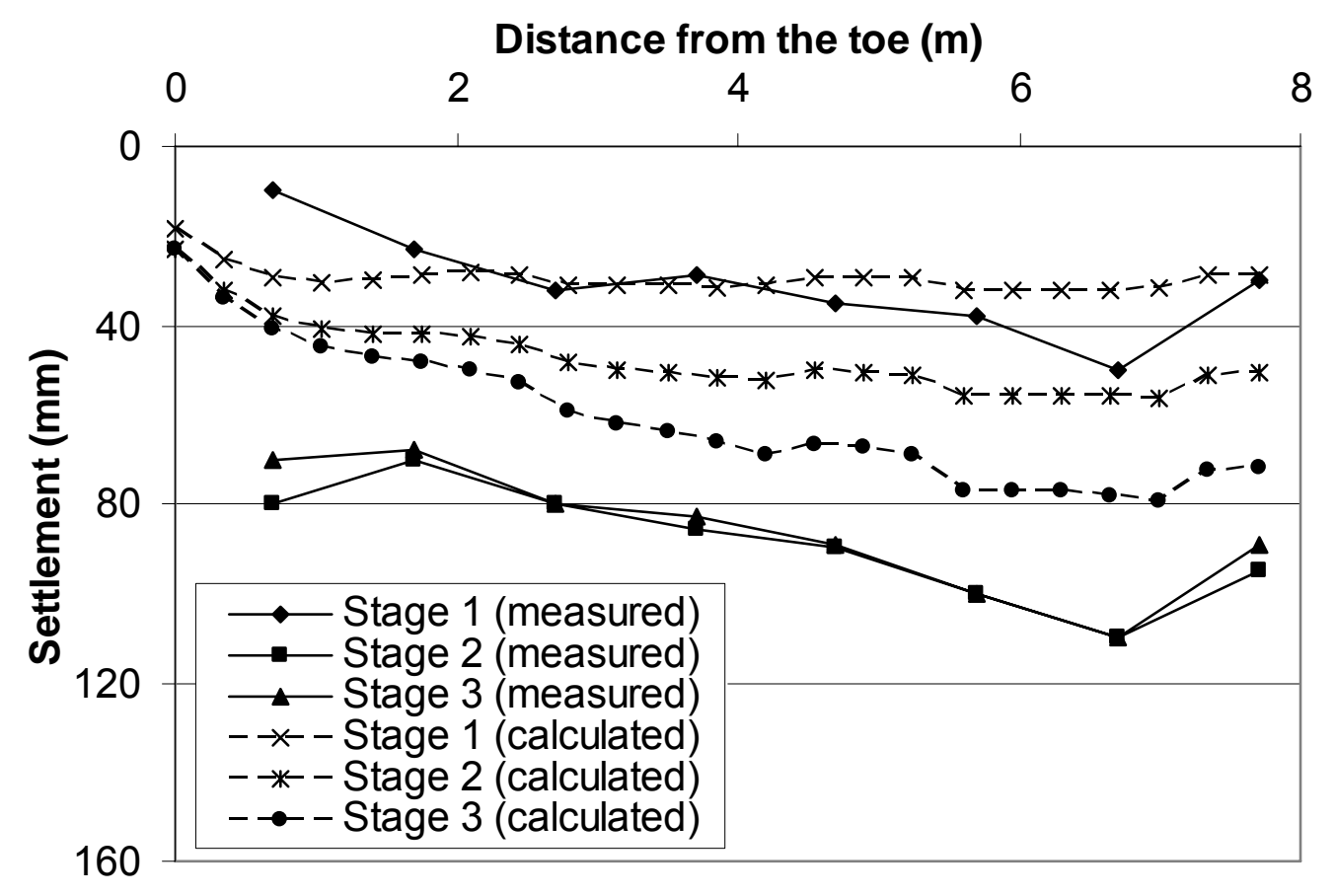

(b) Measured settlement profiles at Station 328.2 and profiles from SC2

Fig. 3-8. Settlement Profiles at Different Stages (2D) 
Fig. 3-8 shows that the settlement profiles from the $\mathrm{SC} 1$ case match the measurements at Station 327.5 reasonably well but the settlement profiles from the SC2 case underestimated the measurements at Station 328.2. Similarly, the SC1 case can fairly well capture the trend of the measured settlements at S1 and S2, however, the SC2 case underestimated the measured settlements at S3 and S4, as shown in Fig. 3-9.

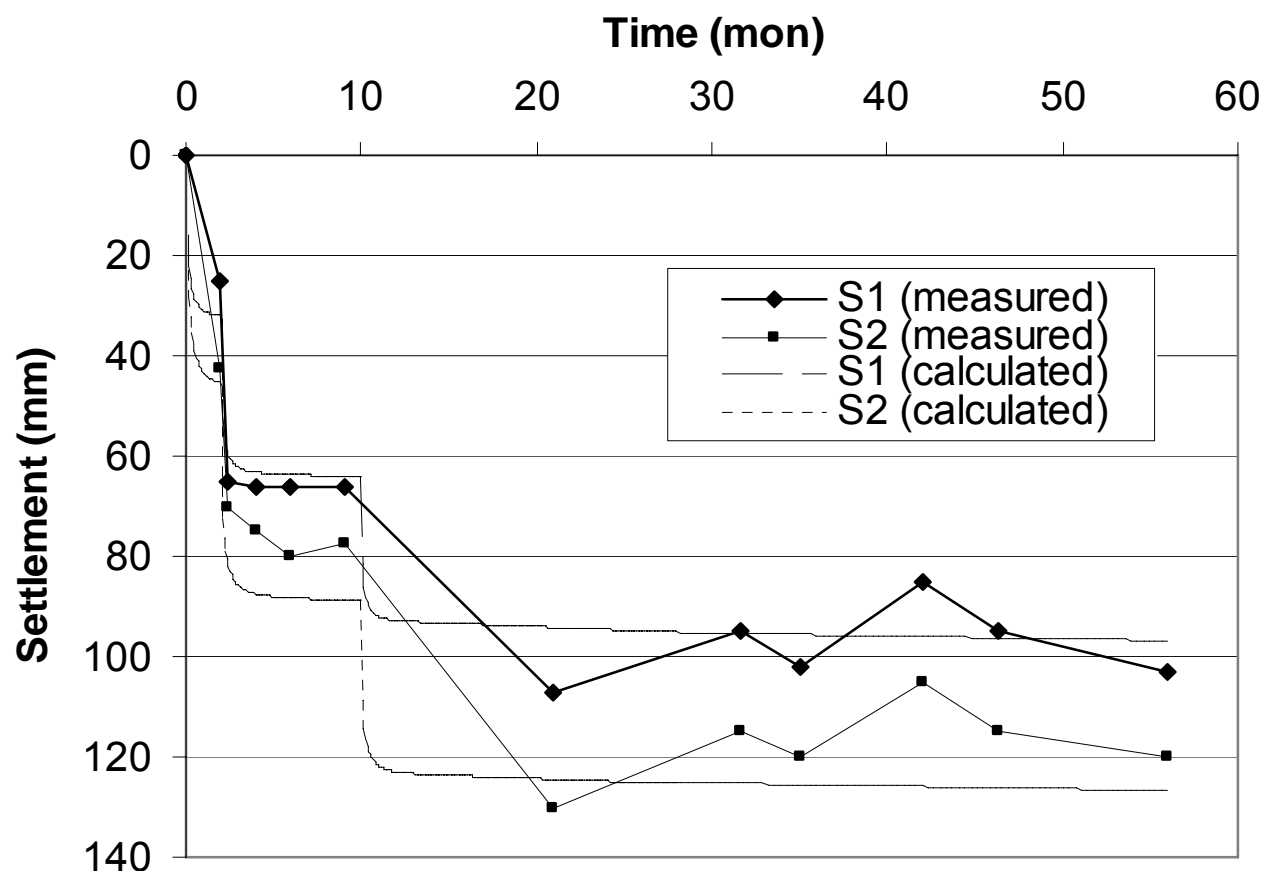

(a) Settlements at S1 and S2

Fig. 3-9. Settlement versus Time (2D) 


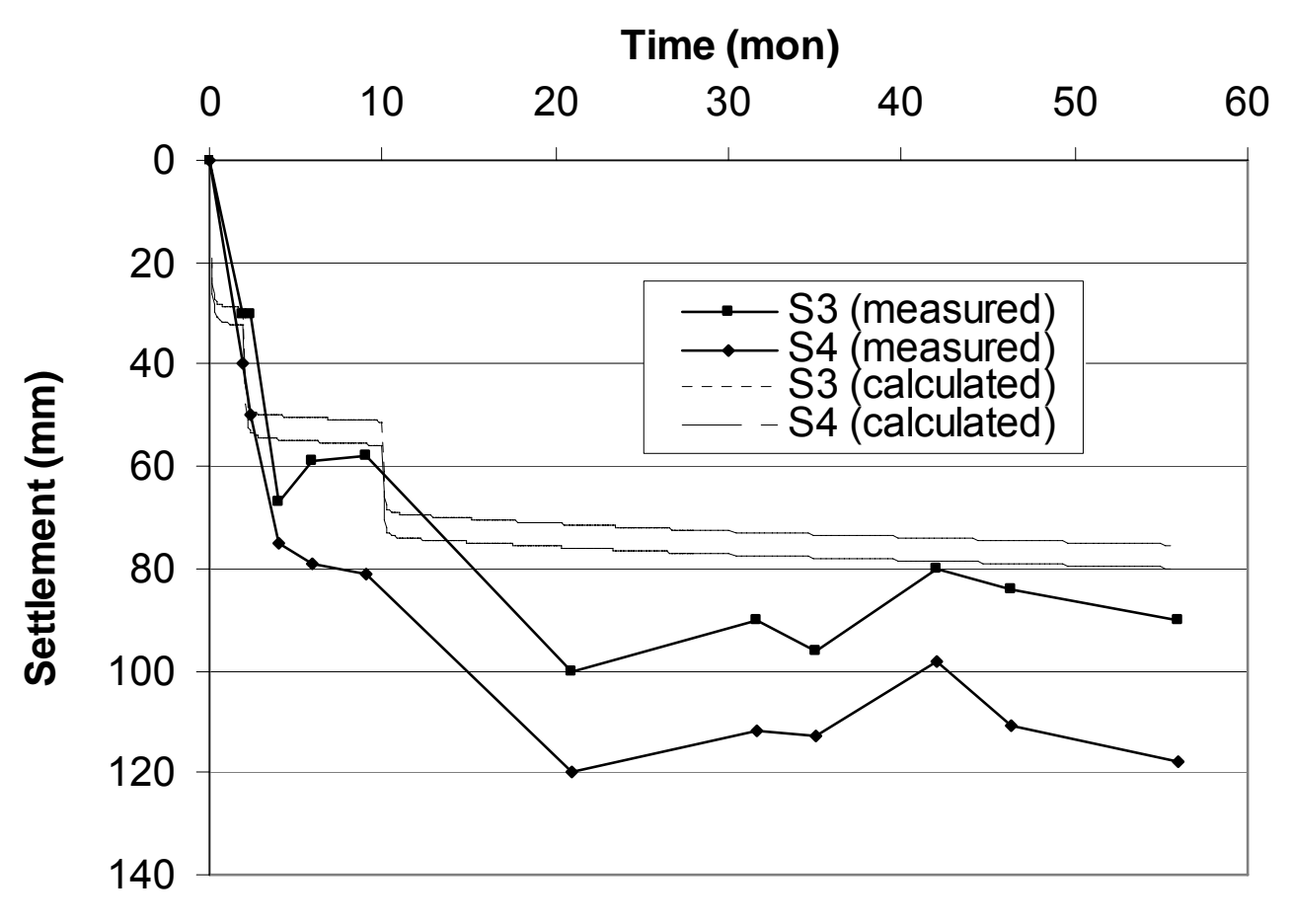

(b) Settlements at S3 and S4

Fig. 3-9. Settlement versus Time (2D) (continued)

Han et al. (2005) conducted a numerical study on the SC1 and SC2 cases under a drained condition (i.e., mechanical modeling with drained moduli). The maximum settlements from the drained analysis, which occurred at the base of the embankment, are presented in Table 3-5 for the comparison with those from the coupled analyses at 30 -year service life. It is shown that the maximum settlement values from the drained analysis are always greater than those from the coupled analysis. 
Table 3-5. Maximum Settlements at the Base of the Embankment

\begin{tabular}{ccccc}
\hline & \multicolumn{4}{c}{ Numerical analysis } \\
\cline { 2 - 5 } & \multicolumn{3}{c}{ SC1 } & \multicolumn{3}{c}{ SC2 } \\
\cline { 2 - 5 } & Coupled & Drained & Coupled & Drained \\
\hline $\begin{array}{c}\text { Maximum settlement between DM walls } \\
(\mathrm{mm})\end{array}$ & 131 & 196 & 94 & 110 \\
\hline $\begin{array}{c}\text { Maximum settlement on DM walls } \\
(\mathrm{mm})\end{array}$ & 109 & 127 & 87 & 100 \\
\hline
\end{tabular}

Even though the settlements on the crest were not measured in the field, it is very important to investigate them since they are more critical to the performance of the embankment. Fig. 3-10 presents the calculated settlement profiles at the base, as well as those at the crest of the embankment, at the end of Stage 3 and at the 30 -year service life using the coupled numerical modeling. It is shown that the maximum settlement at the crest is about $1 / 3$ to $1 / 4$ that at the base of the embankment. Obvious differential settlement occurs at the base of the embankment between DM walls, whereas this local differential settlement does not exist on the crest. Even though the maximum settlement occurs at the base of the embankment, the post-construction settlement at the crest of the embankment is crucial for the serviceability of pavements on embankments or the connection between approach embankments and bridge abutments. The settlement at the crest of the embankment starts to accumulate right after the placement of the asphalt layer; therefore, it is actually the postconstruction settlement. 
Distance from the toe $(\mathrm{m})$

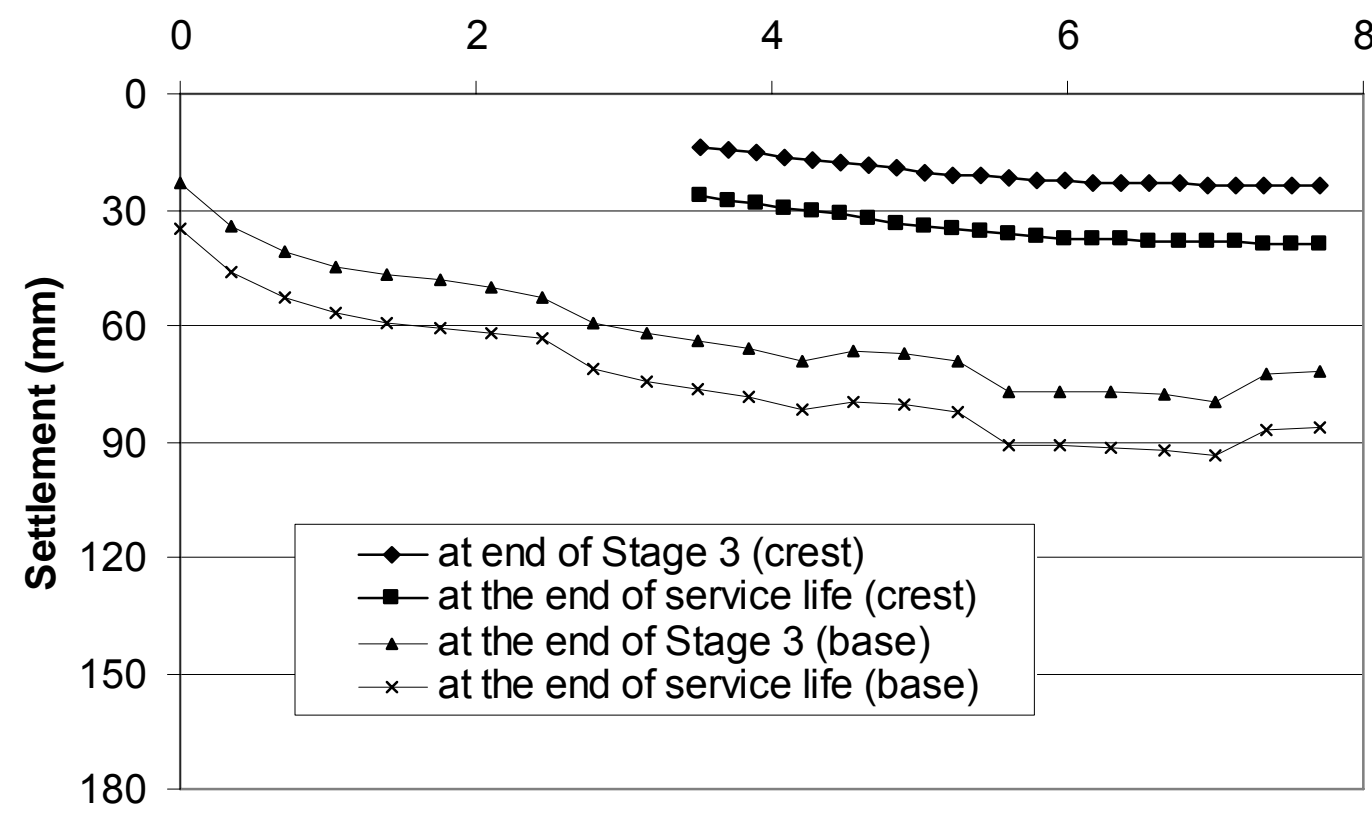

(a) Settlement profiles of SC1

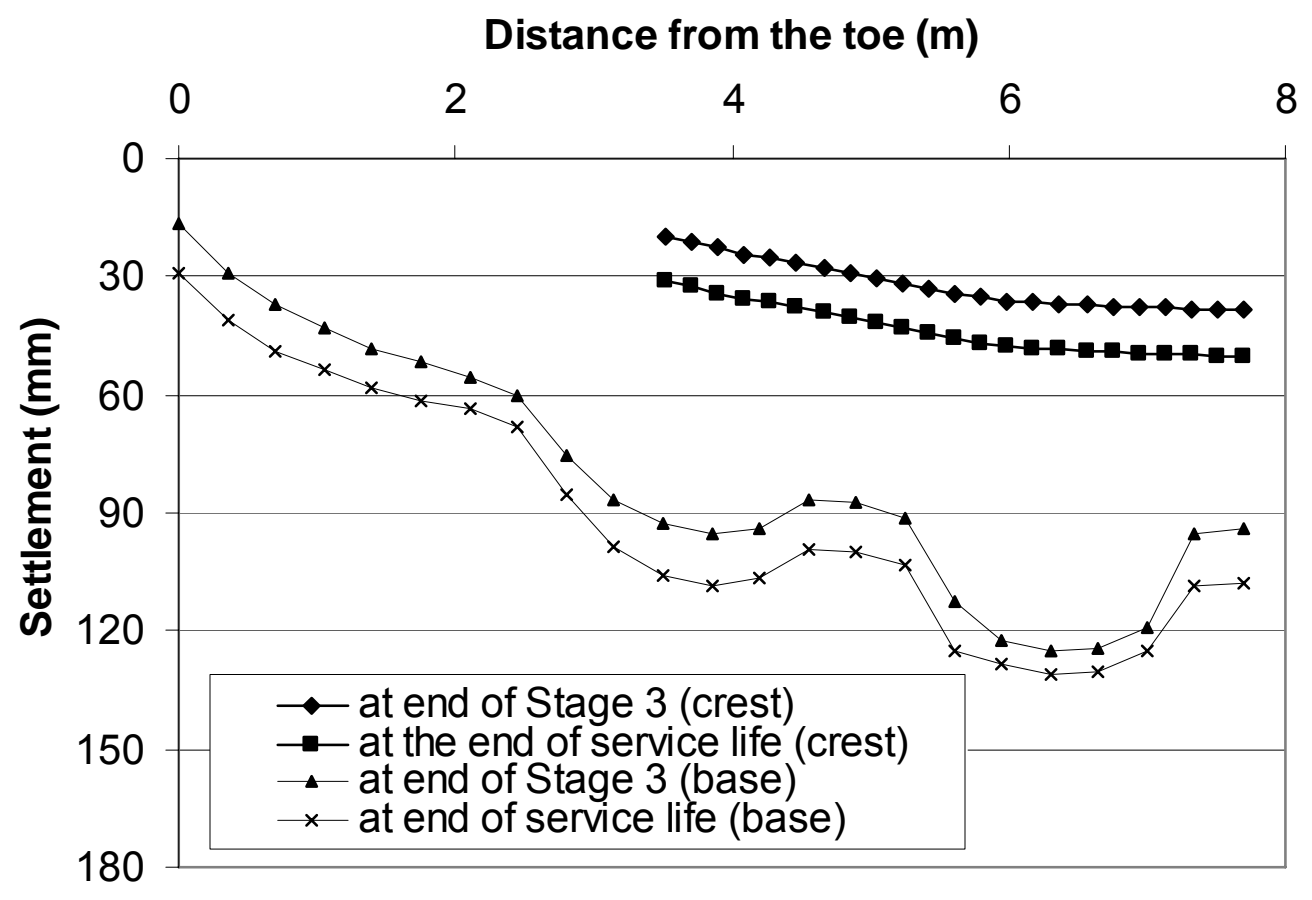

(b) Settlement profiles of SC2

Fig. 3-10. Settlement Profiles at the Base and on the Crest of the Embankment (2D) 
Fig. 3-10 also shows that the SC2 case has less settlement than the SC1 case because the SC2 case has additional mid-DM walls between the regular DM walls. The postconstruction settlement further increases from the end of Stage 3 to the 30 -year service life.

\section{Strain and Tension in Geosynthetic Layer}

Strain gauges were installed near Station 330.0 to monitor the development of strains at different locations as shown in Fig. 3-3 (b) (Forsman 2001). Since B7 and B8 were located along the cross-section without isolated columns, their measurements were compared with results from the SC1 case as shown Fig. 3-11 (a). Since B4 and B5 were located along the cross-section with isolated columns, their measurements were compared with results from the SC2 case as shown in Fig. 3-11 (b). Good agreement was found between field measurements and results from the $\mathrm{SC} 1$ case at B7 and B8. But results from the SC2 case underestimated the measurements at B4 and B5. This finding is consistent with what has been found in the settlement comparison. 


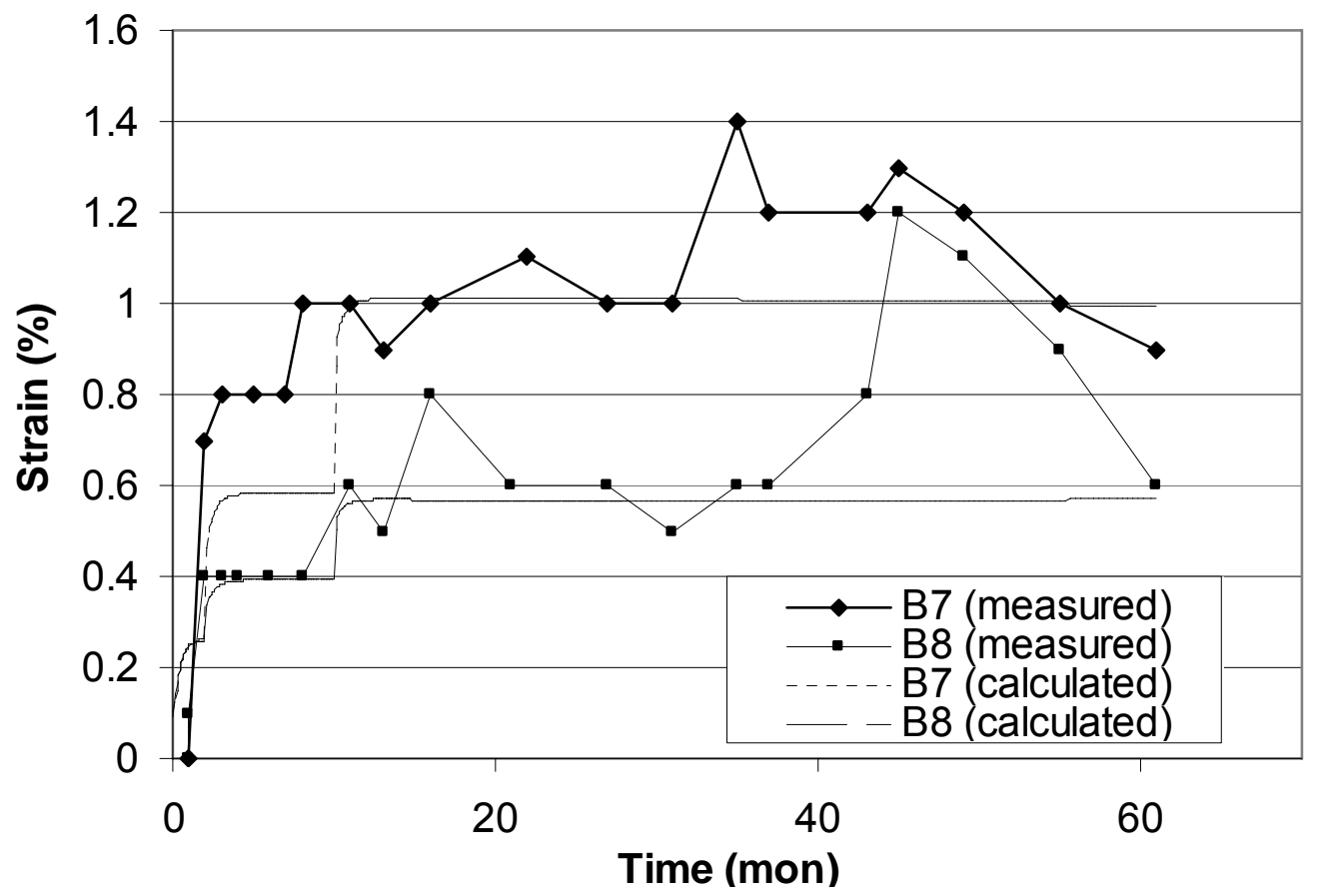

(a) Strains at B7 and B8

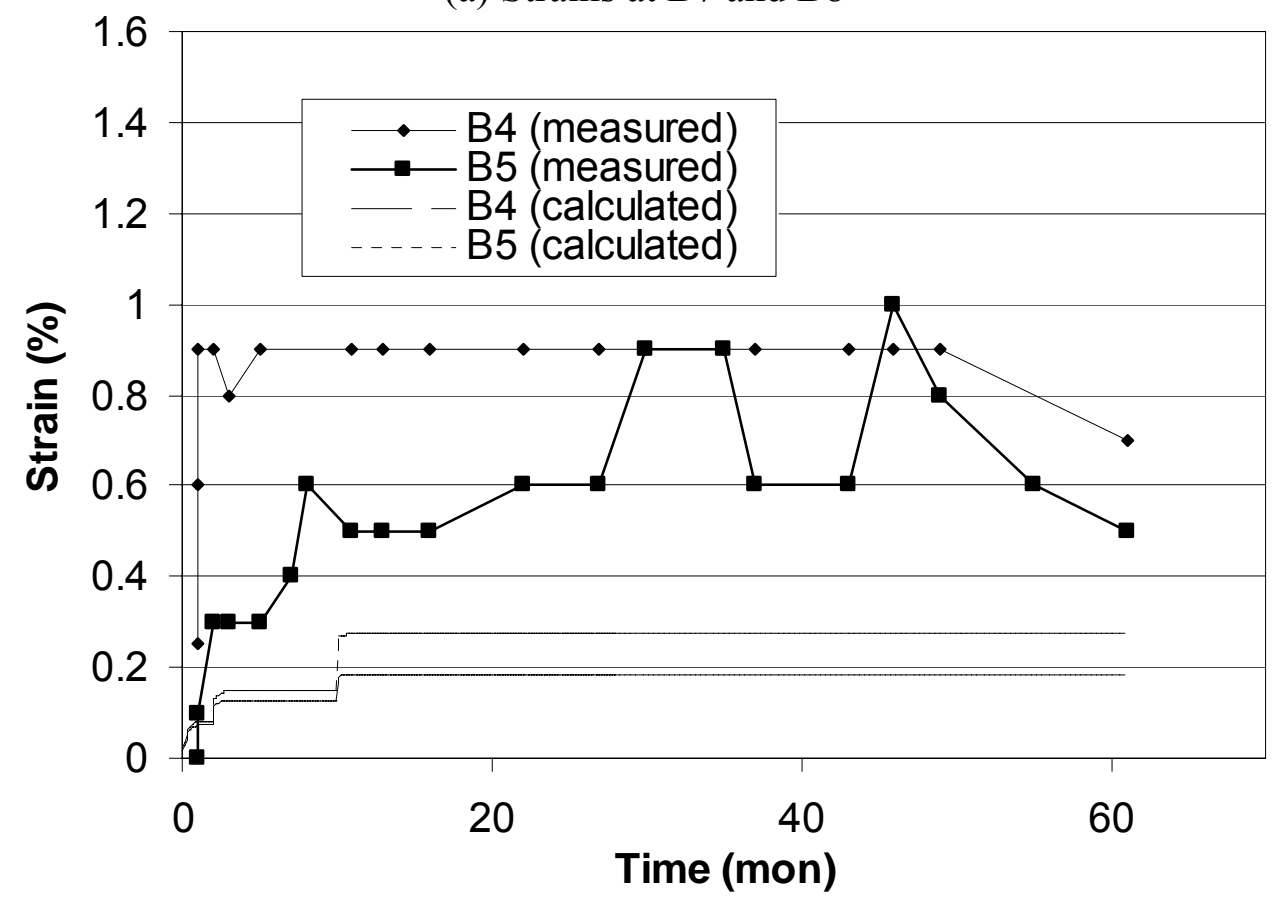

(b) Strains at B4 and B5

Fig. 3-11. Strain versus Time (2D) 
The profiles of tension developed in the geosynthetic layer from the coupled numerical analysis for the $\mathrm{SC} 1$ and $\mathrm{SC} 2$ cases are presented in Fig. 3-12. It is shown that the higher tension is located above the DM columns, which is consistent with the findings from the field measurements and the earlier study on a unit cell model by Han and Gabr (2002). The tension in the reinforcement above the mid-DM walls is lower than that above other DM walls. This phenomenon is attributed to the fact that the equivalent modulus of the mid-DM walls is lower than that of other DM walls. Overall, the tension in the reinforcement for the $\mathrm{SC} 1$ case is higher than that for the $\mathrm{SC} 2$ case. This result is intuitively correct since the mid-DM columns in the SC2 case minimize the tension in the reinforcement.

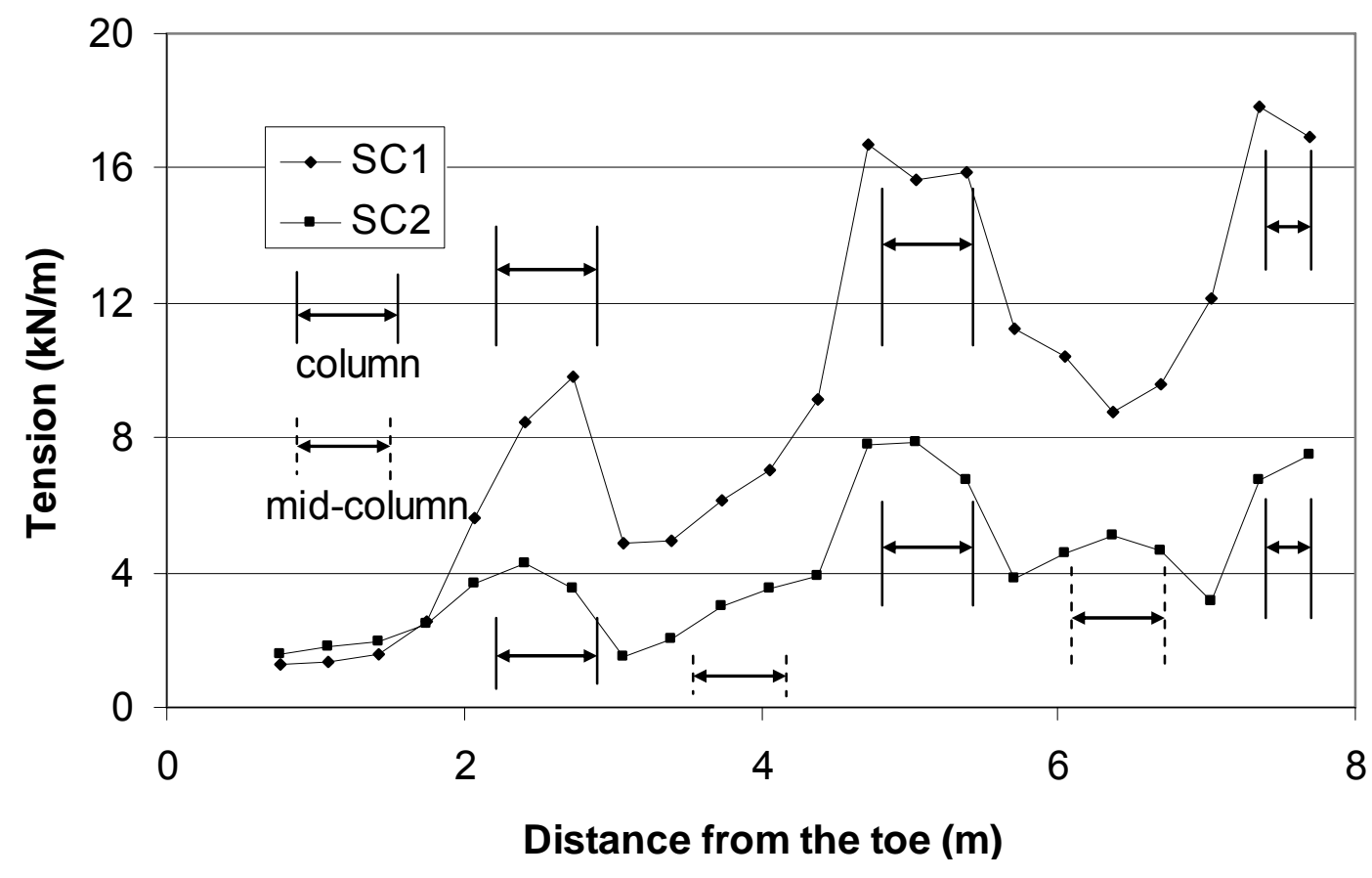

Fig. 3-12. Tension Developed in the Geosynthetic Layer with or without Mid-DM Walls 
Table 3-6 presents the measured tension range of the calculated results using coupled and drained numerical models. Both numerical models for the SC1 case yield the close result for the tension in the geosynthetic layer, whereas those for the SC2 case underestimate the tension in the reinforcement. This comparison can be explained that the maximum span of the geosynthetic sheet in the field is that between two DM walls not between the mid-DM columns and the DM wall since mid-DM columns have gaps in the centerline direction. The case for the geosynthetic sheet across two DM walls is the case of SC1.

Table 3-6. Maximum Tension in the Geosynthetic Layer

\begin{tabular}{lccccc}
\hline & \multicolumn{3}{c}{ Numerical analysis } \\
\cline { 3 - 6 } & & \multicolumn{2}{c}{ SC1 } & \multicolumn{2}{c}{ SC2 } \\
\cline { 3 - 6 } & Measured & Coupled & Drained & Coupled & Drained \\
\hline Tension $(\mathrm{kN} / \mathrm{m})$ & $3.6-18.0$ & $1.5-17.8$ & $1.9-18.3$ & $1.5-7.8$ & $1.8-7.3$ \\
\hline
\end{tabular}

On the completion of the 2D model calibration, 3D model calibration was conducted on the same case history with the same modeling procedure as $2 \mathrm{D}$.

\subsection{Three-dimensional (3D) Model Calibration}

Similar to the 2D model calibration, DM columns, soft soil, firm soil, and embankment fill were modeled as Mohr-Coulomb materials in the 3D model 
calibration. The geosynthetic reinforcement was modeled as built-in geogrid elements, which are plane triangular elements and can take axial load only.

\subsubsection{Numerical Modeling}

The three-dimensional (3D) numerical model for this case study is presented in Fig. 3-13. And the elevation view and plan view of the FLAC3D model are presented in Fig. 3-14 (a) and (b), respectively.

To save computing time, only half span in the traffic direction was modeled. For simplicity, the DM column walls and isolated DM columns were simplified to rectangular and square shape, which have effective thickness and effective size of $0.7 \mathrm{~m}$ and $0.7 \mathrm{~m}$, respectively. The material properties used are the same as those used in $2 \mathrm{D}$ (refer to Table $3-4)$.

The modeling procedure in the $3 \mathrm{D}$ analysis is the same as that in the $2 \mathrm{D}$ analyses. 


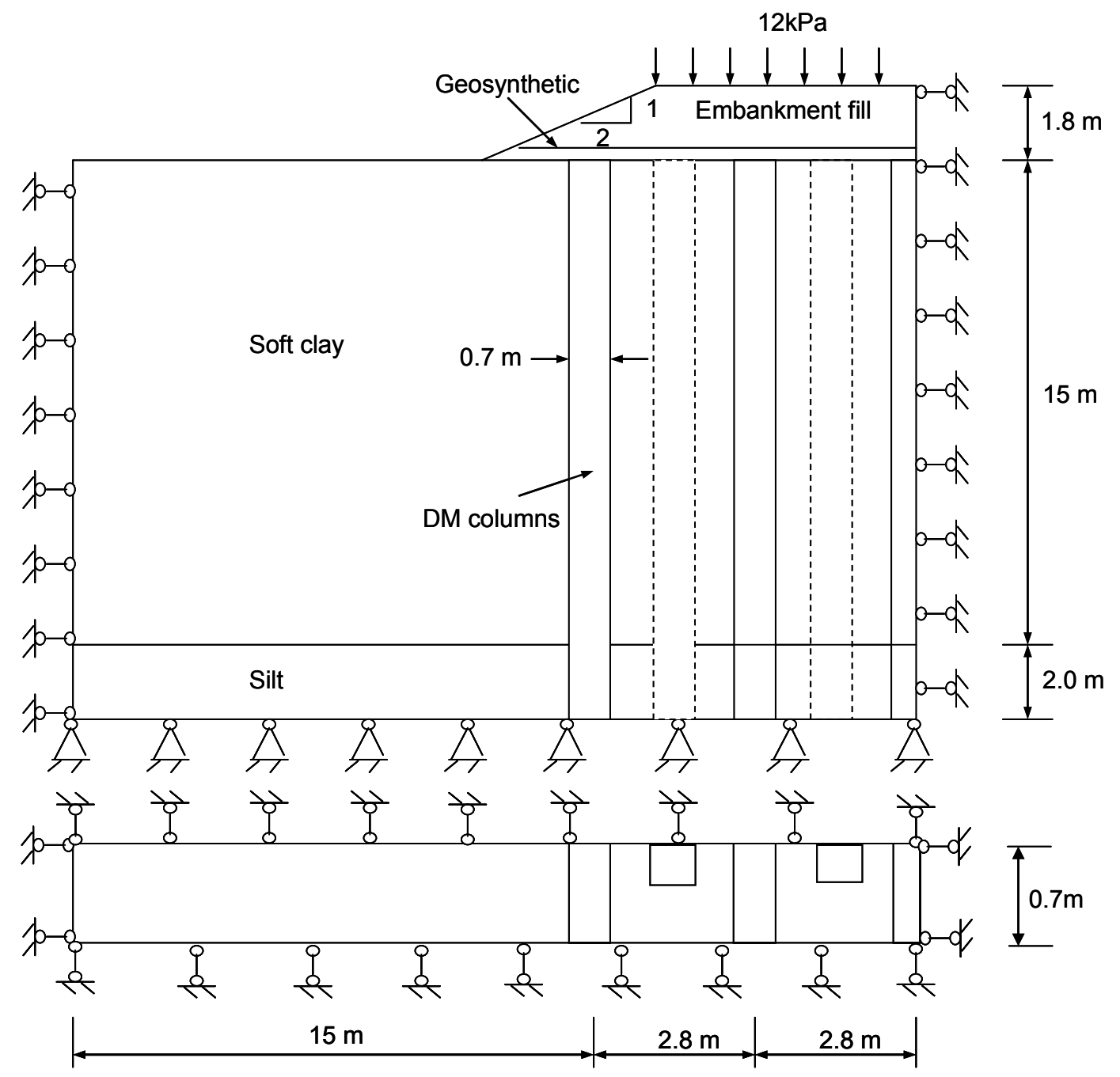

Fig. 3-13. 3D Numerical Model 


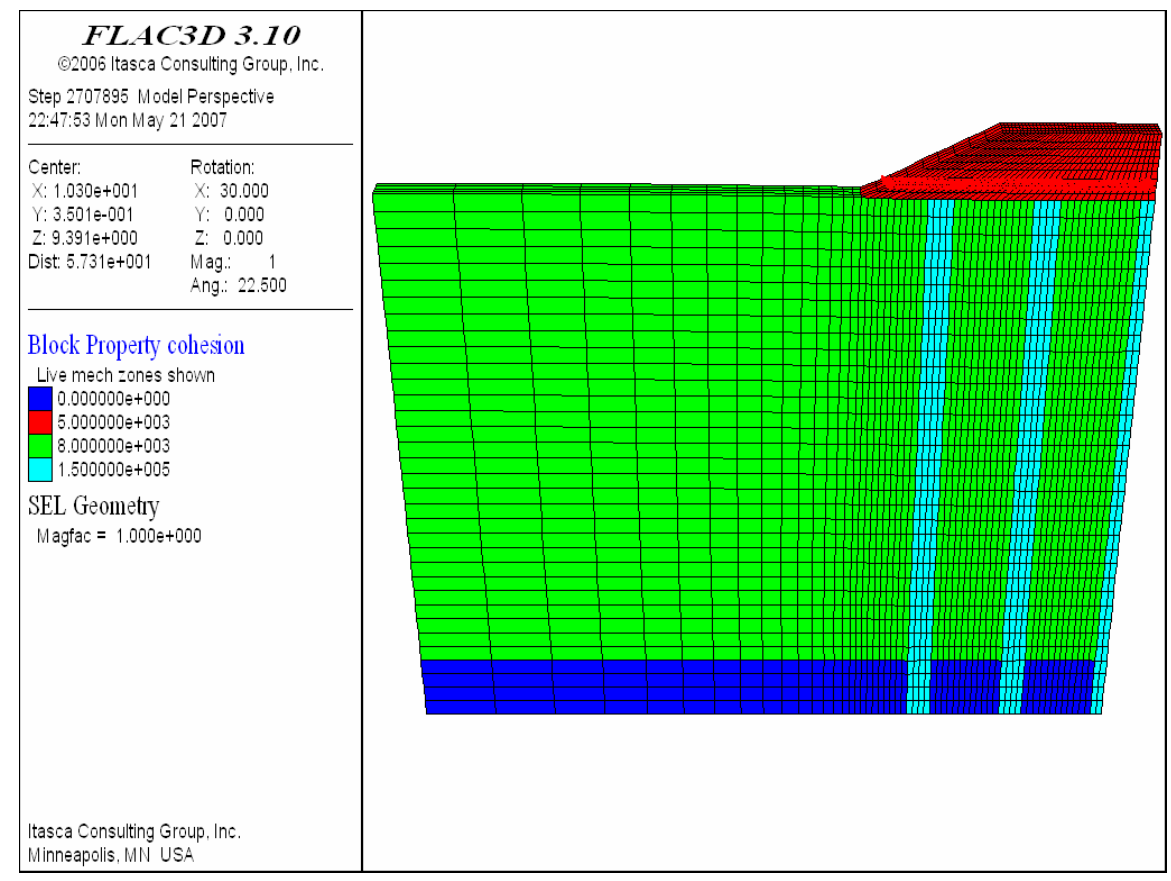

(a) Elevation view

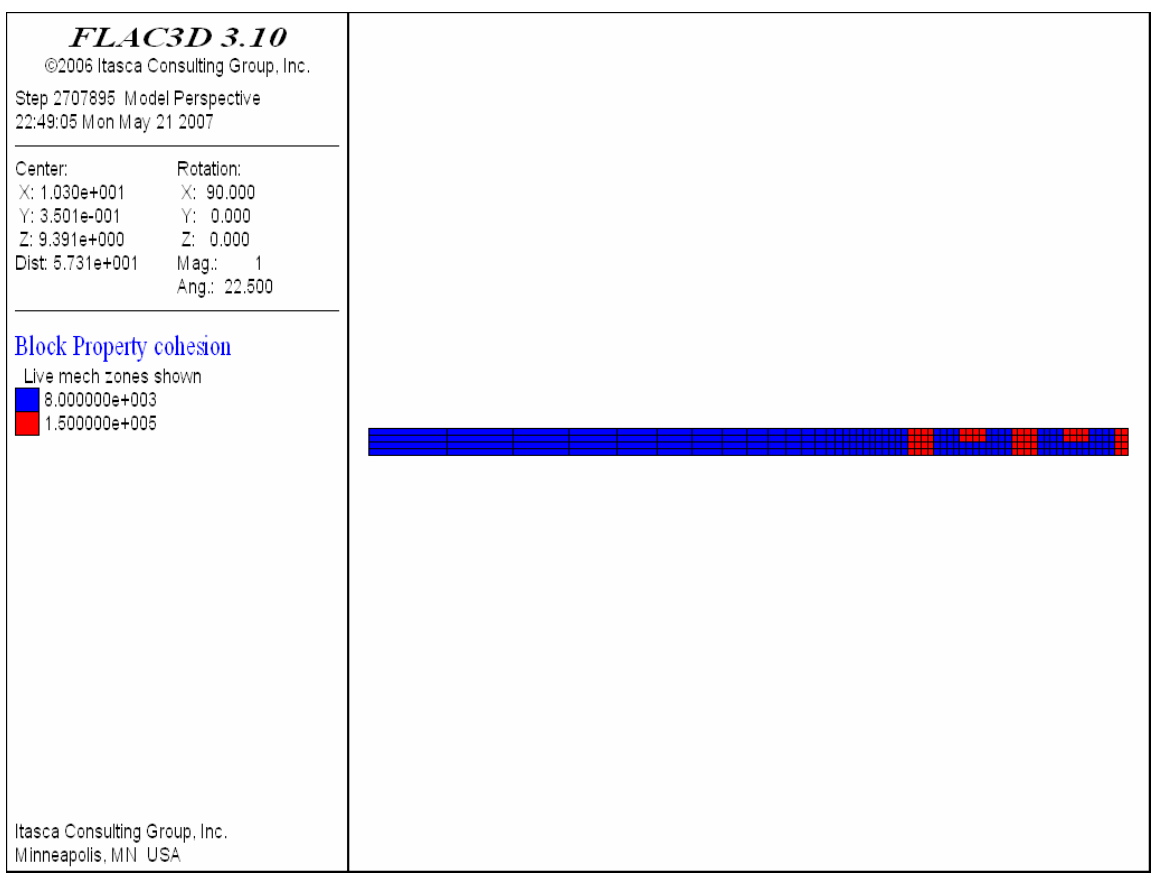

(b) Plan view

Fig. 3-14. FLAC3D Model 


\subsubsection{Results and Comparison}

In the numerical modeling, pore water pressure, effective stress, settlement, and tension in both traffic and transverse directions were recorded. Settlements and strains in geosynthetic at certain locations are compared with field data below.

\section{Settlement}

The settlement profiles at Station 327.5 and Station 328.2 based on the measurements by hydrostatic profile gauges are compared with 3D numerical results in Fig. 3-15.

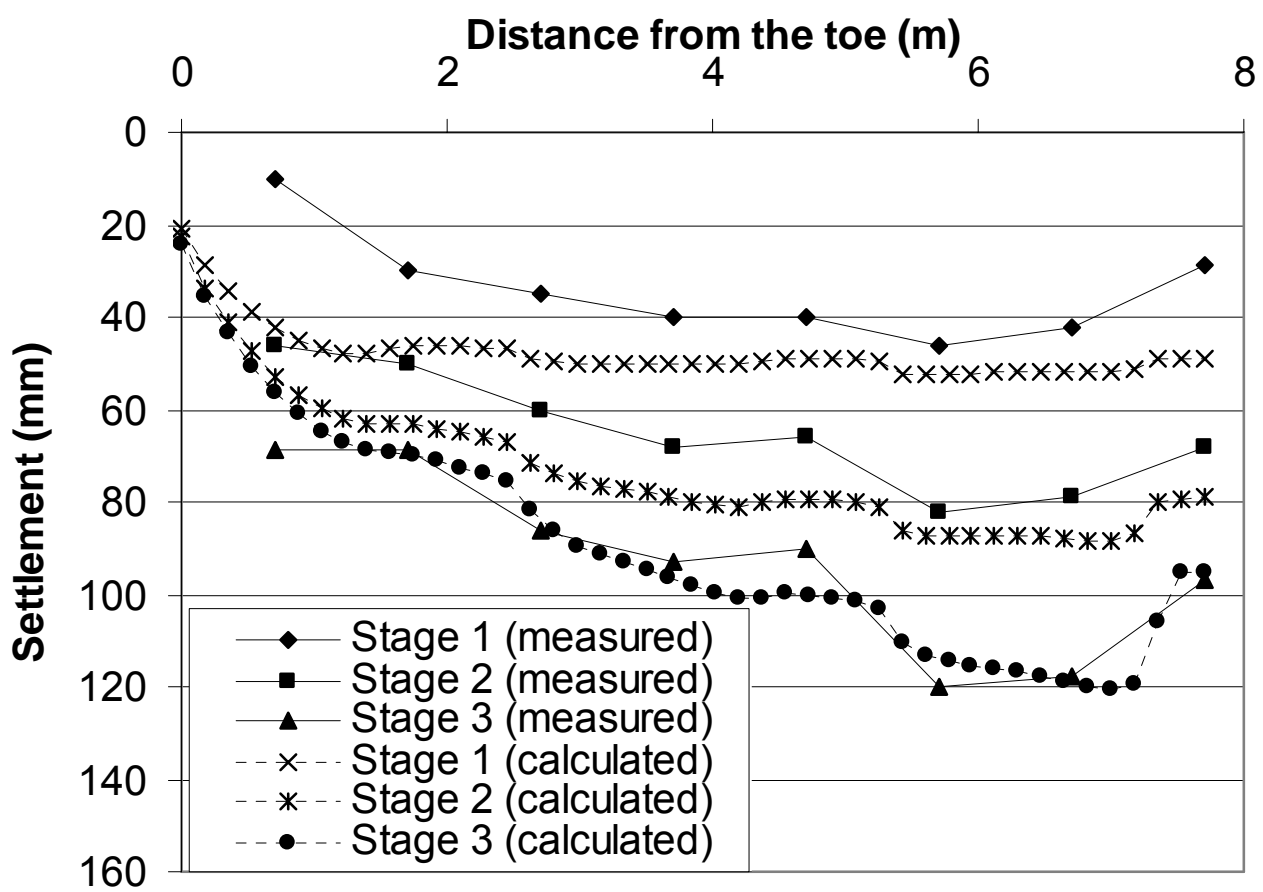

(a) Measured and calculated settlement profiles at Station 327.5

Fig. 3-15. Settlement Profiles at Different Stages (3D) 


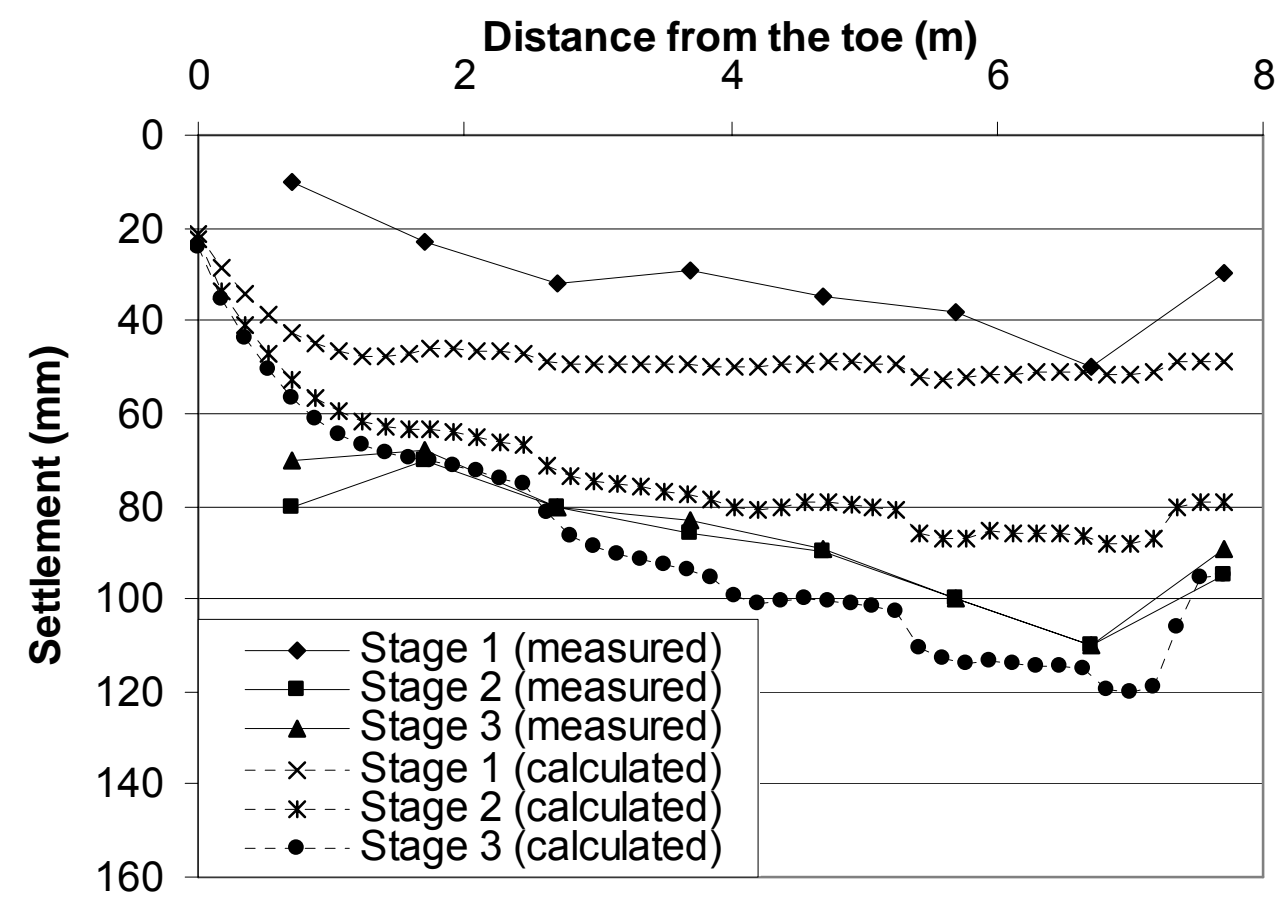

(b) Measured and calculated settlement profiles at Station 328.2

Fig. 3-15. Settlement Profiles at Different Stages (3D) (continued)

It can be found that numerical analysis provided reasonably good prediction, especially at Stage 3 at Station 327.5. Even though deviations exist between measurements and numerical results at Stage 1 and Stage 2, the numerical analysis can capture the trend of the development of the settlement across the sections.

In addition, the settlements monitored by the settlement plates at S1, S2, S3 and S4 (refer to Fig. 3-3 (a)) were also compared with the 3D numerical results in Fig. 3-16. Similarly, the 3D numerical results slightly overestimate the field measurements at 
Stage 1 and Stage 2 at S1, S2, S3, and S4. Nevertheless, it yields fairly good agreement on the final settlements at those four locations.

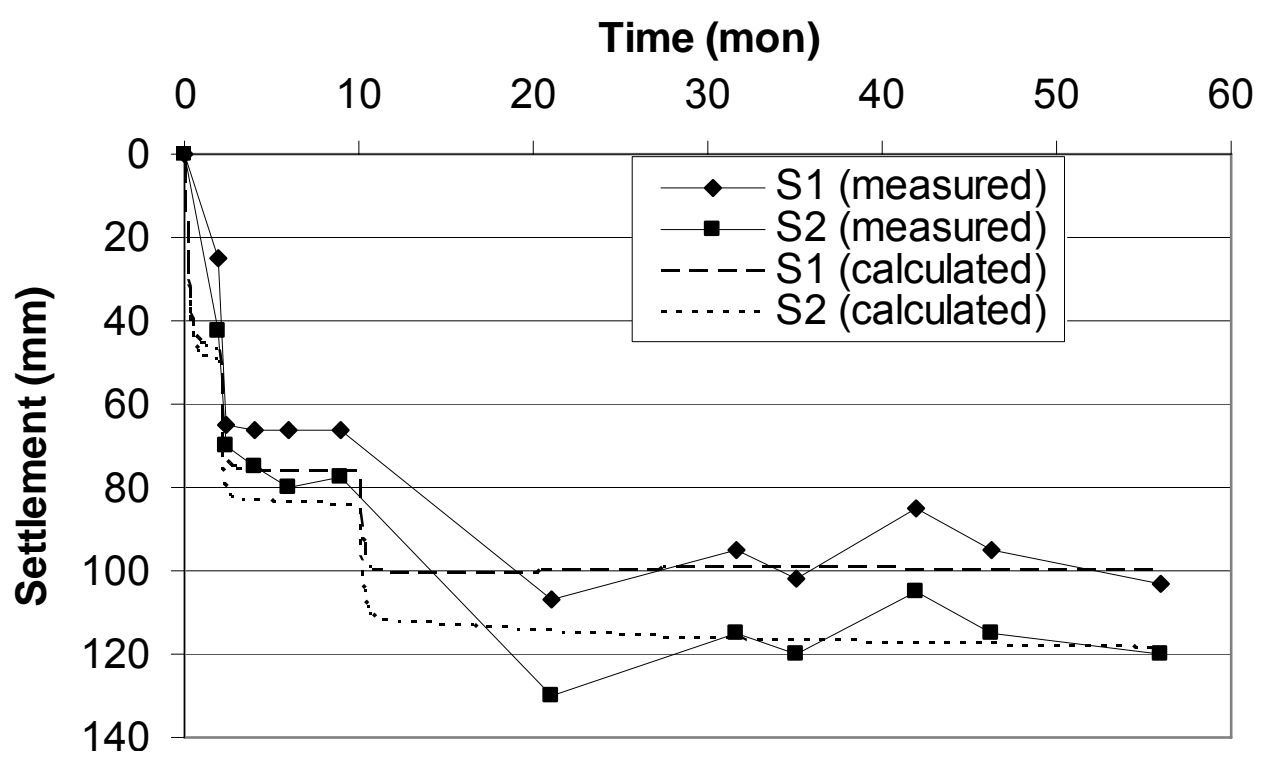

(a) Settlements at S1 and S2

Time (mon)

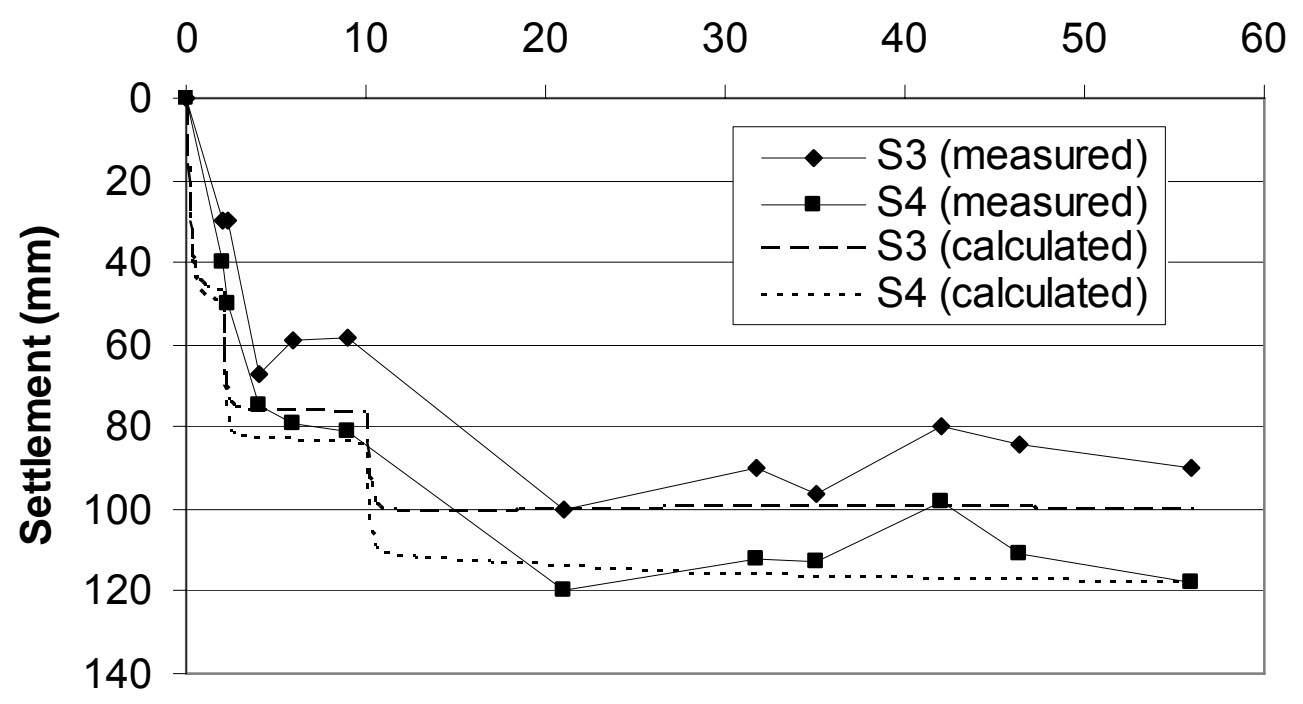

(b) Settlements at S3 and S4

Fig. 3-16. Settlement versus Time (3D) 
The settlement profiles from the numerical analysis at the crest and at the base are presented in Fig. 3-17. Due to the computing time, the 3D numerical analysis was only implemented up to ten years after service. Based on the settlement increment from at the end of Stage 3 to ten years after service, it can be anticipated that the settlement increment from 10 years to 30 years after service will be small. Apparently, the post-construction settlements at the crest are much less than those at the base. More importantly, the local differential settlements between columns and soft soil at the base are not directly reflected to the crest.

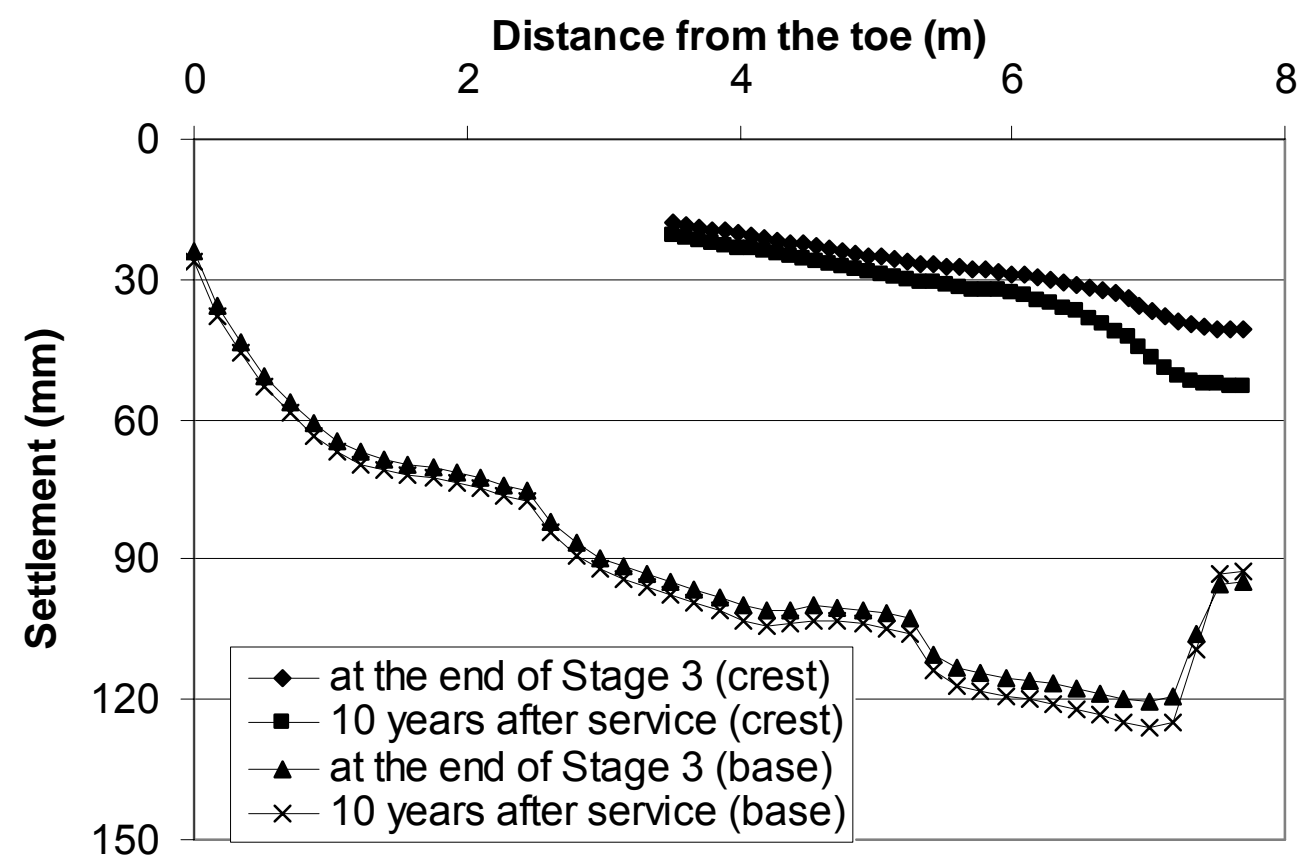

Fig. 3-17. Settlement Profiles on the Crest and at the Base (3D) 


\section{Strain and Tension in Geosynthetic Layer}

As mentioned previously, strain gauges were installed near Station 330.0 to monitor the development of strains at different locations (refer to Fig. 3-3). The computed strains at two locations in each direction, i.e., B4 and B5 in the transverse direction and A1 and A6 in the traffic direction, were compared with measured results as shown in Fig. 3-18. It was found that at B4 and B5 the numerical results were less than the measurements. The computed strains along the traffic direction at two locations (A1 and A6) are also less than measurements. The deviation between calculation and measurements may be attributed to the properties used in the modeling. The properties used in the modeling were based on short-term laboratory tests, while the field performance was a long-term behavior.

It is a common knowledge that the settlement measurements in the field are more accurate and reliable than strain measurements (Dunnicliff 1988).

Overall, it can be concluded that the $2 \mathrm{D}$ and $3 \mathrm{D}$ models can reasonably predict the performance of GRCS embankments in the field as demonstrated for this selected case history. The 2D and 3D model calibrations ensure the basis for the following parametric studies. 


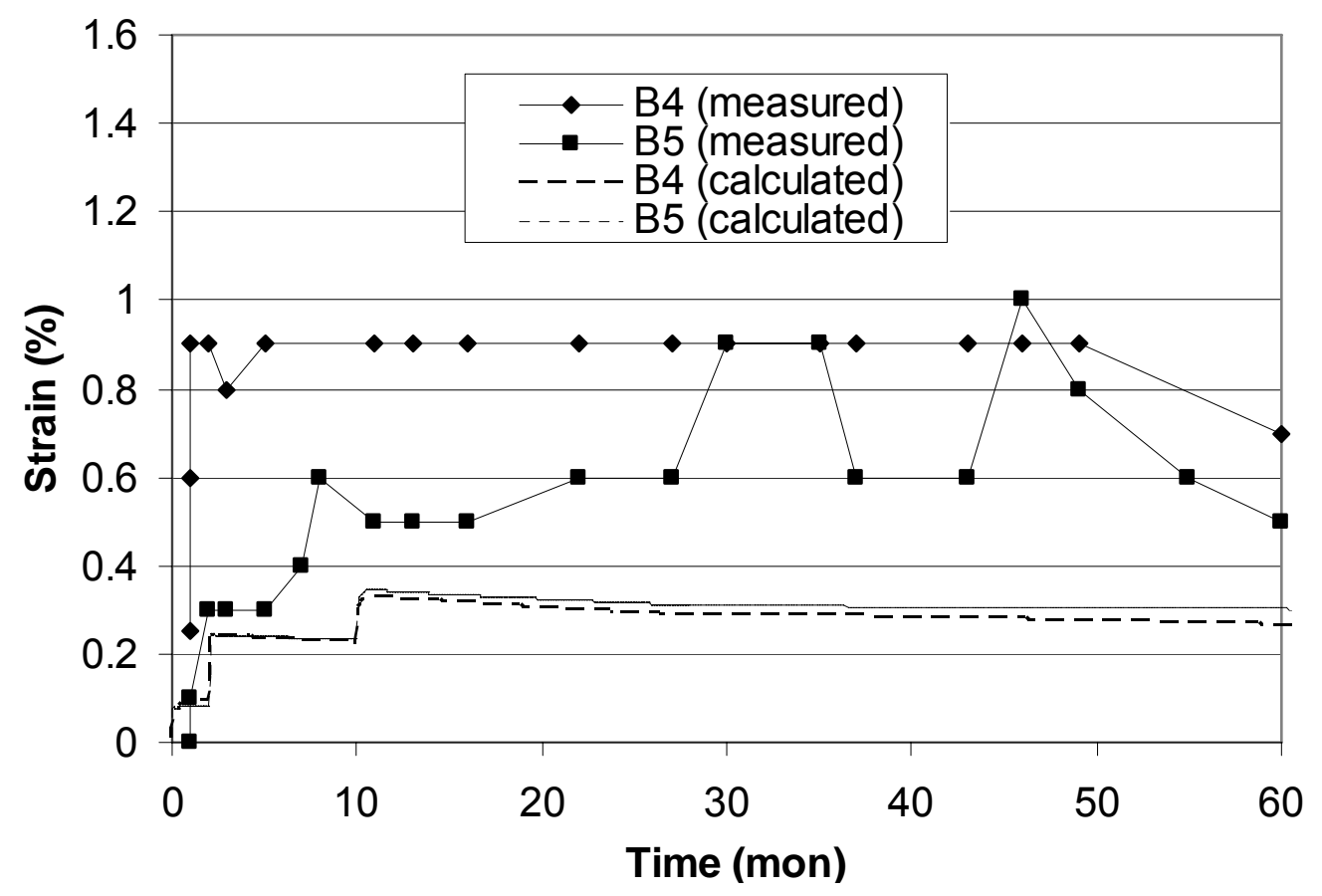

(a) Strain at B4 and B5

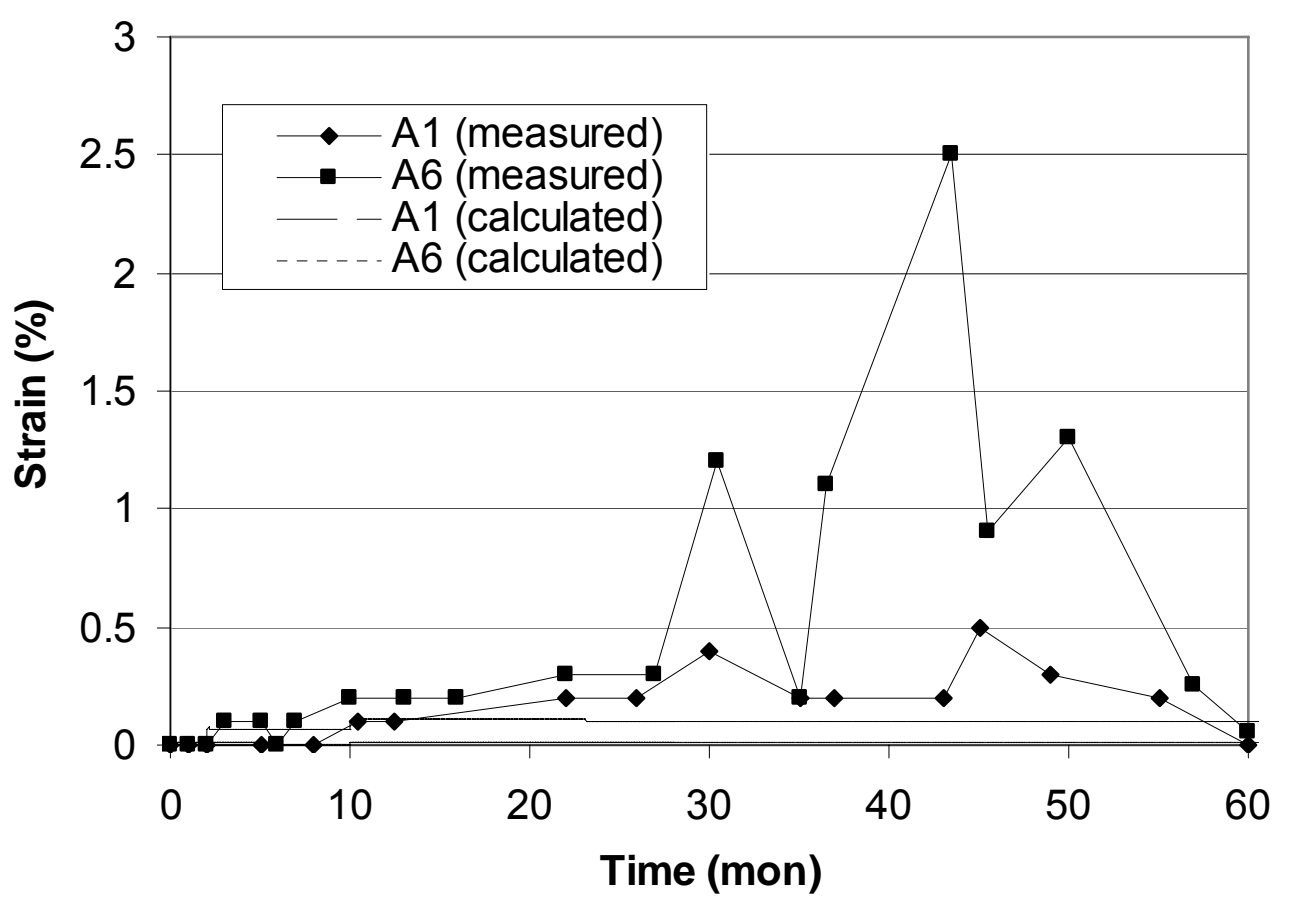

(b) Strain at A1 and A6

Fig. 3-18. Strain versus Time Relationship (3D) (continued) 


\section{CHAPTER FOUR}

\section{TWO-DIMENSIONAL PARAMETRIC STUDY}

On the basis of the model calibration, a two-dimensional (2D) parametric study was conducted to investigate the influence of key factors on total settlements, differential settlements, tension developed in geosynthetic reinforcement, stress concentration ratio, and excess pore water pressure generation and dissipation.

\subsection{D Baseline Case}

A baseline case was first selected as a typical case in the field and analyzed to develop a basis for comparisons when parameters were deviated from the baseline base. The deviations of the parameters were considered to cover their typical ranges in most actual projects.

\subsubsection{D Dimensions and Properties}

To make the results comparable, a baseline case was determined based on a typical configuration. The dimensions and properties are presented in Fig. 4-1 and Table 4-1, respectively. 


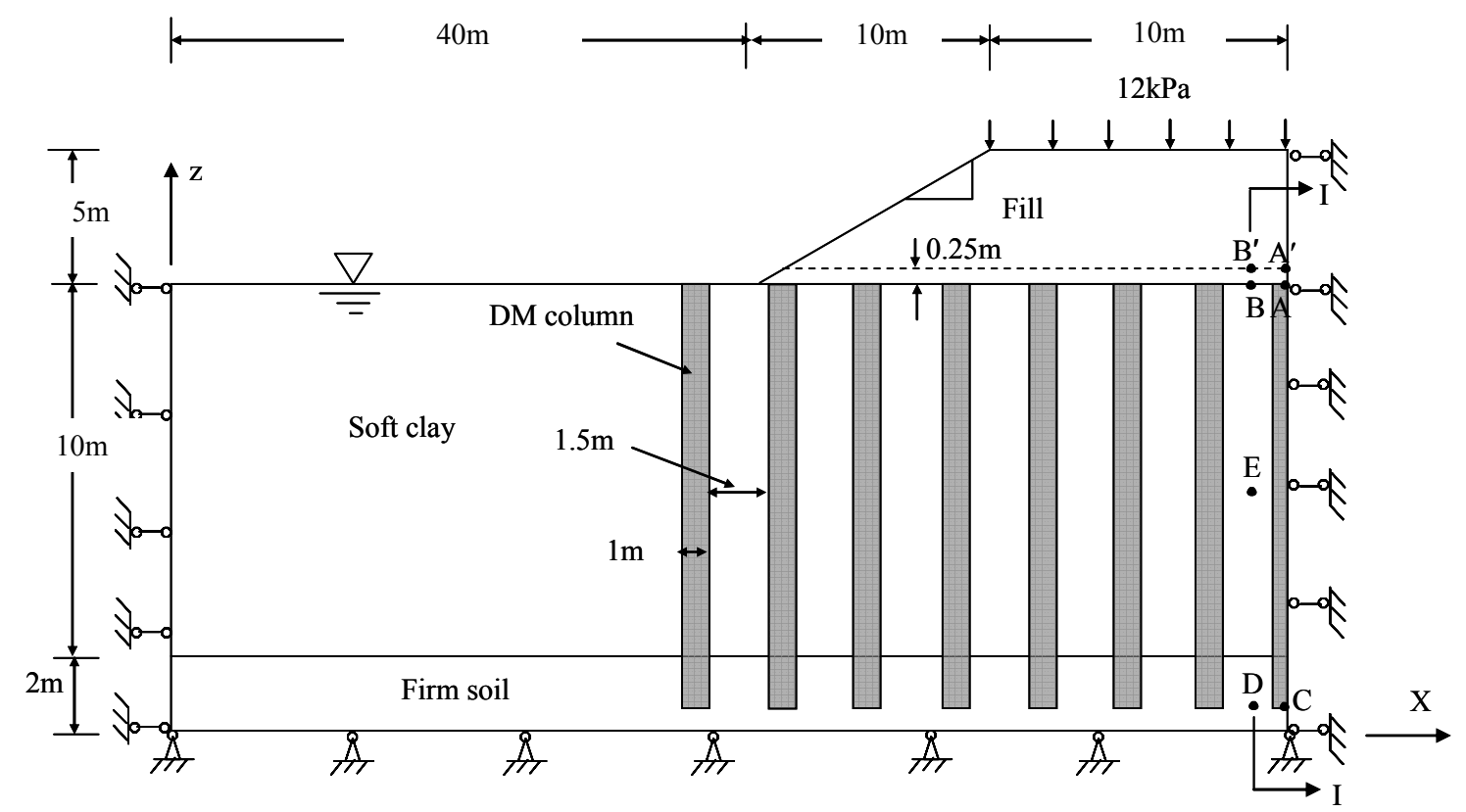

Fig. 4-1. Two-dimensional Model of the 2D Baseline Case

Due to its symmetry, only half of the embankment was modeled to save computing time as shown in Fig. 4-1. The embankment slope was assumed to be 2:1 (H:V), which is widely adopted in practice. The height of the embankment was $5 \mathrm{~m}$. Half width of the crest, equal to $10 \mathrm{~m}$, was selected based on a two-lane highway in each direction plus a shoulder. The in-situ soils below the embankment included a layer of $10 \mathrm{~m}$ thick soft clay and a layer of $2 \mathrm{~m}$ thick underlying firm soil. The DM columns were assumed to penetrate $1 \mathrm{~m}$ into the firm soil. No settlement was allowed below the firm soil layer to simulate the underlying bedrock. A geosynthetic layer was placed $0.25 \mathrm{~m}$ above the heads of the columns. The end of the geosynthetic sheet at the centerline was fixed laterally but free vertically and the end toward the toe was 
free in both directions. The boundary effect was eliminated by extending the left boundary of the model far enough from the toe of the embankment. The traffic load was simulated by applying a uniformly distributed load of $12 \mathrm{kPa}$ on the crest of the embankment. The ground water level was assumed at the ground surface.

Table 4-1. Properties of Materials in the 2D Baseline Case

\begin{tabular}{|c|l|}
\hline Material & \multicolumn{1}{|c|}{ Properties } \\
\hline DM columns & $\begin{array}{l}\gamma=18 \mathrm{kN} / \mathrm{m}^{3}, \mathrm{c}=500 \mathrm{kPa}, \phi^{\prime}=0^{\circ}, \mathrm{E}=100 \mathrm{MPa}, v=0.3, \\
\mathrm{c}_{\mathrm{t}}=100 \mathrm{kPa}, \mathrm{k}=1 \times 10^{-9} \mathrm{~m} / \mathrm{s}\end{array}$ \\
\hline Soft Soil & $\begin{array}{l}\gamma=18 \mathrm{kN} / \mathrm{m}^{3}, \mathrm{c}^{\prime}=0 \mathrm{kPa}, \phi^{\prime}=25^{\circ}, \mathrm{E}=2 \mathrm{MPa}, \mathrm{v}=0.3, \\
\mathrm{c}_{\mathrm{t}}=0 \mathrm{kPa}, \mathrm{k}=1 \times 10^{-9} \mathrm{~m} / \mathrm{s}\end{array}$ \\
\hline Firm Soil & $\begin{array}{l}\gamma=18 \mathrm{kN} / \mathrm{m}^{3}, \mathrm{c}^{\prime}=0 \mathrm{kPa}, \phi^{\prime}=30^{\circ}, \mathrm{E}=100 \mathrm{MPa}, v=0.3, \\
\mathrm{c}_{\mathrm{t}}=0 \mathrm{kPa}, \mathrm{k}=1 \times 10^{-9} \mathrm{~m} / \mathrm{s}\end{array}$ \\
\hline Embankment Fill & $\begin{array}{l}\gamma=18 \mathrm{kN} / \mathrm{m}^{3}, \mathrm{c}^{\prime}=5 \mathrm{kPa}, \phi^{\prime}=32^{\circ}, \mathrm{E}=30 \mathrm{MPa}, v=0.3, \\
\mathrm{c}_{\mathrm{t}}=0 \mathrm{kPa}\end{array}$ \\
\hline Geosynthetics & $\begin{array}{l}\mathrm{t}=0.002 \mathrm{~m}, \mathrm{E}_{\mathrm{r}}=500 \mathrm{MPa}, \mathrm{T}_{\mathrm{a}}=100 \mathrm{kN} / \mathrm{m}, \mathrm{k}_{\mathrm{s}}=20 \mathrm{MN} / \mathrm{m} / \mathrm{m}, \\
\mathrm{c}_{\mathrm{a}}=0 \mathrm{kPa}, \delta=24.8^{\circ}\end{array}$ \\
\hline Ground water & $\mathrm{K}=200 \mathrm{MPa}$ \\
\hline
\end{tabular}

Note: $\gamma=$ unit weight of soil; $\mathrm{c}=$ shear strength of soil-cement; $\mathrm{c}^{\prime}=$ effective cohesion of soil; $\phi^{\prime}=$ effective friction angle of soil; $\mathrm{k}=$ permeability; $\mathrm{E}=$ elastic modulus of soil; $v=$ Poisson's ratio; $\mathrm{c}_{\mathrm{t}}=$ tensile strength of soil-cement/soil; $t=$ thickness of geosynthetic reinforcement; $E_{r}=$ elastic modulus of geosynthetic reinforcement; $\mathrm{T}_{\mathrm{a}}=$ allowable tensile strength of geosynthetic reinforcement; $\mathrm{ks}=$ bond stiffness between geosynthetic and embankment fill; $\mathrm{ca}=$ bond strength between geosynthetic and embankment fill; $\delta=$ bond friction angle between geosynthetic and embankment fill; $\mathrm{K}=$ water bulk modulus.

The properties of DM columns, soft soil and embankment fill of the baseline case were in the middle of their typical ranges to leave enough margins for property variations in the parametric study (EPRI 1990; Budhu 2000). The shear strength of DM columns was determined from the common correlation of $E=200 \cdot c$ (Bruce 2001), where $\mathrm{c}$ is the undrained shear strength of DM columns and equal to half of the unconfined compressive strength. In addition, the DM columns were assumed to 
have a tensile strength, $\mathrm{c}_{\mathrm{t}}$, equal to $20 \%$ of the undrained shear strength, $\mathrm{c}$. The pure water bulk modulus is $2 \mathrm{GPa}$. However, since the natural ground water includes dissolved air and some trapped air bubbles, which greatly increase the compressibility of the ground water, a reduction factor of 0.1 was applied to the pure water bulk modulus to obtain the ground water bulk modulus, K, as suggested by Itasca (2002). A typical reduction factor 0.8 was applied to the soil-geosynthetic interface strength as compared with the soil strength. Unsaturated flow was not modeled in this study. Therefore, the pore water pressure at and above the ground water surface was always fixed at zero. The right boundary in Fig. 4-1 was assumed to be impervious, i.e., no water enters or leaves the plane of symmetry. The left boundary was also assumed to be impervious since it was far enough away from the embankment and would not make any influence on the numerical results.

\subsubsection{D Modeling Procedure}

The modeling can be divided into three phases according to the execution sequence: the generation of the initial ground stress field and the hydrostatic pore water distribution, the simulation of the embankment construction, and the application of the traffic load. Among all the phases, the simulation of the embankment construction is the key to the modeling. The basic modeling procedure is listed in Table 4-2. 
Table 4-2. Modeling Procedure

\begin{tabular}{|c|c|c|c|}
\hline Phase & Procedure & & Description \\
\hline 1 & Initial condition & $\begin{array}{l}\text { Generate } \\
\text { hydrosta } \\
\text { table }\end{array}$ & $\begin{array}{l}\text { the initial stress field in the ground and the } \\
\text { pore water pressure below the ground water }\end{array}$ \\
\hline \multirow{5}{*}{2} & \multirow{5}{*}{$\begin{array}{l}\text { Construction of } \\
\text { embankment }\end{array}$} & Stage 1 & $\begin{array}{l}\text { Install DM columns and geosynthetic } \\
\text { reinforcement, build the embankment to } 1 \mathrm{~m} \\
\text { high and allow the consolidation for } 1 \text { month }\end{array}$ \\
\hline & & Stage 2 & $\begin{array}{l}\text { Build the embankment to } 2 \mathrm{~m} \text { high and allow } \\
\text { the consolidation for } 1 \text { month }\end{array}$ \\
\hline & & Stage 3 & $\begin{array}{l}\text { Build the embankment to } 3 \mathrm{~m} \text { high and allow } \\
\text { the consolidation for } 1 \text { month }\end{array}$ \\
\hline & & Stage 4 & $\begin{array}{l}\text { Build the embankment to } 4 \mathrm{~m} \text { high and allow } \\
\text { the consolidation for } 1 \text { month }\end{array}$ \\
\hline & & Stage 5 & $\begin{array}{l}\text { Build the embankment to } 5 \mathrm{~m} \text { high and allow } \\
\text { the consolidation for } 1 \text { month }\end{array}$ \\
\hline 3 & Traffic load & \multicolumn{2}{|c|}{$\begin{array}{l}\text { Apply a traffic load of } 12 \mathrm{kPa} \text { and allow the consolidation } \\
\text { up to } 30 \text { years }\end{array}$} \\
\hline
\end{tabular}

The construction of the embankment over soft soil was in stages (i.e., staged construction) to ensure its stability and minimize its post-construction settlement. The basic concept of staged construction has already been discussed in Chapter Three and is schematically presented in Fig. 4-2. The required waiting time depends on several factors, such as the permeability, the depth of the ground water table, the shear strength of soft soil, the embankment height, the drainage conditions and so on. Similarly as the model calibration, a simplified procedure was followed in this study as shown in Fig. 4 (b), which is often used in design. In this study, the $5 \mathrm{~m}$ high embankment was constructed in five stages of equal thickness, i.e., the thickness of each lift was $1 \mathrm{~m}$. To keep consistent with common practice, the duration of each stage was 1 month (30 days). The traffic load was applied 1 month after the 
completion of the embankment. The coupled modeling was lasted up to 30 years after the service to simulate the typical service life of highways before major maintenance.

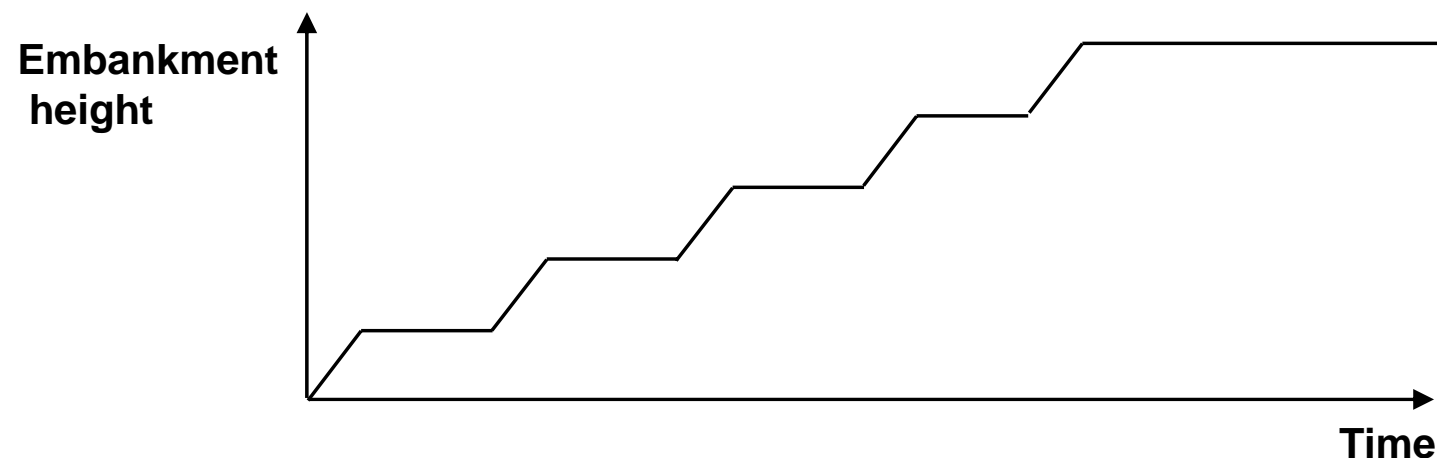

(a) Actual process

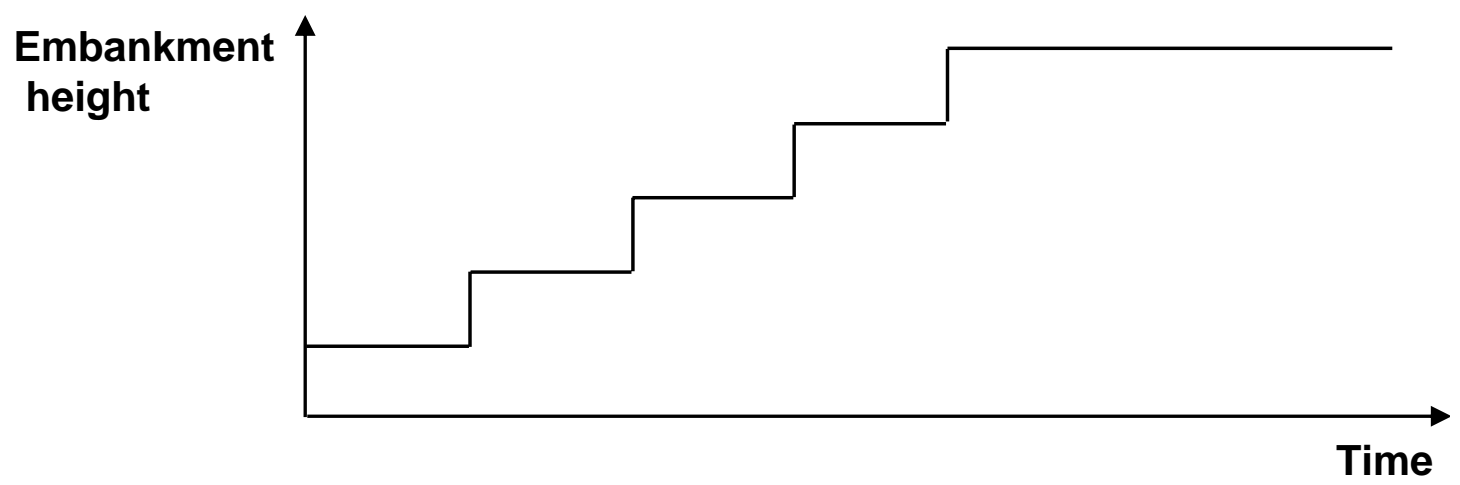

(b) Simplified process

Fig. 4-2. Modeling of Staged Construction 


\subsubsection{Results of 2D Baseline Case}

\section{Settlement}

The settlement contour of the baseline case at 1 month after service is presented in Fig. 4-3. The unit of the settlement is meter. It can be seen that the maximum settlement developed at the base of the embankment. Apparent differential settlement also developed at this elevation because of the stiffness and strength difference between DM columns and soft soil.

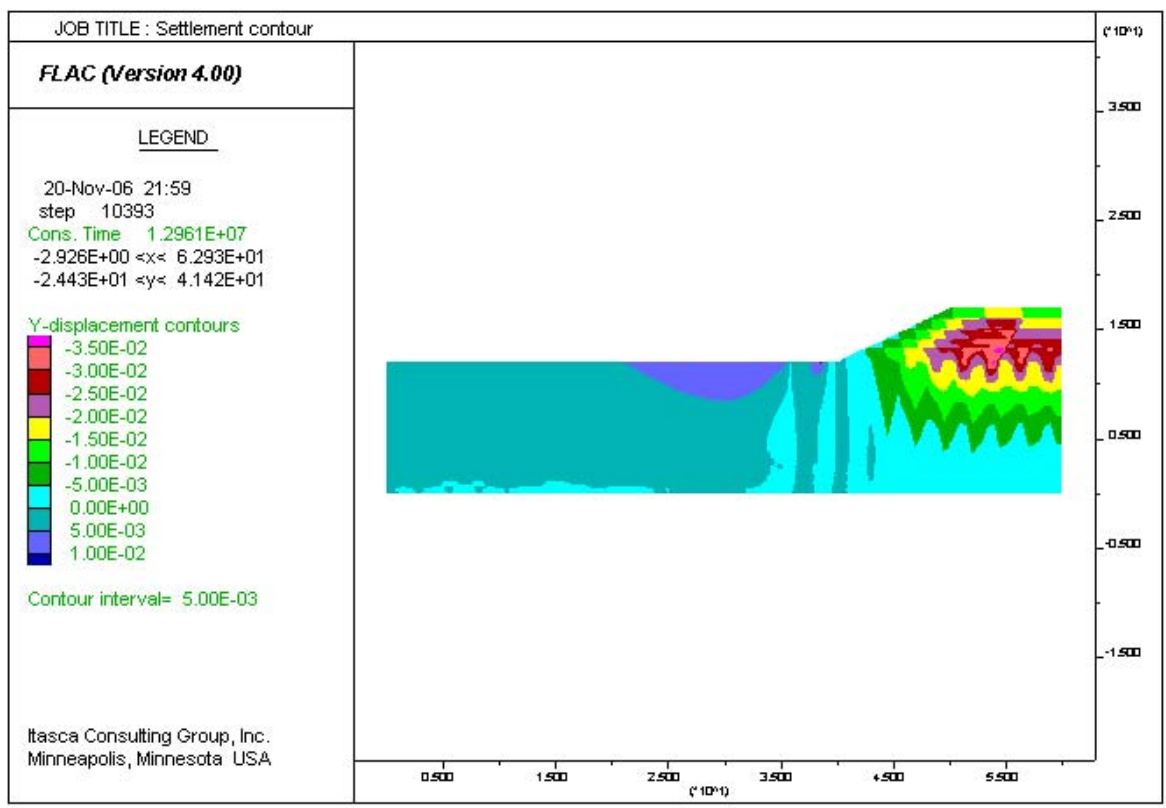

Fig. 4-3. Settlement Contour of the 2D Baseline Case 
The development of settlements at two locations, A and B (refer to Fig. 4-1), is presented in Fig 4-4. In each stage, the settlement was accumulated with a sudden increase, which indicated the immediate settlement at the completion of each stage. After each sudden increase, the settlement increased gradually due to the process of consolidation. As shown in Fig. 4-4 (b), the settlement became stable after approximately 20 months after service, which is much shorter than that predicted using Terzaghi's one-dimensional consolidation theory. The consolidation process of the column-supported embankment will be discussed in the excess pore water pressure section.

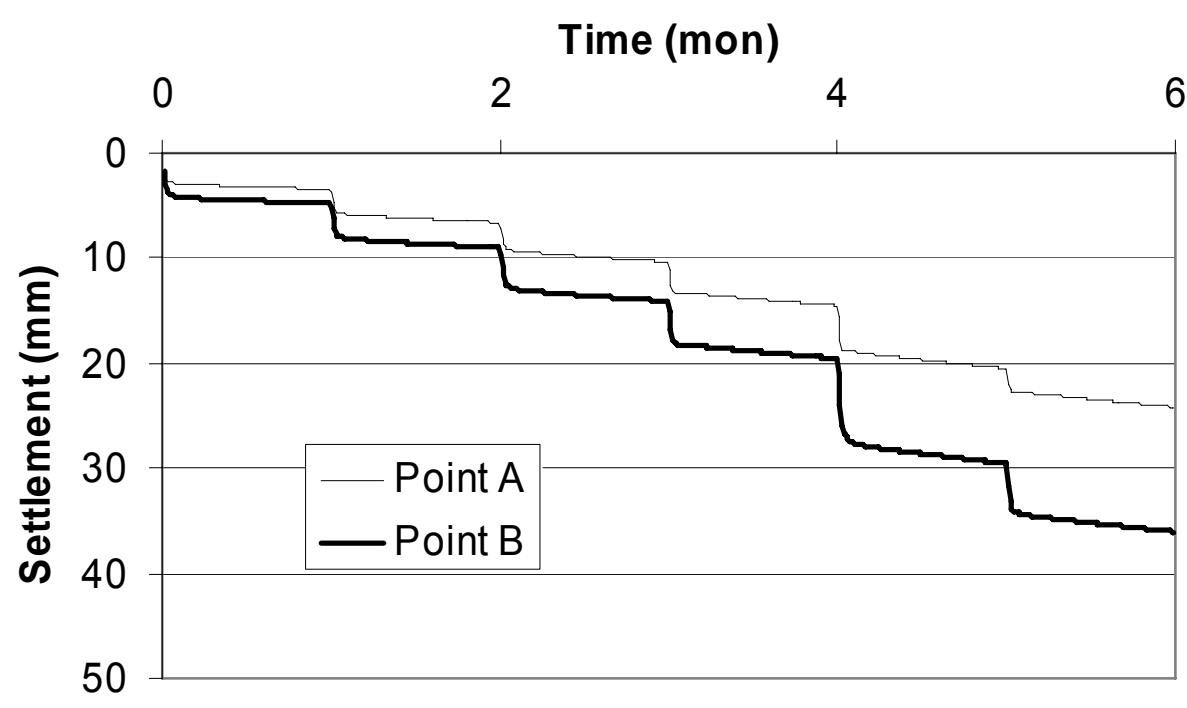

(a) 1 month after service

Fig. 4-4. Settlement versus Time of the 2D Baseline Case 


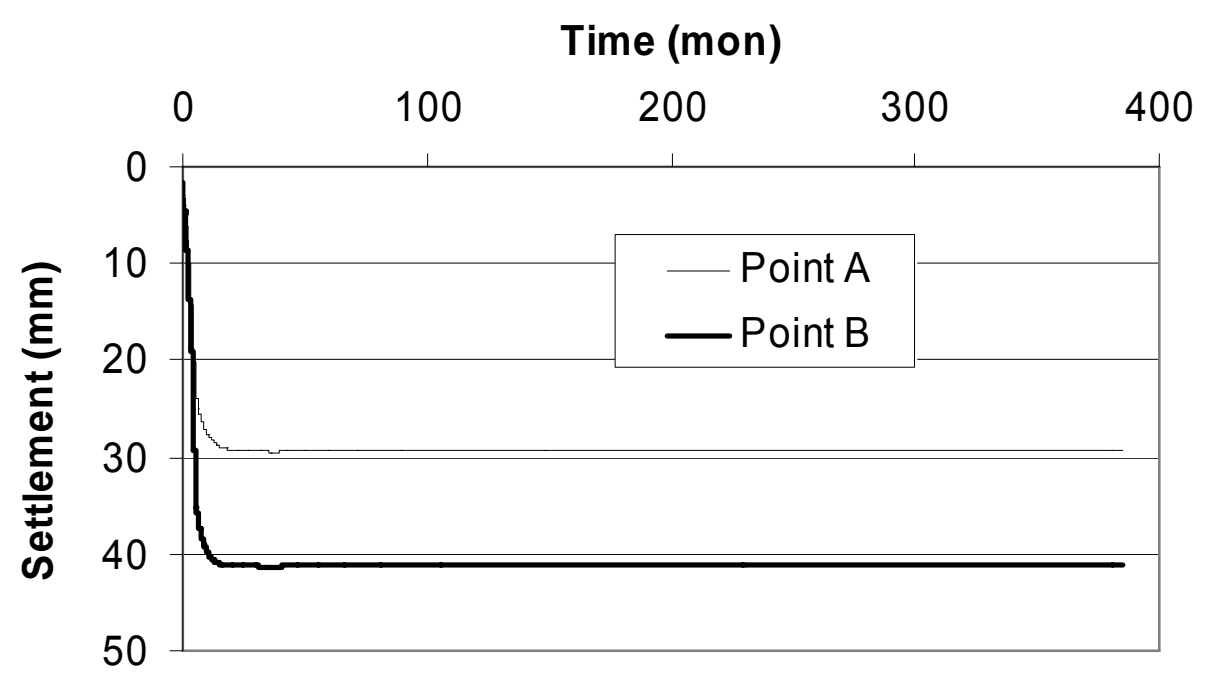

(b) 30 years after service

Fig. 4-4. Settlement versus Time of the 2D Baseline Case (continued)

However, since in the numerical analysis, the embankment was built to a predetermined elevation rather than a total thickness, the settlement occurring in the previous stage was leveled off in the following stage. As a result, the settlement on the crest of the embankment occurred after the completion of construction, which is often called the post-construction settlement. The post-construction settlement of the GRCS embankment system is more crucial to the performance of the pavement on the embankment or the connection between the approach embankment and the bridge abutment than the total settlement at the base of the embankment. The settlement on the crest, $\mathrm{S}_{\mathrm{p}}$, can be expressed as follows:

$$
\mathrm{S}_{\mathrm{p}}=\mathrm{S}_{\mathrm{cc}}+\mathrm{S}_{\mathrm{it}}+\mathrm{S}_{\mathrm{ct}}+\mathrm{S}_{\mathrm{ss}}
$$


where $S_{p}=$ the settlement at the crest up to the designed service life, $S_{c c}=$ the settlement due to the dissipation of the excess pore water pressure accumulated during the construction, $\mathrm{S}_{\mathrm{it}}=$ the immediate settlement due to traffic load, $\mathrm{S}_{\mathrm{ct}}=$ the settlement due to the dissipation of the excess pore water pressure induced by the traffic load within the designed service life, and $\mathrm{S}_{\mathrm{ss}}=$ the secondary settlement due to the creep of soft soils, which is not included in this study.

Another fact worthy of being pointed out is that in this study the pavement was modeled as part of the last stage of the embankment construction, therefore, the settlement on the crest started to accumulate as long as the last stage of the embankment (the $5^{\text {th }}$ stage) was constructed. $S_{\text {it }}$ was the immediate settlement induced by the last stage of the embankment load and the traffic load in this study. The settlements on the crest and at the base of the embankment at different time periods are presented in Fig. 4-5. It can be seen that the maximum settlements at the base were much larger than those on the crest at the same time. In addition, at the base of the embankment, the soft soil between the DM columns settled much more than the DM columns, therefore, the differential settlements at this elevation were much more obvious than those on the crest. 


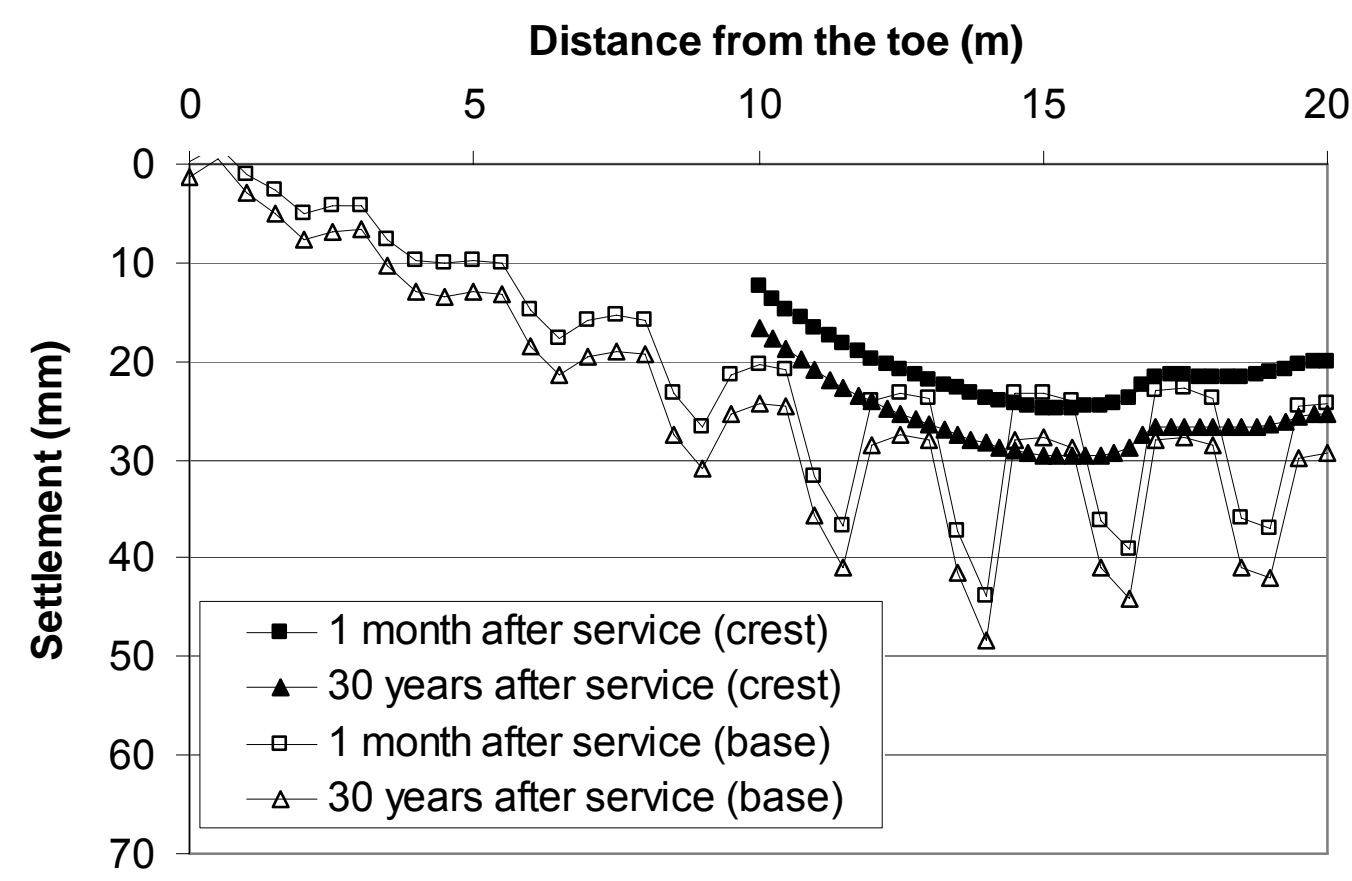

Fig. 4-5. Settlement Profiles of the 2D Baseline Case at Different Time

Differential settlements, especially those on the crest, are even more critical, because they can induce cracks on the pavement, which affect the serviceability of the pavement.

In this study, the differential settlement is defined as the absolute settlement difference between the peak and the adjacent valley as illustrated in Fig. 4-6. Another important parameter reflecting the degree of differential settlement is called the distortion, which is defined as:

$$
I_{i}=\frac{\Delta s s_{i}}{L_{i}}
$$


where $\Delta \mathrm{ss}_{\mathrm{i}}$ - the differential settlement, i.e., the absolute settlement difference between the peak and the adjacent valley; $\mathrm{L}_{\mathrm{i}}-$ the distance between the peak and the valley as shown in Fig. 4-6.

The maximum differential settlement and the maximum distortion are two important indices in evaluating the smoothness of the embankment surface, which will be discussed in the settlement section in details.

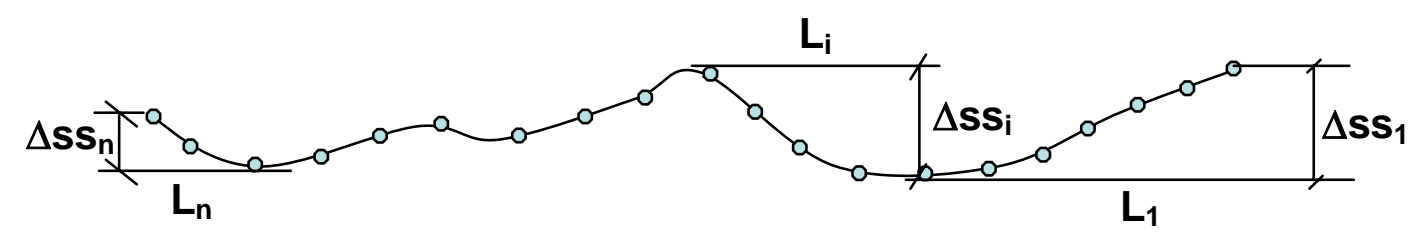

Fig. 4-6. Differential Settlement

The maximum differential settlement and the maximum distortion of the 2D baseline case are presented in Table 4-3. It can be seen that the maximum differential settlement and the maximum distortion at the base is much larger than those on the crest. Even though the maximum differential settlement and the maximum distortion at the base were much larger, they are not that critical for design. As a result, the differential settlements and the related distortions on the crest are discussed in more details in this chapter. 
Table 4-3. Maximum Differential Settlement and Maximum Distortion of the 2D Baseline case

\begin{tabular}{|l|c|c|}
\hline & Maximum differential settlement (mm) (Maximum distortion, $\%)$ \\
\hline & 1 month after service & 30 years after service \\
\hline On the crest & $12.28(0.246 \%)$ & $13.01(0.260 \%)$ \\
\hline At the base & $20.67(2.067 \%)$ & $20.90(2.090 \%)$ \\
\hline
\end{tabular}

\section{Tension in Geosynthetic Reinforcement}

The tension developed in geosynthetic reinforcement is presented in Fig. 4-7. The unit of tension in the figure is $\mathrm{N} / \mathrm{m}$. It indicates that the tensile force developed within the geosynthetic reinforcement in unit length along the traffic direction, which is the direction perpendicular to the cross-section of the embankment.

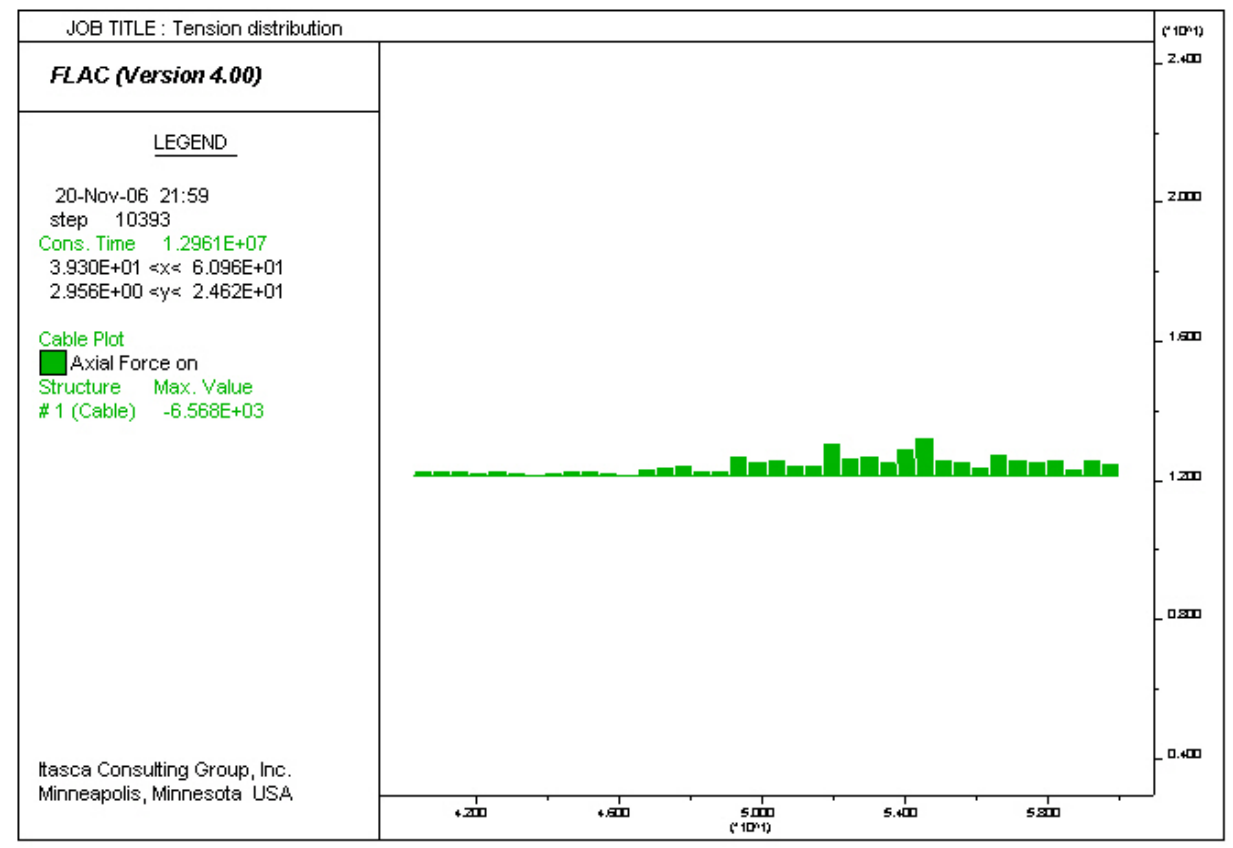

Fig. 4-7. Tension Distribution of the 2D Baseline Case 
The tension distributions at different time periods are presented in Fig. 4-8. Since the geosynthetic reinforcement was placed close to the heads of the DM columns, the tension accumulated from the first stage. The post-construction tension was obtained by subtracting the tension accumulated up to Stage 4 . The post-construction tension is shown in Fig. 4-9. It can be seen that the tension increment due to consolidation from 1 month after service to 30 years after service is very small. Since the total tension in the reinforcement is more of a concern than the post-construction tension, only the total tension will be studied in the section of this parametric study.

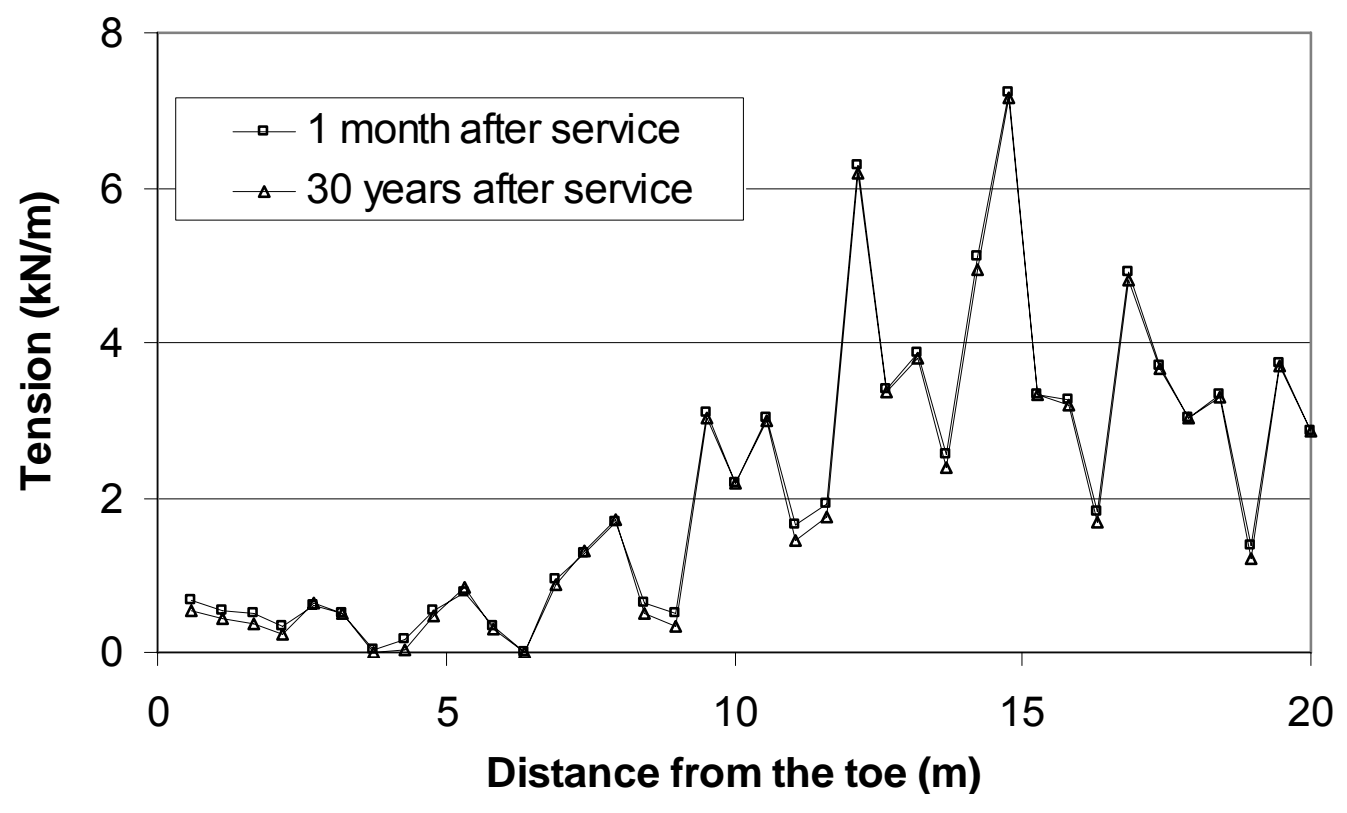

Fig. 4-8. Tension Profiles of the 2D Baseline Case 


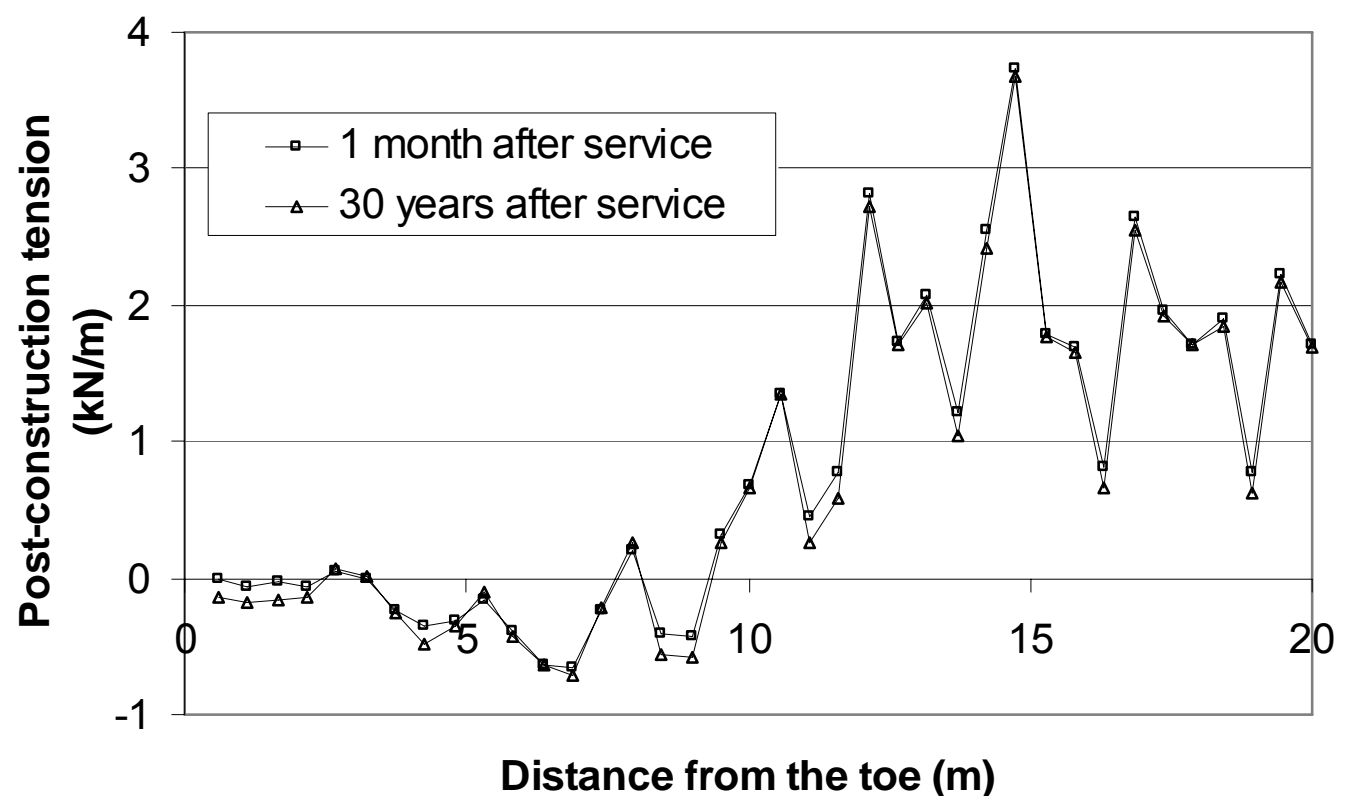

Fig. 4-9. Post-construction Tension Profiles of the 2D Baseline Case

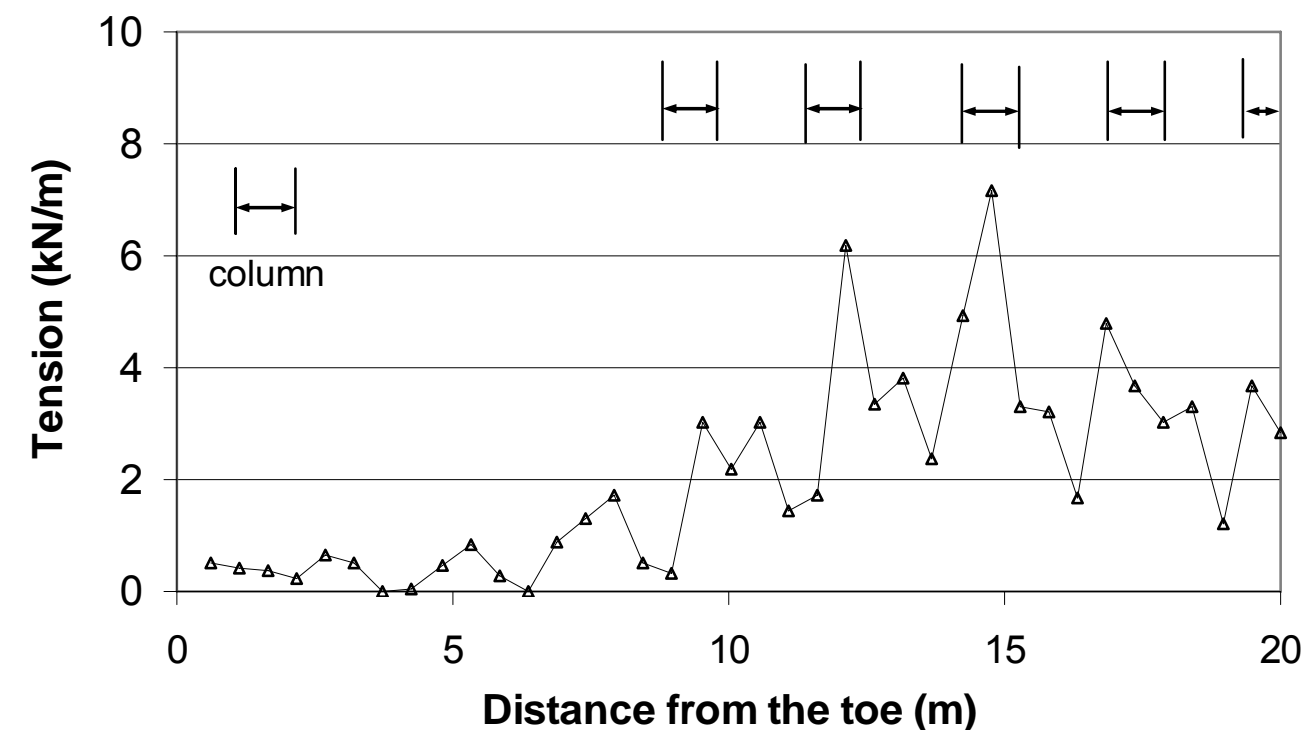

Fig. 4-10. Tension Profiles of the 2D Baseline Case at 30 Years after Service

The tension in geosynthetic reinforcement after 30-year service is presented in Fig. 410. It can be seen that higher tension developed above the DM columns rather than 
the soil between DM columns. This finding is consistent with what was found in previous study by Han and Gabr (2002).

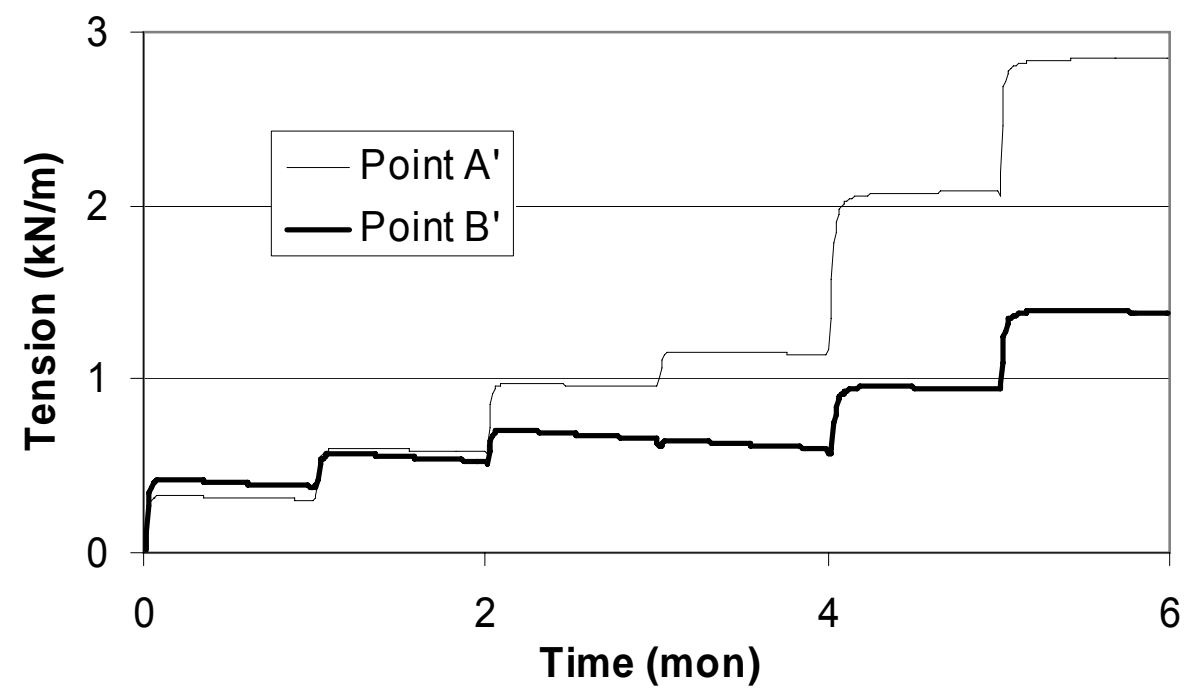

(a) 1 month after service

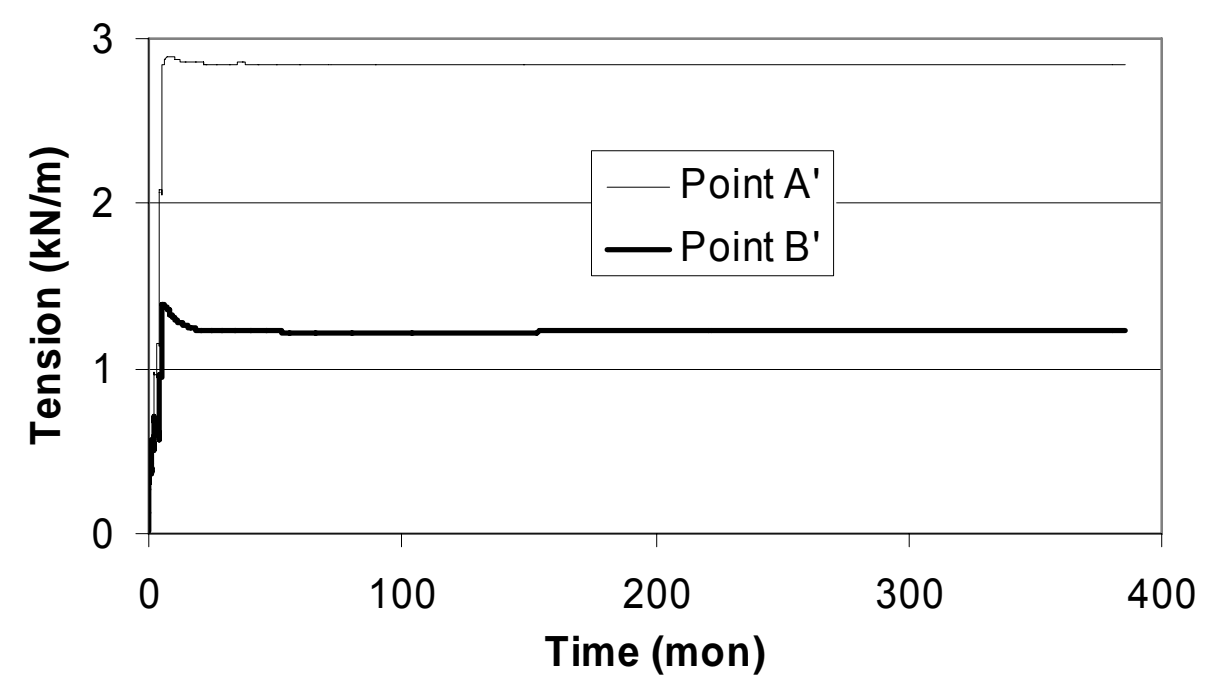

(b) 30 years after service

Fig. 4-11. Tension versus Time of the $2 D$ Baseline Case 
The development of tension with time is presented in Fig. 4-11. The locations of Points $\mathrm{A}^{\prime}$ and $\mathrm{B}^{\prime}$ can be found in Fig. 4-1 and they are at the same elevation. Point $\mathrm{A}^{\prime}$ is above the column, while Point $\mathrm{B}^{\prime}$ is at the middle of the span. It can be seen that the tension developed at Point $\mathrm{A}^{\prime}$ was always higher than that developed at Point $\mathrm{B}^{\prime}$ at various stages.

\section{Vertical Effective Stress}

The vertical effective stress contour at 1 month after service is shown in Fig. 4-12. The unit of the stress in the figure is Pa (Pascal). Higher vertical stress developed within the columns than that within the soft soil, which indicates that the embankment load was transferred to the columns by soil arching and membrane effect.

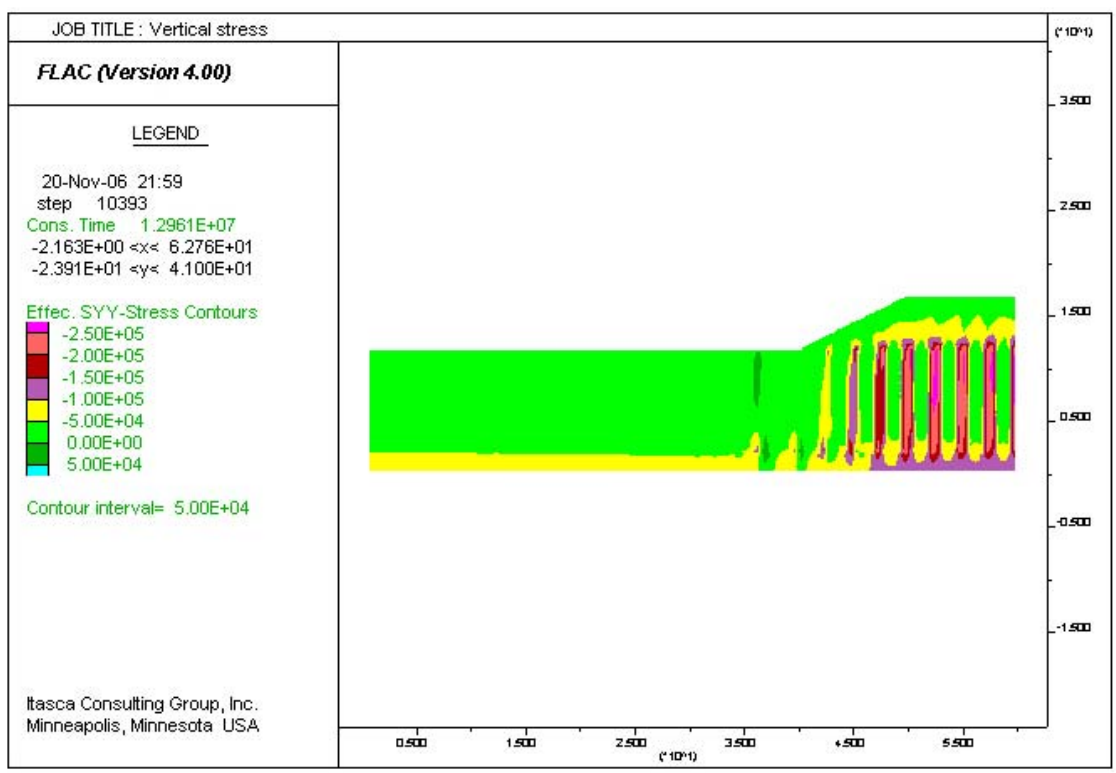

Fig. 4-12. Vertical Effective Stress Contour of the 2D Baseline Case 
To investigate the membrane effect in transferring the load, the vertical stresses above and below the geosynthetic are presented in Fig. 4-13. The vertical stress over the columns but below the geosynthetic was higher than that above the geosynthetic. On the other hand, the vertical stress above the soft soil but below the geosynthetic was slightly less than that above the geosynthetic but the difference cannot be well presented in Fig. 4-13, since compared with the vertical stress range in the figure the difference is too small to be distinguished. This phenomenon implies that some load was transferred from that above the soft soil to above columns by the tensioned geosynthetic sheet.

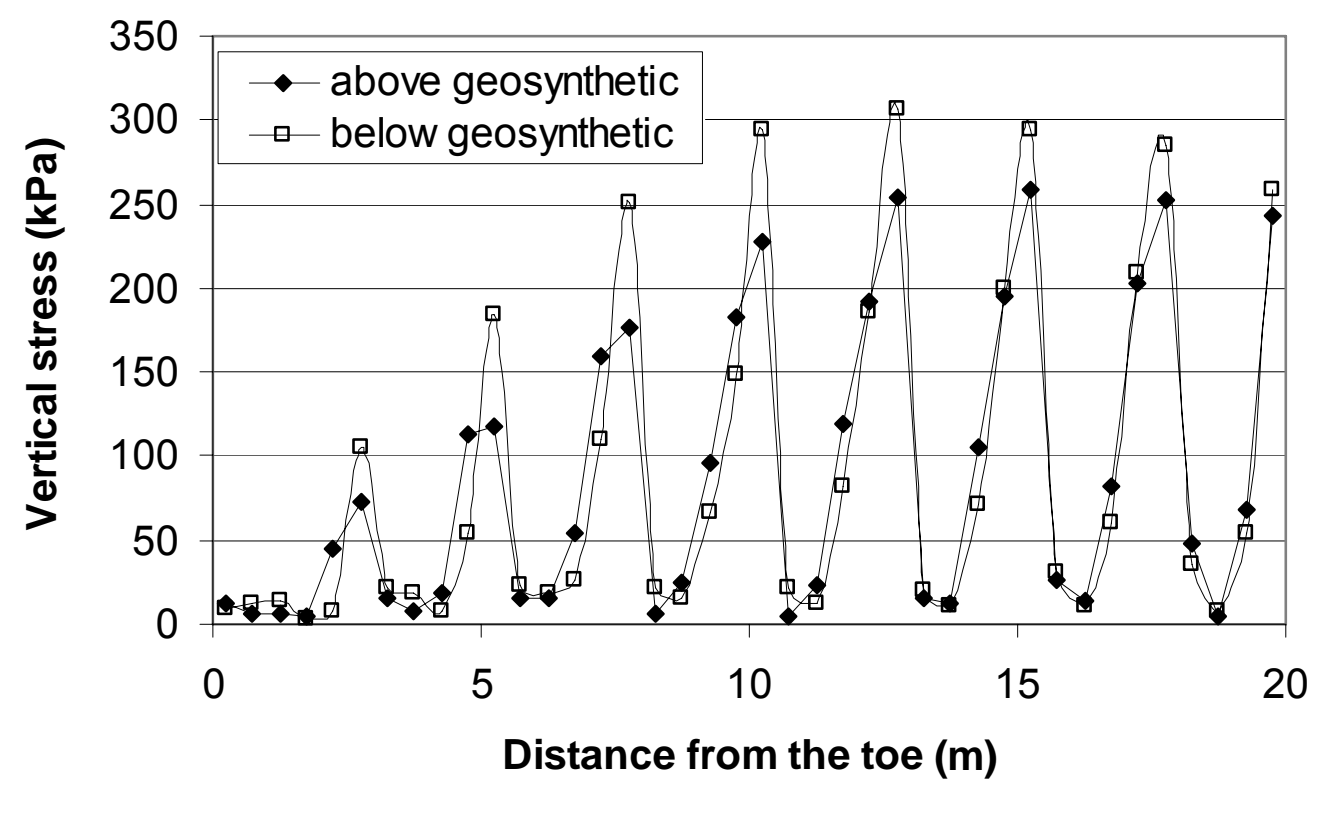

Fig. 4-13. Vertical Stress Distribution of the 2D Baseline Case

The development of additional vertical effective stresses, defined as the effective stresses induced by the embankment and traffic load, at Point C and Point D are 
presented in Fig. 4-14. Point C is at the tip of the DM column and Point D is at the same elevation of soft soil (refer to Fig. 4-1 for the locations of C and D). Fig. 4-14(a) shows that the effective stresses in DM columns increased instantaneously after each loading and then further increased gradually as time elapsed. However, the effective stresses in the soft soil decreased after the loading and then increased gradually as time elapsed. The gradual increase of the effective stresses in the DM columns and the soft soil was attributed to the dissipation of excess pore water pressure. The difference in the effective stress change in the columns and the soft soil immediately after each loading can be explained as follows. At the moment of each loading, since the bulk modulus of the columns was at the same order of magnitude as that of the ground water, the load was shared by pore water and the solids in DM columns. As a result, there was an instantaneous increase on the effective vertical stress in the DM columns and then followed by a gradual increase due to consolidation. However, since the bulk modulus of the soft soil was much lower than that of the ground water, according to Terzaghi's effective stress theory (1943), the load was taken by pore water but not by soil skeleton. As a result, the pore water pressure within in the soft soil increased instantaneously, which lead to a decrease in the effective stress in the soft soil. Then the effective stress in the soft soil increased with time due to consolidation. Eventually, the excess pore water pressure would dissipate and the effective stresses within the DM columns and the soft soil became stable as shown in Fig. 4-14 (b). 


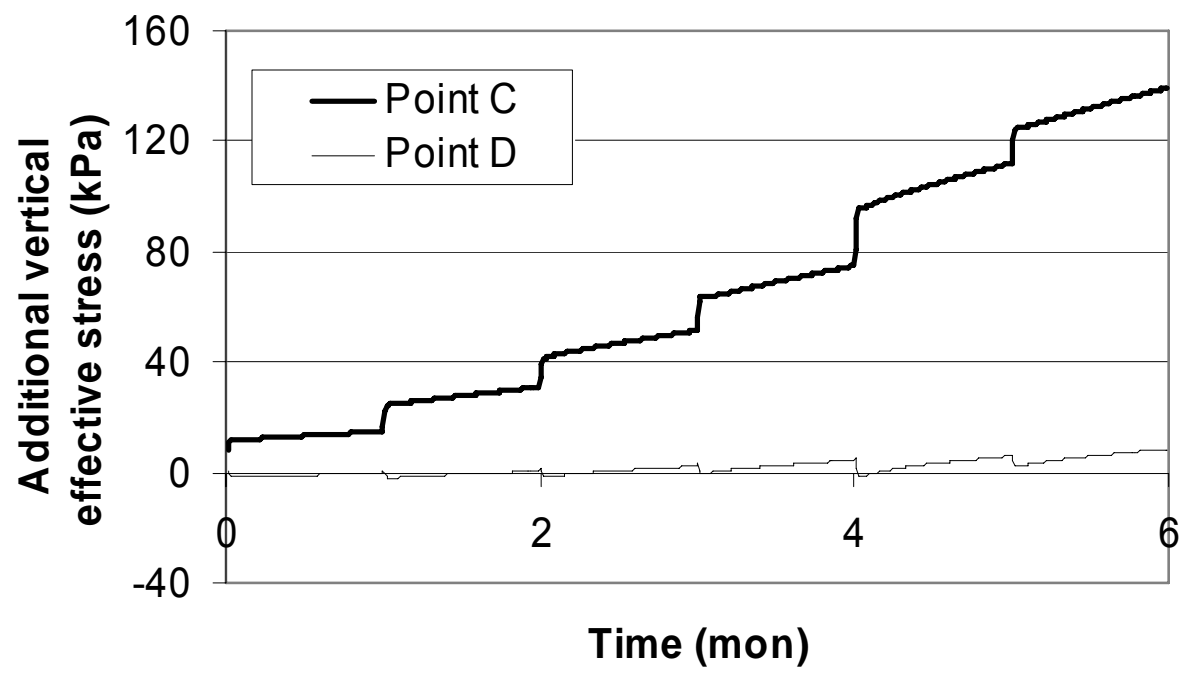

(a) 1 month after service

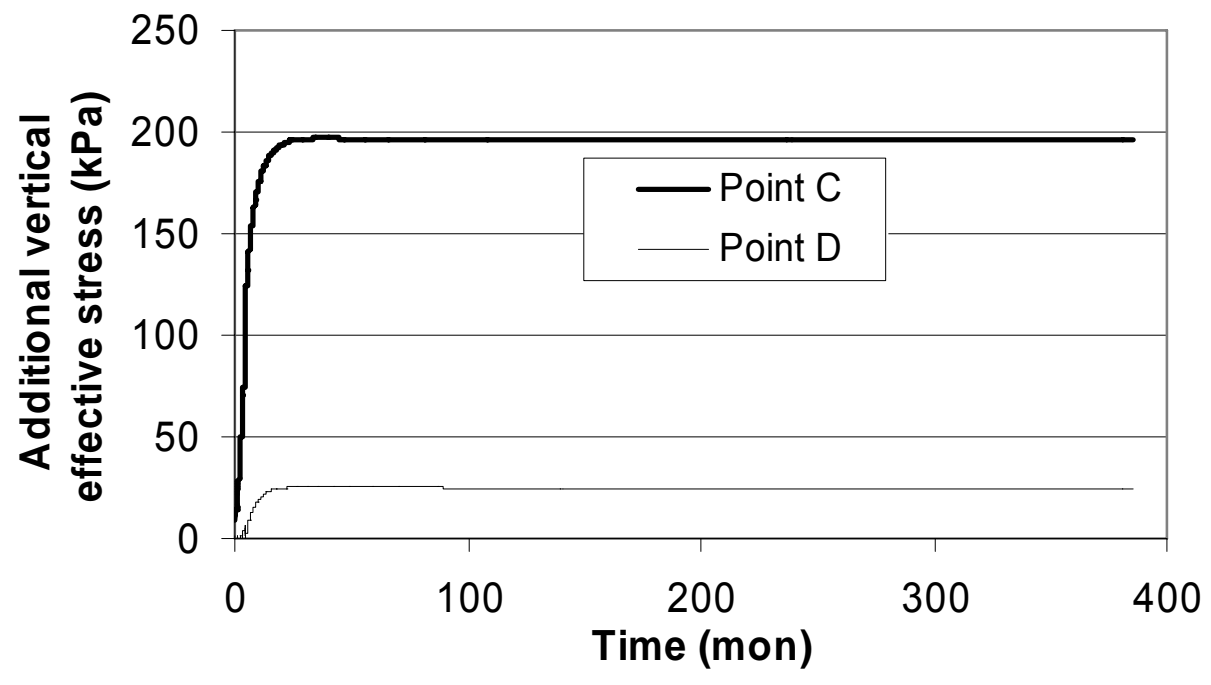

(b) 30 years after service

Fig. 4-14. Additional Vertical Effective Stress versus Time of the 2D Baseline Case 


\section{Stress Concentration Ratio}

Stress concentration ratio, $\mathrm{n}$, is an important index to evaluate the efficiency of load transfer between columns and soft soil. Stress concentration ratio is defined as the ratio of the average vertical stress over columns to the average vertical stress over soft soil and can be calculated as follows:

$$
n=\frac{\frac{1}{2}\left(\sigma_{c l}+\sigma_{c r}\right)}{\sigma_{s}}
$$

The notation is schematically shown in Fig. 4-15.

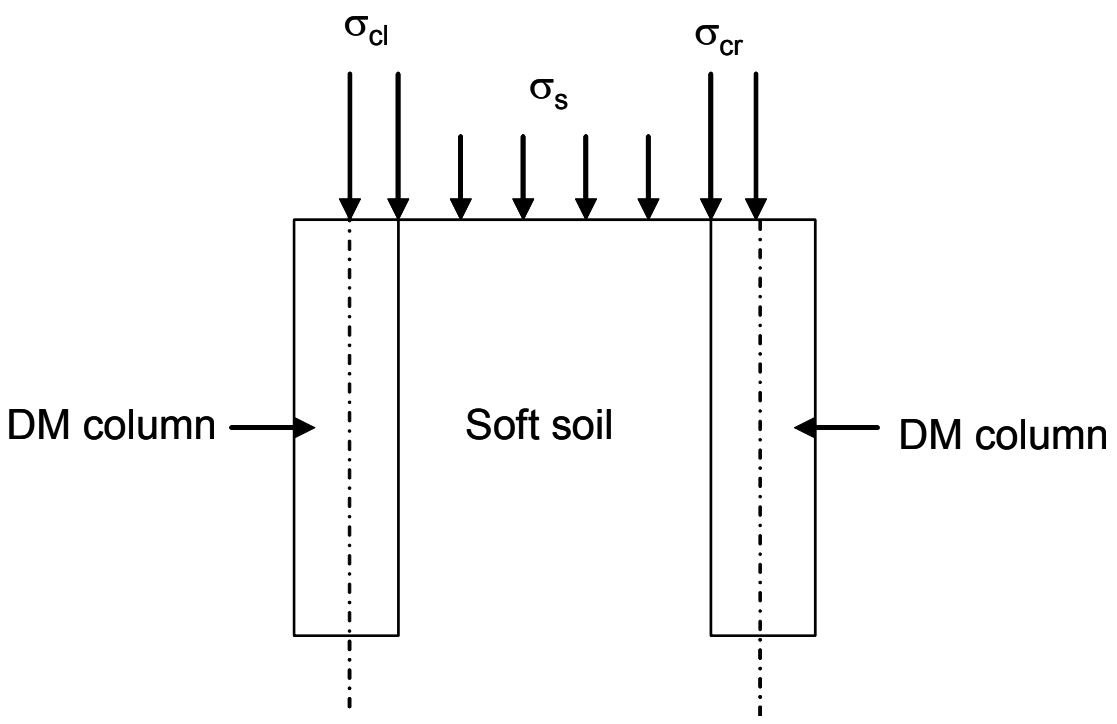

Fig. 4-15. Stress Concentration Ratio Calculation Illustration 
Since the embankment and traffic loads are shared by the soft soil and the columns, the additional vertical effective stresses were used in calculating the stress concentration ratio. The stress concentration ratio profiles for the baseline case are presented in Fig. 4-16, which shows that the stress concentration ratio decreased as being away from the centerline. The maximum stress concentration ratio was 16.3 at the span closest to the centerline of the embankment. The stress concentration ratio increased slightly from 1 month to 30 years after service.

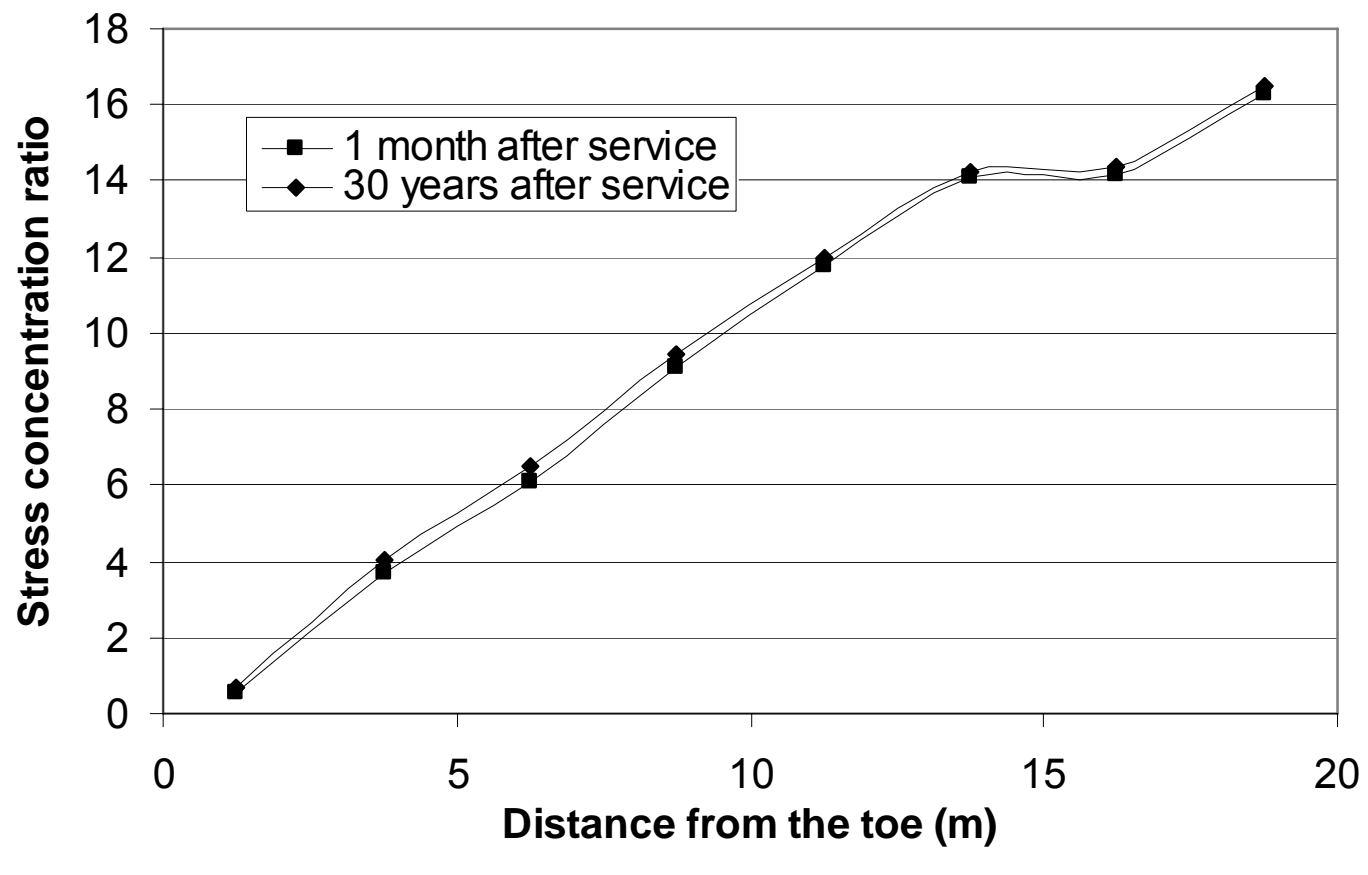

Fig. 4-16. Stress Concentration Ratio Profiles of the 2D Baseline Case 


\section{Pore Water Pressure}

The pore water pressure contours after partial dissipation are presented in Fig. 4-17. The unit of the pore water pressure in the figure is Pascal $(\mathrm{Pa})$. The excess pore water pressures at four different locations with time up to 1 month after service and up to 30 years after service are presented in Fig. 4-18 and 4-19, respectively. The locations of these points can be found in Fig. 4-1. Since Point D and C are located at the same elevation, the excess pore water pressure are almost the same at those two points as shown in Fig. 4-18. The excess pore water pressure at point $\mathrm{D}$ is higher than that at Point $\mathrm{E}$ at 1 month after service, since Point $\mathrm{D}$ is further from the ground surface (drainage surface) than Point E. However, at 30 years after service, the excess pore water pressure at those two points almost dissipates completely as shown in Fig. 4-19.

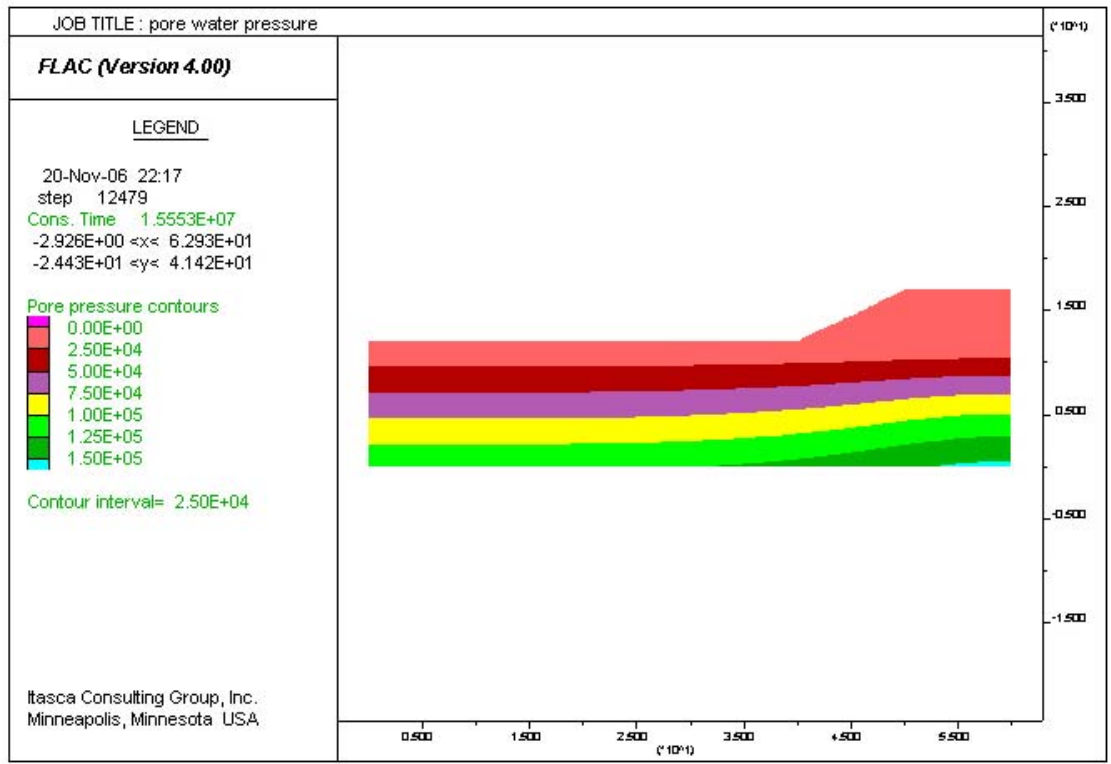

Fig. 4-17. Pore Water Pressure Contour of the 2D Baseline Case 


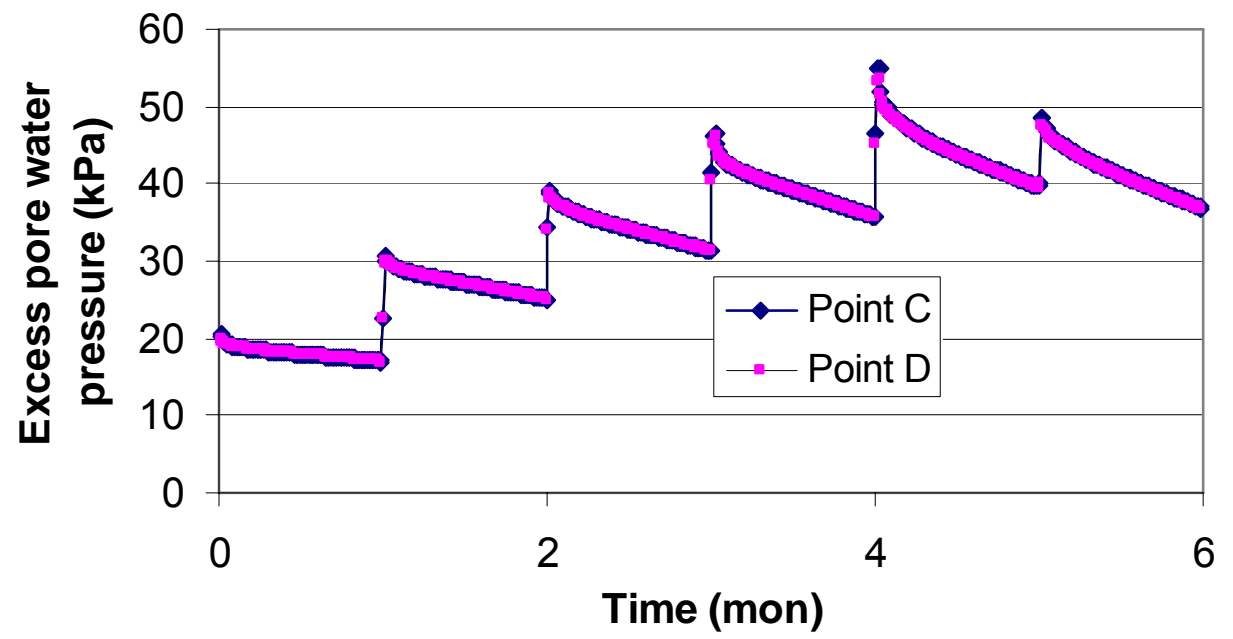

(a) 1 month after service

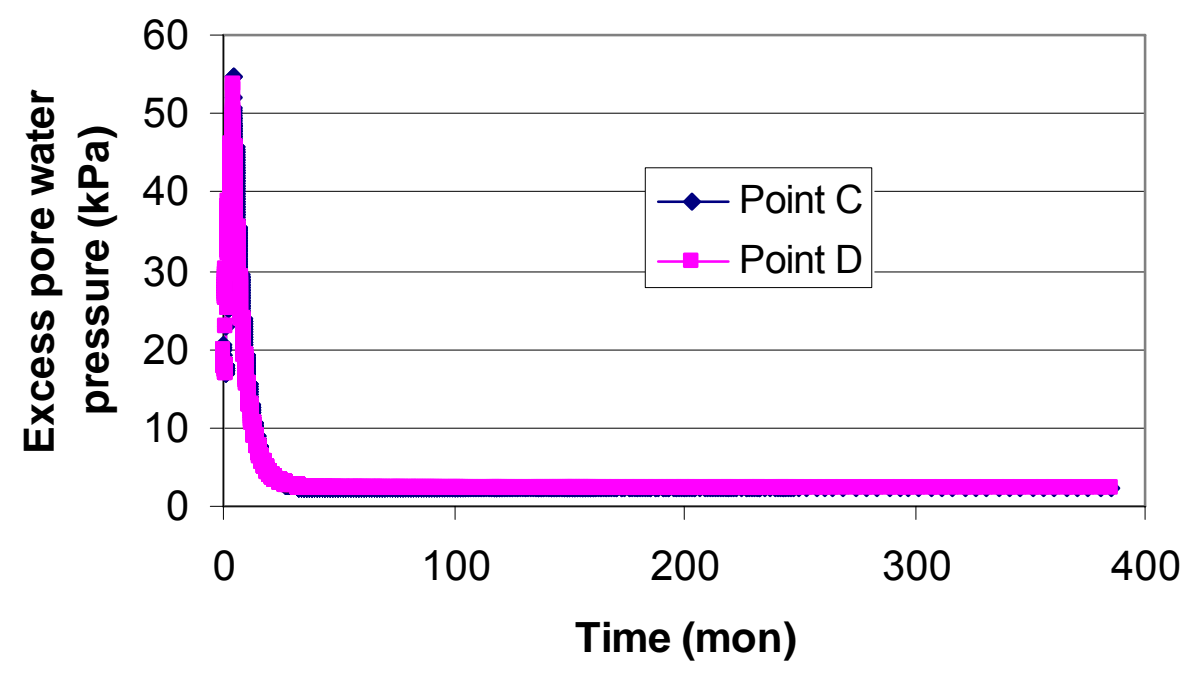

(b) 30 years after service

Fig. 4-18. Excess Pore Water Pressure at Point $C$ and $D$ versus Time of the $2 D$ Baseline Case 


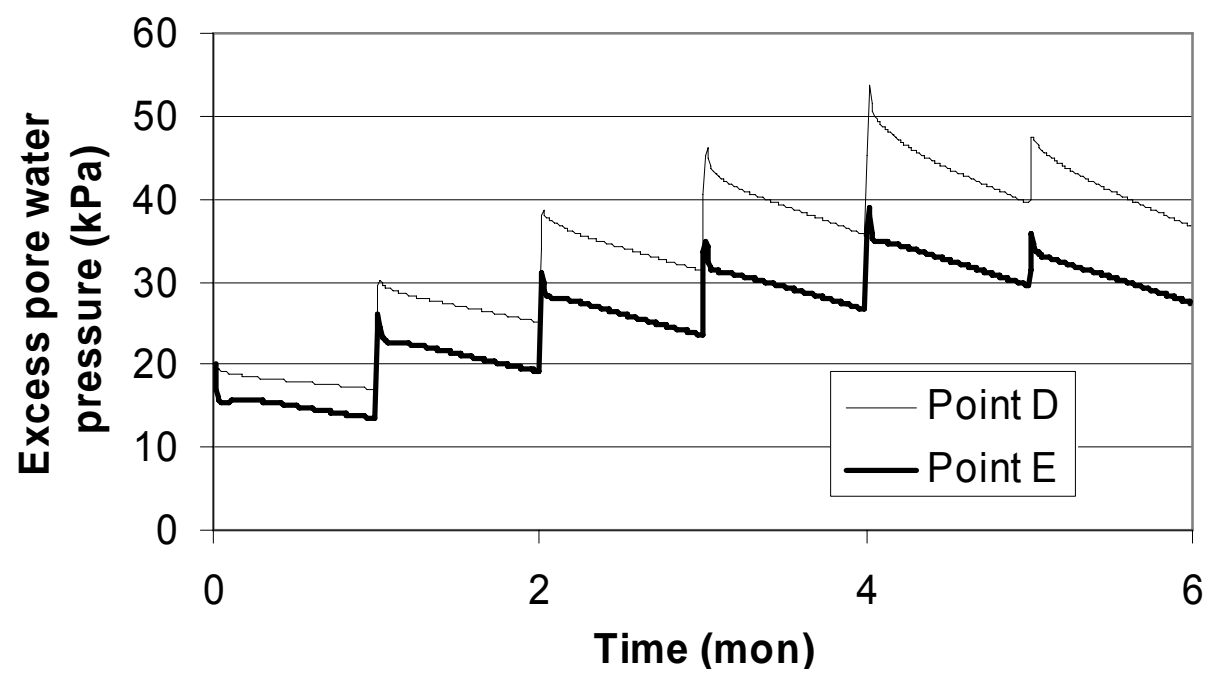

(a) 1 month after service

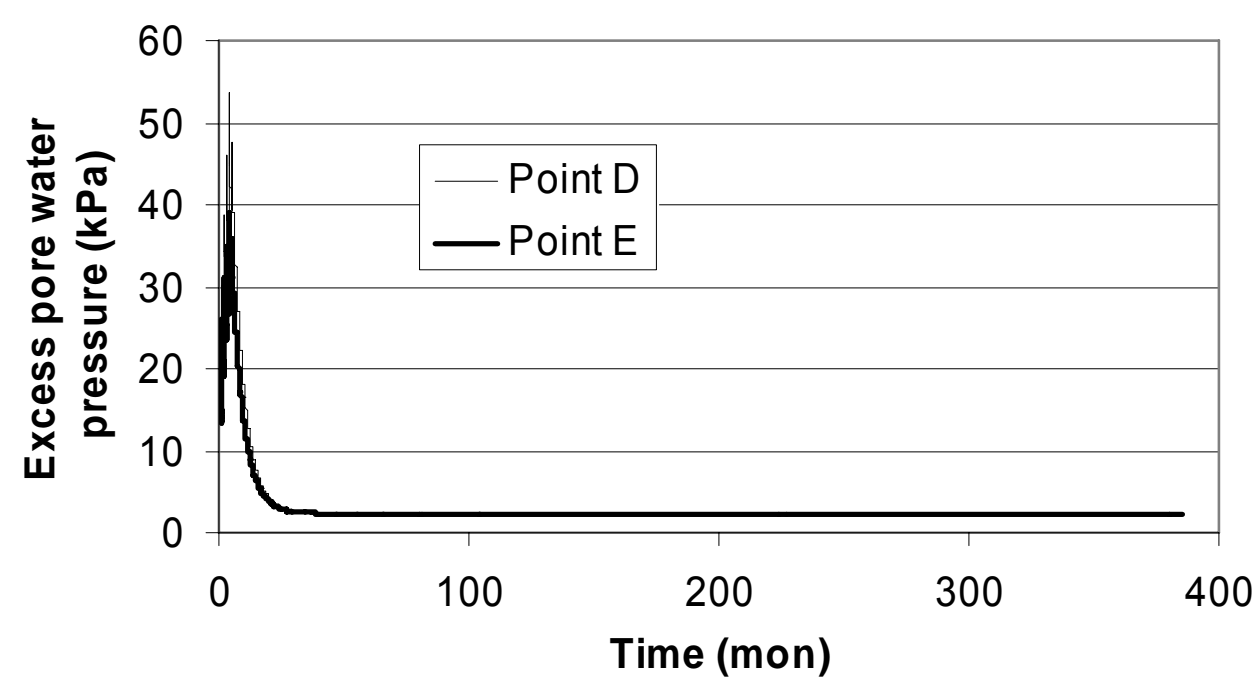

(b) 30 years after service

Fig. 4-19. Excess Pore Water Pressure at Point $D$ and $E$ versus Time of the 2D Baseline Case

Fig. 4-20 presents the excess pore water pressure distribution along section I-I (refer to Fig. 4-1). At the moment the embankment load was applied, since the bulk modulus of the soft soil was much lower than that of water, the load was mainly 
carried by water, which is attributed to the generation of excess pore water pressure. As the time elapsed, the excess pore water pressure within the soft soil dissipated in two ways: hydraulically and mechanically (Han and Ye 2001). Hydraulically, portion of the excess pore water pressure dissipated by drainage and the corresponding load was transferred to soil skeleton, which lead to the increase of the effective stress. On the other hand, mechanically, as the effective stress in the soil increased, the soil tended to settle more than the columns. As a result, portion of the load taken by pore water would be transferred to the columns with the aid of shear stresses induced by relative movement between the soft soil and the columns. This phenomenon was discussed by Han and Ye (2001) when they studied the consolidation of the soft soil treated by stone columns. In other words, the consolidation process in the GRCS embankment system can not be evaluated by Terzaghi's consolidation theory alone.

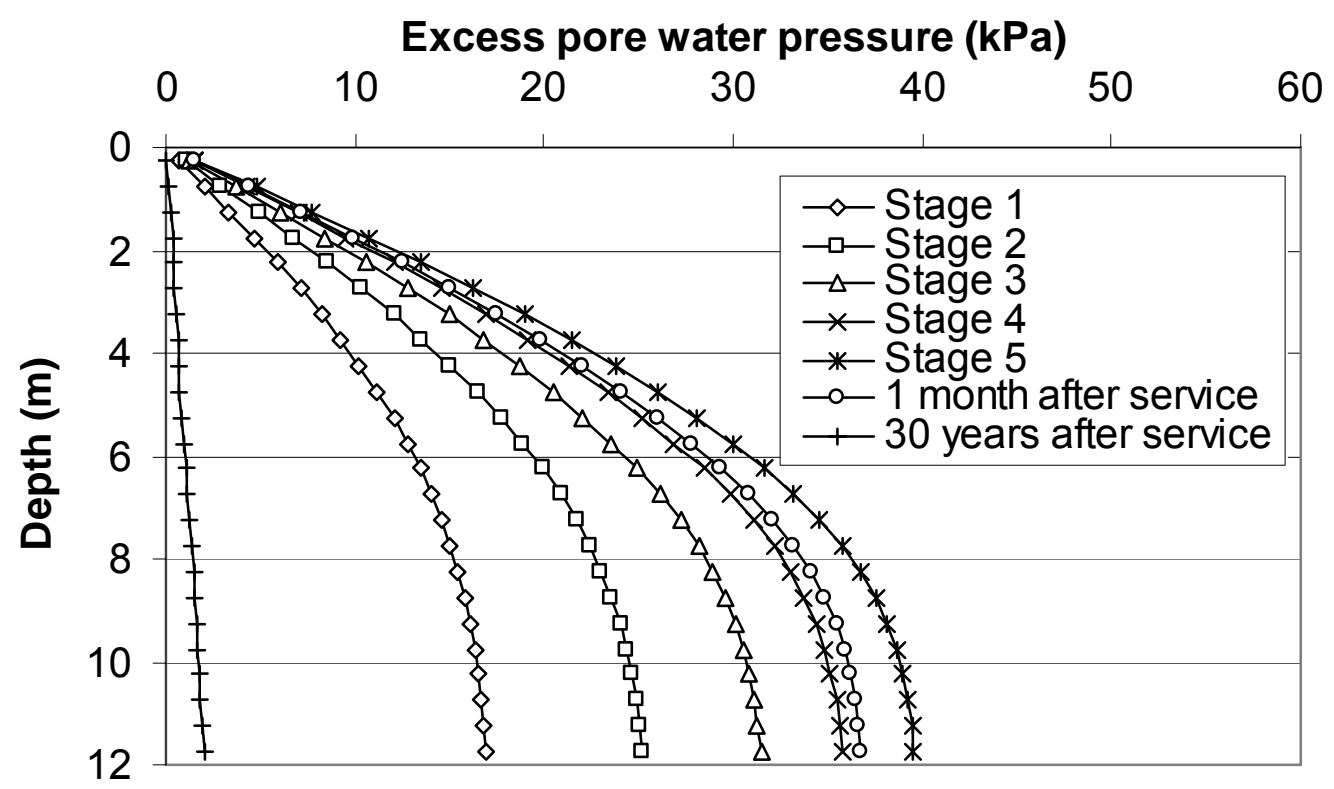

Fig. 4-20. Excess Pore Water Pressure versus Depth of the 2D Baseline Case 
The excess pore water pressure and the effective stress with time at Point D (refer to Fig. 4-1) is shown in Fig. 4-21. Eventually, the excess pore water pressure dissipated and the effective stress reached a constant value.

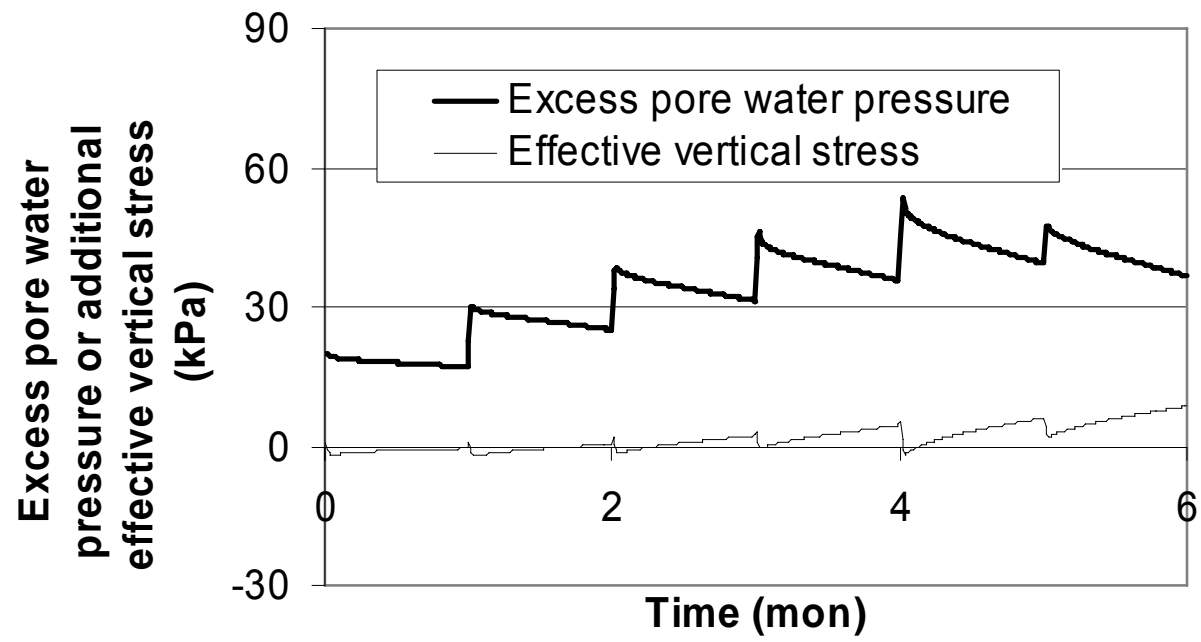

(a) 1 month after service

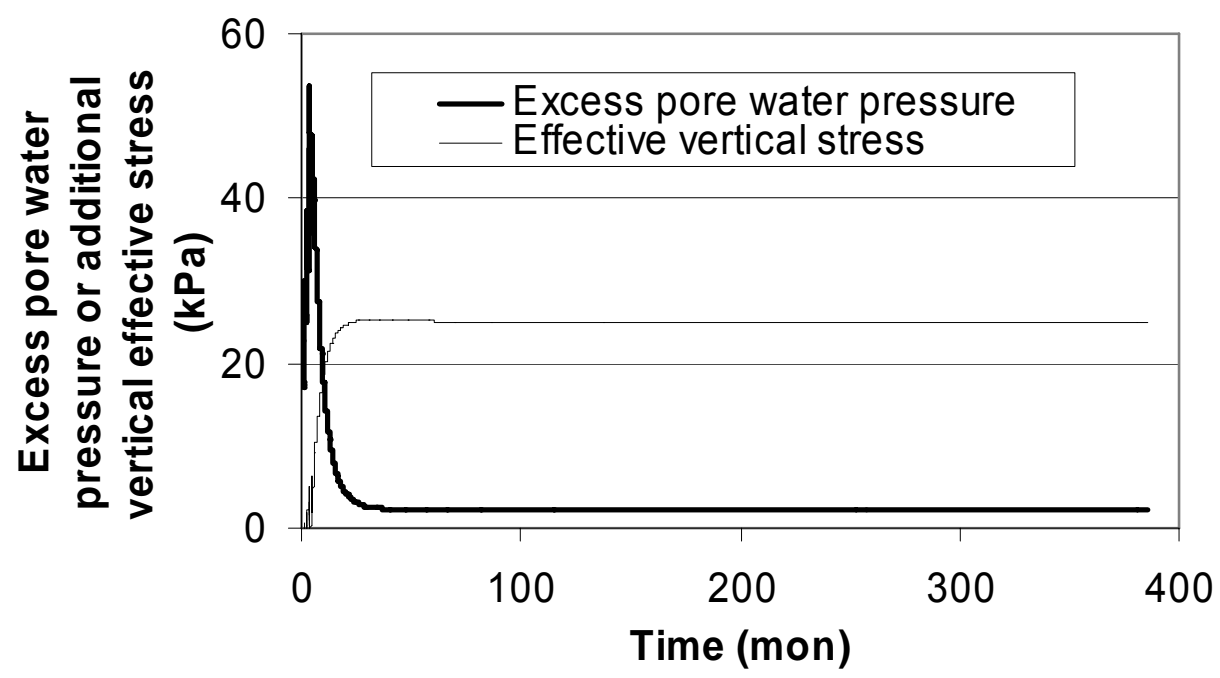

(b) 30 years after service

Fig. 4-21. Excess Pore Water Pressure or Additional Vertical Effective Stress versus Time of the 2D Baseline Case 


\subsection{D Parametric Study}

\subsubsection{Outline of 2D Parametric Study}

Upon completion of the baseline case, a parametric study was performed by deviating one property from the baseline case one at one time to investigate the influence of that specific factor. The investigated factors are listed in Table 4-4. The elastic modulus and friction angle of the embankment fill are controlled by the selection of material and quality of compaction. The variations of those two parameters are not significant in the practice. Consequently, these two parameters are not subjected to change in this parametric study.

Table 4-4. Parameter and Variation Used in the Two-Dimensional Study

\begin{tabular}{|c|l|l|}
\hline Item & \multicolumn{1}{|c|}{ Parameter } & \multicolumn{1}{c|}{ Range of value } \\
\hline \multirow{3}{*}{ Soft soil } & Elastic modulus $(\mathrm{MPa})$ & $1.0,2.0^{*}, 4.0,8.0$ \\
\cline { 2 - 3 } & ${\text { Friction angle }\left({ }^{\circ}\right)}^{*}$ & $15,20,25^{*}, 30$ \\
\cline { 2 - 3 } & Permeability $(\mathrm{m} / \mathrm{s})$ & $10^{-8}, 10^{-9} *, 10^{-10}$ \\
\hline \multirow{2}{*}{ DM column } & Elastic modulus $(\mathrm{MPa})$ & $100^{*}, 150,200$ \\
\cline { 2 - 3 } & Spacing $(\mathrm{m})$ & $2.0,2.5^{*}, 3.0$ \\
\hline Geosynthetic & Tensile stiffness $(\mathrm{kN} / \mathrm{m})$ & $0,1000^{*}, 5000,10000$ \\
\hline Construction & Average construction rate (meter/mon) & $0.25,1^{*}, 4$ \\
\hline
\end{tabular}

* parameters used in the baseline case

The soft soil modulus usually ranges from $1 \mathrm{MPa}$ to $15 \mathrm{MPa}$ (Budhu 2000). However, the GRCS embankment system has been rarely used for soft soil with an elastic 
modulus equal to $8 \mathrm{MPa}$ or higher. Therefore, the selected elastic moduli of the soft soil were $1 \mathrm{MPa}, 2 \mathrm{MPa}, 4 \mathrm{MP}$, and $8 \mathrm{MPa}$. Since the friction angle of the soft soil typically ranges from $15^{\circ}$ to $30^{\circ}$ (Budhu 2000), the following friction angles were selected in this study: $15^{\circ}, 20^{\circ}, 25^{\circ}$, and $30^{\circ}$. The permeability of a homogeneous clay is usually less than $10^{-8} \mathrm{~m} / \mathrm{s}$ (Das 2001), therefore. The selected permeability values of the soft soil were $10^{-8} \mathrm{~m} / \mathrm{s}, 10^{-9} \mathrm{~m} / \mathrm{s}$, and $10^{-10} \mathrm{~m} / \mathrm{s}$.

Three elastic moduli of DM columns were included in this parametric study: $100 \mathrm{MPa}, 150 \mathrm{MPa}$, and $200 \mathrm{MPa}$, which fall into the typical range of soil-cement moduli (EPRI 1990). Based on constructed GRCS embankments, Han (1999) found that the area replacement ratio of columns, defined as the ratio of column area to the area of the embankment footprint, ranged from about $10 \%$ to about $22 \%$. Therefore, three DM column spacing were adopted in this study: $3 \mathrm{~m}, 2.5 \mathrm{~m}$, and $2 \mathrm{~m}$, which are equivalent to the area replacement ratio of $11 \%, 16 \%$, and $25 \%$, respectively.

The tensile stiffness of geosynthetics used in this study ranges from 0 to $10,000 \mathrm{kN} / \mathrm{m}$. The $0 \mathrm{kN} / \mathrm{m}$ tensile stiffness represents an unreinforced condition, while $10,000 \mathrm{kN} / \mathrm{m}$ is almost the highest tensile stiffness of geosynthetics in the current market. A tensile stiffness of $1,000 \mathrm{kN} / \mathrm{m}$ has been commonly used for geosynthetic reinforcement.

The construction rate of the baseline case was at 1 meter/mon, which is commonly used in the practice. In this parametric study, the construction rate was reduced to 
one-forth and increased by four times to yield $0.25 \mathrm{~meter} / \mathrm{mon}$ and $4 \mathrm{~meter} / \mathrm{mon}$, respectively. The rates of $4 \mathrm{~meter} / \mathrm{mon}$ and $0.25 \mathrm{~meter} / \mathrm{mon}$ represent the fast construction and the prolonged construction, respectively.

Many data can be extracted from all the numerical runs. It is impossible to present all the numerical results in this dissertation; therefore, selected numerical results will be presented and discussed, which are mainly focused on settlement, tension in geosynthetic reinforcement, vertical stress, and excess pore water pressure.

\subsubsection{Settlement}

As usual, settlement is one of the focuses when the GRCS embankment is designed to support roadways, railways, etc. In the past, however, most investigations have paid attention to the settlement at the base of the embankment since the maximum longterm settlement typically develops at this elevation. As illustrated in the analysis of the baseline case, the post-construction settlement on the crest is actually more critical to the serviceability of the structures on the embankment. Therefore, in this study, more attention is paid to the settlement on the crest changing with time. 


\section{Influence of Soft Soil Elastic Modulus}

Soft soil is characterized as high compressibility and low modulus. The influence of the soft soil modulus was investigated by varying its value used in baseline case. The settlement profiles on the crest and at the base of the embankment are presented at different elastic moduli of soft soil in Fig. 4-22 and 4-23. It can be seen that the increase of the soft soil modulus reduced the total and differential settlements both on the crest and at the base. This phenomenon is more clearly presented in Fig. 4-24 and 4-25 for the maximum total and differential settlements on the crest and at the base of the embankment. The degree of settlement reduction gradually decreased as the soft soil modulus increased as indicated by the decrease of the curves' slopes in Fig. 4-24 and 4-25. From 1 month to 30 years after service, both the maximum total settlement and the maximum differential settlement increased due to the consolidation of soft soil. However, the increase of the maximum settlement was much greater than that of the maximum differential settlement. 
Distance from the toe $(m)$

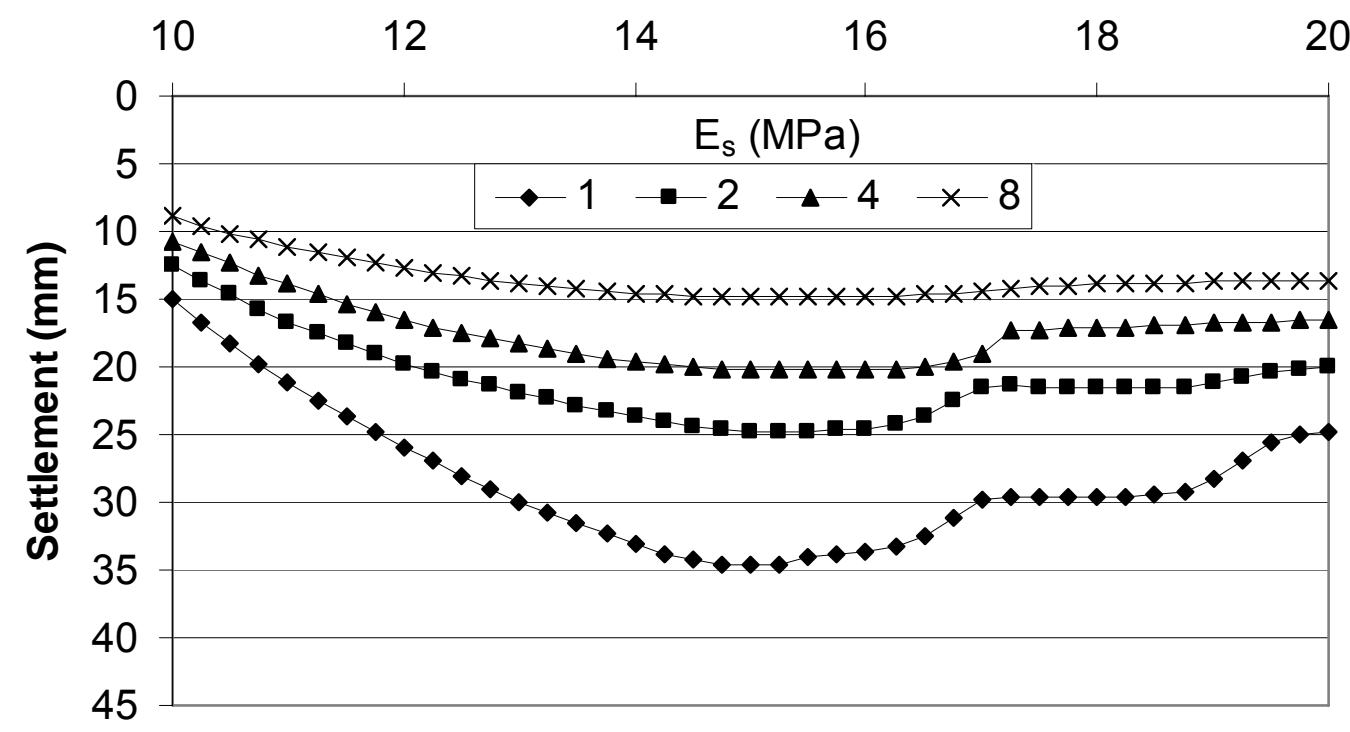

(a) On the crest

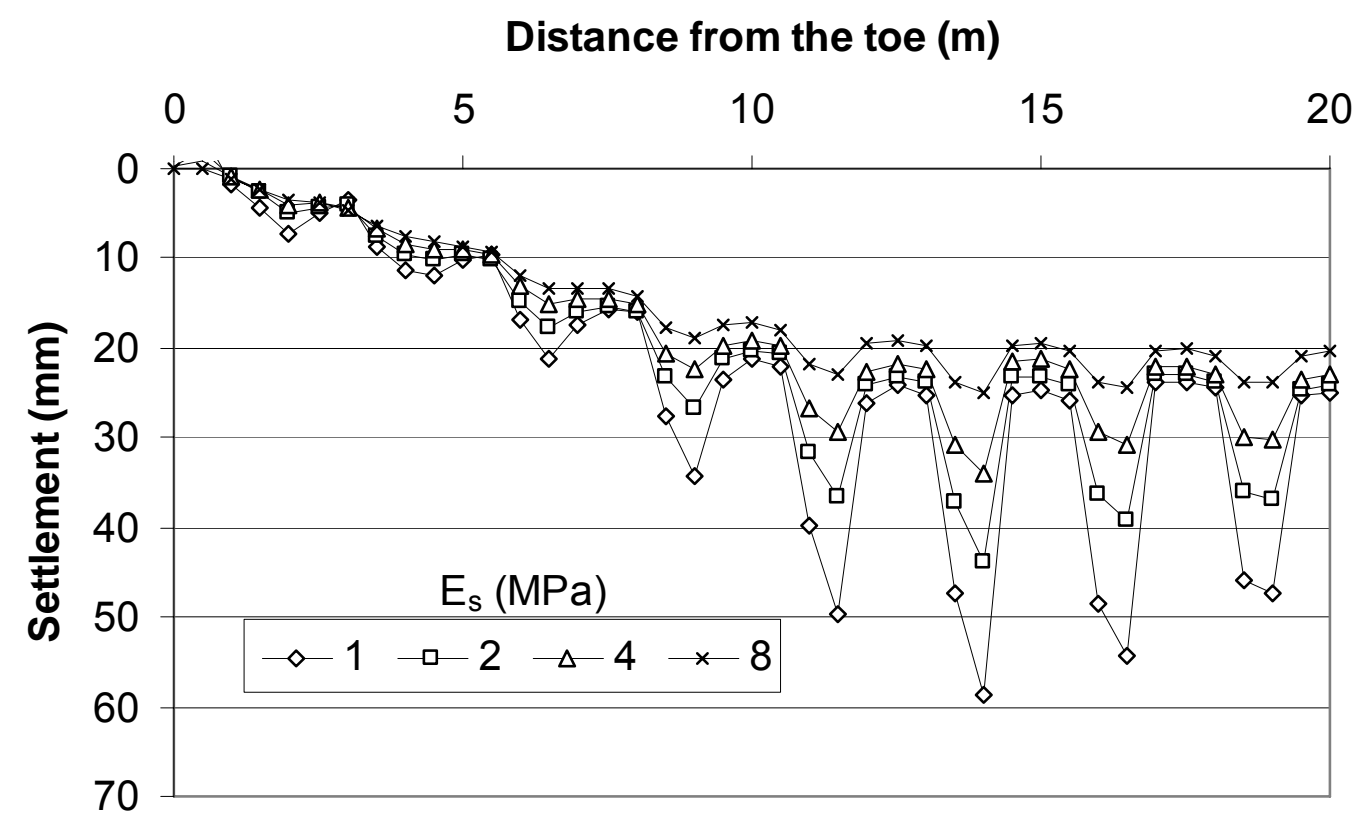

(b) At the base

Fig. 4-22. Settlement Profiles for Various Soil Moduli at 1 Month after Service (2D) 
Distance from the toe $(\mathrm{m})$

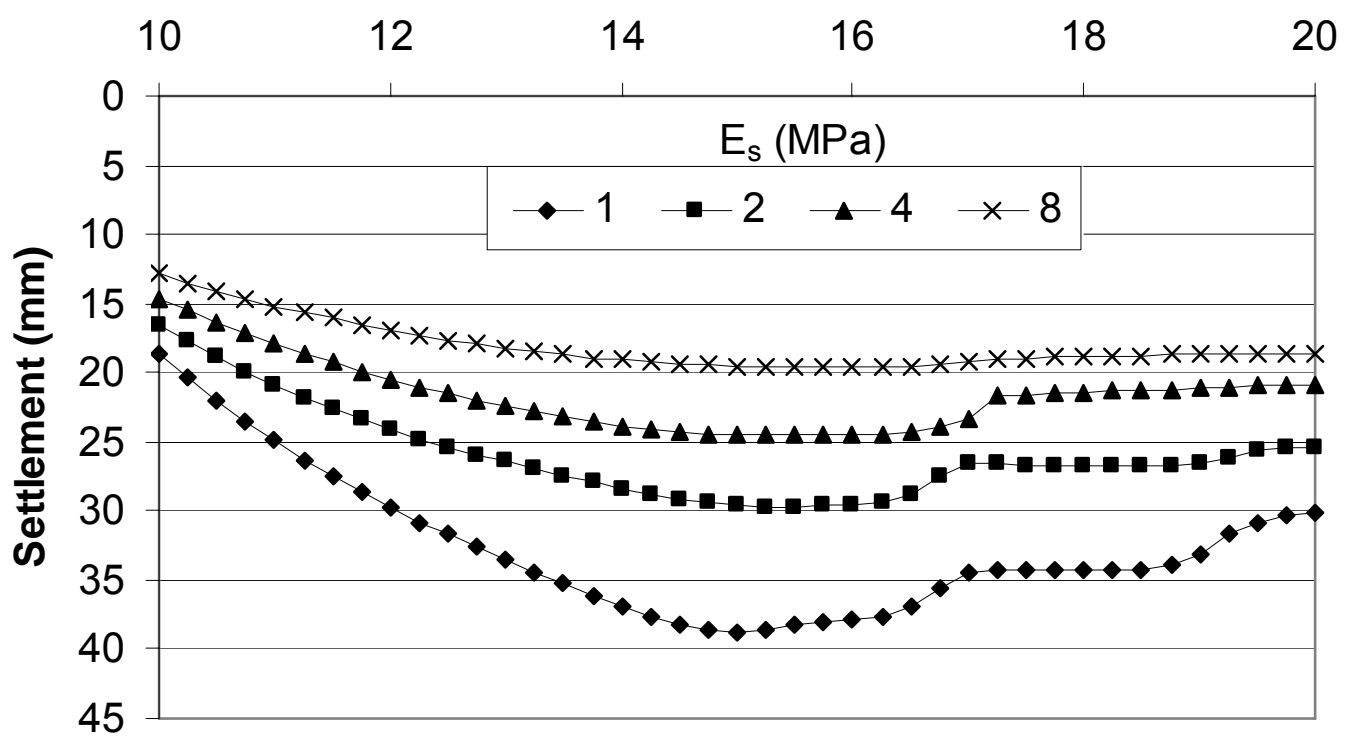

(a) On the crest

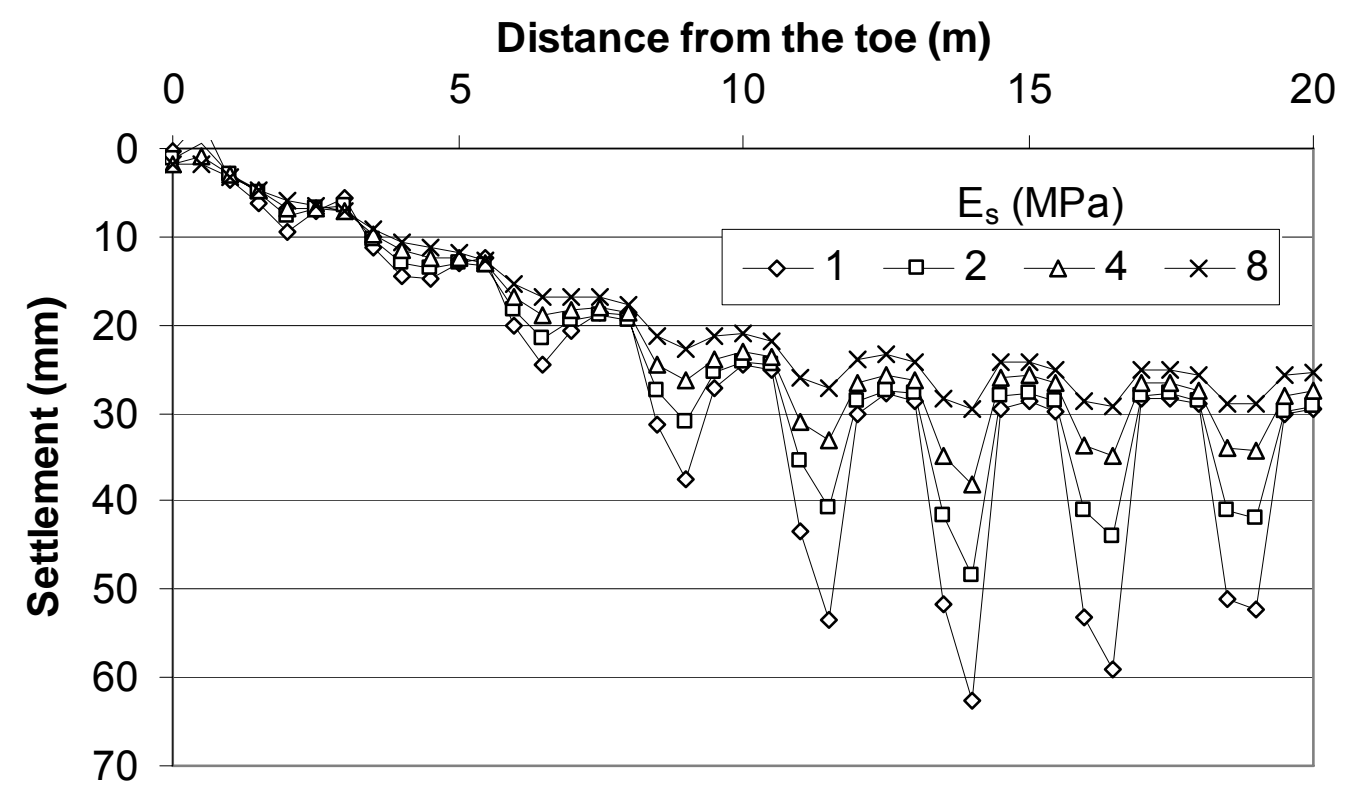

(b) At the base

Fig. 4-23. Settlement Profiles for Various Soil Moduli at 30 Years after Service (2D) 


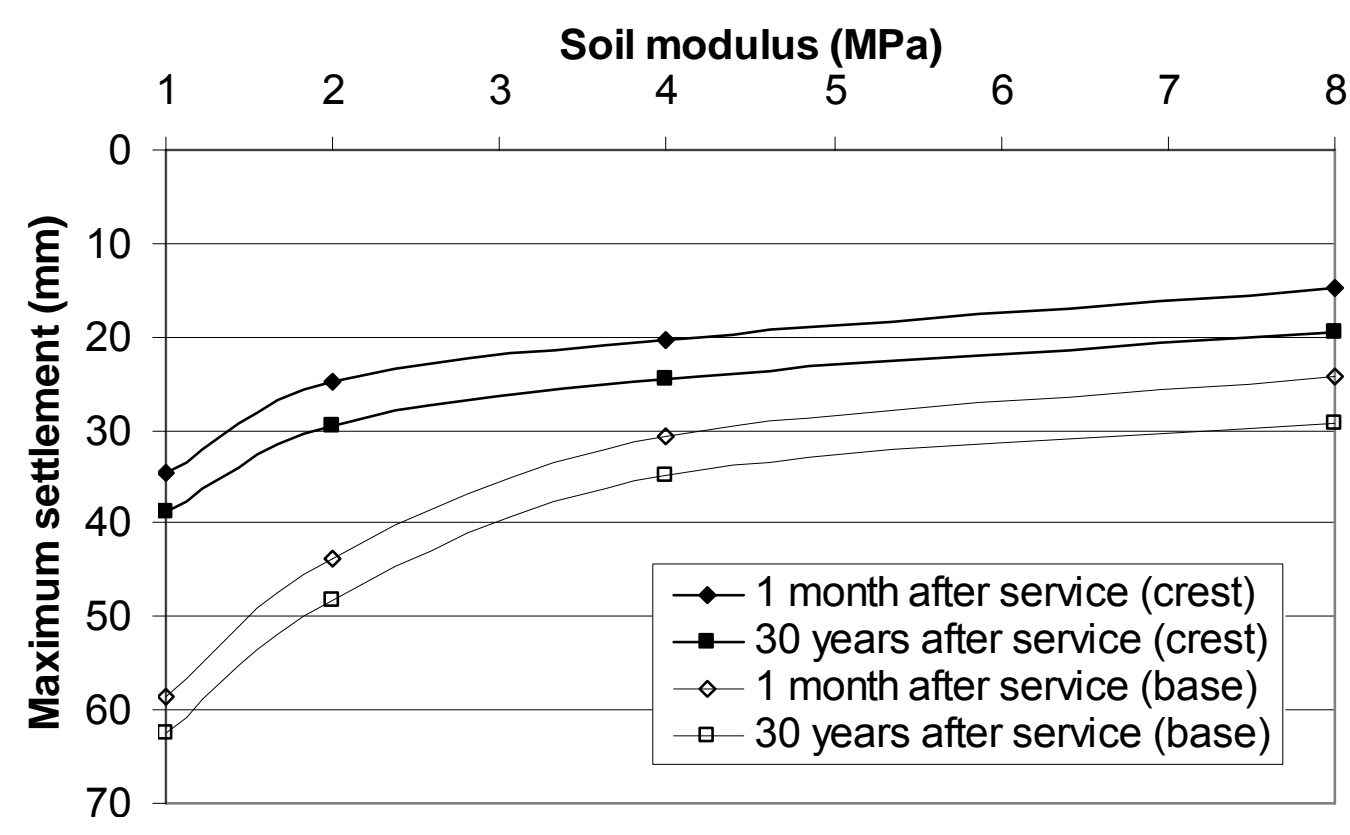

Fig. 4-24. Maximum Settlement versus Soil Modulus (2D)

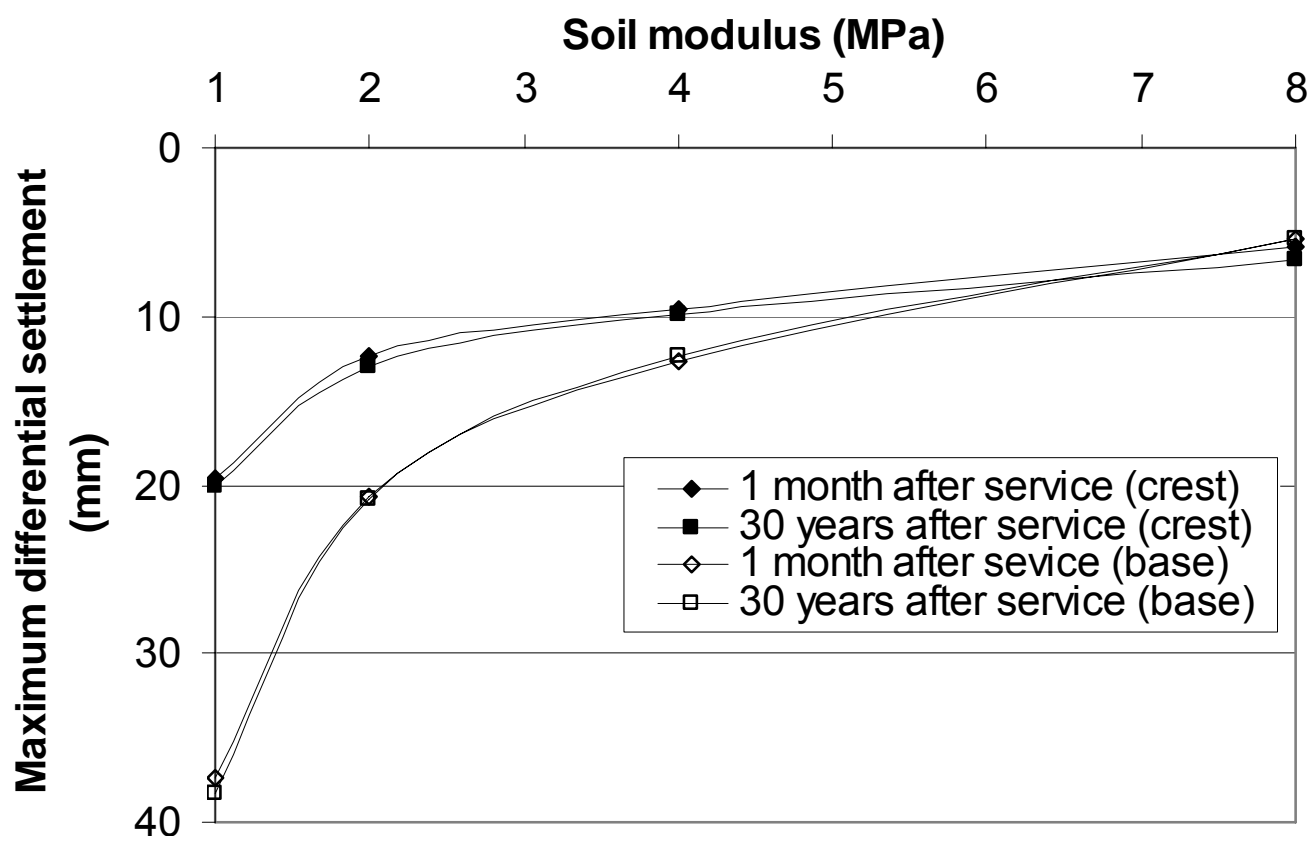

Fig. 4-25. Maximum Differential Settlement versus Soil Modulus (2D) 
Since the differential settlements at the crest are crucial to the serviceability, they are evaluated using the distortion concept defined in the earlier section in the baseline case. Fig. 4-26 presents the influence of the soft soil modulus on the maximum distortion. Obviously, the increase of soft soil modulus reduced the maximum distortion and the consolidation had limited influence on the distortion at various soft soil moduli.

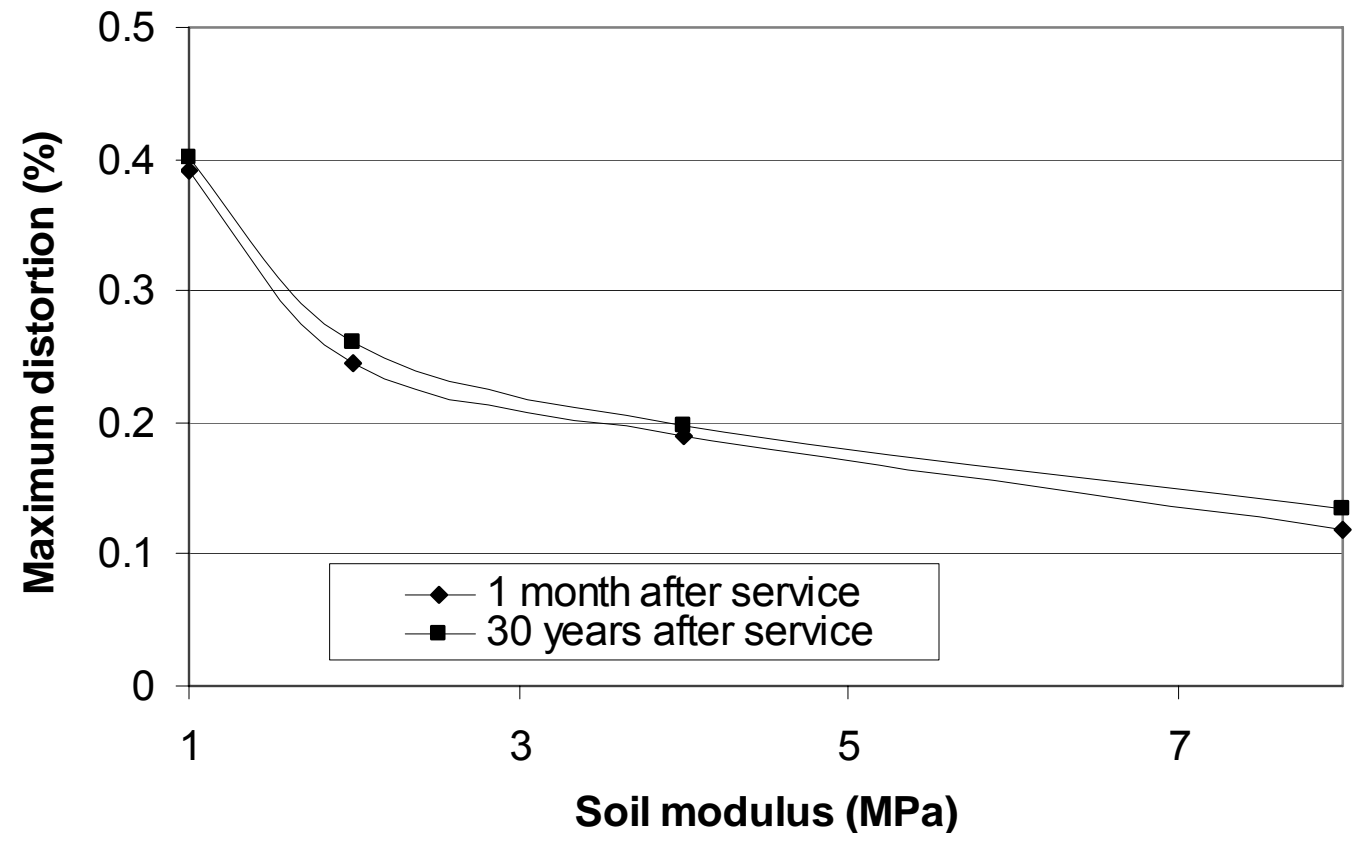

Fig. 4-26. Maximum Distortion on the Crest versus Soil Modulus (2D)

\section{Influence of Soft Soil Friction Angle}

Effective friction angle $\left(\phi^{\prime}\right)$ is a strength parameter and should not influence the settlement as long as the soil remains elastic. However, local yielding or failure is 
almost inevitable in this system; therefore, the friction angle is expected to have some influence on the settlement of the GRCS embankment system. The influence of the friction angle is investigated by changing the soft soil effective friction angle from the baseline case. The settlement profiles at 1 month and 30 years after service are presented in Fig. 4-27 and 4-28, respectively. Generally speaking, the increase of the friction angle led to a decrease in the settlement. This phenomenon is also demonstrated in Fig. 4-29 and 4-30.

When the soft soil friction angle ranged from $20^{\circ}$ to $30^{\circ}$, their settlements were close. However, the settlements at the friction angle of $15^{\circ}$ were much larger than those with higher friction angles. This difference resulted from the fact that a greater extent of yielding or failure occurred at the friction angle of $15^{\circ}$. In addition, the soil friction angle had much less effect on the settlements on the crest than those at the base. In Fig. 4-29, the curve of the maximum settlement on the crest is almost flat after the friction angle is higher than $20^{\circ}$. Therefore, it may be concluded that the influence of the friction angle on the settlement on the crest is insignificant as long as no considerable failure develops in the soft soil. 
Distance from the toe $(\mathrm{m})$

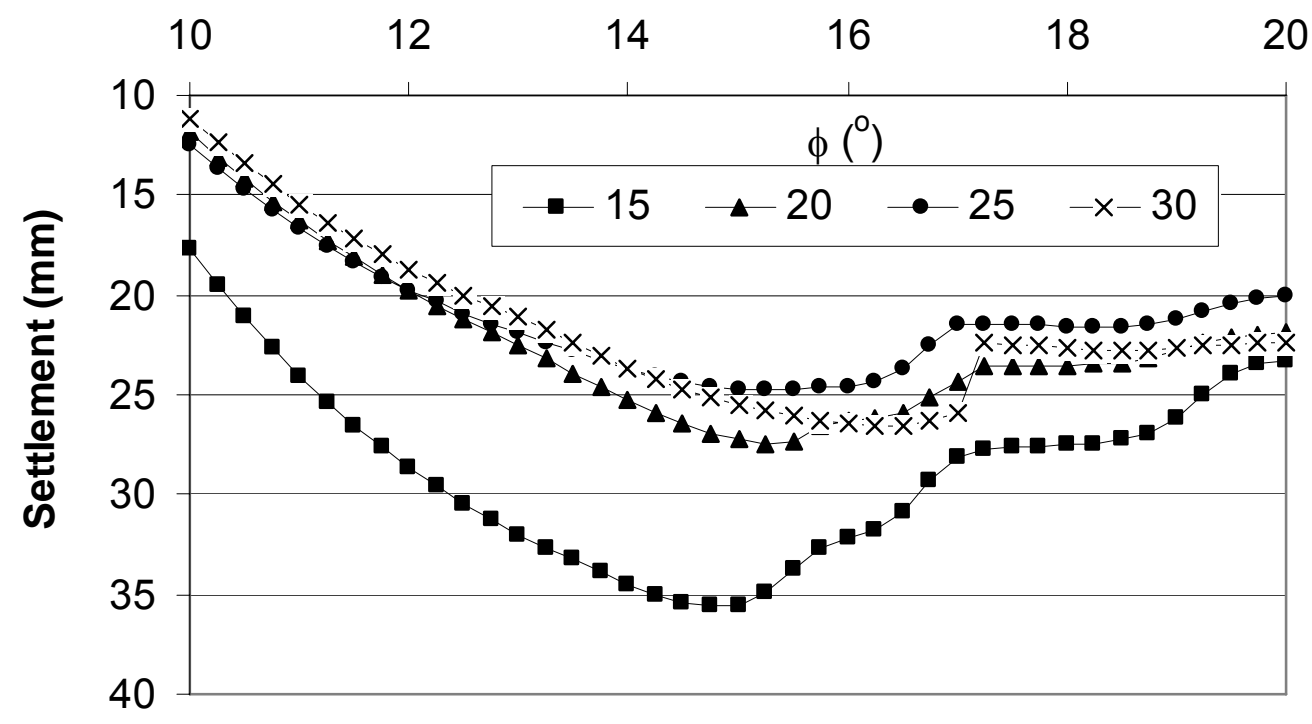

(a) On the crest

Distance from the toe $(\mathrm{m})$

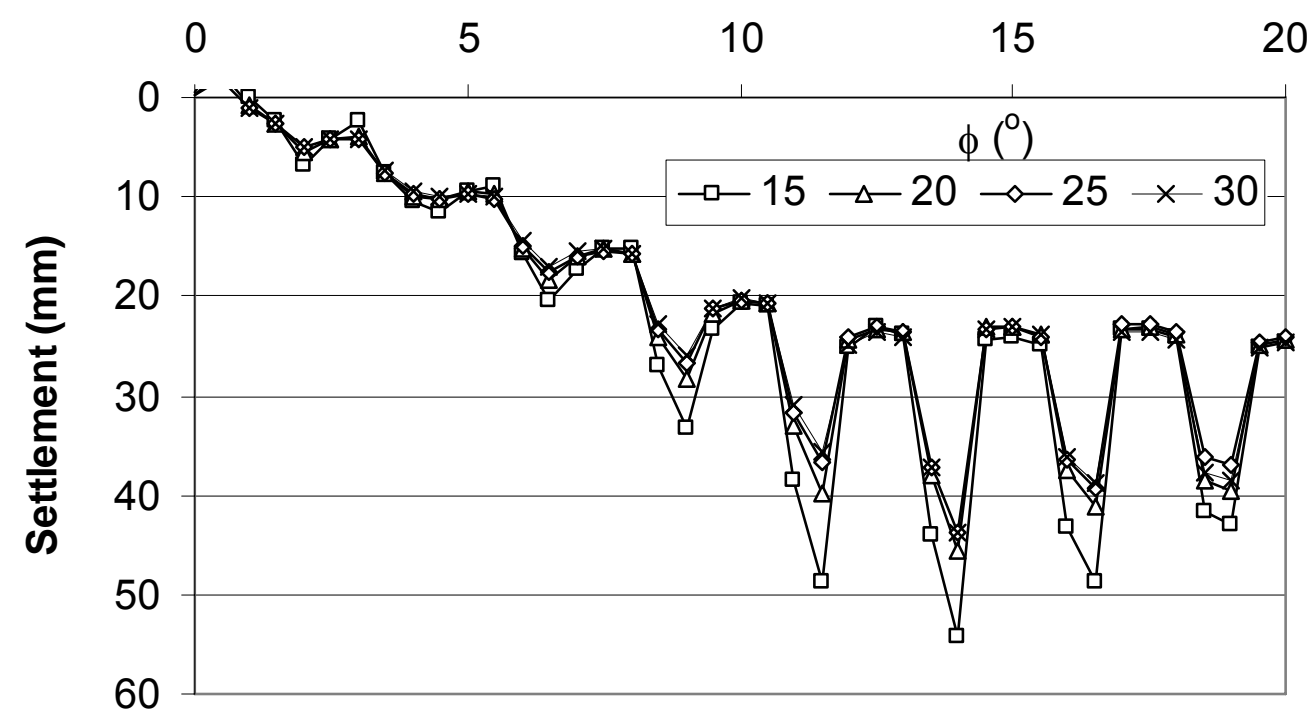

(b) At the base

Fig. 4-27. Settlement Profiles for Various Friction Angles at 1 Month after Service (2D) 


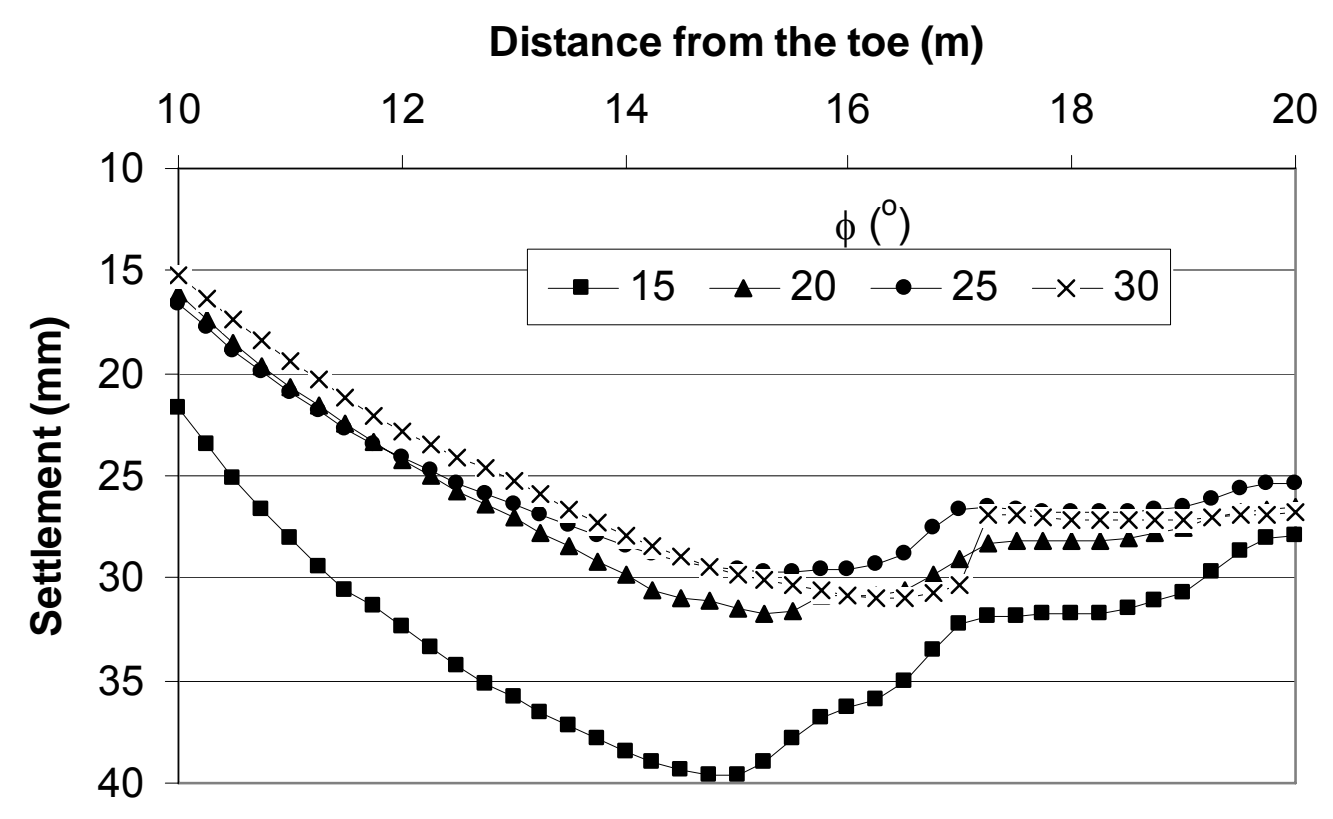

(a) On the crest

Distance from the toe (m)

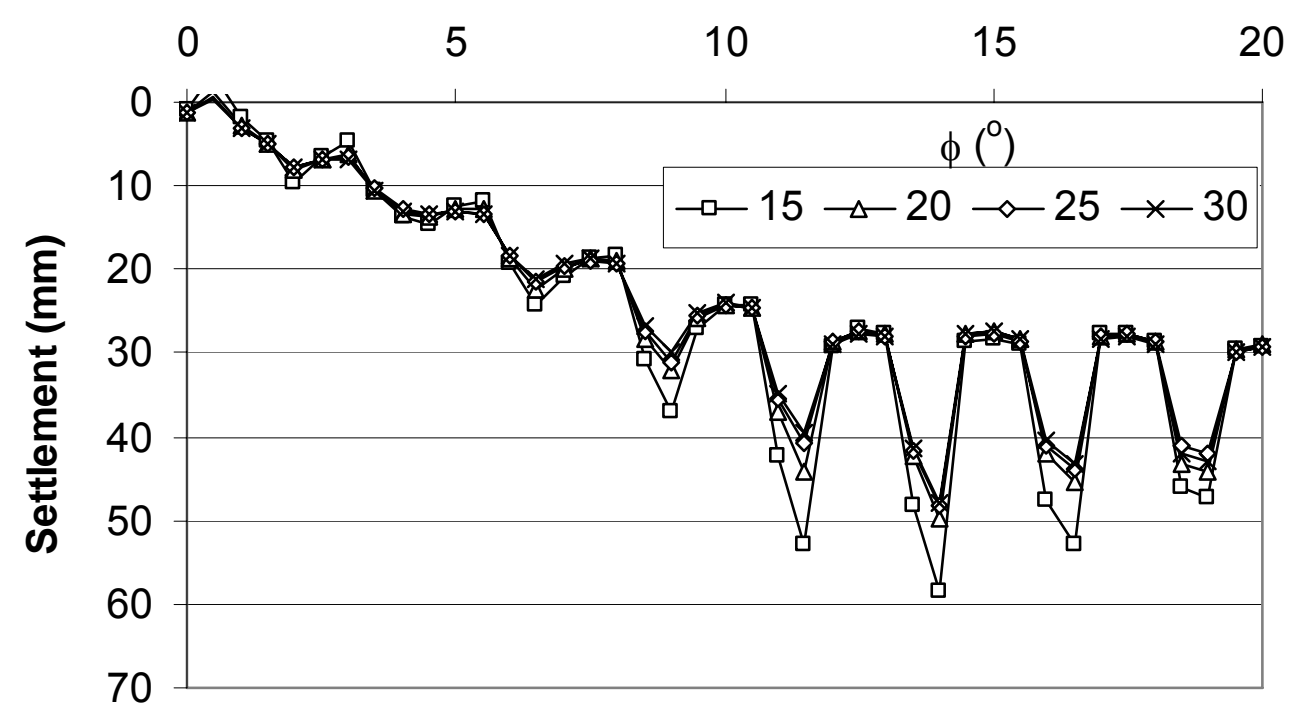

(b) At the base

Fig. 4-28. Settlement Profiles for Various Friction Angles at 30 Years after Service (2D) 


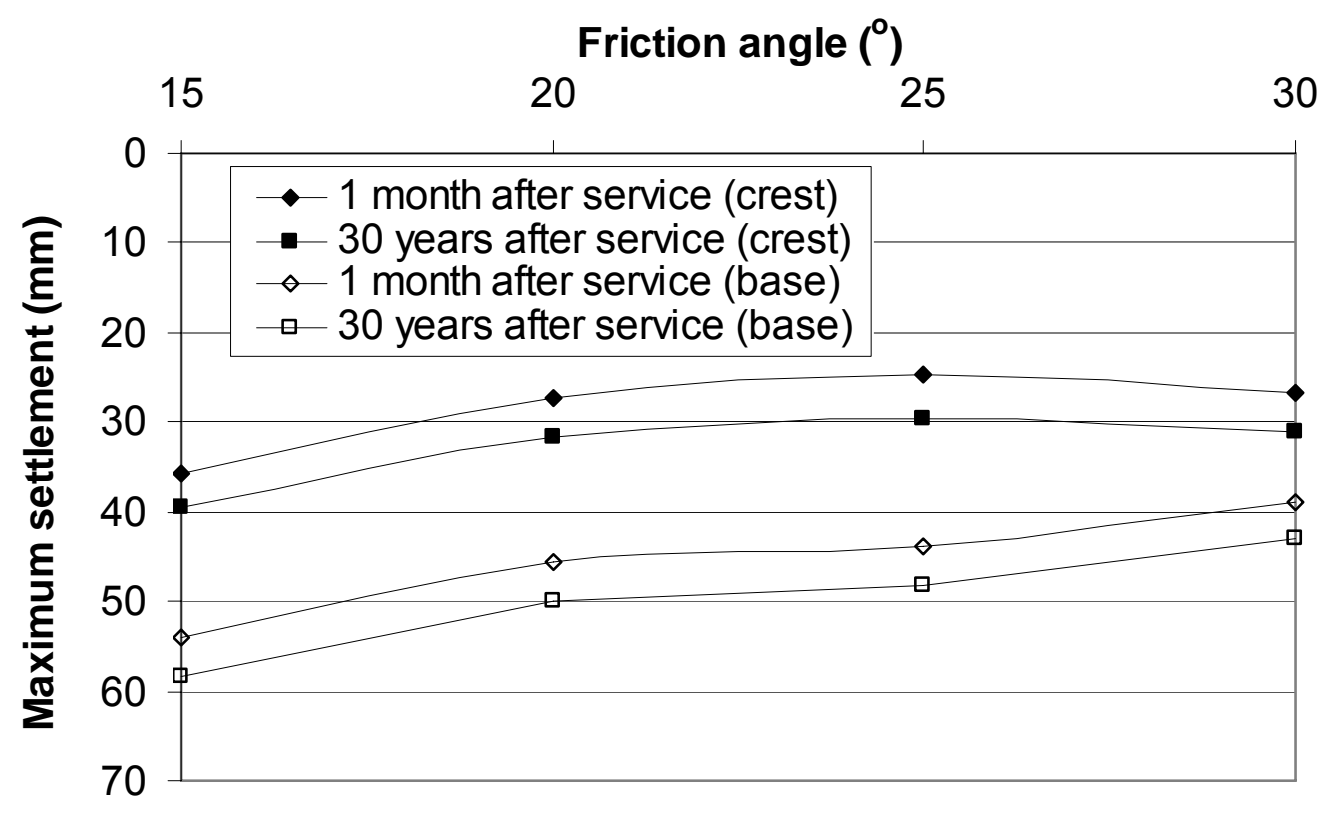

Fig. 4-29. Maximum Settlement versus Friction Angle (2D)

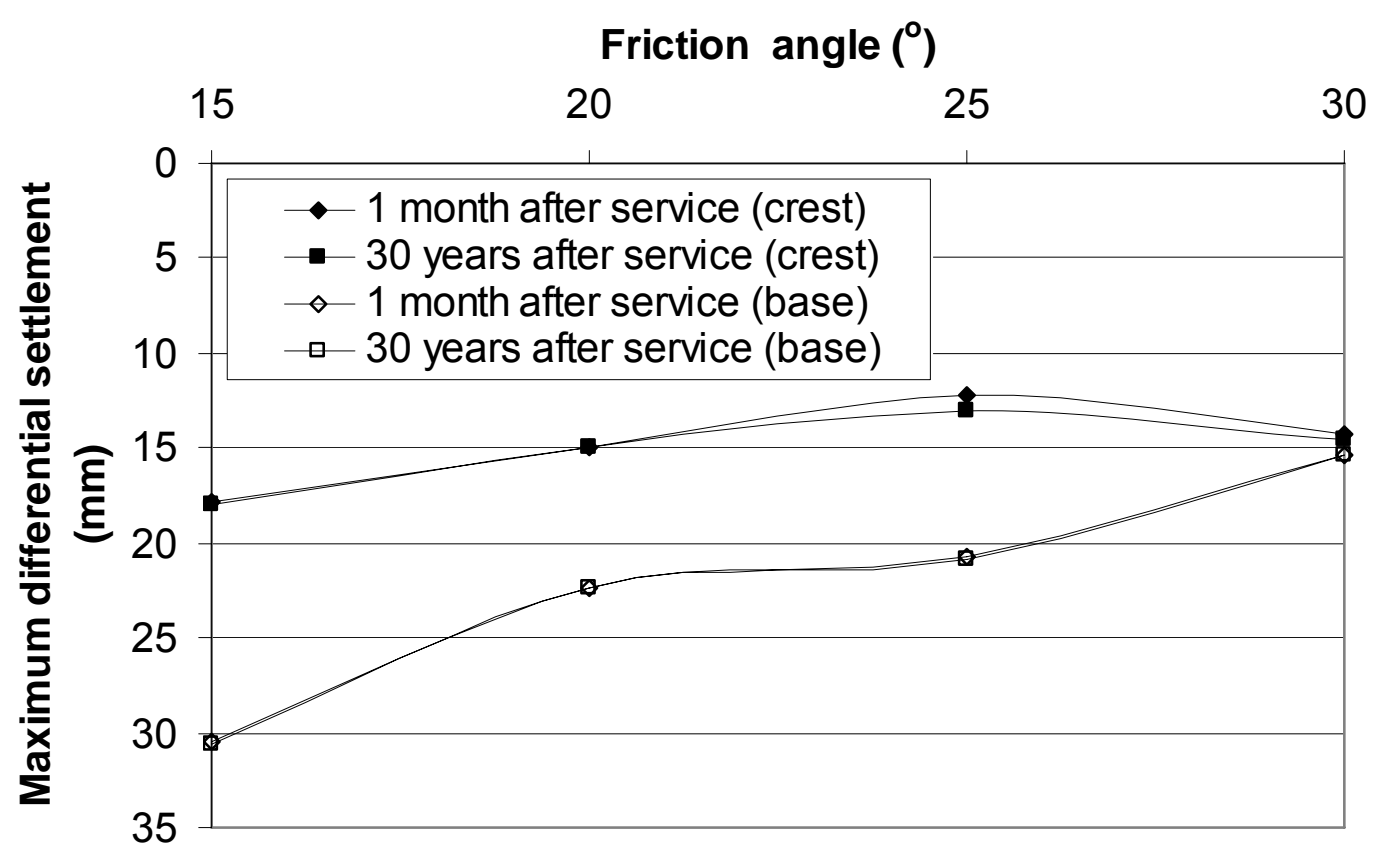

Fig. 4-30. Maximum Differential Settlement versus Friction Angle (2D) 
Similarly, the influence of the friction angle on the maximum distortion was evaluated and is shown in Fig. 4-31. It can be found that the variation of the distortion with respect to the friction angle was limited.

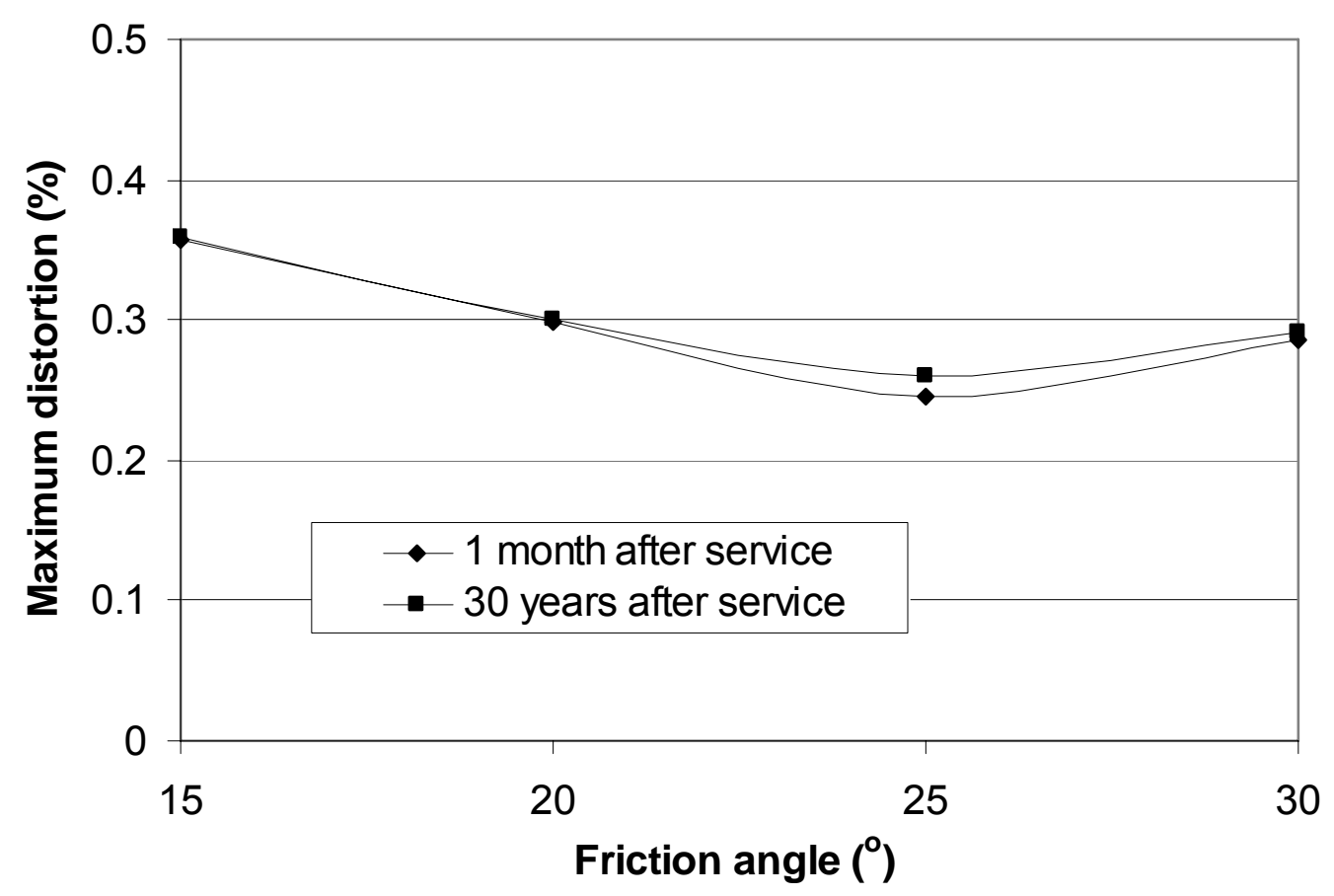

Fig. 4-31. Maximum Distortion on the Crest versus Friction Angle (2D)

\section{Influence of Soft Soil Permeability}

The permeability of the soft soil is expected to greatly influence the generation and dissipation of the excess pore water pressure; therefore, it should have a profound influence on the post-construction settlements on the crest as well, which have not been well studied in the past. 


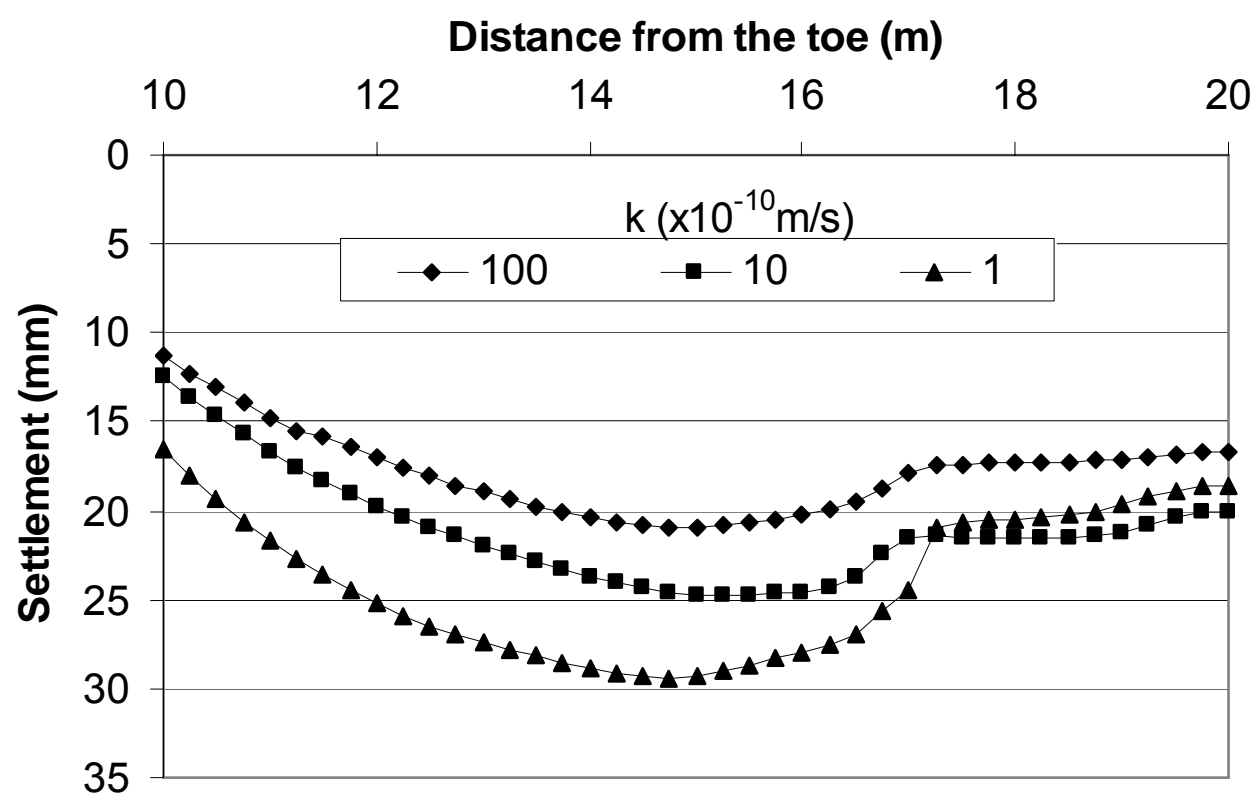

(a) On the crest

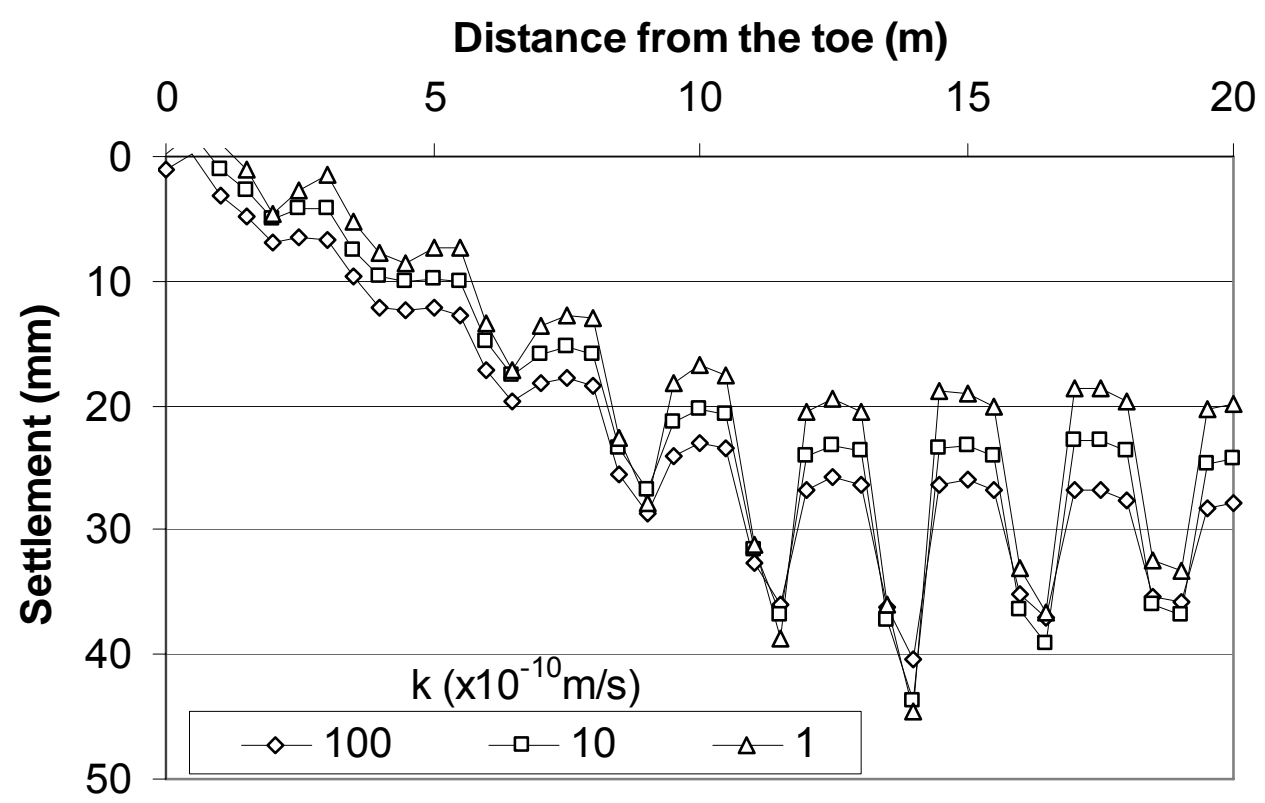

(b) At the base

Fig. 4-32. Settlement Profiles for Various Permeability at 1 Month after Service (2D) 


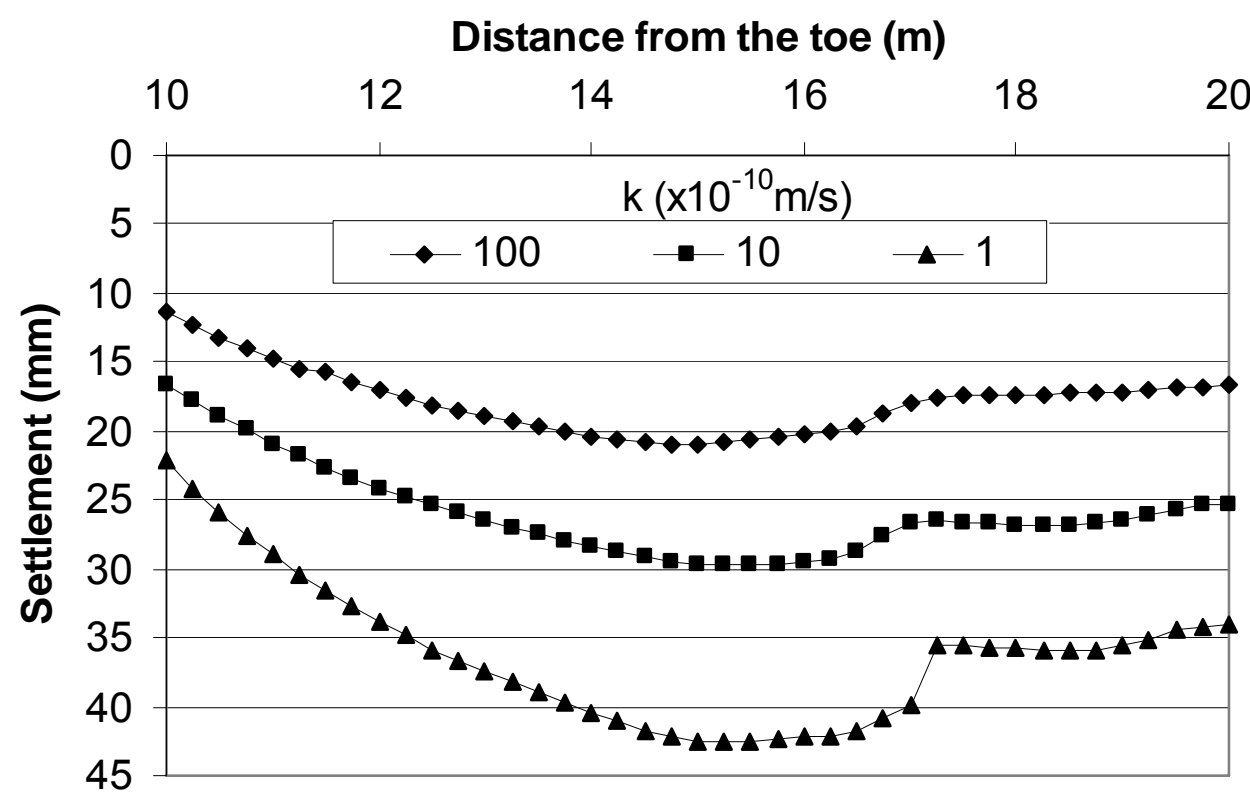

(a) On the crest

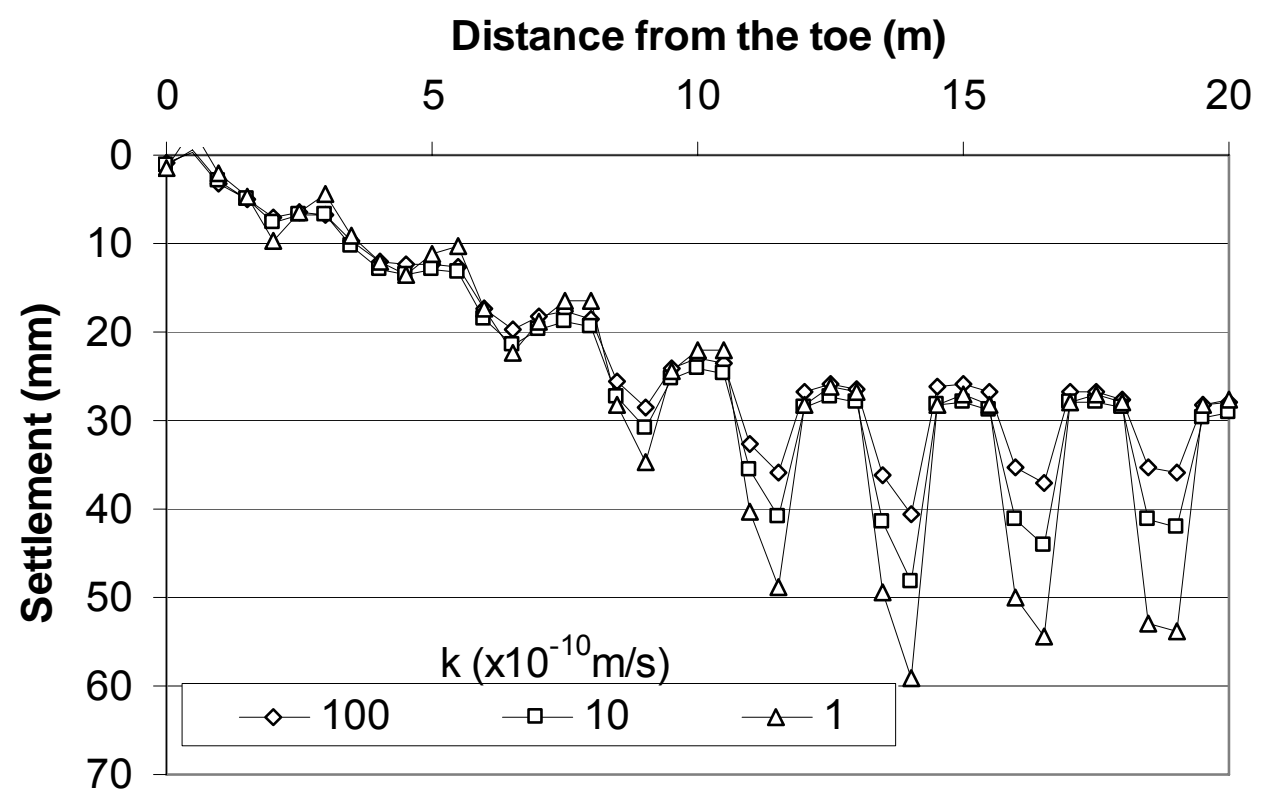

(b) At the base

Fig. 4-33. Settlement Profiles for Various Permeability at 30 Years after Service (2D) 
Figures 4-32 and 4-33 present the numerical results which show the higher permeability of the soft soil having the lower settlements, both at the base and on the crest. This finding is more clearly illustrated in Fig. 4-34 and Fig. 4-35, i.e., the maximum settlement and the maximum differential settlement decreased with the increase of the soil permeability.

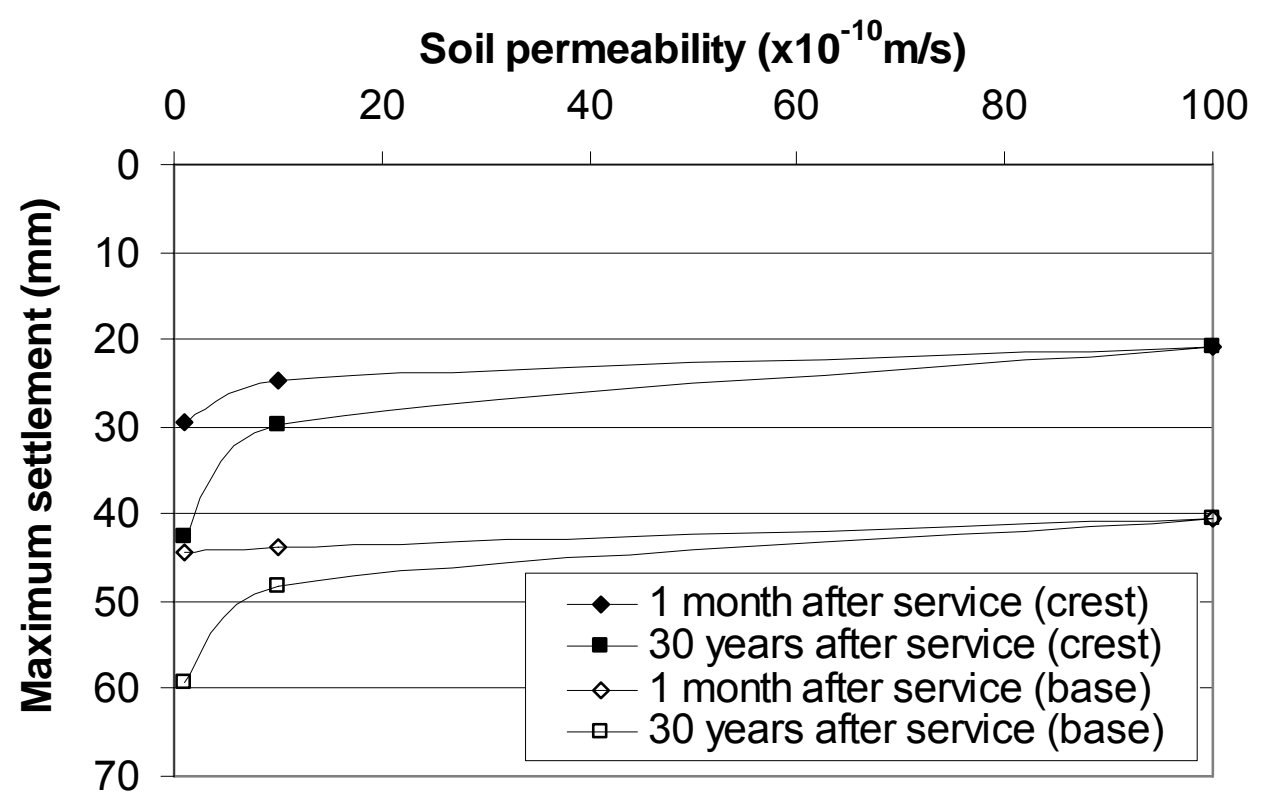

Fig. 4-34. Maximum Settlement versus Soil Permeability (2D)

In addition, the difference in the maximum settlement and the maximum differential settlement at 1 month and 30 years after service decreased with the increase of the soil permeability. In other words, the post-construction settlements can be minimized by increasing the soil permeability. Figure 4-35 shows that the slopes of curves for the differential settlements at 30 years after service were very steep when the soil permeability was lower than $10^{-9} \mathrm{~m} / \mathrm{s}$. This phenomenon implies that it is effective to 
reduce the post-construction settlement by increasing the soil permeability while the permeability is lower than $10^{-9} \mathrm{~m} / \mathrm{s}$.

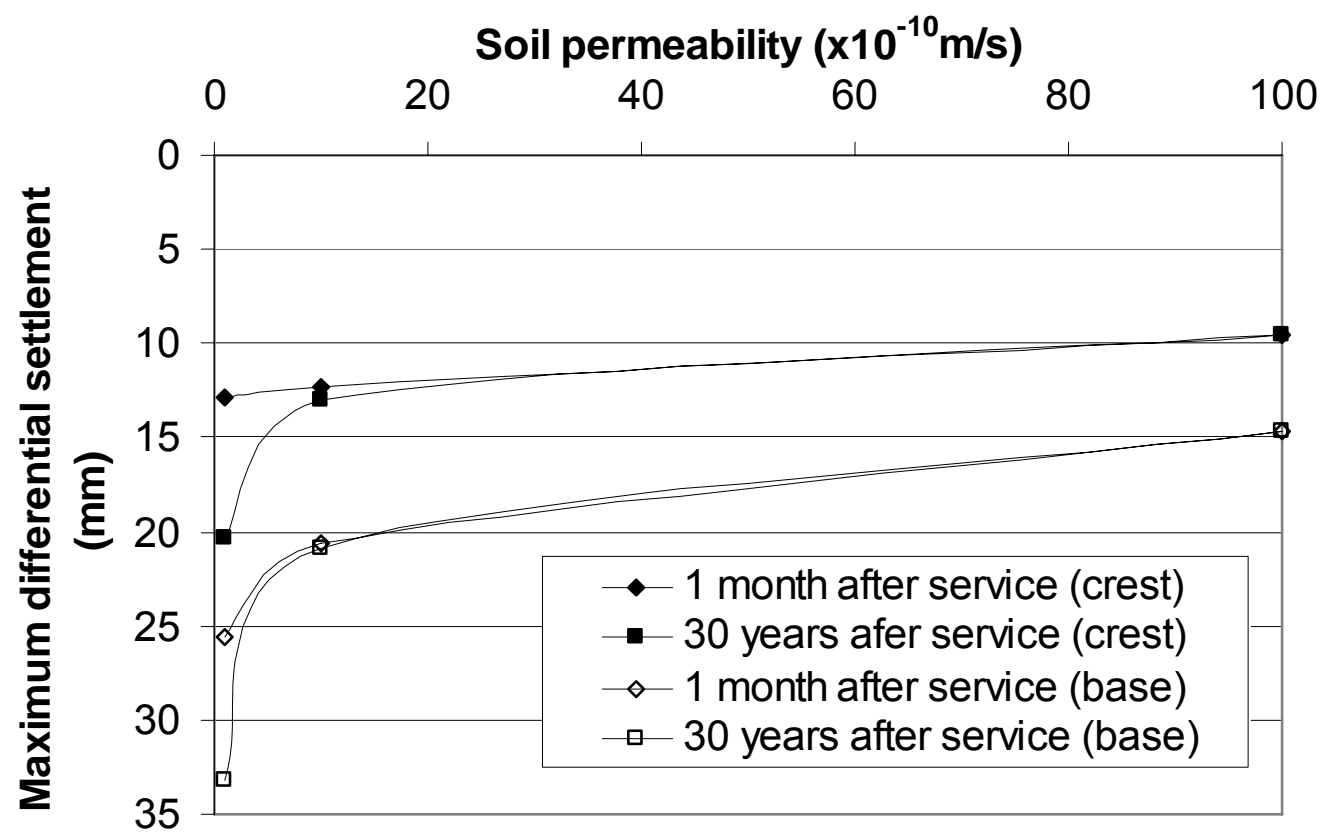

Fig. 4-35. Maximum Differential Settlement versus Soil Permeability (2D)

Another interesting finding from Fig. 4-32 (b) is that at 1 month after service, the soft soil with lower permeability had larger settlement in the soft soil but smaller settlement in the columns. This phenomenon is associated with fact that the lower the soil permeability, the higher the excess pore water pressure in the soft soil. The higher excess pore water pressure in the soft soil shared more load from the embankment. Therefore, the lower permeability soil led to smaller settlements in the columns. Meanwhile, the higher excess pore water pressure in the soft soil led to a greater reduction in the effective stress in the soft soil. Since the soil strength is effective 
stress dependant, the soil at the lower effective stress fails more easily. As a result, the soil settled more when the permeability of the soft soil was lower. As the consolidation proceeded, the load carried by pore water was transferred back to the columns and/or the soft soil. The higher excess pore water pressure would have more load transferred. Consequently, the lower permeability of the soft soil induced the greater increase of the settlement from 1 month to 30 years after service.

The maximum distortion is plotted against the soil permeability in Fig. 4-36.

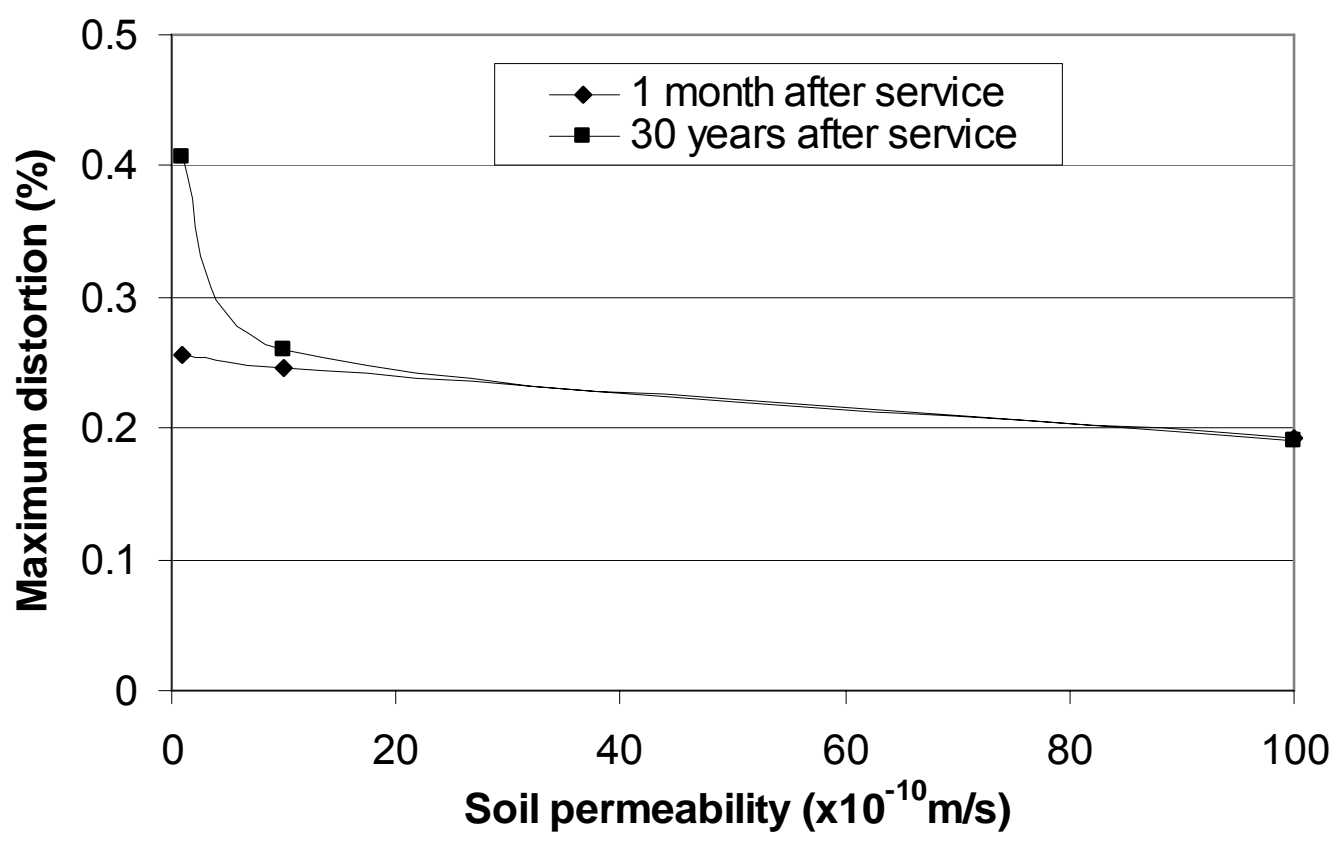

Fig. 4-36. Maximum Distortion on the Crest versus Soil Permeability (2D)

Apparently, the higher permeability yielded less distortion. As mentioned earlier, part of the distortion on the crest was induced by the continued consolidation of the 
soft soil after the construction. As the soil permeability was higher, the less excess pore water pressure accumulated during the construction, which led to less distortion. Figure 4-36 also shows that there was a great increase in the distortion from 1 month to 30 years after service when the soil permeability was low. The finding implies that it is necessary to consider the influence of the soil permeability on the serviceability of the GRCS embankment, especially when the soil permeability is low.

\section{Influence of Column Elastic Modulus}

In this study, DM columns are investigated and their moduli can be correlated to their undrained shear strengths using the generally accepted equation: $\mathrm{E}_{\mathrm{c}}=200 \mathrm{c}$, where $\mathrm{c}$ is the cohesion of the columns. Therefore, the column modulus is not only an indicator of stiffness but also an indicator of strength. It is expected that the stiffness of the columns plays an important role in limiting the settlements. Stiffer columns are expected to carry a larger portion of the embankment and traffic loads to reduce the settlements because less load is taken by the soft soil. The effect of the elastic moduli of the columns on the settlements is presented in Fig. 4-37 and 4-38. 


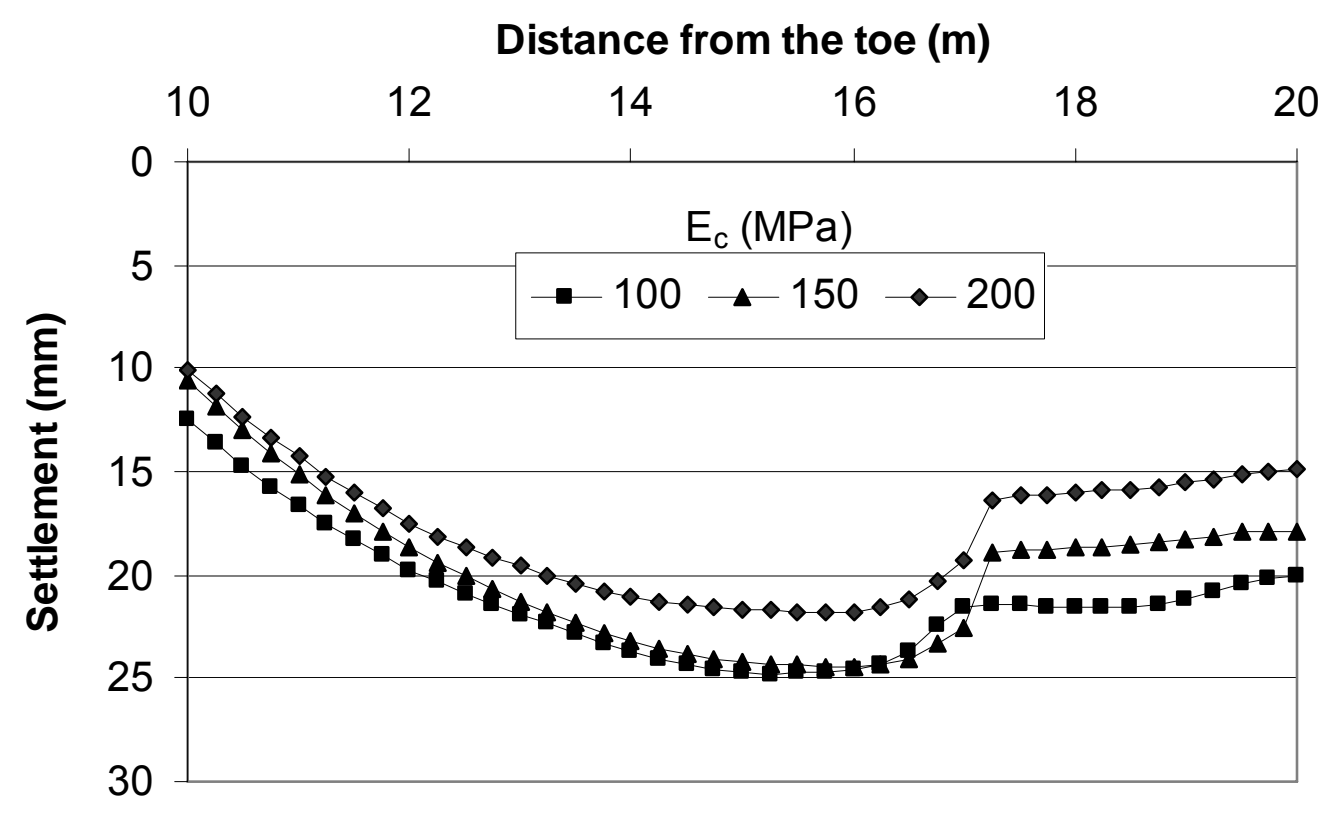

(a) On the crest

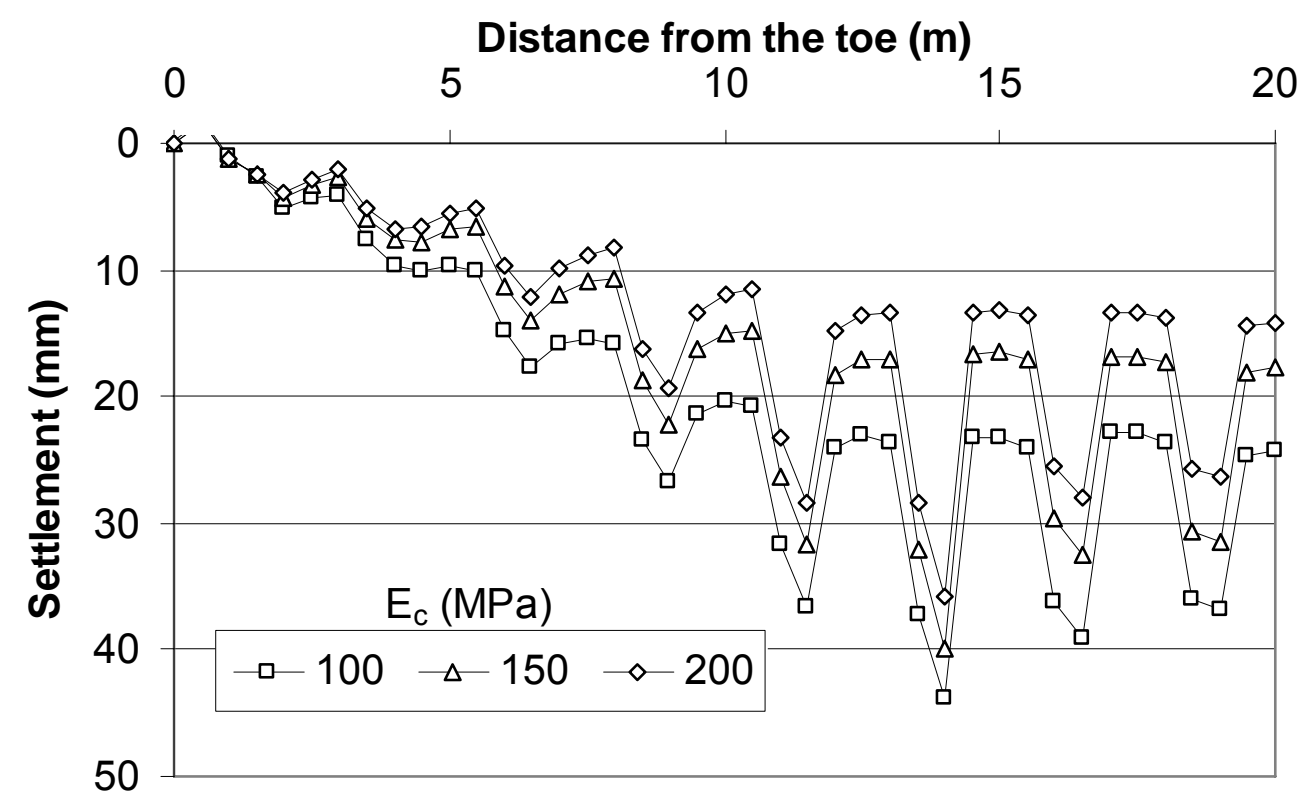

(b) At the base

Fig. 4-37. Settlement Profiles for Various Column Moduli at 1 Month after Service (2D) 


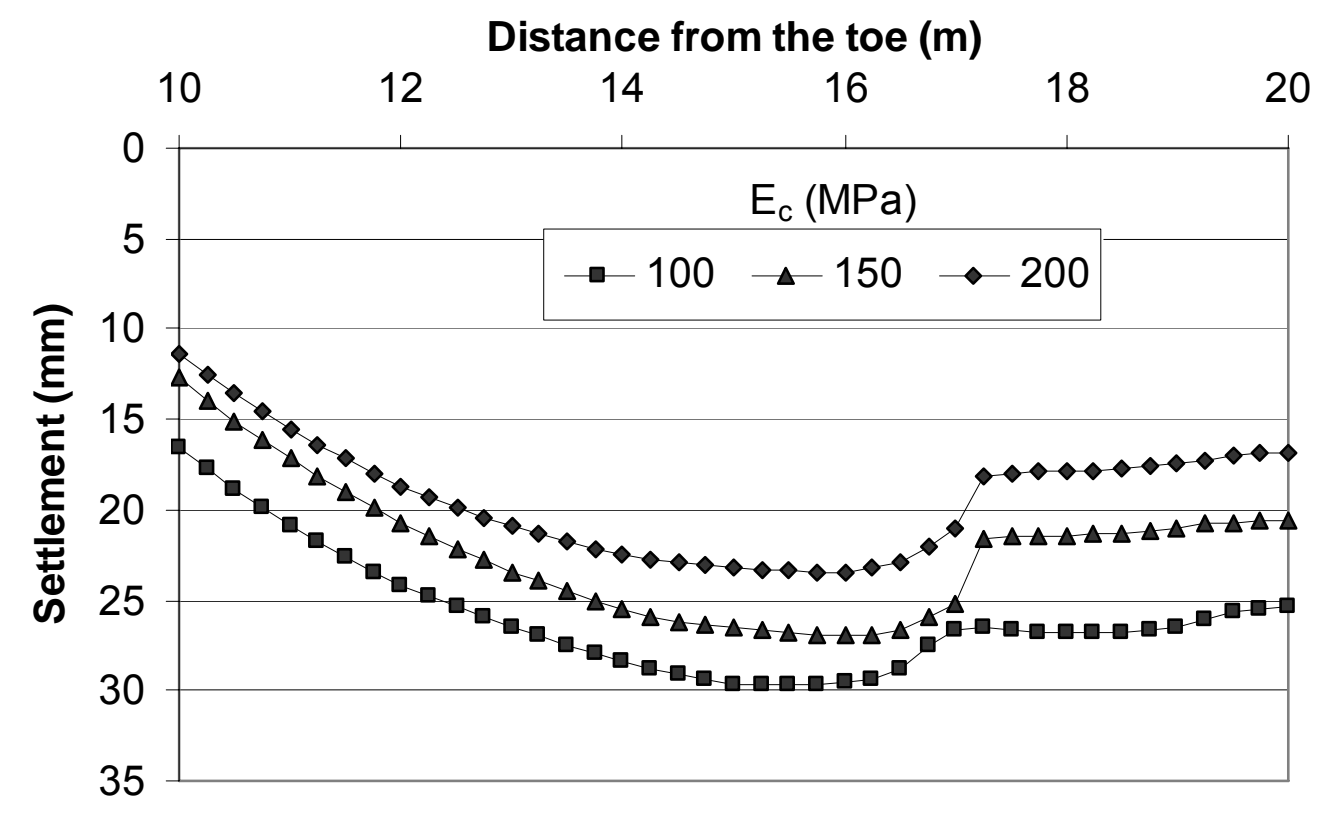

(a) On the crest

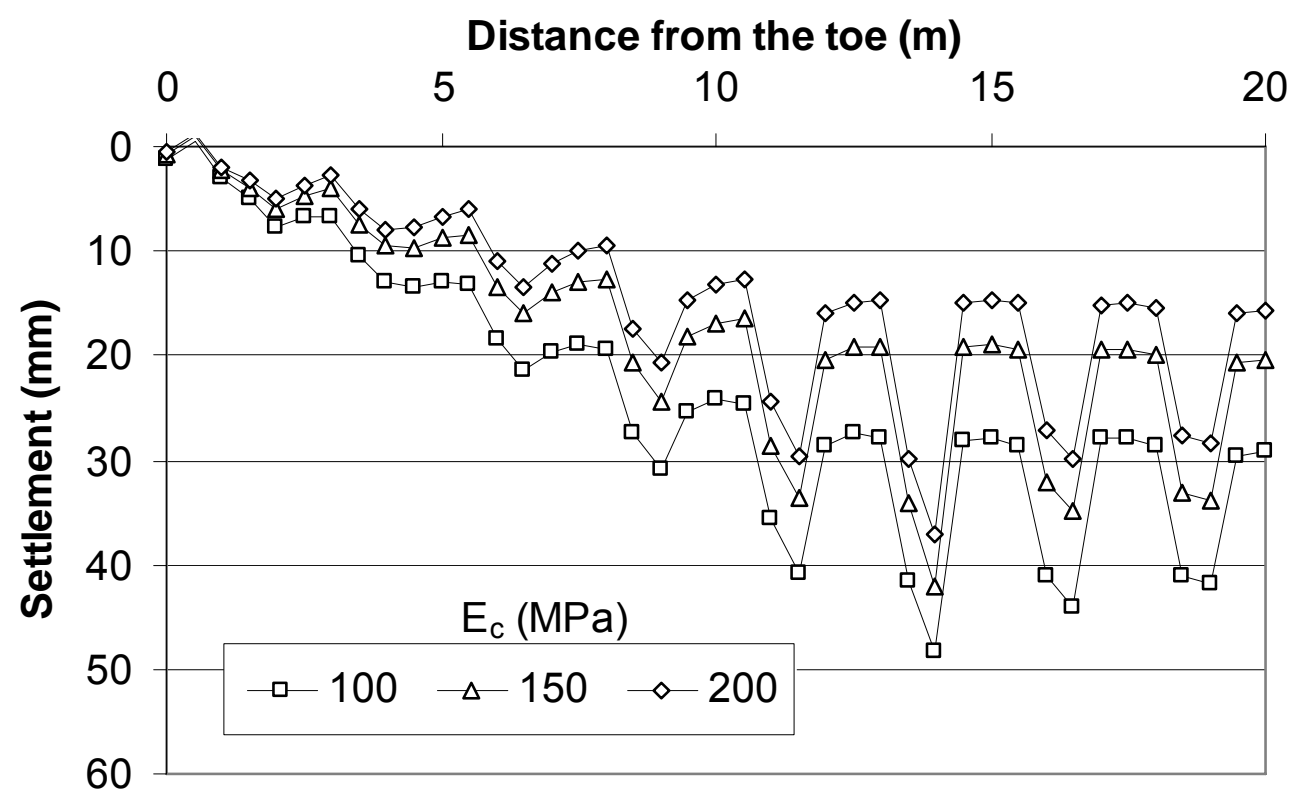

(b) At the base

Fig. 4-38. Settlement Profiles for Various Column Moduli at 30 Years after Service (2D) 


\section{Column modulus (MPa)}

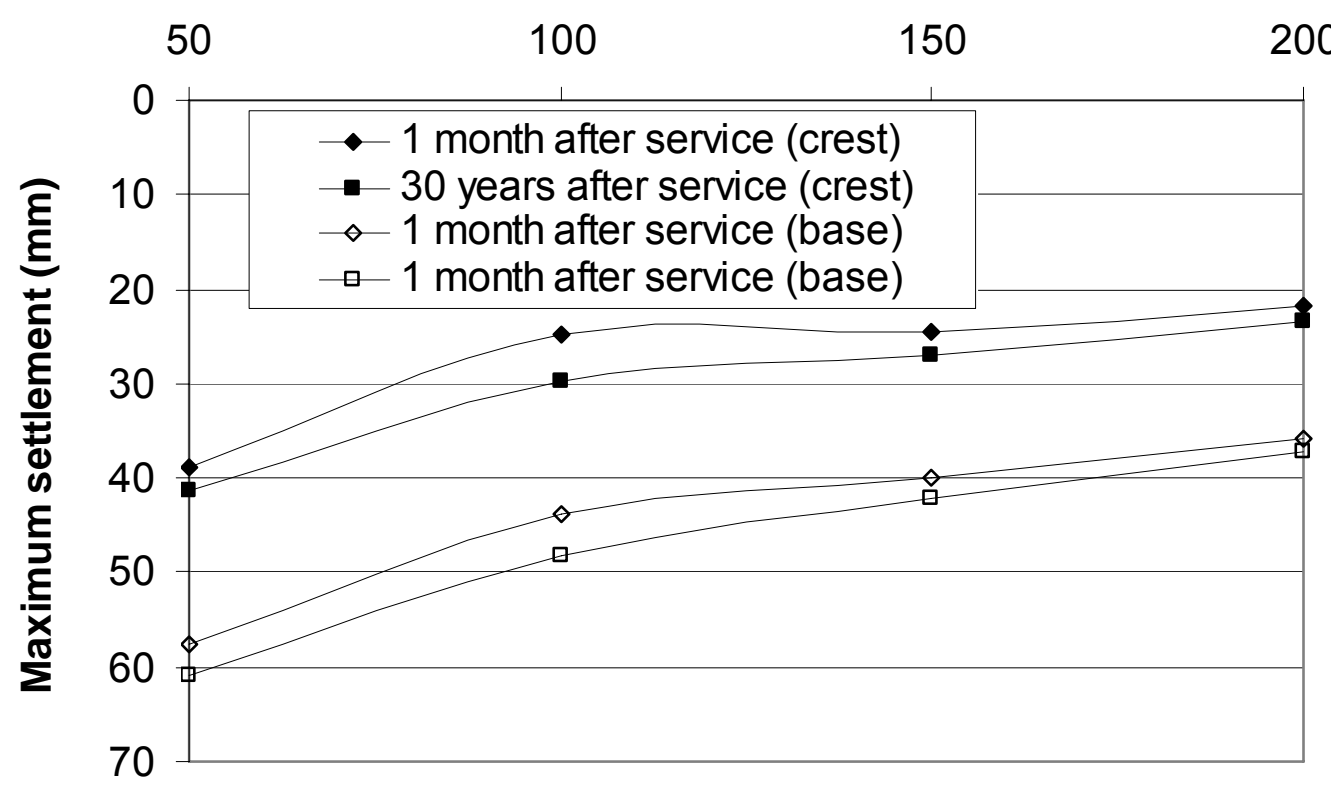

Fig. 4-39. Maximum Settlement versus Column Modulus (2D)

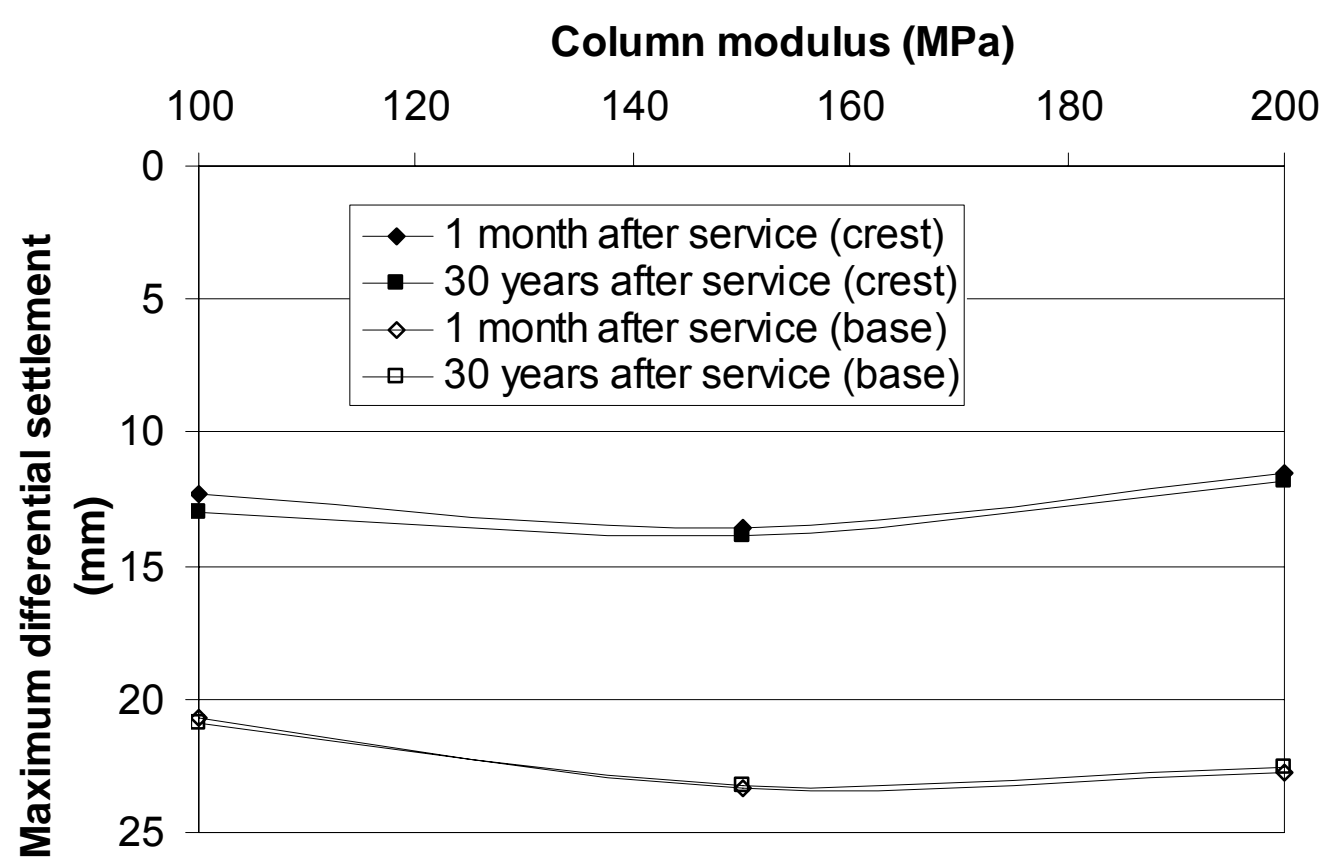

Fig. 4-40. Maximum Differential Settlement versus Column Modulus (2D) 
A comparison between Fig. 4-39 and 4-40 shows that the increase of the column modulus had a greater effect on the reduction of the maximum settlement than that of the maximum differential settlement. Figure 4-40 also shows that the curves of maximum differential settlement on the crest against the column modulus are so flat that the reduction in the maximum differential settlement was less than $2 \mathrm{~mm}$ as the column modulus increased from $100 \mathrm{MPa}$ to $200 \mathrm{MPa}$. The major reason for this phenomenon may be because the columns were stiff enough as compared with the soft soil and the stable soil arching was formed. In this study, the modulus ratios of column to soft soil ranged from 50 to 100 . The high modulus ratio makes the column behave as a rigid support with respect to the soft soil. As a result, beyond a certain height of the embankment, the embankment settlements are almost uninfluenced by the column modulus.

Due to its limited influence on the differential settlement, the column modulus also had limited influence on the maximum distortion as shown in Fig. 4-41. Figure 4-41 shows that the maximum distortion increased slightly with consolidation. 


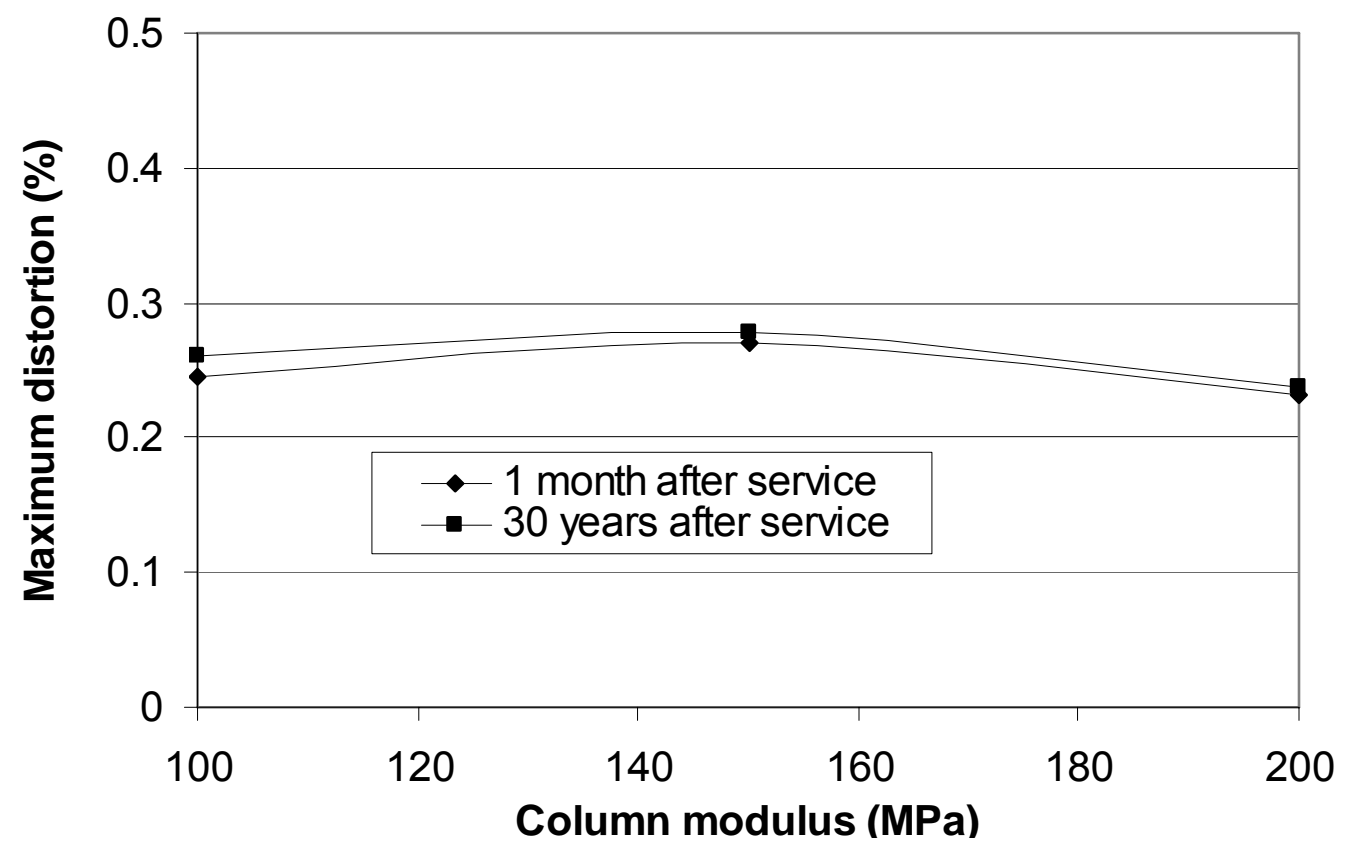

Fig. 4-41. Maximum Distortion on the Crest versus Column Modulus (2D)

\section{Influence of Column Spacing}

Column spacing is another important design parameter. Once the column size is determined, the column spacing is directly related to the area replacement ratio of the columns, i.e., larger spacing of columns leads to a smaller area replacement. Figures $4-42,4-43,4-44$, and $4-45$ show that larger spacing of columns resulted in larger total and differential settlements at the base and on the crest of the embankment. The increase of column spacing reduced the area replacement ratio so that the percentage of the soft soil area increased but the percentage of the column area decreased. Since the soft soil was much softer than the columns and it settled more than the columns, the differential settlement between the columns and the soft soil increased. Figures 4- 
42 and 4-43 also show that apparent local differential settlements developed at the crest when the column spacing equaled to $3.0 \mathrm{~m}$. Figure $4-45$ indicates that the maximum differential settlement was more than doubled as the column spacing increased from 2.0 to $3.0 \mathrm{~m}$. The comparison between Fig. 4-44 and 4-45 shows that the time from 1 month to 30 years after service had more effect on the maximum settlement than the maximum differential settlement.

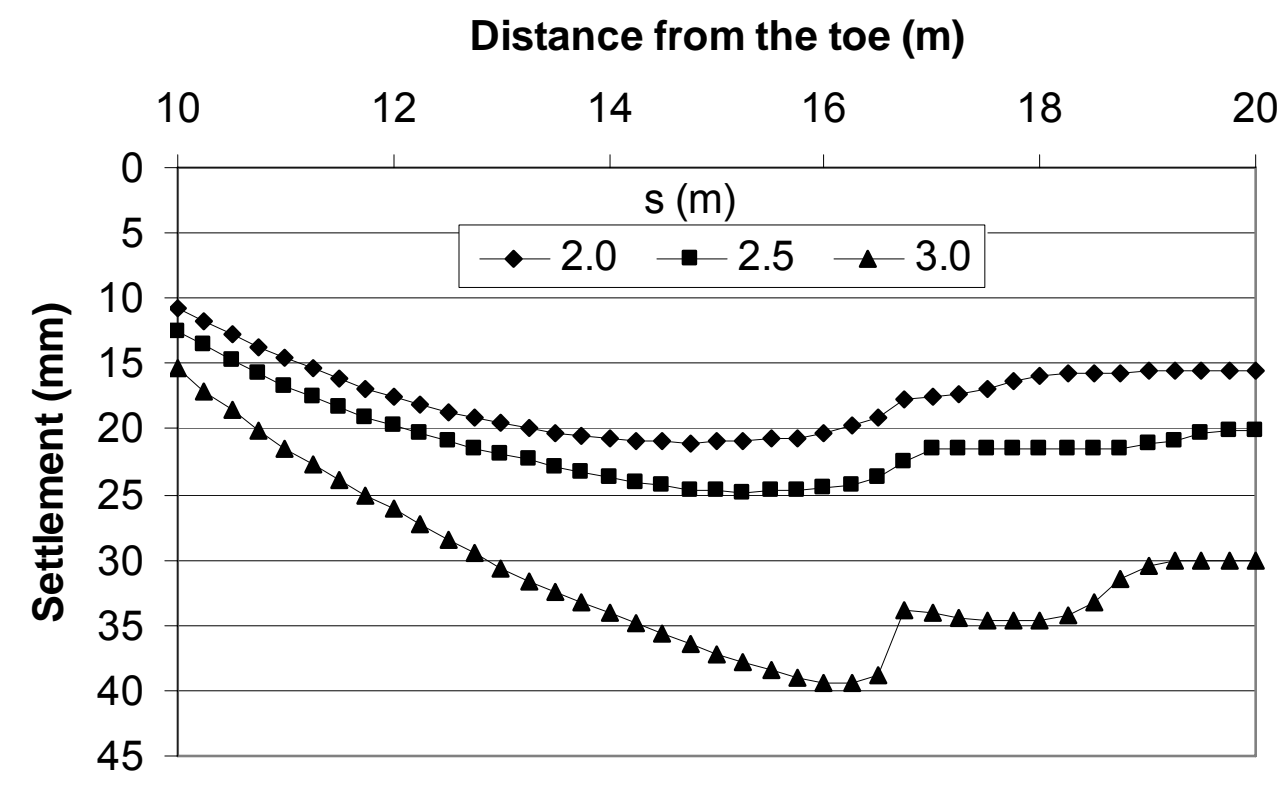

(a) On the crest

Fig. 4-42. Settlement Profiles for Various Column Spacing at 1 Month after Service (2D) 


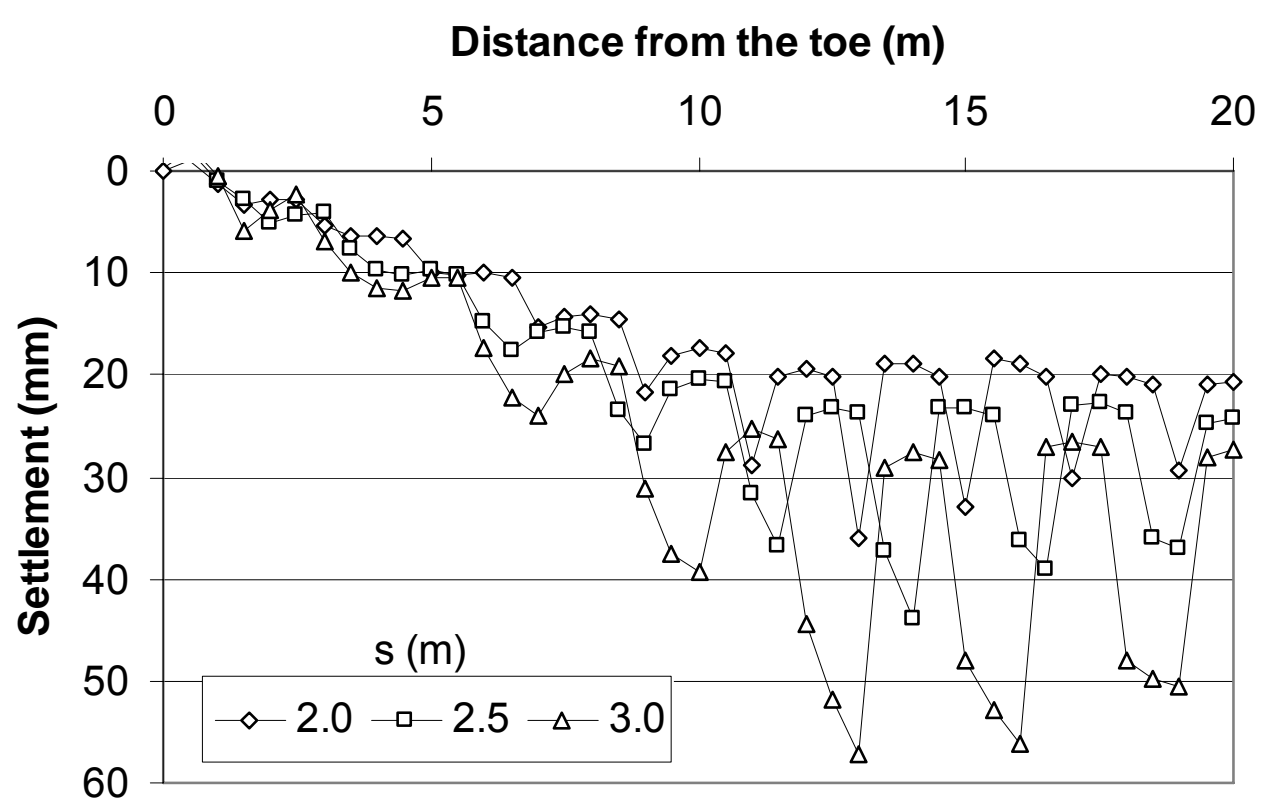

(b) At the base

Fig. 4-42. Settlement Profiles for Various Column Spacing at 1 Month after Service (2D) (continued)

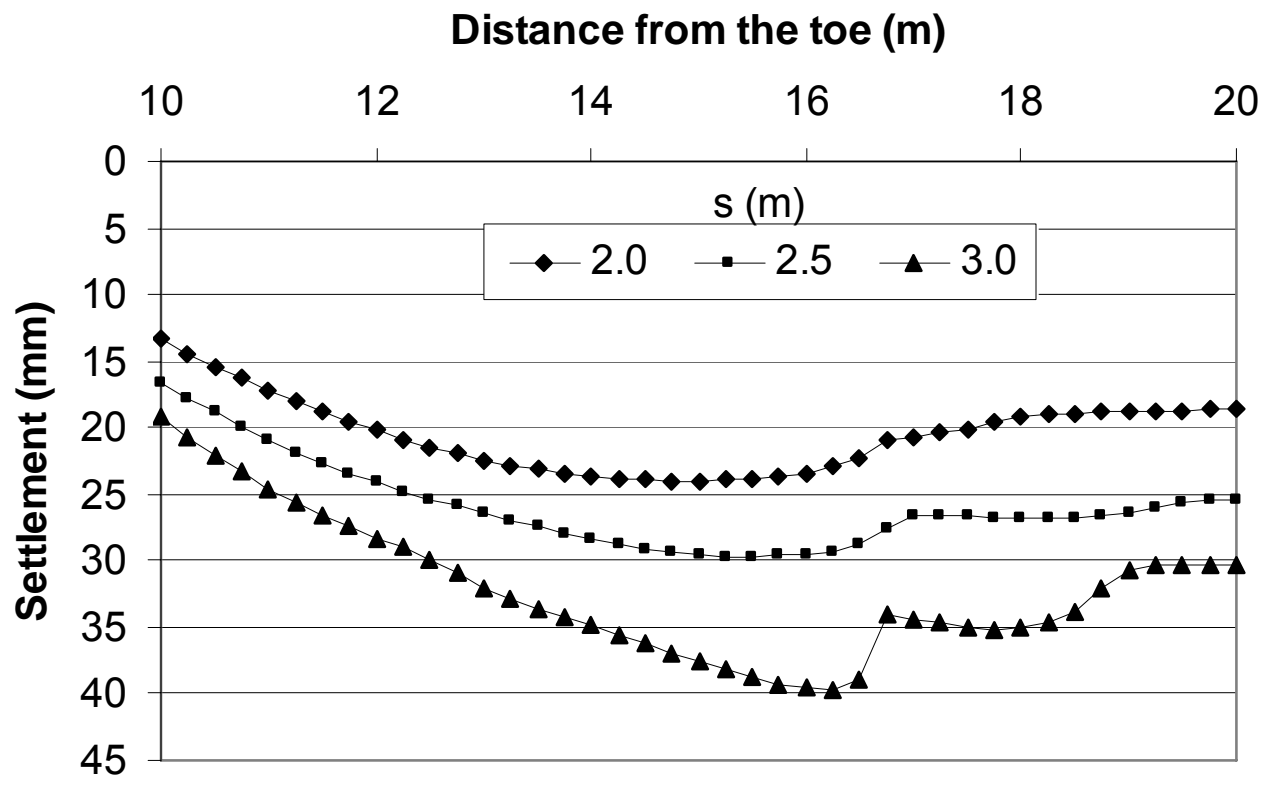

(a) On the crest

Fig. 4-43. Settlement Profiles for Various Column Spacing at 30 Years after Service (2D) 


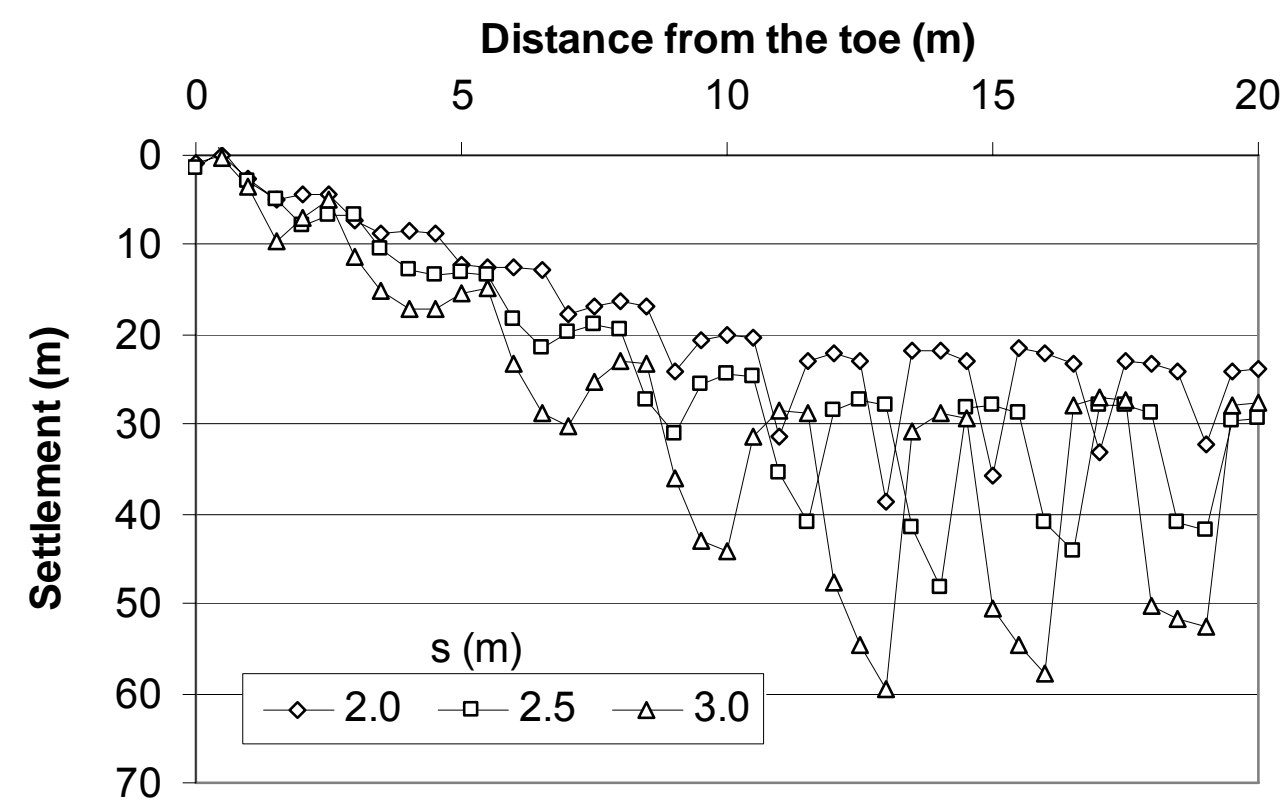

(b) At the base

Fig. 4-43. Settlement Profiles for Various Column Spacing at 30 Years after Service (2D) (continued)

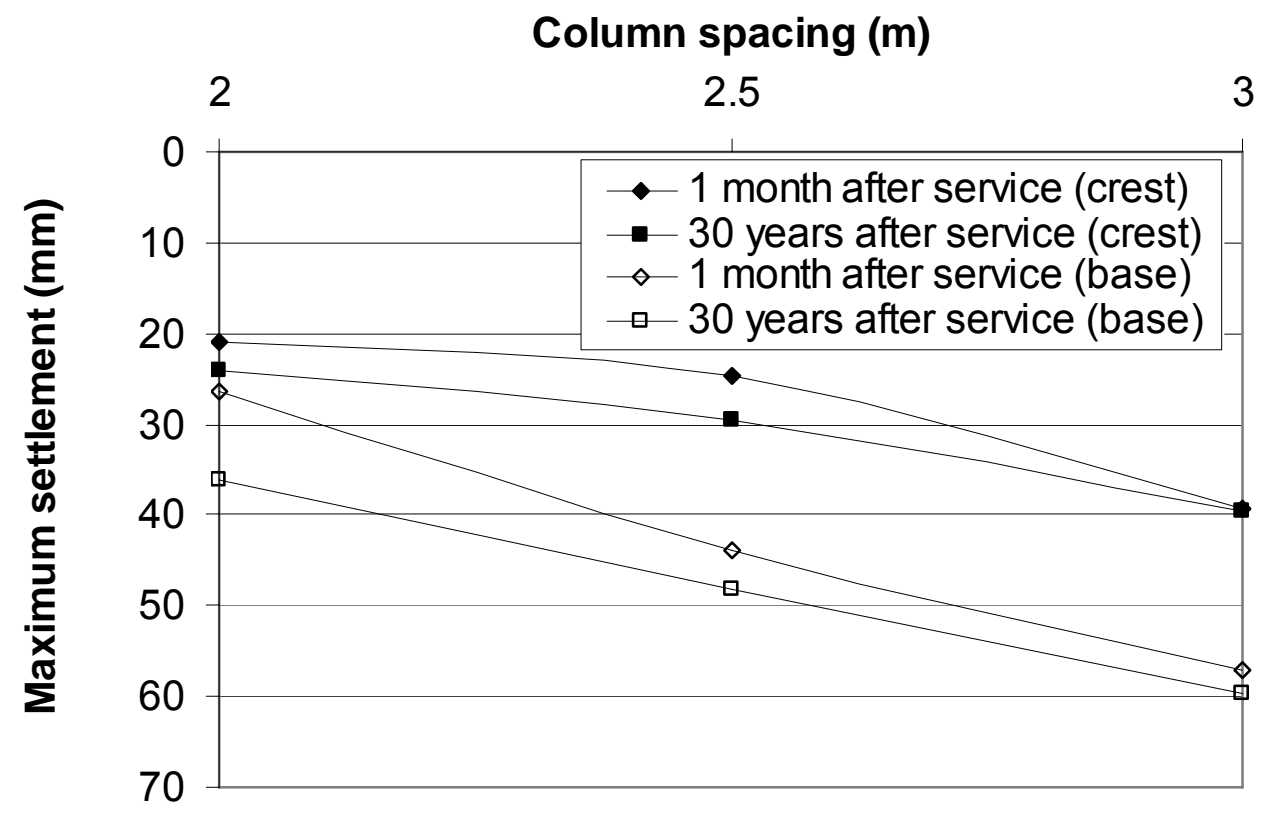

Fig. 4-44. Maximum Settlement versus Column Spacing (2D) 


\section{Column spacing $(\mathrm{m})$}

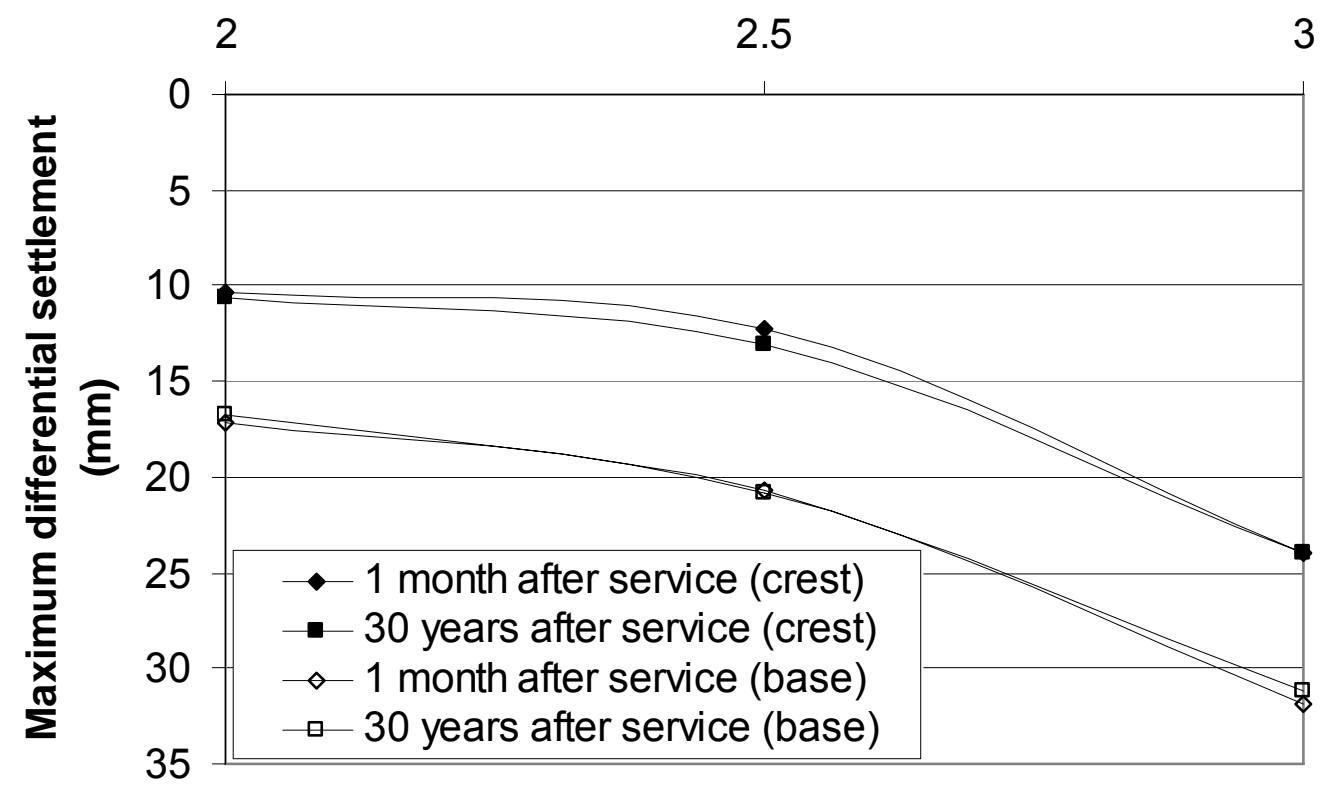

Fig. 4-45. Maximum Differential Settlement versus Column Spacing (2D)

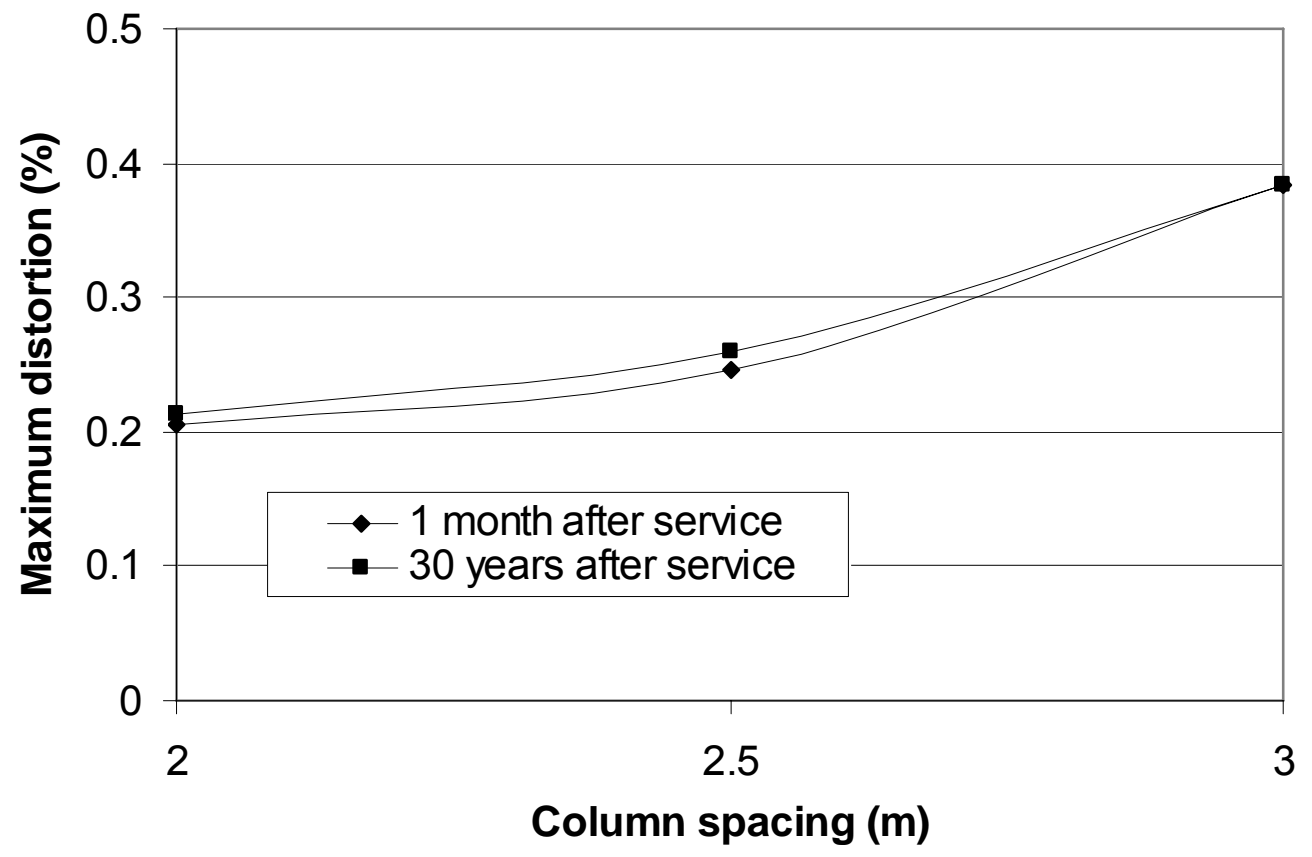

Fig. 4-46. Maximum Distortion on the Crest versus Column Spacing (2D) 
The maximum distortion is plotted against the column spacing in Fig. 4-46 to investigate the influence of the column spacing on the distortion. It is shown that the column spacing had a noticeable influence on the distortion and the larger column spacing had the greater distortion.

\section{Influence of Geosynthetic Tensile Stiffness}

Geosynthetic tensile stiffness, J, is an important material property of geosynthetics. Depending on the type of geosynthetic used, the tensile stiffness can vary greatly. In this study, the tensile stiffness varied from zero to $10,000 \mathrm{kN} / \mathrm{m}$. Zero tensile stiffness represents a case without reinforcement, while $10,000 \mathrm{kN} / \mathrm{m}$ is almost the highest tensile stiffness of geosynthetics available in the current market.

Figures 4-47 and 4-48 present the settlement profiles at the base and on the crest of the embankment using one layer geosynthetic at different tensile stiffness. Clearly, the influence of the geosynthetic tensile stiffness on the settlement was limited. Especially for the geosynthetic at the tensile stiffness from 1,000 to $10,000 \mathrm{kN} / \mathrm{m}$, the reduction in the settlement on the crest was almost negligible. This finding is more clearly demonstrated in Figs. 4-49 and 4-50. Even though the geosynthetic tensile stiffness had some impact on the settlement at the base, its influence on the settlement at the crest was much less. 


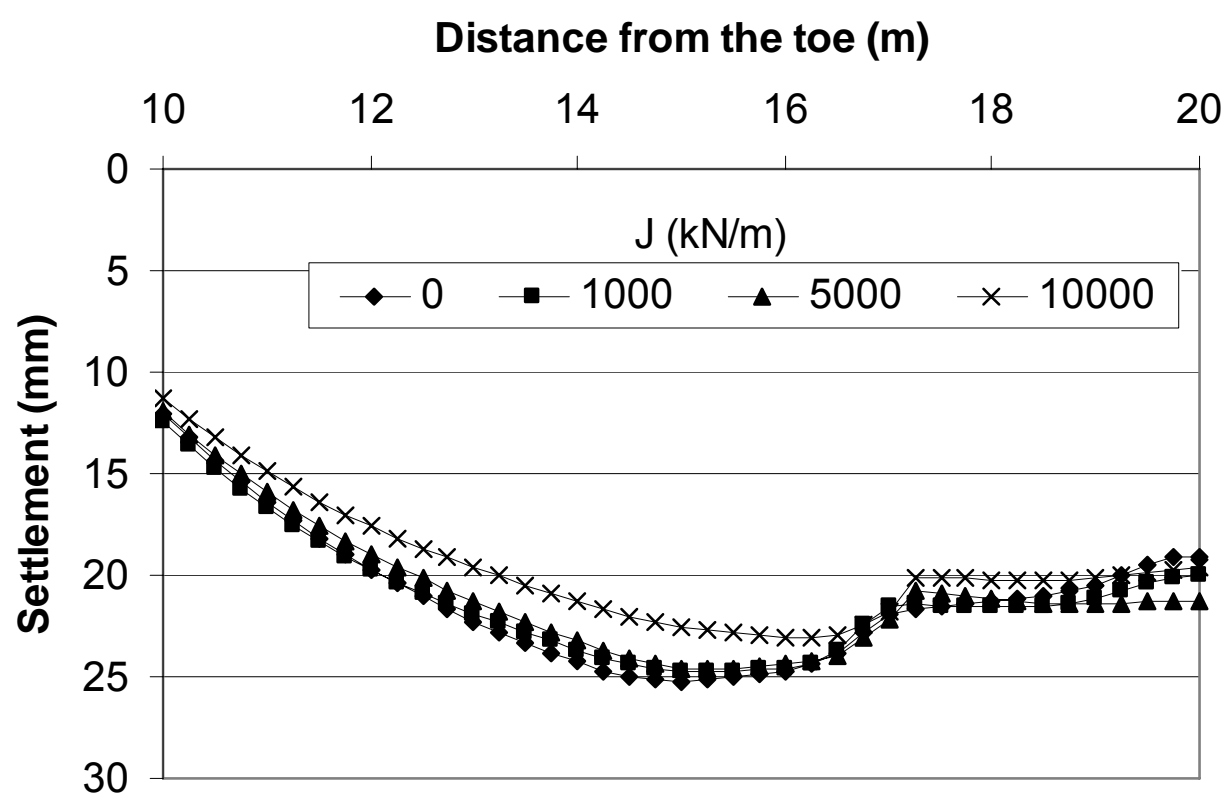

(a) On the crest

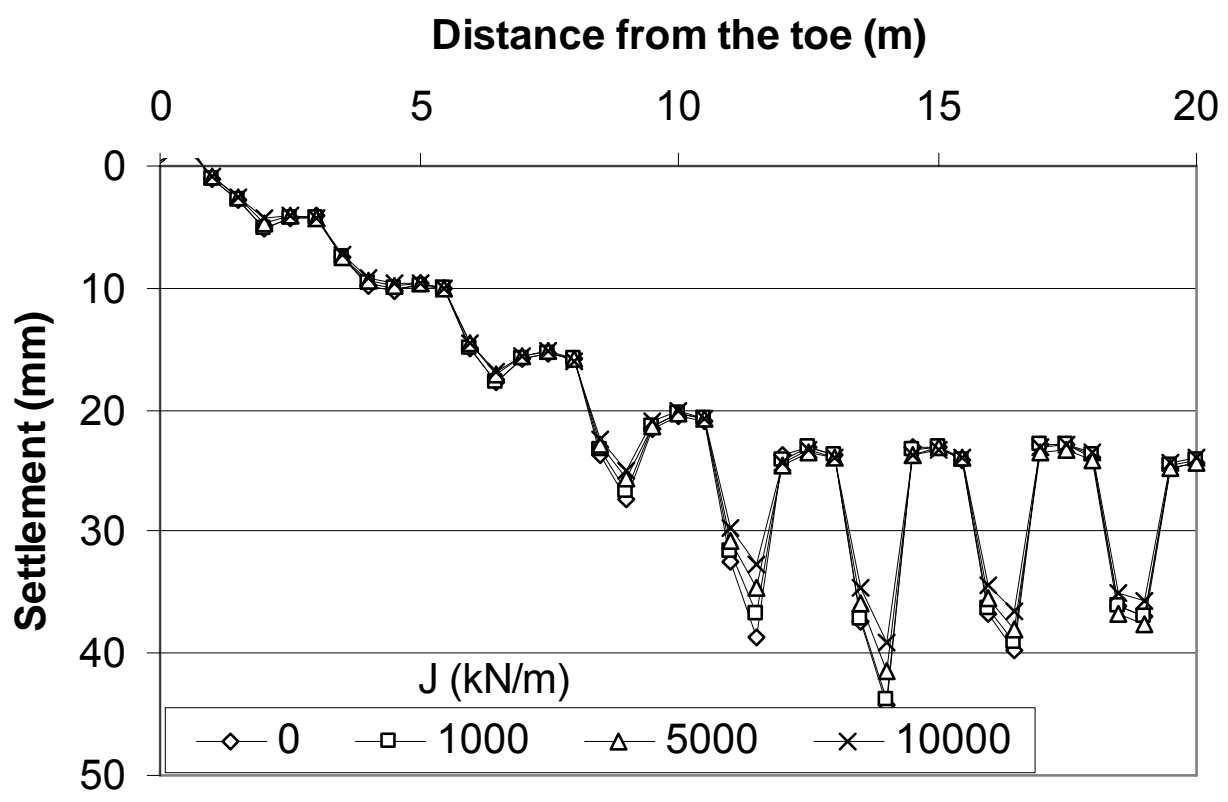

(b) At the base

Fig. 4-47. Settlement Profiles for Various Tensile Stiffness at 1 Month after Service (2D) 


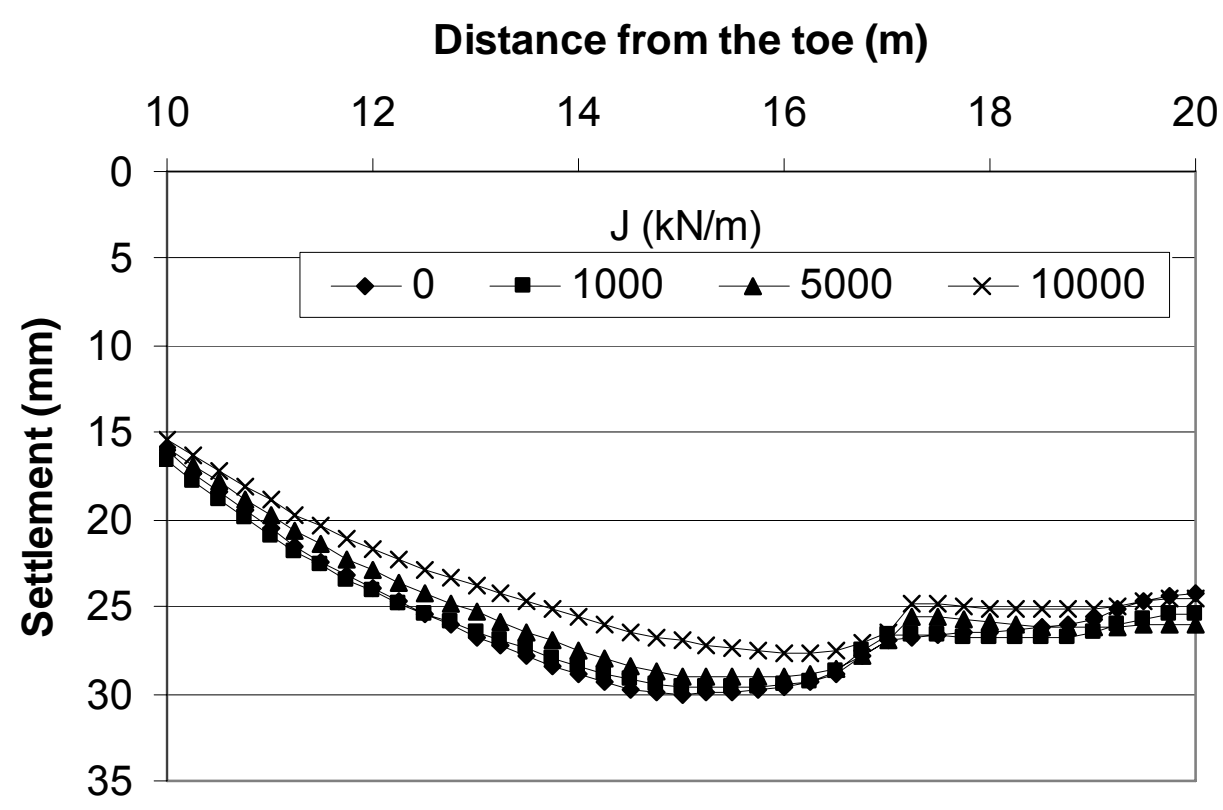

(a) On the crest

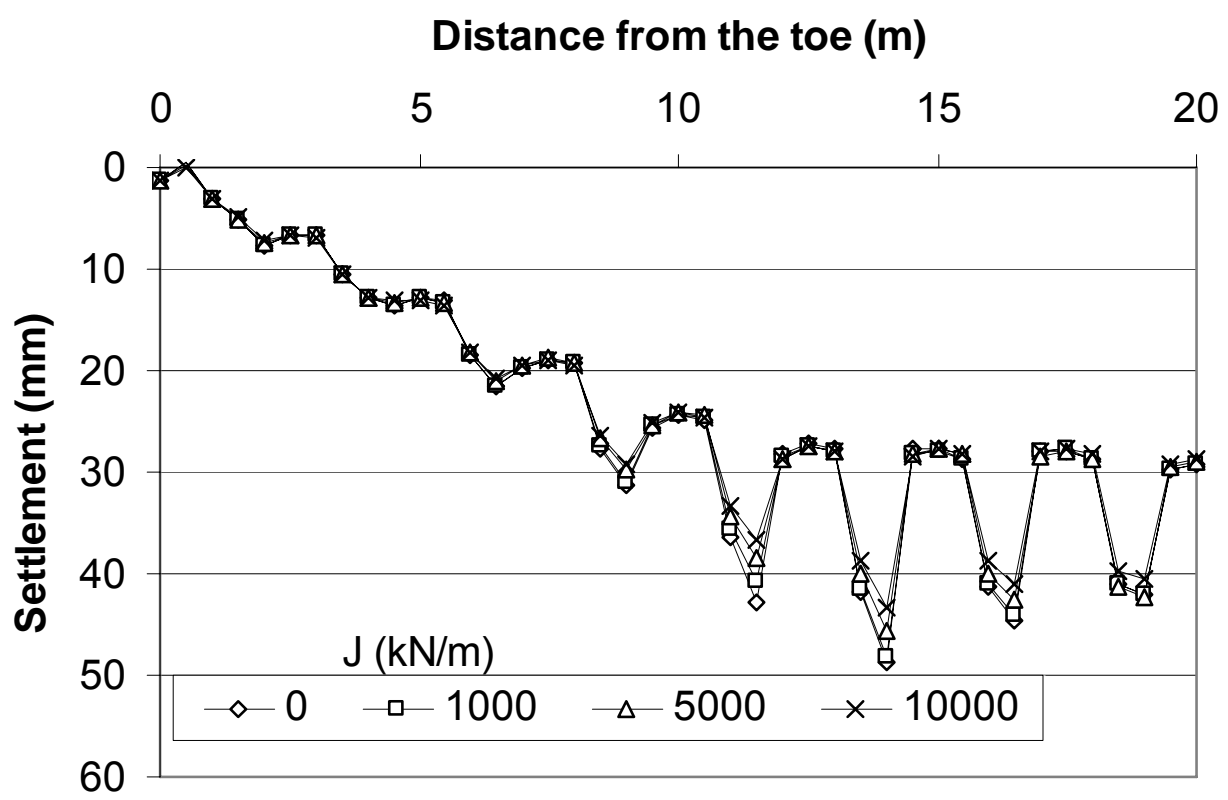

(b) At the base

Fig. 4-48. Settlement Profiles for Various Tensile Stiffness at 30 Years after Service (2D) 


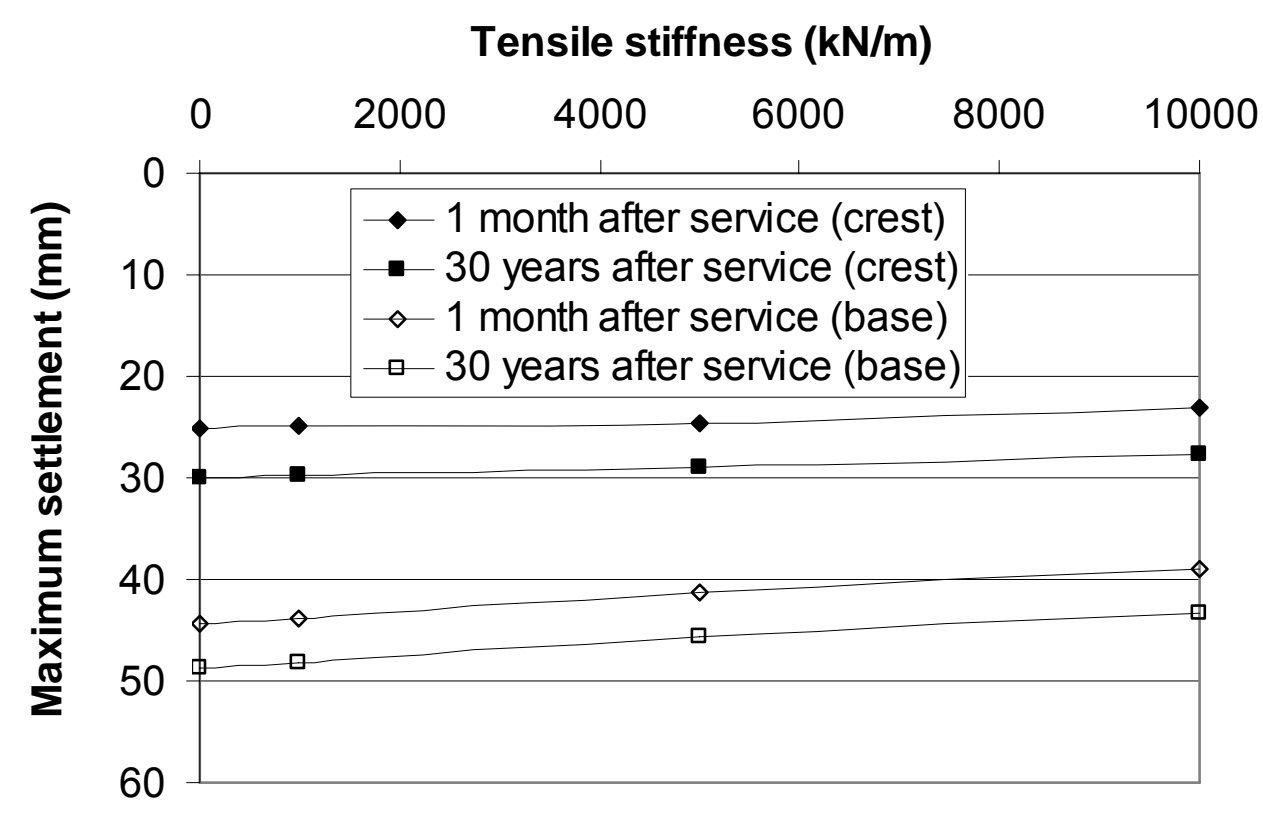

Fig. 4-49. Maximum Settlement versus Tensile Stiffness (2D)

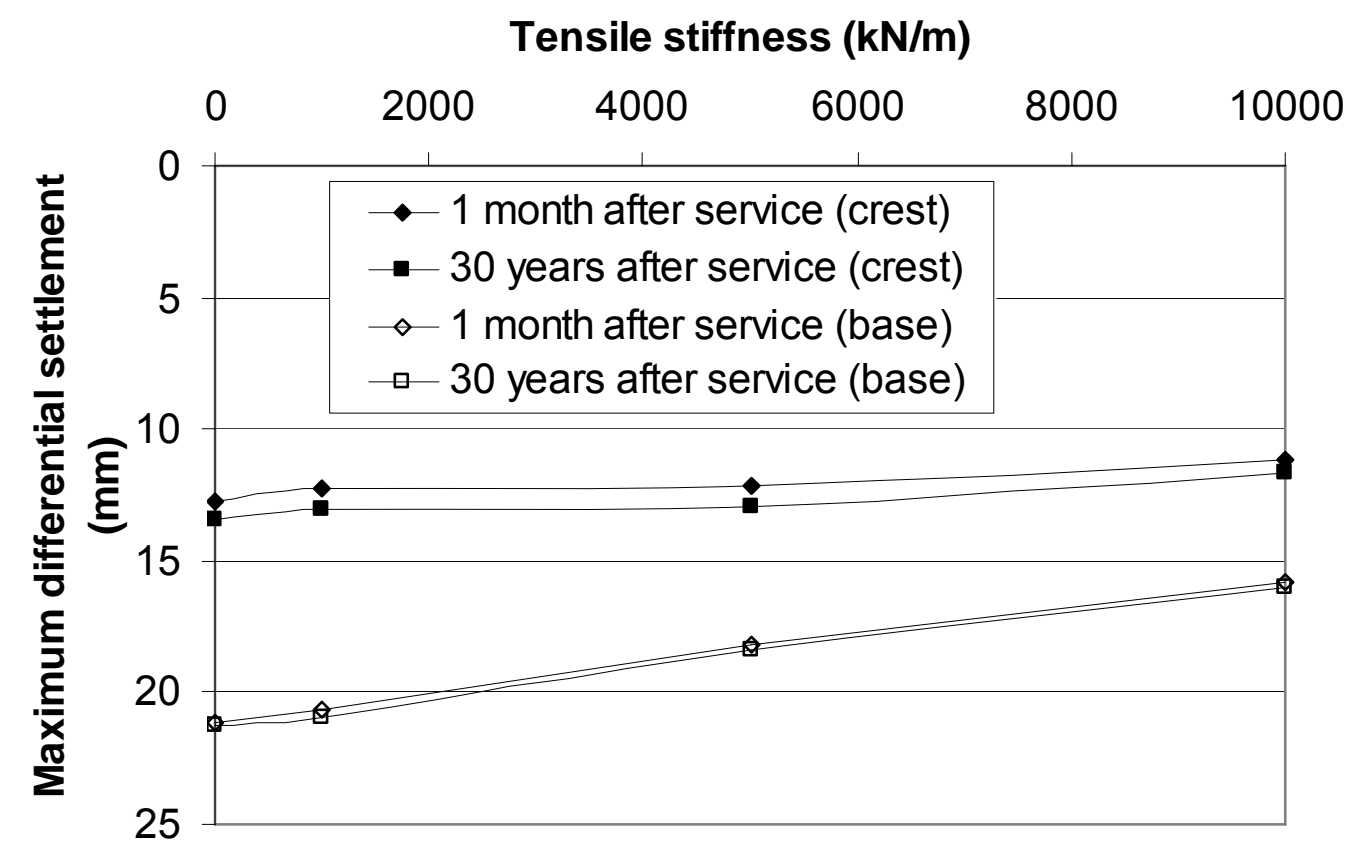

Fig. 4-50. Maximum Differential Settlement versus Tensile Stiffness (2D) 
Similar to its negligible influence on the differential settlement, the geosynthetic tensile stiffness also exhibited negligible influence on the distortion as shown in Fig. $4-51$.

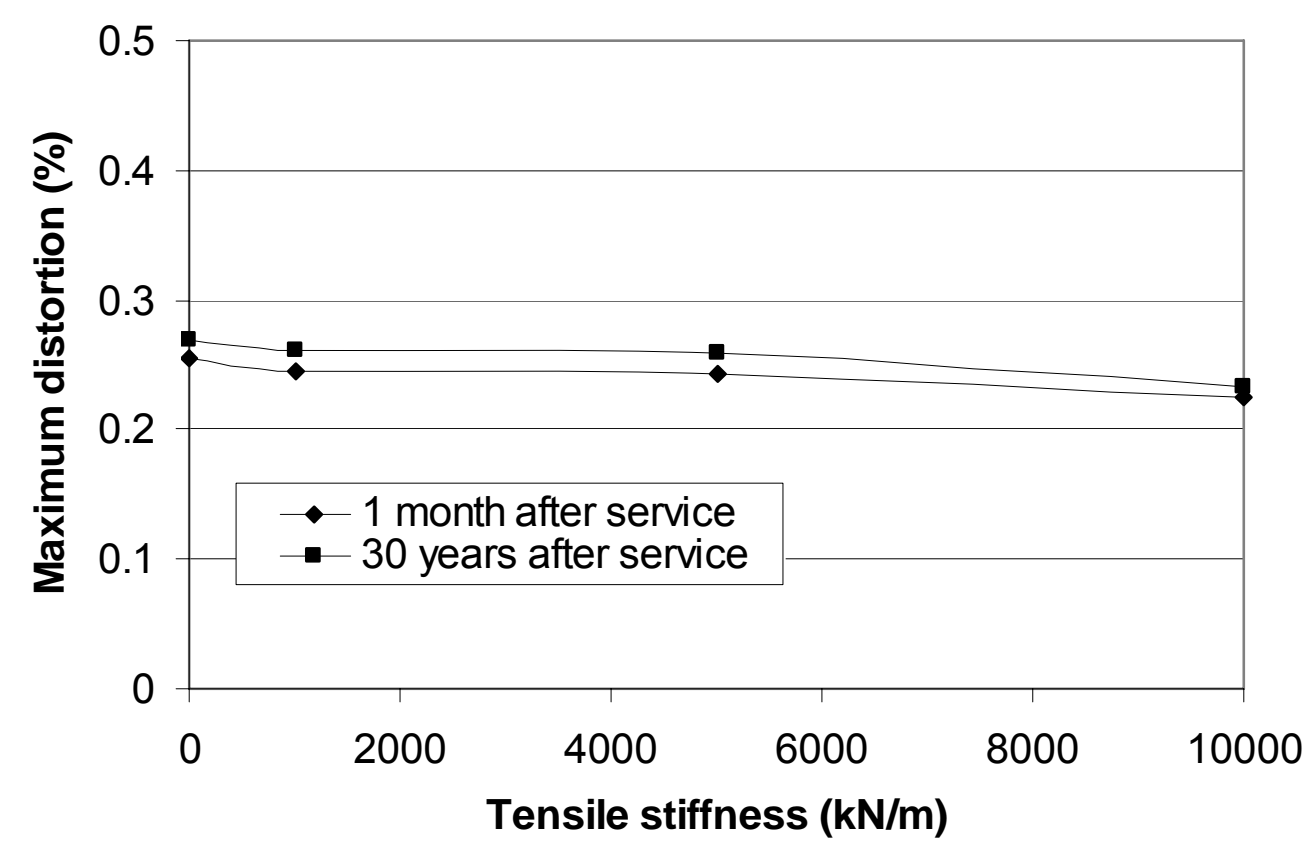

Fig. 4-51. Maximum Distortion on the Crest versus Tensile Stiffness (2D)

\section{Influence of Construction Rate}

In addition to soil properties (elastic modulus, friction angle, and permeability) and column dimensions and properties (spacing and elastic modulus), the rate of construction can have profound influence on the performance of the GRCS embankments. In this study, one of the most important construction parameters, the average construction rate, was investigated. The average construction rate here was 
defined as the thickness of the lift built in unit time. As discussed earlier in the baseline case, the embankment was built into five stages of equal thickness, i.e., $1 \mathrm{~m}$ at each stage. The duration of each stage was one month. Therefore, the average construction rate for the baseline case was 1 meter/mon, which is the rate commonly used in practice. In this study, the average construction rate of the baseline case decreased to one-fourth (i.e., $0.25 \mathrm{~meter} / \mathrm{mon}$ ) and increased to 4 times (i.e., 4meter/mon) to represent the prolonged construction and the fast construction, respectively.

The influence of the average construction rate on the settlements is shown in Fig. 4$52,4-53,4-54$, and 4-55, which show that the higher construction rate induced greater settlement. As compared with the effect of soil permeability, the lower average construction rate had the effect on the accumulated less excess pore water pressure, which is similar to the effect of the higher permeability of the soil as discussed in the permeability section. Figure 4-52 also shows that the settlements of columns were smaller but the settlements of the soft soil were larger at a higher average construction rate. The same explanation can be offered as that stated in the permeability section. 
Distance from the toe $(\mathrm{m})$

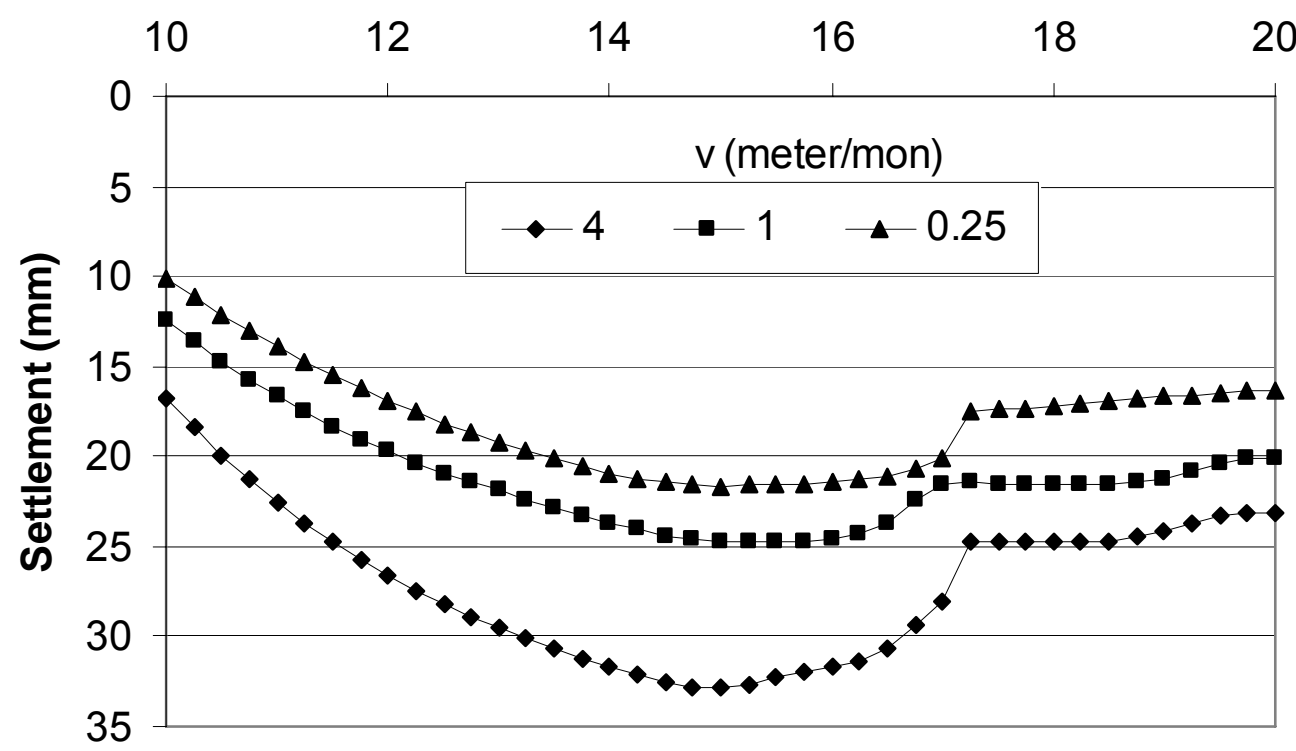

(a) On the crest

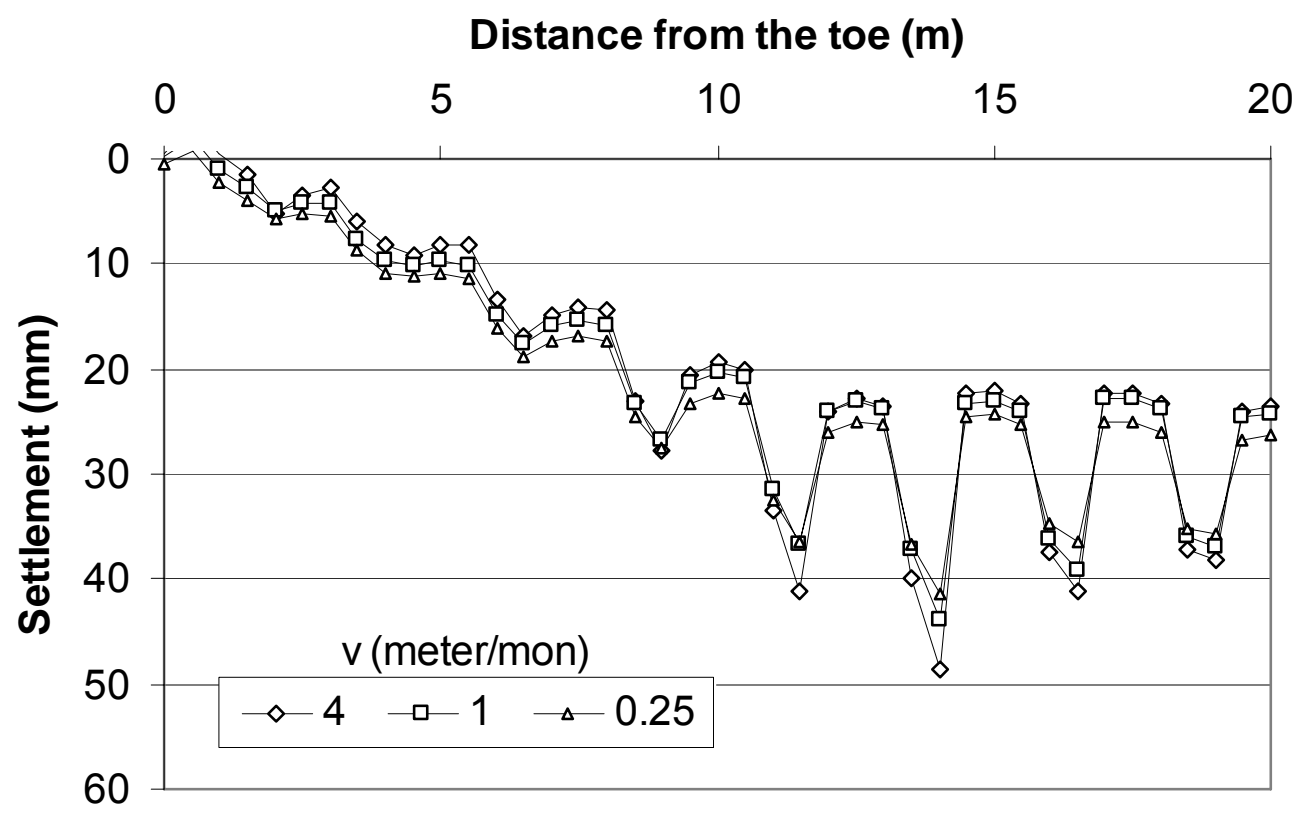

(b) At the base

Fig. 4-52. Settlement Profiles for Various Average Construction Rates at 1 Month after Service (2D) 


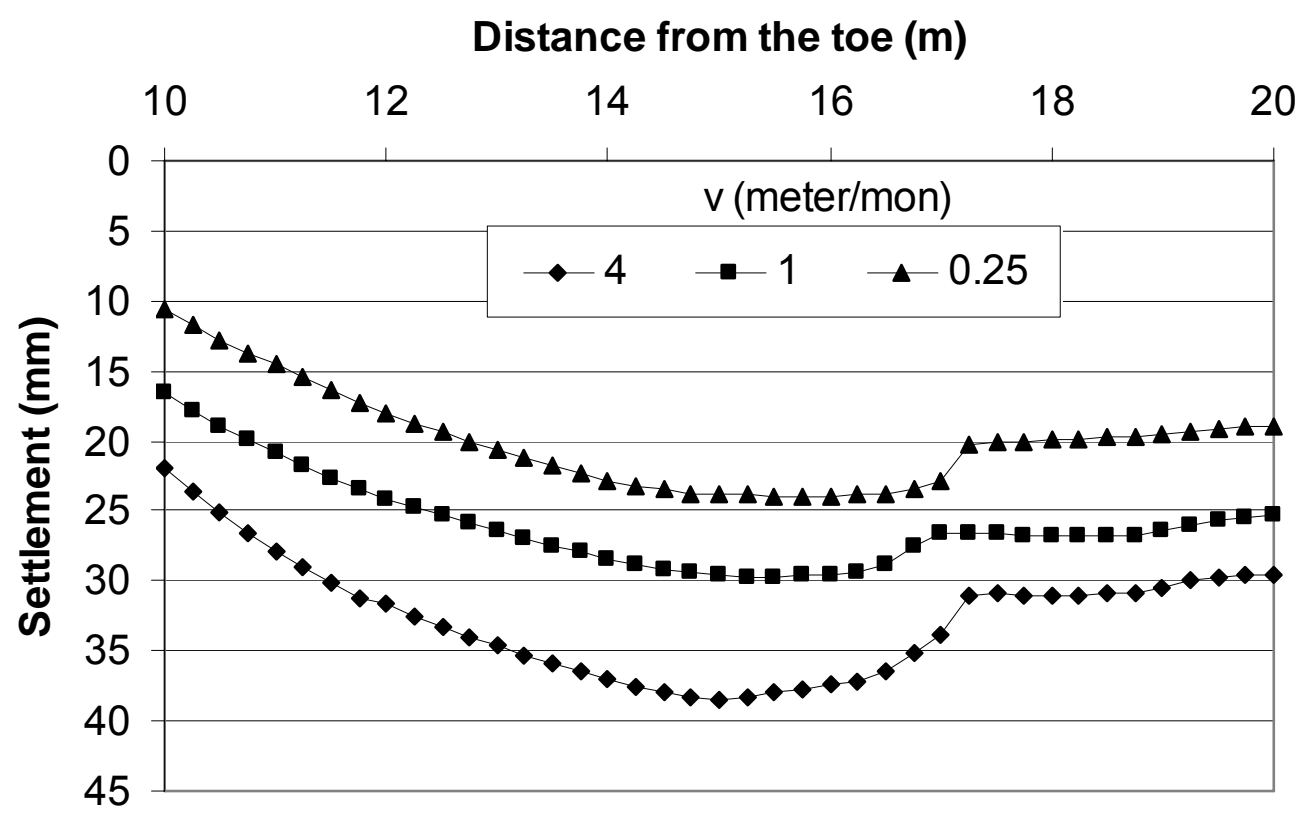

(a) On the crest

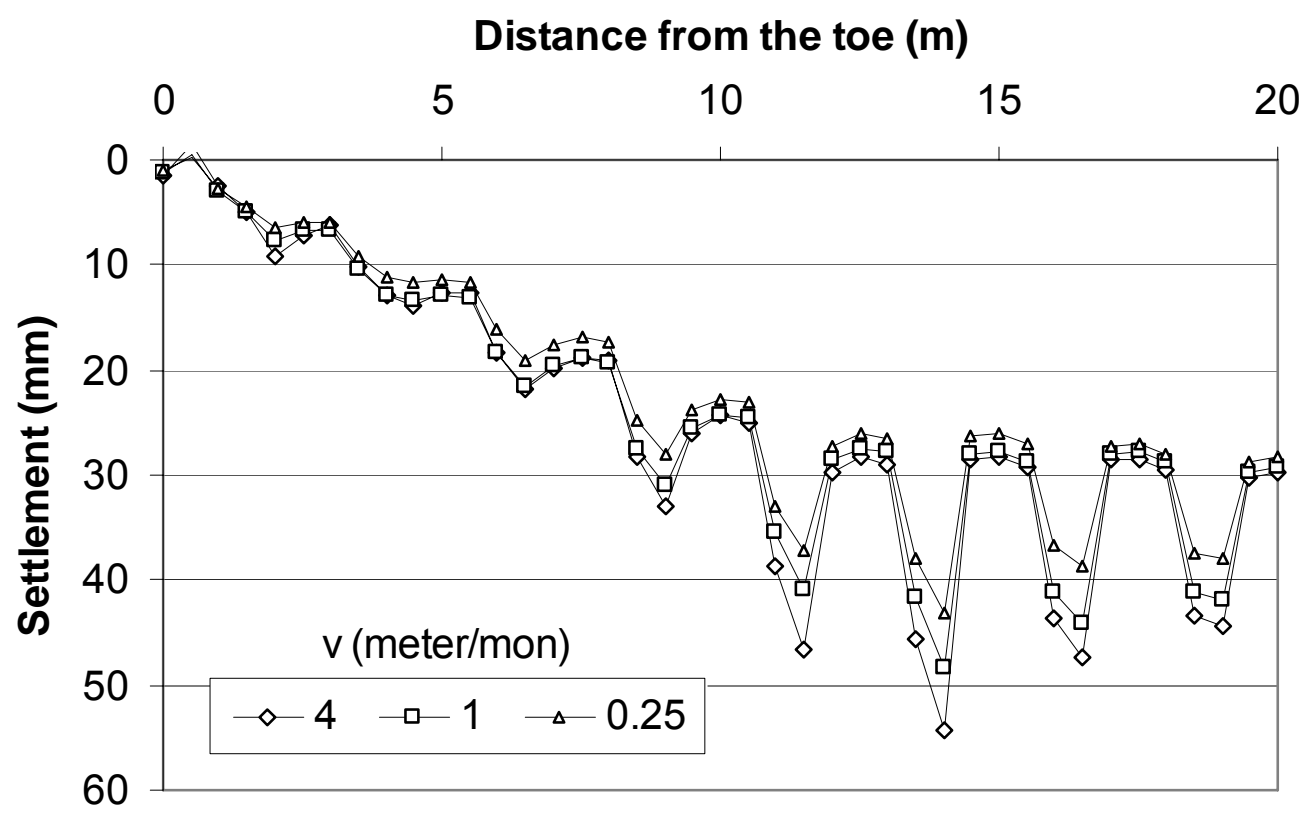

(b) At the base

Fig. 4-53. Settlement Profiles for Various Average Construction Rates at 30 Years after Service (2D) 


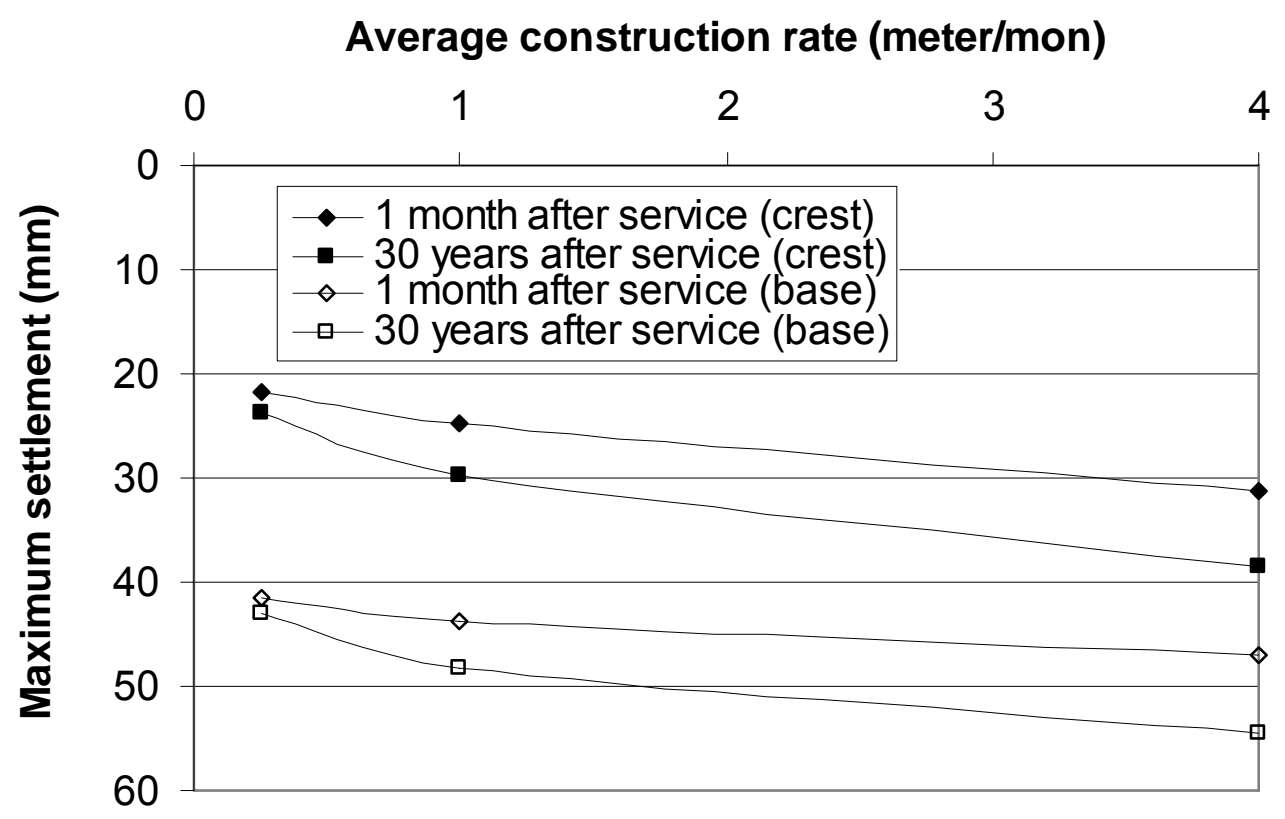

Fig. 4-54. Maximum Settlement versus Average Construction Rate (2D)

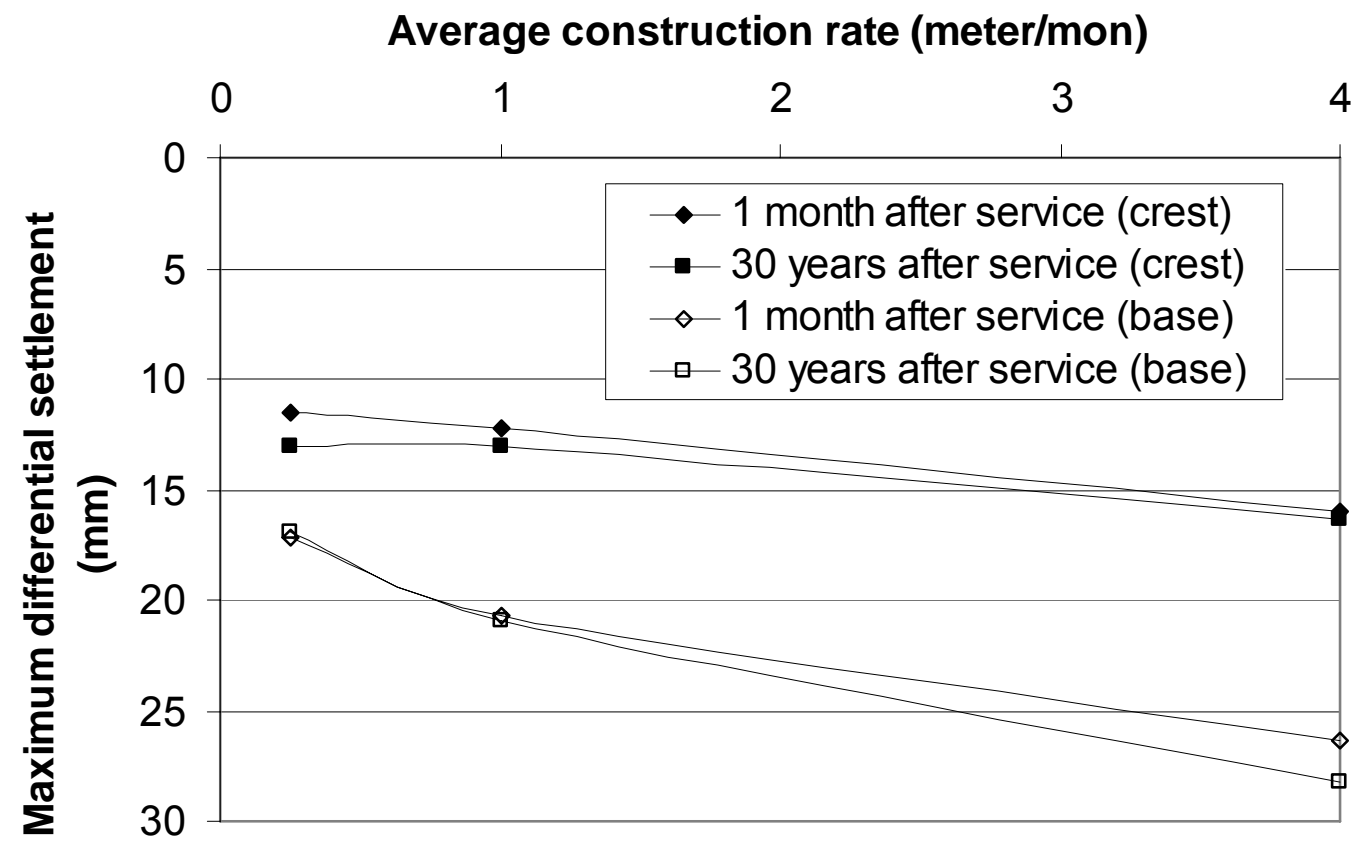

Fig. 4-55. Maximum Differential Settlement versus Average Construction Rate (2D) 
The influence of the average construction rate on the maximum distortion is presented in Fig. 4-56. The lower average construction rate yielded the smaller maximum distortion.

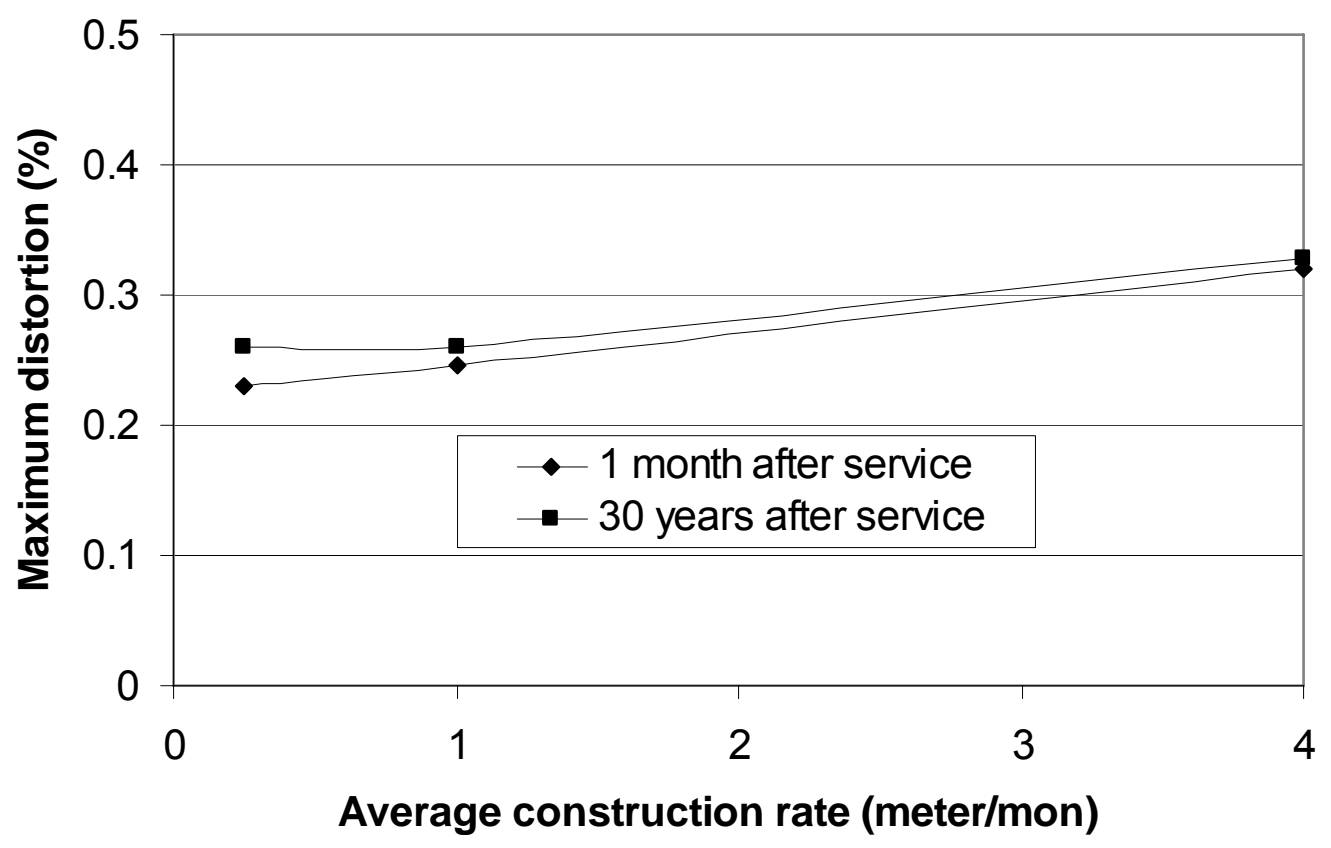

Fig. 4-56. Maximum Distortion on the Crest versus Average Construction Rate (2D)

\subsubsection{Tension Developed in Geosynthetics}

In the GRCS embankment, geosynthetic reinforcement plays dual functions. Primarily, it works a flexible layer bridging over soft soil to transfer load from the soft soil to the columns. This function has been widely accepted and considered in the 
design. Secondarily, it can counteract lateral spreading of the embankment fill. Hence, the tension developed in the geosynthetic reinforcement is the resultant of the tension induced by these two effects.

Tension in geosynthetic reinforcement is one of the focuses in research and design. In a few GRCS embankment projects, the tension in the geosynthetic reinforcement was monitored by strain gauges. The level of tension developed in geosynthetic reinforcement may have some influence on its creep behavior, which needs to be accounted for in some applications. However, the creep behavior is beyond the scope of this study. In this study, the geosynthetic was assumed to have constant tensile stiffness and cross section. The influences of the soft soil modulus, the soil friction angle, the soil permeability, the column modulus, the column spacing, the tensile stiffness of geosynthetic, and the average construction rate on the tension in the geosynthetic reinforcement were investigated.

\section{Influence of Soft Soil Elastic Modulus}

In the 2D parametric study, the geosynthetic sheet was modeled as lineal cable elements and only the tension developed in the direction perpendicular to traffic direction was available. The tension profiles at different soft soil moduli are presented in Fig. 4-57 and the maximum tension against soft soil modulus is presented in Fig. 458. Obviously, the higher soft soil modulus yielded the lower tension in the 
geosynthetic sheet. As discussed in the settlement section, smaller differential settlement occurred at a higher soft soil modulus, as a consequence, the geosynthetic sheet was less stretched and lower tension was generated. Figure 4-57 shows that higher tension in the geosynthetic reinforcement developed over columns, which is consistent with the finding by Han and Gabr (2002). It is also shown that the maximum tension developed at a certain distance from the centerline of the embankment, which is consistent with the location of the maximum settlement at the base of the embankment. In addition, the tension was almost unchanged from one month to 30 years after service. This phenomenon implies that the post-construction consolidation had a limited effect on the tension in the geosynthetic reinforcement.

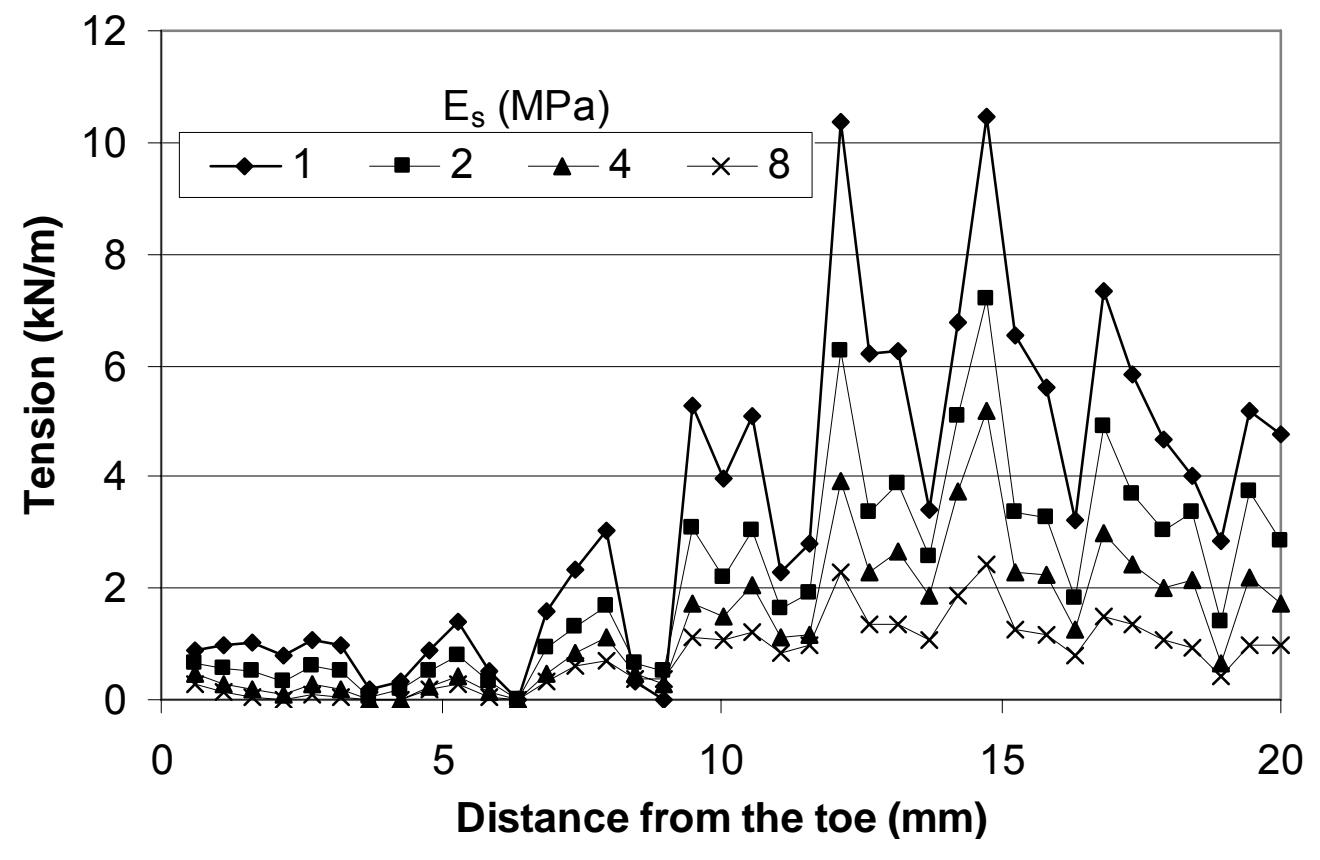

(a) 1 month after service

Fig. 4-57. Tension Profiles for Various Soil Moduli at 1 Month and 30 Years after Service (2D) 


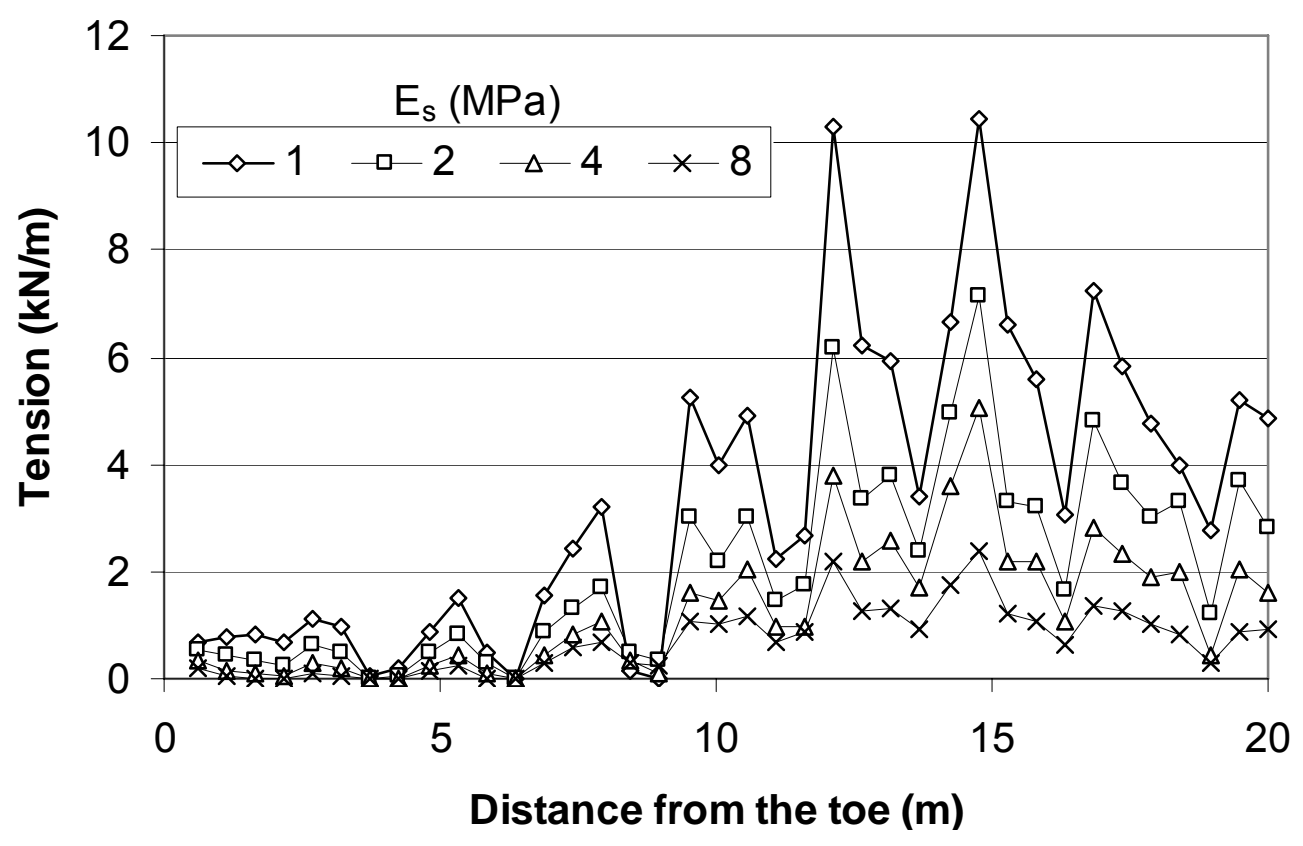

(b) 30 years after service

Fig. 4-57. Tension Profiles for Various Soil Moduli at 1 Month and 30 Years after Service (2D) (continued)

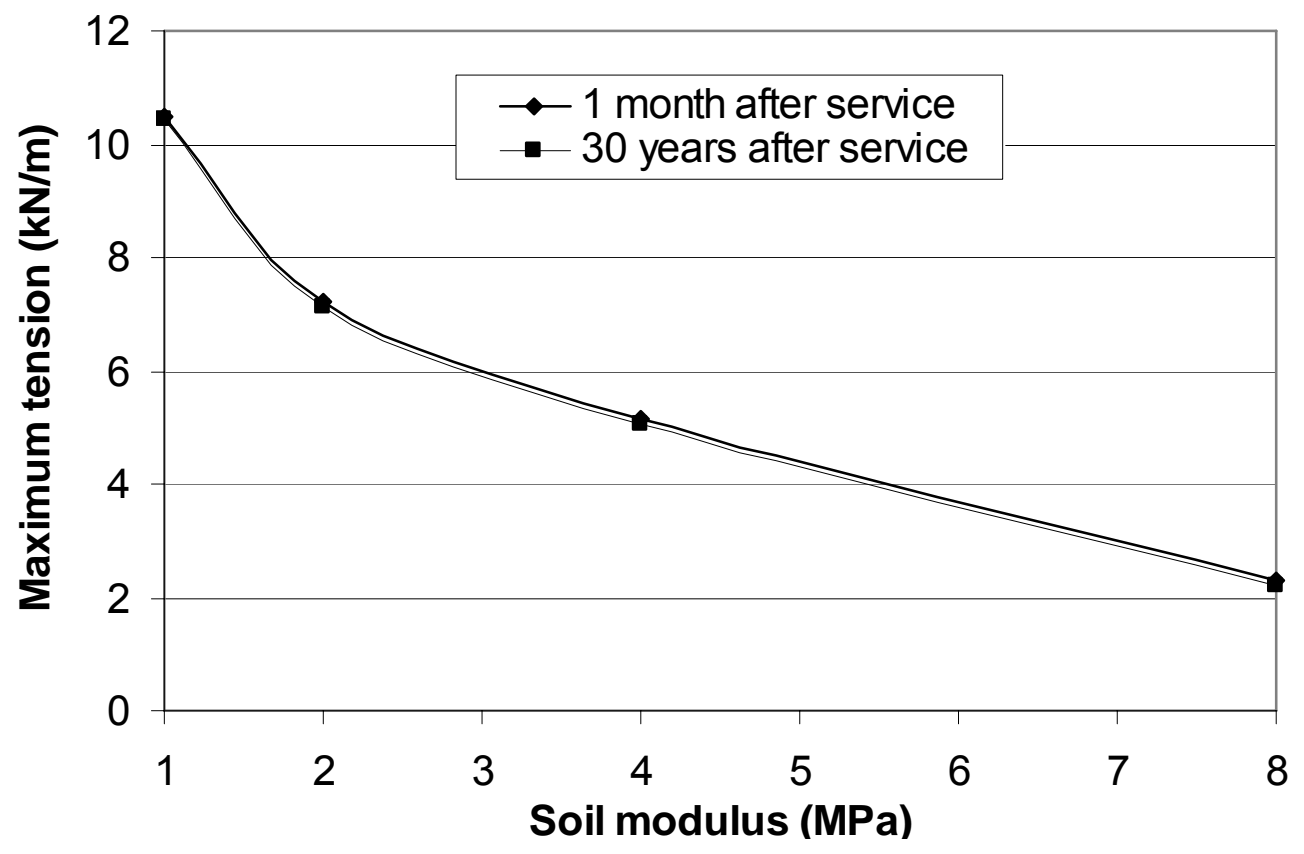

Fig. 4-58. Maximum Tension versus Soil Modulus (2D) 


\section{Influence of Soft Soil Friction Angle}

The tension profiles at different soil friction angles are presented in Fig 4-59. It is shown that the tension developed at the soil friction angle from $20^{\circ}$ to $30^{\circ}$ was close. However, the tension developed at the soil friction angle of $15^{\circ}$ was much higher than that at the other soil friction angles from $20^{\circ}$ to $30^{\circ}$. This trend can be seen more clearly in Fig. 4-60. This finding is consistent with the development of settlement as discussed earlier, i.e., as long as the soil remained in an elastic state, the soil friction angle would not have much influence on the tension.

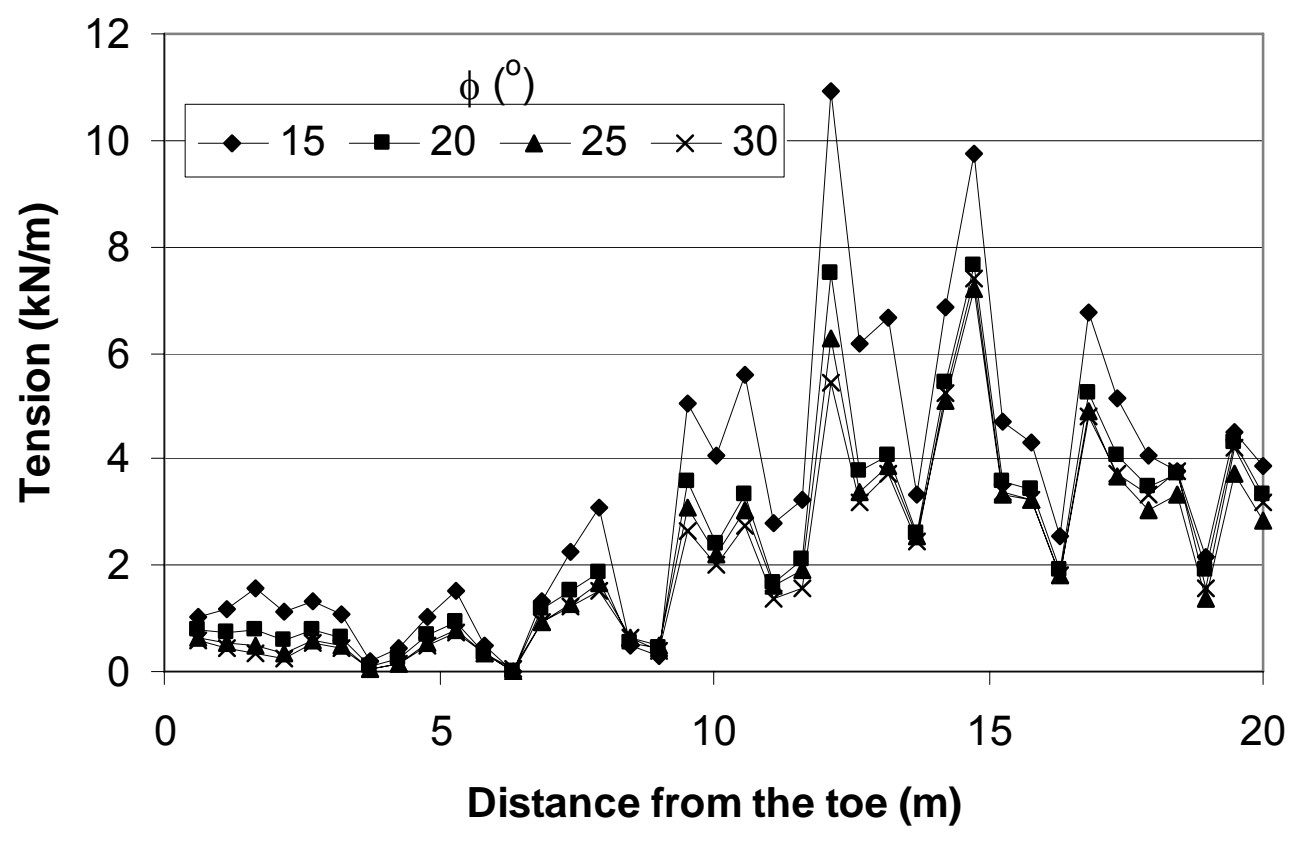

(a) 1 month after service

Fig. 4-59. Tension Profiles for Various Friction Angles at 1 Month and 30 Years after Service (2D) 


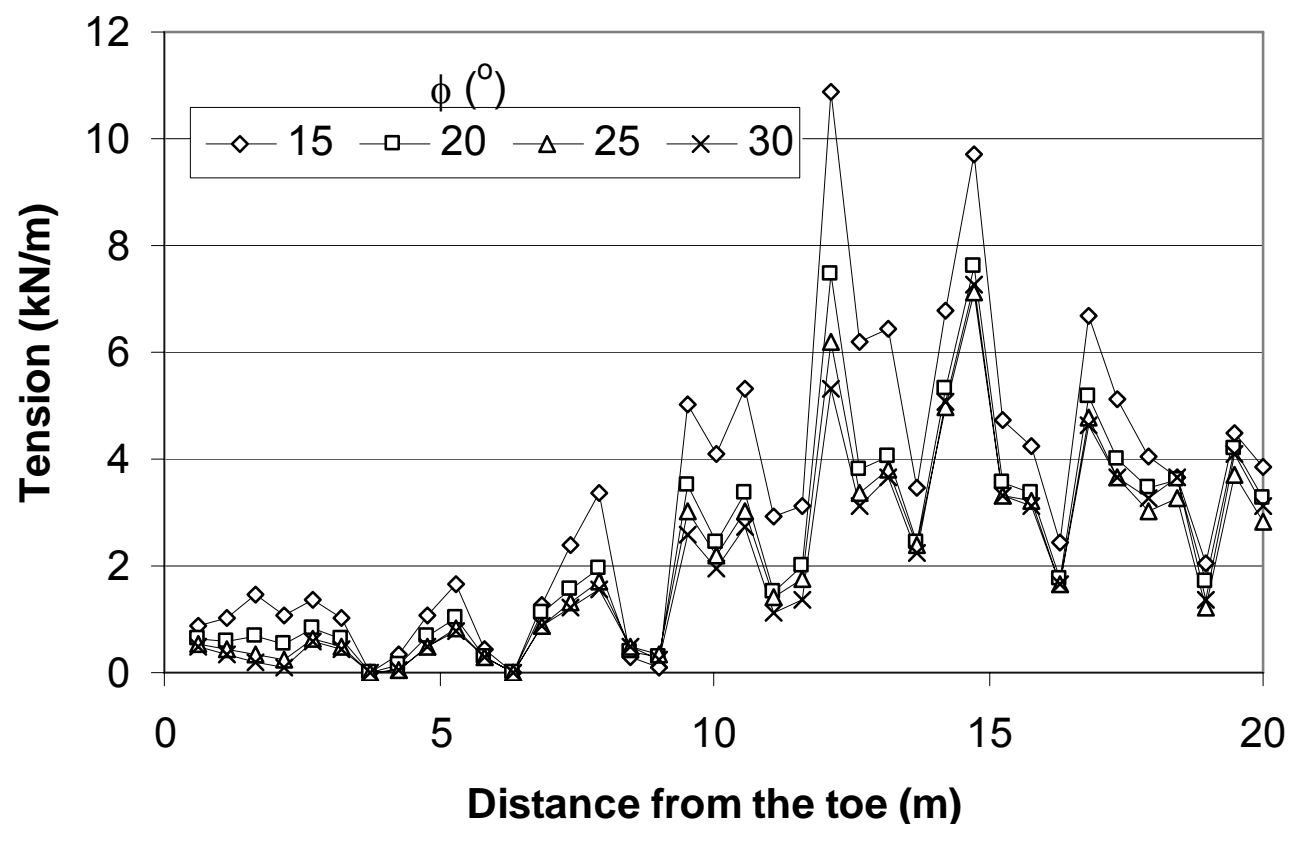

(b) 30 years after service

Fig. 4-59. Tension Profiles for Various Friction Angles at 1 Month and 30 Years after Service (2D) (continued)

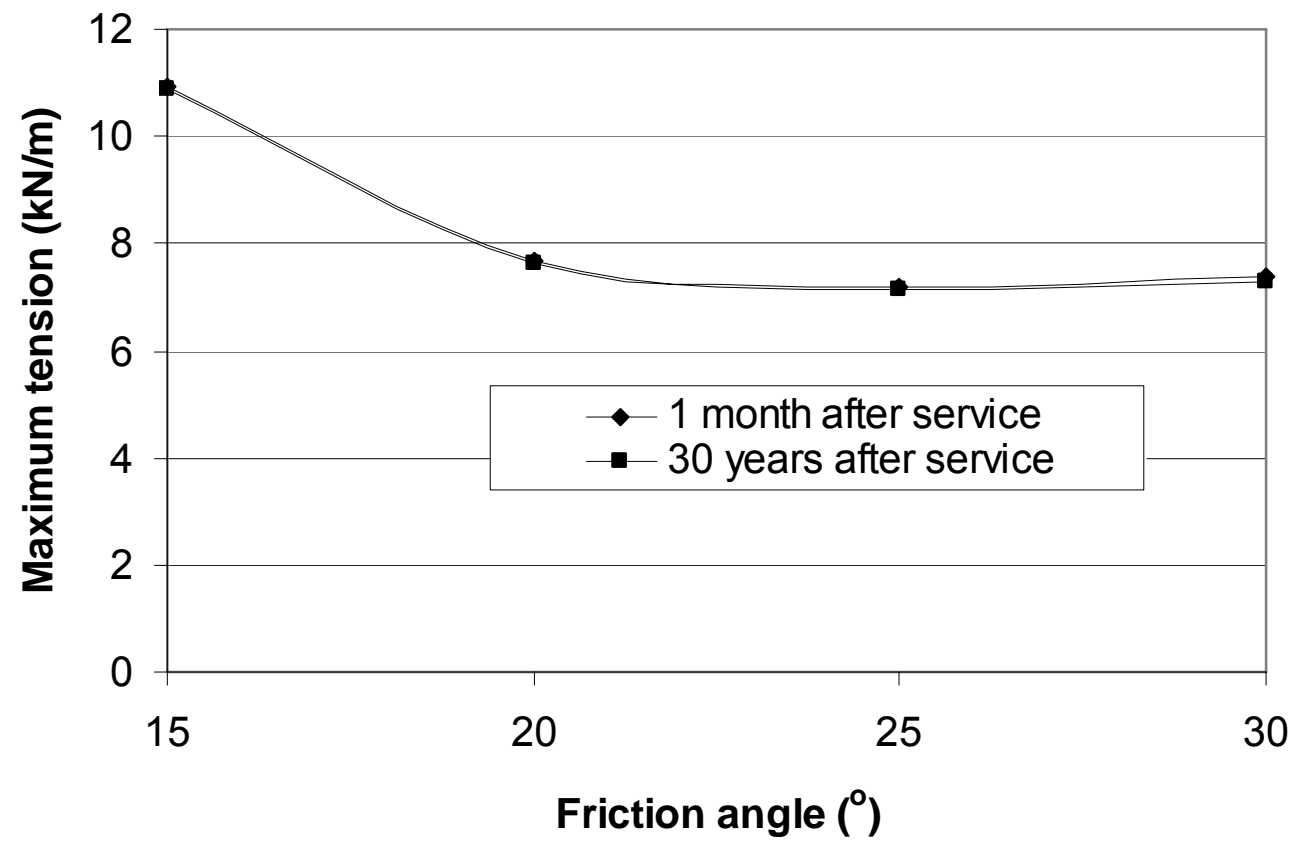

Fig. 4-60. Maximum Tension versus Friction Angle (2D) 


\section{Influence of Soft Soil Permeability}

Related to the lower soil permeability leading to the larger differential settlement at the base, the lower soil permeability also induced the higher tension in the geosynthetic reinforcement as shown in Fig. 4-61 and 4-62. There was a noticeable increase in the maximum tension from one month to 30 years after service at the soil permeability lower or equal to $10^{-10} \mathrm{~m} / \mathrm{s}$. However, this difference became insignificant when the soil permeability was higher than $10^{-10} \mathrm{~m} / \mathrm{s}$. This finding is consistent with the result of the differential settlement from one month to 30 years after service.

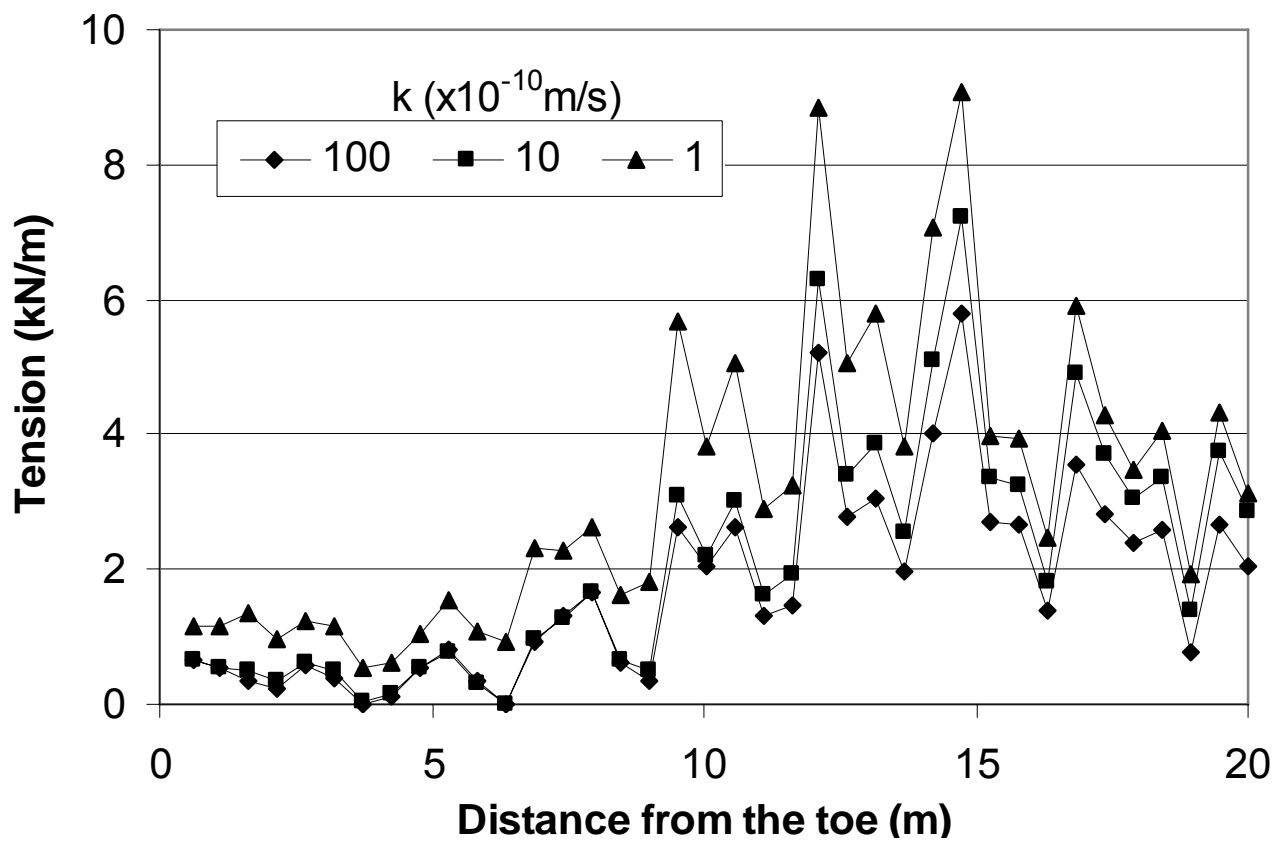

(a) 1 month after service

Fig. 4-61. Tension Profiles for Various Soil Permeability at 1 Month and 30 Years after Service (2D) 


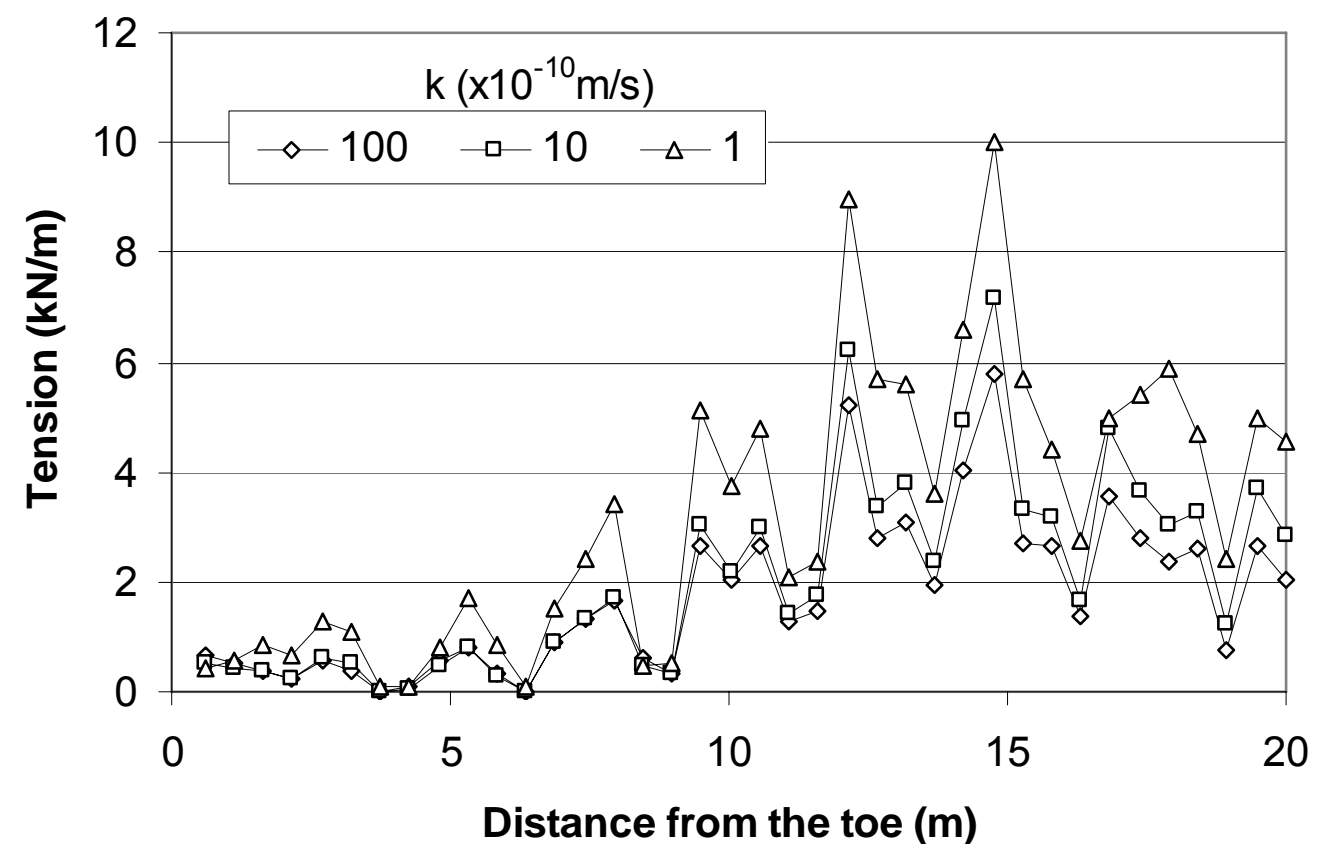

(b) 30 years after service

Fig. 4-61. Tension Profiles for Various Soil Permeability at 1 Month and 30 Years after Service (2D) (continued)

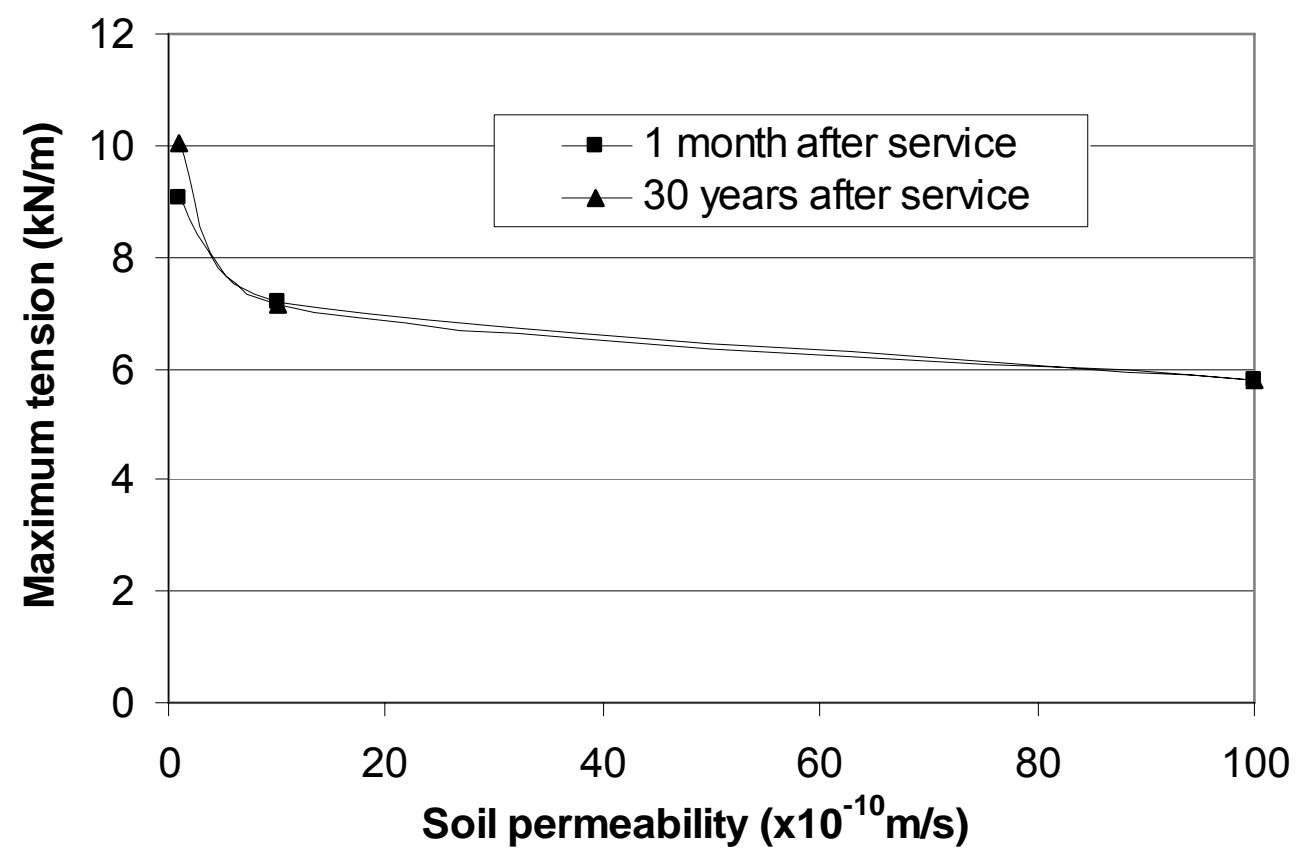

Fig. 4-62. Maximum Tension versus Soil Permeability (2D) 


\section{Influence of Column Elastic Modulus}

Similar to the influence on the differential settlement at the base, the column modulus had a very limited influence on the tension in the geosynthetic reinforcement. Compared with the soft soil, the columns in this study were rigid enough to help the development of stable soil arching. As a consequence, the increase of column modulus did not considerably reduce the load carried by the geosynthetic reinforcement. Consolidation of the soft soil did not have any significant influence on the maximum tension either as shown in Fig. 4-64.

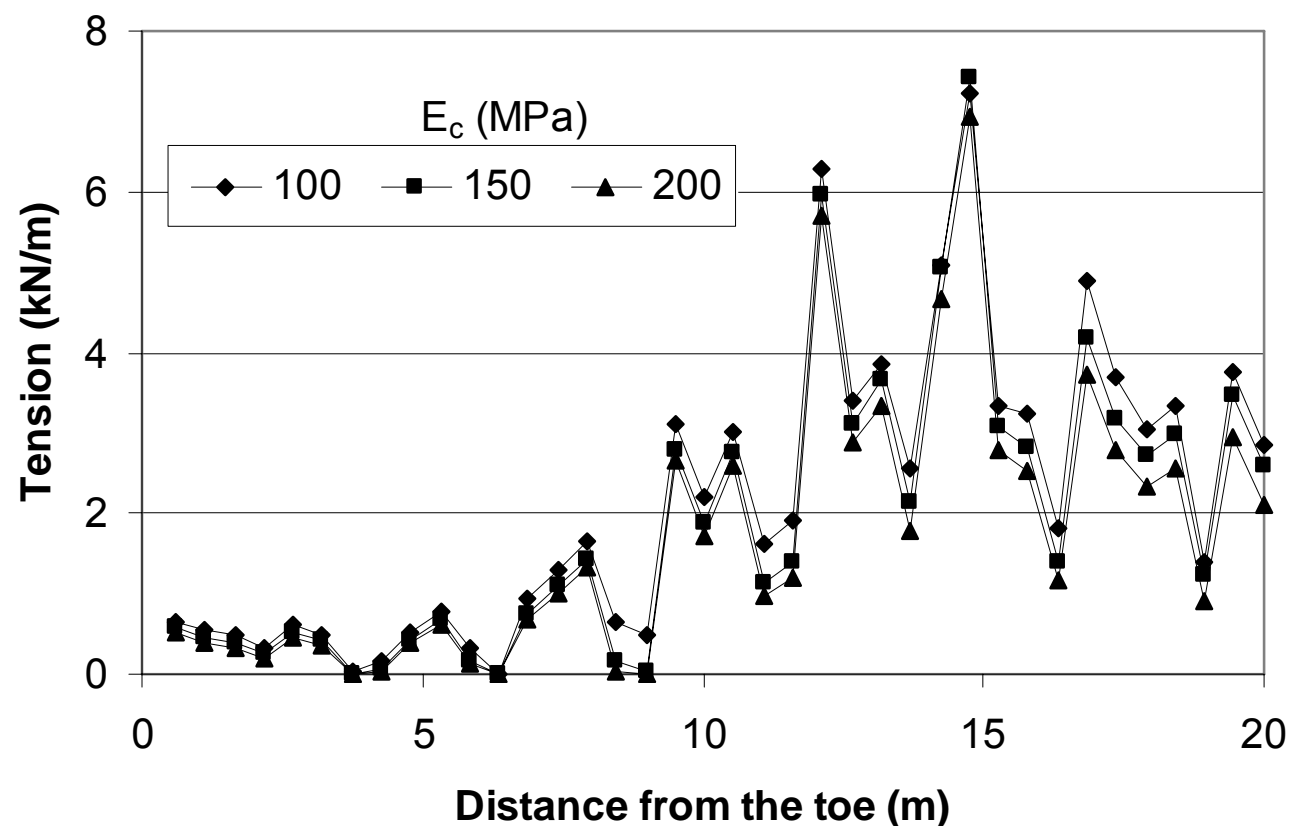

(a) 1 month after service

Fig. 4-63. Tension Profiles for Various Column Moduli at 1 Month and 30 Years after Service (2D) 


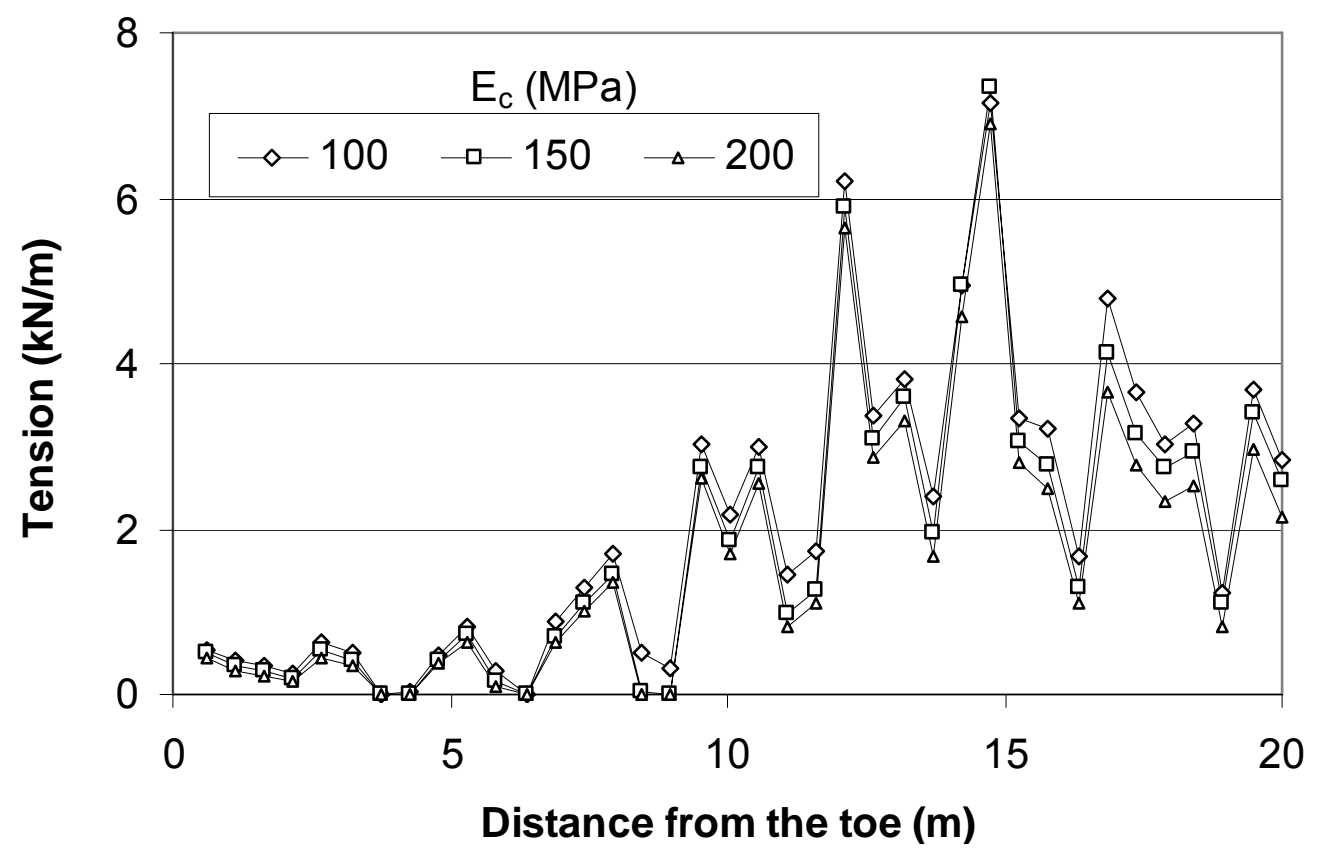

(b) 30 years after service

Fig. 4-63. Tension Profiles for Various Column Moduli at 1 Month and 30 Years after Service (2D) (continued)

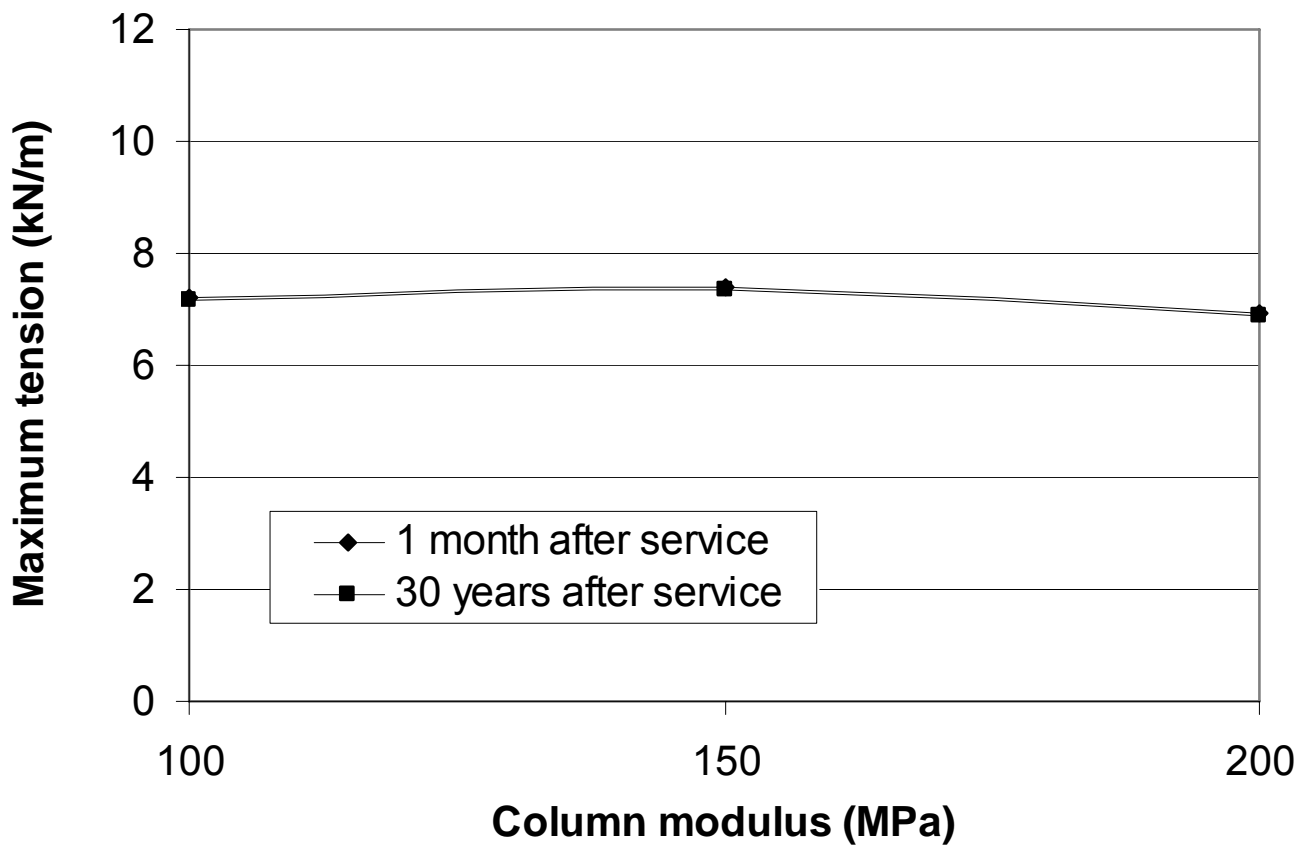

Fig. 4-64. Maximum Tension versus Column Modulus (2D) 


\section{Influence of Column Spacing}

As discussed earlier, the column spacing at a fixed column size is directly related to the area replacement ratio. Figures 4-65 and 4-66 present the tension profiles at different column spacing. Due to the difference in the column spacing, the maximum tension did not occur at the same location. However, it was located over a column and at a certain distance from the centerline. Figure 4-66 shows that the larger spacing yielded the higher maximum tension. In addition, the consolidation had a limited influence on the maximum tension within the range of the column spacing investigated.

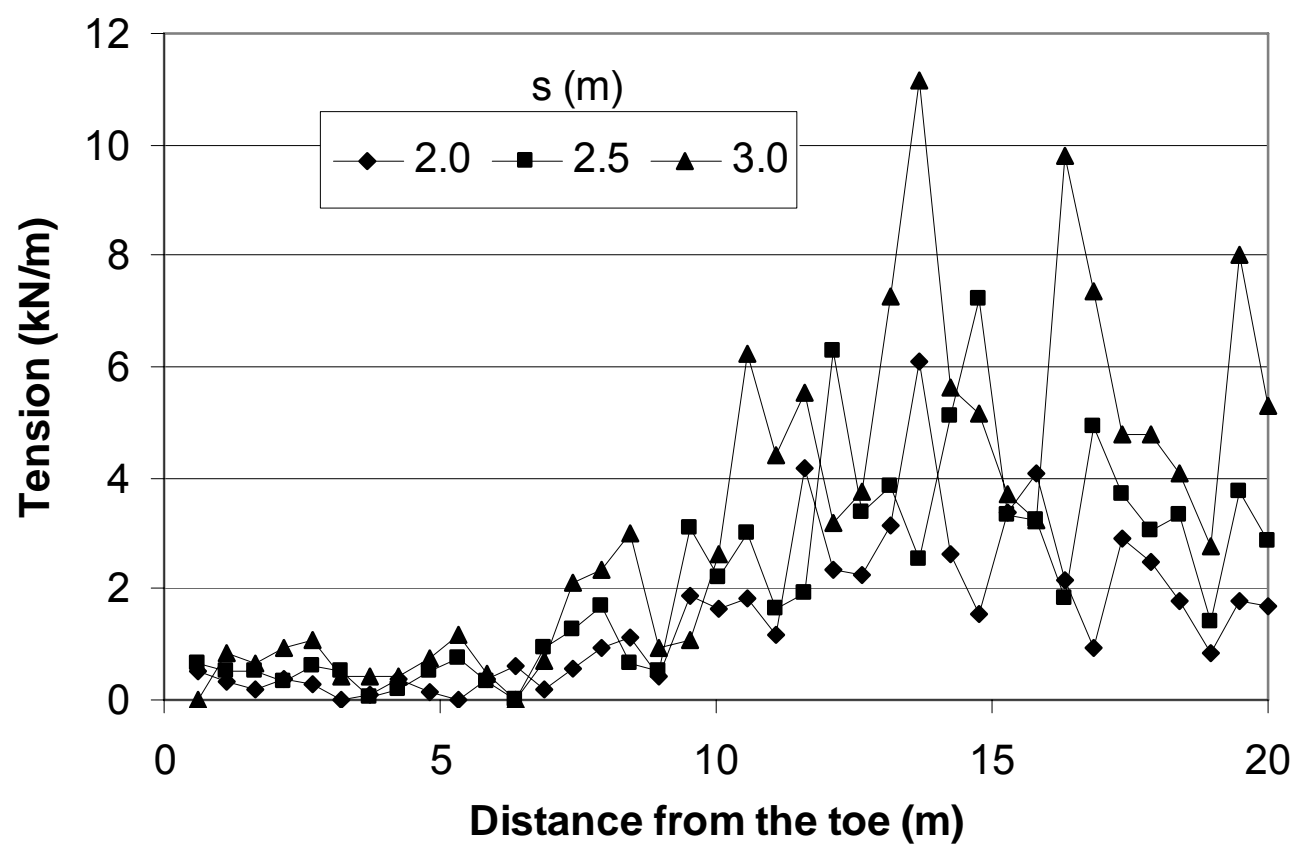

(a) 1 month after service

Fig. 4-65. Tension Profiles for Various Column Spacing at 1 Month and 30 Years after Service (2D) 


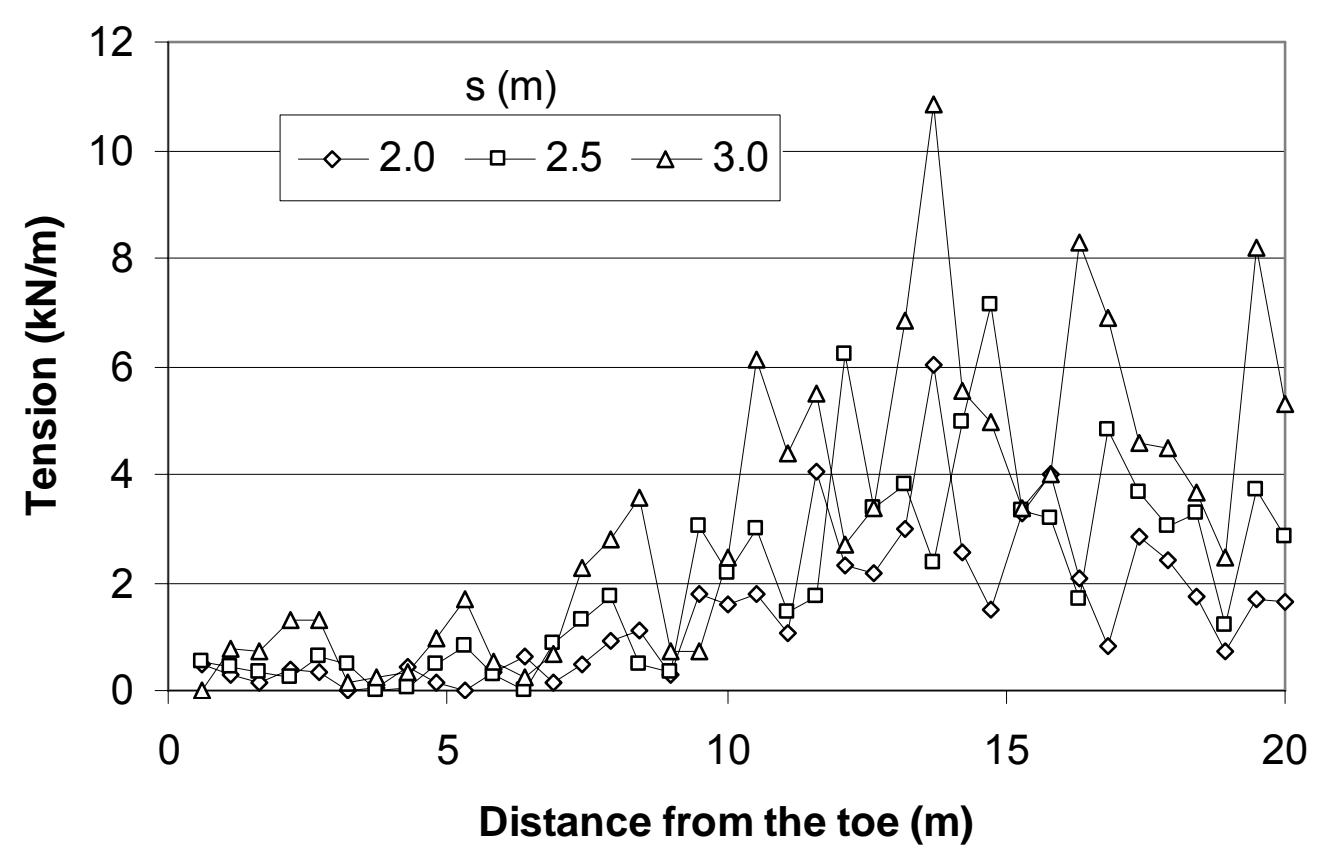

(b) 30 years after service

Fig. 4-65. Tension Profiles for Various Column Spacing at 1 Month and 30 Years after Service (2D) (continued)

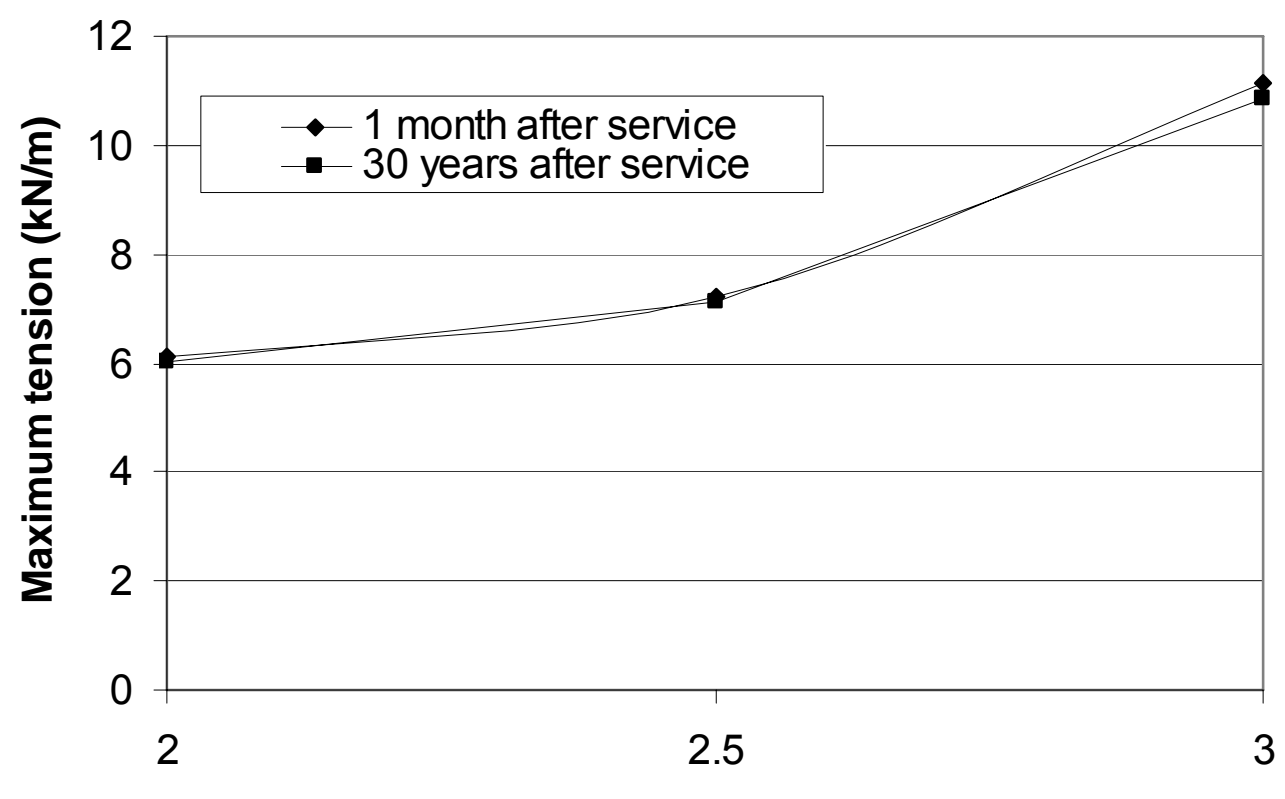

Column spacing $(\mathrm{m})$

Fig. 4-66. Maximum Tension versus Column Spacing (2D) 


\section{Influence of Geosynthetic Tensile Stiffness}

Unlike the influence on the settlements, the geosynthetic tensile stiffness had a significant influence on the tension as shown in Fig. 4-68. The maximum tension almost increased linearly when the tensile stiffness increased from 1,000 to $10,000 \mathrm{kN} / \mathrm{m}$. It is known that the tension is equal to the product of the tensile stiffness and the strain. Under various tensile stiffness levels, the differential settlement at the base was almost unchanged, which led to the unchanged strain. As a result, the product of the tensile stiffness and the strain increased almost linearly.

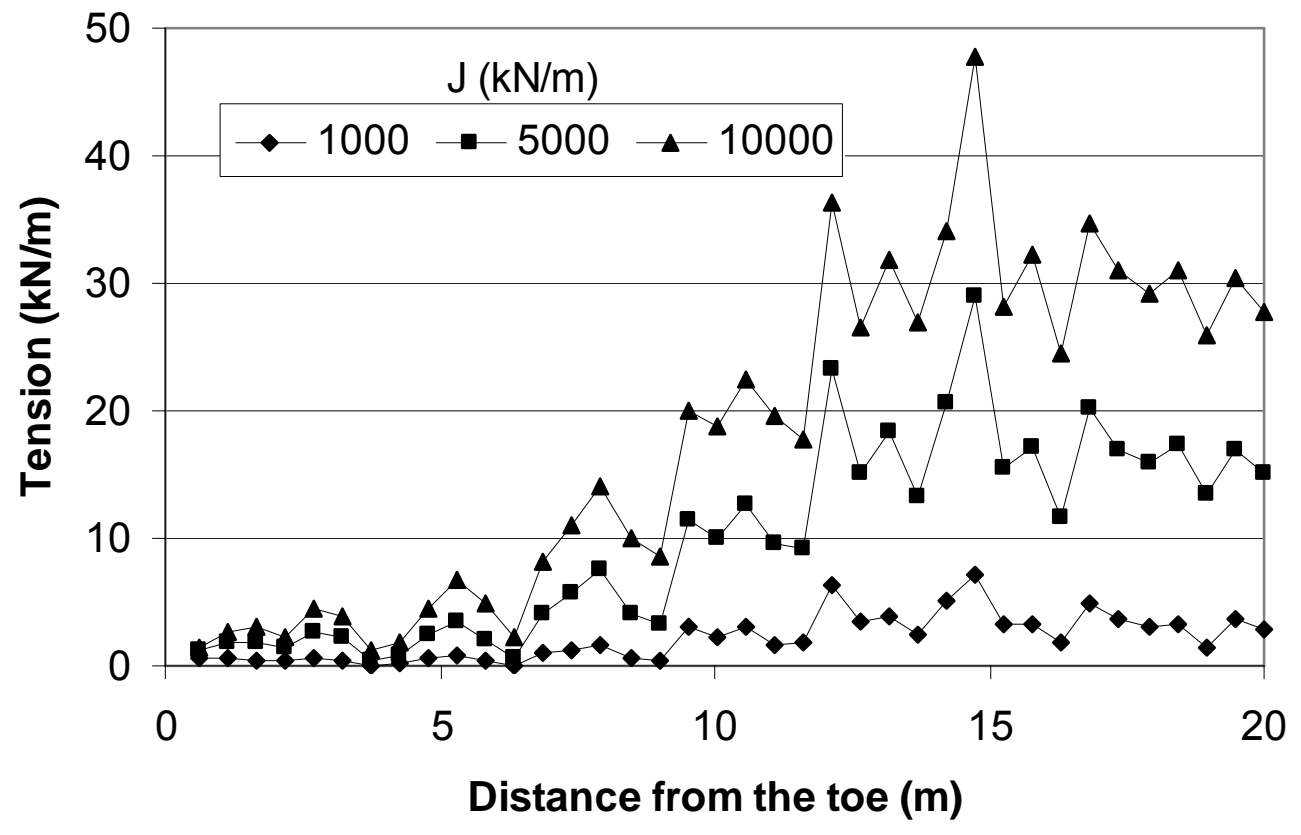

(a) 1 month after service

Fig. 4-67. Tension Profiles for Various Tensile Stiffness at 1 Month and 30 Years after Service (2D) 


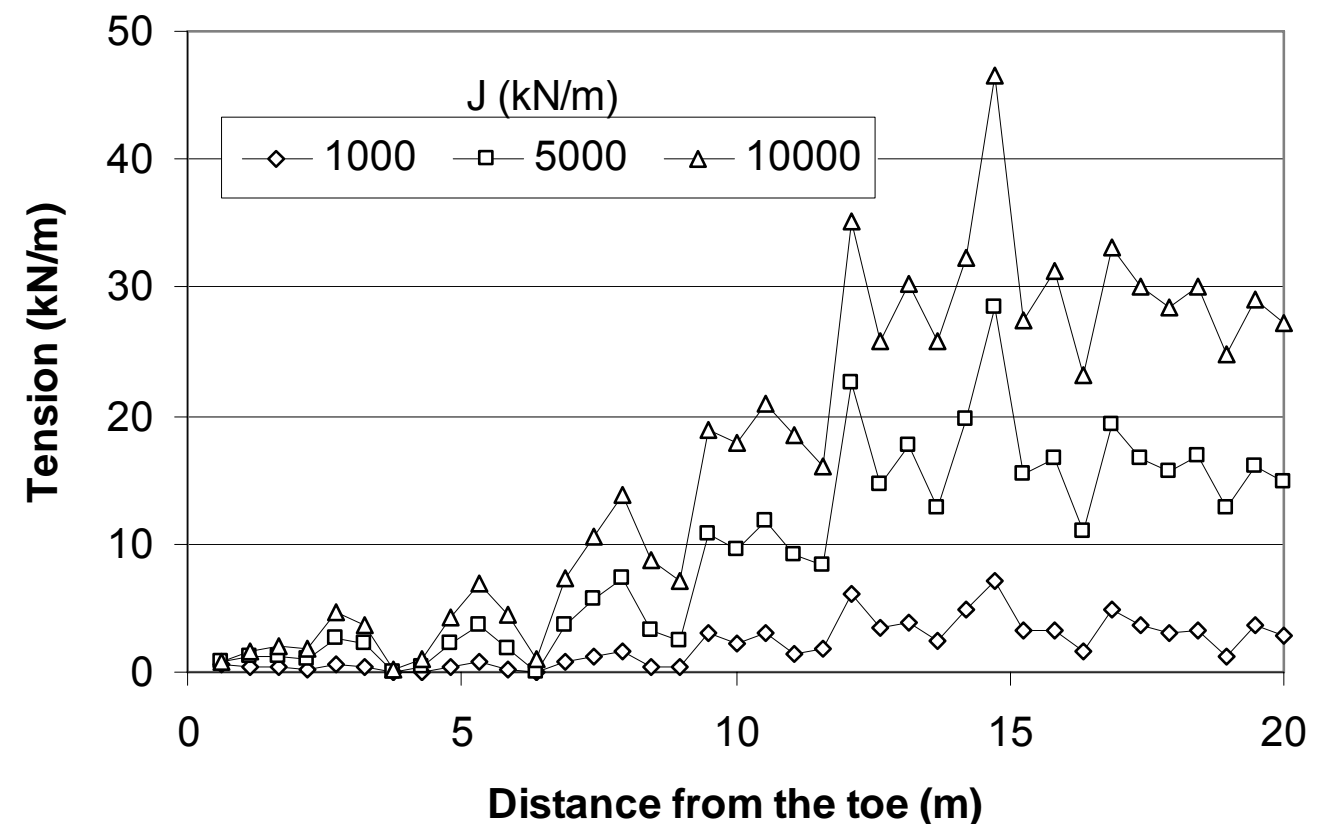

(b) 30 years after service

Fig. 4-67. Tension Profiles for Various Tensile Stiffness at 1 Month and 30 Years after Service (2D) (continued)

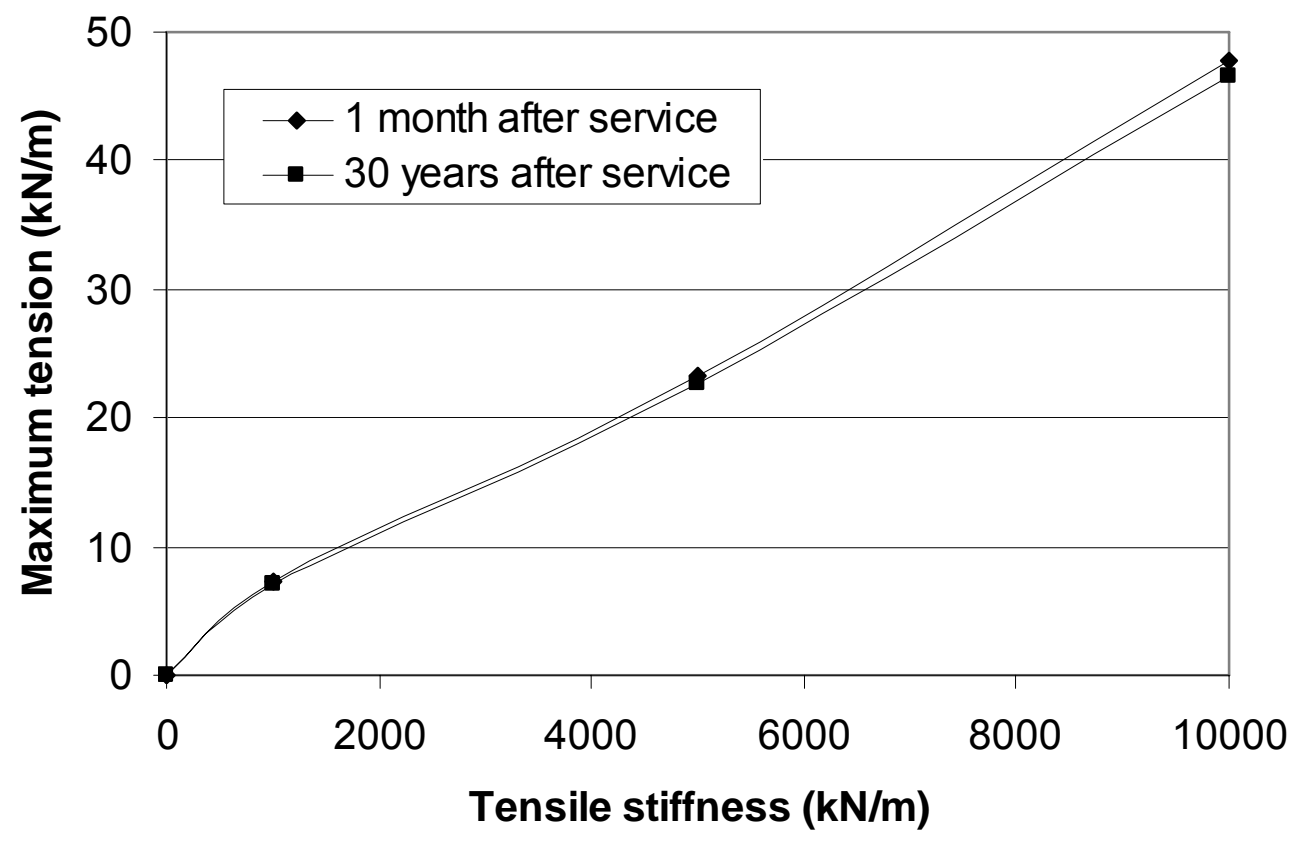

Fig. 4-68. Maximum Tension versus Tensile Stiffness (2D) 


\section{Influence of Construction Rate}

Figures 4-69 and 4-70 present the tension profiles at different construction rates. As discussed in the settlement section, the higher construction rate led to the larger differential settlement, especially at the base of the embankment, which induced the higher tension.

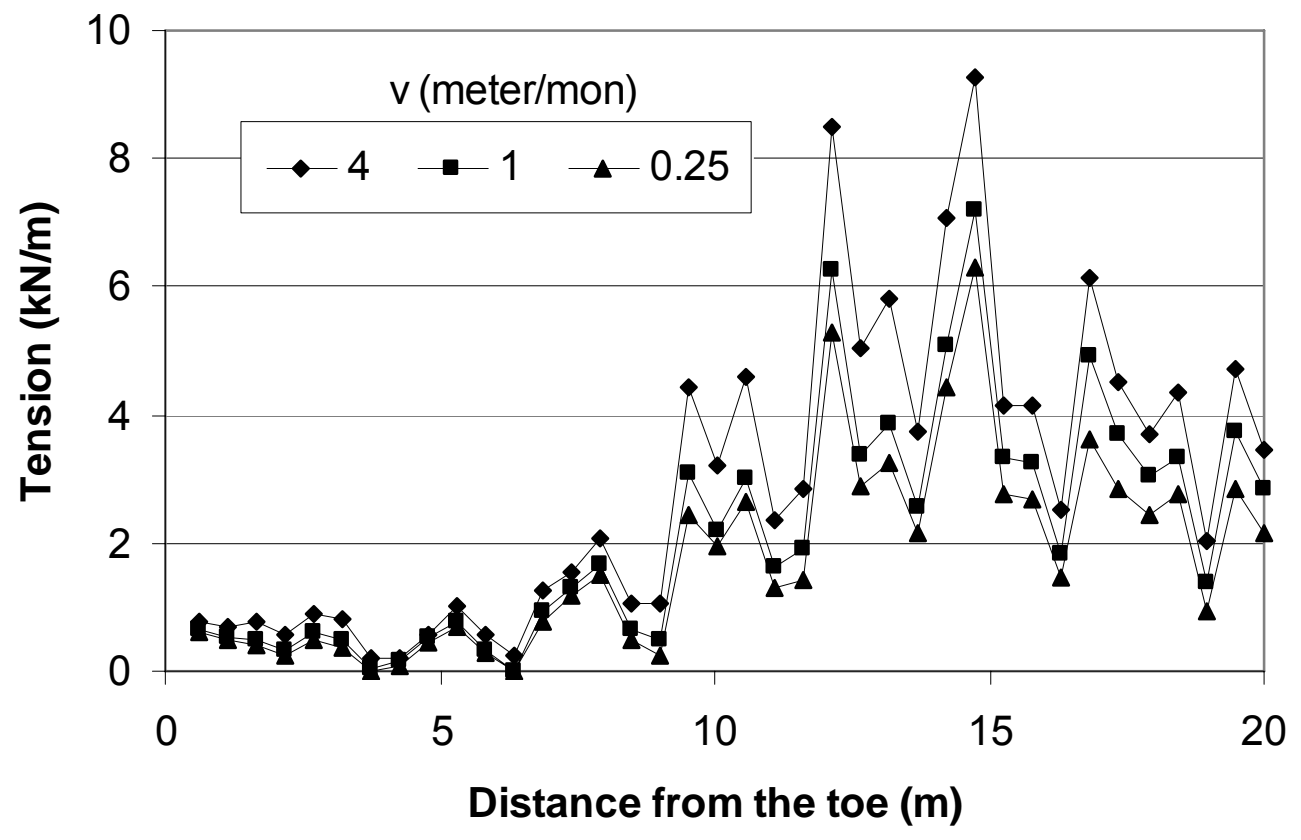

(a) 1 month after service

Fig. 4-69. Tension Profiles for Various Average Construction Rates at 1 Month and 30 Years after Service (2D) 


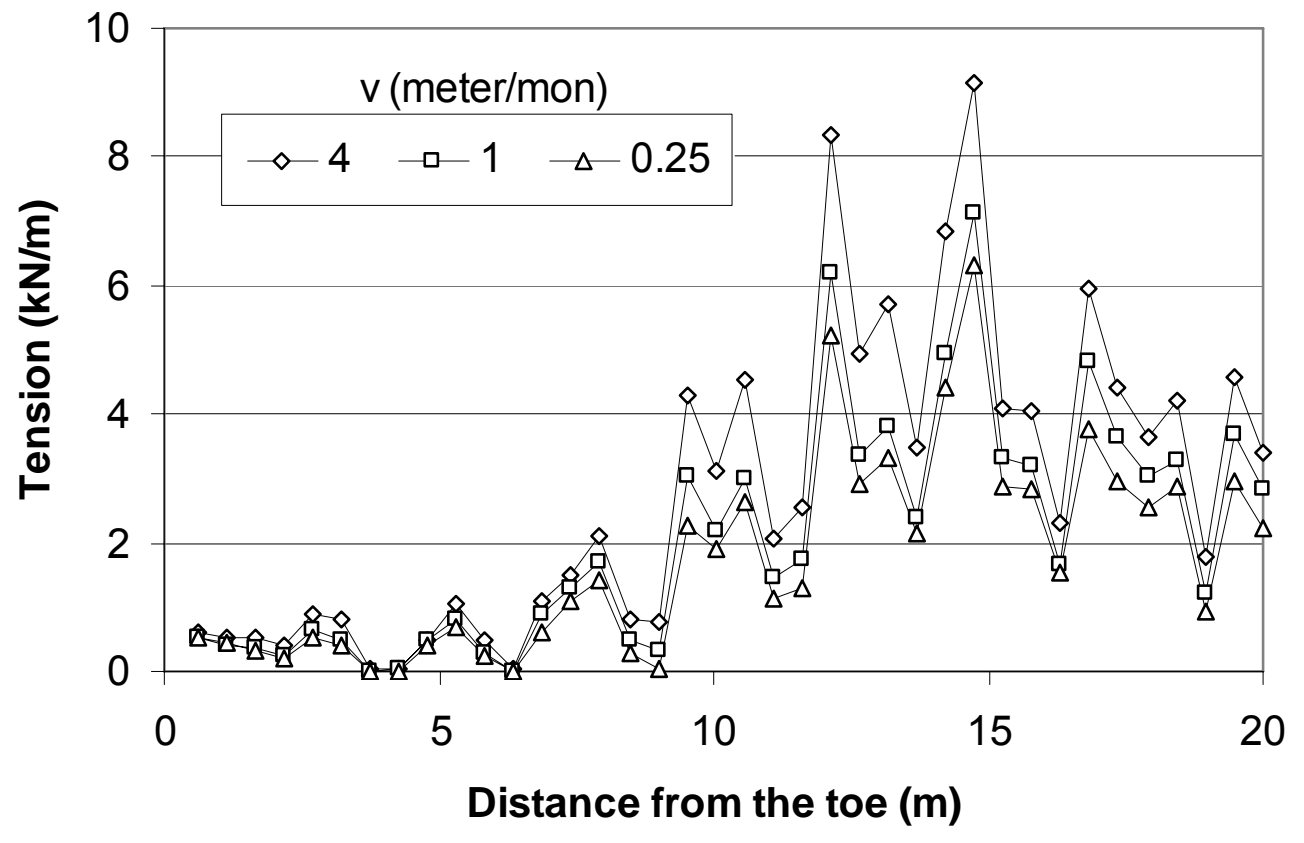

(b) 30 years after service

Fig. 4-69. Tension Profiles for Various Average Construction Rates at 1 Month and 30 Years after Service (2D) (continued)

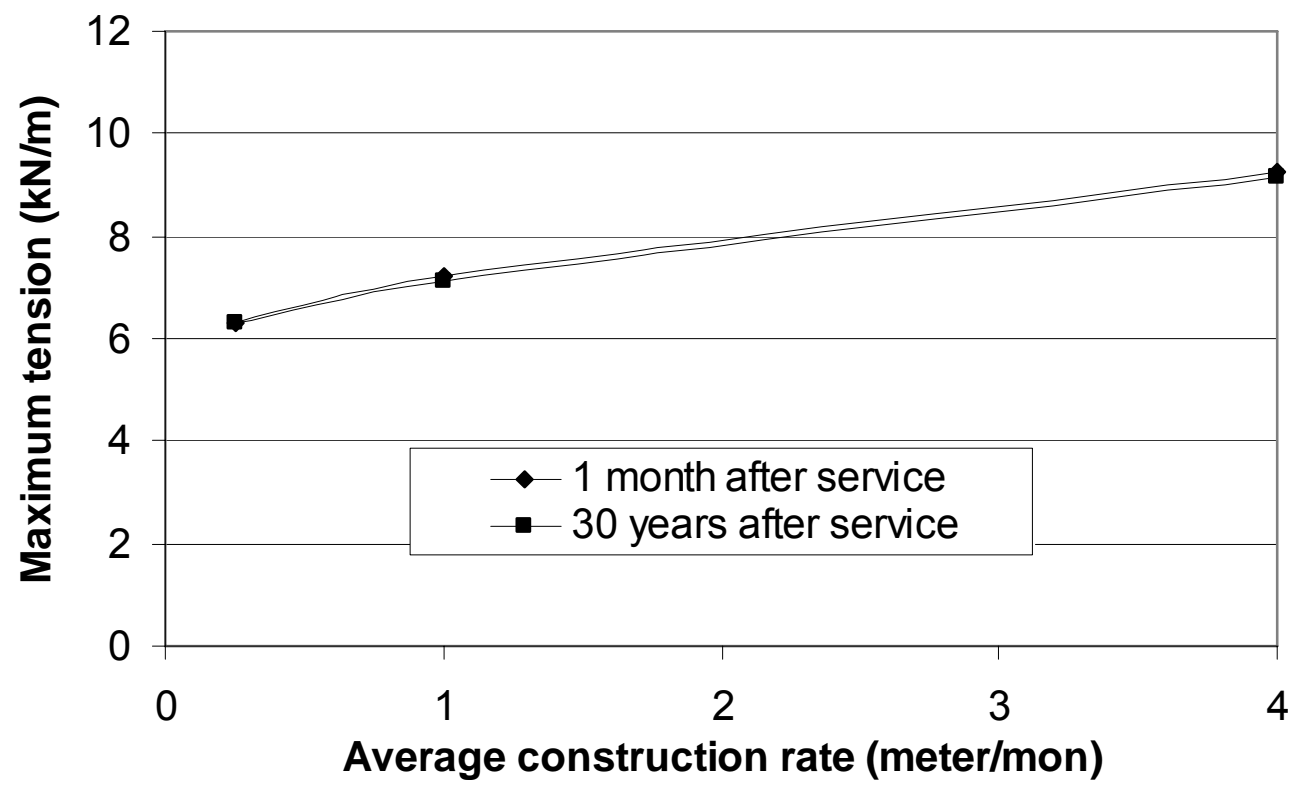

Fig. 4-70. Maximum Tension versus Average Construction Rate (2D) 


\subsubsection{Vertical Stress and Stress Concentration Ratio}

One of the key mechanisms of the GRCS embankment is to transfer the load from the soft soil to the columns through soil arching. As the load is transferred from the soft soil to the columns, higher vertical stresses develop in the columns than in the soft soil. As discussed in the baseline section of this chapter, the stress concentration ratio, $\mathrm{n}$, is commonly used to evaluate the load transfer efficiency. The stress concentration ratio is defined as the average vertical stress on the column heads to the average vertical stress in the soft soil at the same elevation.

Similar to the approach used in the baseline case, the additional vertical effective stress at the base of the embankment due to the embankment and traffic load was used to calculate the stress concentration ratio. The influence of various factors on the stress concentration ratio is presented below.

\section{Influence of Soft Soil Elastic Modulus}

The additional vertical effective stress profiles at the elevation of the column heads are presented with the different soft soil moduli in Fig. 4-71. 


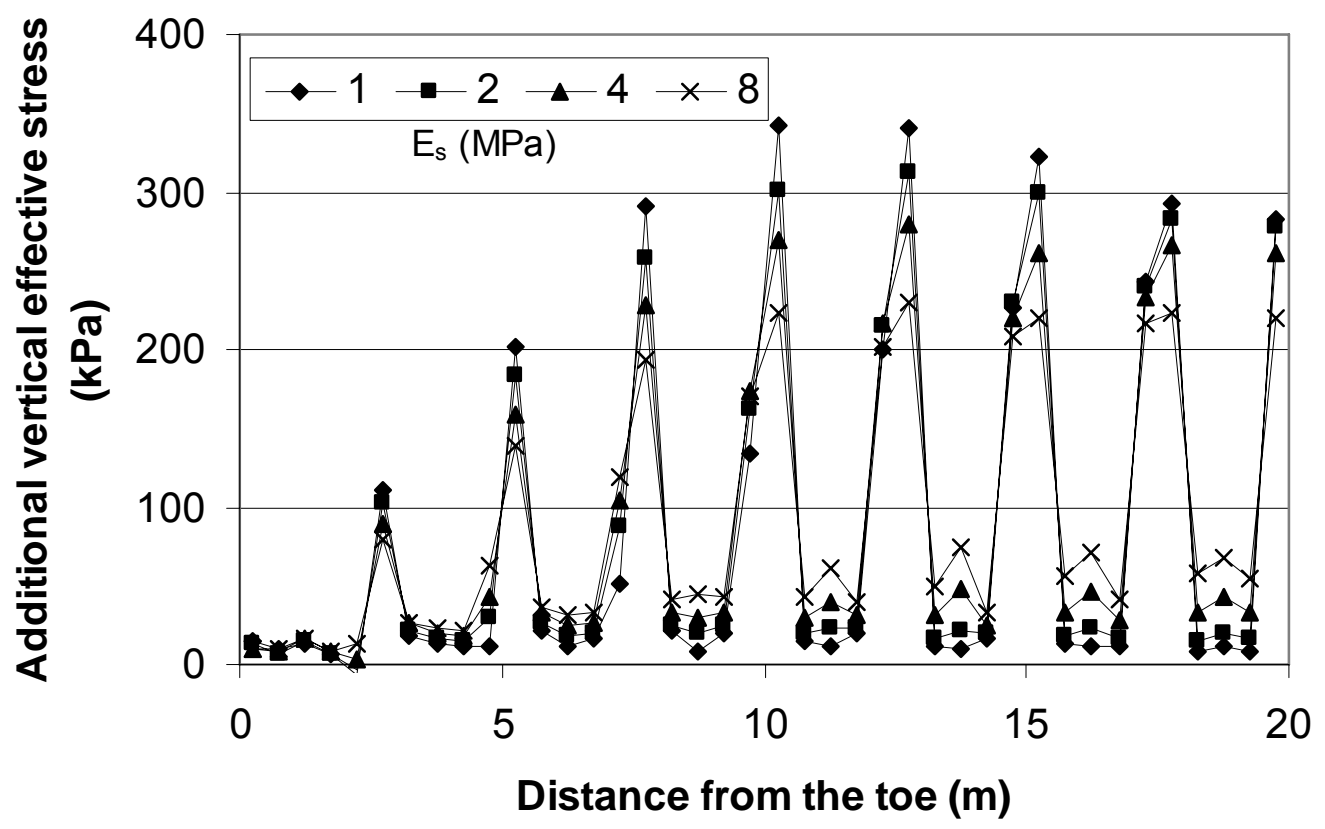

(a) 1 month after service

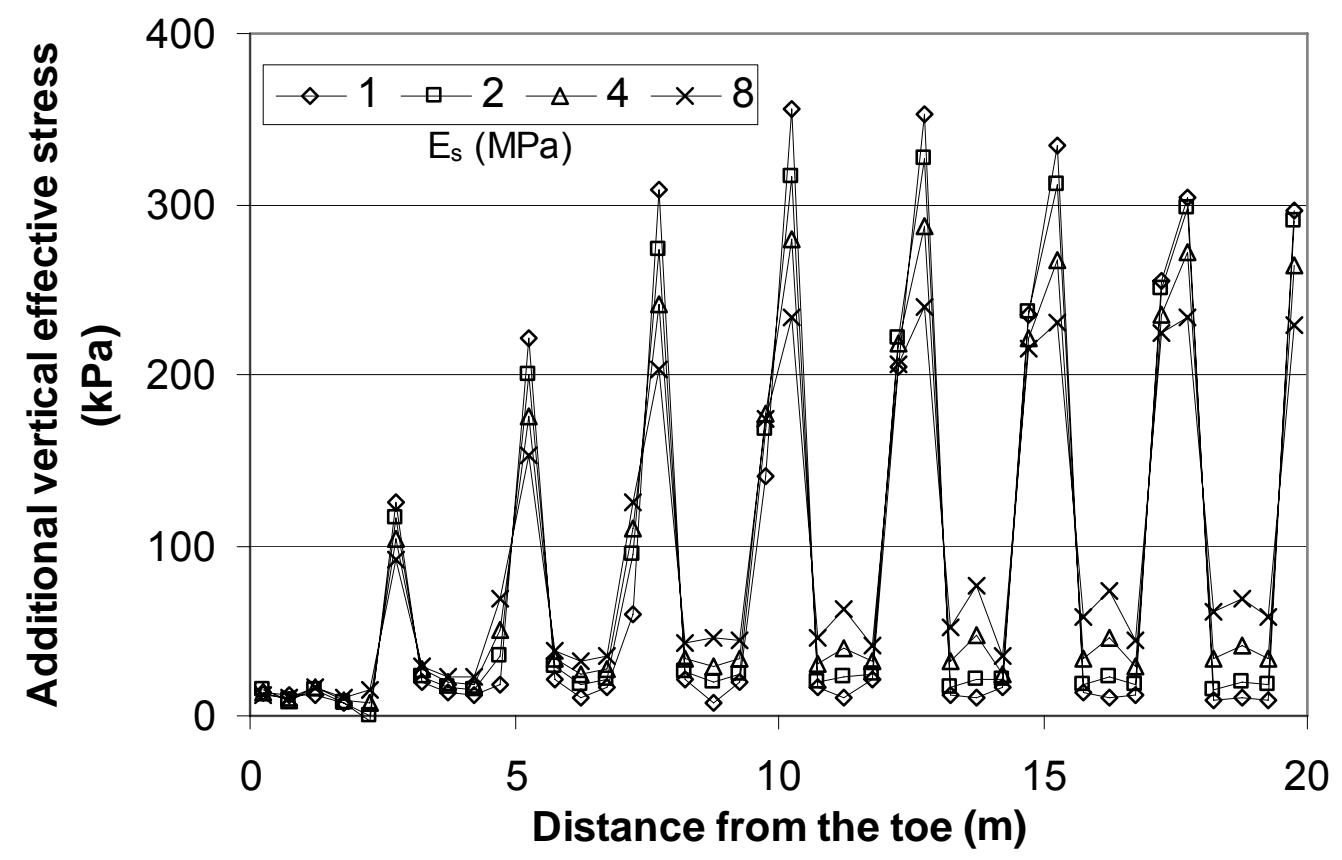

(b) 30 years after service

Fig. 4-71. Additional Vertical Effective Stress Profiles for Various Soil Moduli (2D) 
It was indicated in Fig. 4-71 that the increase of the soft soil modulus reduced the additional vertical effective stress on the column heads but increased that on the soft soil. This result can be explained that the increase of the soft soil modulus reduced the stiffness difference between the soft soil and the columns; consequently, the soft soil shared more load with the columns. Figure 4-71 shows that the additional effective stresses slightly increased both over the columns and over the soft soil from 1 month to 30 years after service due to the dissipation of excess pore water pressure.

The stress concentration ratio profiles are presented in Fig. 4-72. It can be seen that the higher stress concentration ratio was close to the centerline. In addition, the higher soft soil modulus yielded the lower stress concentration ratio. The profiles of the stress concentration ratios at one month or 30 years after service show that consolidation had a slight influence on the stress concentration ratio. 


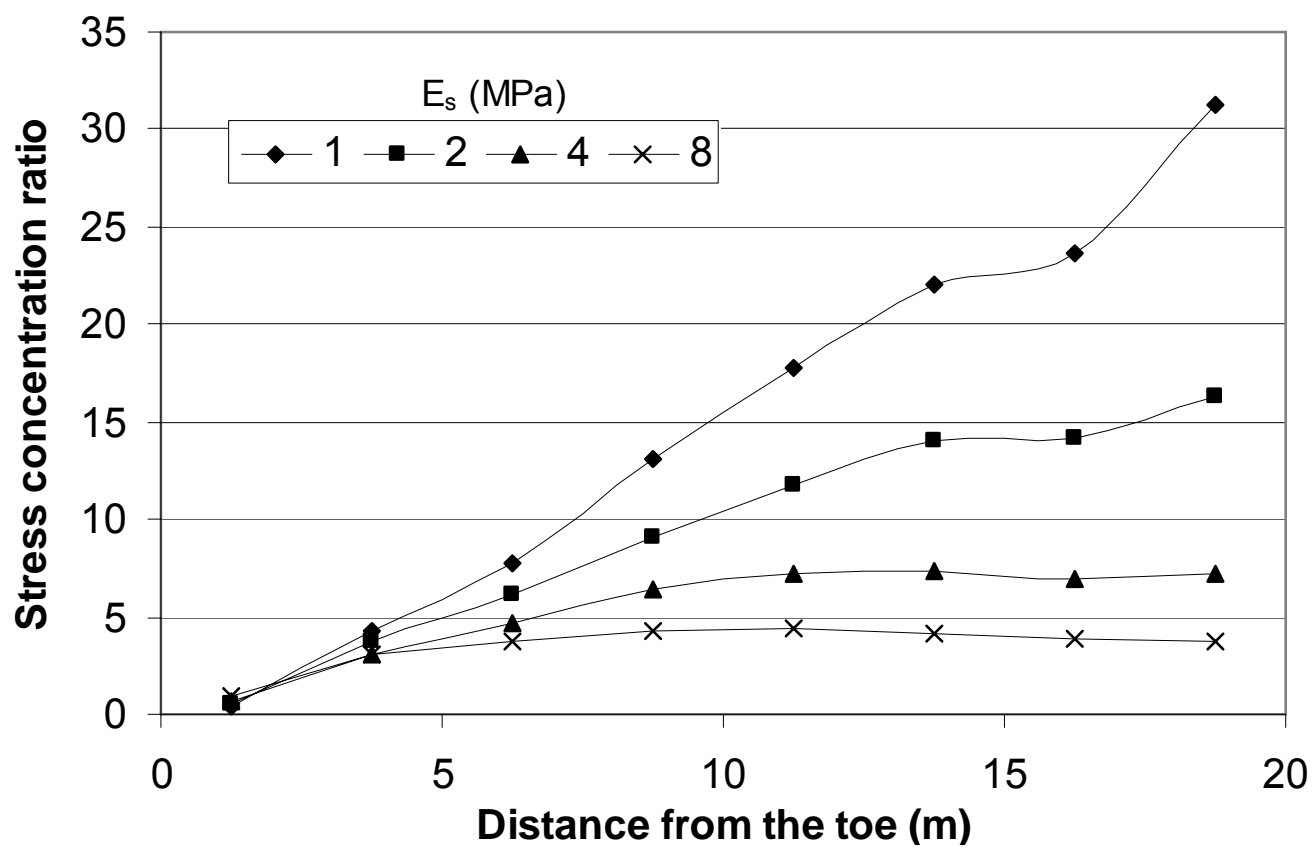

(a) 1 month after service

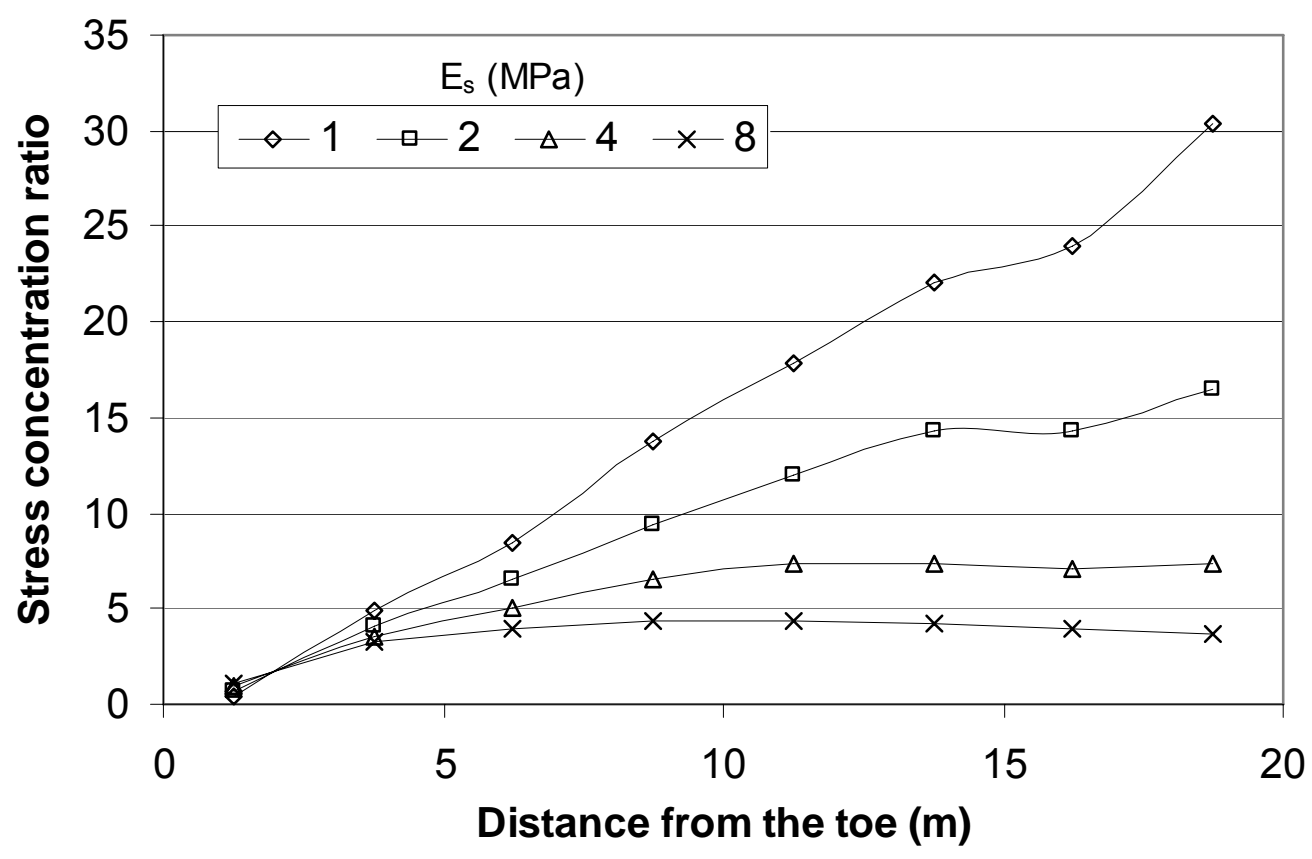

(b) 30 years after service

Fig. 4-72. Stress Concentration Ratio Profiles for Various Soil Moduli (2D) 


\section{Influence of Soft Soil Friction Angle}

The profiles of the additional vertical effective stresses at various soil friction angles are presented in Fig. 4-73, which shows that a higher soil friction angle led to slightly higher additional vertical effective stresses in the soft soil and slightly lower additional vertical effective stresses in the columns. The phenomenon was attributed to the reduction in the differential settlement at the base with the increase of the soil friction angle. In addition, the consolidation of the soft soil did not have much influence on the additional vertical effective stress.

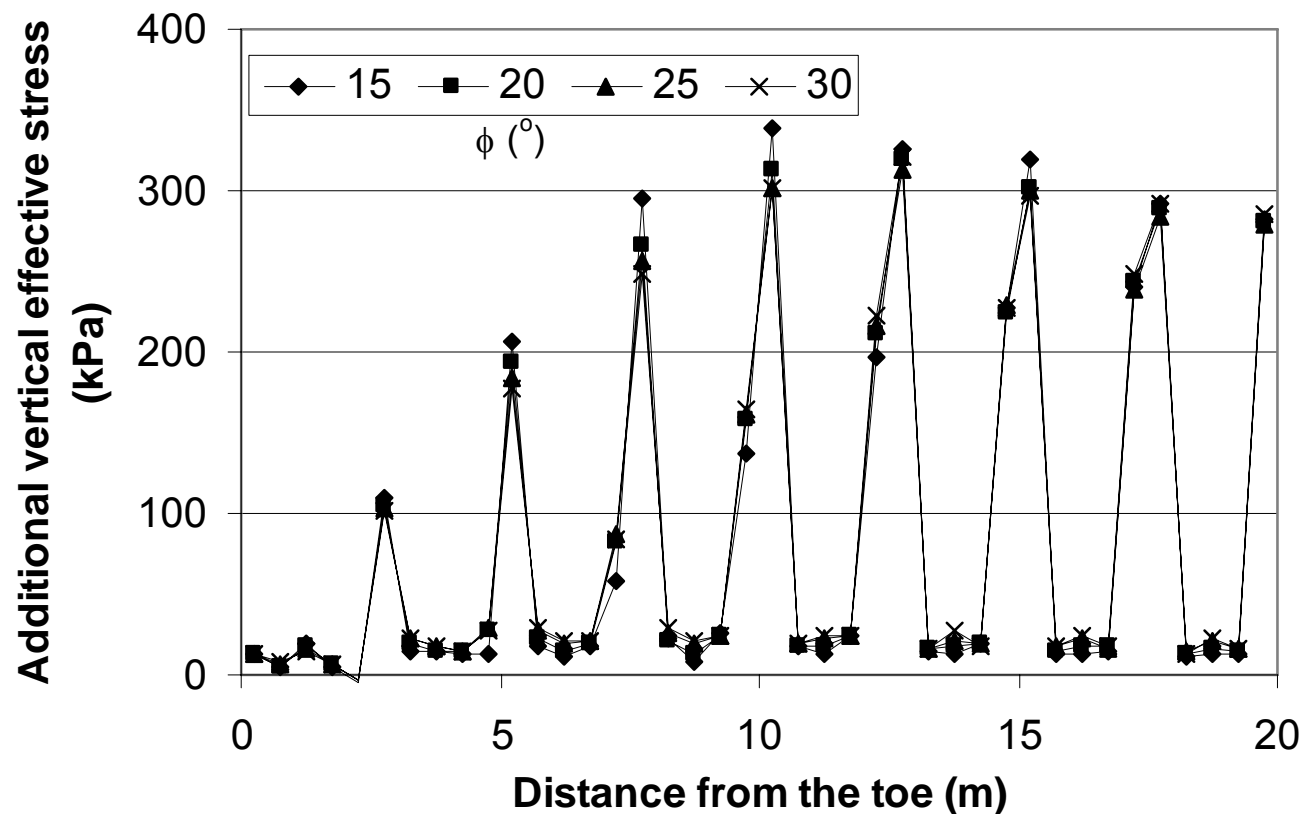

(a) 1 month after service

Fig. 4-73. Additional Effective Stress Profiles for Various Friction Angles (2D) 


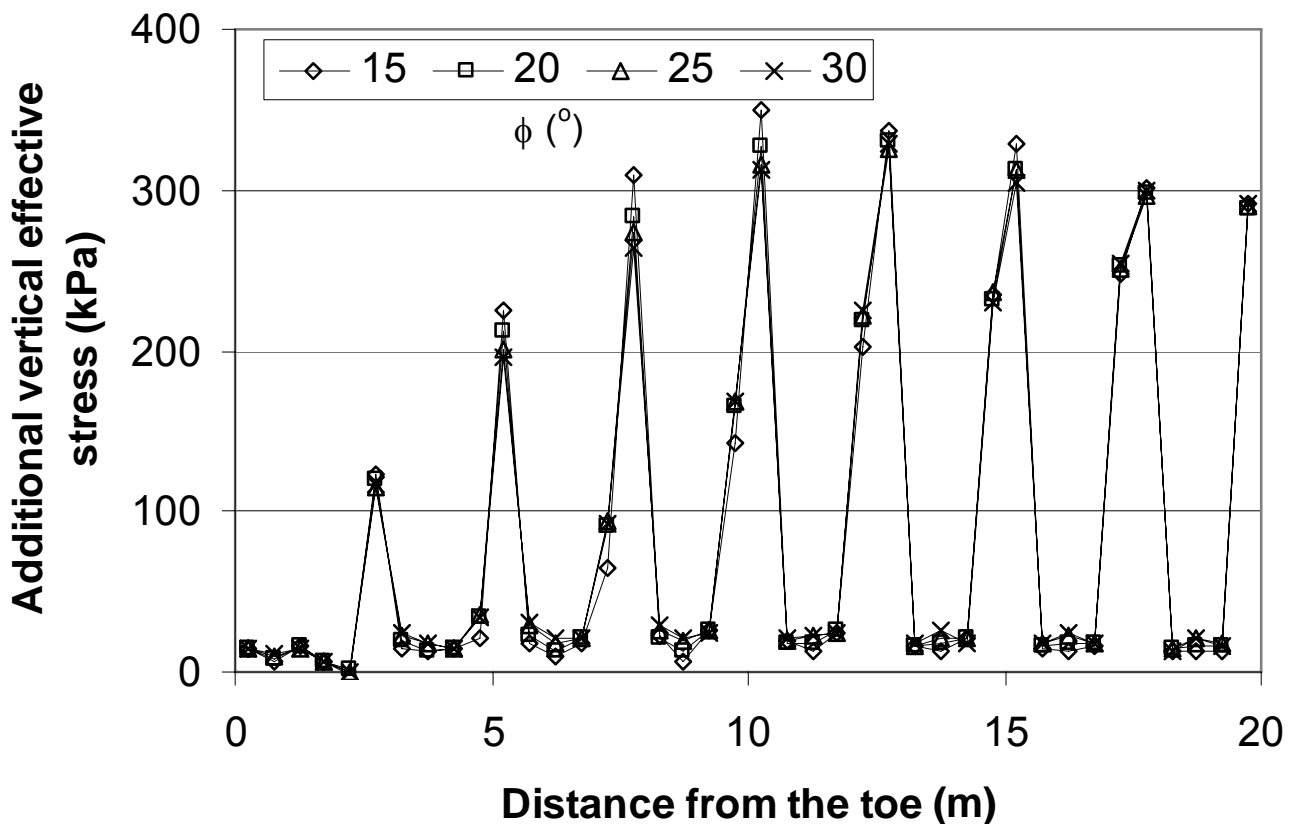

(b) 30 years after service

Fig. 4-73. Additional Effective Stress Profiles for Various Friction Angles (2D) (continued)

The profiles of the stress concentration ratio at different soil friction angles are presented in Fig. 4-74. Similarly, the stress concentration ratio increased from the toe to the center. The lower soil friction angle led to a higher stress concentration ratio. This result is consistent with the influence of the soil friction angle on the additional vertical effective stress. However, the stress concentration ratios at the soil friction angles of $25^{\circ}$ and $30^{\circ}$ had a minor difference. 


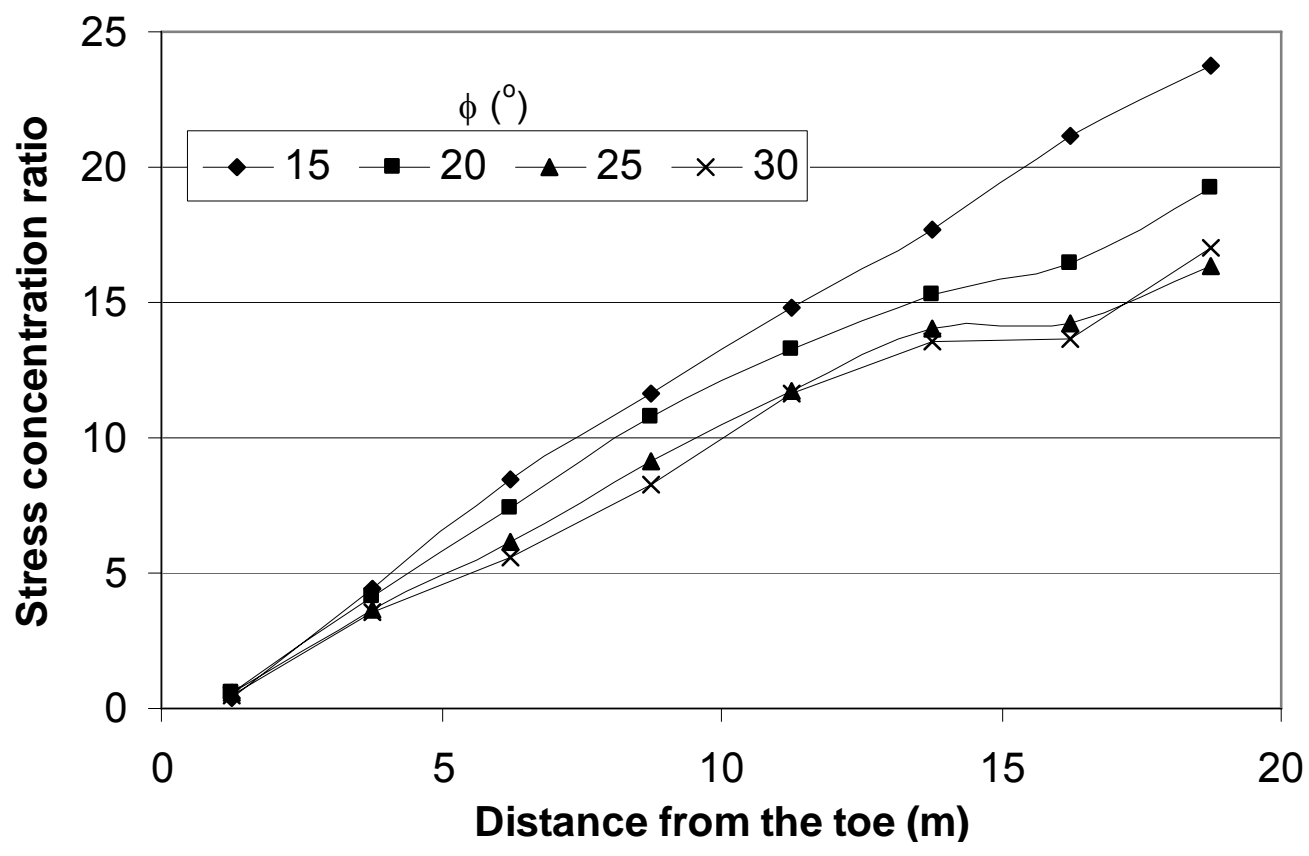

(a) 1 month after service

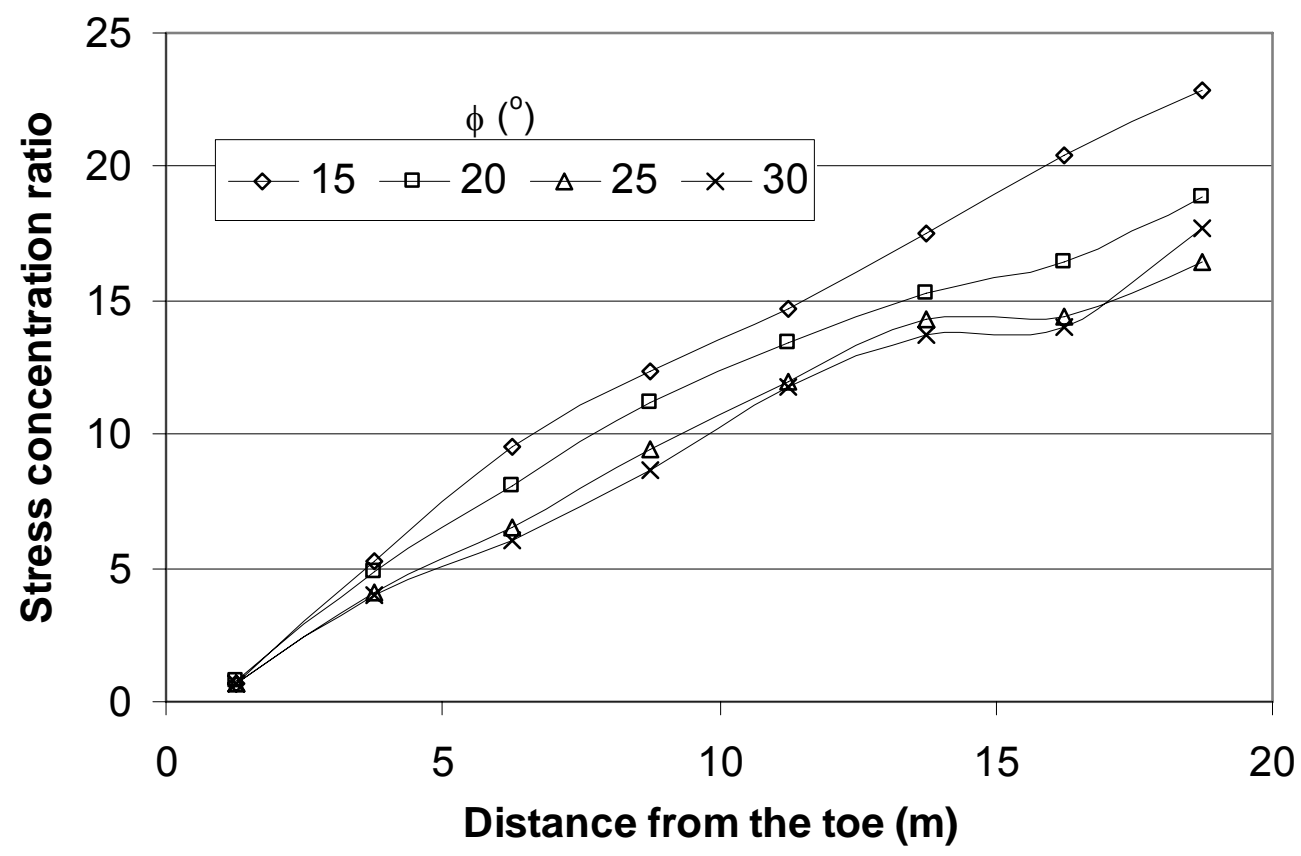

(b) 30 years after service

Fig. 4-74. Stress Concentration Ratio Profiles for Various Friction Angles (2D) 


\section{Influence of Soft Soil Permeability}

The profiles of the additional vertical effective stress and the stress concentration ratio are presented in Fig. 4-75 and 4-76, respectively. Figure 4-75 shows that the higher soil permeability led to the lower additional vertical effective stress on the columns but the higher additional vertical effective stress on the soft soil at the same elevation. The difference in the additional vertical effective stresses at different soil permeability values was small. Figure 4-76(a) shows that at one month after service, the stress concentration ratios at the soil permeability of $10^{-9} \mathrm{~m} / \mathrm{s}$ and $10^{-10} \mathrm{~m} / \mathrm{s}$ were similar while the stress concentration ratios at the soil permeability of $10^{-8} \mathrm{~m} / \mathrm{s}$ were less than those at the soil permeability of $10^{-9} \mathrm{~m} / \mathrm{s}$ and $10^{-10} \mathrm{~m} / \mathrm{s}$. At 30 years after service, however, the stress concentration ratios increased when the soil permeability decreased from $10^{-8} \mathrm{~m} / \mathrm{s}$ to $10^{-10} \mathrm{~m} / \mathrm{s}$ as shown in Fig. 4-76 (b). 


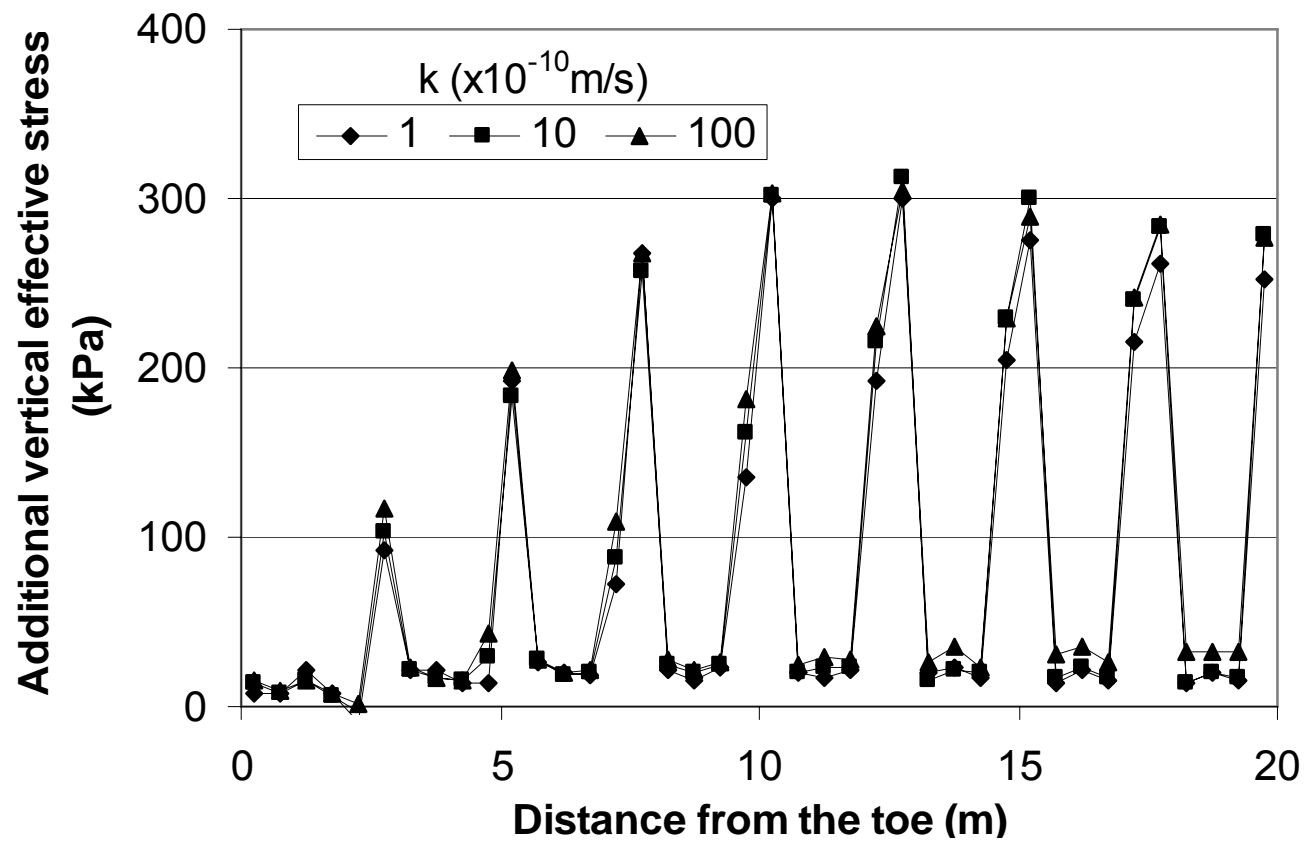

(a) 1 month after service

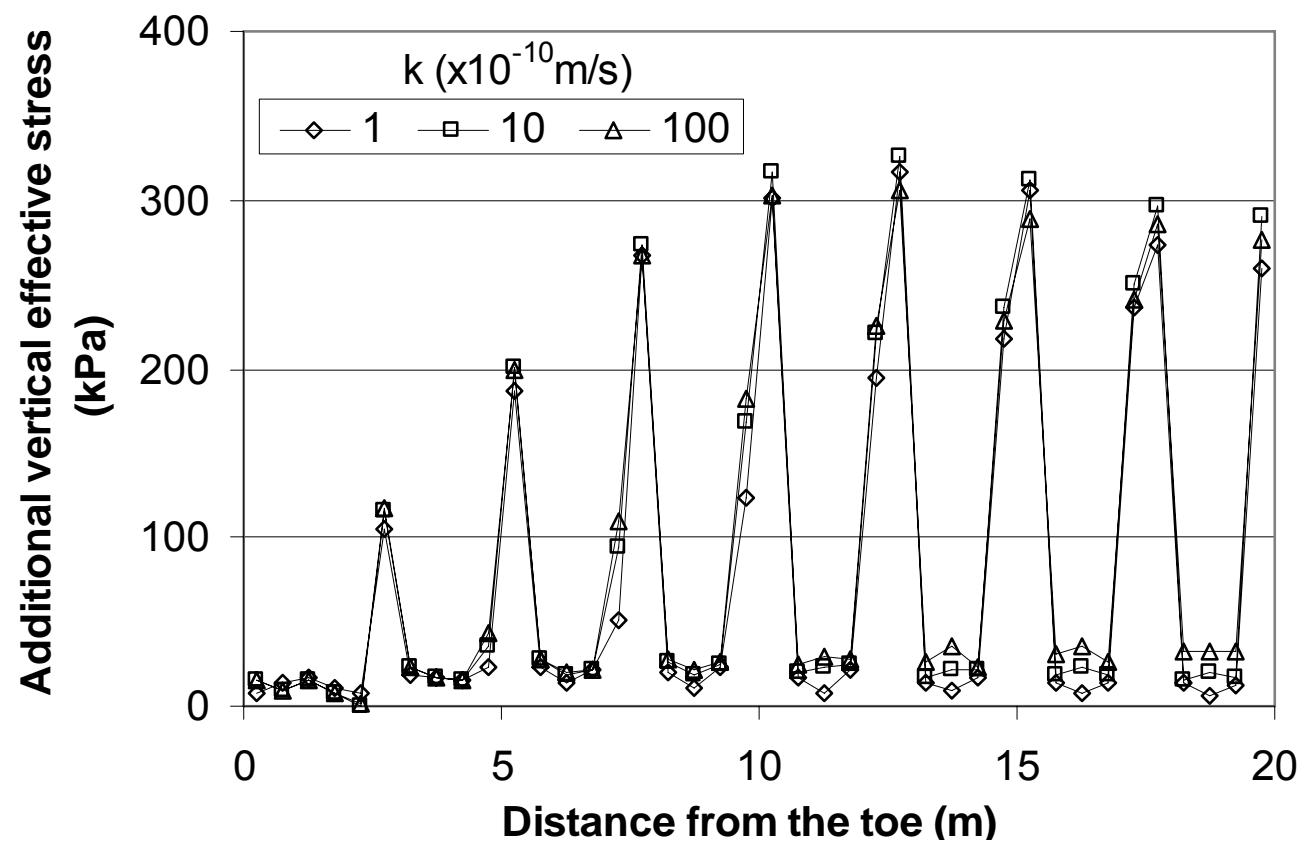

(b) 30 years after service

Fig. 4-75. Additional Effective Stress Profiles for Various Soil Permeability (2D) 


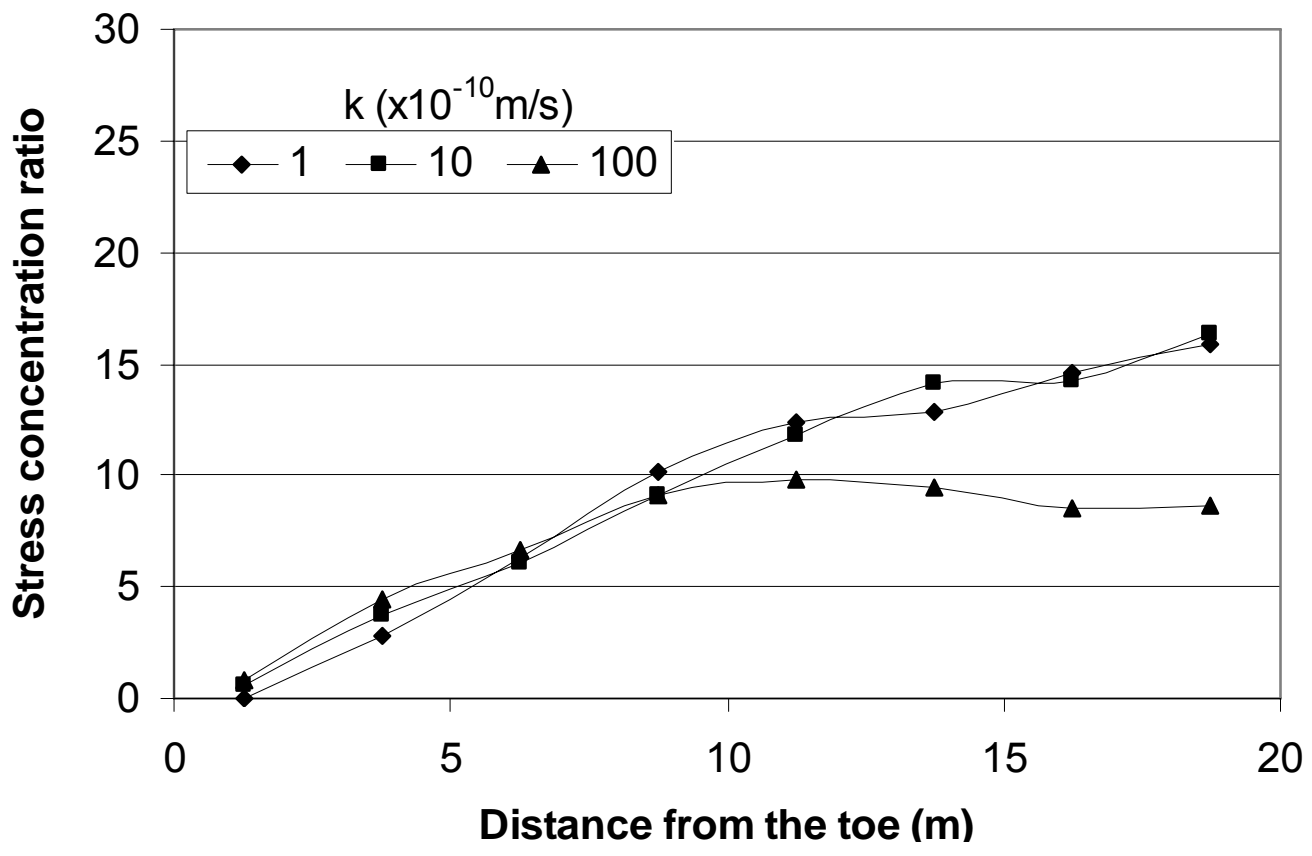

(a) 1 month after service

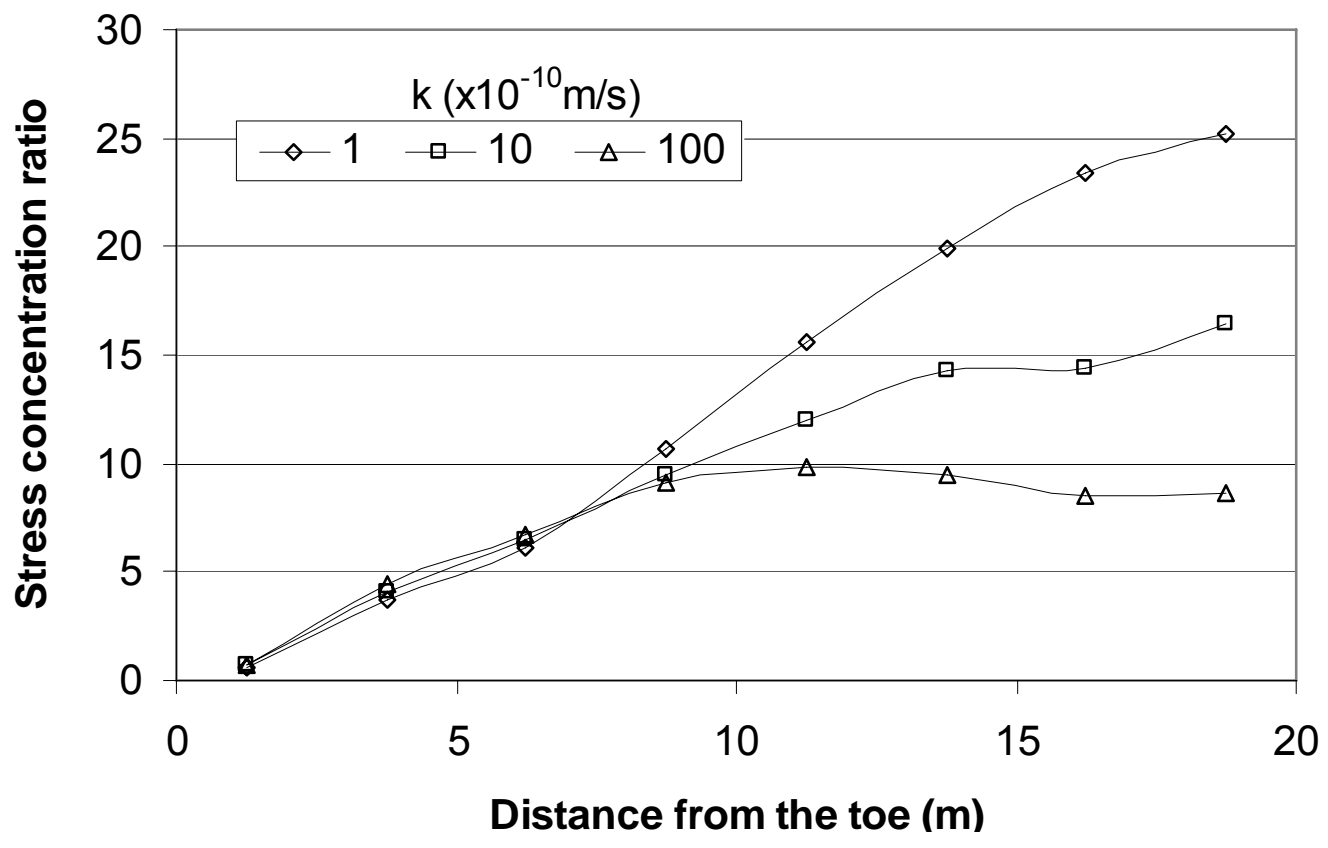

(b) 30 years after service

Fig. 4-76. Stress Concentration Ratio Profiles for Various Soil Permeability (2D) 


\section{Influence of Column Elastic Modulus}

The profiles of the additional vertical effective stress and the stress concentration ratio at different column moduli are presented in Fig. 4-77 and 4-78, respectively. It can be seen that the higher column modulus led to slightly higher additional vertical effective stresses on the columns and lower stresses on the soft soil. As a result, the higher column modulus yielded the higher stress concentration ratio.

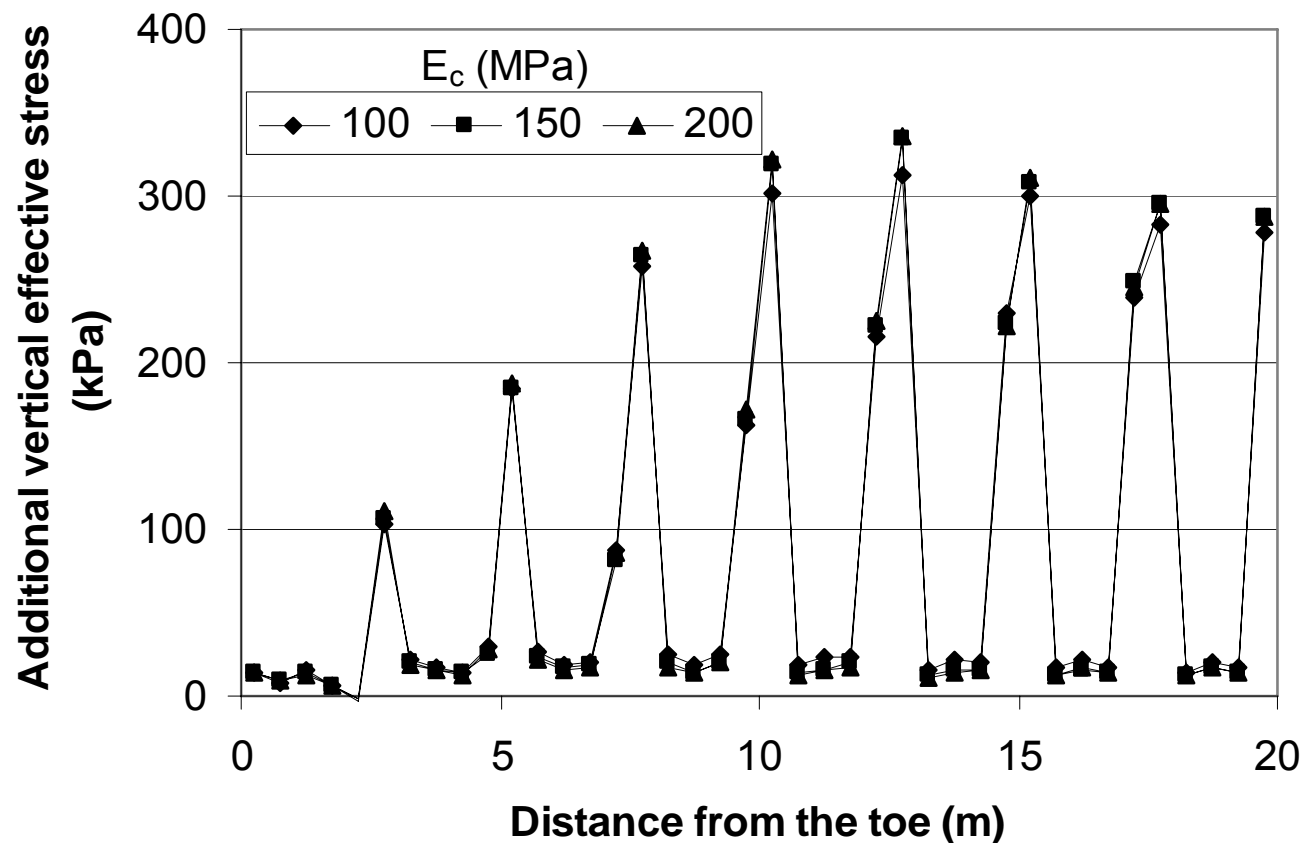

(a) 1 month after service

Fig. 4-77. Additional Vertical Effective Stress Profiles for Various Column Moduli (2D) 


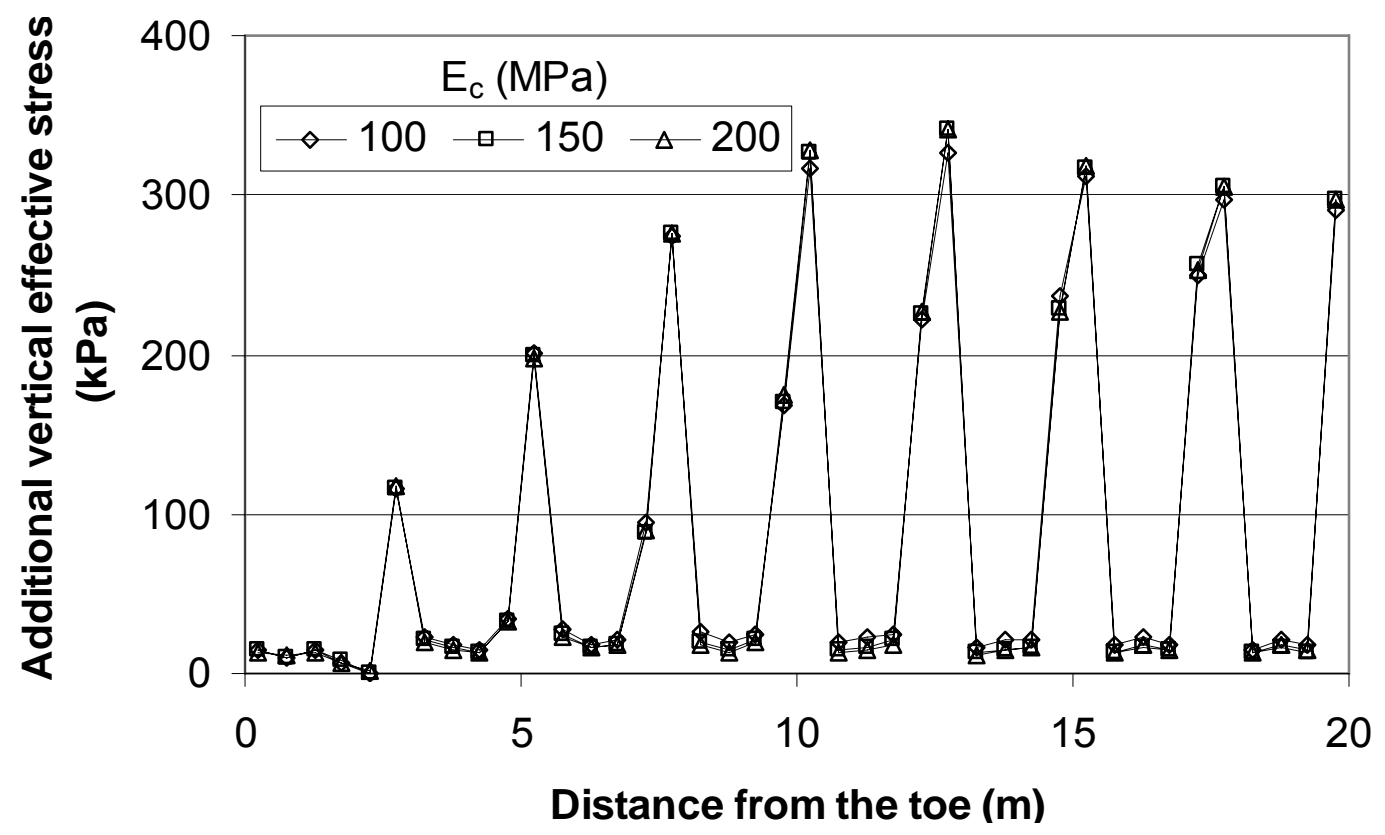

(b) 30 years after service

Fig. 4-77. Additional Vertical Effective Stress Profiles for Various Column Moduli (2D) (continued)

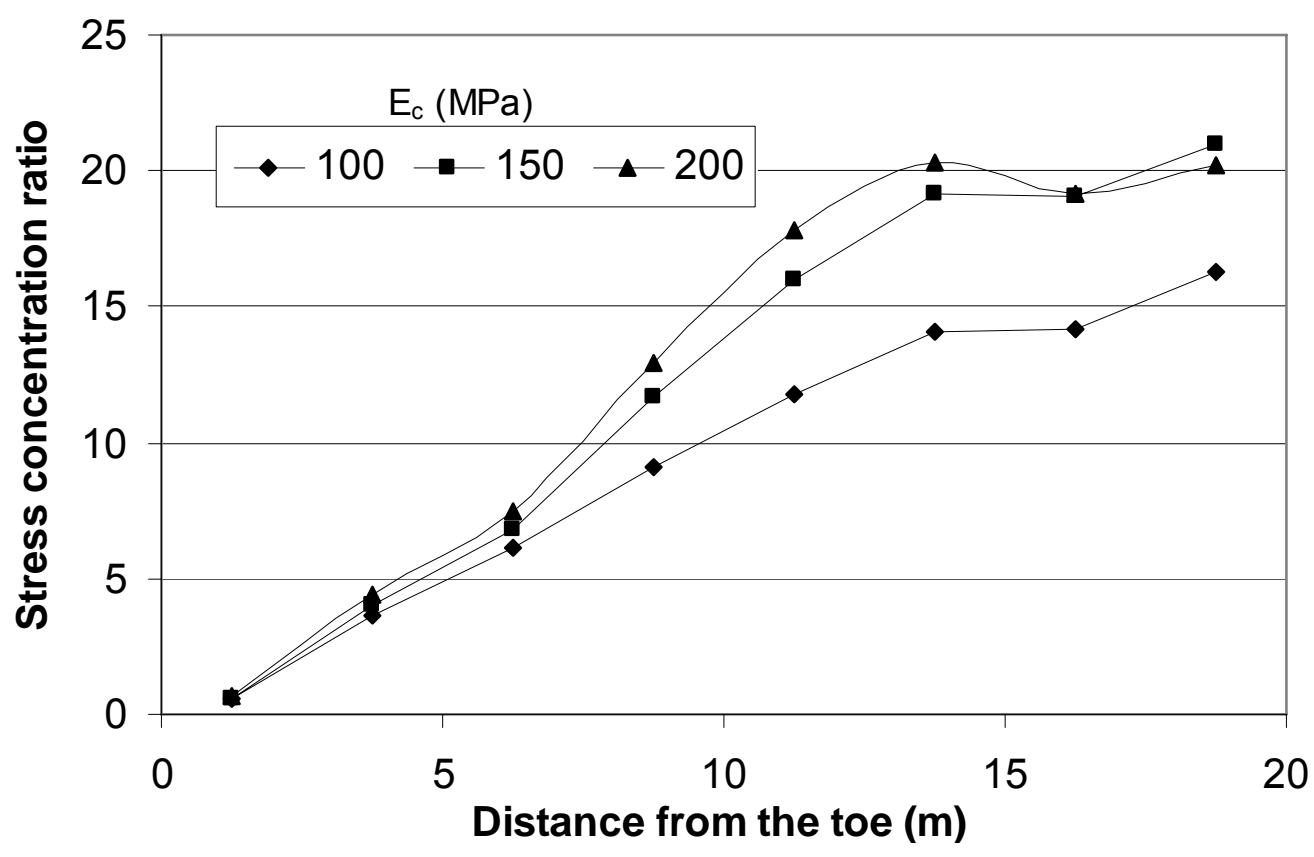

(a) 1 month after service

Fig. 4-78. Stress Concentration Ratio Profiles for Various Column Moduli (2D) 


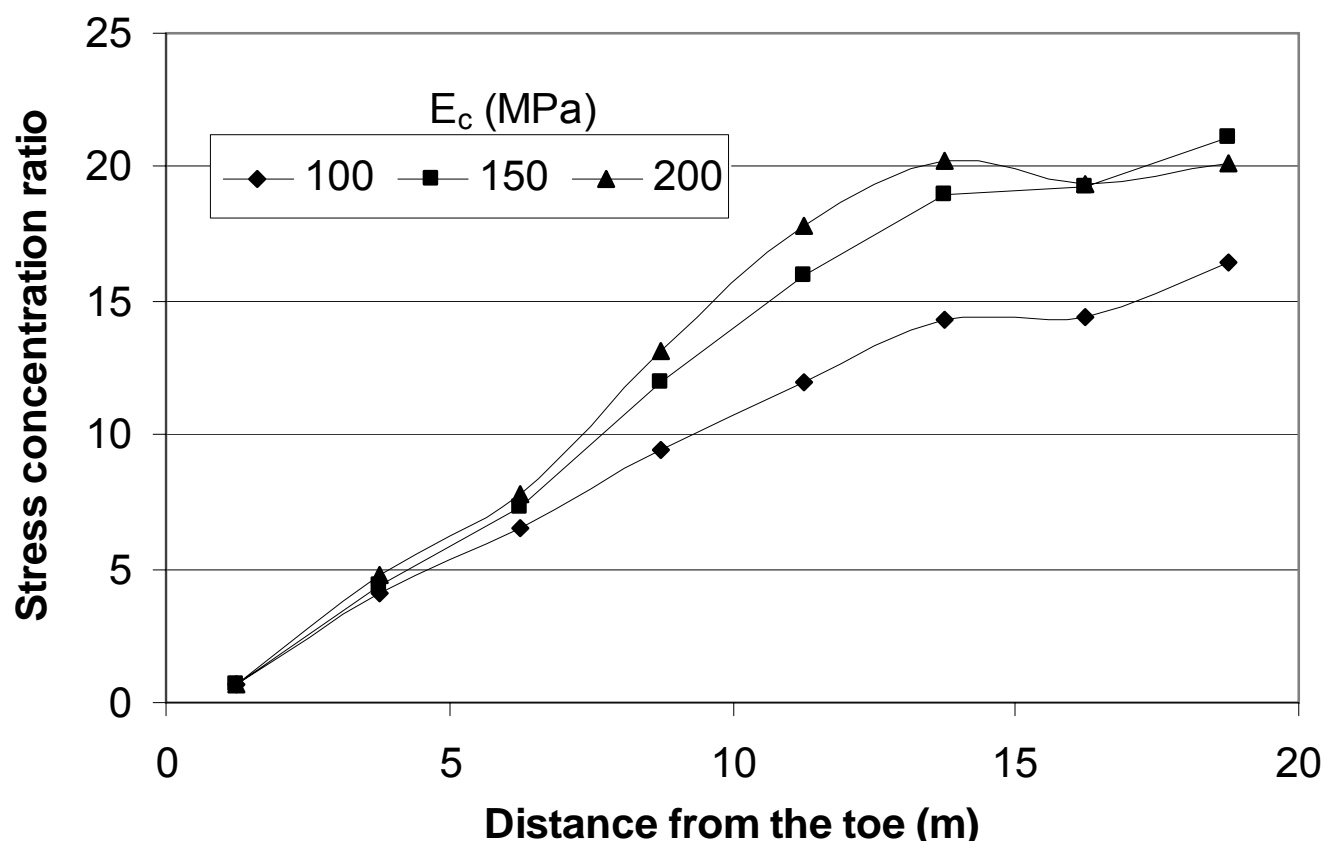

(b) 30 years after service

Fig. 4-78. Stress Concentration Ratio Profiles for Various Column Moduli (2D) (continued)

\section{Influence of Column Spacing}

The profiles of the additional effective stress and the stress concentration ratio are presented in Fig. 4-79 and 4-80, respectively. Due to the difference in the column spacing, the locations of the columns for each case were different. In terms of the maximum additional vertical effective stresses on the columns and in the soil, however, it still can be concluded that the larger column spacing led to the higher additional vertical effective stresses on both the columns and the soil. 


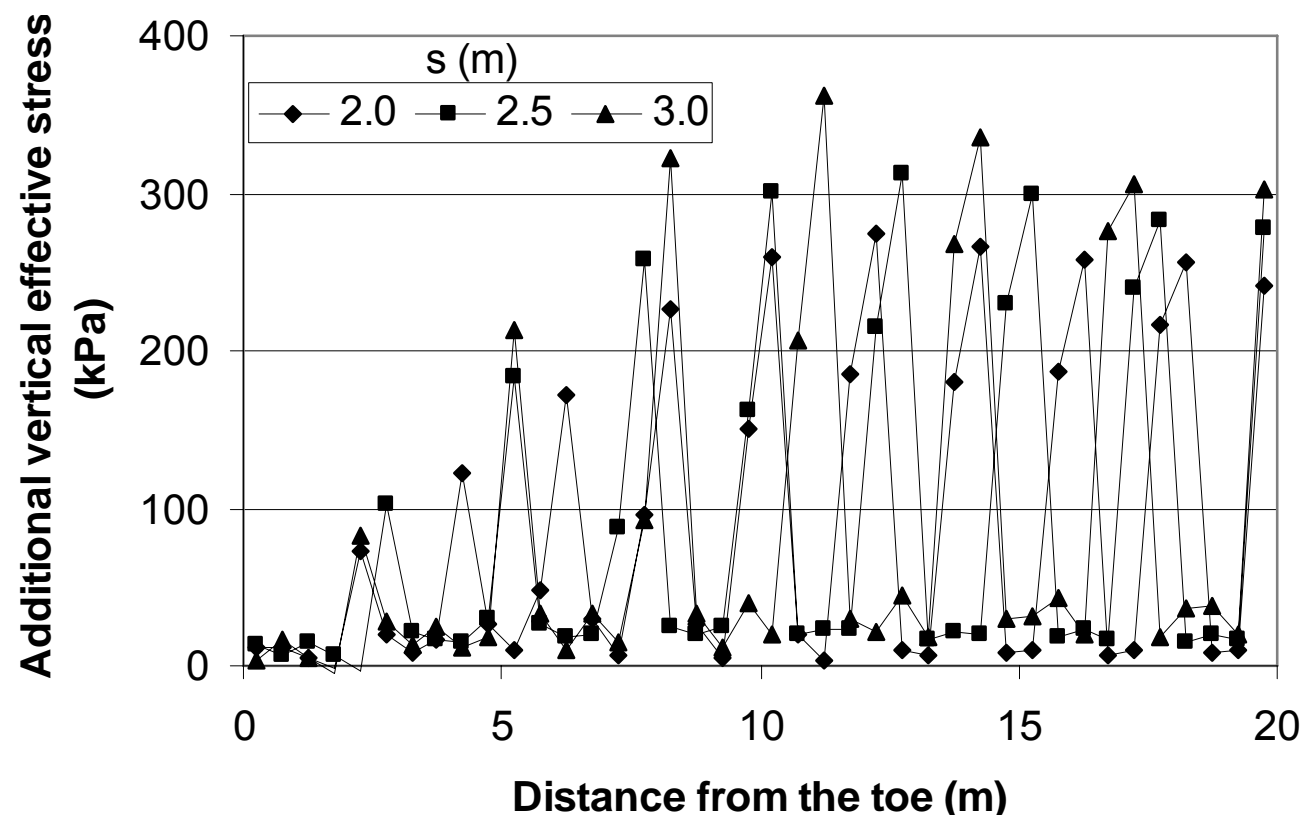

(a) 1 month after service

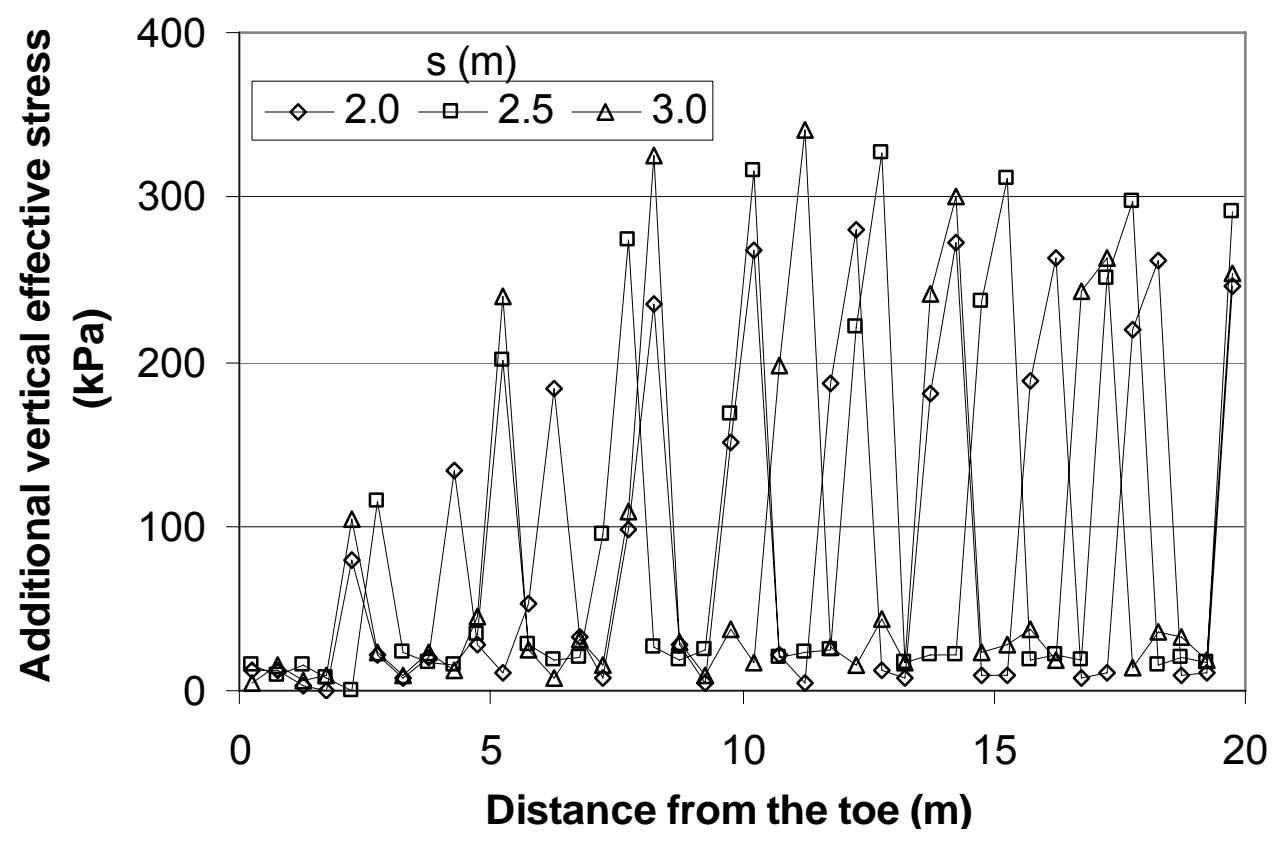

(b) 30 years after service

Fig. 4-79. Additional Vertical Effective Stress Profiles for Various Column Spacing (2D) 


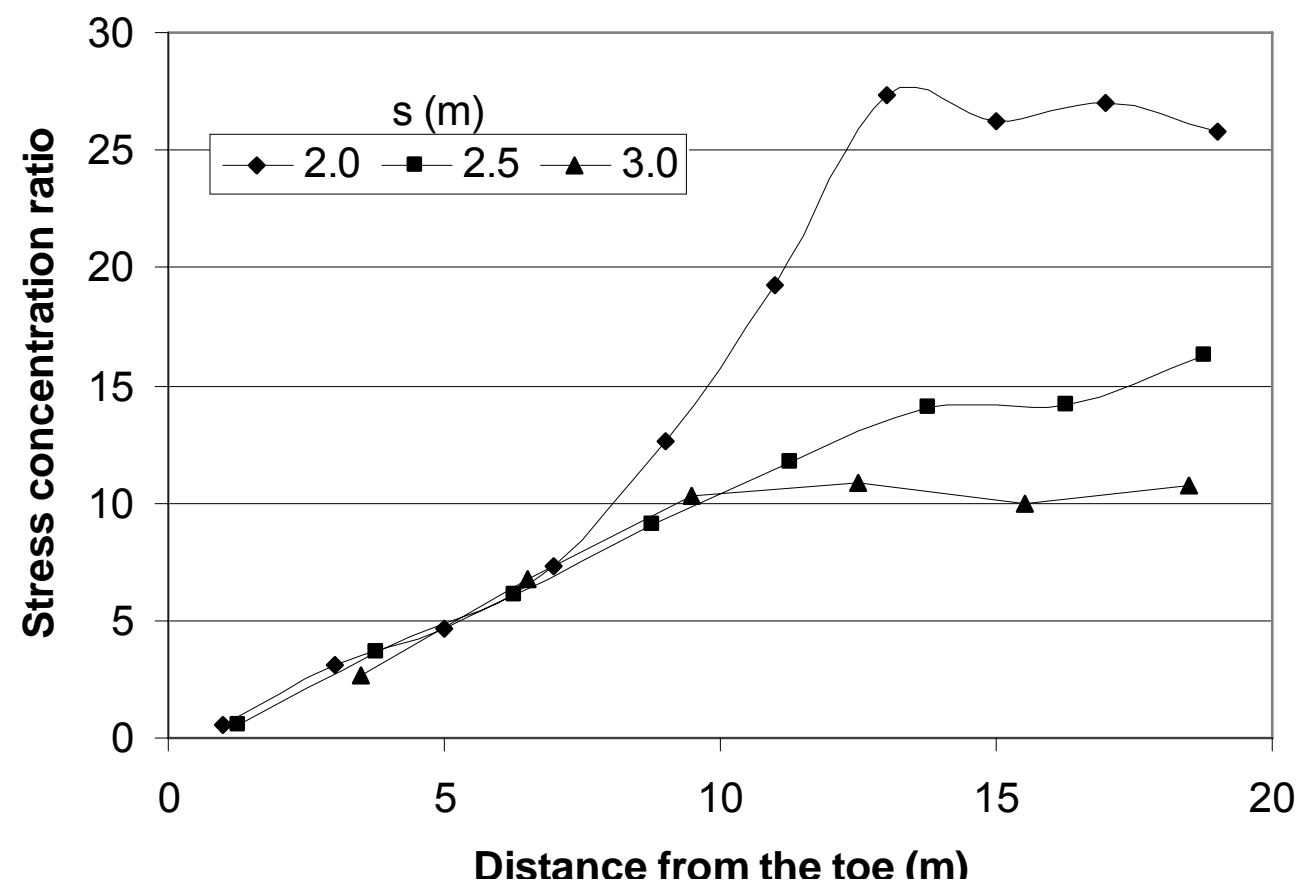

(a) 1 month after service

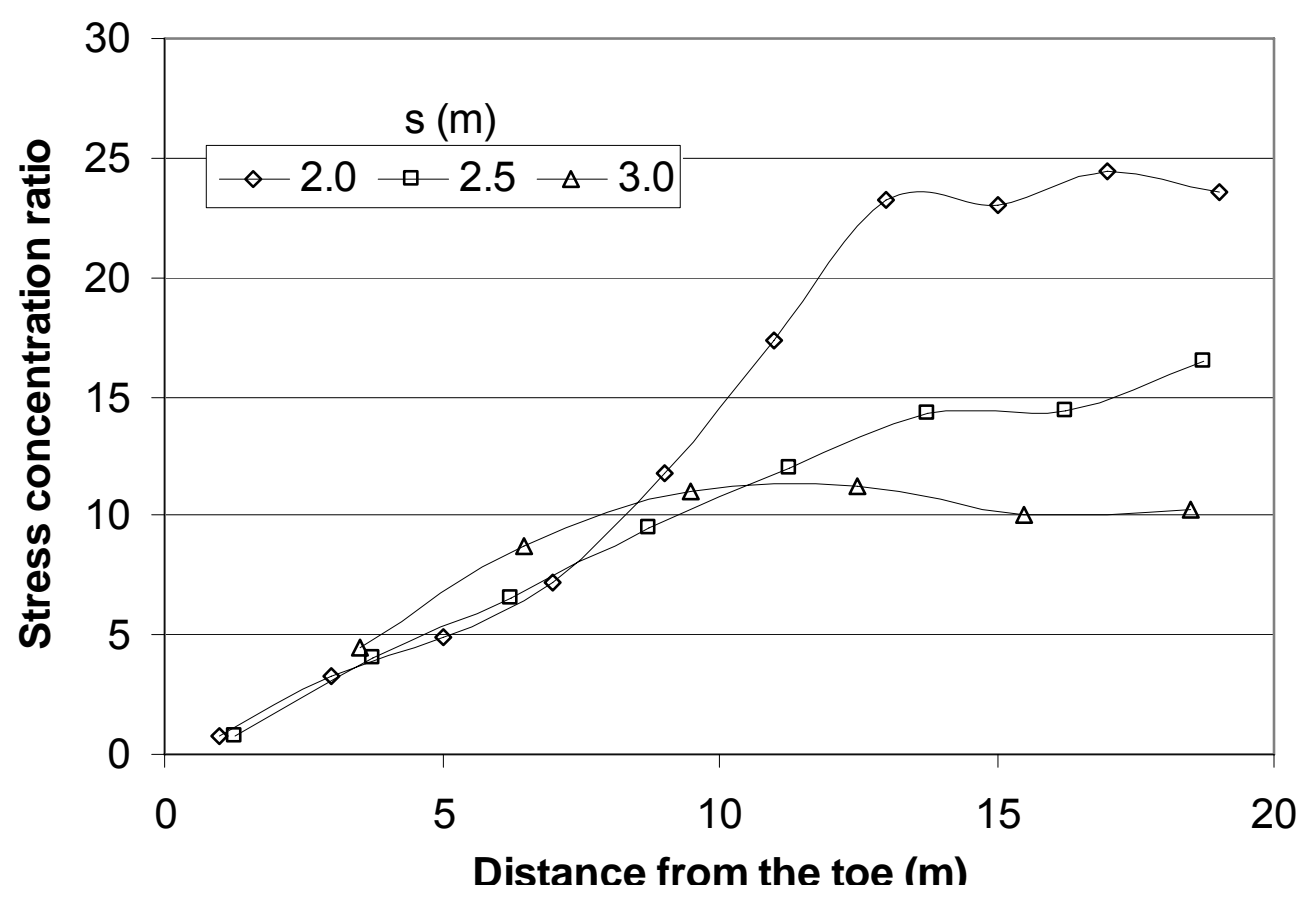

(b) 30 years after service

Fig. 4-80. Stress Concentration Ratio Profiles for Various Column Spacing (2D) 
Figure 4-80 shows that the overall effect of the increase in the additional vertical effective stresses due to the larger column spacing yielded to a reduction in the stress concentration ratio.

\section{Influence of Geosynthetic Tensile Stiffness}

The influences of the tensile stiffness on the additional vertical effective stress and the stress concentration ratio are presented in Fig. 4-81 and 4-82, respectively.

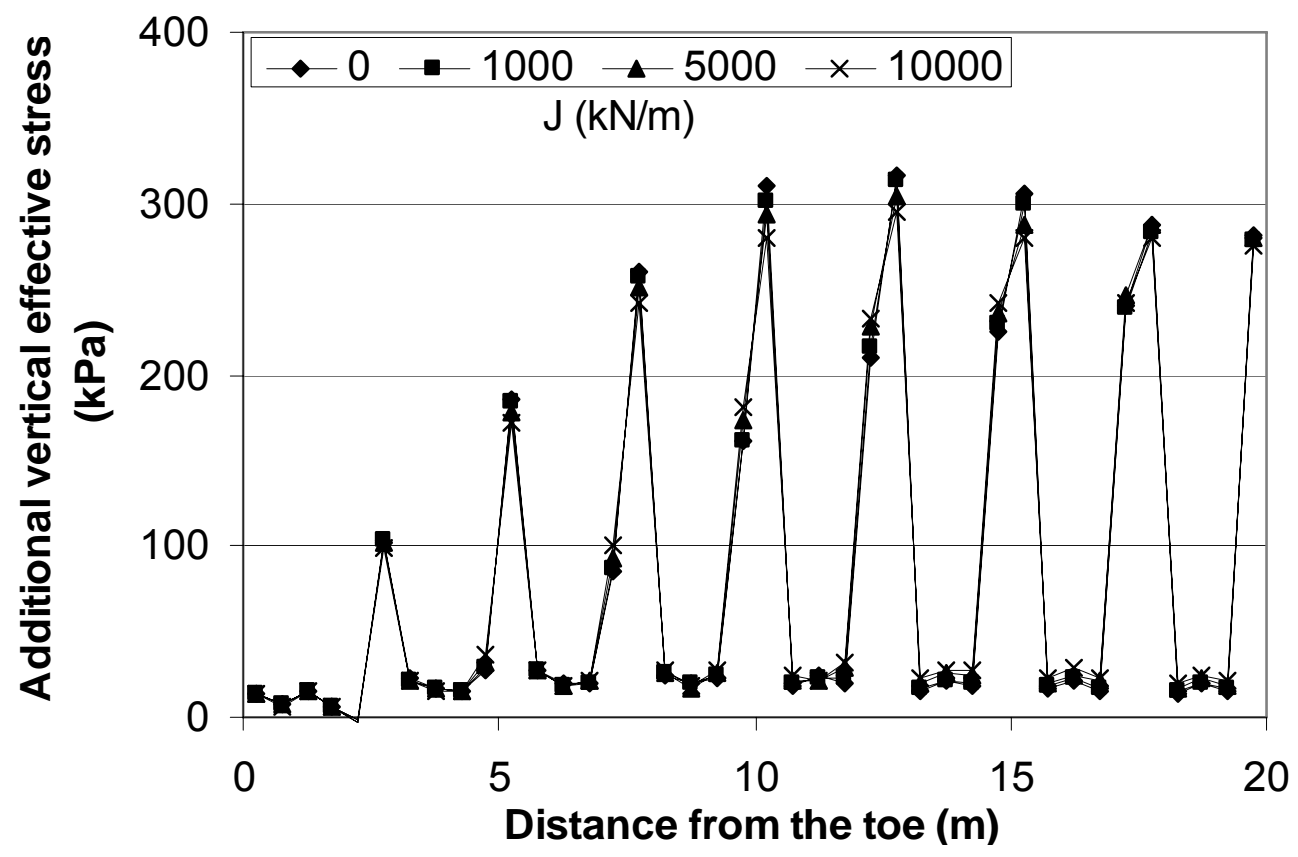

(a) 1 month after service

Fig. 4-81. Additional Vertical Effective Stress Profiles for Various Tensile Stiffness (2D) 


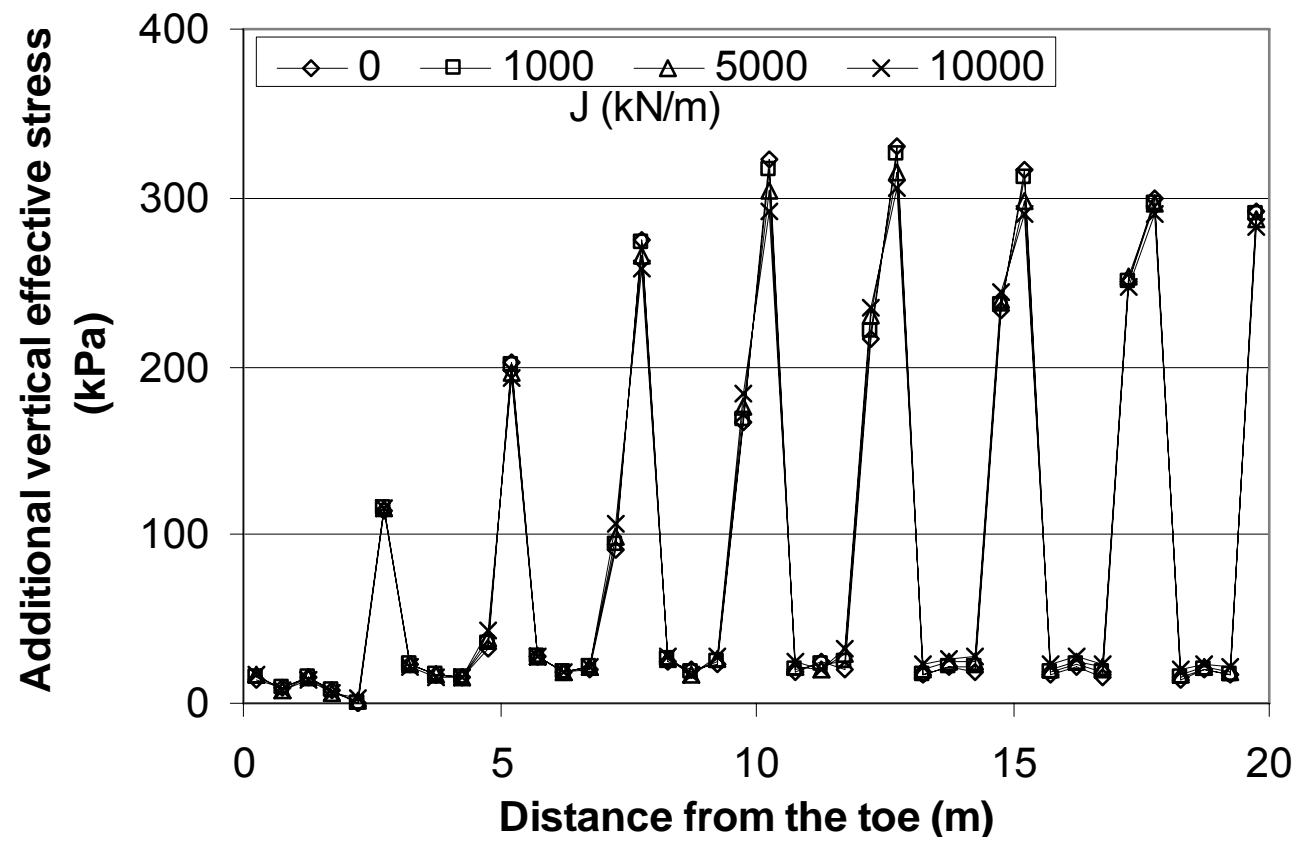

(b) 30 years after service

Fig. 4-81. Additional Vertical Effective Stress Profiles for Various Tensile Stiffness (2D) (continued)

The increase of the tensile stiffness slightly reduced the additional vertical effective stress on the columns but increased the stress in the soil. Hence, the increase of the geosynthetic tensile stiffness yielded a slight decrease on the stress concentration ratio. 


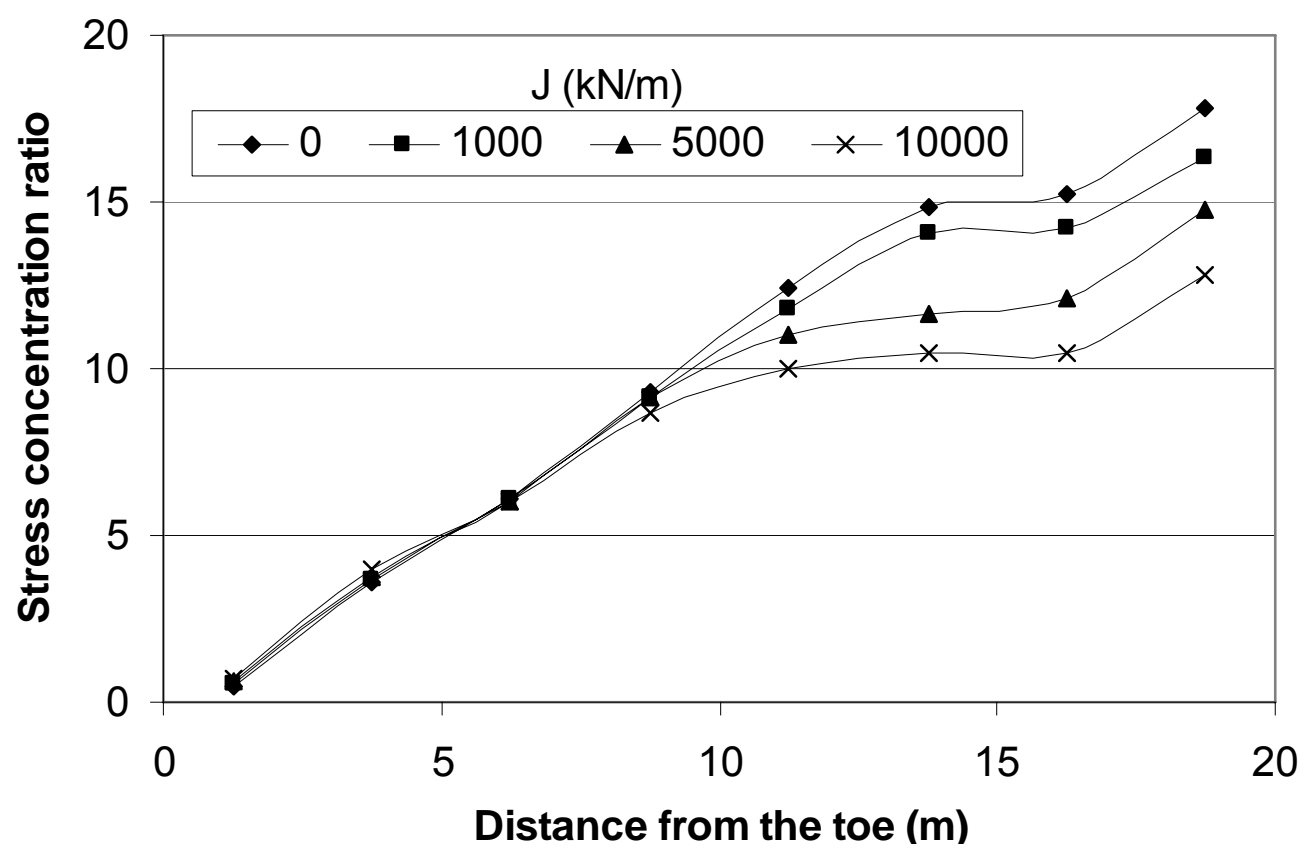

(a) 1 month after service

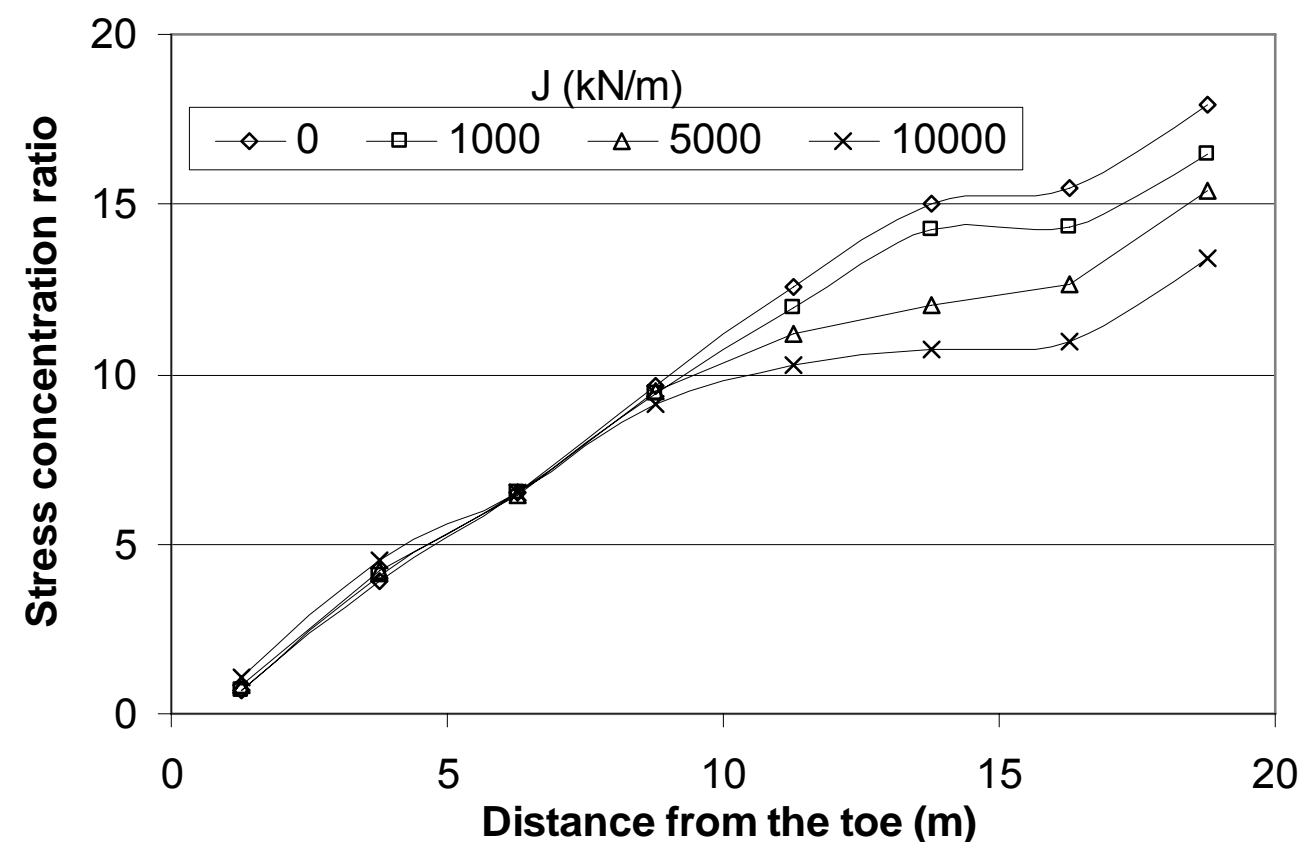

(b) 30 years after service

Fig. 4-82. Stress concentration Ratio Profiles for Various Tensile Stiffness (2D) 


\section{Influence of Construction Rate}

The profiles of the additional vertical effective stress and the stress concentration ratio are presented in Fig. 4-83 and 4-84, respectively. It can be seen that the higher construction rate led to a higher stress on the columns but a lower stress in the soft soil.

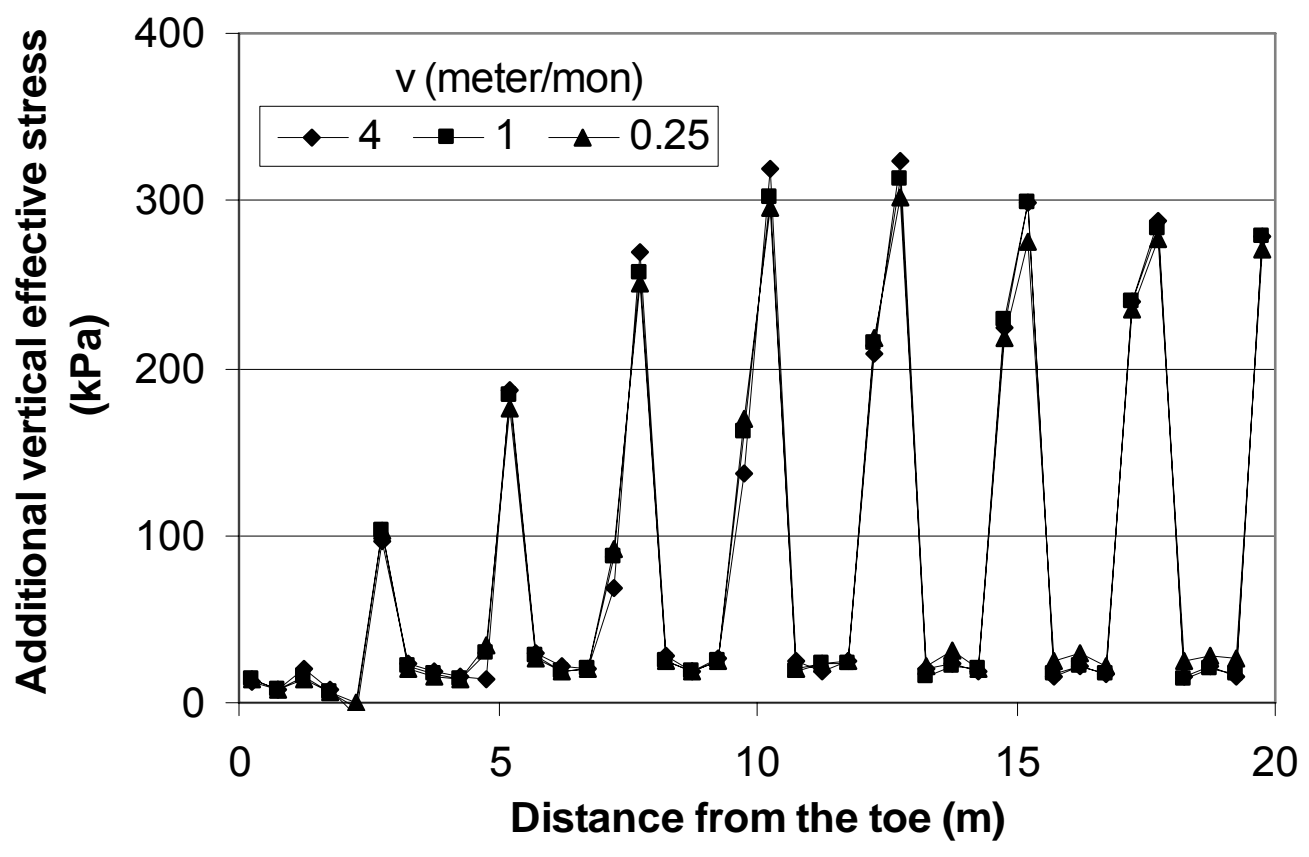

(a) 1 month after service

Fig. 4-83. Additional Vertical Effective Stress Profiles for Various Average Construction Rates (2D) 


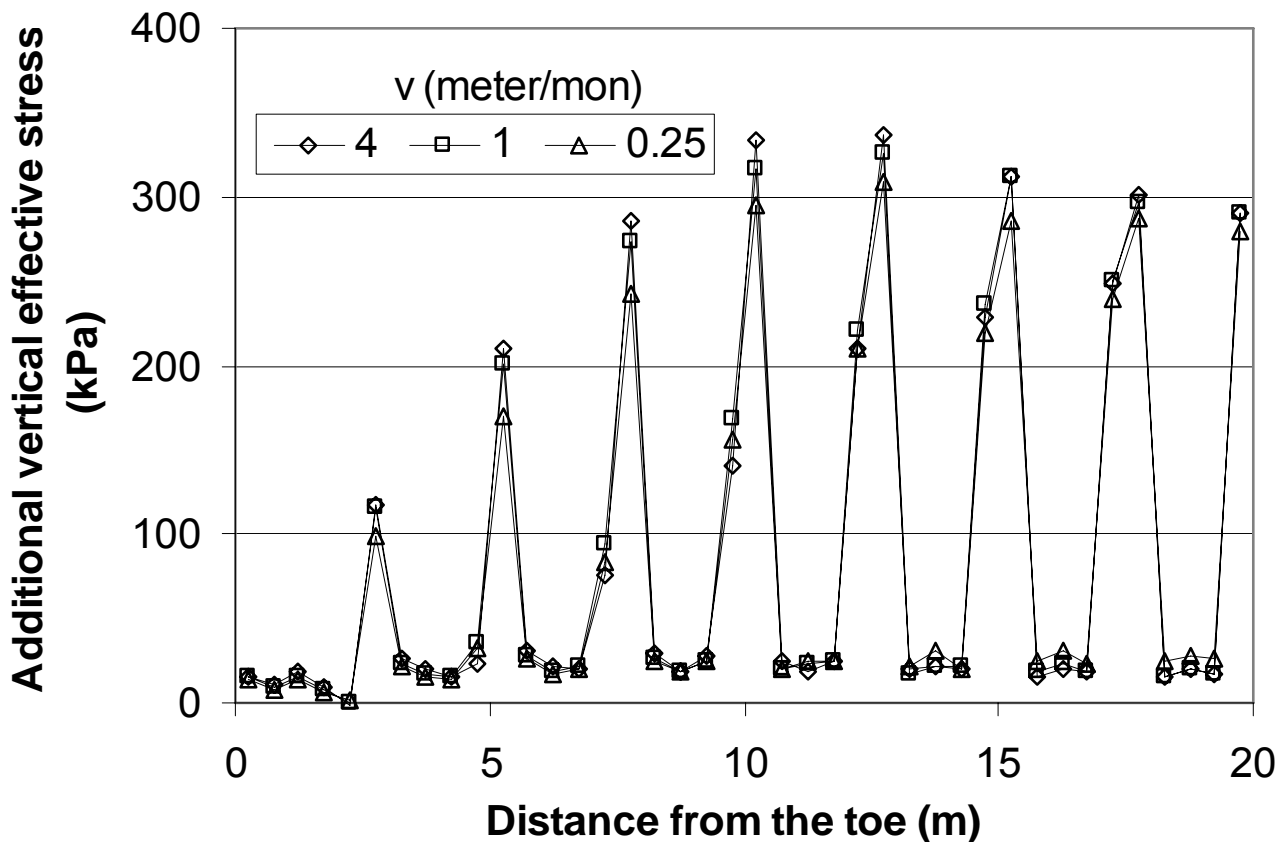

(b) 30 years after service

Fig. 4-83. Additional Vertical Effective Stress Profiles for Various Average Construction Rates (2D) (continued)

The profiles of the stress concentration ratios at different construction rates are similar to those at different soil permeability values. It is shown that the higher construction rate led to the higher stress concentration ratio. 


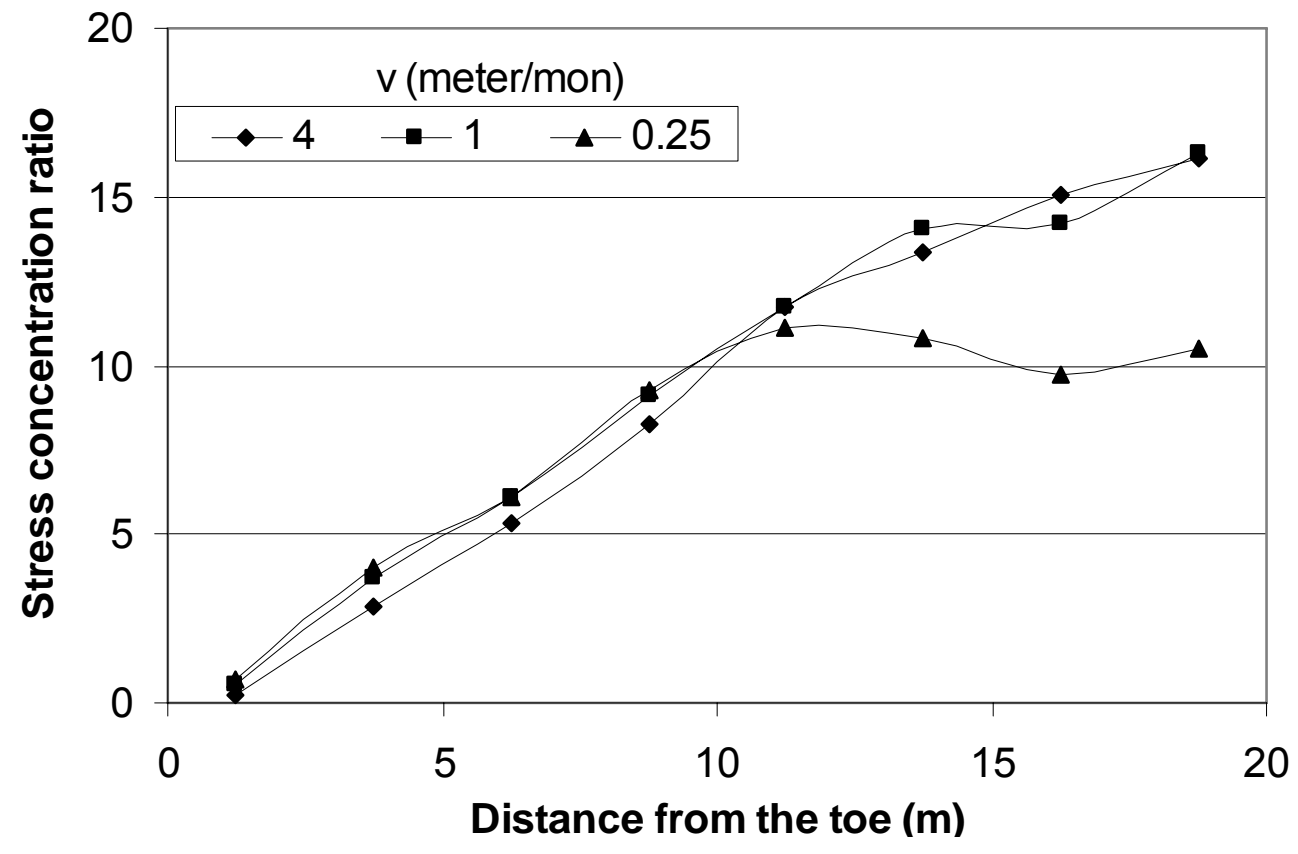

(a) 1 month after service

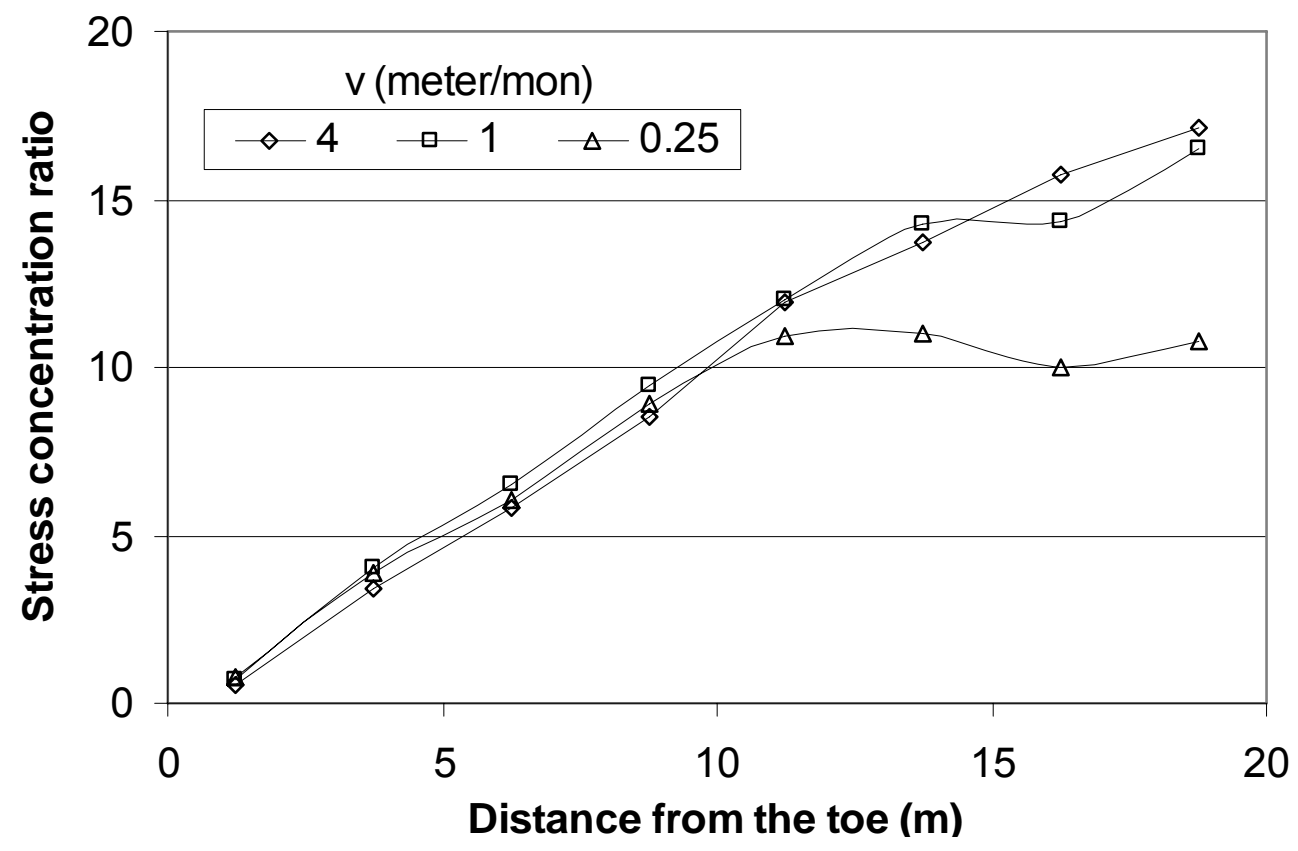

(b) 30 years after service

Fig. 4-84. Stress Concentration Ratio Profiles for Various Average Construction Rates (2D) 


\subsubsection{Excess Pore Water Pressure}

During construction and traffic loading, excess pore water pressure is generated within soft soil. Generated excess pore water pressure dissipates simultaneously through two ways: (1) drainage and (2) load transfer from pore water to the columns (Han and Ye 2001). As a result, the excess pore water pressure in the soft soil generated under the GRCS embankment dissipates much faster than through the drainage alone. Traditional consolidation theories would underestimate the degree of consolidation under the GRCS embankments.

In this study, the influence of various factors on the excess pore water pressure and the degree of consolidation was evaluated. Based on the excess pore water pressure at a certain time, the degree of consolidation can be calculated using the following equation:

$$
U(\%)=\frac{\sum\left(u_{i} \cdot h_{i}\right)}{(\gamma \cdot H+q) \cdot H_{o}} \times 100
$$

where $u_{i}$ - the excess pore water pressure at the center of the $i^{\text {th }}$ zone;

$\mathrm{h}_{\mathrm{i}}$ - the vertical dimension of the $\mathrm{i}^{\text {th }}$ zone;

$\gamma$ - the unit weight of the embankment fill;

$\mathrm{H}$ - the height of the embankment; 


$$
\begin{aligned}
& \mathrm{H}_{\mathrm{o}} \text { - thickness of the foundation soil, which is } 12 \mathrm{~m} \text { in this study; } \\
& \mathrm{q} \text { - the traffic load. }
\end{aligned}
$$

In this study, the embankment height, $H$, the unit weight of embankment fill, $\gamma$, and the traffic load, q were constant. Hence, the denominator of Equation 4-4 was $18 \times 5+12=102 \mathrm{kPa}$.

Since the excess pore water pressure completely dissipated at the end of 30 year service, i.e., $100 \%$ consolidation, only the excess pore water pressure distribution and the degree of consolidation at one month after service are presented below.

\section{Influence of Soft Soil Elastic Modulus}

The excess pore water distributions within the soft soil along the depth at various soft soil moduli are presented in Fig. 4-85. Generally speaking, the higher soft soil modulus resulted in higher excess pore water pressures at one month after service. This phenomenon resulted from the lower stress concentration ratio at the higher soft soil modulus. As demonstrated by Han and Ye (2001), the higher stress concentration ratio accelerated the dissipation of excess pore water pressure. 


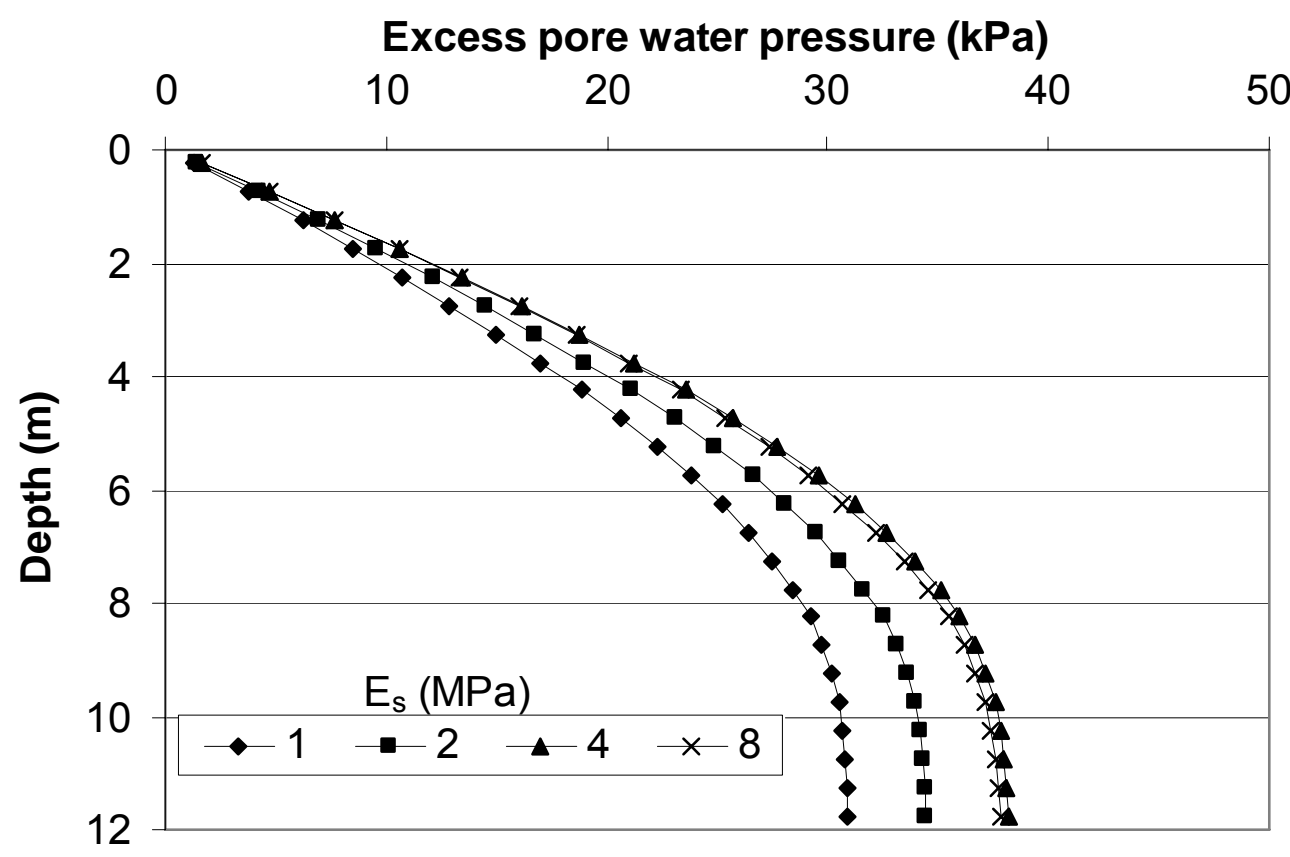

Fig. 4-85. Excess Pore Water Pressure Distributions for Various Soil Moduli (2D)

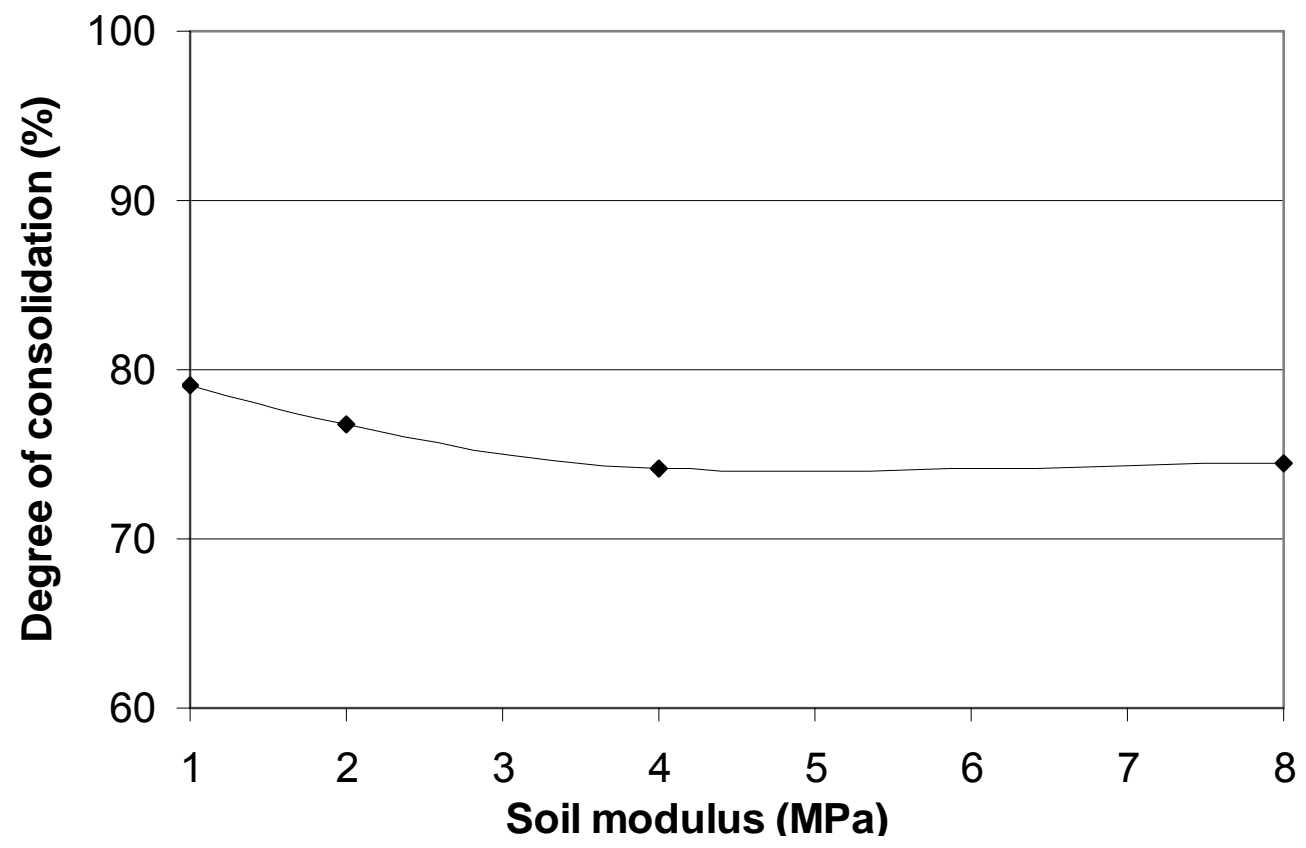

Fig. 4-86. Degree of Consolidation versus Soil Modulus (2D) 
Figure 4-86 presents the degree of consolidation versus the soft soil modulus. It is shown that the lower soft soil modulus yielded the higher degree of consolidation.

\section{Influence of Soft Soil Friction Angle}

The excess pore water distributions along the depth at different soil friction angles are shown in Fig. 4-87. It is shown that a smaller soil friction angle yielded lower excess pore water pressure at one month after service as a result of a higher stress concentration ratio. However, the difference in the excess pore water pressures at different soil friction angles was relatively small. As a result, the soil friction angle had an insignificant effect on the degree of consolidation as shown in Fig. 4-88.

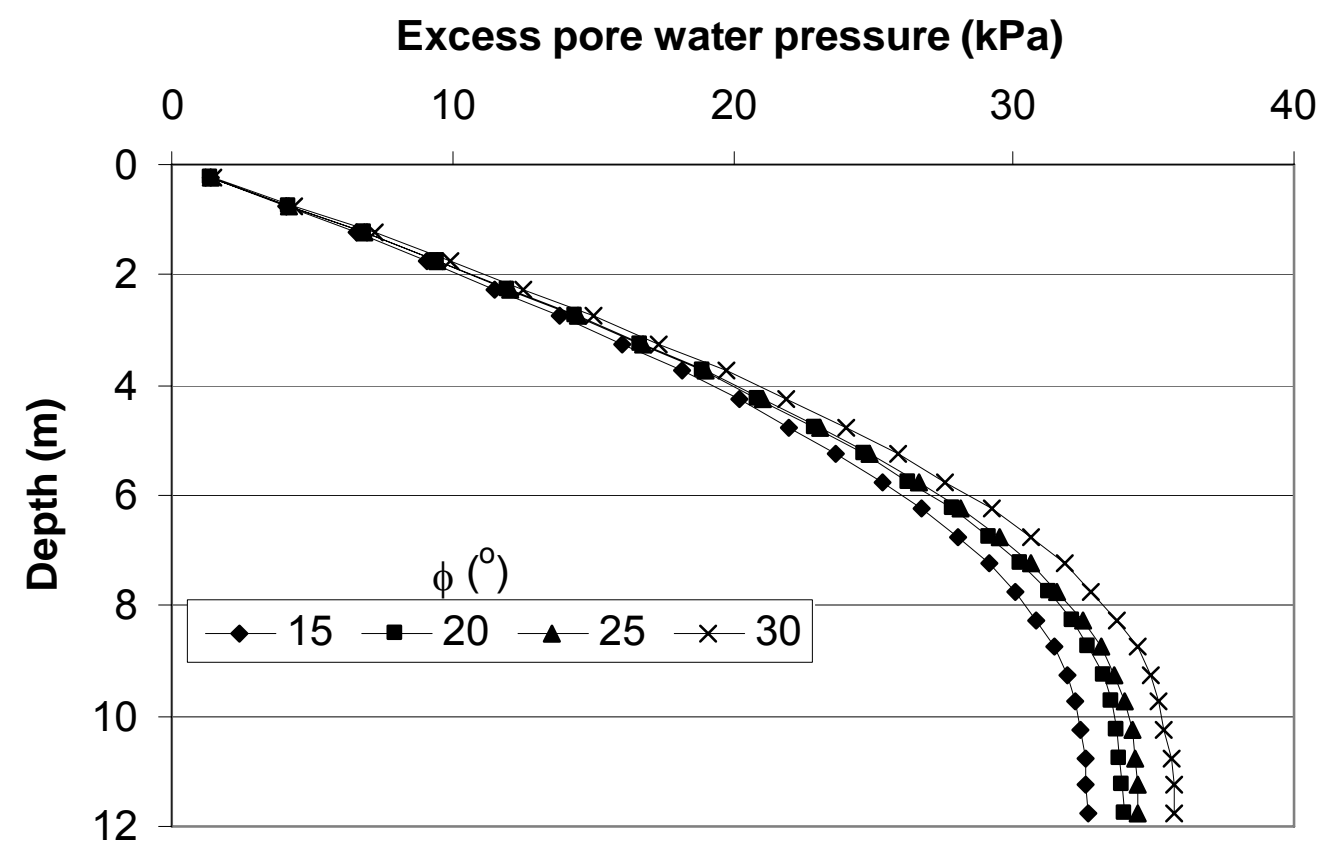

Fig. 4-87. Excess Pore Water Pressure Distributions for Various Friction Angles (2D) 


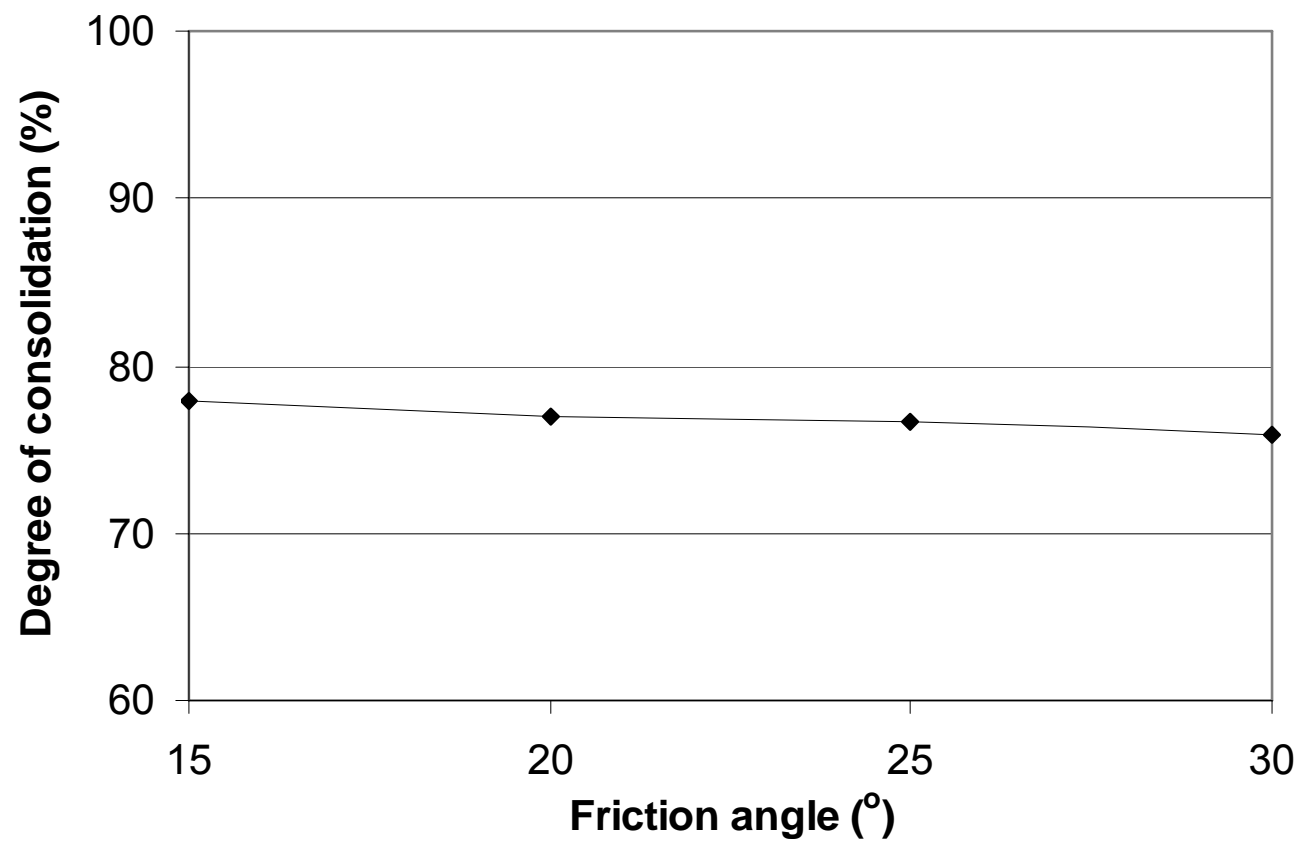

Fig. 4-88. Degree of Consolidation versus Friction Angle (2D)

\section{Influence of Soft Soil Permeability}

As expected, the soil permeability had a significant influence on the excess pore water pressure as shown in Fig. 4-89 because the increase in the soil permeability accelerated the drainage of the excess pore water. Figure 4-90 shows the effect of the soil permeability on the degree of consolidation. It is found that the degree of consolidation reached approximately $100 \%$ at the soil permeability of $10^{-8} \mathrm{~m} / \mathrm{s}$ at one month of service. 


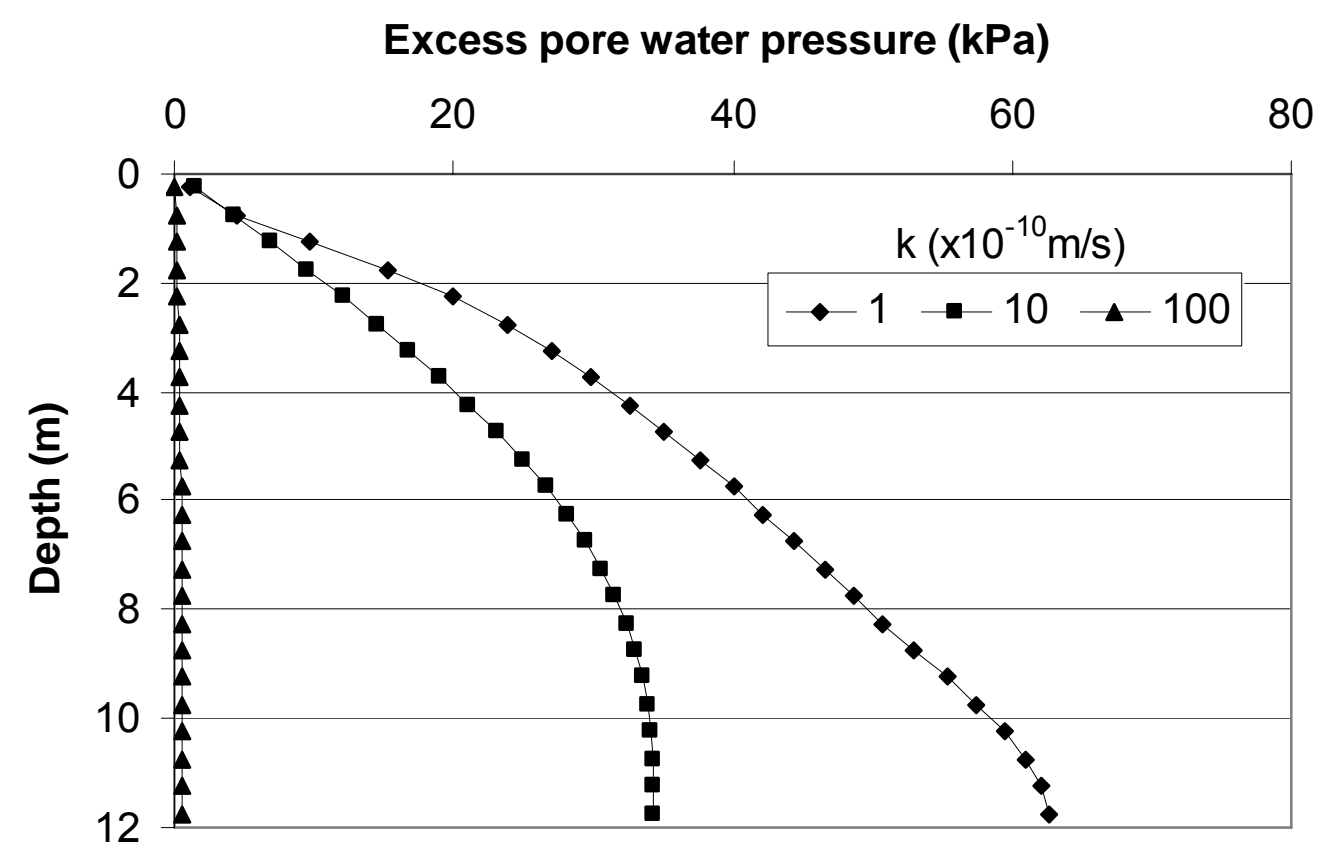

Fig. 4-89. Excess Pore Water Pressure Distributions for Various Soil Permeability (2D)

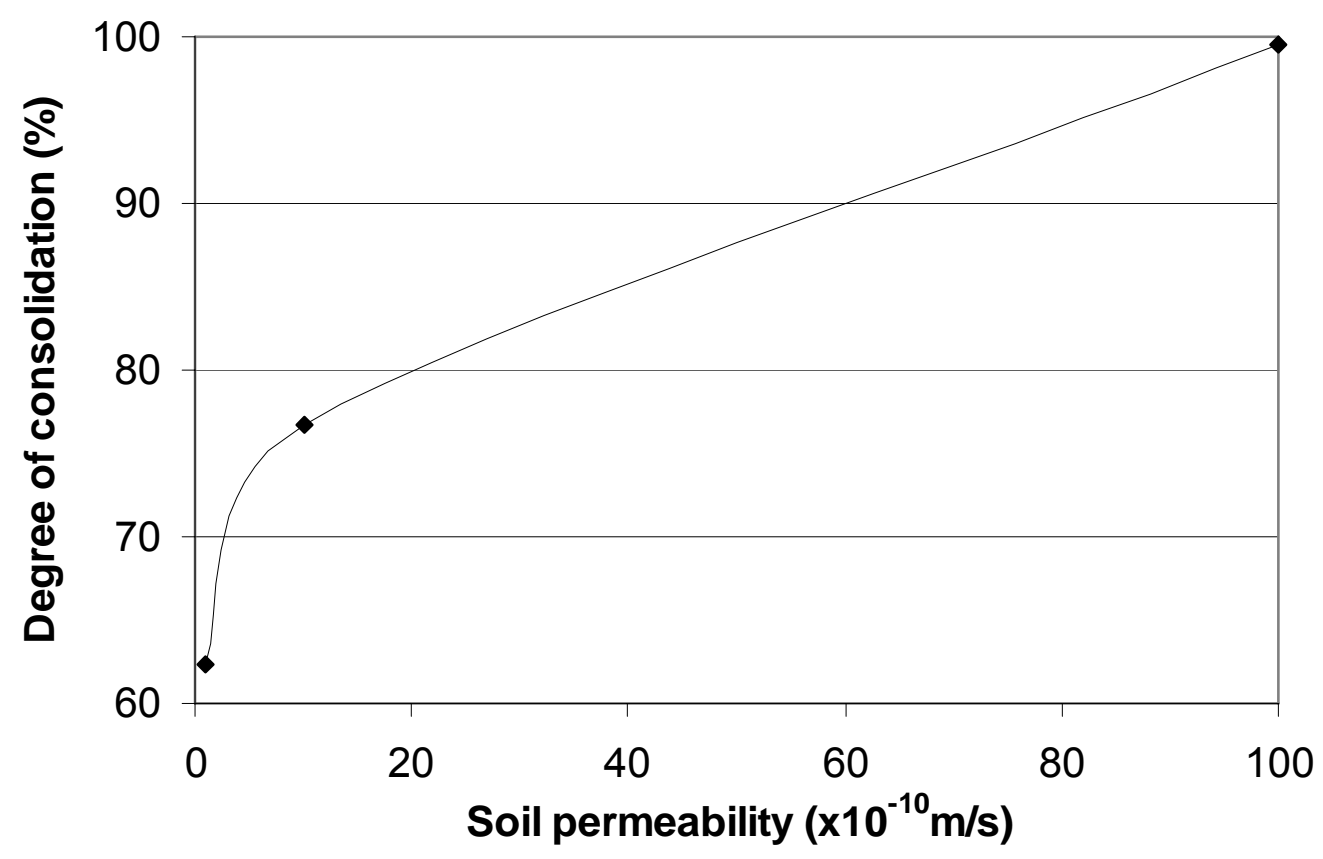

Fig. 4-90. Degree of Consolidation versus Soil Permeability (2D) 


\section{Influence of Column Elastic Modulus}

The distributions of the excess pore water pressures along the depth and the degree of consolidation versus the column modulus are presented in Fig. 4-91 and 4-92, respectively. It is shown that the higher the column modulus, accelerated the dissipation of the excess pore water pressure was accelerated by transferring more load from the soil to the columns.

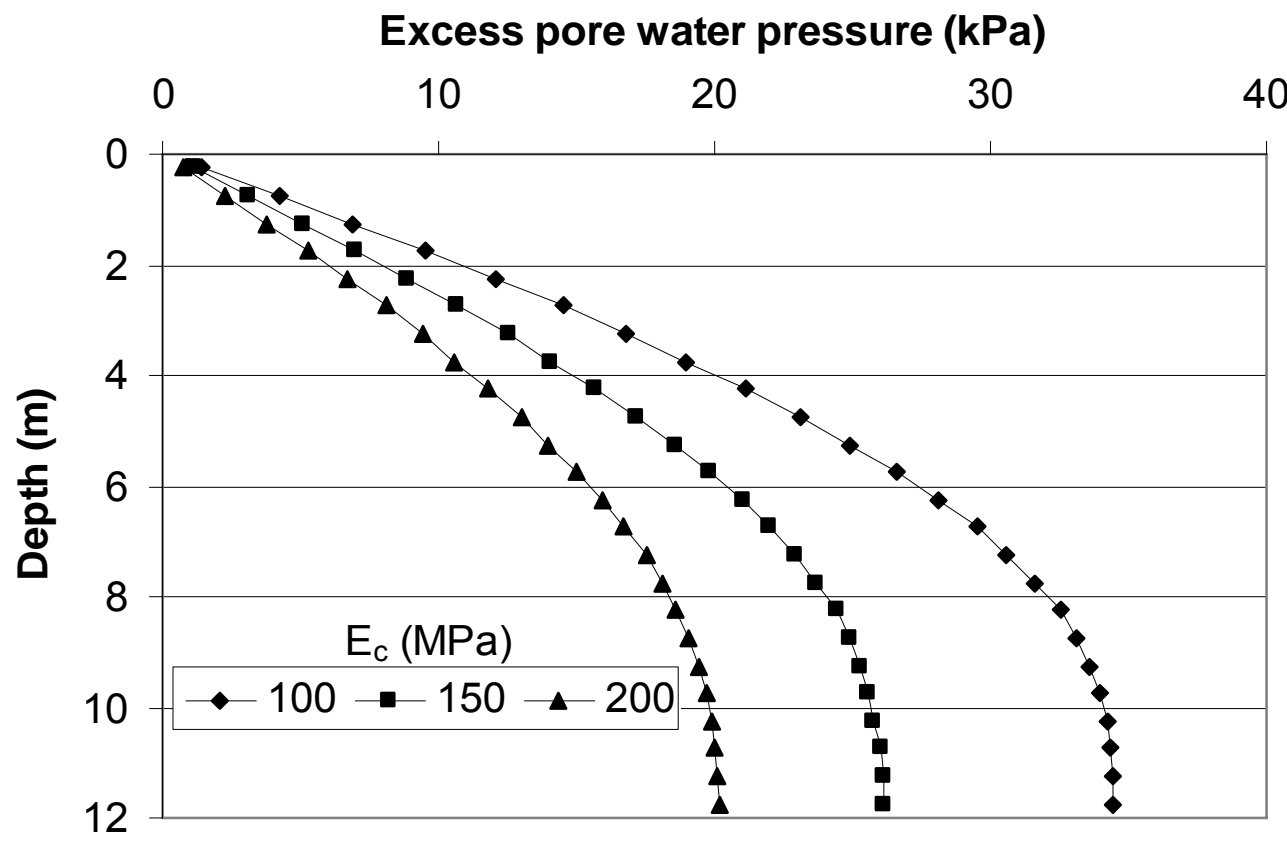

Fig. 4-91. Excess Pore Water Pressure Distributions for Various Column Moduli (2D) 


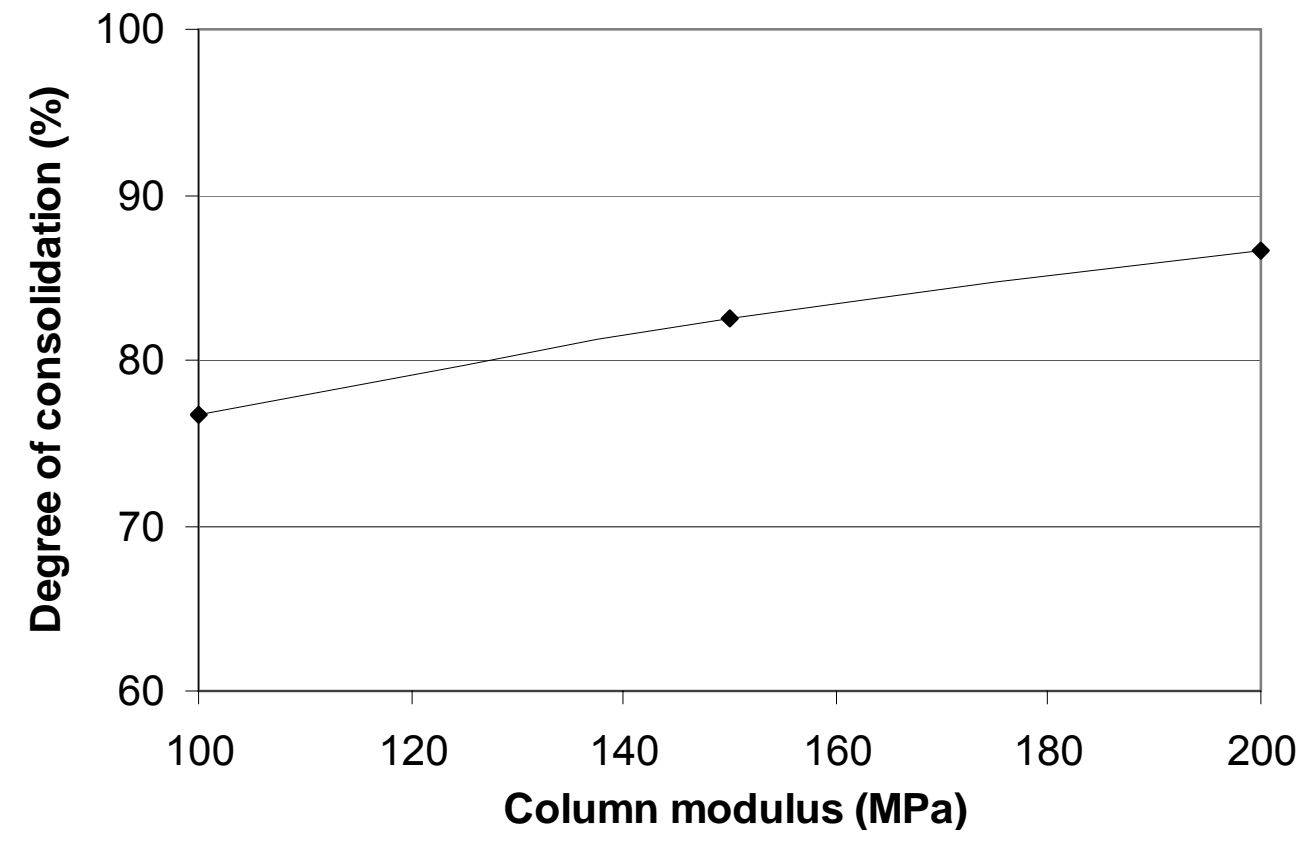

Fig. 4-92. Degree of Consolidation versus Column Modulus (2D)

\section{Influence of Column Spacing}

The influence of column spacing on excess pore water pressure is presented in Fig. 493 and on the degree of consolidation is presented in Fig. 4-94. It is shown that the larger column spacing yielded the higher excess pore water pressure and the lower degree of consolidation. This outcome resulted from a combination of less load transferred to the columns and larger pore water volume for dissipation. 


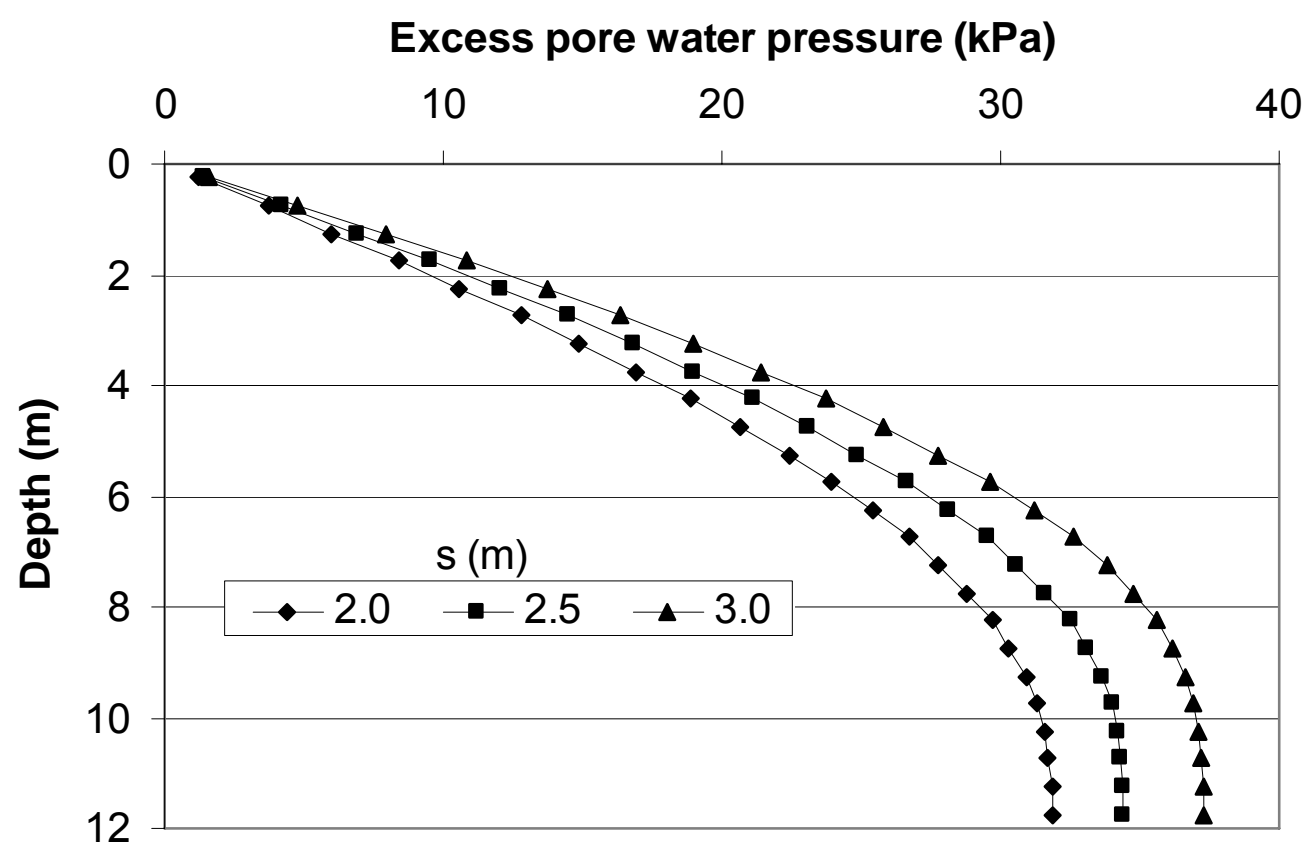

Fig. 4-93. Excess Pore Water Pressure Distributions for Various Column Spacing (2D)

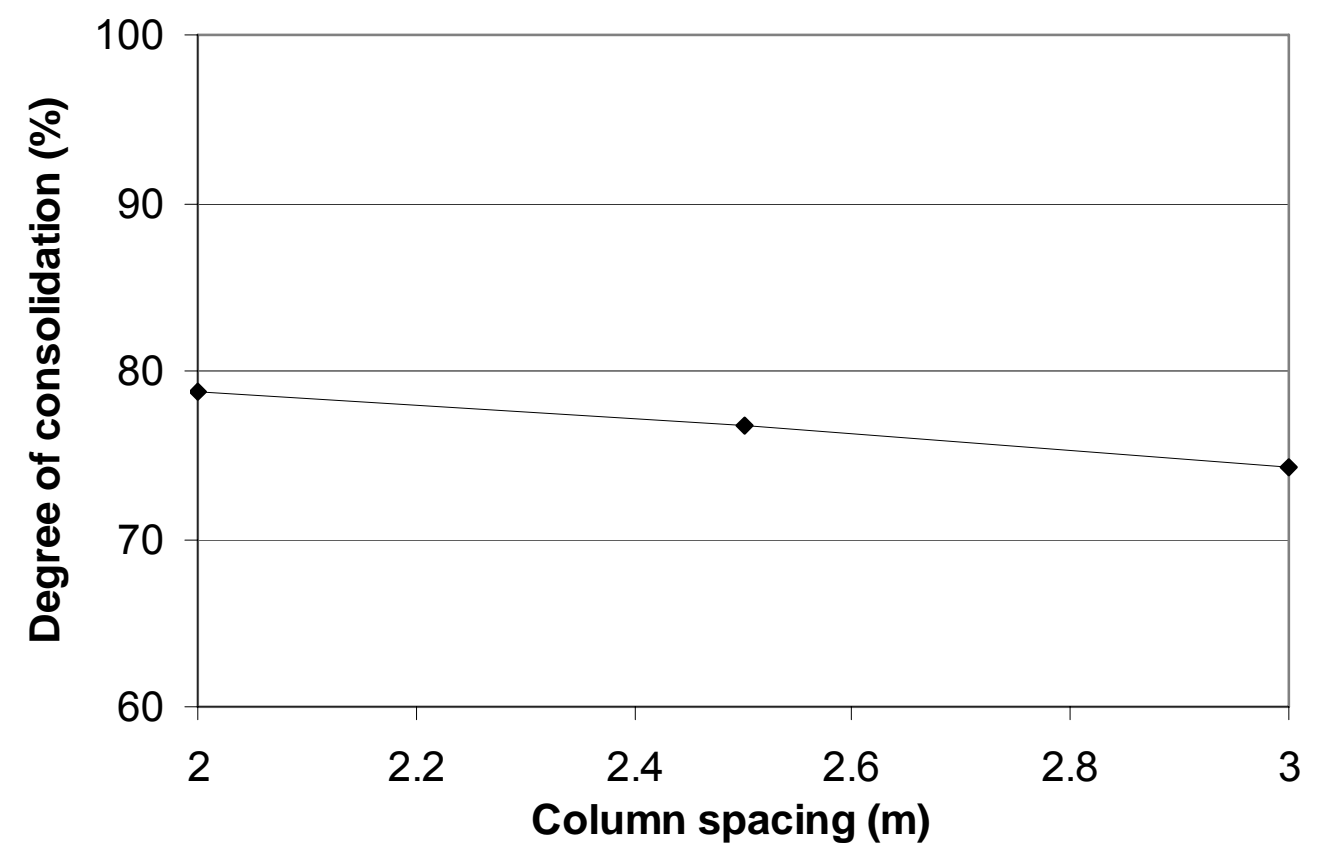

Fig. 4-94. Degree of Consolidation versus Column Spacing (2D) 


\section{Influence of Geosynthetic Tensile Stiffness}

The influences of the geosynthetic tensile stiffness on the excess pore water pressure are presented in Figs. 4-95 and 4-96. The increase of the geosynthetic tensile stiffness led to a slight increase in the excess pore water pressure and a slight decrease in the degree of consolidation. The geosynthetic with the higher tensile stiffness can reduce the differential settlement and make the problem closer to an equal strain condition. Huang (1983) indicated that the equal strain condition has a lower degree of consolidation than the equal stress condition. However, the overall influence is marginal.

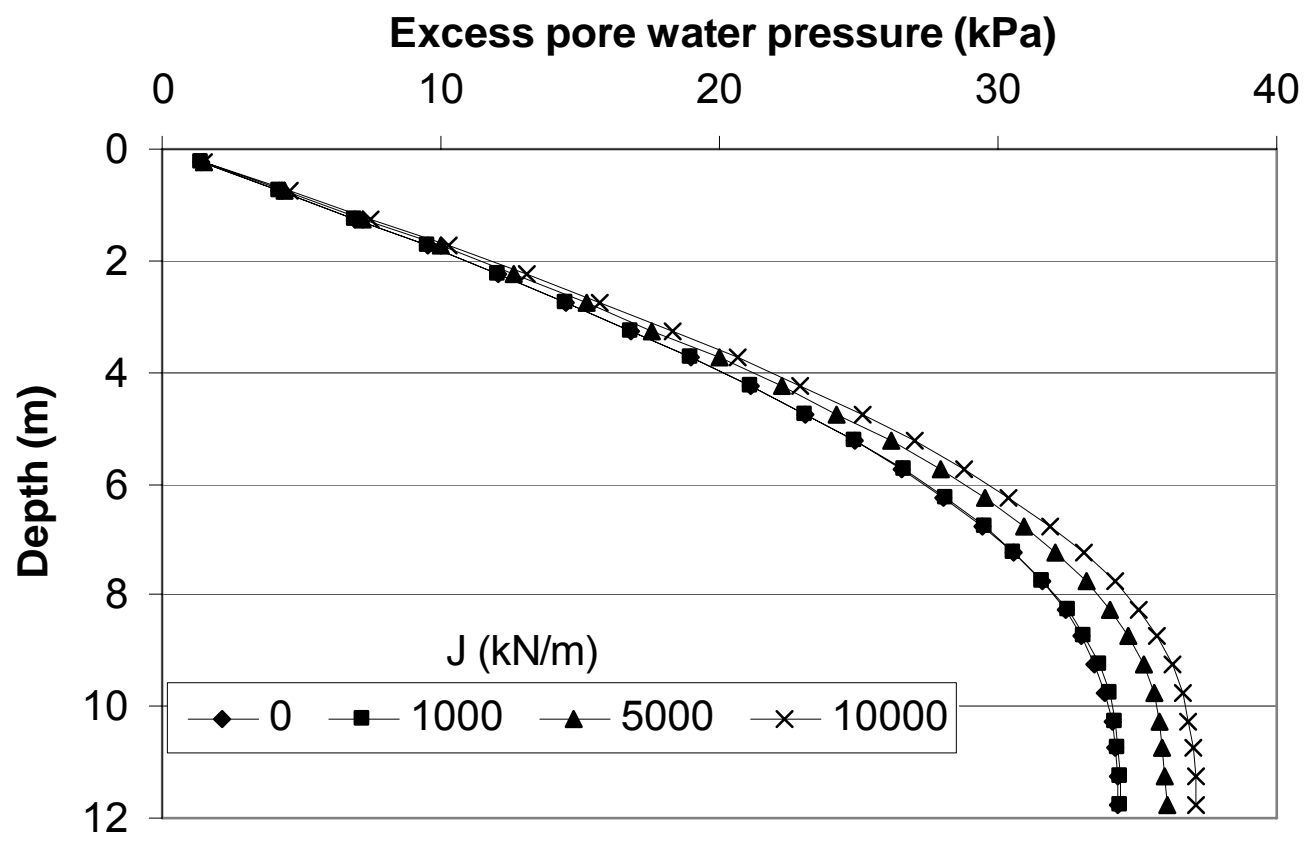

Fig. 4-95. Excess Pore Water Pressure Distributions for Various Tensile Stiffness (2D) 


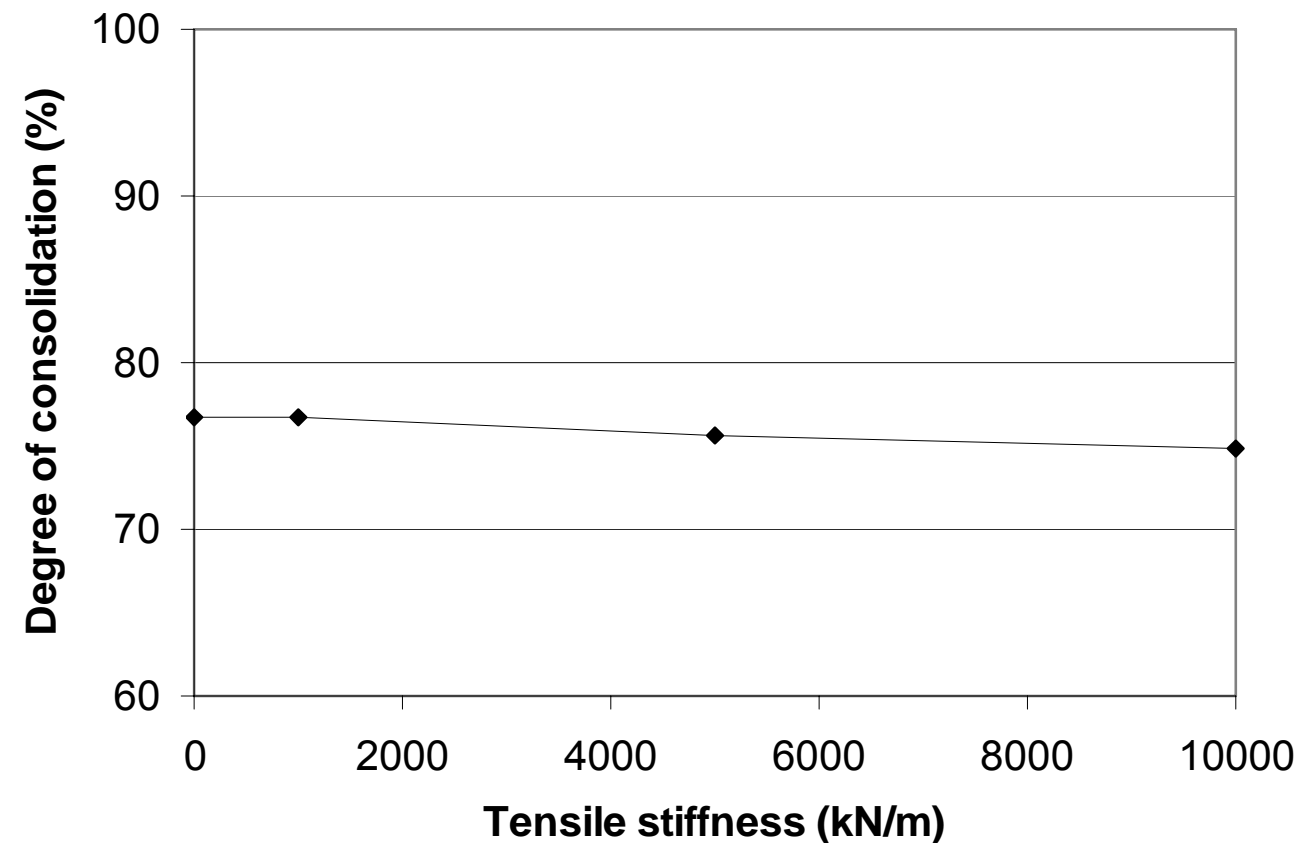

Fig. 4-96. Degree of Consolidation versus Tensile Stiffness (2D)

\section{Influence of Construction Rate}

Figure 4-97 presents the distributions of the excess pore water pressure at different construction rates. It is shown that the higher construction rate had less time for the dissipation of the excess pore water pressure during the construction; thus, more excess pore water pressure remained. As a result, the higher construction rate led to the lower degree of consolidation as shown in Fig. 4-98. 


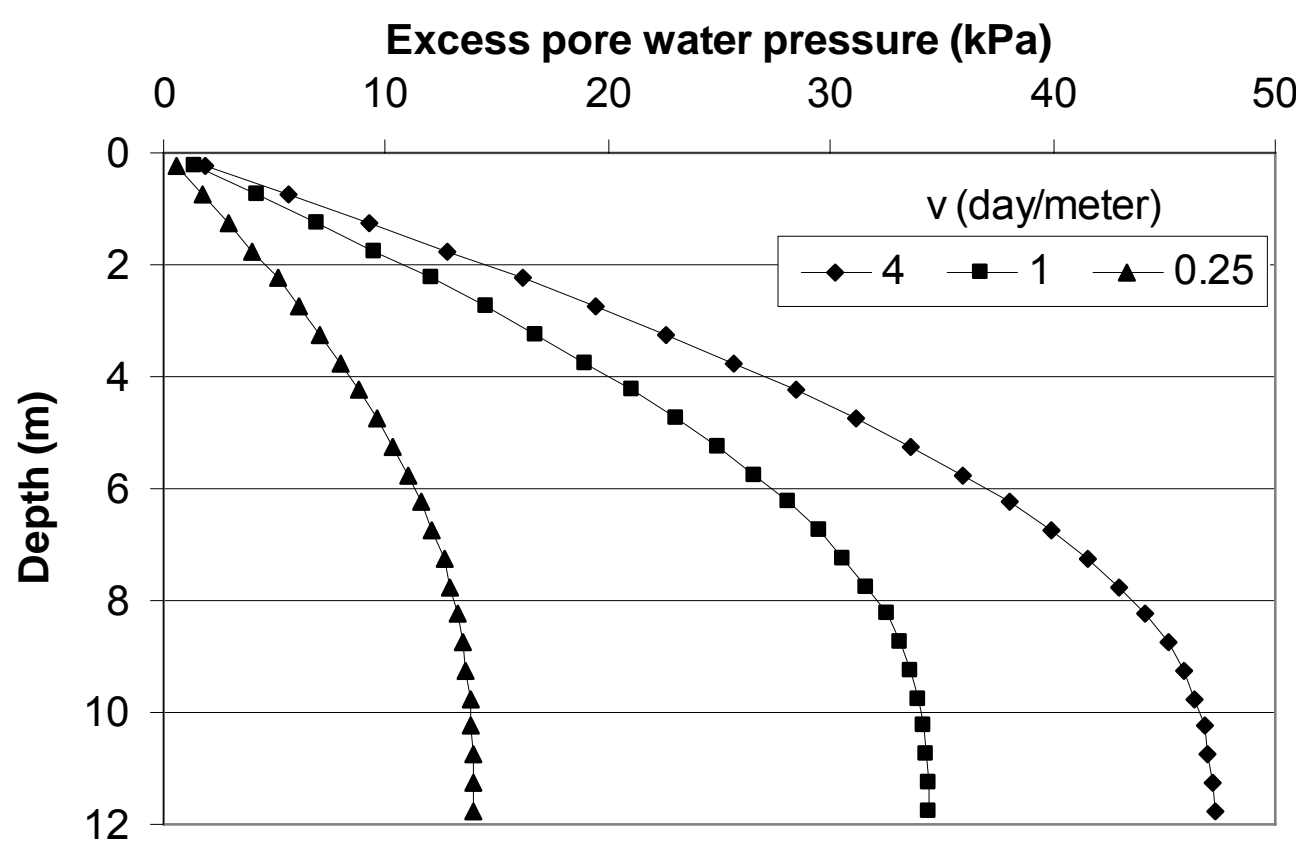

Fig. 4-97. Excess Pore Water Pressure Distributions for Various Average Construction Rates (2D)

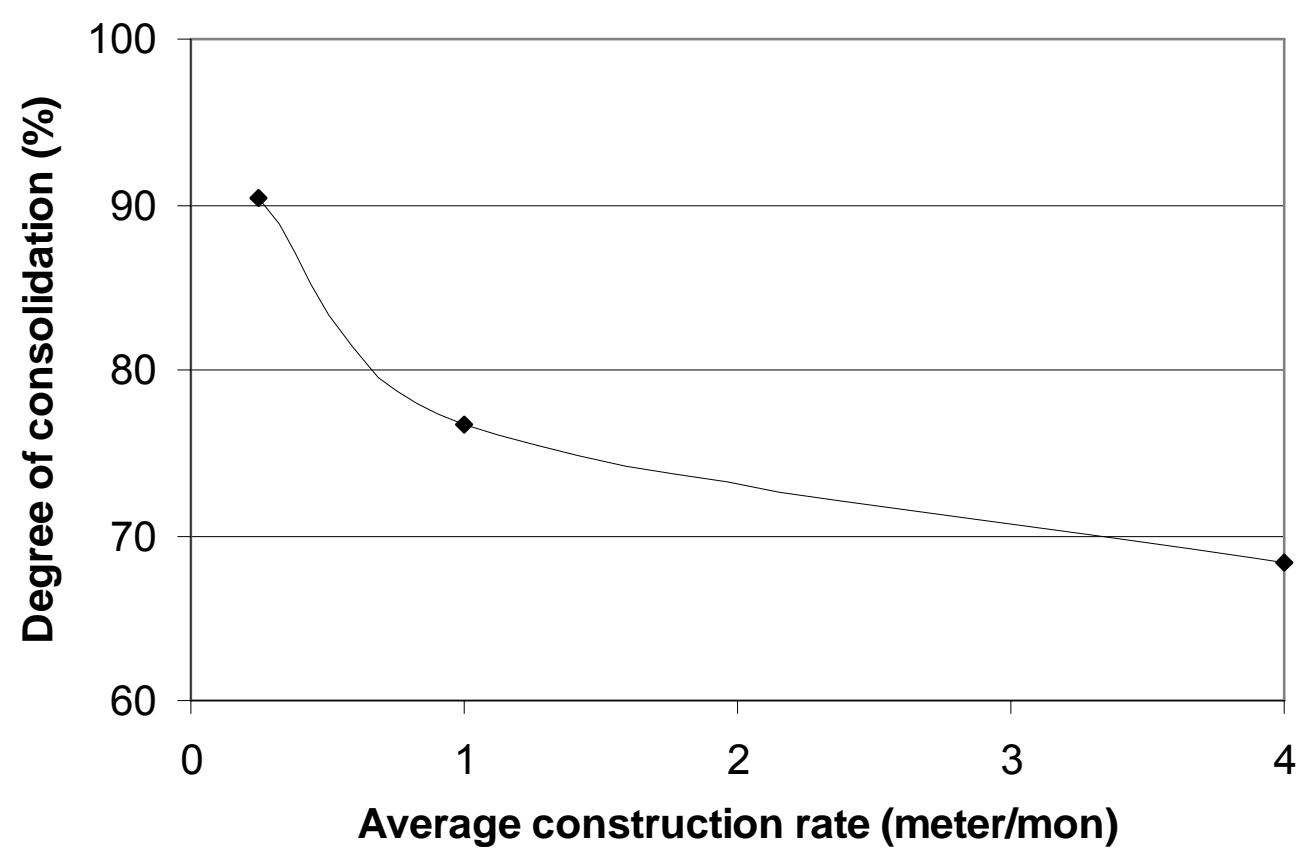

Fig. 4-98. Degree of Consolidation versus Average Construction Rate (2D) 


\section{CHAPTER FIVE}

\section{THREE-DIMENSIONAL PARAMETRIC STUDY}

A comprehensive parametric study presented in Chapter Four was conducted using FLAC to study the GRCS embankments under a plane strain condition. However, in many situations, DM columns are installed in a three-dimensional pattern, such as a square or triangular pattern, which cannot be simplified into a plane strain condition according to its geometric configuration. To study the performance of a GRCS embankment under a three-dimensional situation, a three-dimensional parametric study was conducted with the assistance of FLAC3D, a finite difference software developed by Itasca Consulting Group, Inc.

Similar to the two-dimensional parametric study, a three-dimensional parametric study was also conducted in the coupled mechanical and hydraulic modeling scenario. A selected baseline case was first simulated. The selected baseline was assumed to have DM columns installed in a square pattern, which is commonly used in practice. A parametric study was performed by deviating one parameter at a time from the baseline to investigate the influence of the specific factor on settlement, tension, vertical stress, and excess pore water pressure. The investigated factors include what have been studied in two-dimensional parametric study plus the column installation

pattern. The investigation of the influence of the installation pattern was conducted by 
changing the square pattern in the baseline case to a triangular pattern or plane strain pattern with the same area replacement ratio.

Due to extreme time consumption, the 3D simulation was performed up to five years after service but not up to 30 years after service as the $2 \mathrm{D}$ simulation.

\subsection{D Baseline Case}

\subsubsection{D Dimensions and Properties}

To ensure the 3D results were comparable with the 2D ones presented in Chapter 4, a 3D baseline case was determined based on the 2D baseline case. The elevation and plan views of the 3D baseline case are presented in Fig. 5-1. Only one span in the traffic direction (the y-direction in Fig. 5-1) was modeled to save the computation time and rollers were used in the two boundaries in the y-direction to simulate the symmetry of the problem in this direction. Columns were assumed to be arranged in a square pattern with a spacing of $2.5 \mathrm{~m}$. Due to the symmetry to the centerline of the embankment, only half of the embankment was modeled. The mechanical boundary conditions in the $\mathrm{x}$ and $\mathrm{z}$ directions are shown in Fig. 5-1. In terms of the hydraulic boundary conditions, the bottom of the model and the boundaries in the x-direction 
were assumed impervious. These assumptions are consistent with those adopted in the 2D modeling in Chapter 4. The two boundaries in the y-direction were also assumed impervious to account for the symmetry in the y-direction; therefore, no water left or entered these two boundaries.

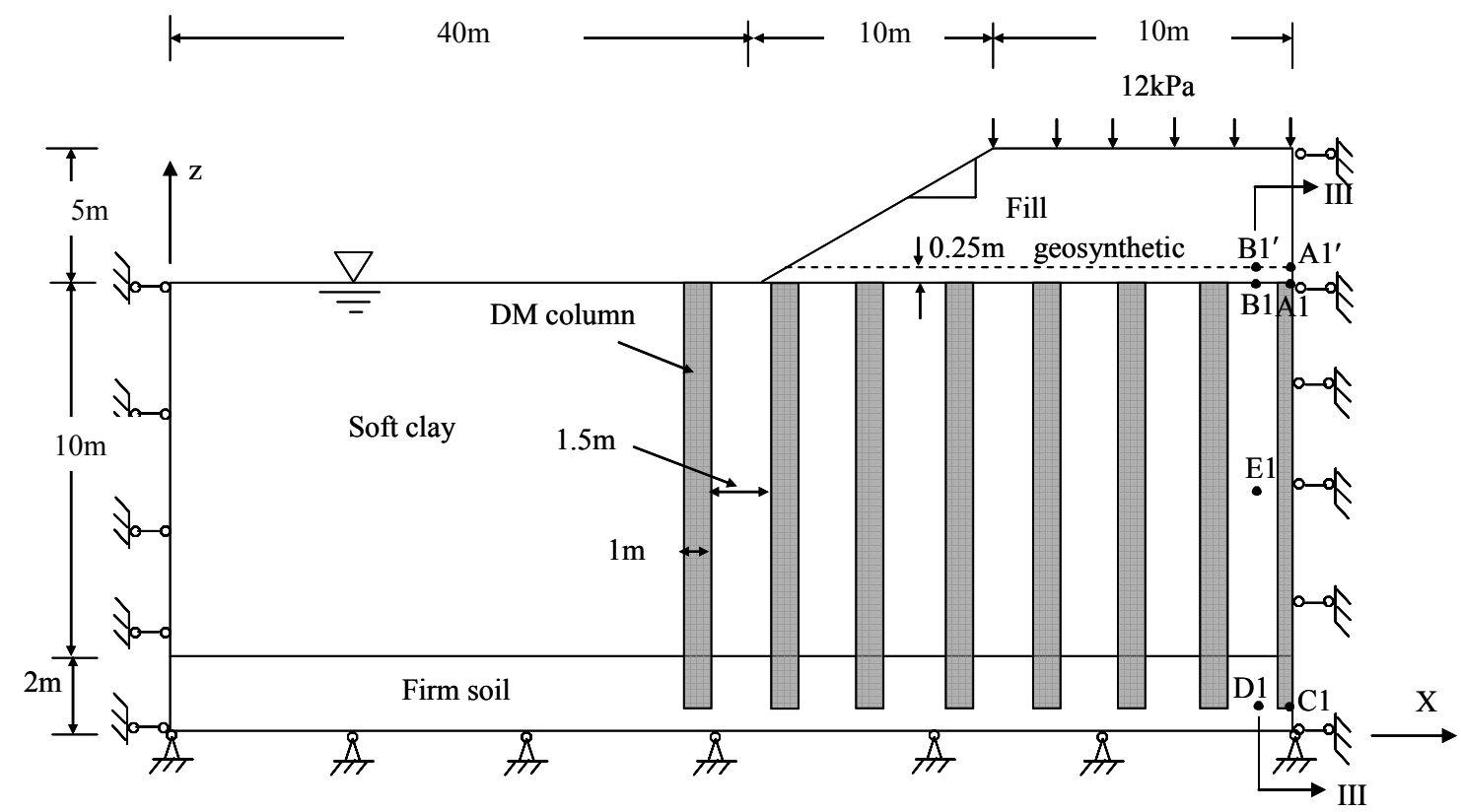

(a) Elevation view

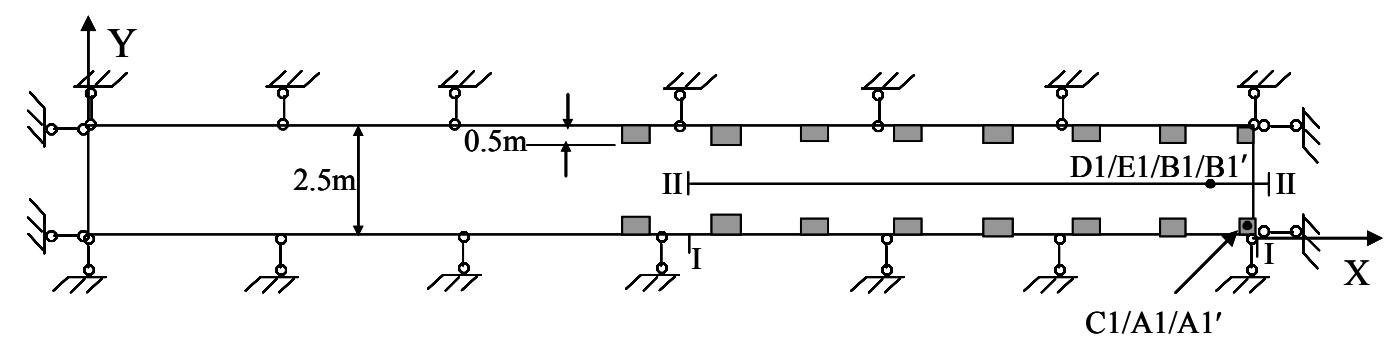

(b) Plane view

Fig. 5-1. Three-dimensional Model of the 3D Baseline Case 
To ensure the comparability of the $3 \mathrm{D}$ and $2 \mathrm{D}$ results, the column modulus used in the $3 \mathrm{D}$ baseline case was back-calculated by converting each $2 \mathrm{D}$ column wall into a row of individual columns and soil between those columns along the traffic direction based on the area-weighted modulus. The spacing of the columns in the rows is the same as that in the column walls. As a result, a square-pattern of columns was formed. This approach is just opposite to the approach used in the 2D model calibration by converting isolated columns into $2 \mathrm{D}$ column walls. This conversion is illustrated in Fig. 5-2. The column modulus in a square pattern was obtained by converting from the 2D column wall according to the following equation:

$$
E_{c} \times 1 \times 0.5+E_{c} \times 1 \times 0.5+E_{s} \times 1 \times 1.5=E_{c}^{\prime} \times 1 \times 2.5
$$

Using the same elastic modulus of soft soil for the 2D and 3D baseline cases, the column modulus in the 3D baseline case was determined to be 247MPa. The same correlation used in the $2 \mathrm{D}$ study was used in the $3 \mathrm{D}$ study to obtain the shear strength and the tensile strength of the columns. The other parameters remained unchanged from the 2D baseline case. The parameters of the $3 \mathrm{D}$ baseline case are presented in Table 5-1. The ground water table was also assumed at the ground surface. Unsaturated flow was not modeled in the 3D analysis either. 


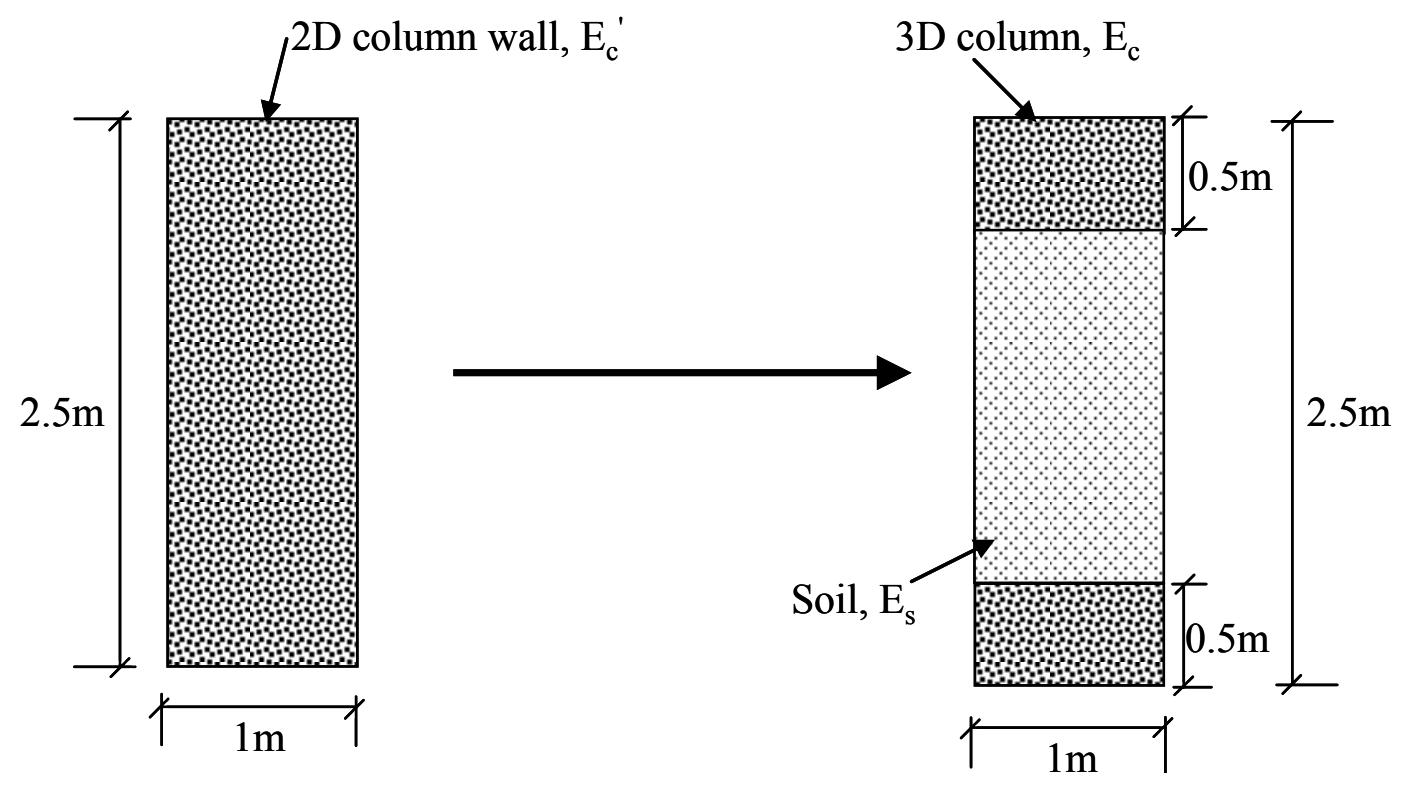

Fig. 5-2. Conversion of Column Modulus (Plan View)

Table 5-1. Properties of Materials in the 3D Baseline Case

\begin{tabular}{|l|l|}
\hline \multicolumn{1}{|c|}{ Material } & \multicolumn{1}{c|}{ Properties } \\
\hline DM columns & $\begin{array}{l}\gamma=18 \mathrm{kN} / \mathrm{m}^{3}, \mathrm{c}=1235 \mathrm{kPa}, \phi^{\prime}=0^{\circ}, \mathrm{E}_{\mathrm{c}}=247 \mathrm{MPa}, v=0.3, \\
\mathrm{c}_{\mathrm{t}}=247 \mathrm{kPa}, \mathrm{k}=1 \times 10^{-9} \mathrm{~m} / \mathrm{s}\end{array}$ \\
\hline Soft Soil & $\begin{array}{l}\gamma=18 \mathrm{kN} / \mathrm{m}^{3}, \mathrm{c}^{\prime}=0 \mathrm{kPa}, \phi^{\prime}=25^{\circ}, \mathrm{E}_{\mathrm{s}}=2 \mathrm{MPa}, v=0.3, \\
\mathrm{c}_{\mathrm{t}}=0 \mathrm{kPa}, \mathrm{k}=1 \times 10^{-9} \mathrm{~m} / \mathrm{s}\end{array}$ \\
\hline Firm Soil & $\begin{array}{l}\gamma=18 \mathrm{kN} / \mathrm{m}^{3}, \mathrm{c}^{\prime}=0 \mathrm{kPa}, \phi^{\prime}=30^{\circ}, \mathrm{E}_{\mathrm{sf}}=100 \mathrm{MPa}, v=0.3, \\
\mathrm{c}_{\mathrm{t}}=0 \mathrm{kPa}, \mathrm{k}=1 \times 10^{-9} \mathrm{~m} / \mathrm{s}\end{array}$ \\
\hline Embankment Fill & $\begin{array}{l}\gamma=18 \mathrm{kN} / \mathrm{m}^{3}, \mathrm{c}^{\prime}=5 \mathrm{kPa}, \phi^{\prime}=32^{\circ}, \mathrm{E}_{\mathrm{se}}=30 \mathrm{MPa}, v=0.3, \\
\mathrm{c}_{\mathrm{t}}=0 \mathrm{kPa}\end{array}$ \\
\hline Geosynthetics & $\begin{array}{l}\mathrm{t}=0.002 \mathrm{~m}, \mathrm{E}_{\mathrm{x}}=500 \mathrm{MPa}, \mathrm{E}_{\mathrm{y}}=500 \mathrm{MPa}, \mathrm{T}_{\mathrm{a}}=100 \mathrm{kN} / \mathrm{m}, \\
\mathrm{k}_{\mathrm{s}}=20 \mathrm{MN} / \mathrm{m} / \mathrm{m}, \mathrm{c}_{\mathrm{a}}=0 \mathrm{kPa}, \delta=24.8^{\circ}\end{array}$ \\
\hline Ground water & $\mathrm{K}=200 \mathrm{MPa}$ \\
\hline
\end{tabular}

Note: $\gamma=$ unit weight of soil; $\mathrm{c}=$ shear strength of soil-cement; $\mathrm{c}^{\prime}=$ effective cohesion of soil; $\phi^{\prime}=$ effective friction angle of soil; $\mathrm{k}=$ permeability; $\mathrm{E}=$ elastic modulus of soil; $v=$ Poisson's ratio; $\mathrm{c}_{\mathrm{t}}=$ tensile strength of soil-cement/soil; $t=$ thickness of geosynthetic reinforcement; $E_{r}=$ elastic modulus of geosynthetic reinforcement; $\mathrm{T}_{\mathrm{a}}=$ allowable tensile strength of geosynthetic reinforcement; $\mathrm{ks}=$ bond stiffness between geosynthetic and embankment fill; $\mathrm{ca}=$ bond strength between geosynthetic and embankment fill; $\delta=$ bond friction angle between geosynthetic and embankment fill; $\mathrm{K}=$ water bulk modulus. 


\subsubsection{D Modeling Procedure}

Similar to the 2D analysis, the 3D simulation was divided into three steps: the generation of the initial ground stress field and the hydrostatic pore water distribution, the simulation of the embankment construction, and the application of the traffic load. Since the modeling procedure of the $3 \mathrm{D}$ analysis is the same as that of $2 \mathrm{D}$ analysis described in Chapter Four, it is not repeated herein. One noteworthy difference from the $2 \mathrm{D}$ modeling is that the $3 \mathrm{D}$ modeling was only carried out up to 4.5 years after service by evaluating the computer capacity and the research necessity.

\subsubsection{D Results of Baseline Case}

\section{Settlement}

The settlement contour at one month after service is presented in Fig. 5-3. The unit in the figure is meters. It can be seen that the settlement contour has a similar pattern as that shown in the $2 \mathrm{D}$ baseline case. The maximum settlement developed at the base of the embankment. In addition, the apparent differential settlement developed at the base of the embankment. The settlements against time at two locations (A1 and B1, refer to Fig. 5-1) are presented in Fig. 5-4. A1 was located at one of the column heads

while B1 was located at the center surrounded by four columns. It is no doubt that the 
settlement at A1 was less than that at B1 at all stages. At each stage, there was a sudden increase of the settlement after loading and followed by a gradual increase of the settlement. The gradual increase of the settlement resulted from the consolidation. The settlement became stable at approximately 12 months after service, which is equivalent to 17 months since the construction. The consolidation process in the baseline case was much faster than that predicted by Terzaghi's one-dimensional consolidation theory. The reason for this difference has been discussed in Chapter Four. The excess pore water pressure and the degree of consolidation at one month after service will be discussed in the section of excess pore water pressure in this chapter.

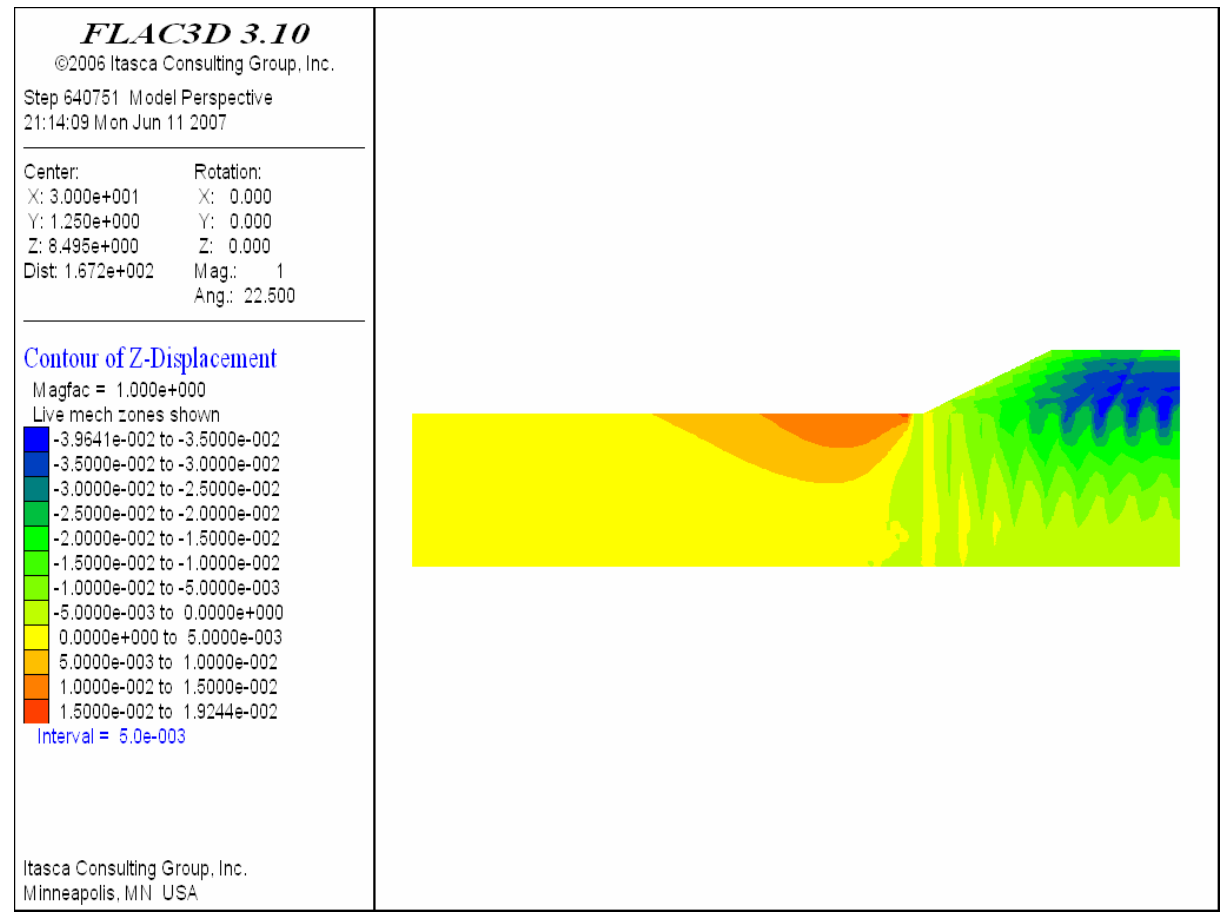

Fig. 5-3. Settlement Contour of the 3D Baseline Case 


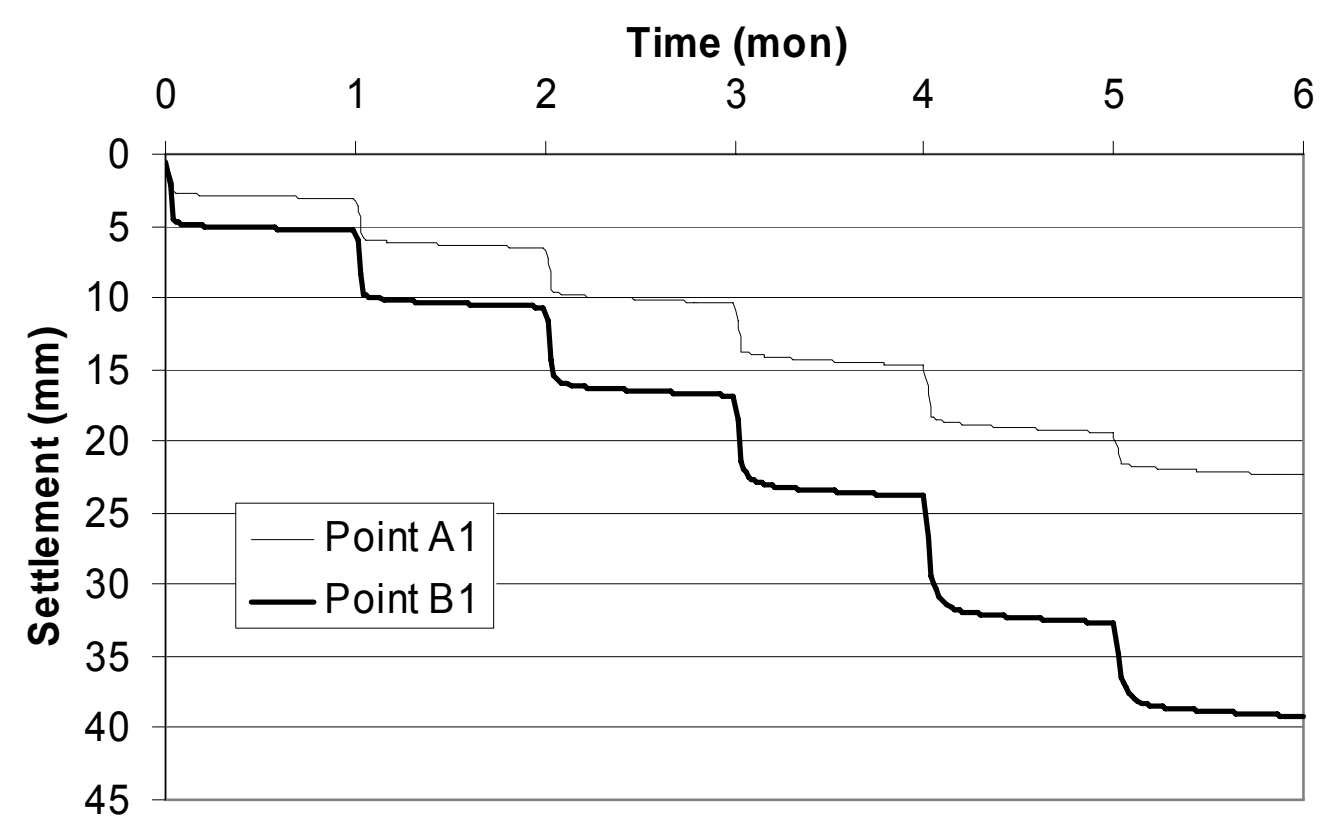

(a) 1 month after service

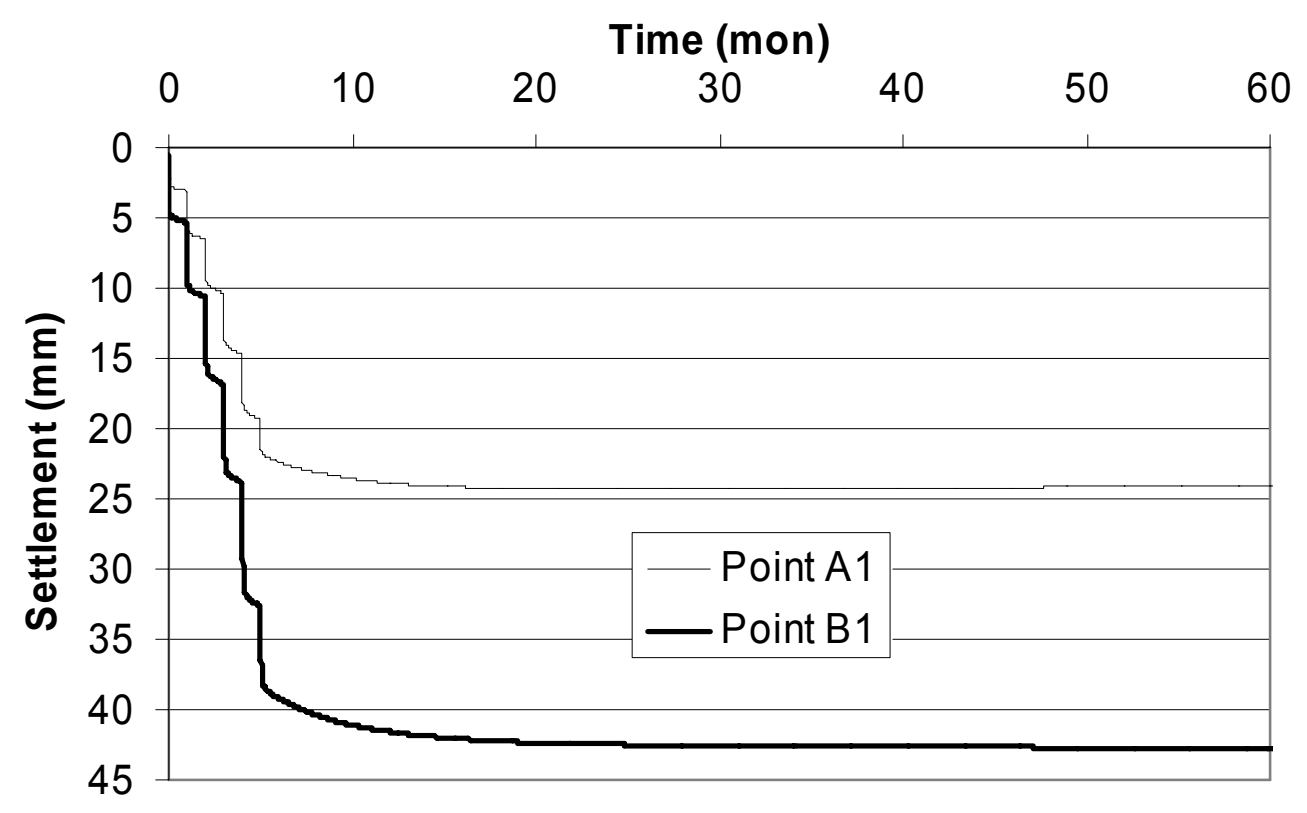

(b) 4.5 years after service

Fig. 5-4. Settlement versus Time of the 3D Baseline Case 
As discussed in Chapter Four, the settlements at the crest (i.e., the post construction settlement) are critical to the performance and presented in Fig. 5-5. As shown in Fig. 5-1, Section I-I cuts through the centers of the columns and is perpendicular to the traffic direction while Section II-II cuts through the middle span of the columns and is parallel to Section I-I. The settlement profiles at different elevations of Sections I-I and II-II are presented in Fig. 5-5. Figure 5-5 shows that the settlements at the base were quite different at these two sections. Since columns at Section I-I were much stiffer than soil, considerable differential settlements developed. At Section II-II, however, the soil in the vicinity of columns settled less than that located farther from the columns. The differential settlement between these two sections was not reflected to the crest. The settlement profiles at the crest overlapped each other at these two sections. This phenomenon implies that the differential settlement along the traffic direction was negligible. The comparison of Fig. 5-5 (a) with Fig. 5-5 (b) shows that the consolidation only led to a slight increase of the settlement. 


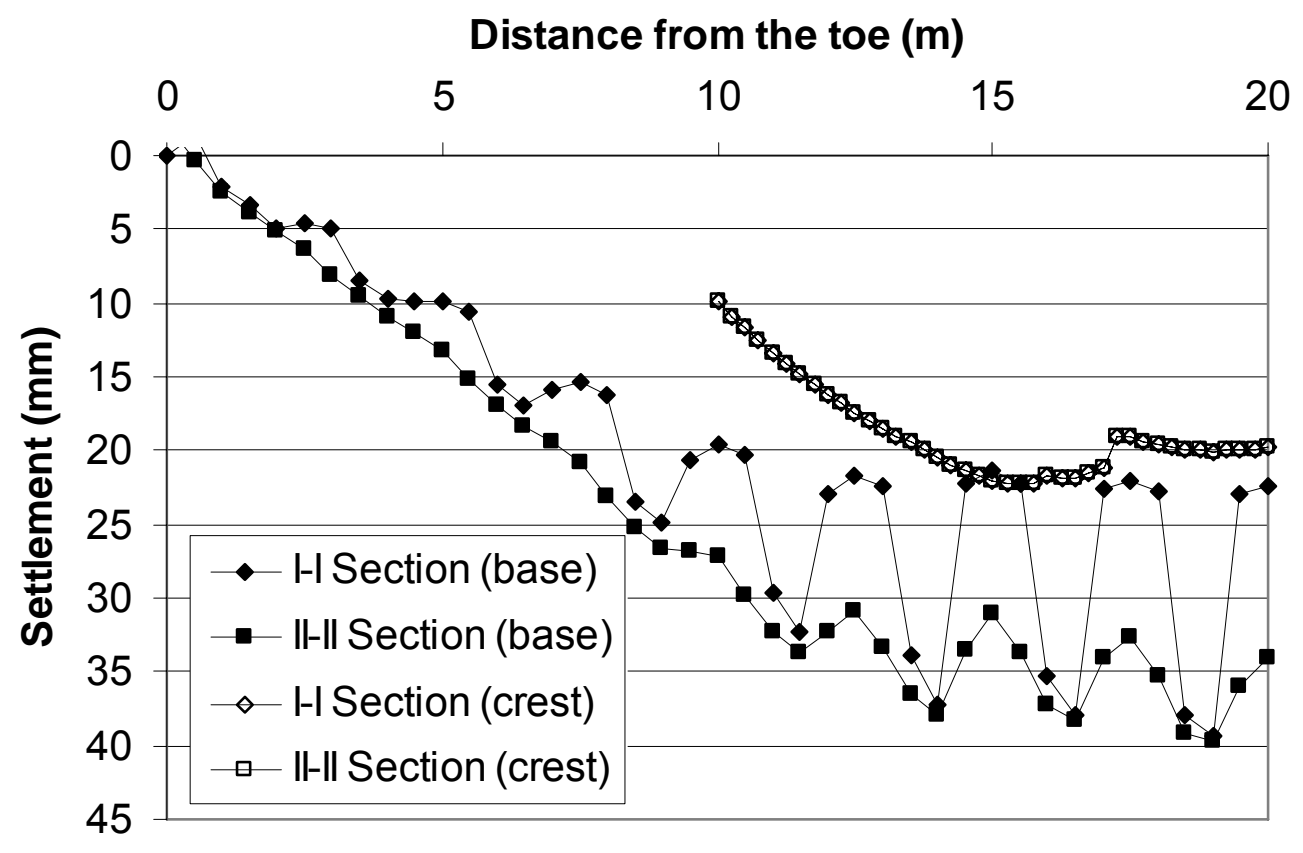

(a) 1 month after service

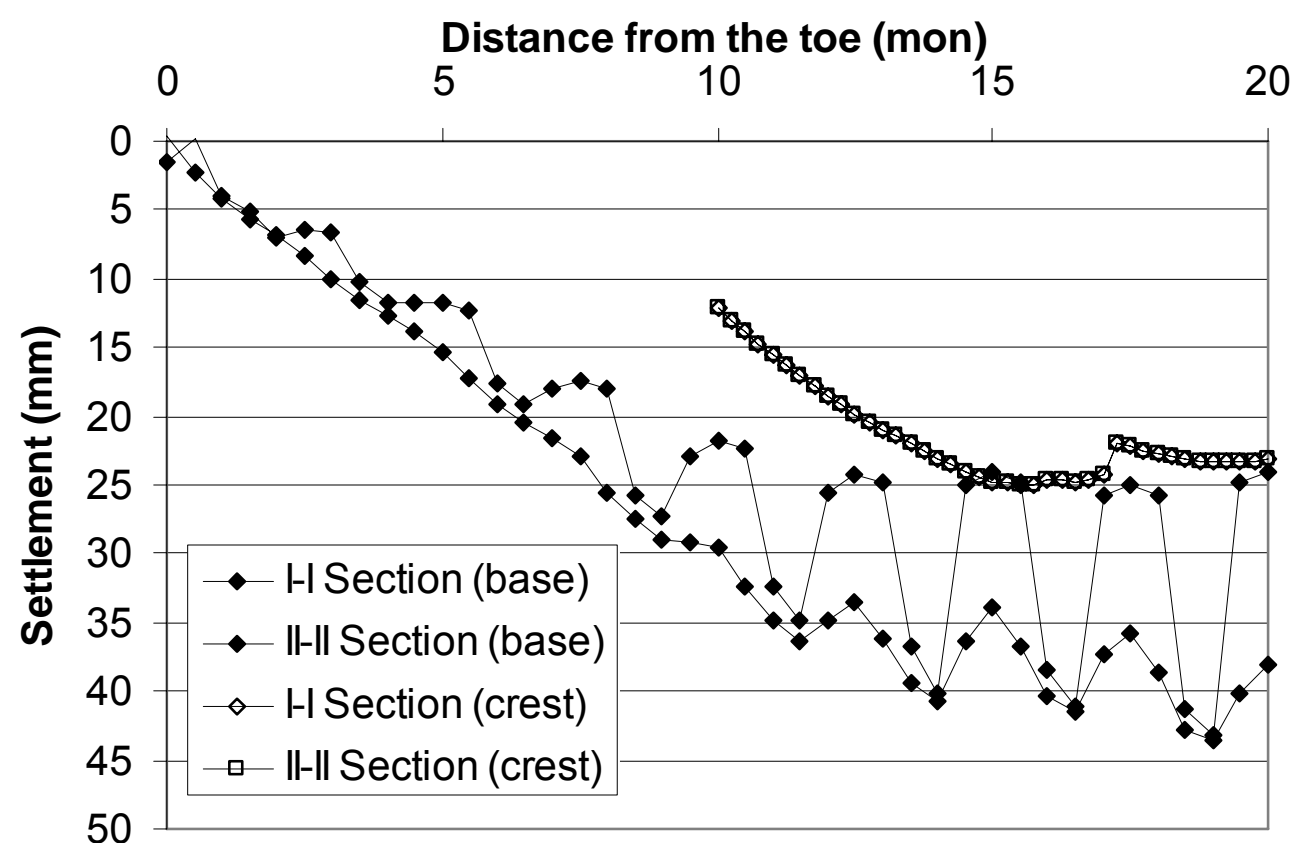

(b) 4.5 years after service

Fig. 5-5. Settlement Profiles of the 3D Baseline Case at Different Time 
Table 5-2 lists the maximum differential settlement and the maximum distortion on the crest and at the base of the embankment. It can be seen that both the maximum differential settlement and the maximum distortion at the base were larger than those on the crest. This conclusion is consistent with that for the 2D baseline case. As discussed before, the differential settlement and the distortion on the crest are more important for serviceability than those at the base.

\section{Table 5-2. Maximum Differential Settlement and Maximum Distortion of the 3D Baseline Case}

\begin{tabular}{|c|c|c|}
\hline Location & \multicolumn{2}{|c|}{ Maximum differential settlement (mm) (Maximum distortion, $\%)$ ) } \\
\hline & 1 month after service & 4.5 Years after service \\
\hline On the crest & $12.29(0.381)$ & $12.90(0.364)$ \\
\hline At the base & $16.89(1.126)$ & $18.48(1.232)$ \\
\hline
\end{tabular}

\section{Tension in Geosynthetic Reinforcement}

In the 2D modeling, the geosynthetic reinforcement was modeled by cable elements incorporated in the software, which can only sustain tension. In the FLAC3D modeling, however, the geosynthetic reinforcement was modeled as geogrid elements, which are a collection of plane triangular elements. The geogrid elements can only sustain tangential load. The developed tension in $\mathrm{x}$ and $\mathrm{y}$ directions for the 3D baseline case is presented in Fig. 5-6. The unit of the tensile forces is Newton per meter $(\mathrm{N} / \mathrm{m})$. The coordinates used in this study are shown in Fig. 5-1. It can be seen that the maximum tension in the $\mathrm{x}$ direction was higher than that in the $\mathrm{y}$ direction. 
Since geogrid elements were treated as elastic materials in the current FLAC3D software, no compressive strength could be set to avoid the generation of compression stresses as what has been done in the $2 \mathrm{D}$ modeling. Some compression stresses were induced in the y direction. In this study, the geosynthetic reinforcement was assumed to be isotropic, i.e., it had the identical strength and stiffness in all directions.

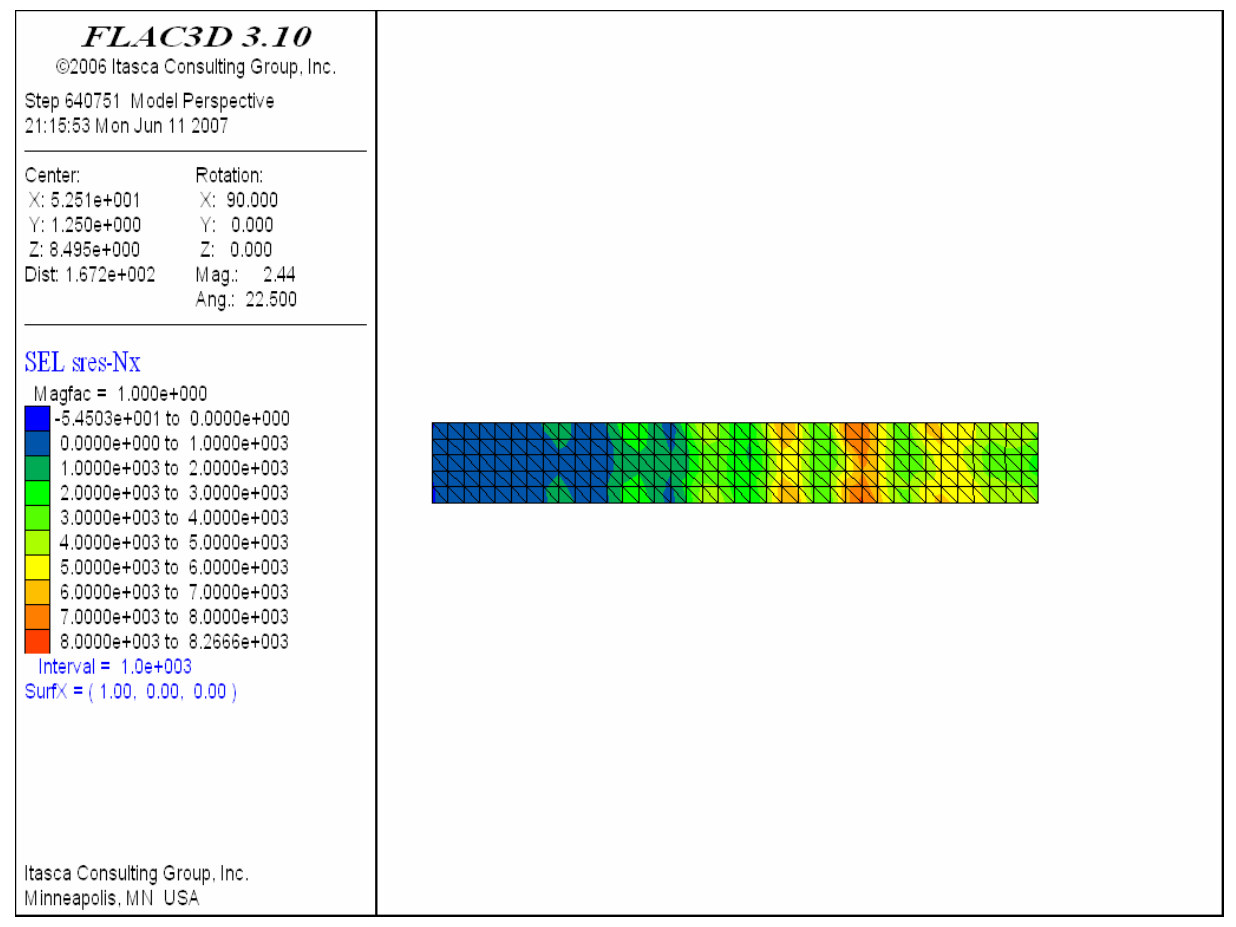

(a) Tension in $\mathrm{x}$ direction

Fig. 5-6. Tension Contours of the 3D Baseline Case 


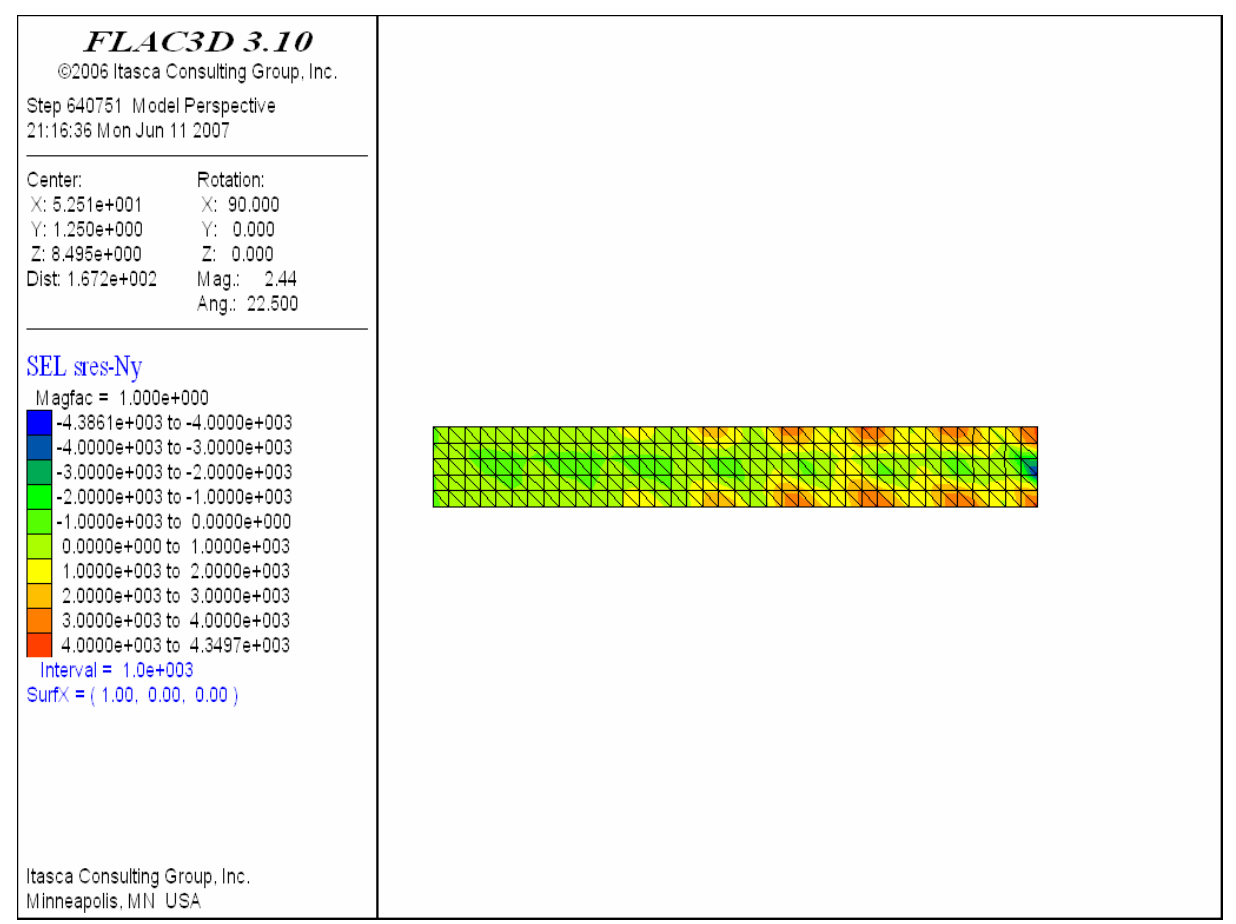

(b) Tension in y direction

Fig. 5-6. Tension Contours of the 3D Baseline Case (continued)

The tension profiles at two sections are presented in Fig. 5-7, which indicates that the tension in the $\mathrm{x}$ direction was higher than that in the $\mathrm{y}$ direction. The tension at Section I-I was higher than that at Section II-II in both $\mathrm{x}$ and $\mathrm{y}$ directions. This result implies that the higher tension developed over the columns and not over the soil. The maximum tension in the $\mathrm{x}$ direction developed at some distance from the center. This finding is consistent with that from the $2 \mathrm{D}$ study. This phenomenon was attributed to the lateral movement of the embankment. In the y direction, however, there was no lateral movement so that the maximum tension under the crest of the embankment was uniform. 


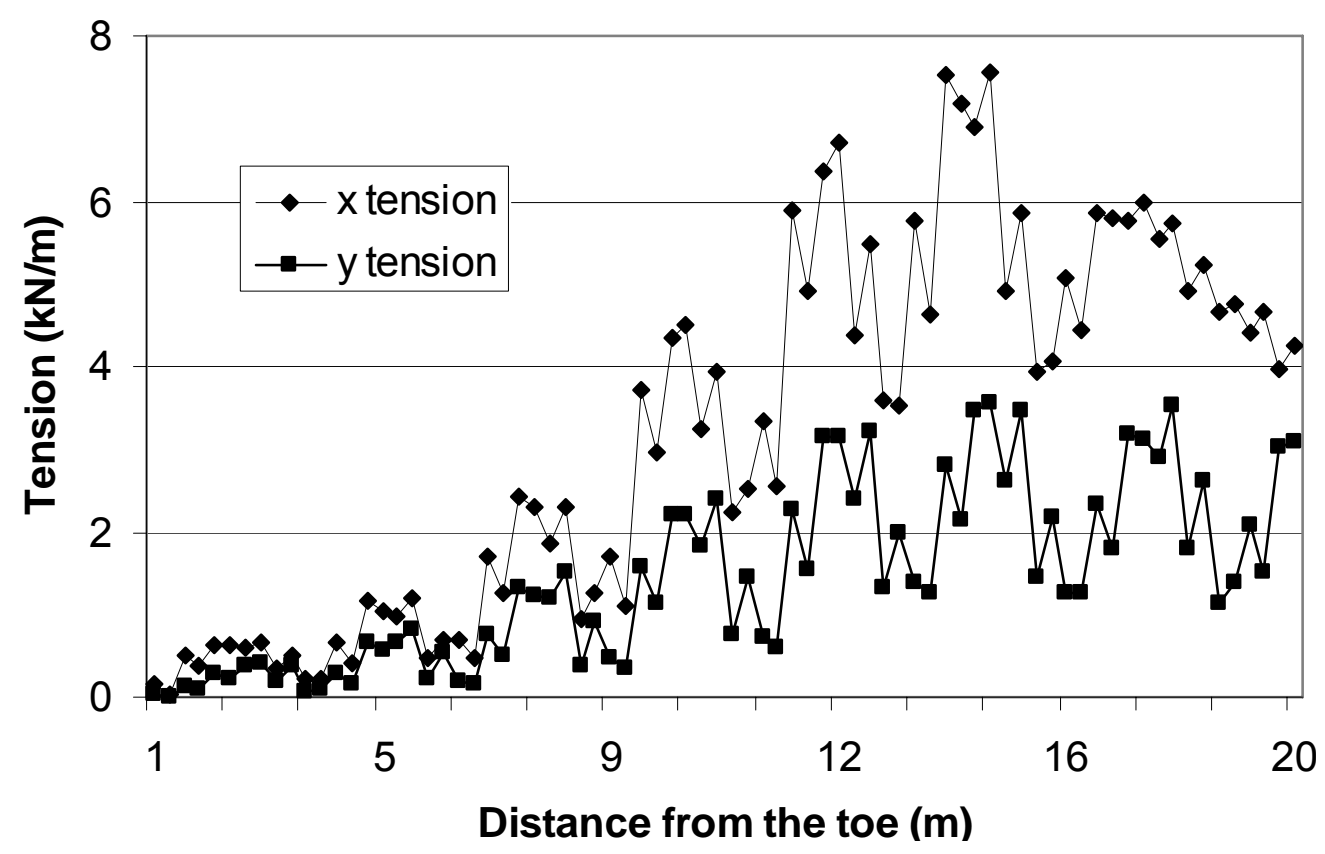

(a) Tension at I-I Section

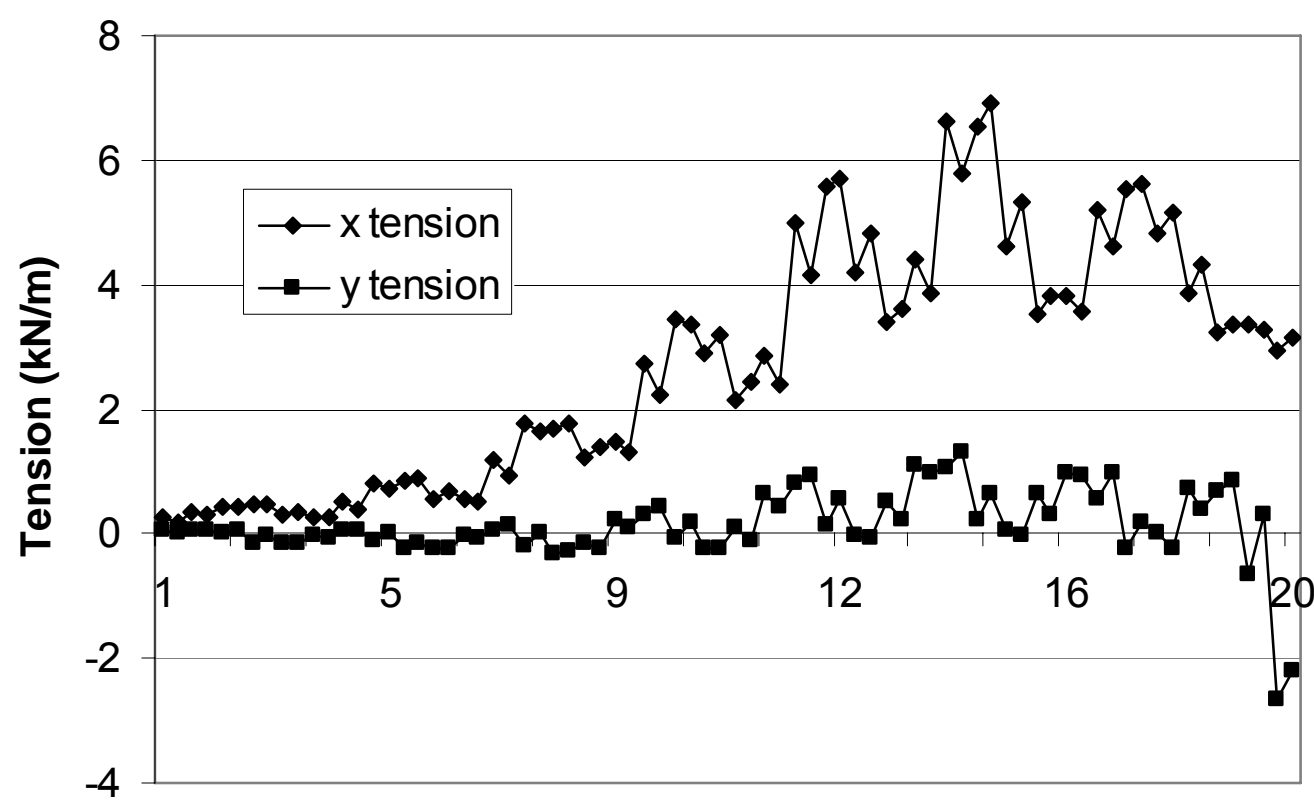

Distance from the toe (m)

(b) Tension at II-II Section

Fig. 5-7. Tension Profiles of the 3D Baseline Case 
The tension in the reinforcement versus the time at two locations (A1' and B1') is presented in Fig. 5-8. The tension increased suddenly after loading and decreased gradually as the consolidation proceeded.

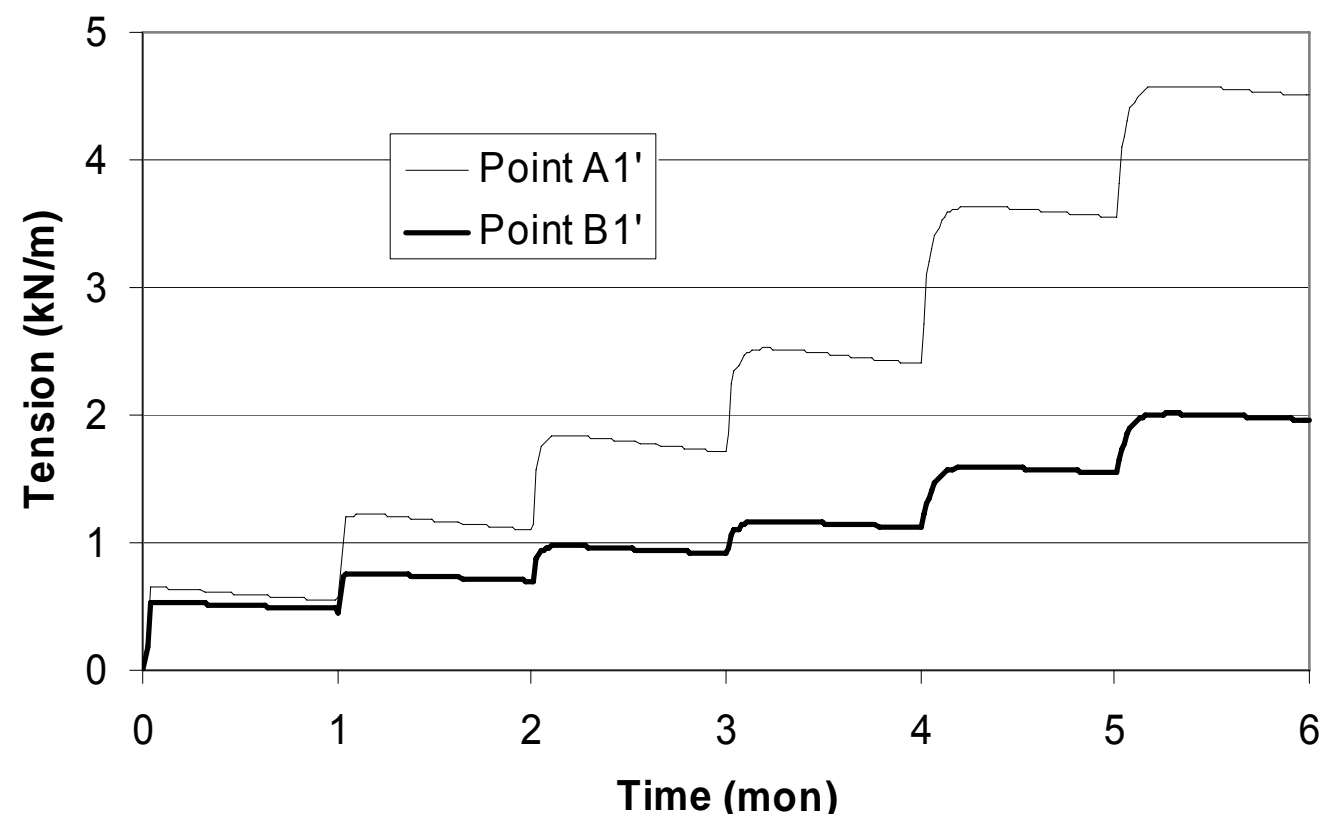

Fig. 5-8. Tension versus Time of the 3D Baseline Case

\section{Vertical Effective Stress}

The vertical total stress contour is presented in Fig. 5-9. The unit of the stress is Pascal (Pa). A negative sign indicates compression. Much higher stresses developed within the columns than within soft soil. This phenomenon is an indication of load transfer from the soft soil to the columns. The vertical effective stresses at Section I-I and Section II-II at the elevation of the column heads are presented in Fig. 5-10. In 
Section I-I, the effective stresses above the soft soil were lower than those in Section II-II. The soft soil in Section I-I settled less than that in Section II-II as shown in Fig. $5-5$.

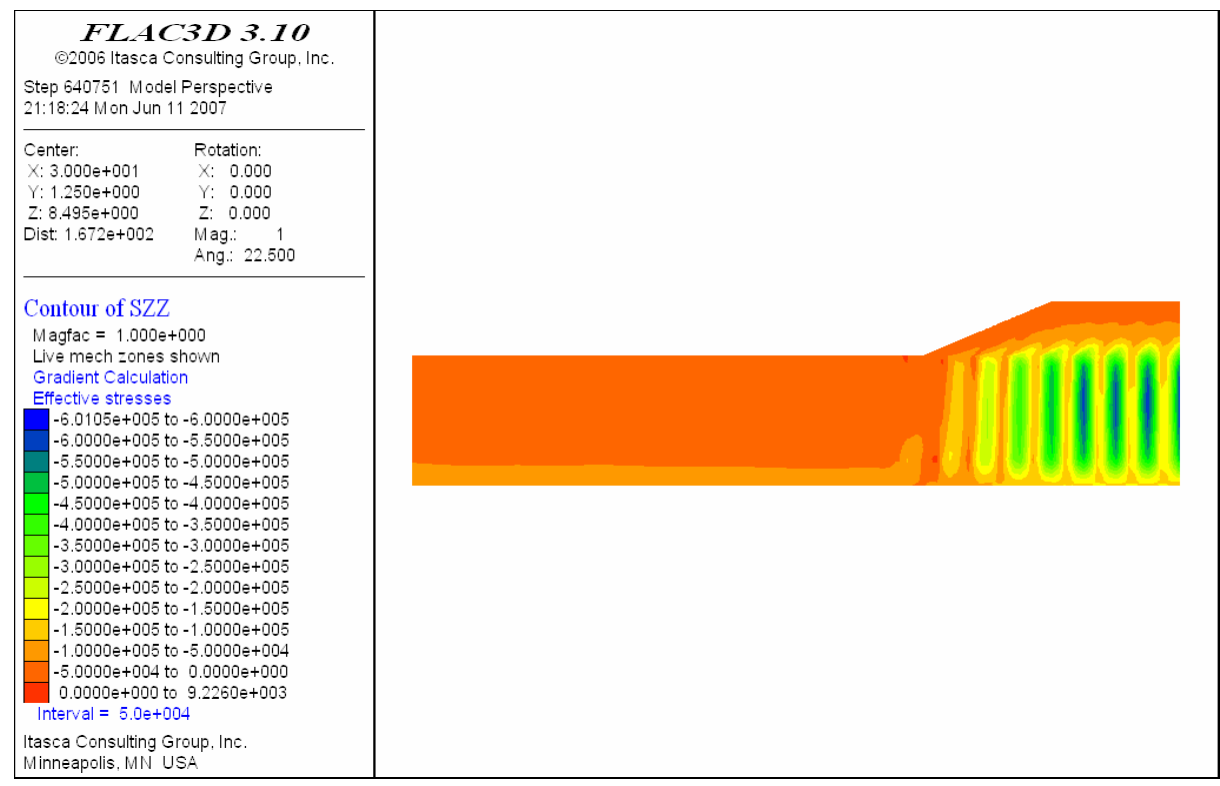

Fig. 5-9. Vertical Effective Stress Contour of the 3D Baseline Case

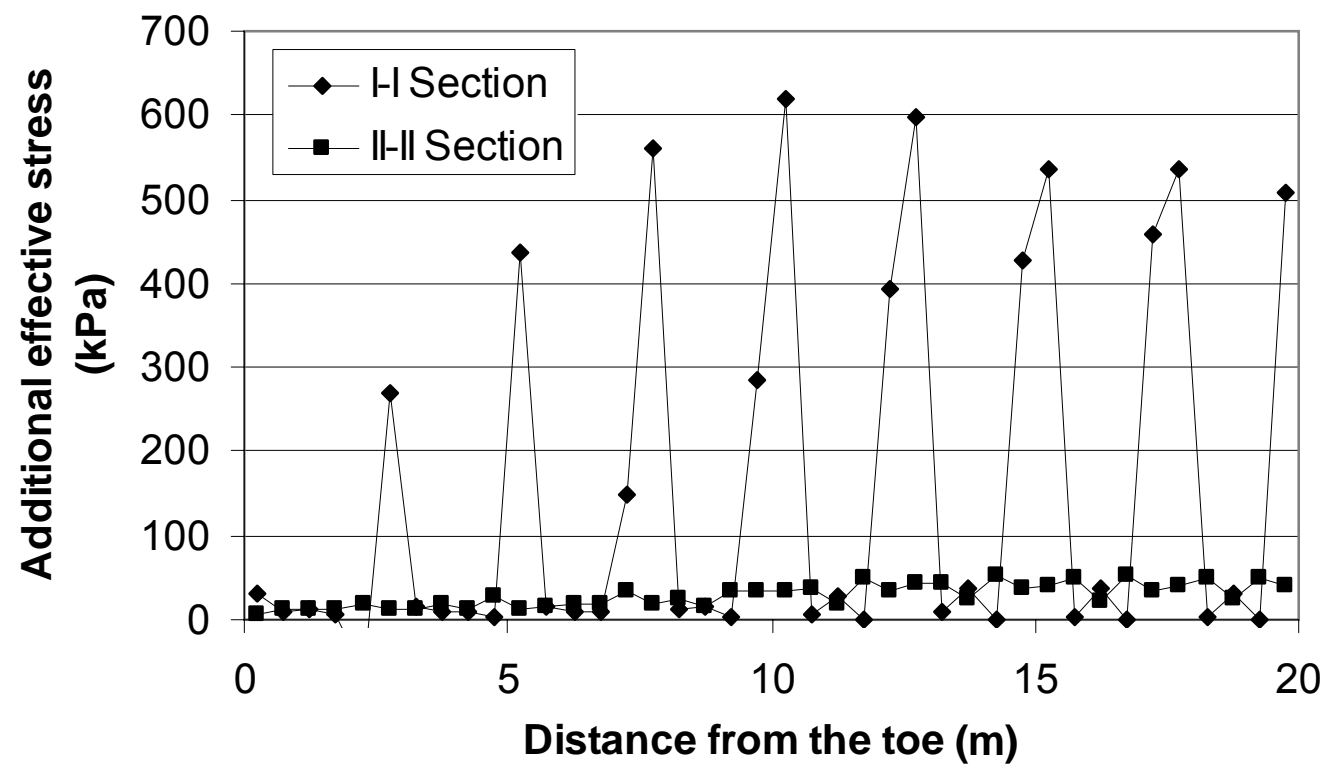

Fig. 5-10. Effective Stress Distribution of the 3D Baseline Case 
The settlements versus the time at two locations (C1 and D1 as shown in Fig. 5-1) were presented in Fig. 5-11. At each stage, there was a sudden increase of the effective stresses followed by a gradual increase of the effective stresses. This process is similar to that in the $2 \mathrm{D}$ analysis.

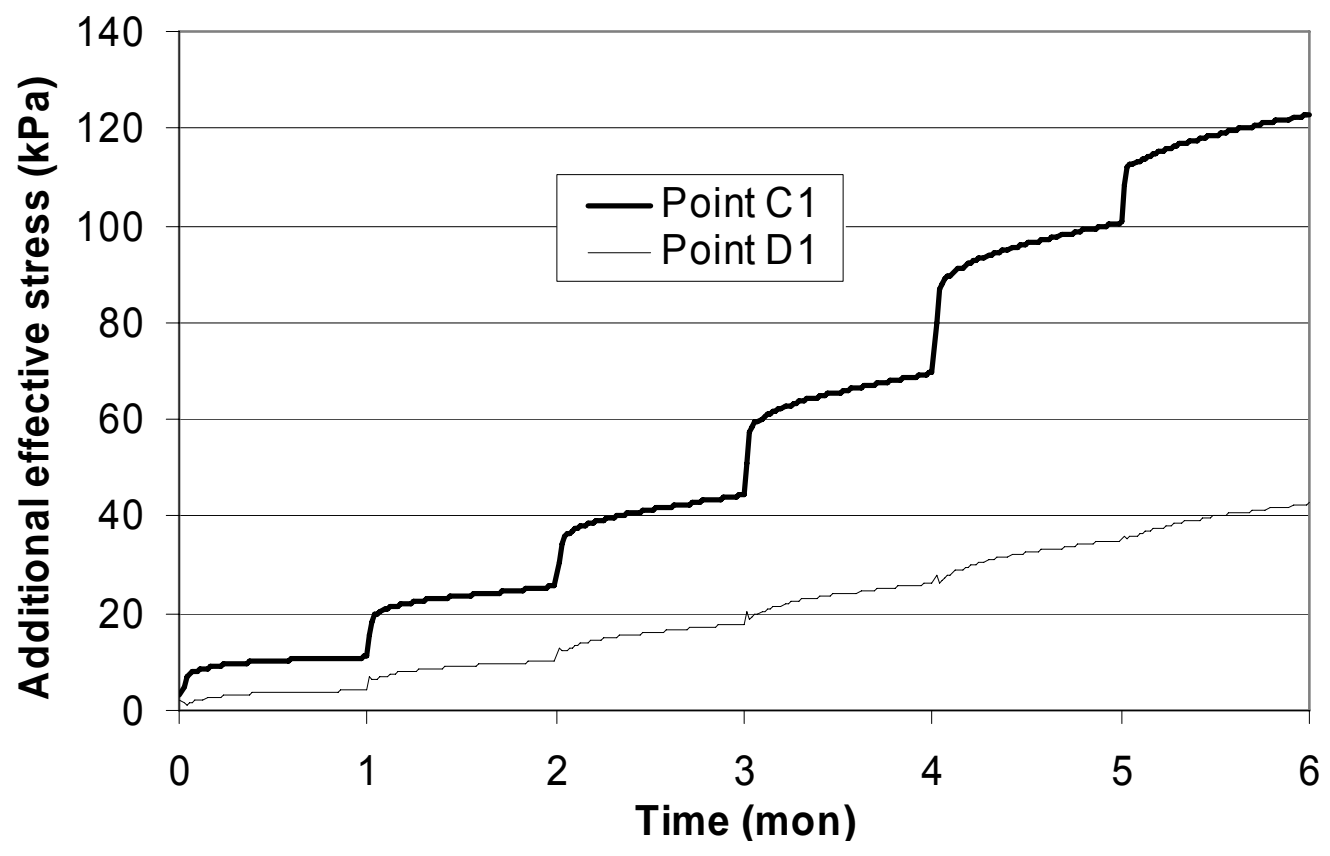

(a) 1 month after service

Fig. 5-11. Additional Vertical Effective Stress versus Time of the 3D Baseline Case 


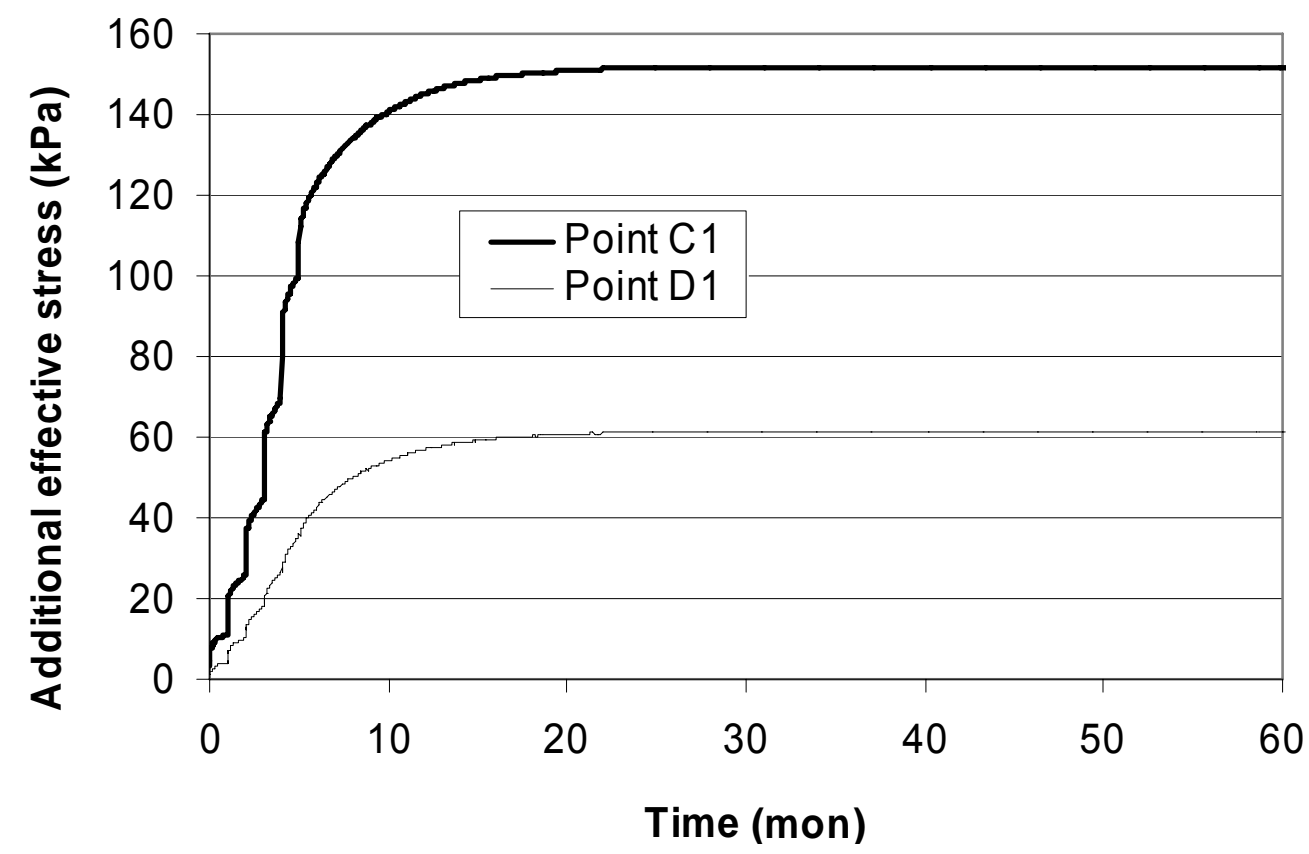

(b) 4.5 years after service

\section{Fig. 5-11. Additional Vertical Effective Stress versus Time of the 3D Baseline} Case (continued)

\section{Stress Concentration Ratio}

As discussed in Chapter Four, the stress concentration ratio is defined as the ratio of the vertical stress over the columns to the vertical stress over the soft soil. For columns in a square pattern, the stress concentration ratio can not be simply calculated using Eq. (4-3) in Chapter Four. Instead, the stress concentration ratio in the $3 \mathrm{D}$ analysis was calculated as the ratio of the average additional vertical effective stress above the column to the average additional vertical effective stress of the soft soil within the influence area of that column. 
The profiles of the stress concentration ratio for the baseline case are presented in Fig. 5-12. The highest stress concentration ratio existed at certain distance from the centerline. The stress concentration ratio increased from one month to 4.5 years after service as the consolidation proceeded.

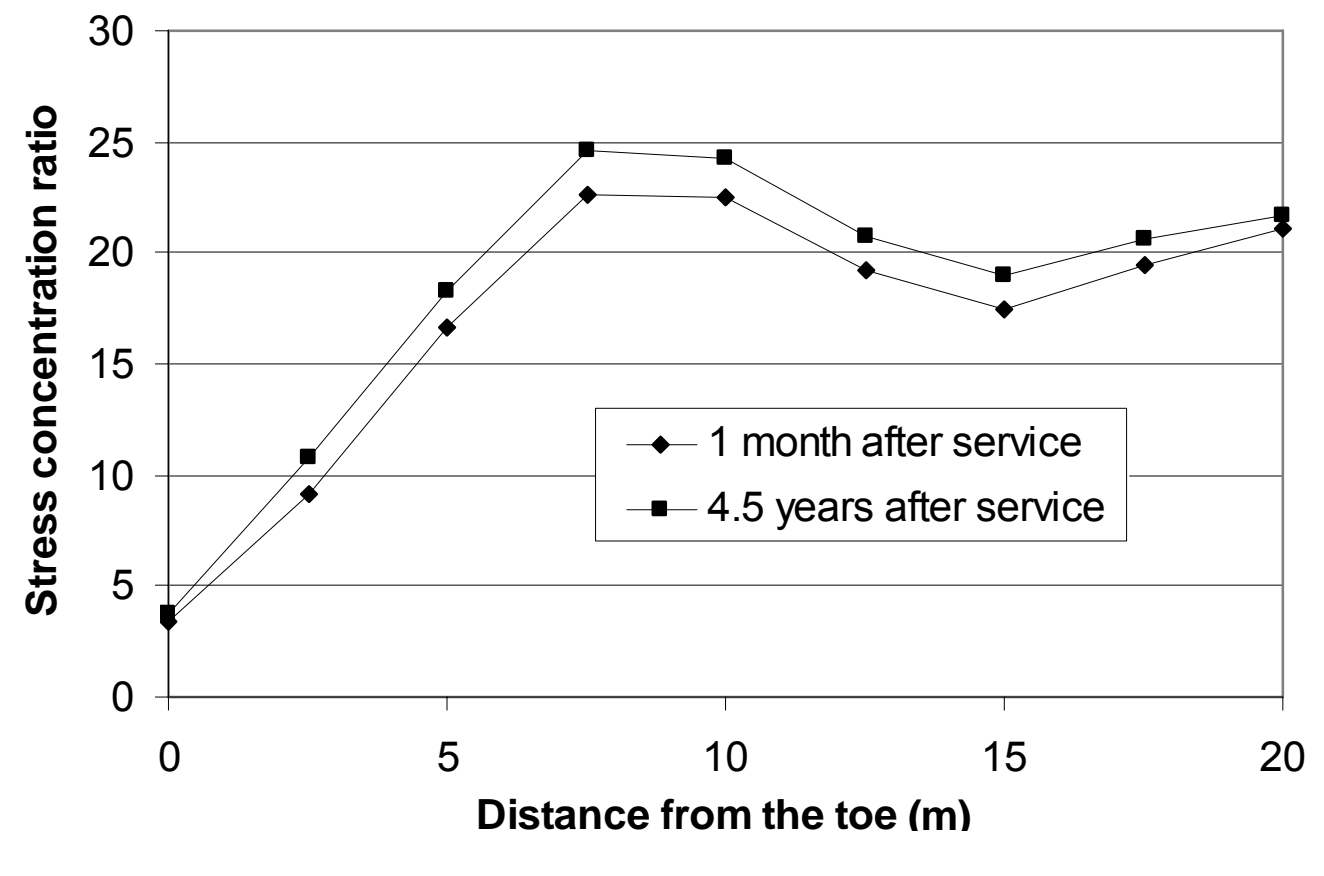

Fig. 5-12. Stress Concentration Ratio Profiles of the 3D Baseline Case

\section{Pore Water Pressure}

The pore water pressure distribution at one month after service is presented in Fig. 513. The unit of the pore water pressure is Pascal $(\mathrm{Pa})$. The variations of excess pore water pressure at four different locations are presented in Fig. 5-14 and 5-15. 


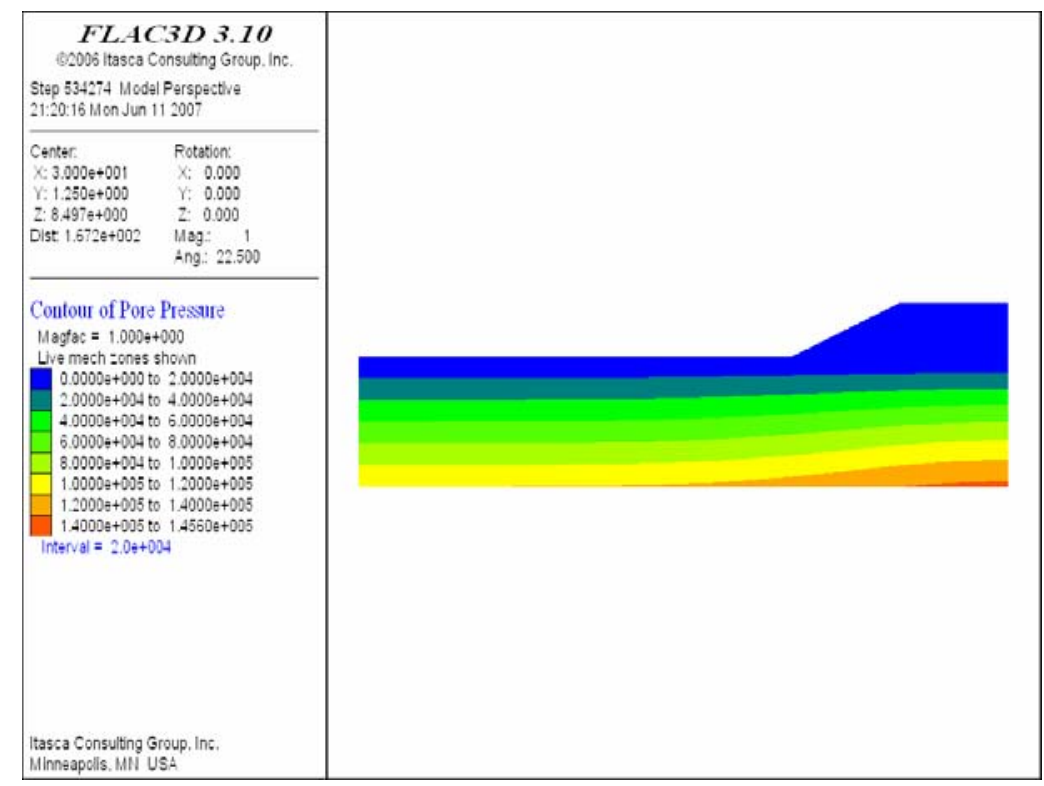

Fig. 5-13. Pore Water Pressure Contour of the 3D Baseline Case

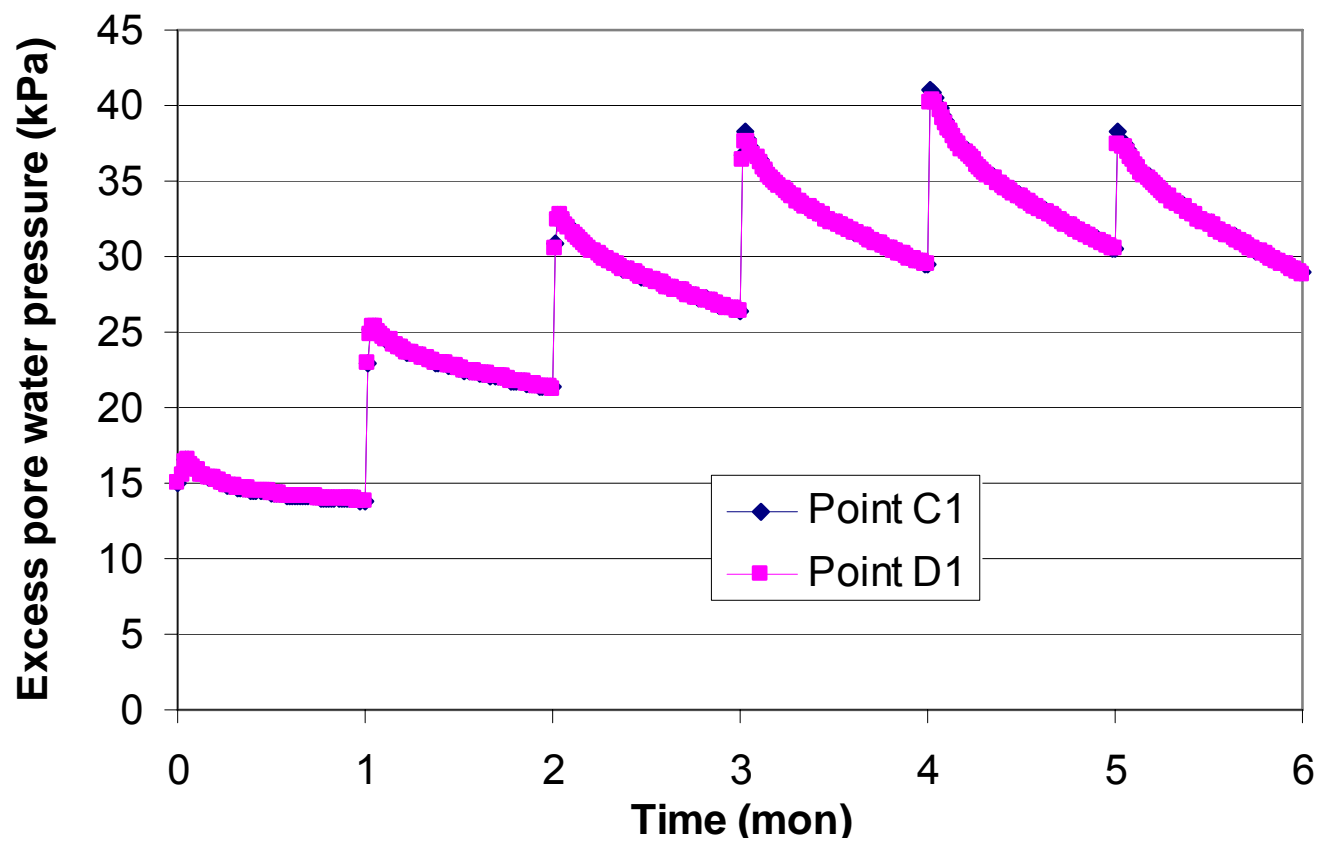

(a) 1 month after service

Fig. 5-14. Excess Pore Water Pressure at Point C1 and D1 versus Time of the 3D Baseline Case 


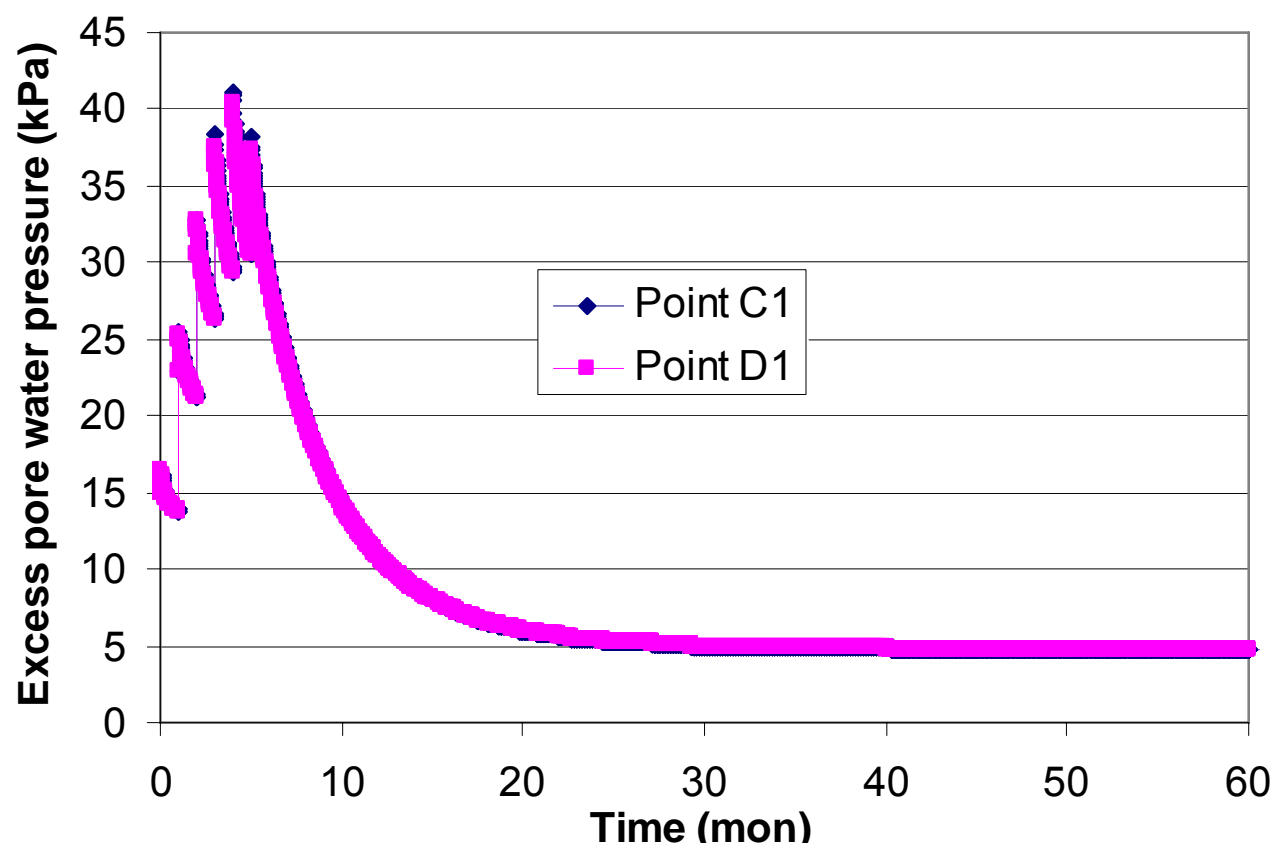

(b) 4.5 years after service

Fig. 5-14. Excess Pore Water Pressure at Point C1 and D1 versus Time of the 3D Baseline Case (continued)

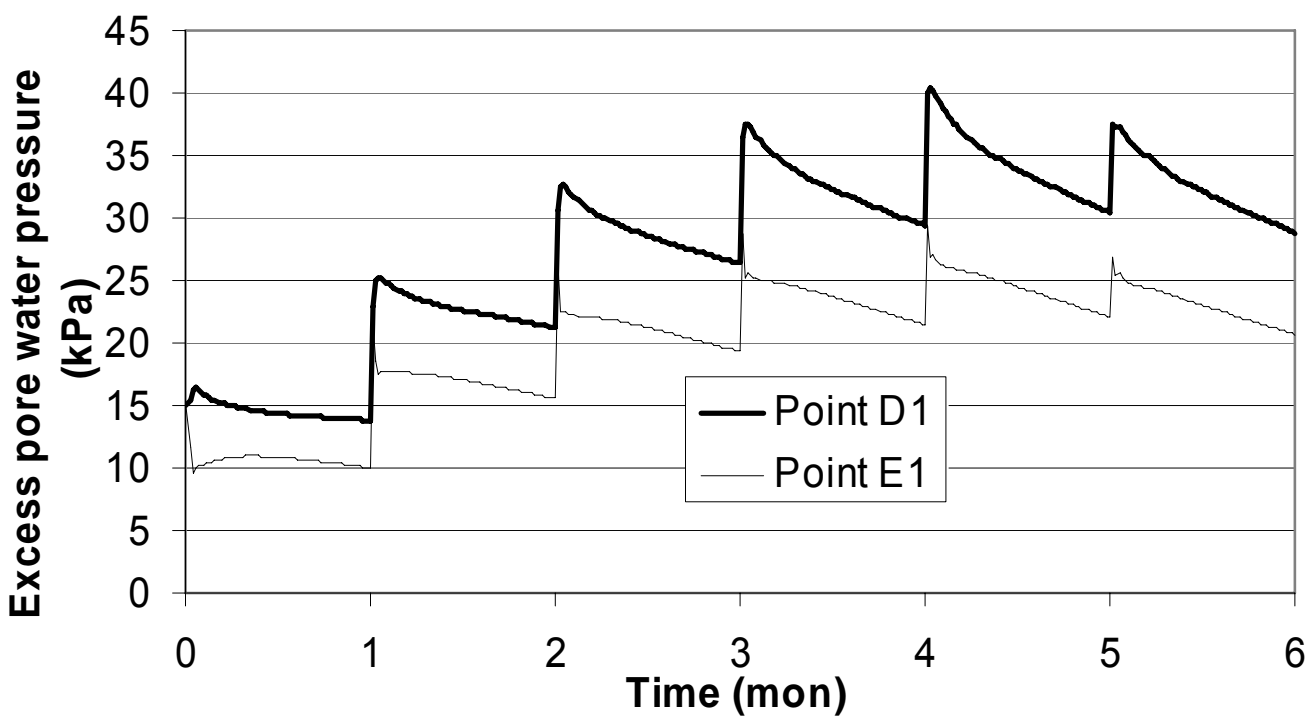

(a) 1 month after service

Fig. 5-15. Excess Pore Water Pressure at Point D1 and E1 versus Time of the 3D Baseline Case 


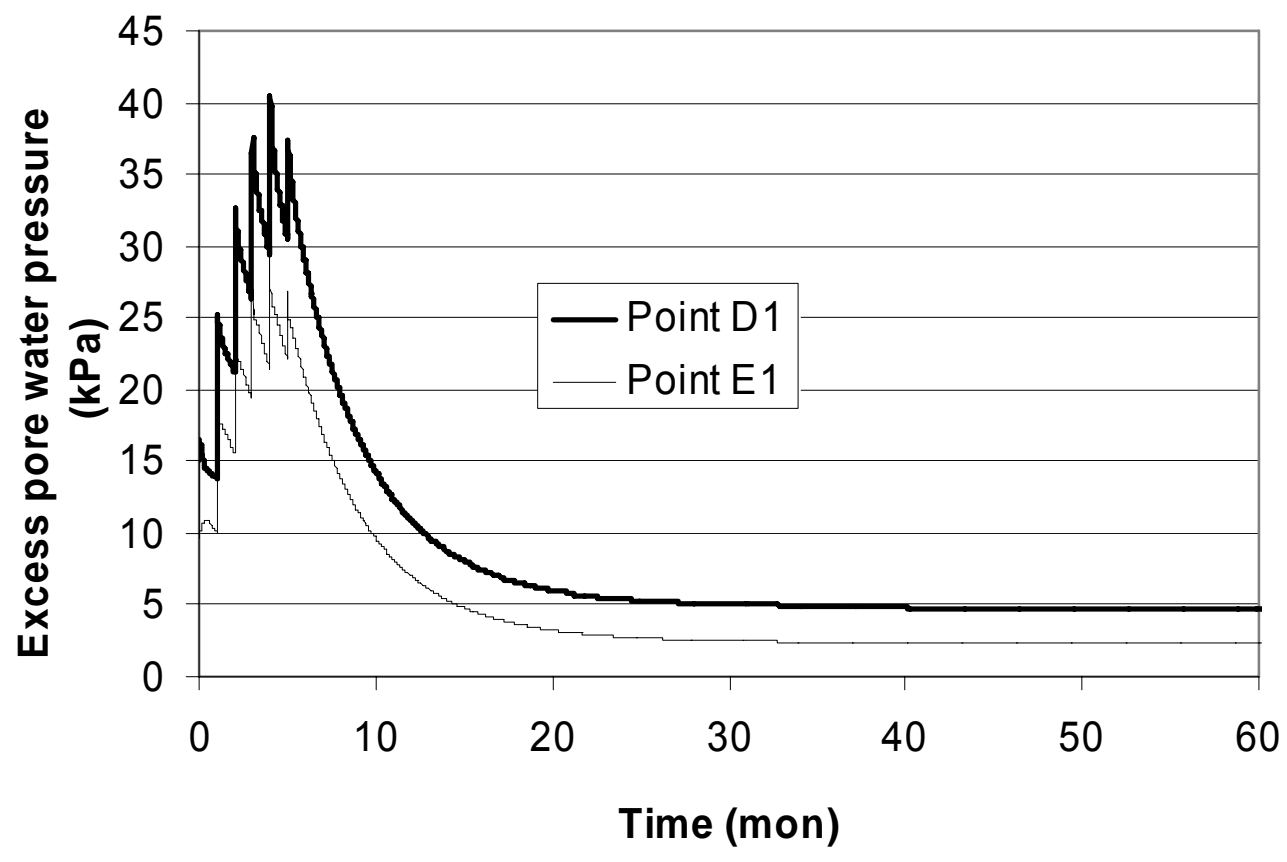

(b) 4.5 years after service

Fig. 5-15. Excess Pore Water Pressure at Point D1 and E1 versus Time of the 3D Baseline Case (continued)

Figure 5-16 shows that the excess pore water distributions along Section III-III changed with the depth and the time. Section III-III passed through B1, E1, and D1. The excess pore water pressure was generated due to the increase of the vertical load and then dissipated through drainage and load transfer. These two dissipation process were discussed in the section of the baseline case in Chapter Four. Figure 5-16 shows that the excess pore water pressure increased with each stage of loading but the magnitude of the increase decreased from stage to stage. At 4.5 years after service, the excess pore water pressure almost dissipated completely. 


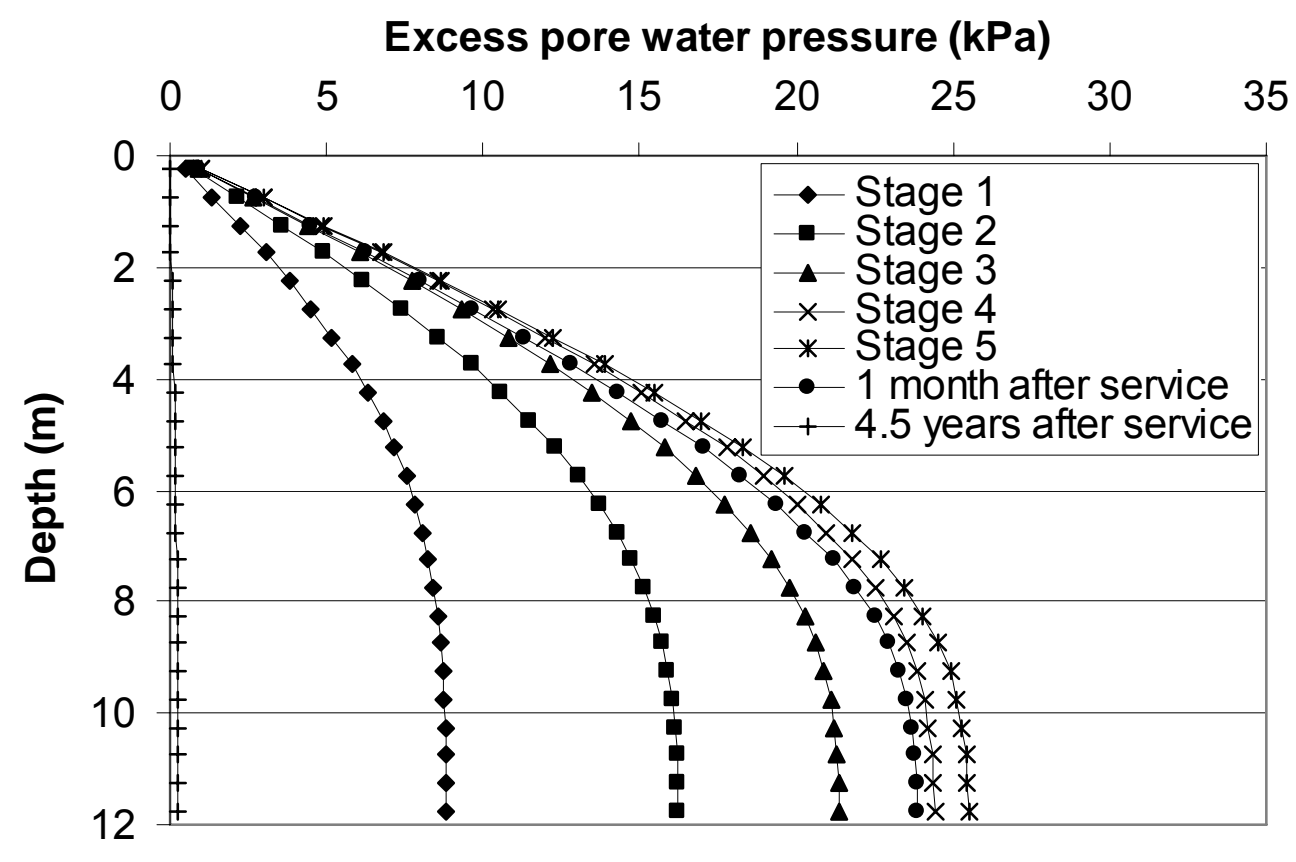

Fig. 5-16. Excess Pore Water Pressure versus Depth of the 3D Baseline Case

Figure 5-17 presents the excess pore water pressure and the additional effective stress changed with time at Point D1 (refer to Fig. 5-1). It is shown that the excess pore water pressure and the additional effective stress suddenly increased after the placement of the embankment fill. The excess pore water pressure then decreased gradually but the additional effective stress continued increasing. This process resulted from the consolidation of the foundation. Figure 5-17 (b) shows that the excess pore water pressure reached a negligible magnitude and the additional effective stress became stable at approximately 12 months after the construction (i.e., 17 months since the construction). 


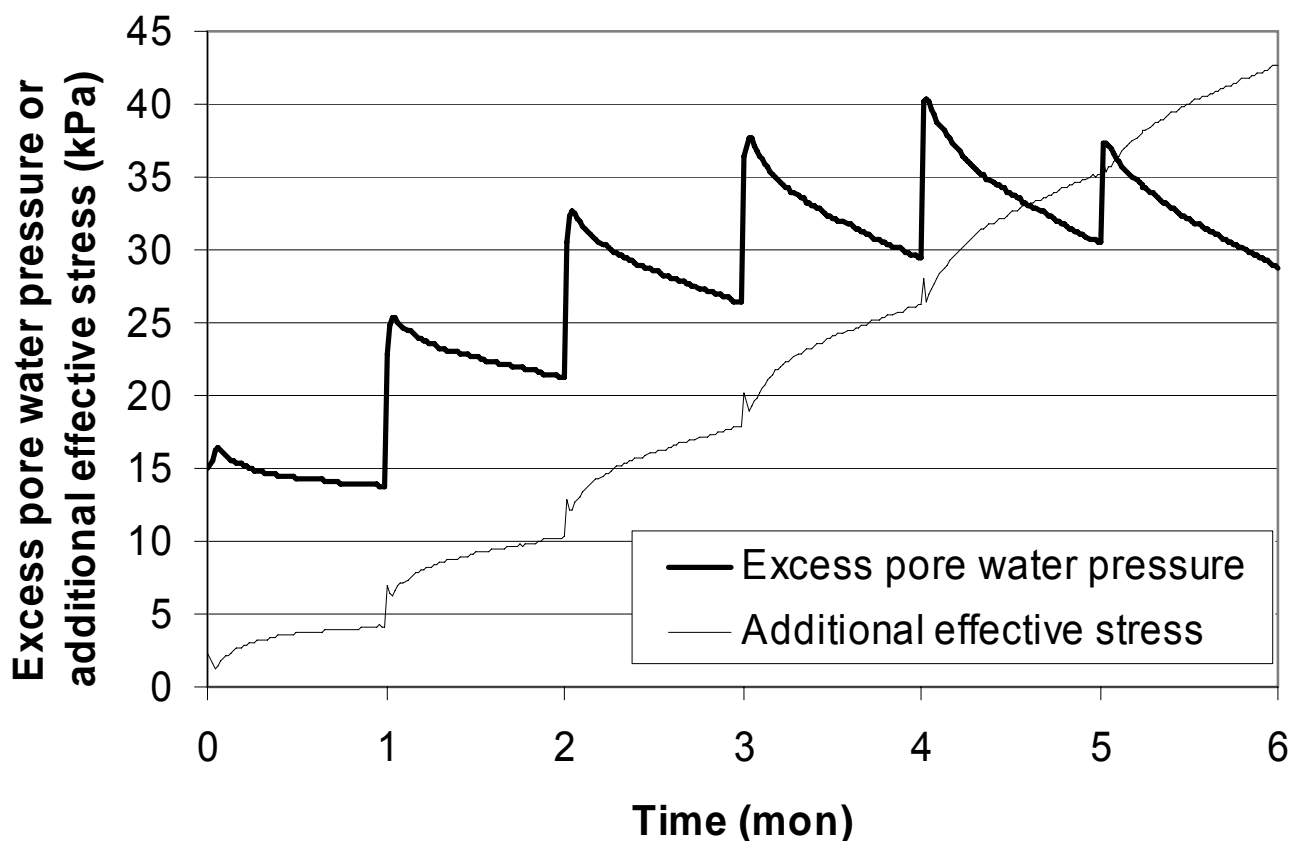

(a) 1 month after service

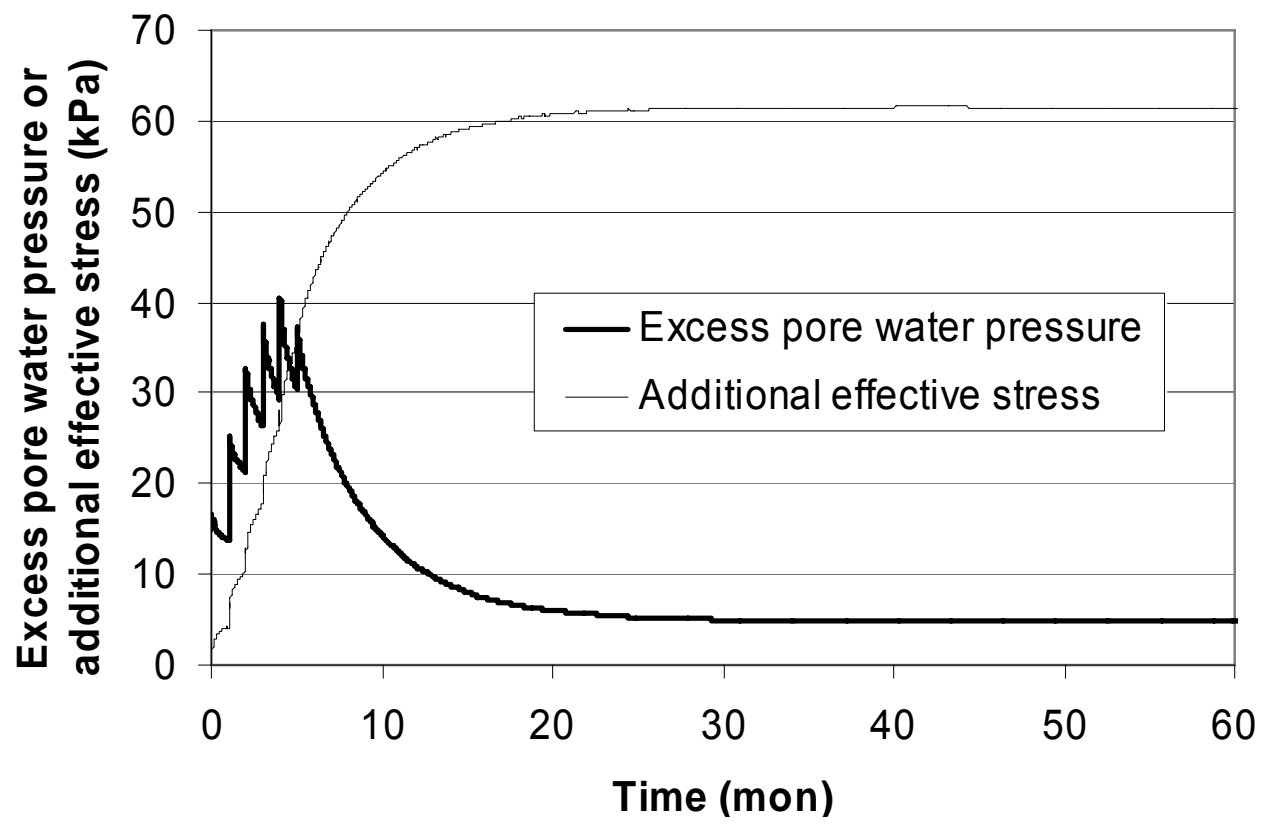

(b) 4.5 years after service

Fig. 5-17. Excess Pore water Pressure or Additional Vertical Effective Stress versus Time of the $3 \mathrm{D}$ Baseline Case 


\subsection{D Parametric Study}

\subsubsection{Outline of 3D Parametric Study}

Upon the completion of the baseline case, a parametric study was performed by deviating each property from the baseline case one at one time to investigate the influence of that specific factor. The column moduli were obtained by converting those used in the $2 \mathrm{D}$ cases. The conversion procedure has been described in the section for the baseline case in this chapter. The column moduli in the 3D parametric study corresponding to $100 \mathrm{MPa}, 150 \mathrm{MPa}$ and $200 \mathrm{MPa}$ in the $2 \mathrm{D}$ parametric study are $247 \mathrm{MPa}, 372 \mathrm{MPa}$ and $497 \mathrm{MPa}$, respectively. Other parameters were the same as those used in the 2D parametric study. The selection of each influence factor has been discussed in Chapter Four. The investigated factors and their values in the 3D parametric study are listed in Table 5-3.

Table 5-3. Parameter and Variation Used in the Three-Dimensional Study

\begin{tabular}{|c|l|l|}
\hline Item & \multicolumn{1}{|c|}{ Parameter } & \multicolumn{1}{c|}{ Range of value } \\
\hline \multirow{3}{*}{ Soft soil } & Elastic modulus $(\mathrm{MPa})$ & $1.0,2.0^{*}, 4.0,8.0$ \\
\cline { 2 - 3 } & Friction angle $\left({ }^{\circ}\right)$ & $15,20,25^{*}, 30$ \\
\cline { 2 - 3 } & Permeability $(\mathrm{m} / \mathrm{s})$ & $10^{-8}, 10^{-9 *}, 10^{-10}$ \\
\hline \multirow{2}{*}{ DM column } & Elastic modulus $(\mathrm{MPa})$ & $247^{*}, 372,497$ \\
\cline { 2 - 3 } & Spacing $(\mathrm{m})$ & $2.0,2.5^{*}, 3.0$ \\
\hline Geosynthetic & Tensile stiffness $(\mathrm{kN} / \mathrm{m})$ & $0,1000^{*}, 5000,10000$ \\
\hline Construction & Average construction rate (meter/mon) & $0.25,1^{*}, 4$ \\
\hline
\end{tabular}

* The parameters used in the baseline case 
Even though numerous results can be obtained from the 3D numerical analysis, only those related to the settlement, the tension, the vertical effective stress, and the excess pore water pressure will be presented herein to be consistent with the results of the 2D parametric study presented in Chapter Four.

\subsubsection{Settlement}

The importance of the settlement of the embankment, especially the settlement on the crest, has been emphasized in both Chapters Three and Four. As the columns were arranged in a square pattern in the $3 \mathrm{D}$ analysis rather than a wall in the $2 \mathrm{D}$ analysis, the settlements are expected to be different in these two analyses. In the 3D analysis, the settlement profiles are presented at both the section cutting through the centers of columns (Section I-I as shown in Fig. 5-1) and that cutting through the mid-span of the columns (Section II-II as shown in Fig. 5-1).

\section{Influence of Soft Soil Elastic Modulus}

Figures 5-18 and 5-19 present the settlement profiles of the embankments having different soft soil elastic moduli at both one month and 4.5 years after service, respectively. It can be seen that the increase of the soft soil modulus reduced the settlements both on the crest and at the base. The comparison between Fig. 5-18 (a) 
and (b) shows that the settlements on the crest along Sections I-I and II-II were almost the same. As a result, it can be concluded that the differential settlements on the crest of the embankment along the traffic direction are negligible. The comparison between Fig. 5-18 (c) with (d) shows that at the base of the embankment, the differential settlement at Section I-I was much greater than that at Section II-II. This difference was attributed to the effect of the columns. Overall, the settlements on the crest of the embankment were much less than those at the base. The comparison of Figs. 5-18 and 5-19 shows an insignificant increase of the settlement from one month to 4.5 years after service.

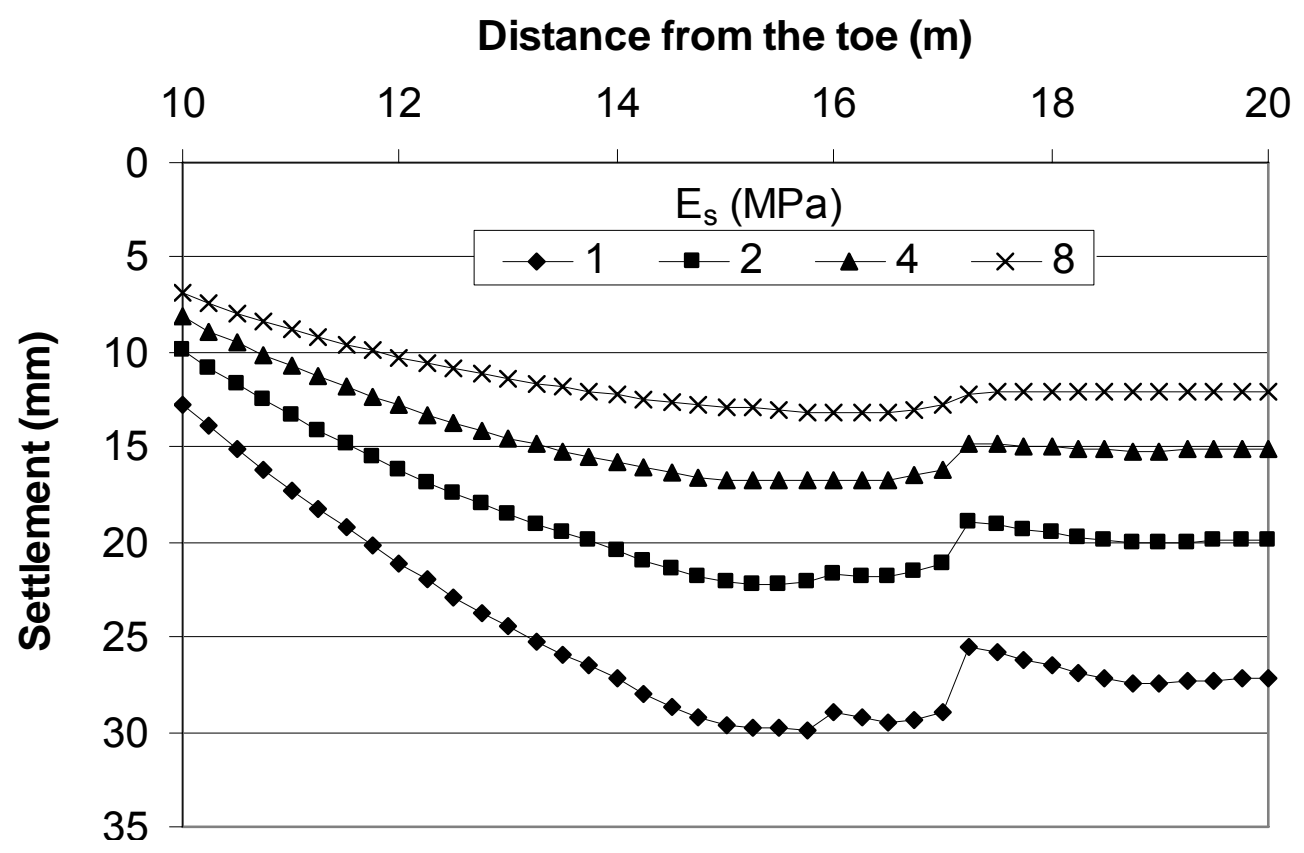

(a) On the crest through Section I-I

Fig. 5-18. Settlement Profiles for Various Soil Moduli at 1 Month after Service (3D) 


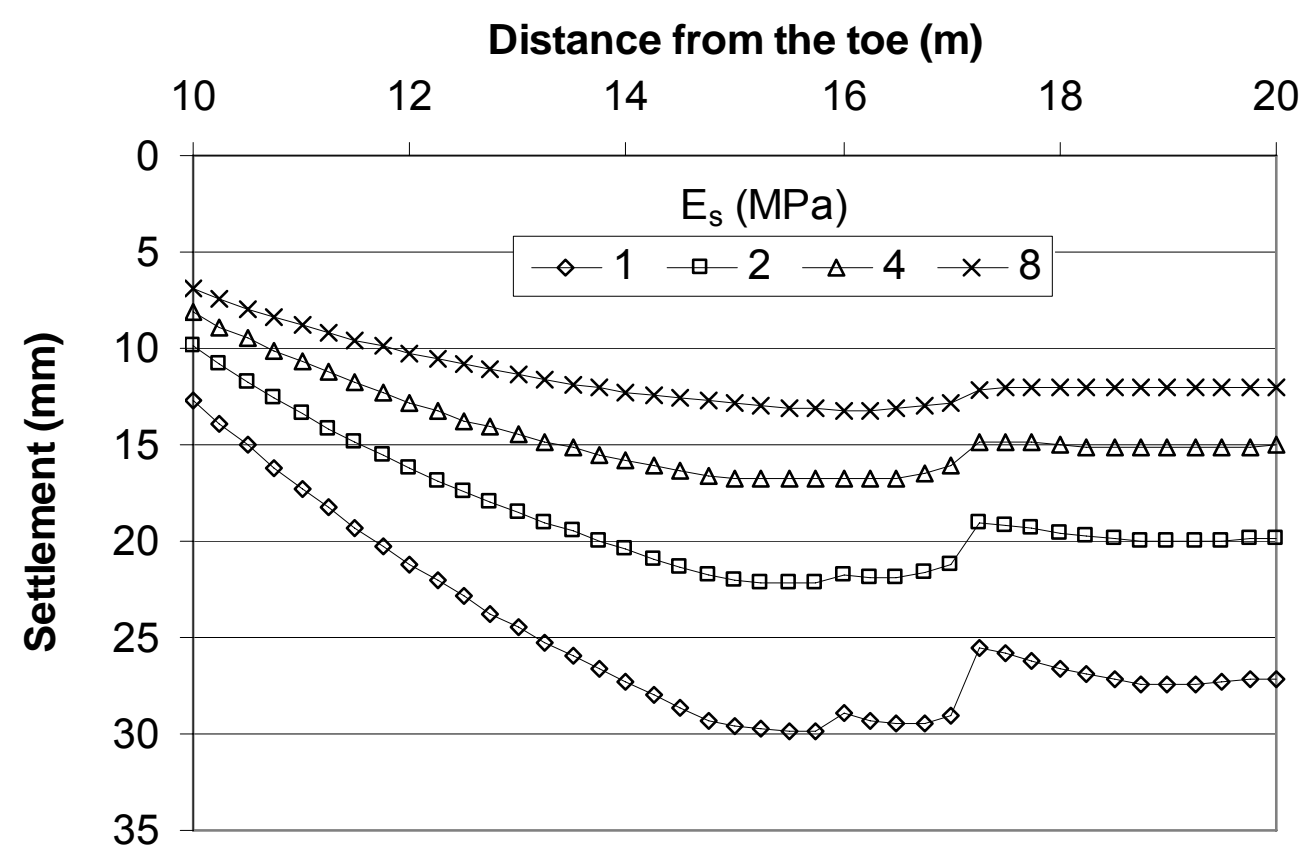

(b) On the crest through Section II-II

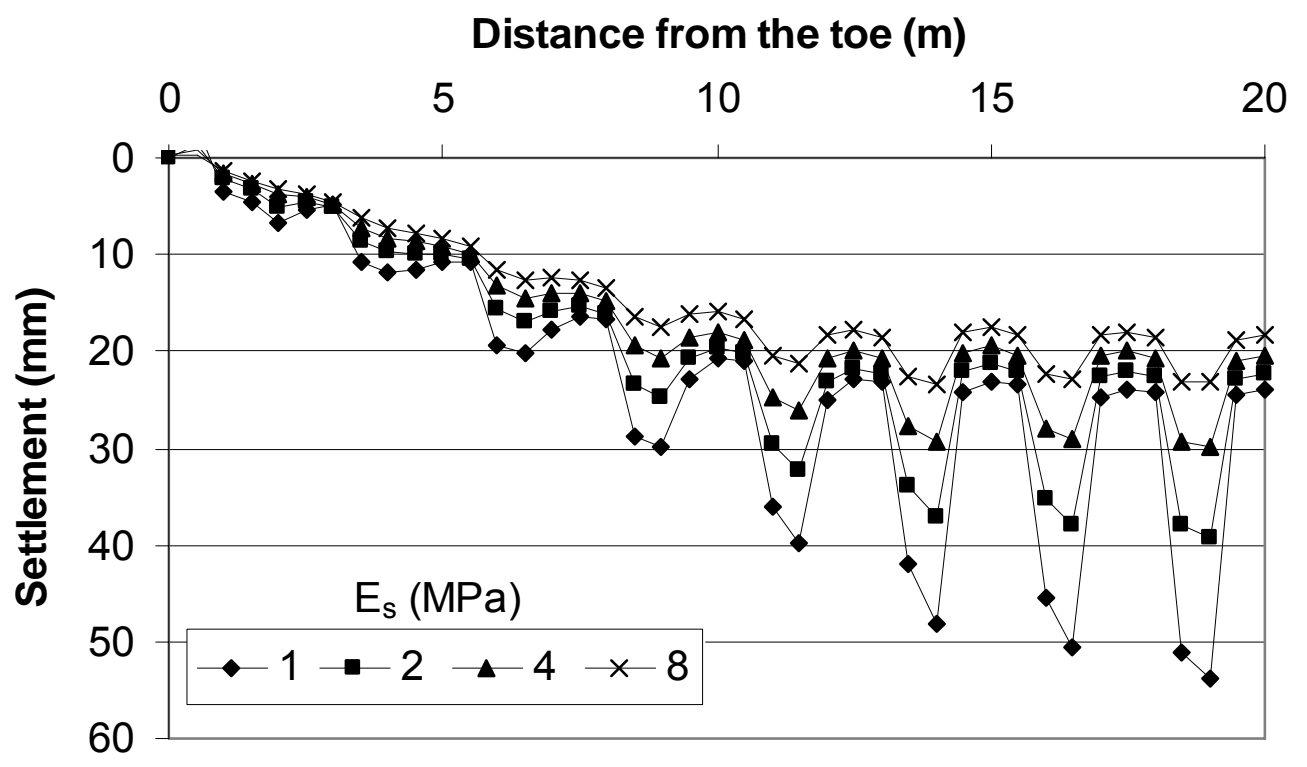

(c) At the base through Section I-I

Fig. 5-18. Settlement Profiles for Various Soil Moduli at 1 Month after Service (3D) (continued) 


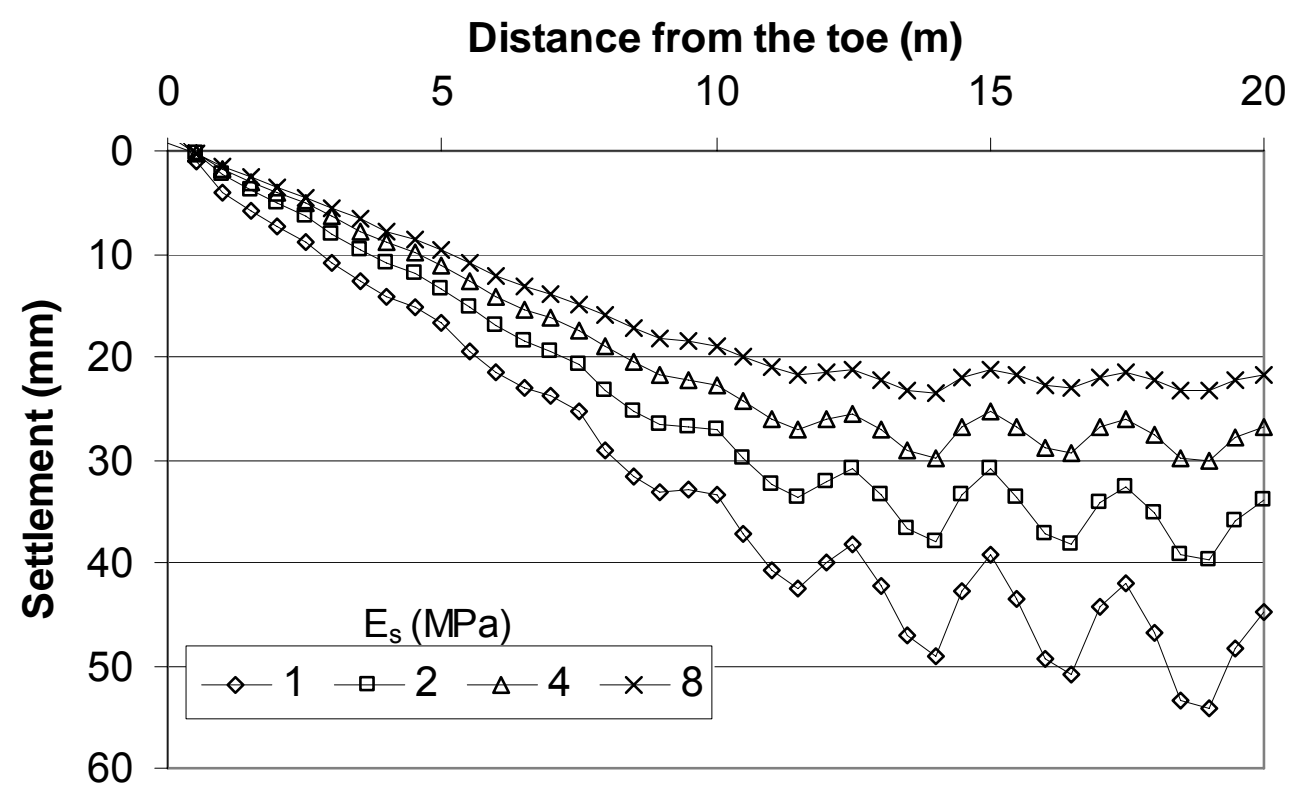

(d) At the base through Section II-II

Fig. 5-18. Settlement Profiles for Various Soil Moduli at 1 Month after Service (3D) (continued)

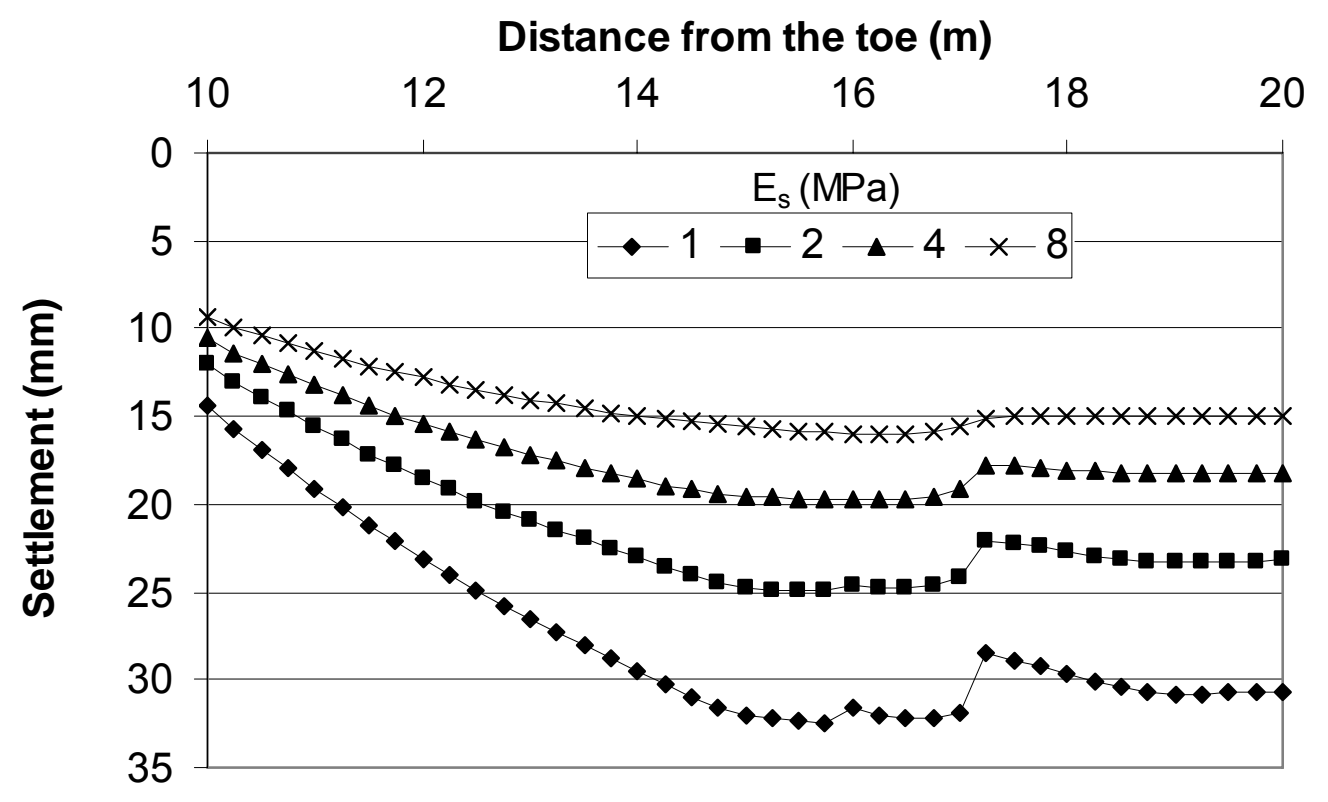

(a) On the crest through Section I-I

Fig. 5-19. Settlement Profiles for Various Soil Moduli at 4.5 Years after Service (3D) 


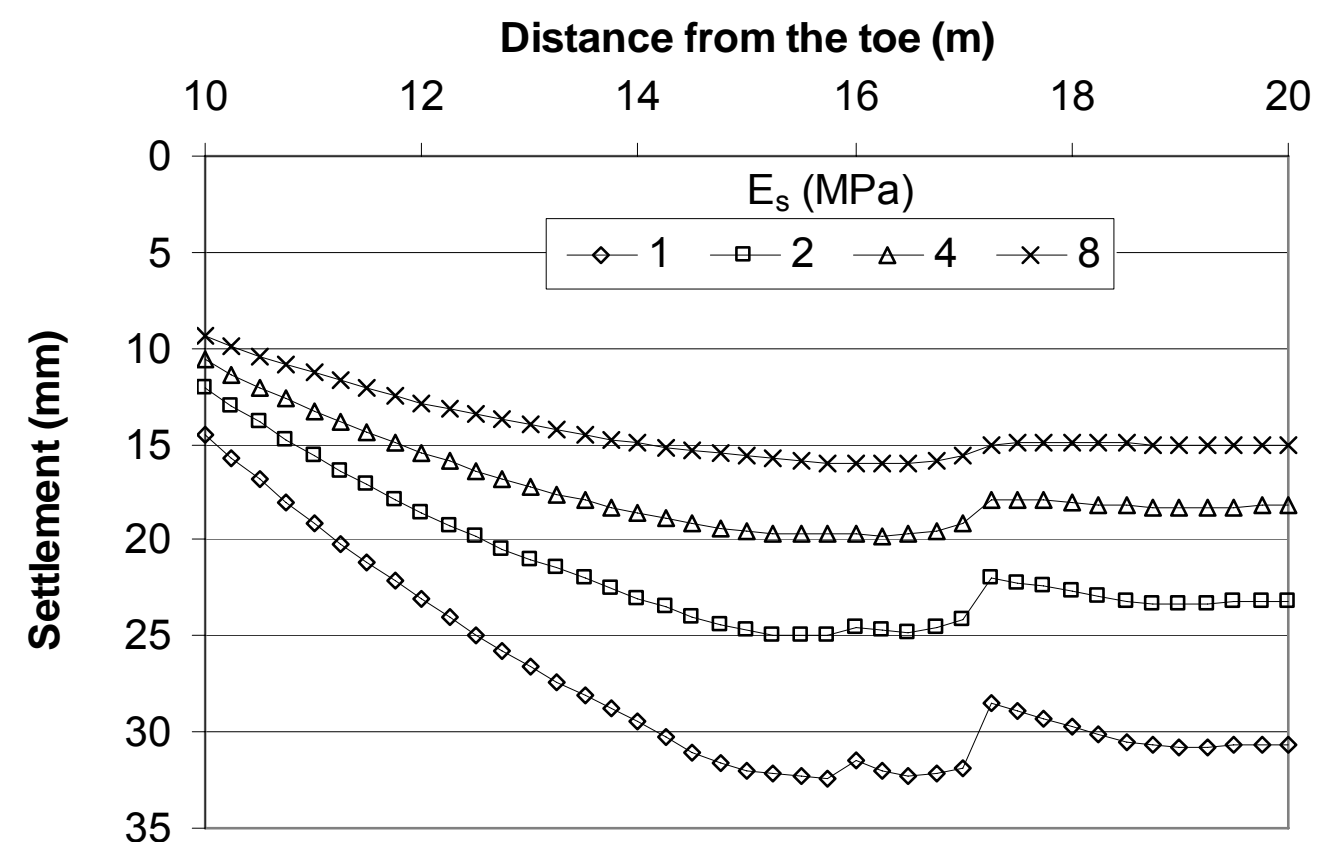

(b) On the crest through Section II-II

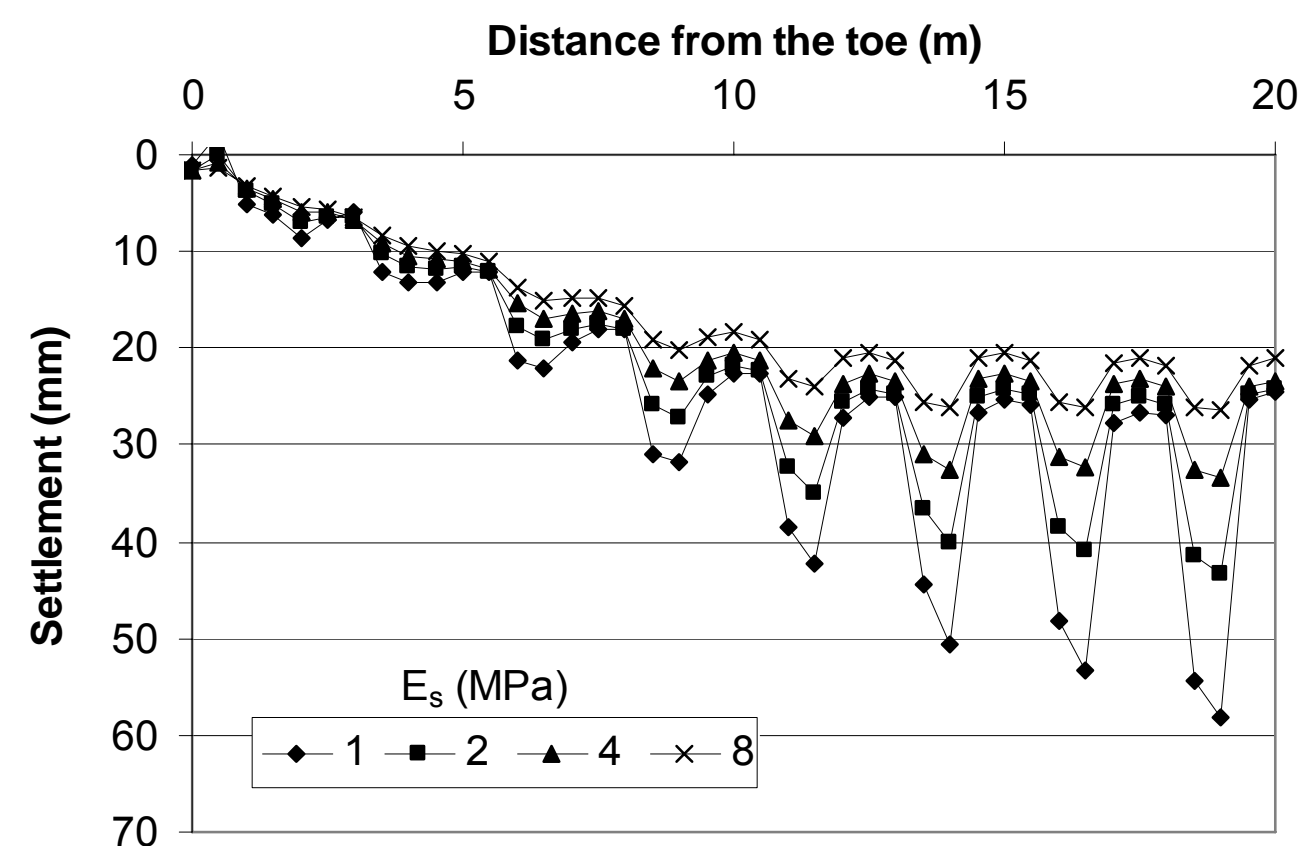

(c) At the base through Section I-I

Fig. 5-19. Settlement Profiles for Various Soil Moduli at 4.5 Years after Service (3D) (continued) 


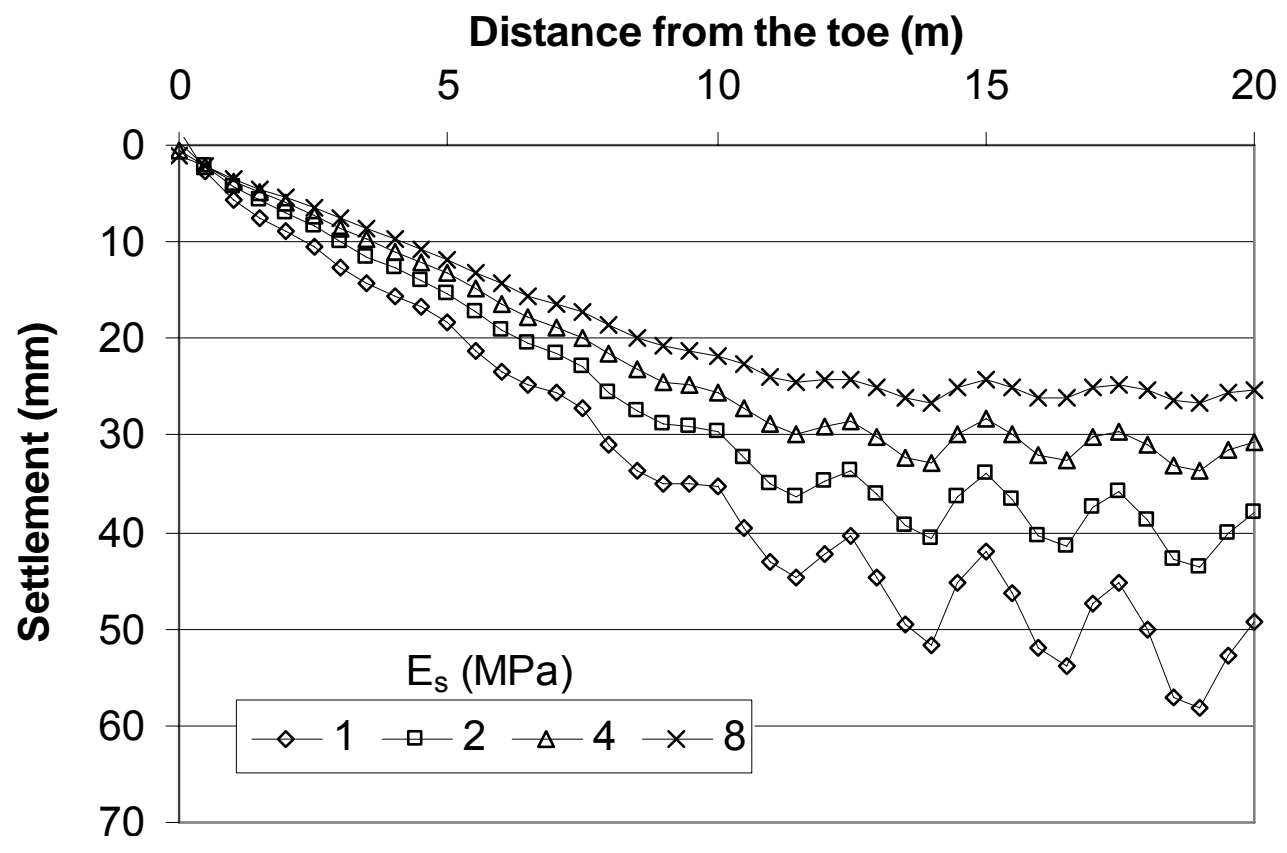

(d) At the base through Section II-II

\section{Fig. 5-19. Settlement Profiles for Various Soil Moduli at 4.5 Years after Service (3D) (continued)}

The influence of the soft soil modulus on the maximum settlement and the maximum differential settlement are presented in Figs. 5-20 and 5-21, respectively. Obviously, the increase of the soft soil modulus reduced both the maximum settlement and the maximum differential settlement. However, the effect of the soft soil modulus became less when the modulus continued increasing. Figure 5-21 shows that the soft soil modulus had the greater effect on the maximum differential settlement at the base than that on the crest. In addition, the increase of the maximum settlement from one month to 4.5 years after service was greater than that of the maximum differential settlement. 


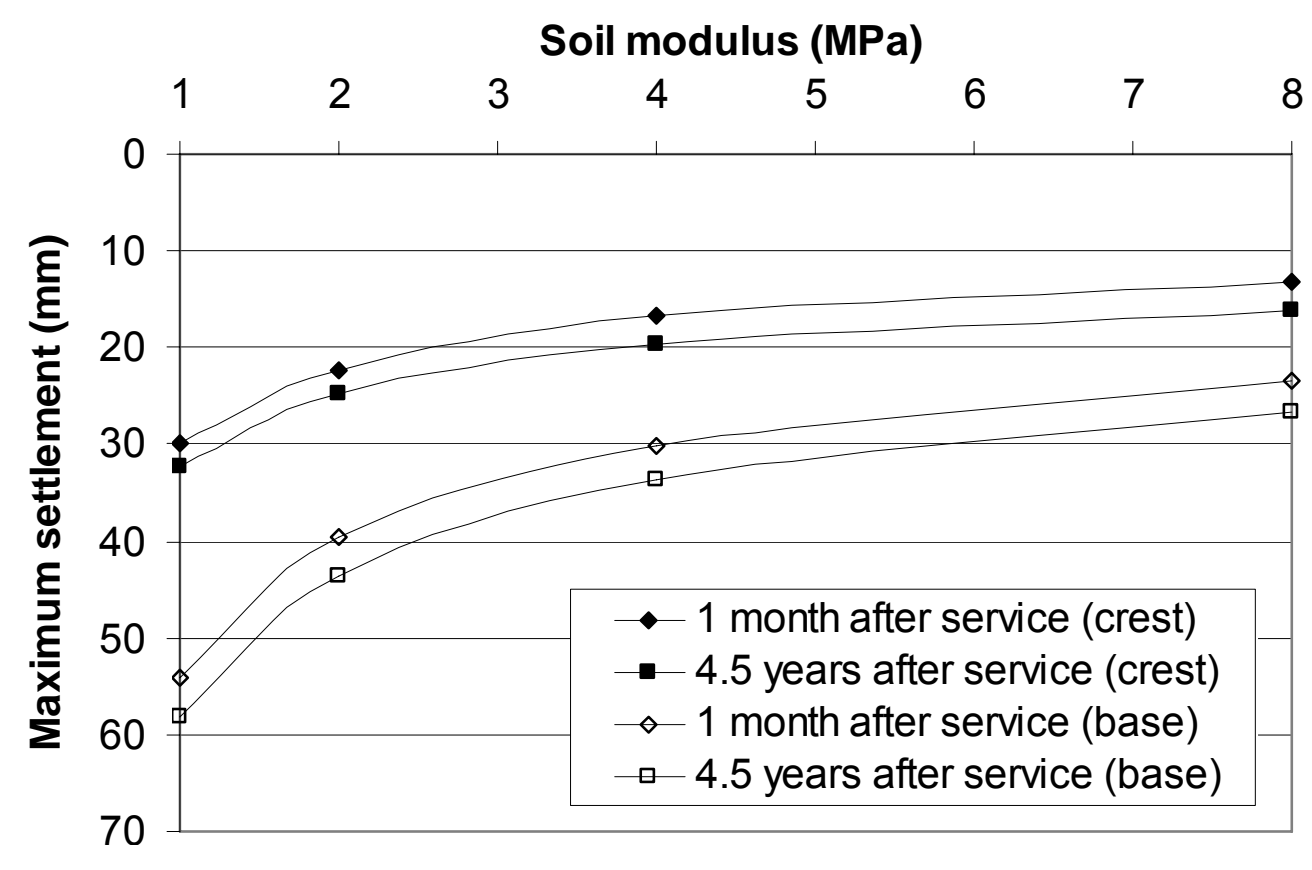

Fig. 5-20. Maximum Settlement versus Soil Modulus (3D)

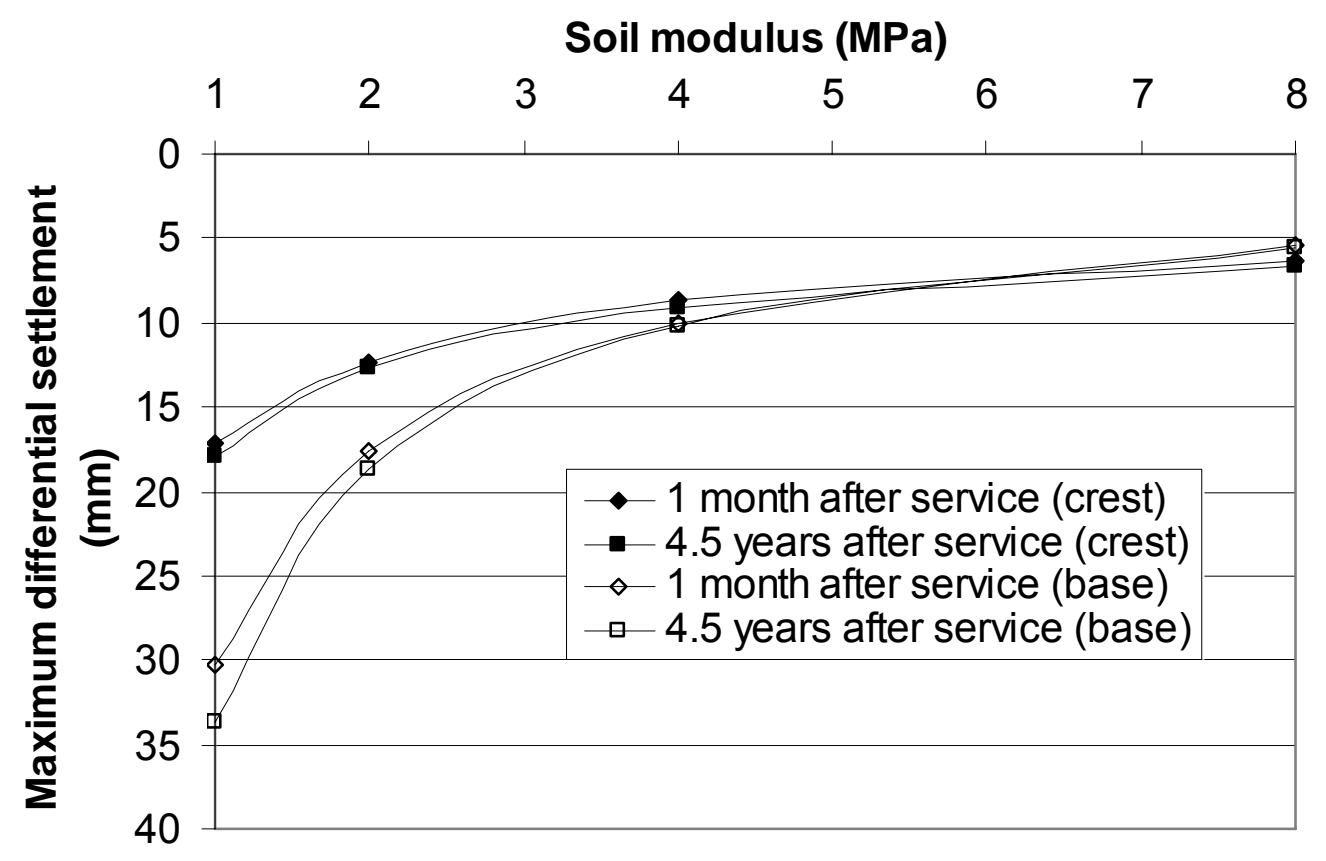

Fig. 5-21. Maximum Differential Settlement versus Soil Modulus (3D) 
Similar to the 2D parametric study, the maximum distortion was also studied in the 3D modeling to evaluate the degree of smoothness on the crest of the embankment. The influence of the soil modulus on the maximum distortion is shown in Fig. 5-22, which shows that the higher soil modulus yielded less maximum distortion. The reduction of the maximum distortion was more than $75 \%$ when the soil modulus varied from $1 \mathrm{MPa}$ to $8 \mathrm{MPa}$. The maximum distortion decreased slightly with the consolidation of the foundation. In addition, the reduction of the maximum distortion due to consolidation was relatively significant at the lower soil modulus as shown in Fig. 5-22.

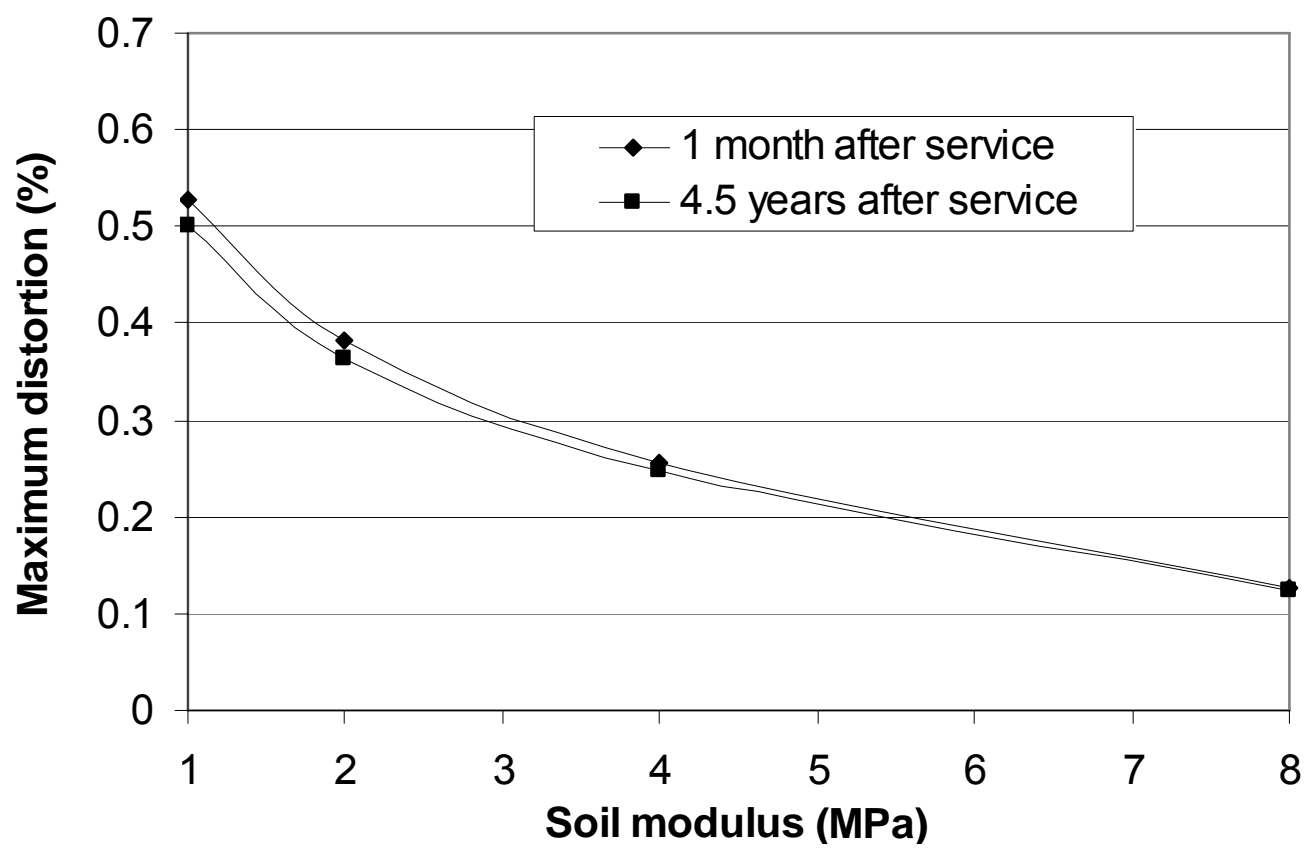

Fig. 5-22. Maximum Distortion on the Crest versus Soil Modulus (3D) 


\section{Influence of Soft Soil Friction Angle}

The settlement profiles at different elevations and sections are presented in Fig. 5-23 and Fig. 5-24. It can be seen that the higher friction angle led to less settlement on the crest. The higher friction angle also resulted less settlement in the soft soil at the base; however, it did not influence the settlement on the columns. There was an apparent difference in the settlement at the base between Sections I-I and II-II while the difference on the crest between these two sections was small enough to be neglected.

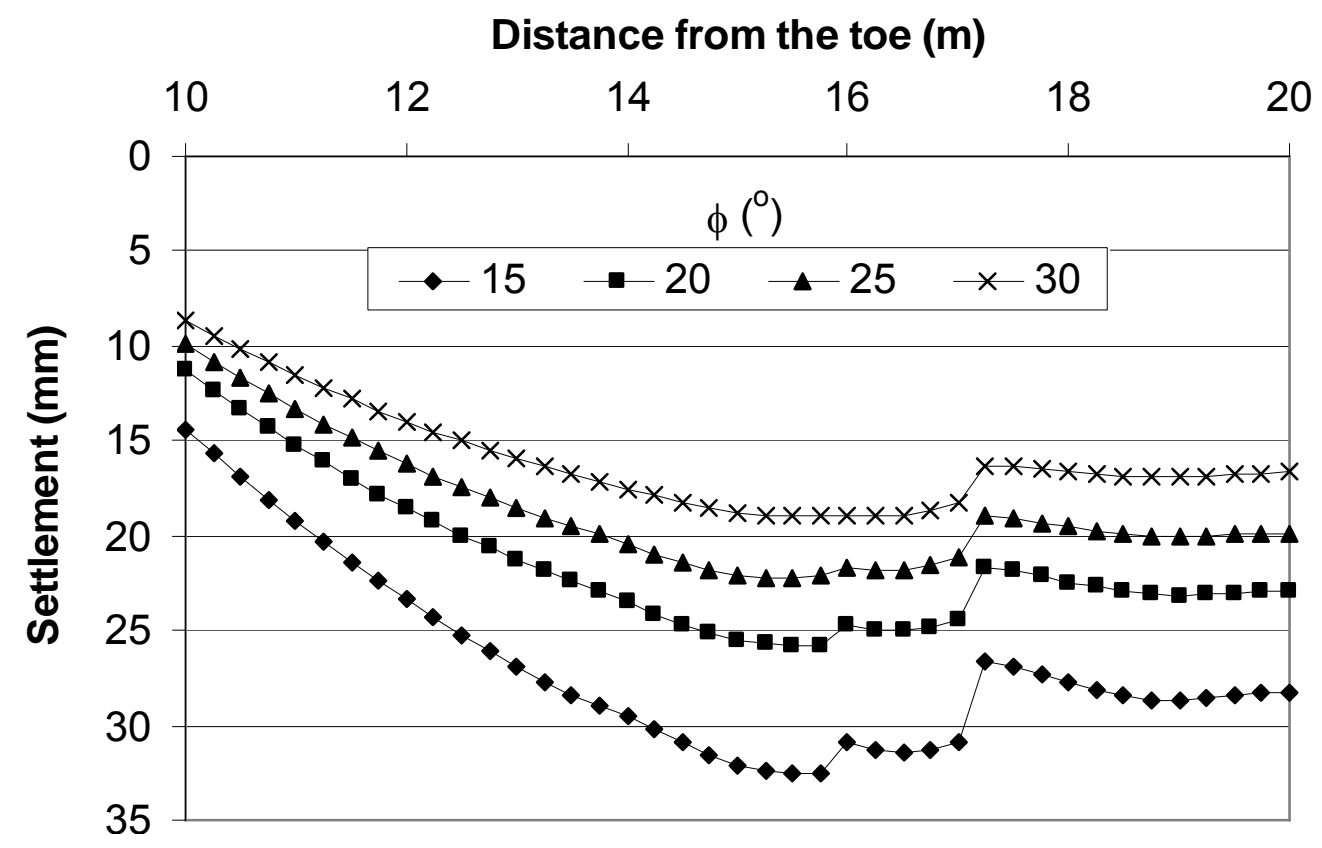

(a) On the crest through Section I-I

Fig. 5-23. Settlement Profiles for Various Friction Angles at 1 Month after Service (3D) 


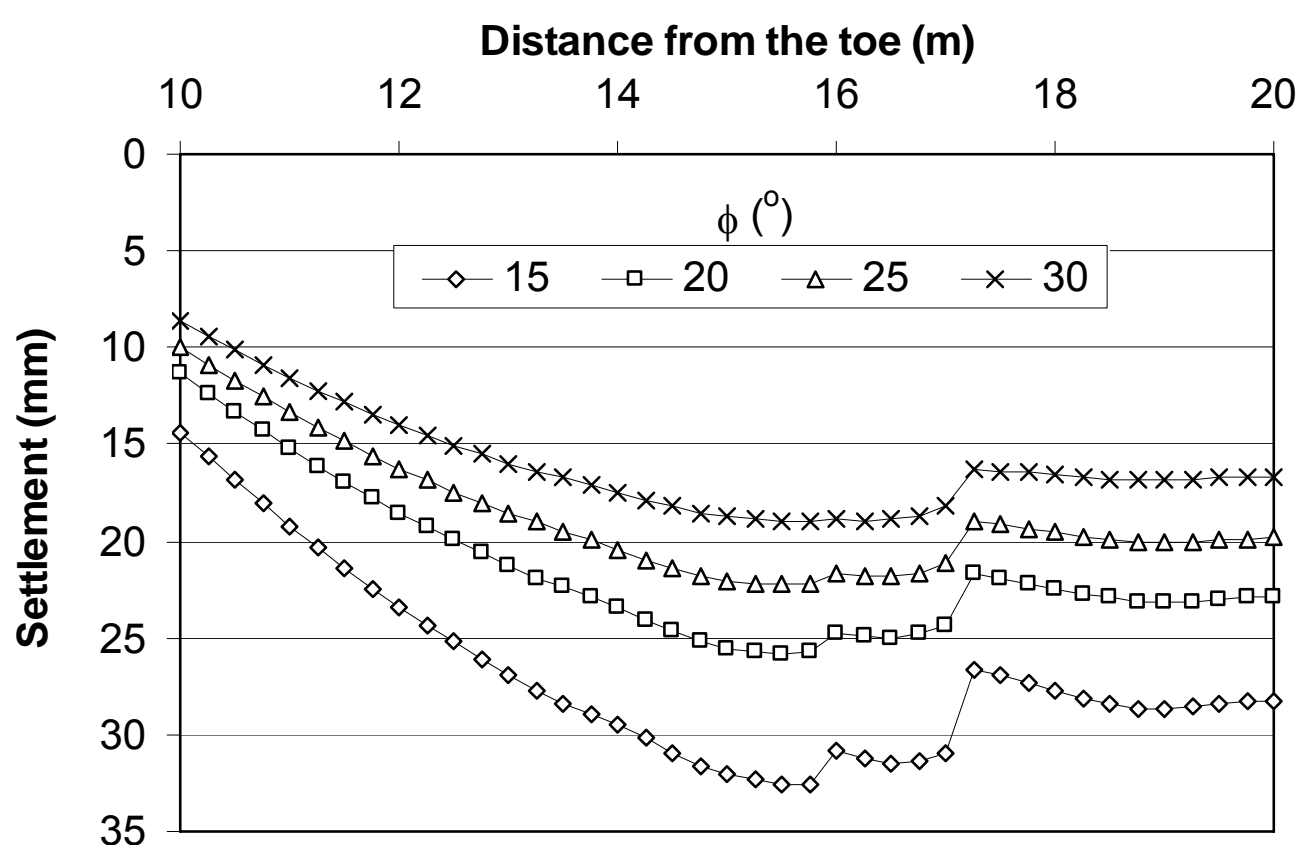

(b) On the crest through Section II-II

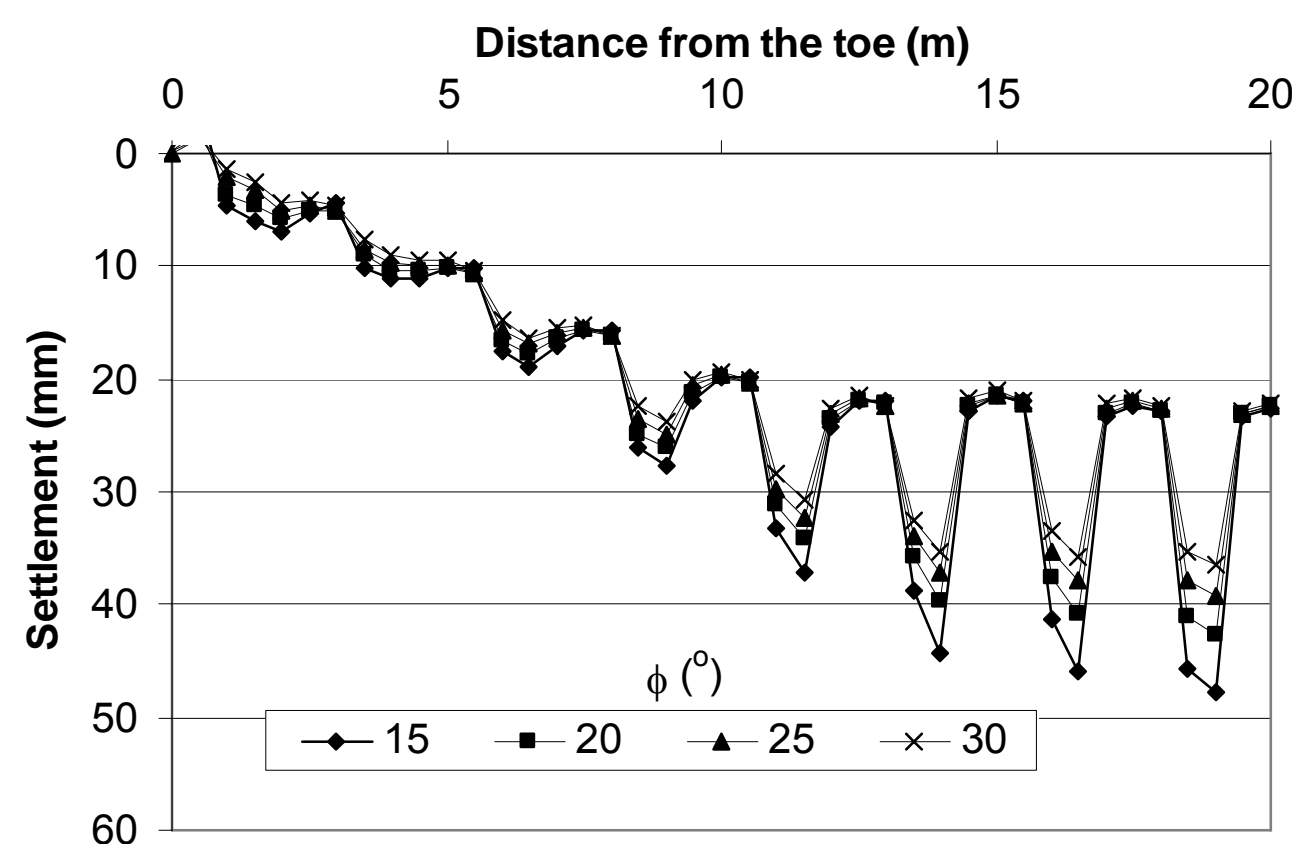

(c) At the base through Section I-I

Fig. 5-23. Settlement Profiles for Various Friction Angles at 1 Month after Service (3D) (continued) 


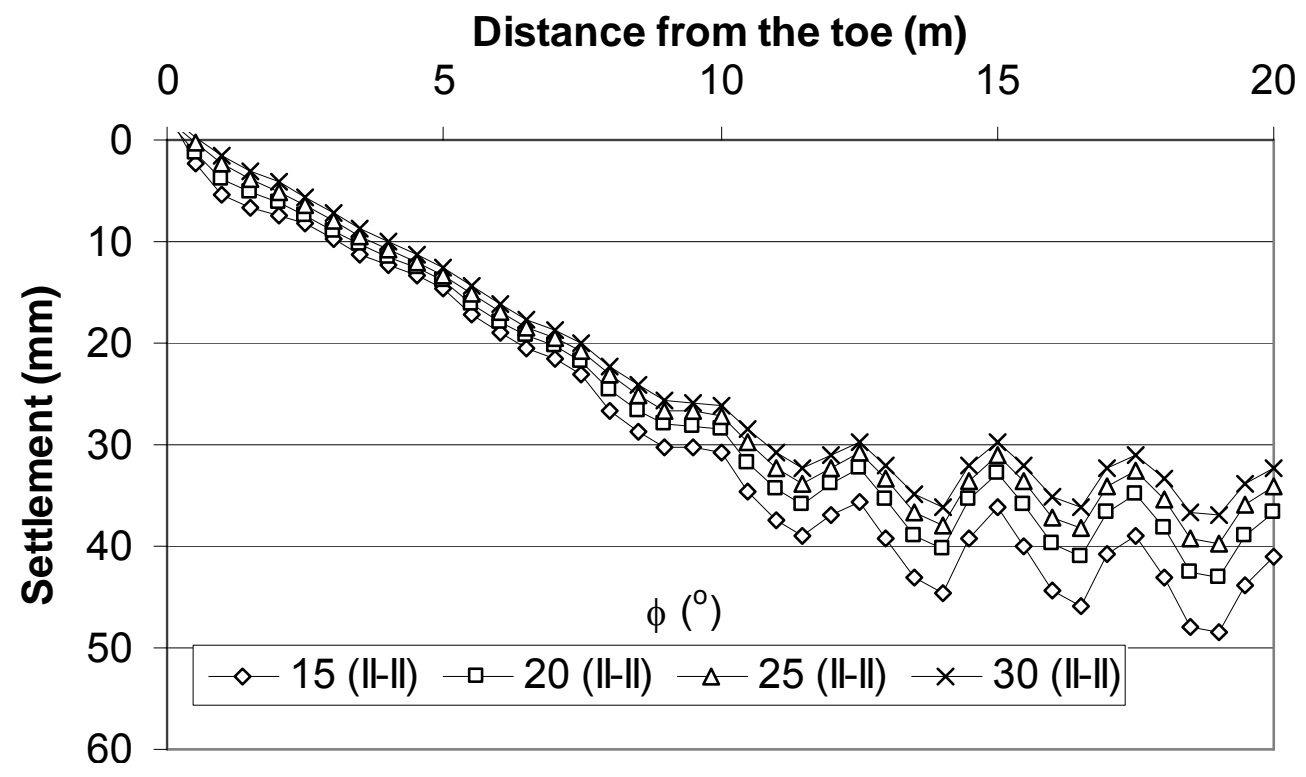

(d) At the base through Section II-II

Fig. 5-23. Settlement Profiles for Various Friction Angles at 1 Month after Service (3D) (continued)

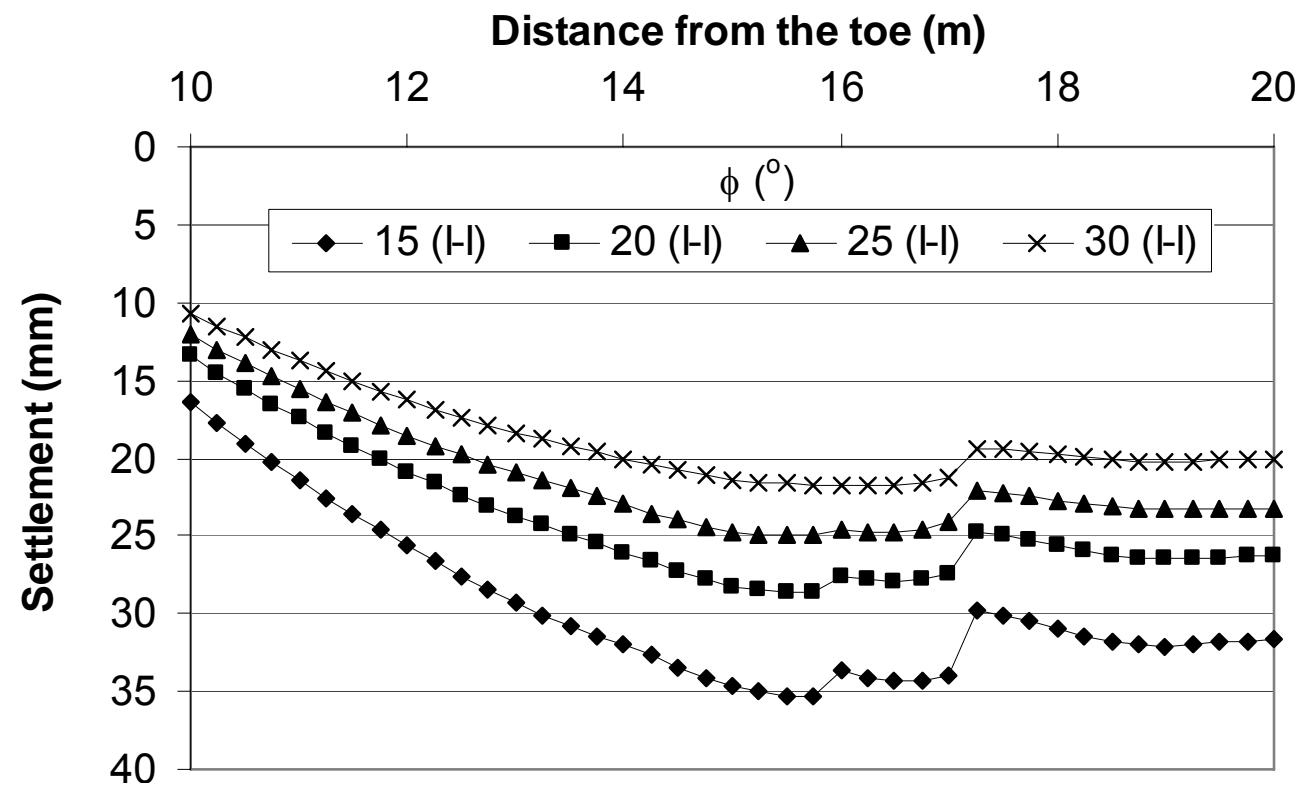

(a) On the crest through Section I-I

Fig. 5-24. Settlement Profiles for Various Friction Angles at 4.5 Years after Service (3D) 


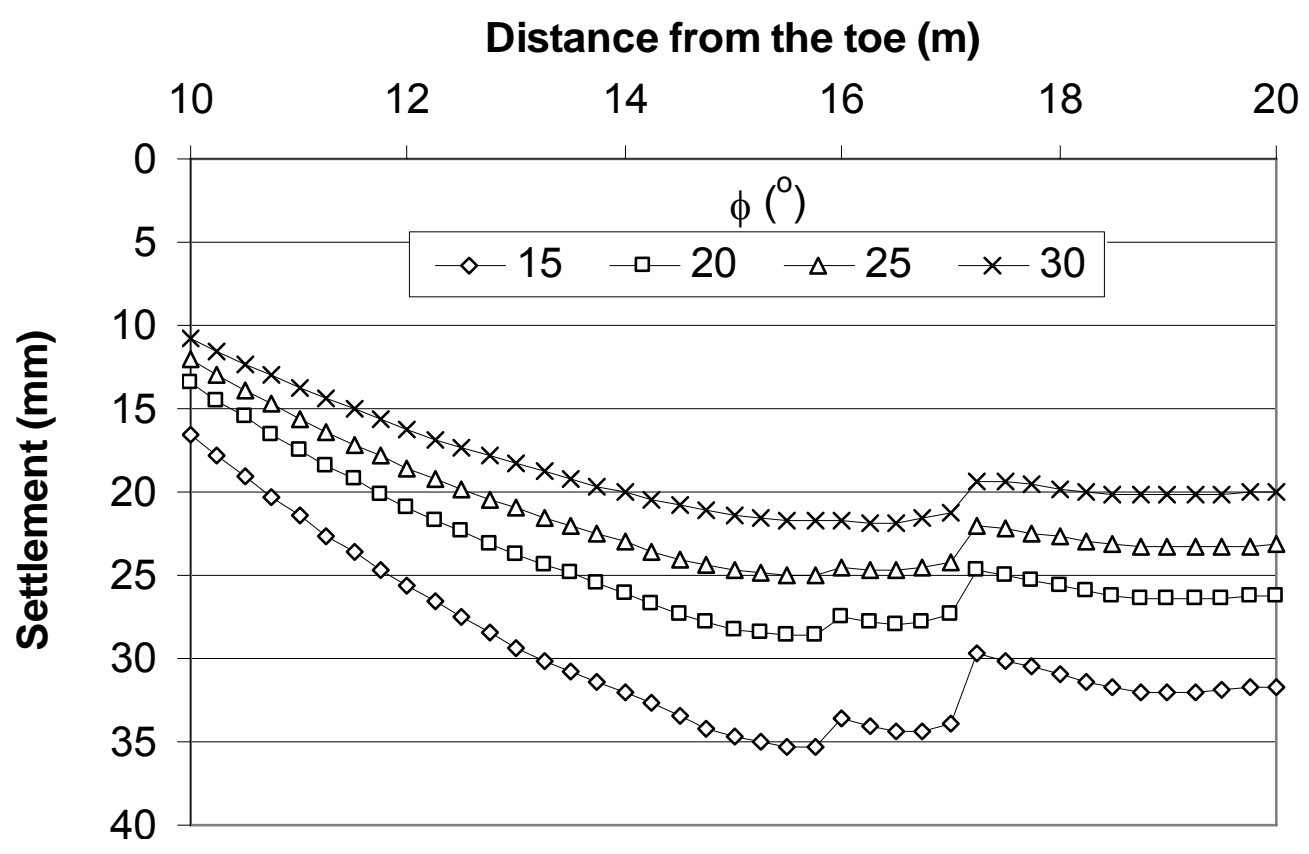

(b) On the crest through Section II-II

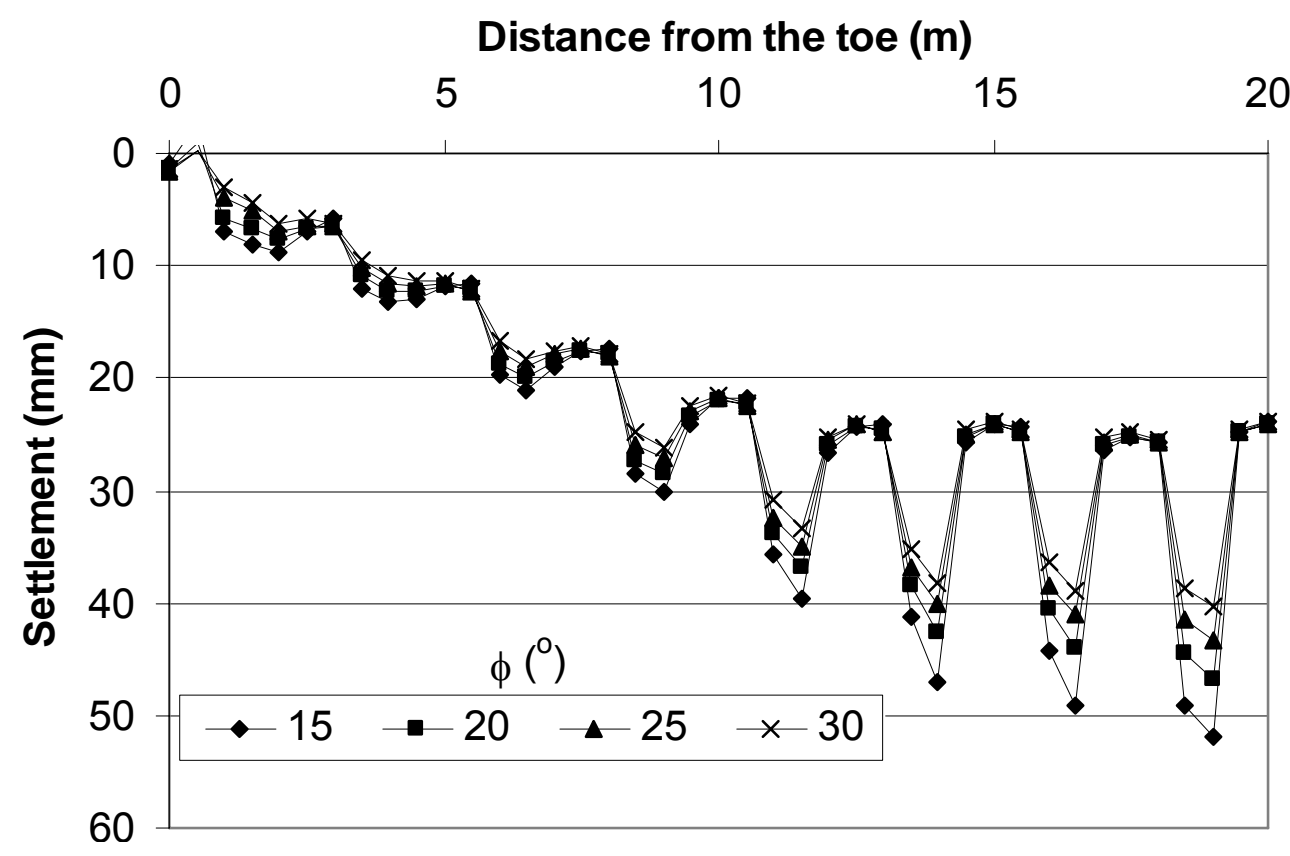

(c) At the base through Section I-I

Fig. 5-24. Settlement Profiles for Various Friction Angles at 4.5 Years after Service (3D) (continued) 


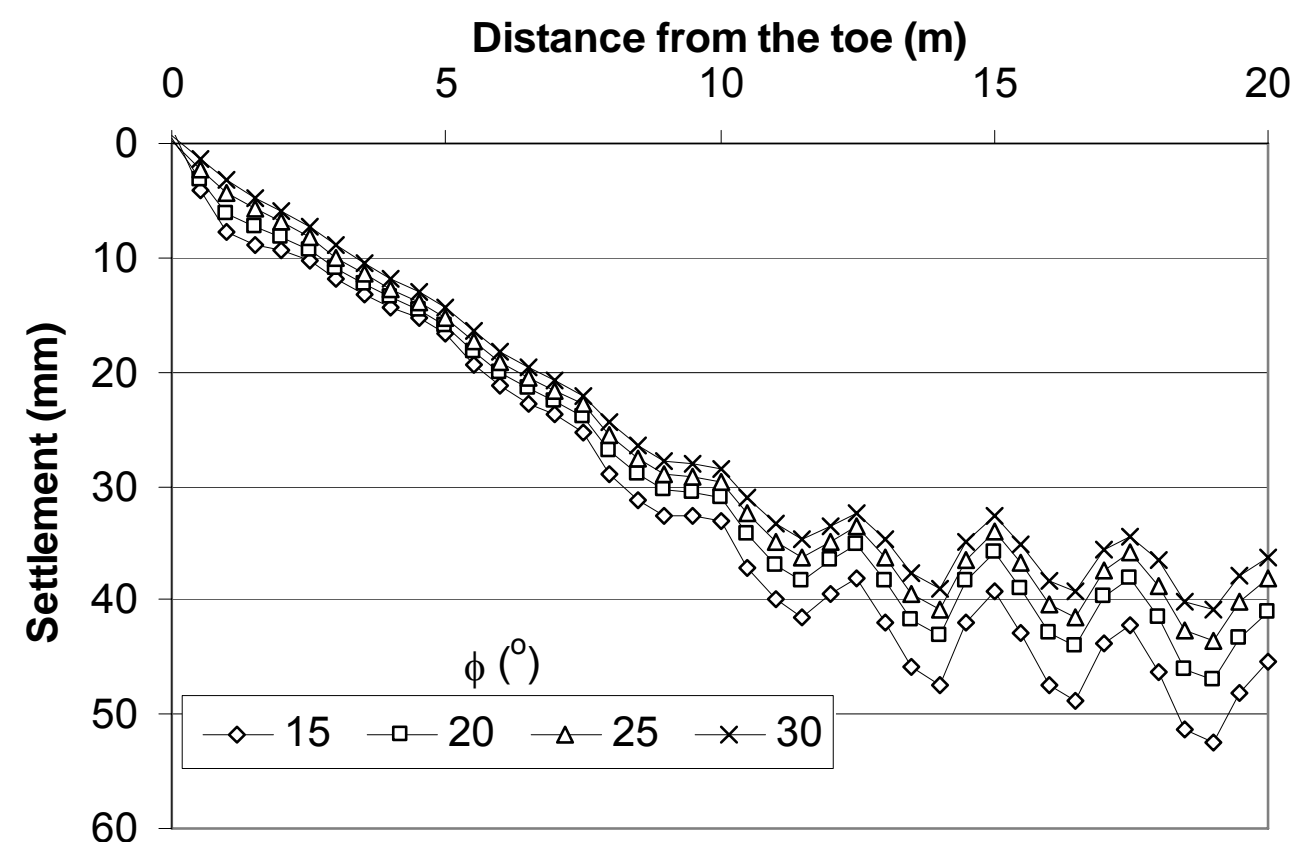

(d) At the base through Section II-II

Fig. 5-24. Settlement Profiles for Various Friction Angles at 4.5 Years after Service (3D) (continued)

The influences of the soil friction angle on the maximum settlement and the maximum differential settlement are shown in Figs. 5-25 and 5-26, respectively. Obviously, both the maximum settlement and the maximum differential settlement decreased with the increase of the soil friction angle. In addition, the relationship between the maximum settlement or the maximum differential settlement and the soil friction angle is almost linear. The influence of the soil friction angle on the maximum settlement was greater than that on the maximum differential settlement. When the soil friction angle increased from $15^{\circ}$ to $30^{\circ}$, the maximum settlement was reduced by approximately $14 \mathrm{~mm}$, whereas the maximum different settlement was reduced by approximately $8 \mathrm{~mm}$. Figures 5-25 and 5-26 show that the consolidation of 
the foundation had more effect on the maximum settlement than that on the maximum differential settlement.

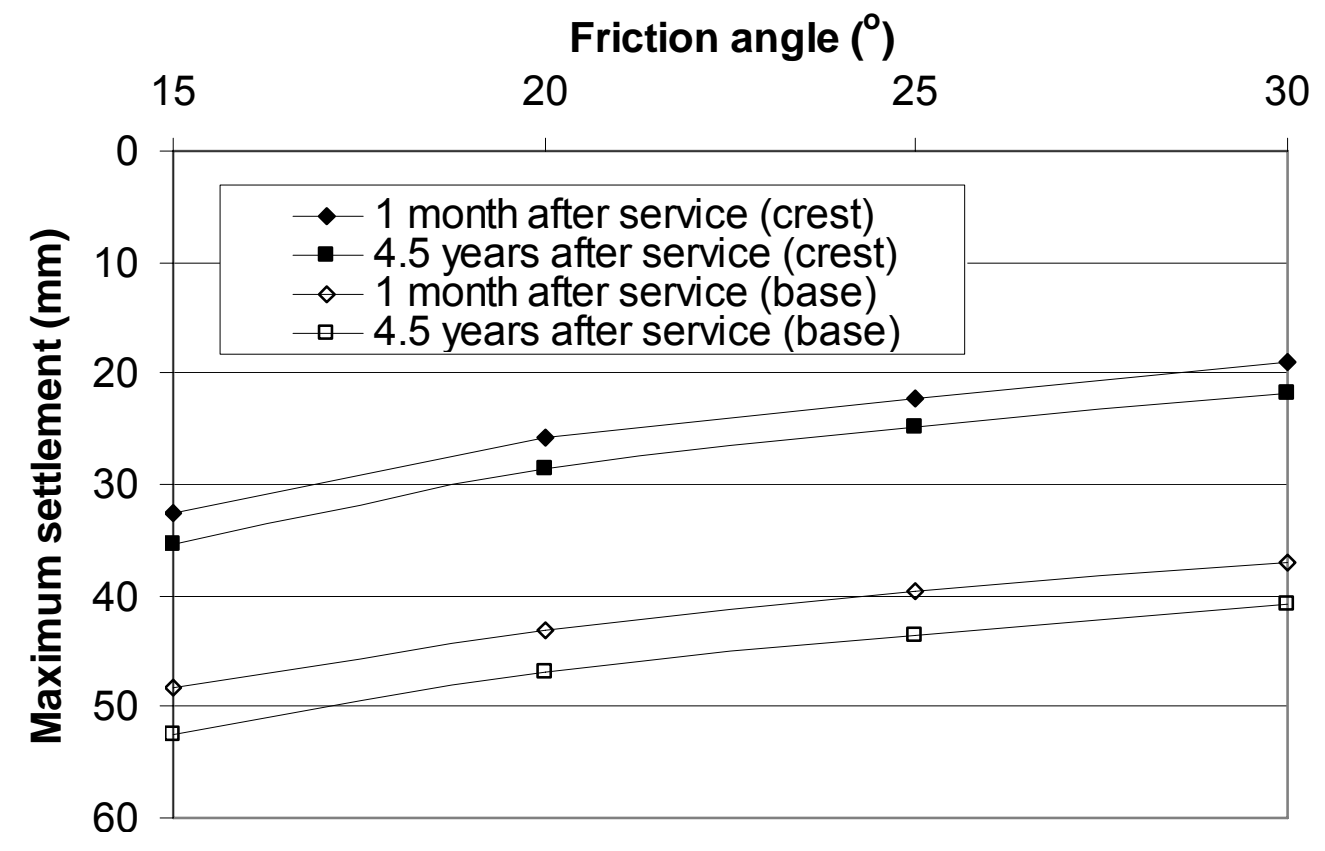

Fig. 5-25. Maximum Settlement versus Friction Angle (3D)

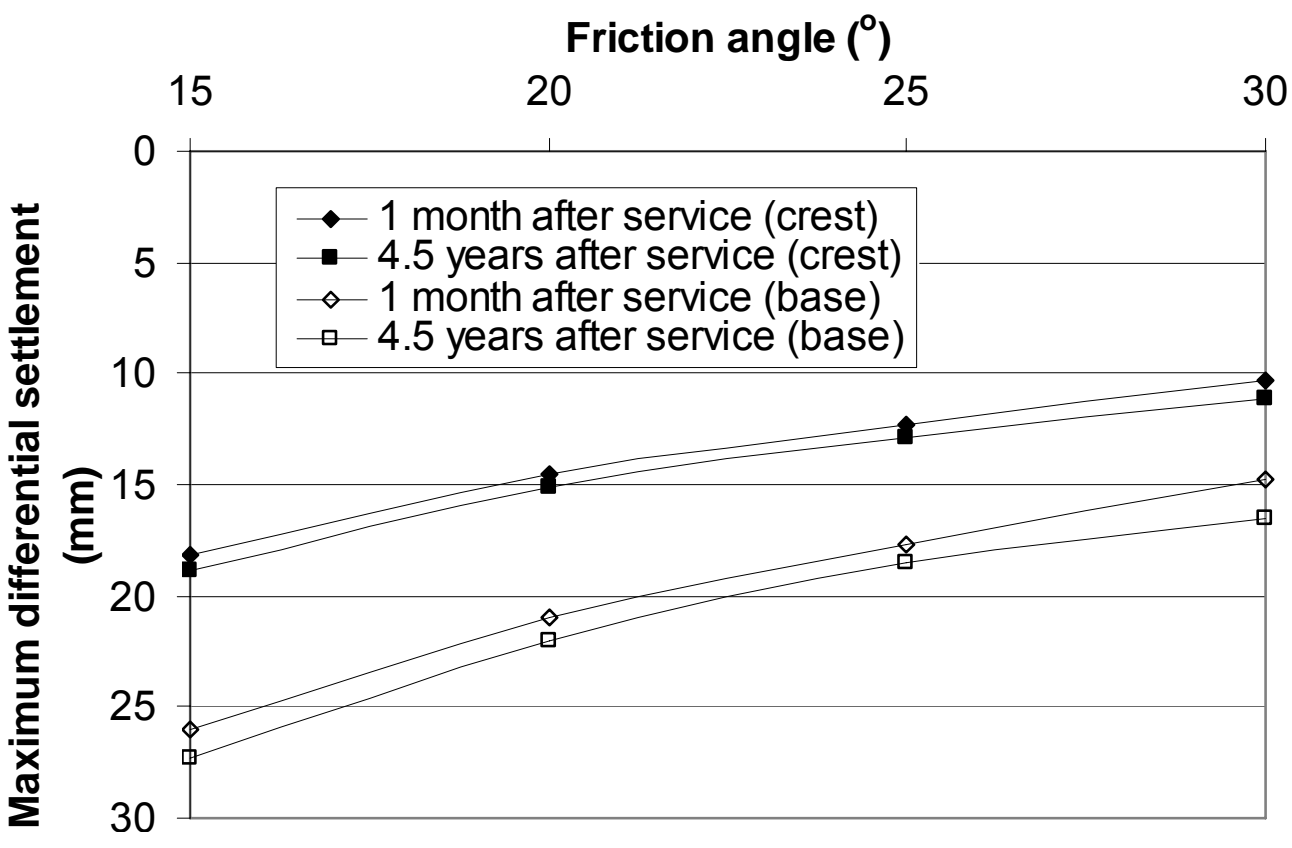

Fig. 5-26. Maximum Differential Settlement versus Friction Angle (3D) 
The influence of the soil friction angle on the maximum distortion is presented in Fig. 5-27. When the soil friction angle increased from $15^{\circ}$ to $30^{\circ}$, the maximum distortion was reduced by more than $50 \%$. Therefore, the increase of soil friction angle is an effective way to reduce the maximum distortion. Figure 5-27 shows that the consolidation of the foundation reduced the maximum distortion slightly.

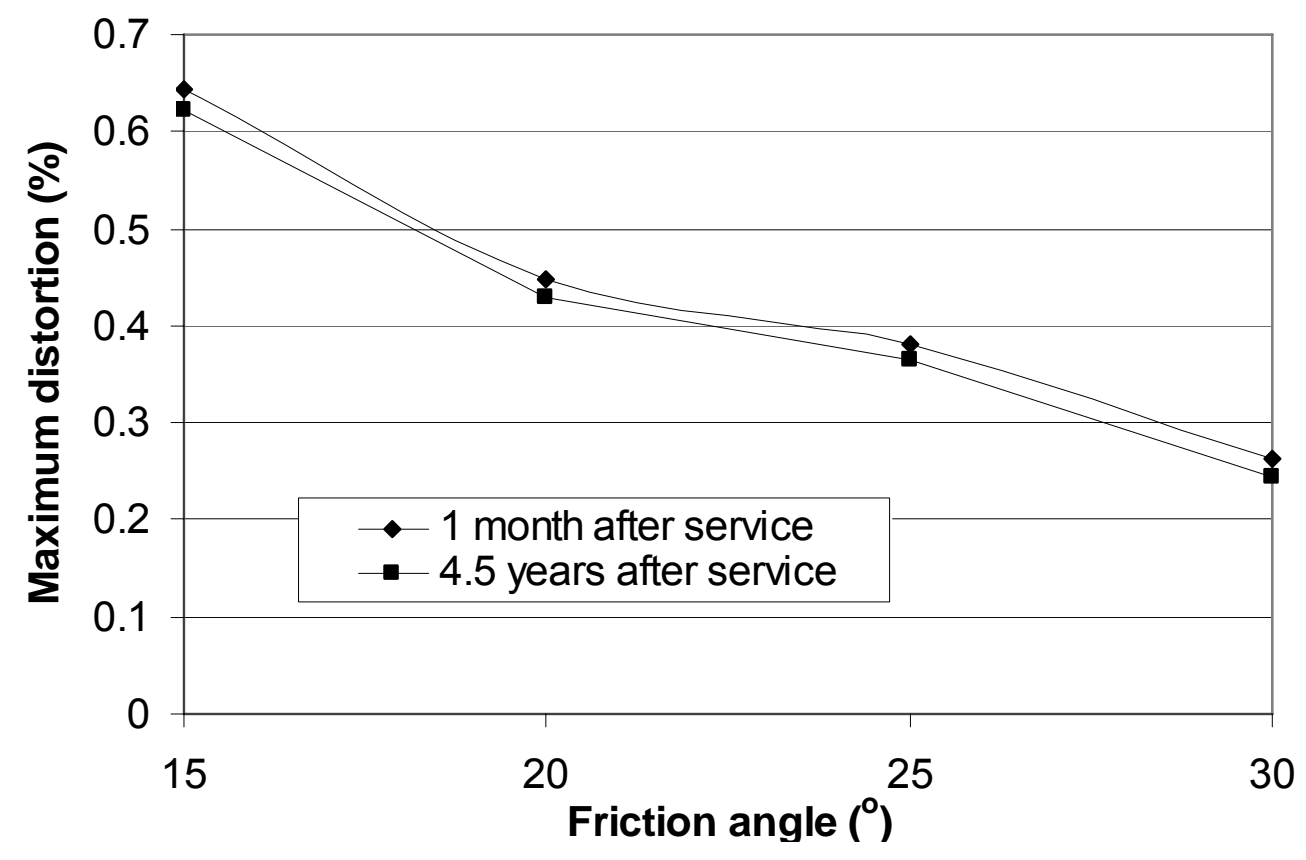

Fig. 5-27. Maximum Distortion on the Crest versus Friction Angle (3D)

\section{Influence of Soft Soil Permeability}

As discussed in Chapter Four, the permeability of soft soil had significant influence on the performance of the GRCS embankment due to the generation and dissipation of the excess pore water pressure. Therefore, the performance of the GRCS 
embankment is time-dependant. So far, the influence of the soil permeability on the GRCS embankment has not been well studied. In this 3D parametric study, the effect of the permeability of the soft soil on the settlement was evaluated by increasing the soil permeability in the baseline case (i.e., $10^{-9} \mathrm{~m} / \mathrm{s}$ ) by 10 times or reducing it by onetenth. The settlement profiles at one month and 4.5 years after service are presented in Figs. 5-28 and 5-29, respectively. It can be seen that the higher soil permeability led to less settlement on the crest. At the base of the embankment, the higher permeability resulted in less settlement in the soil but more settlement on the columns. The reason for these results has been explained in Chapter Four. The comparison of Figs. 5-28 and 5-29 shows that the lower soil permeability had more increase in the settlement from one month to 4.5 years after service. The reason for this phenomenon is that the soil with lower permeability had more excess pore water accumulation during the construction, which resulted in more settlement as the excess pore water pressure dissipated. In addition, no significant differential settlement along the traffic direction was identified by comparing the crest settlement profiles along Sections I-I and II-II. 


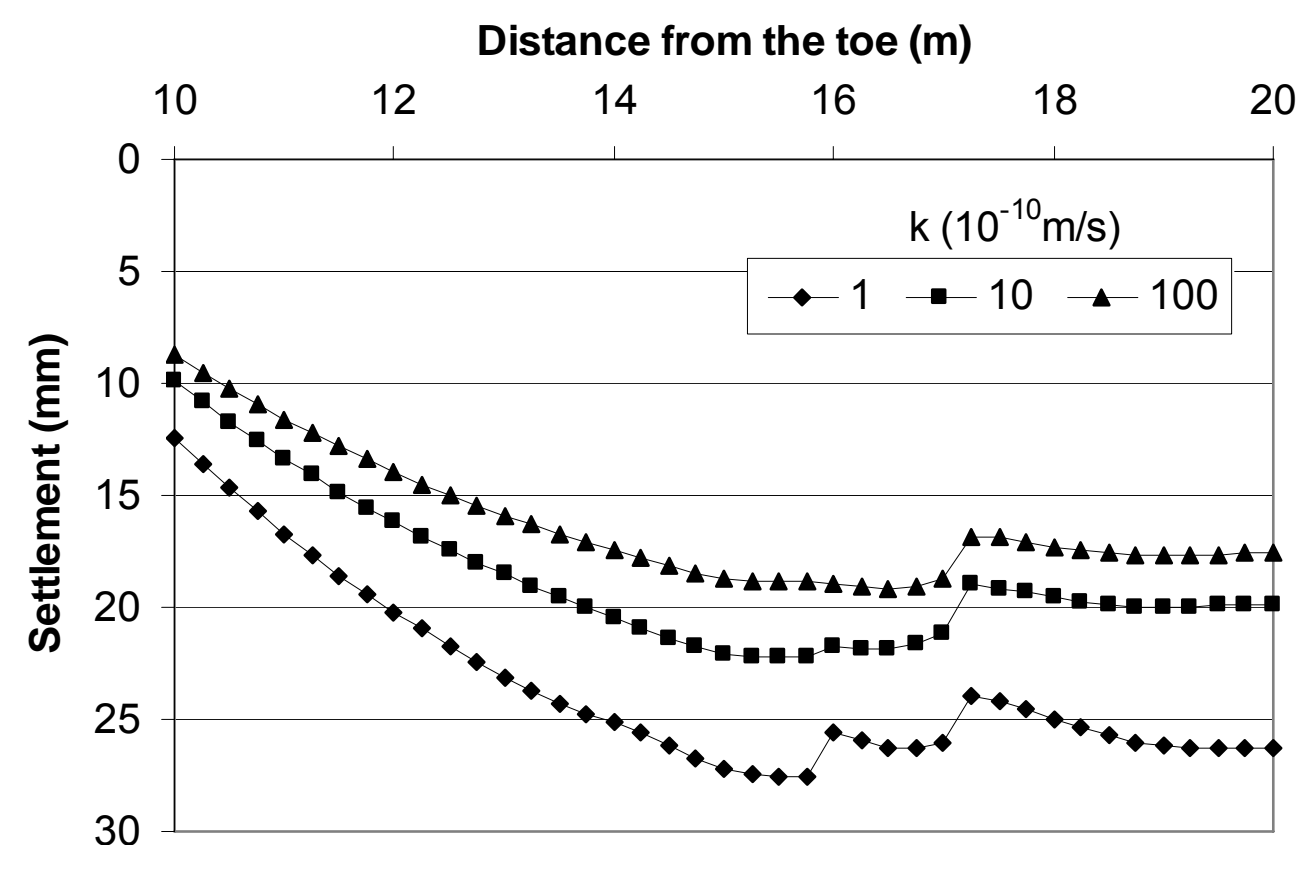

(a) On the crest through Section I-I

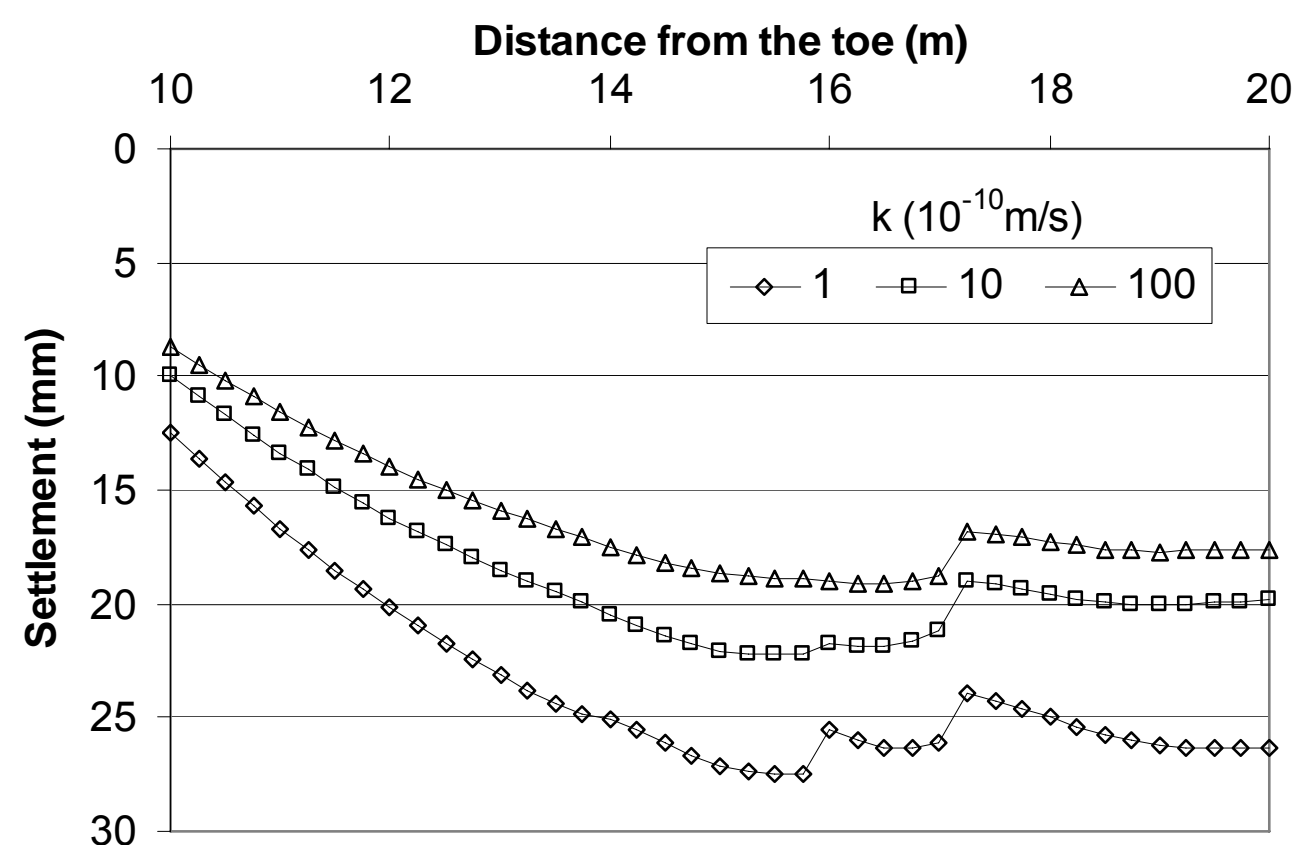

(b) On the crest through Section II-II

Fig. 5-28. Settlement Profiles for Various Soil Permeability at 1 Month after Service (3D) 


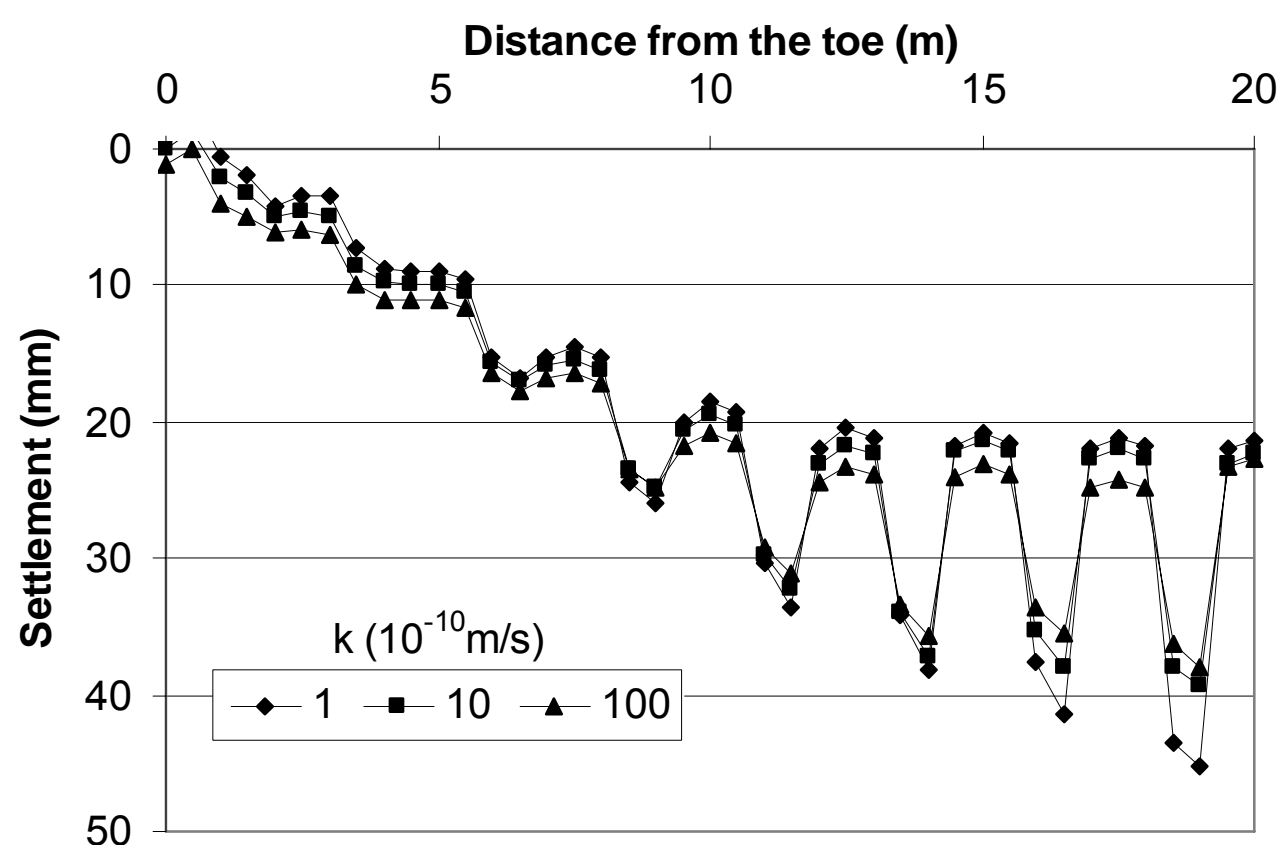

(c) At the base through Section I-I

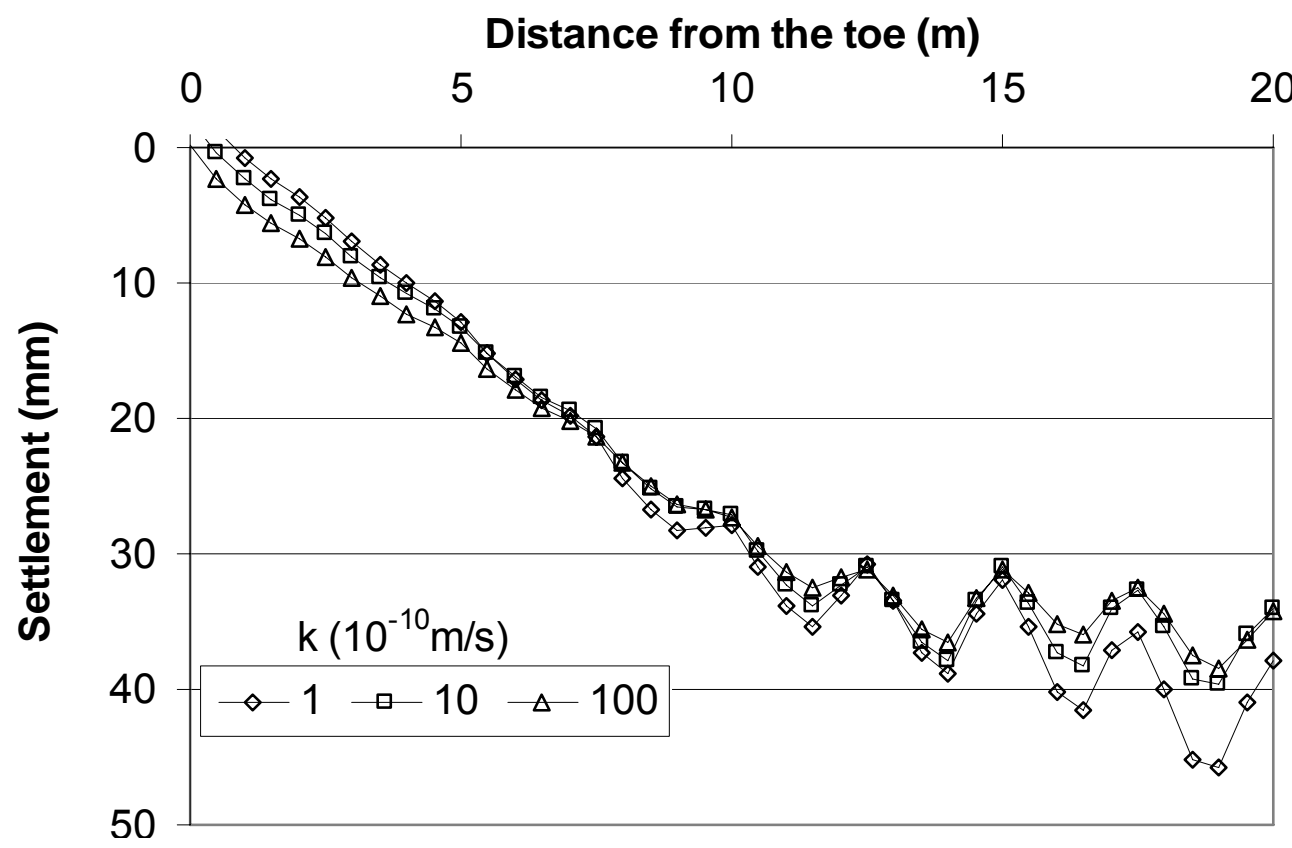

(d) At the base through Section II-II

Fig. 5-28. Settlement Profiles for Various Soil Permeability at 1 Month after Service (3D) (continued) 


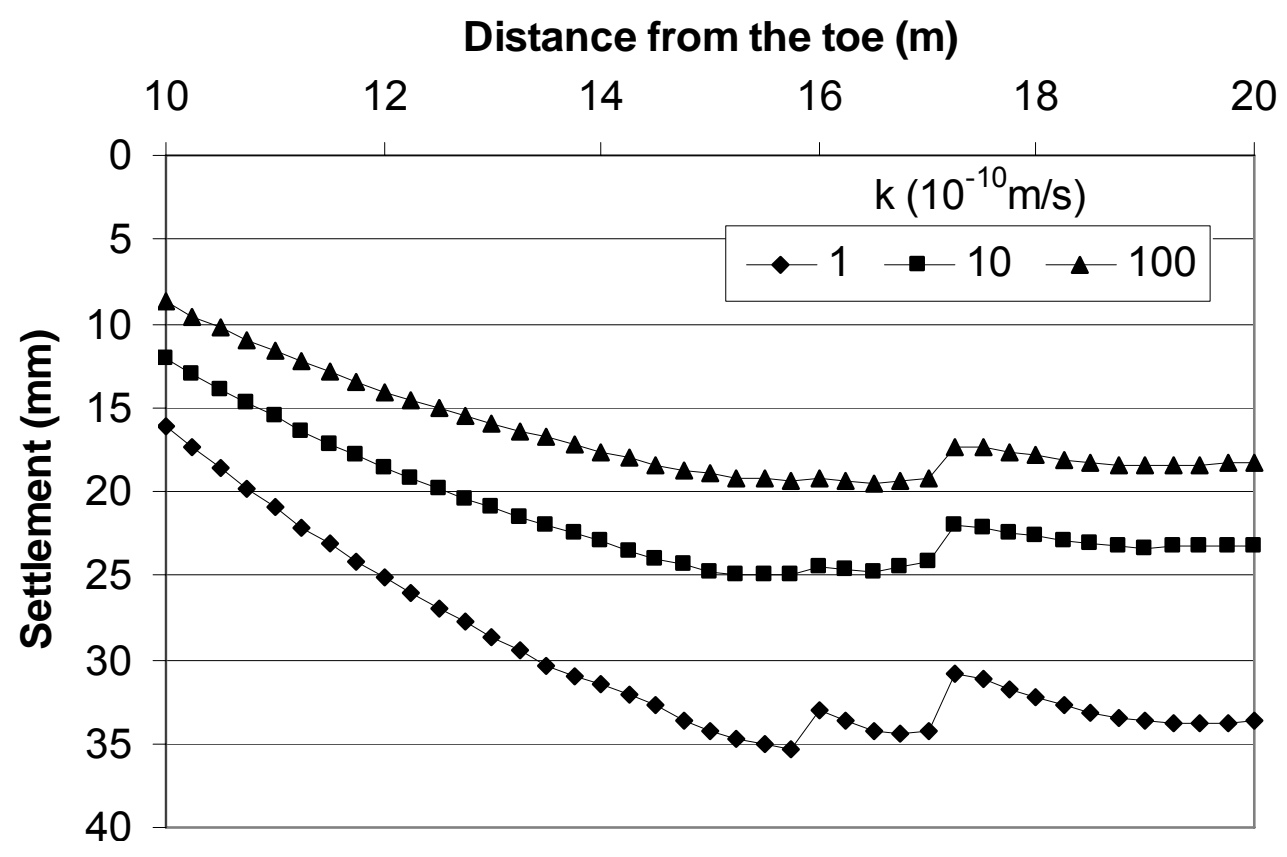

(a) On the crest through Section I-I

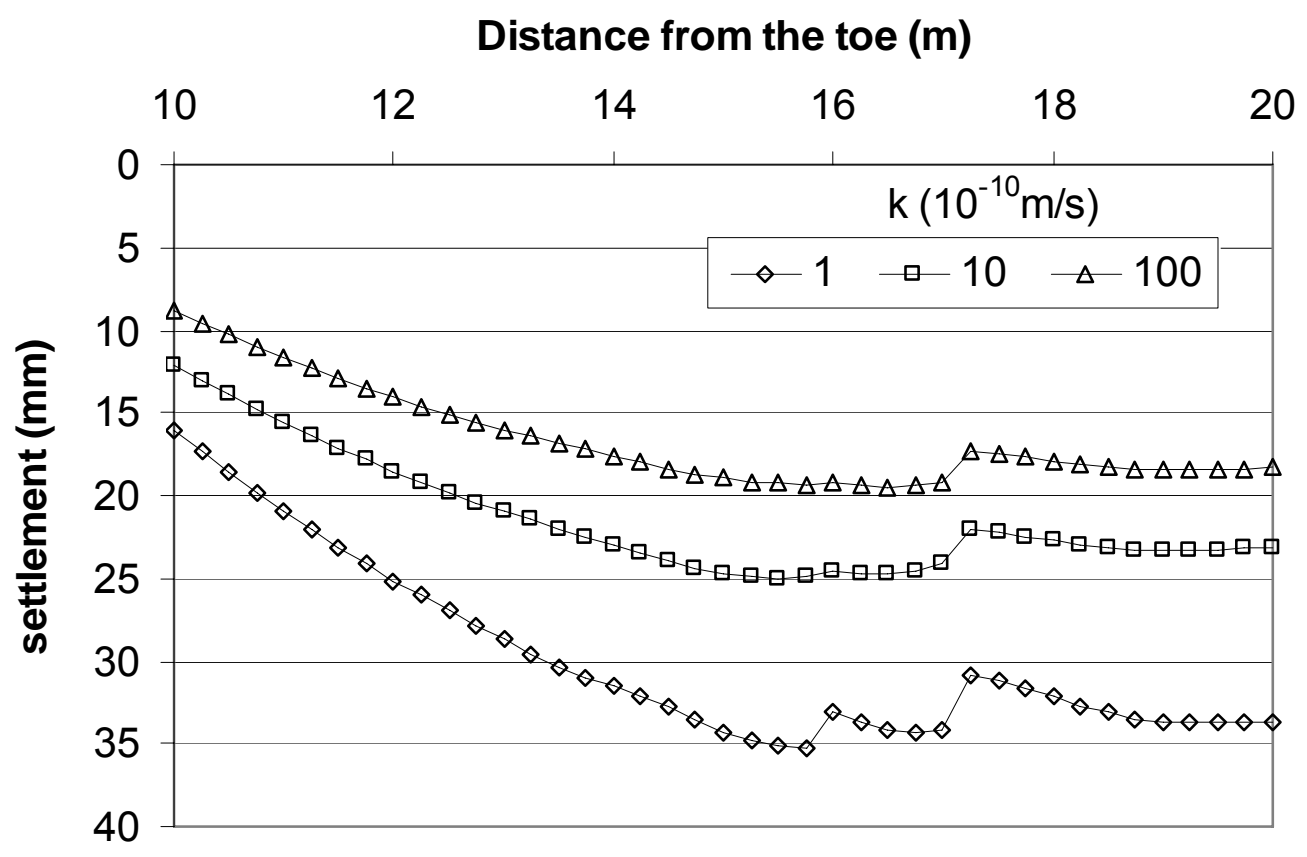

(b) On the crest through Section II-II

Fig. 5-29. Settlement Profiles for Various Soil Permeability at 4.5 Years after Service (3D) 


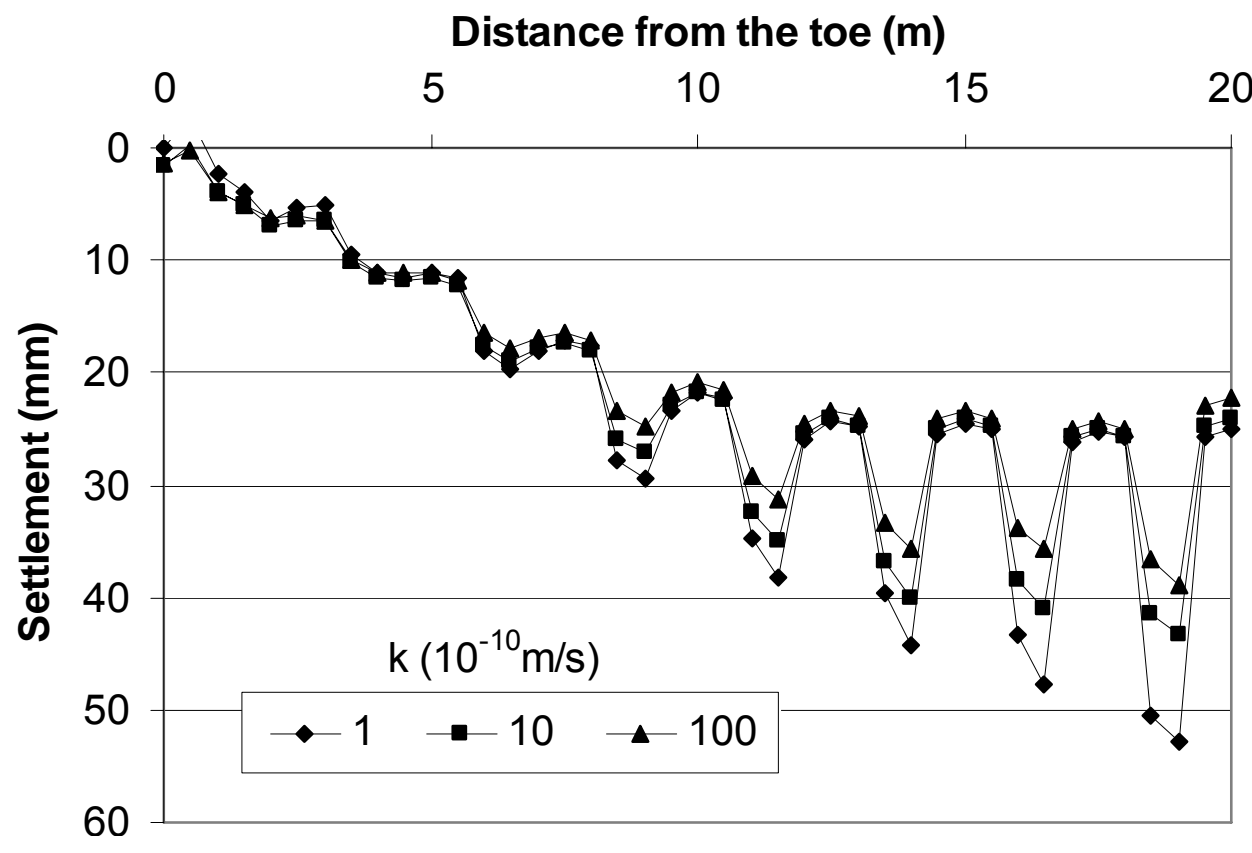

(c) At the base through Section I-I

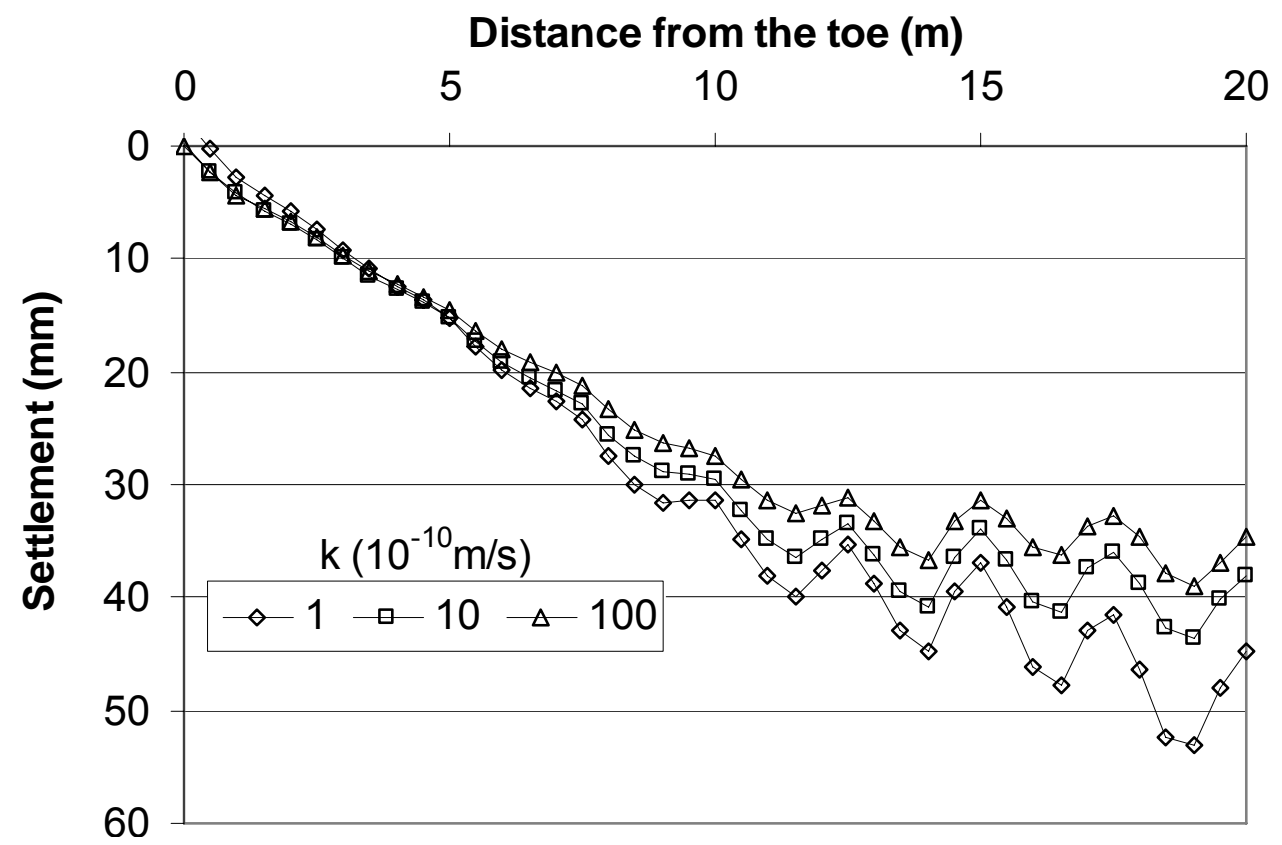

(d) At the base through Section II-II

Fig. 5-29. Settlement Profiles for Various Soil Permeability at 4.5 Years after Service (3D) (continued) 
The influence of the soil permeability on the maximum settlement and the maximum differential settlement are shown in Figs. 5-30 and 5-31, respectively. The lower soil permeability resulted in the higher maximum settlement and the maximum differential settlement. As the soil permeability was higher than $10^{-9} \mathrm{~m} / \mathrm{s}$, however, the influence of the soil permeability on the maximum settlement and the maximum differential settlement became less. In addition, the lower soil permeability resulted in a greater increase of the maximum settlement and the maximum differential settlement from one month to 4.5 years after service.

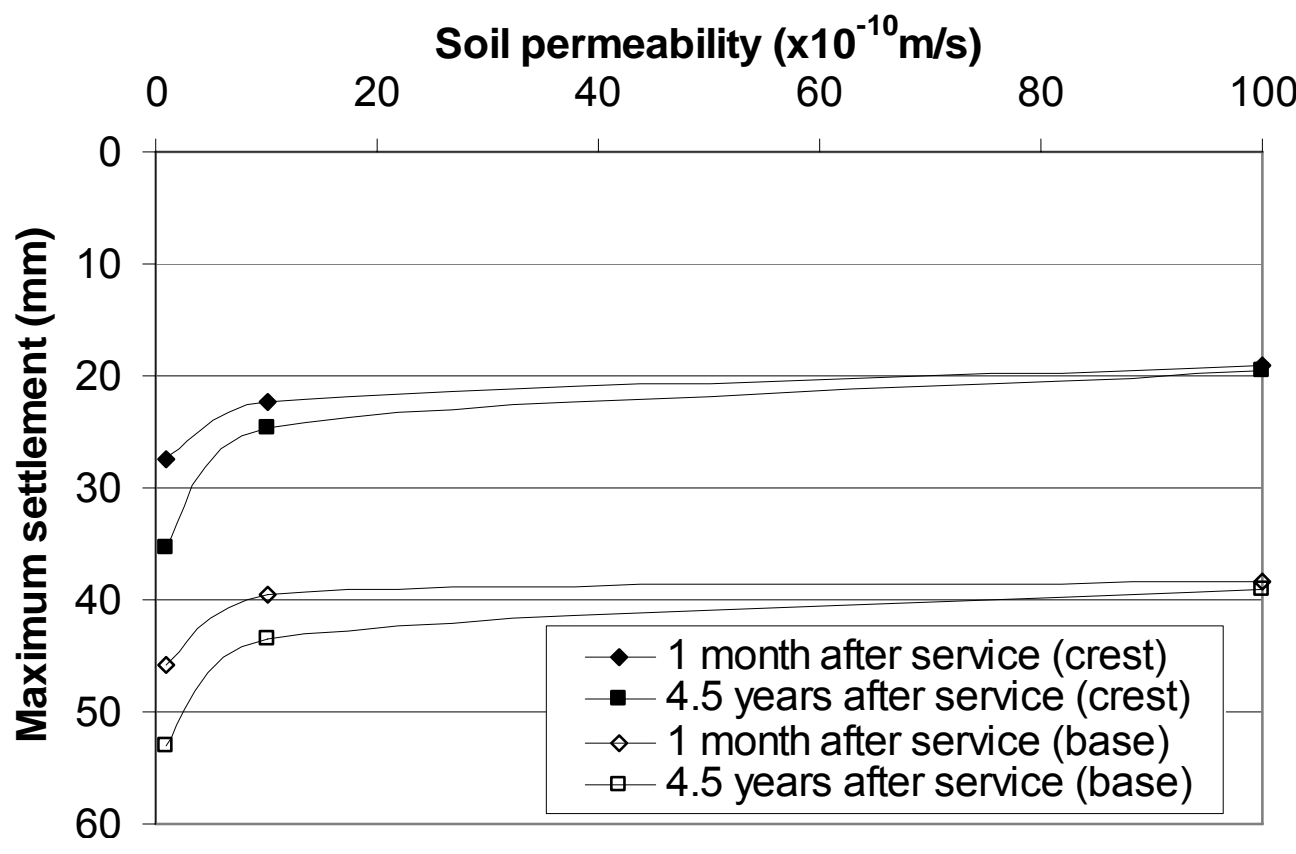

Fig. 5-30. Maximum Settlement versus Soil Permeability (3D) 


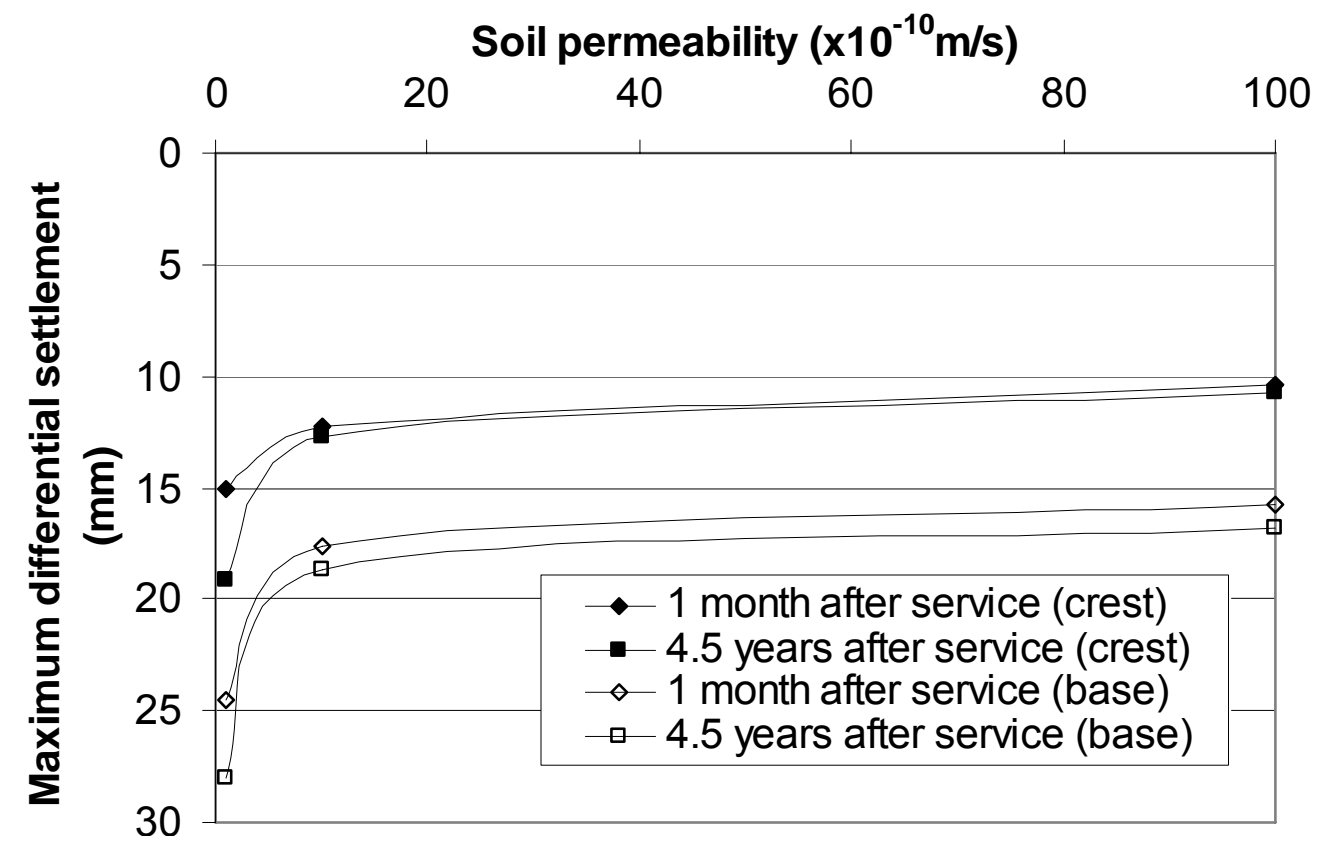

Fig. 5-31. Maximum Differential Settlement versus Soil Permeability (3D)

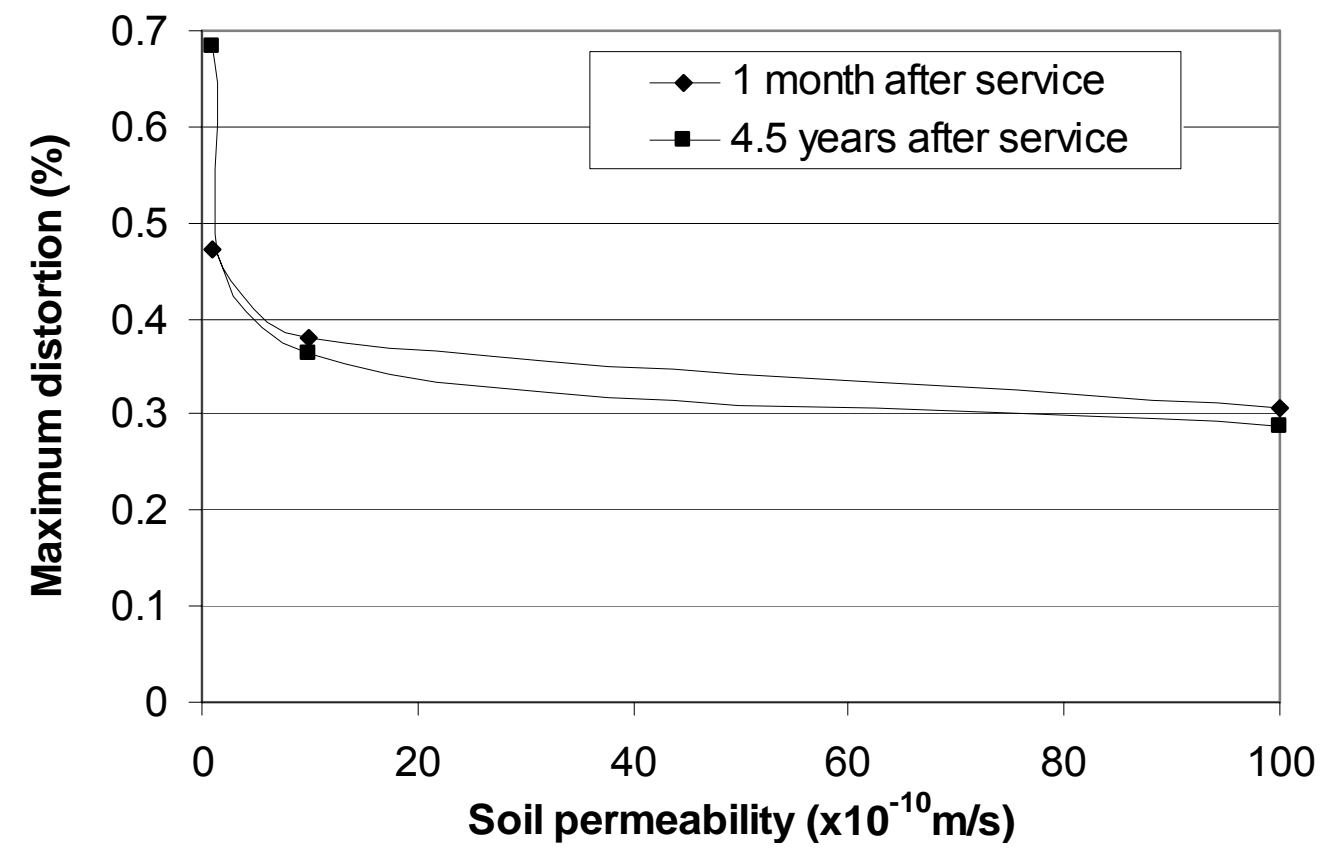

Fig. 5-32. Maximum Distortion on the Crest versus Soil Permeability (3D) 
The influence of the soil permeability on the maximum distortion is presented in Fig. 5-32. It is shown that the maximum distortion on the crest decreased with an increase of the soil permeability. The consolidation of the foundation reduced the maximum distortion.

\section{Influence of Column Elastic Modulus}

The influence of column modulus on settlement is presented in Fig. 5-33 and 5-34. Obviously, the increase of column modulus reduces the settlement at any locations according to the settlement profiles at the crest and at the base. The reason causing the reduction on settlement at the base both in soft soil and in column has already been discussed in Chapter Four. Briefly, the reduction of the soft soil settlement at the base is due to the load transfer to columns, while the reduction of the column settlement at the base is due to increase of stiffness. Similarly, no significant differential settlement is found accruing along the traffic direction. 


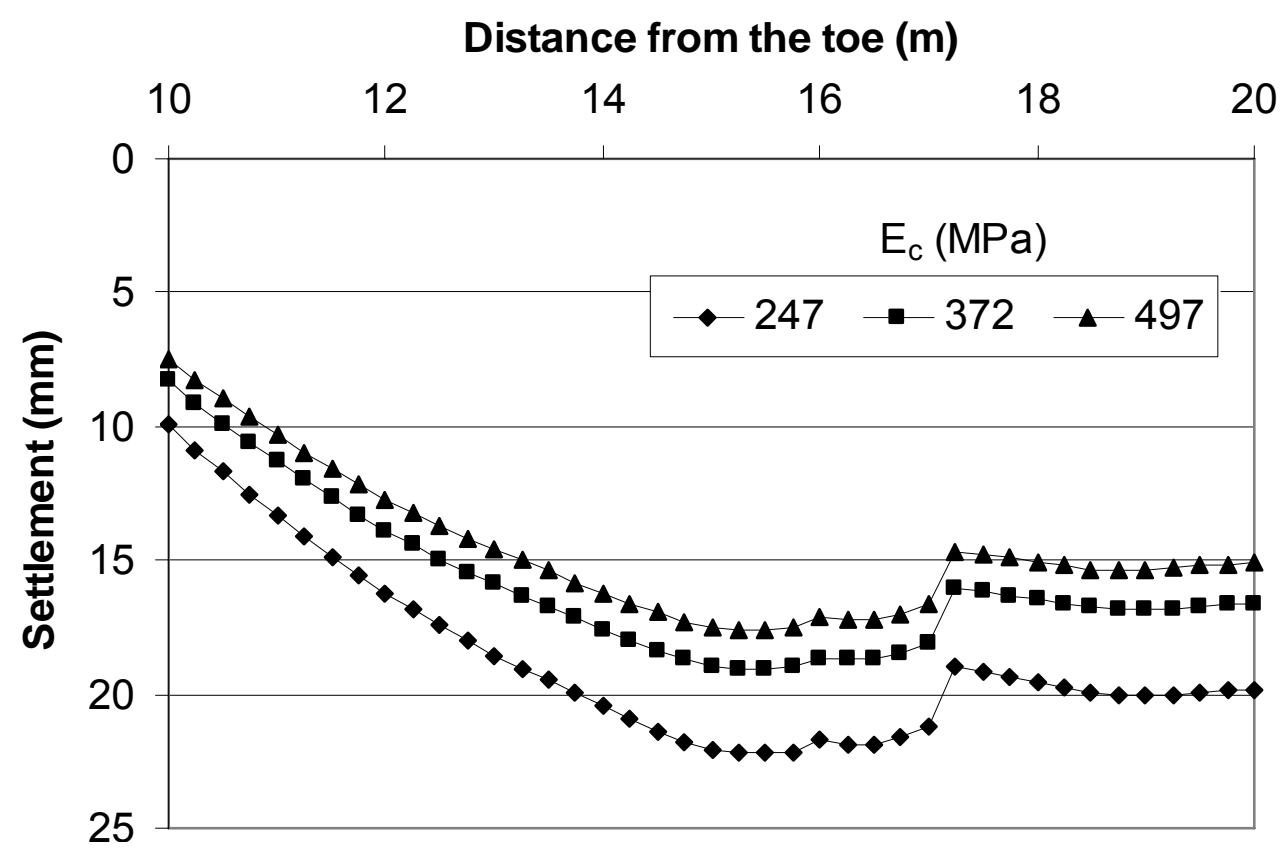

(a) On the crest through Section I-I

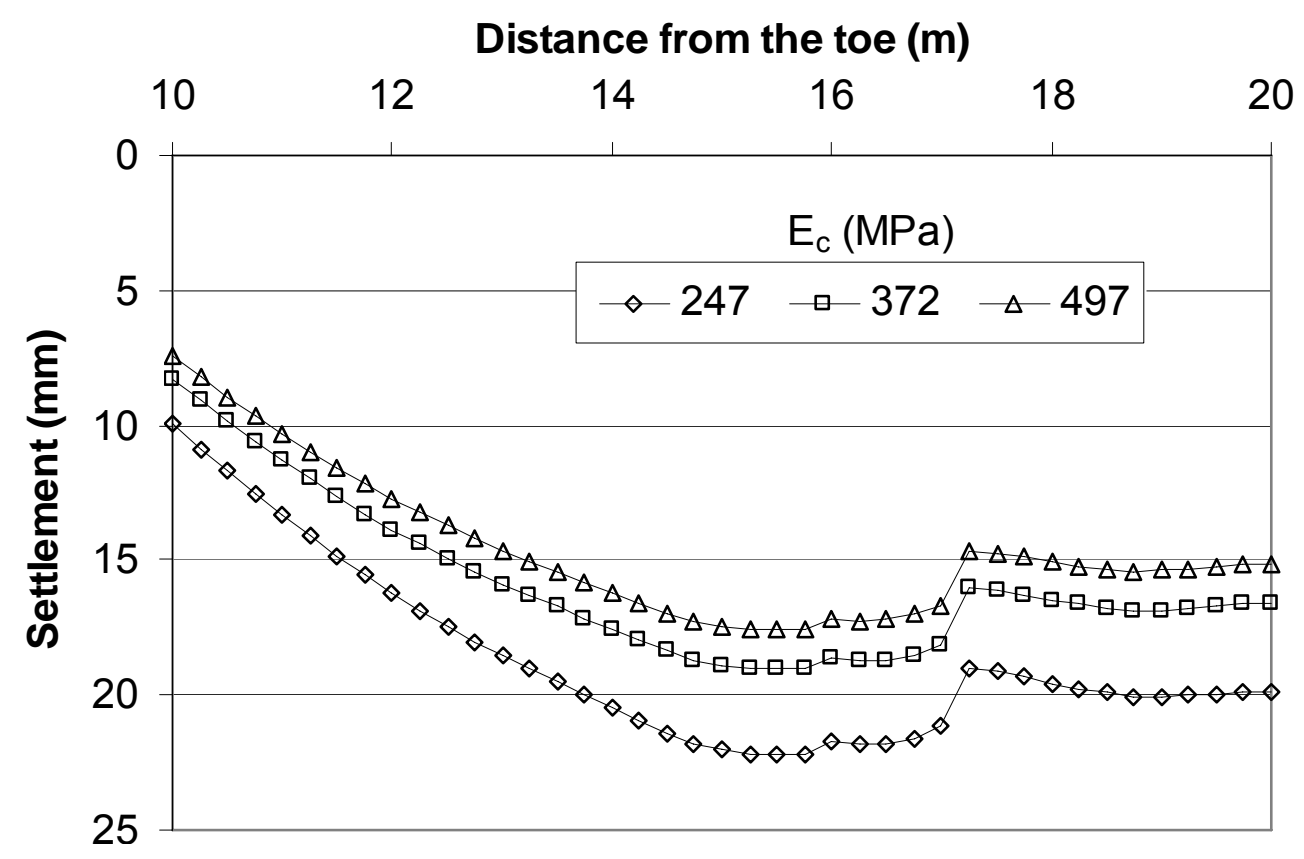

(b) On the crest through Section II-II

Fig. 5-33. Settlement Profiles for Various Column Moduli at 1 Month after Service (3D) 


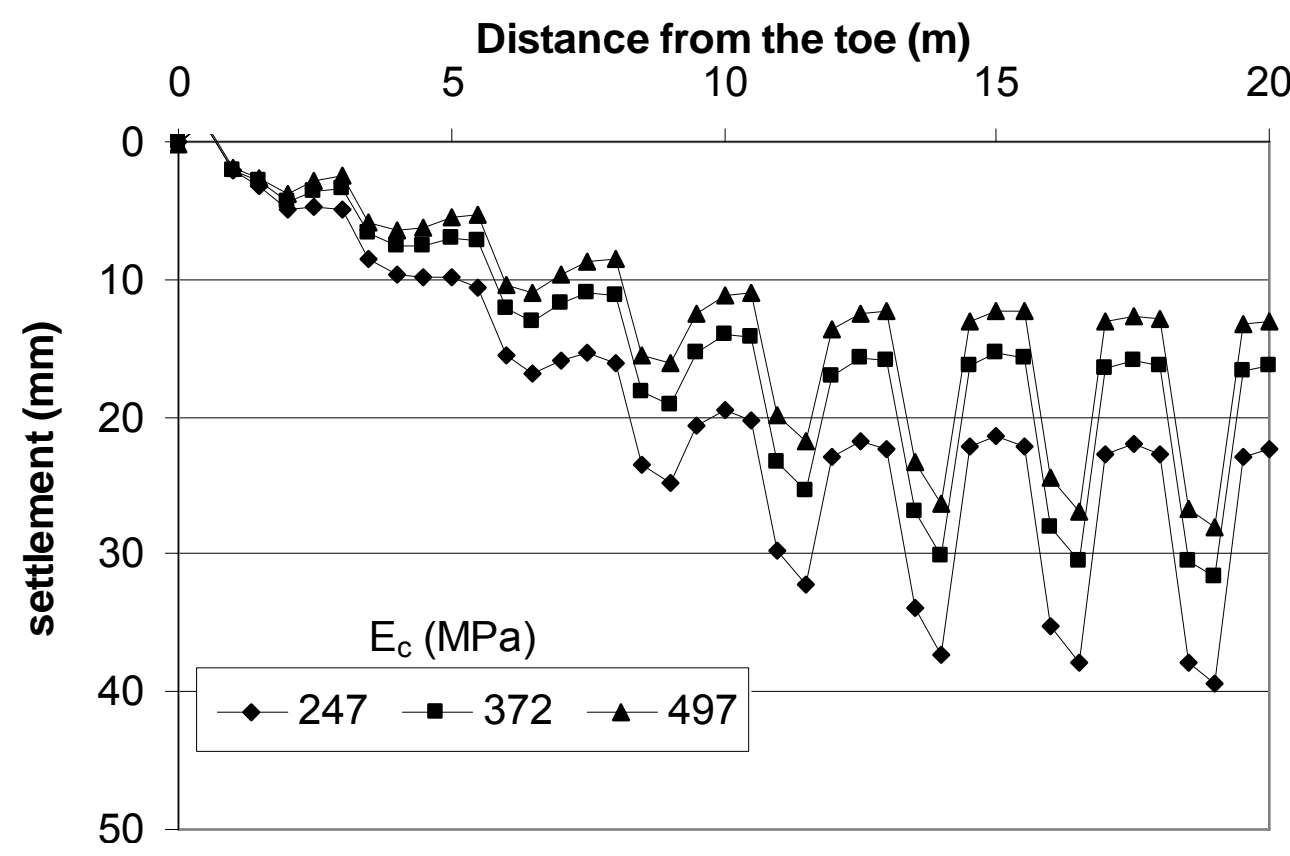

(c) At the base through Section I-I

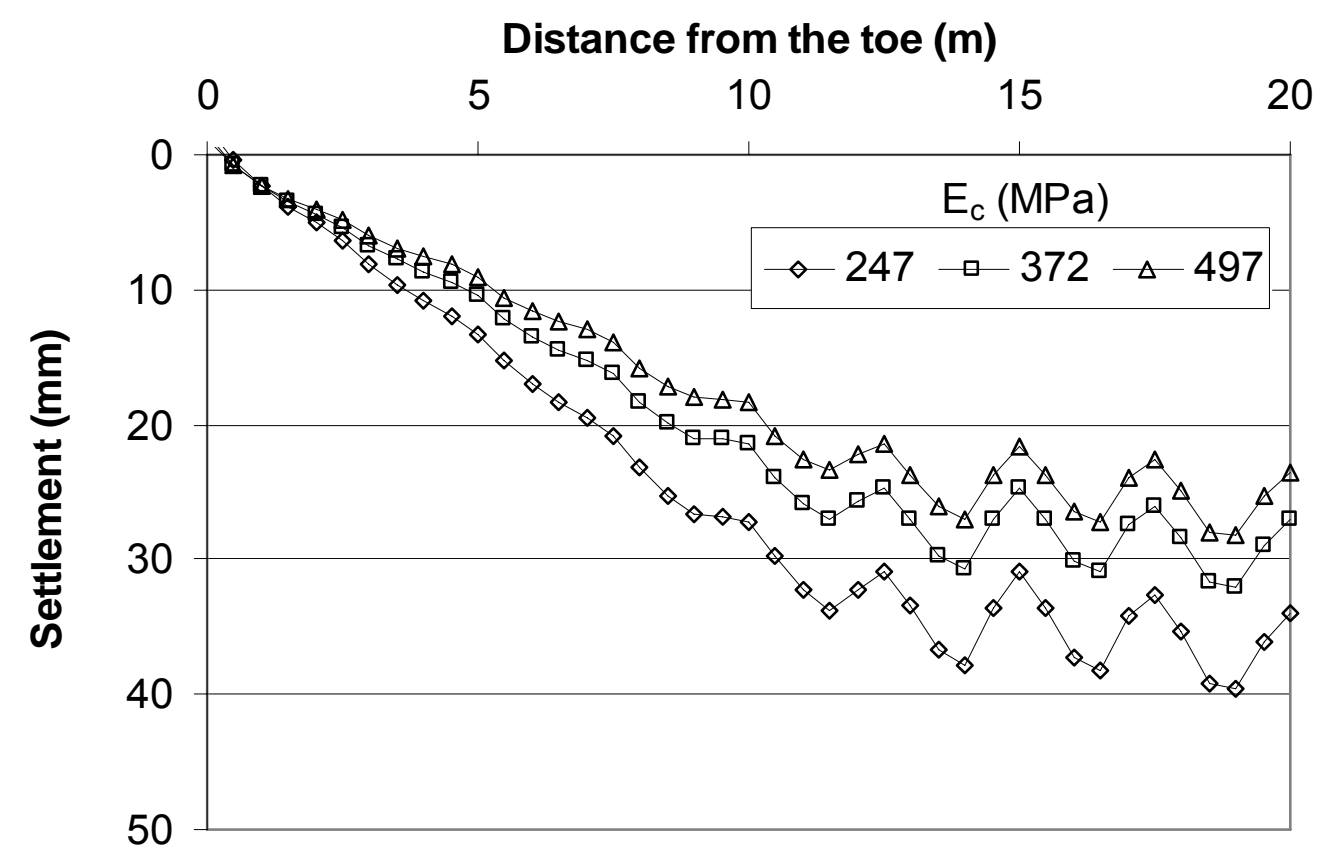

(d) At the base through Section II-II

Fig. 5-33. Settlement Profiles for Various Column Moduli at 1 Month after Service (3D) (continued) 


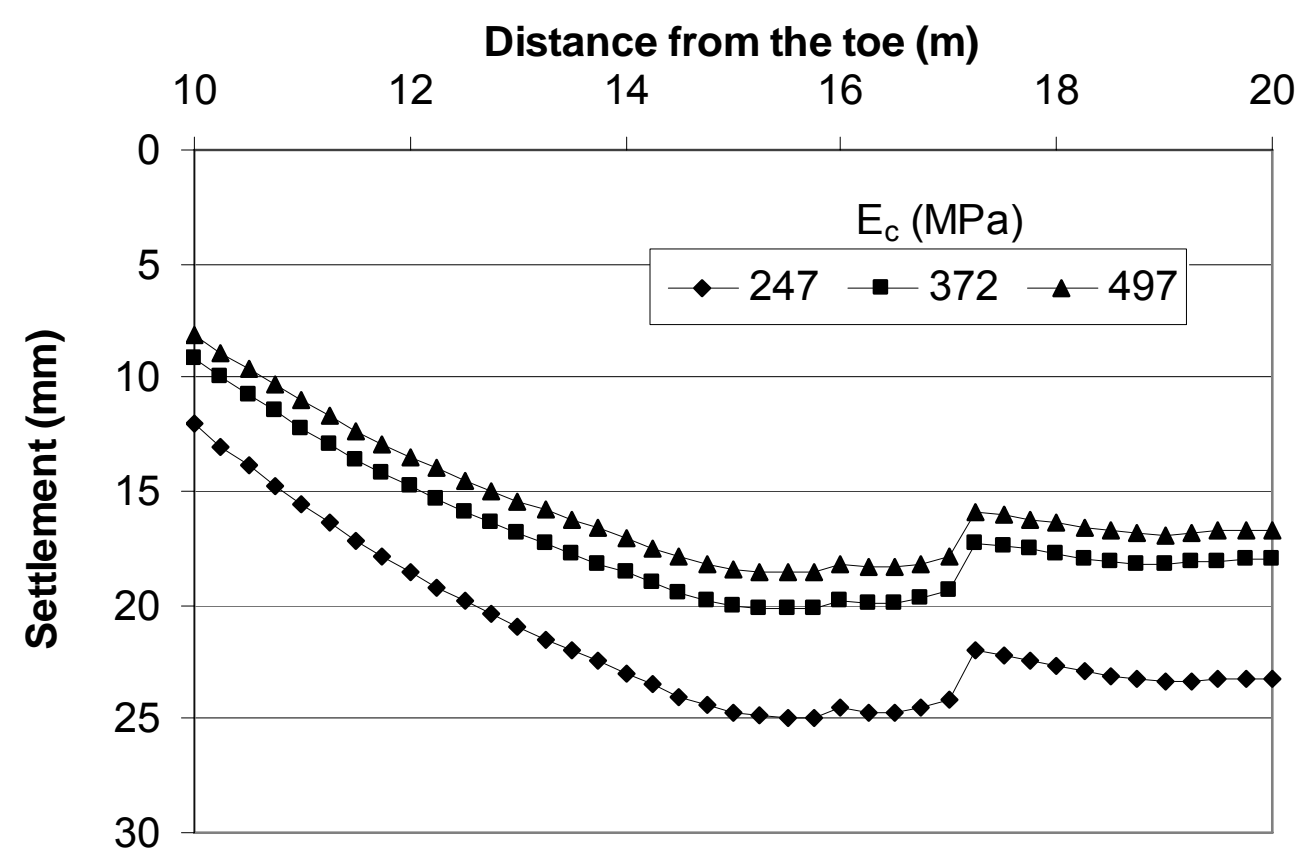

(a) On the crest through Section I-I

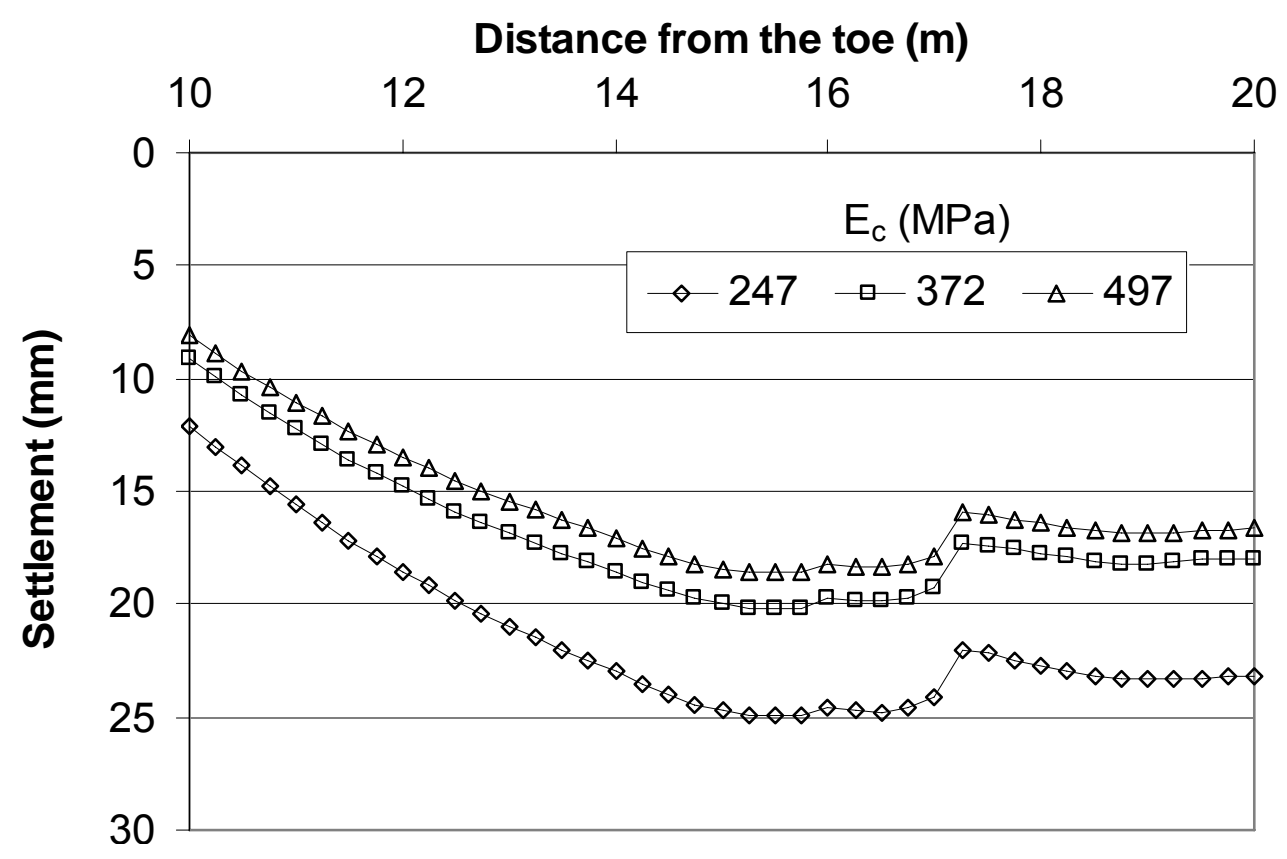

(b) On the crest through Section II-II

Fig. 5-34. Settlement Profiles for Various Column Moduli at 4.5 Years after Service (3D) 


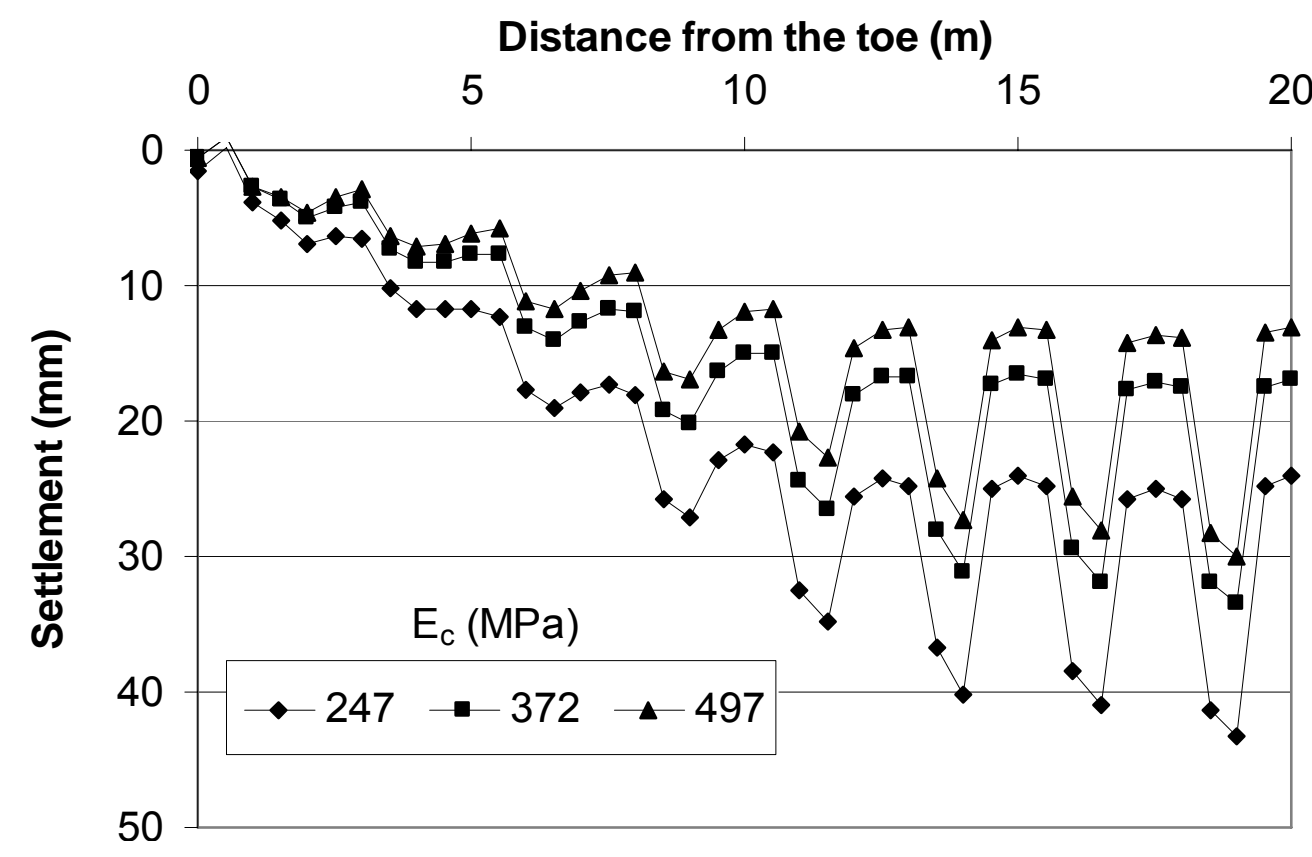

(c) At the base through Section I-I

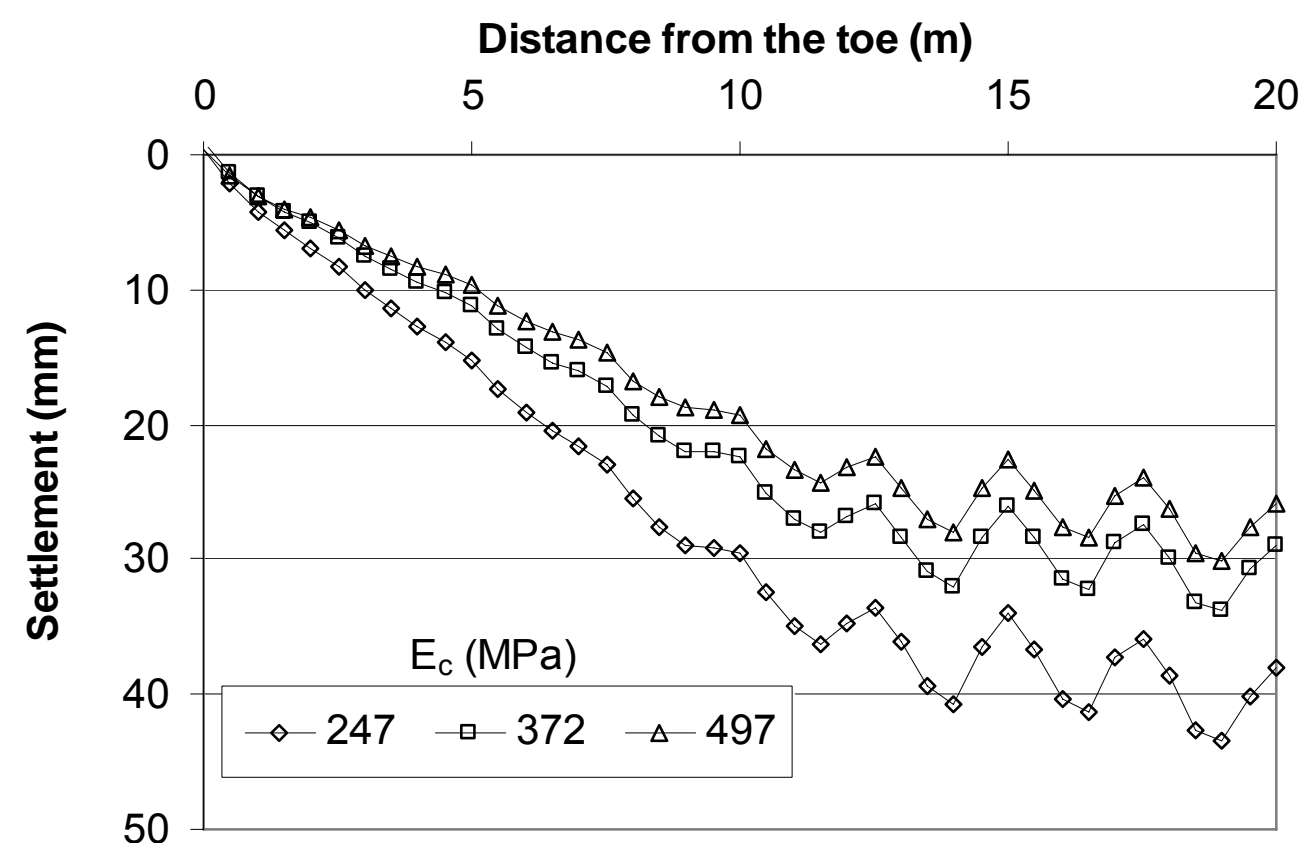

(d) At the base through Section II-II

Fig. 5-34. Settlement Profiles for Various Column Moduli at 4.5 Years after Service (3D) (continued) 
The influence of the column modulus on the maximum settlement and the maximum differential settlement are presented in Fig. 5-35 and Fig. 5-36, respectively, which show that an increase of the column modulus reduced both the maximum settlement and the maximum differential settlement. The degree of the settlement reduction at the base of the embankment was more than that on the crest. The limited influence of the column modulus may be attributed to the range of the column modulus investigated, within which the column modulus was higher enough as compared with the soft soil to ensure the efficiency of load transfer from the soil to the columns.

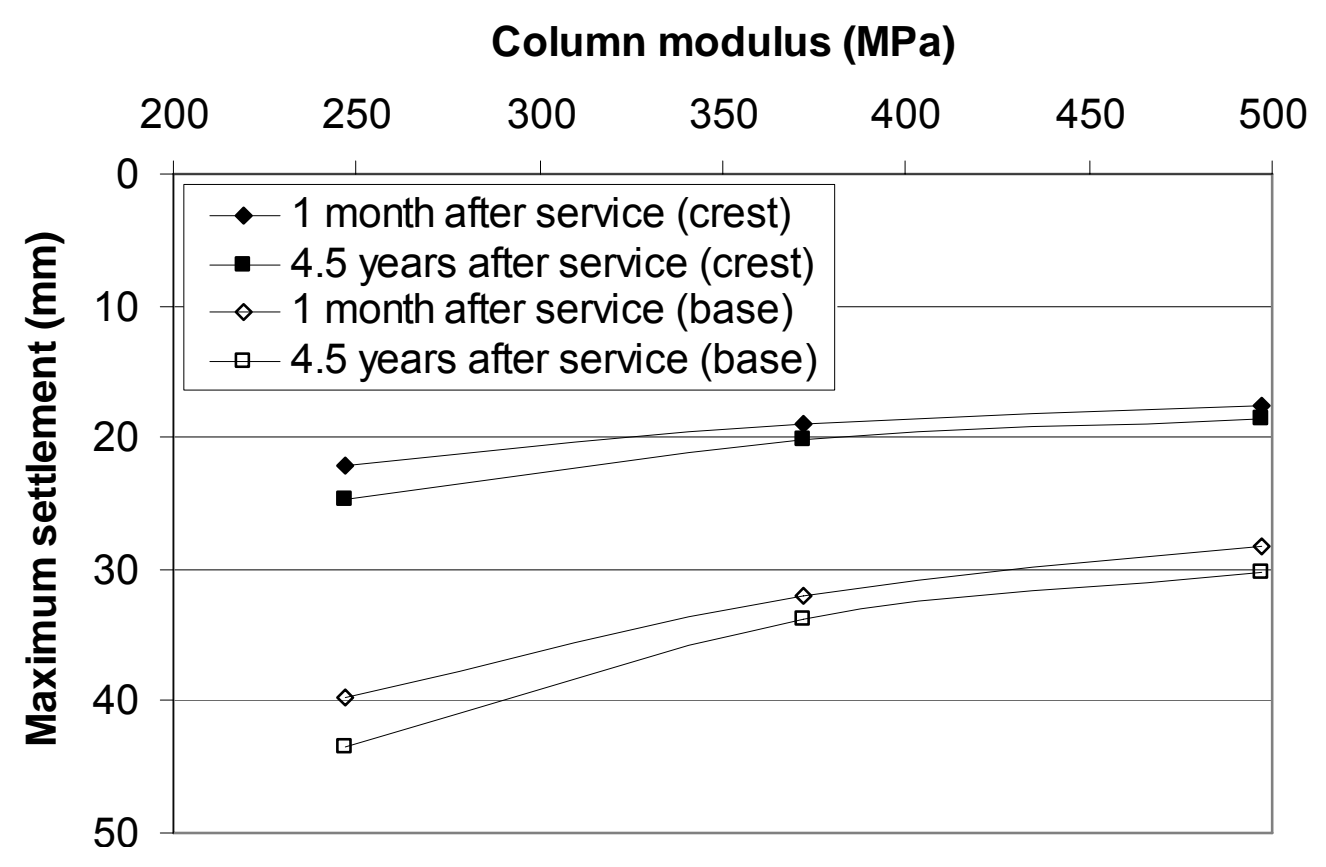

Fig. 5-35. Maximum Settlement versus Column Modulus (3D) 


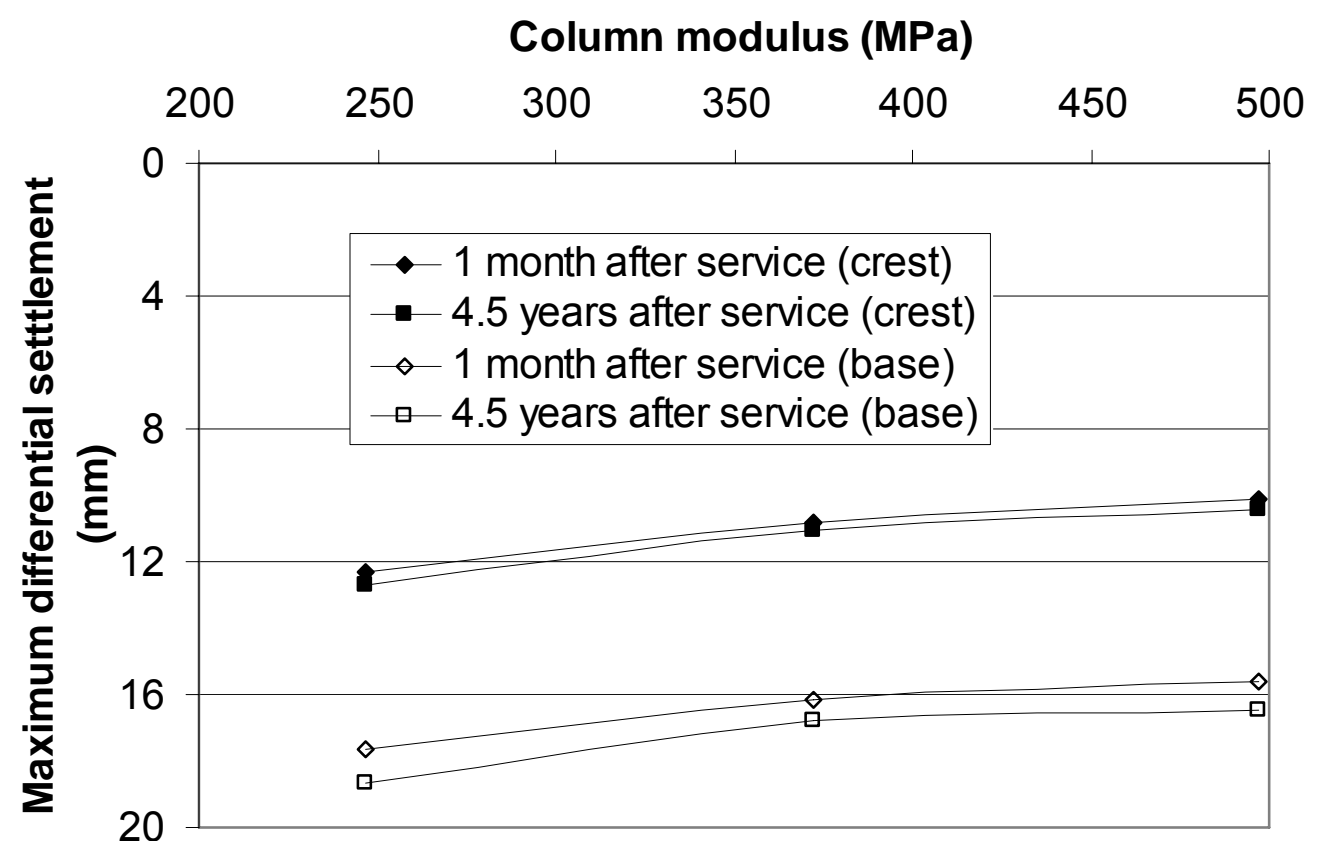

Fig. 5-36. Maximum Differential Settlement versus Column Modulus (3D)

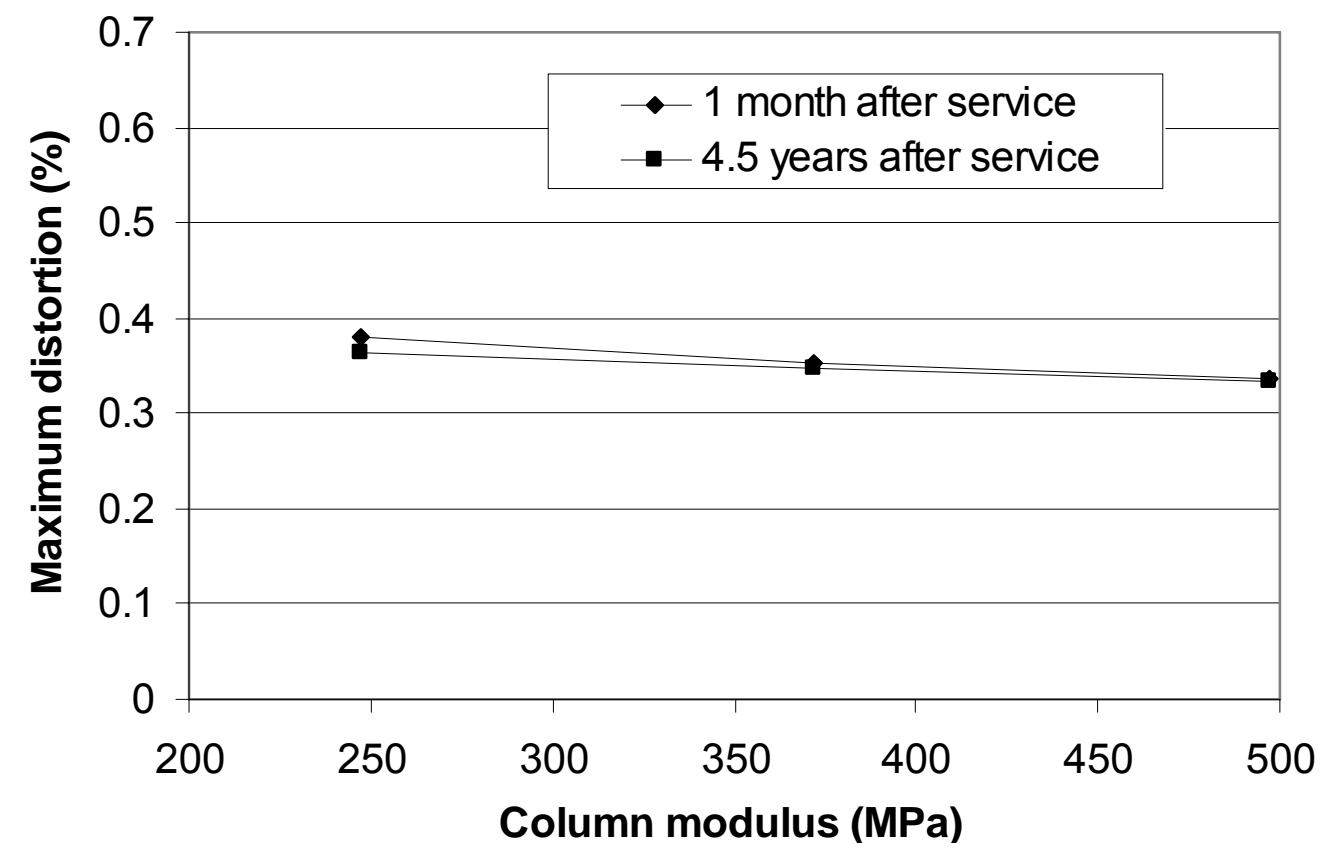

Fig. 5-37. Maximum Distortion on the Crest versus Column Modulus (3D) 
The influence of the column modulus on the maximum distortion is illustrated in Fig. 5-37, which shows that an increase of the column modulus reduced the maximum distortion; however, this influence is rather limited.

\section{Influence of Column Spacing}

The influences of the column spacing on the settlement profiles are presented in Fig. 5-38 and 5-39. Generally, the increase of the column spacing led to larger maximum and differential settlements both on the columns and the soft soil. A detailed discussion on the reasons why the increase of column spacing led to the increase of the maximum and differential settlements was provided in the corresponding section in Chapter Four. In summary, the increase of the column spacing led to an increase of the vertical effective stresses on both the columns and the soft soil. The increase of the settlement on the soft soil was more than that on the columns. Similar to that found in the $2 \mathrm{D}$ parametric study, the larger column spacing led to a larger local differential settlement. 


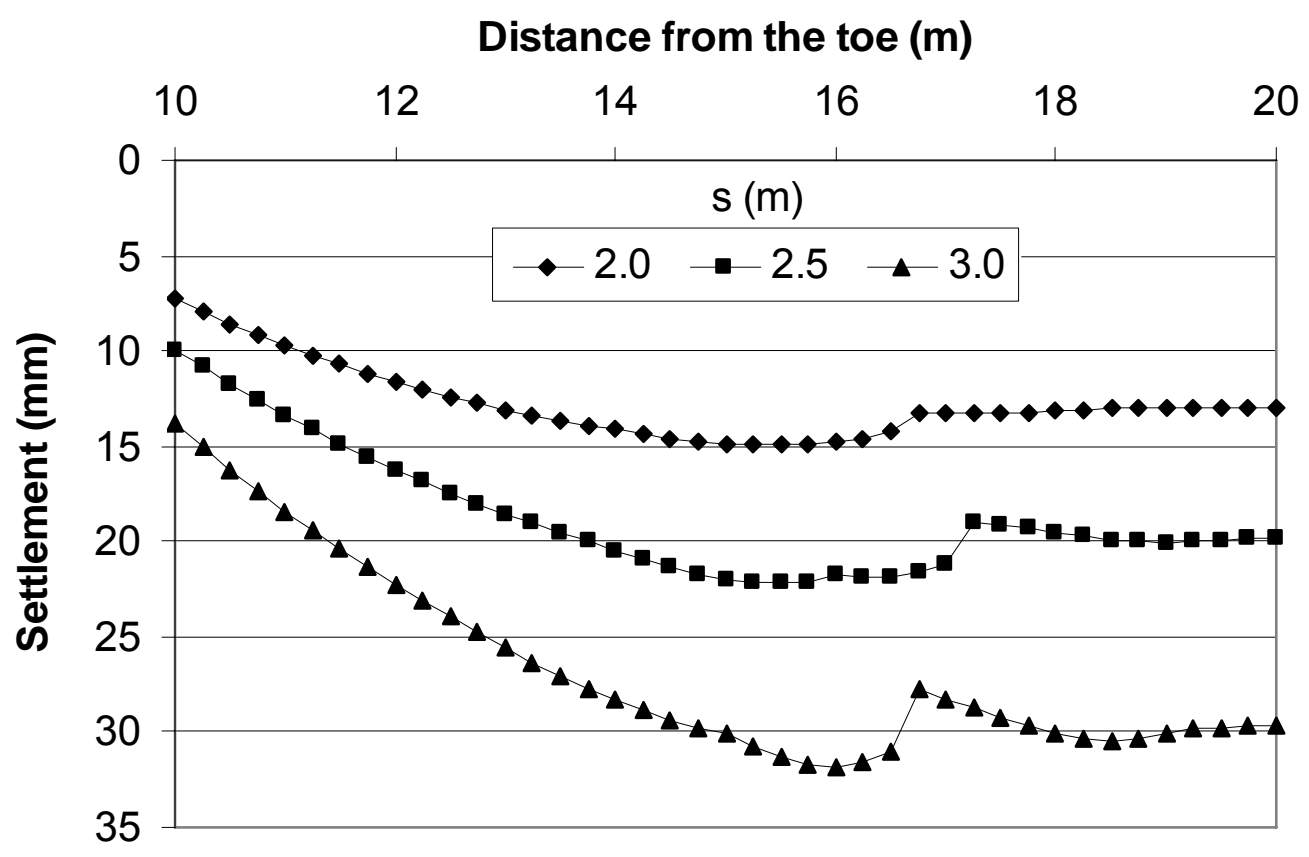

(a) On the crest through Section I-I

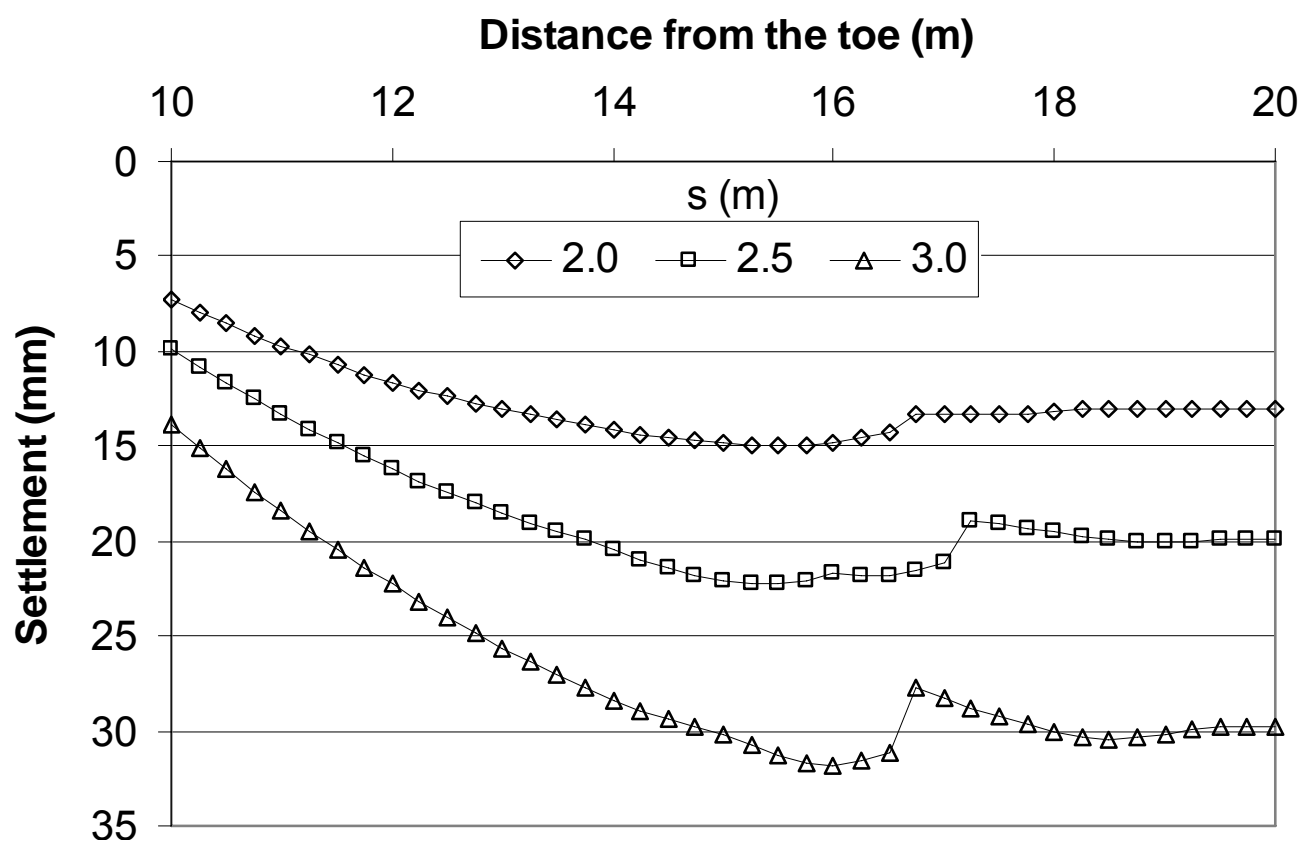

(b) On the crest through Section II-II

Fig. 5-38. Settlement Profiles for Various Column Spacing on at 1 Month after Service (3D) 


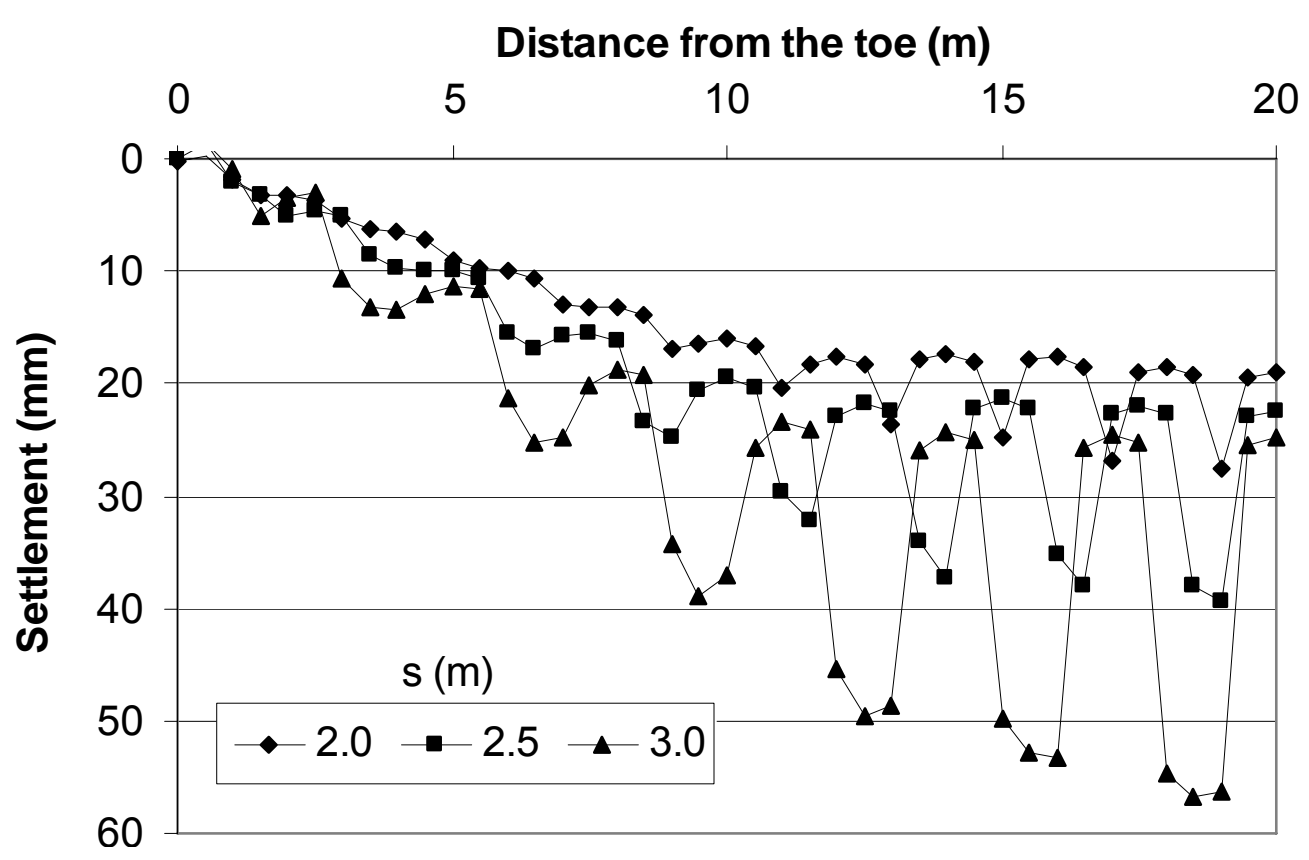

(c) At the base through Section I-I

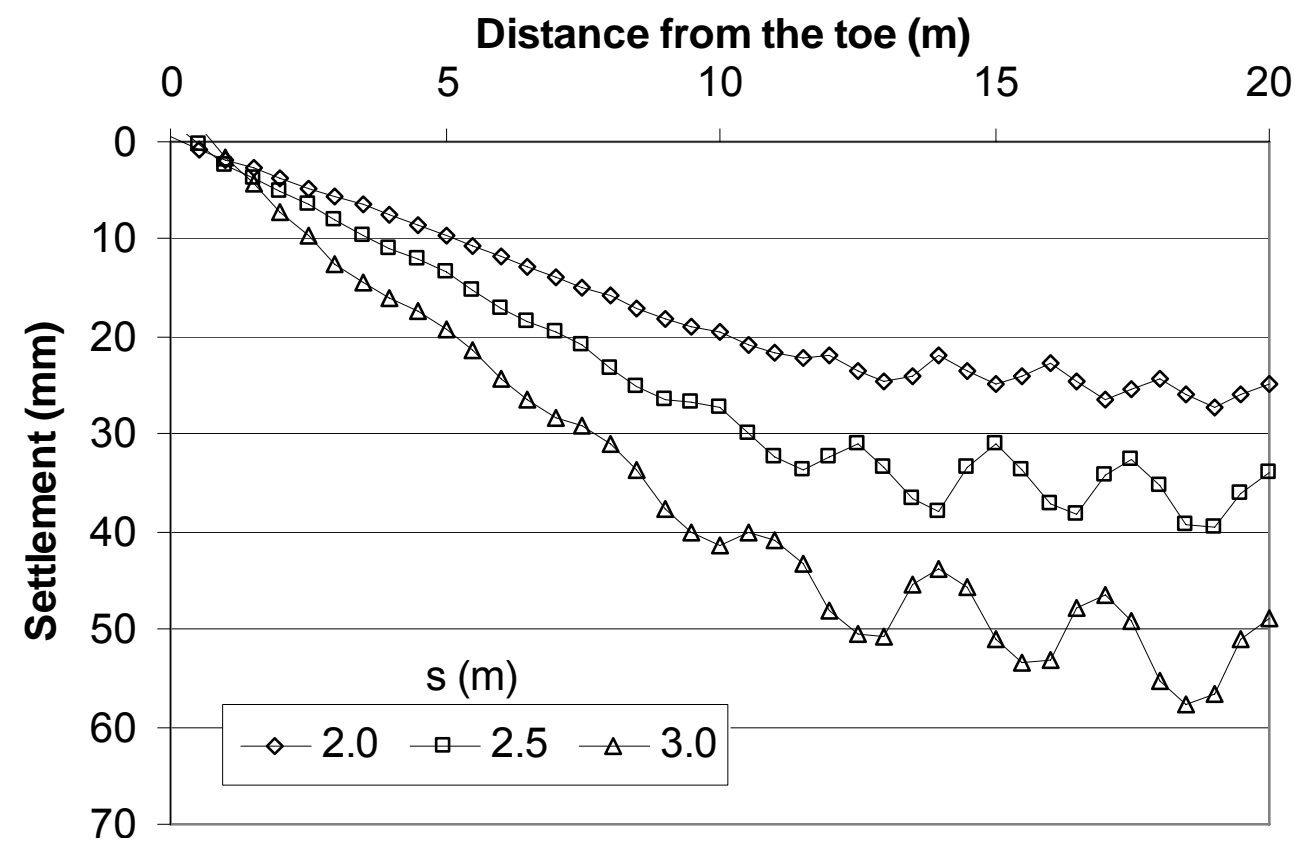

(d) At the base through Section II-II

Fig. 5-38. Settlement Profiles for Various Column Spacing on at 1 Month after Service (3D) (continued) 


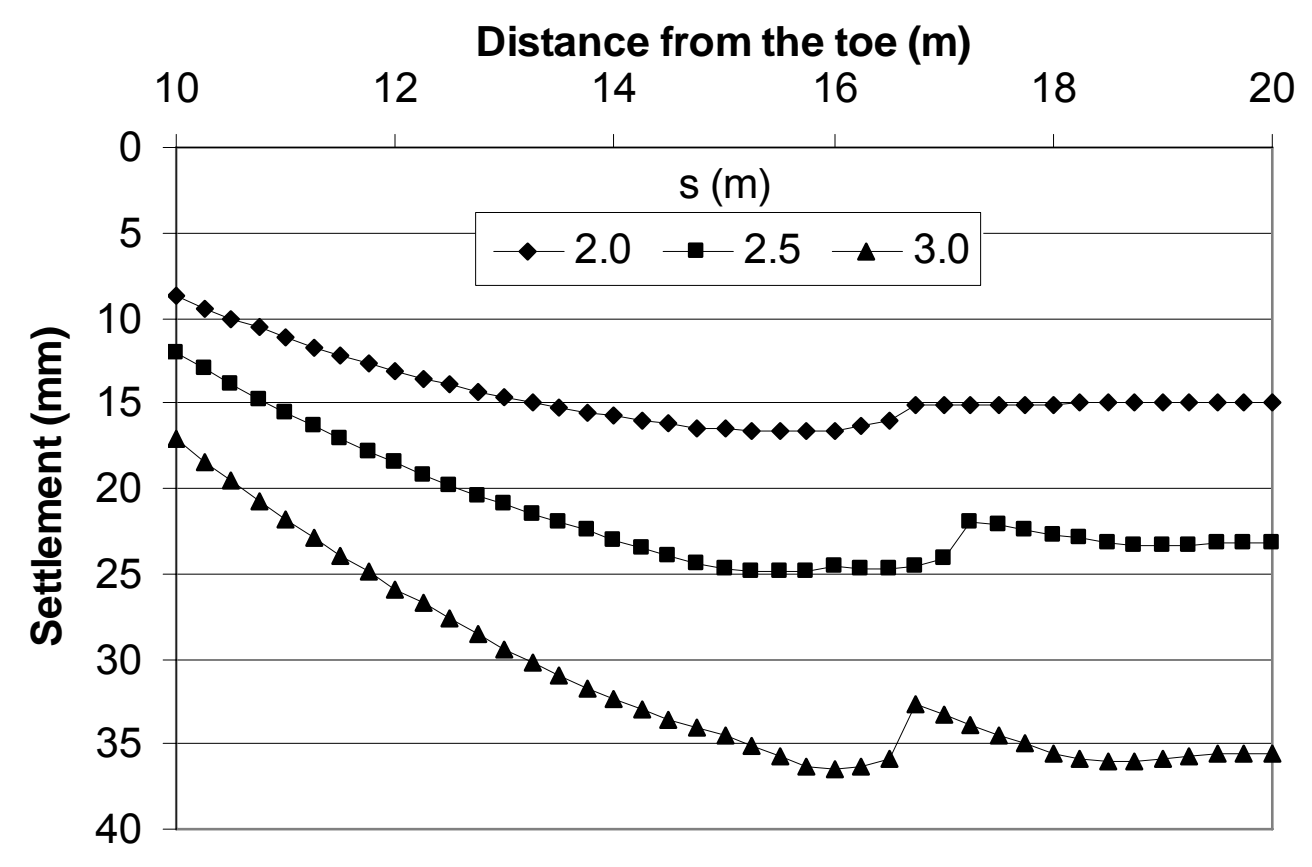

(a) On the crest through Section I-I

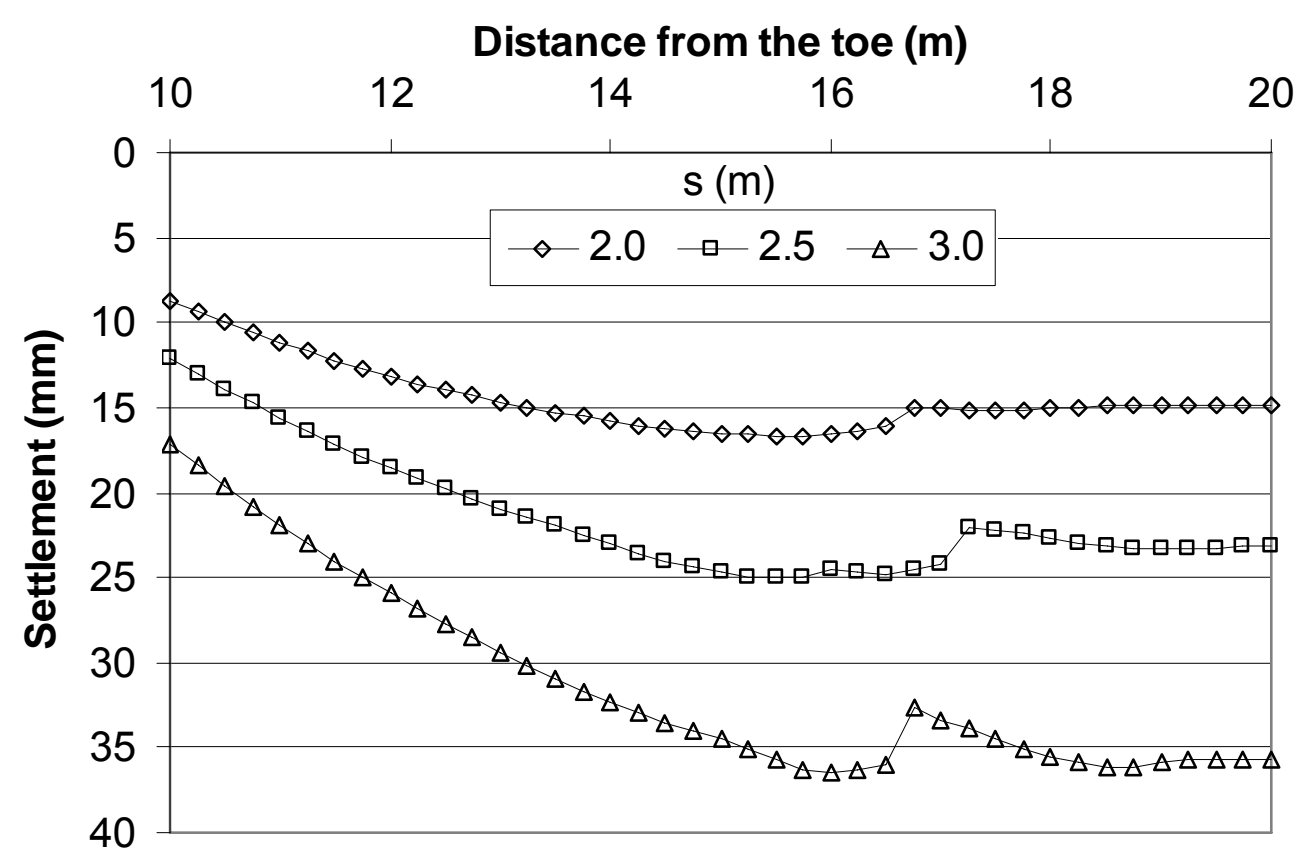

(b) On the crest through Section II-II

Fig. 5-39. Settlement Profiles for Various Column Spacing on at 4.5 Years after Service (3D) 


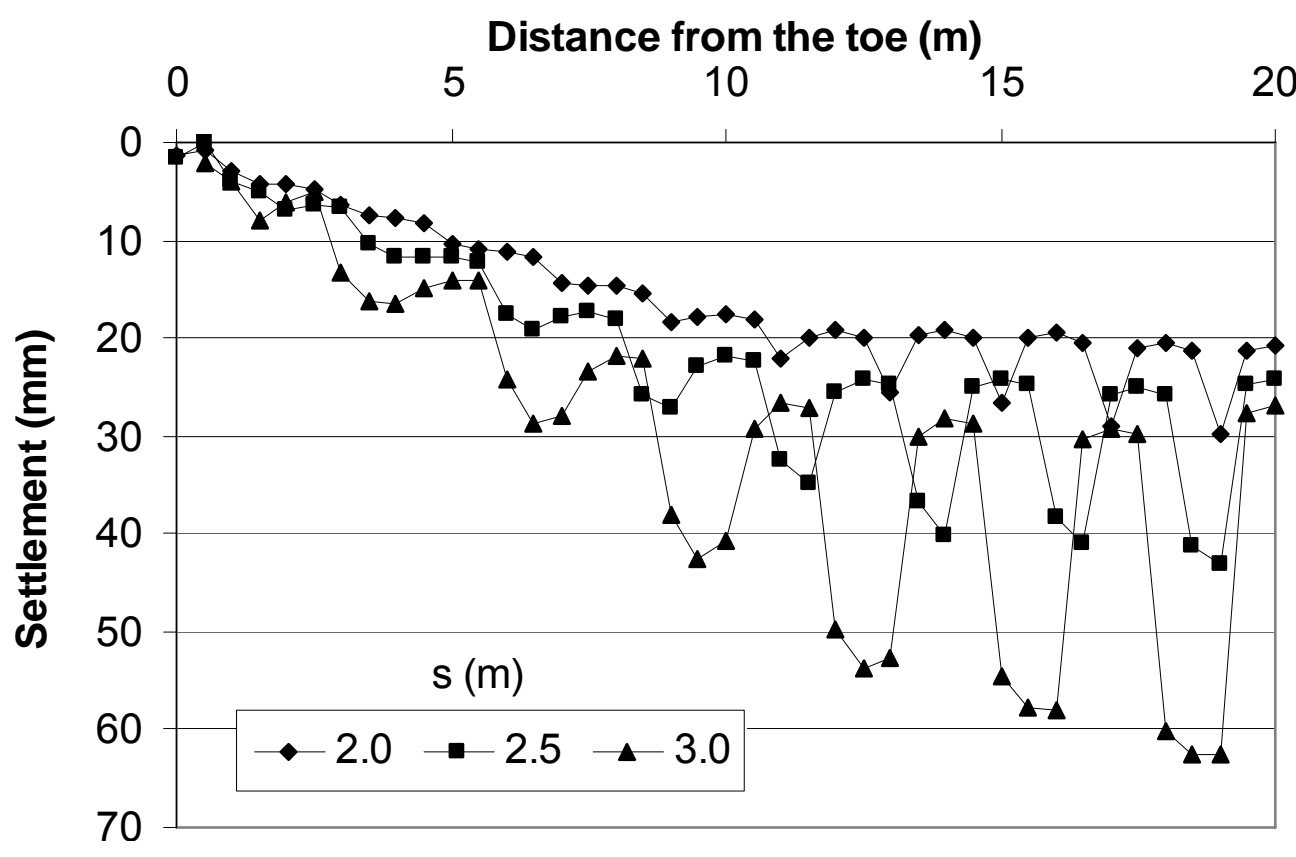

(c) At the base through Section I-I

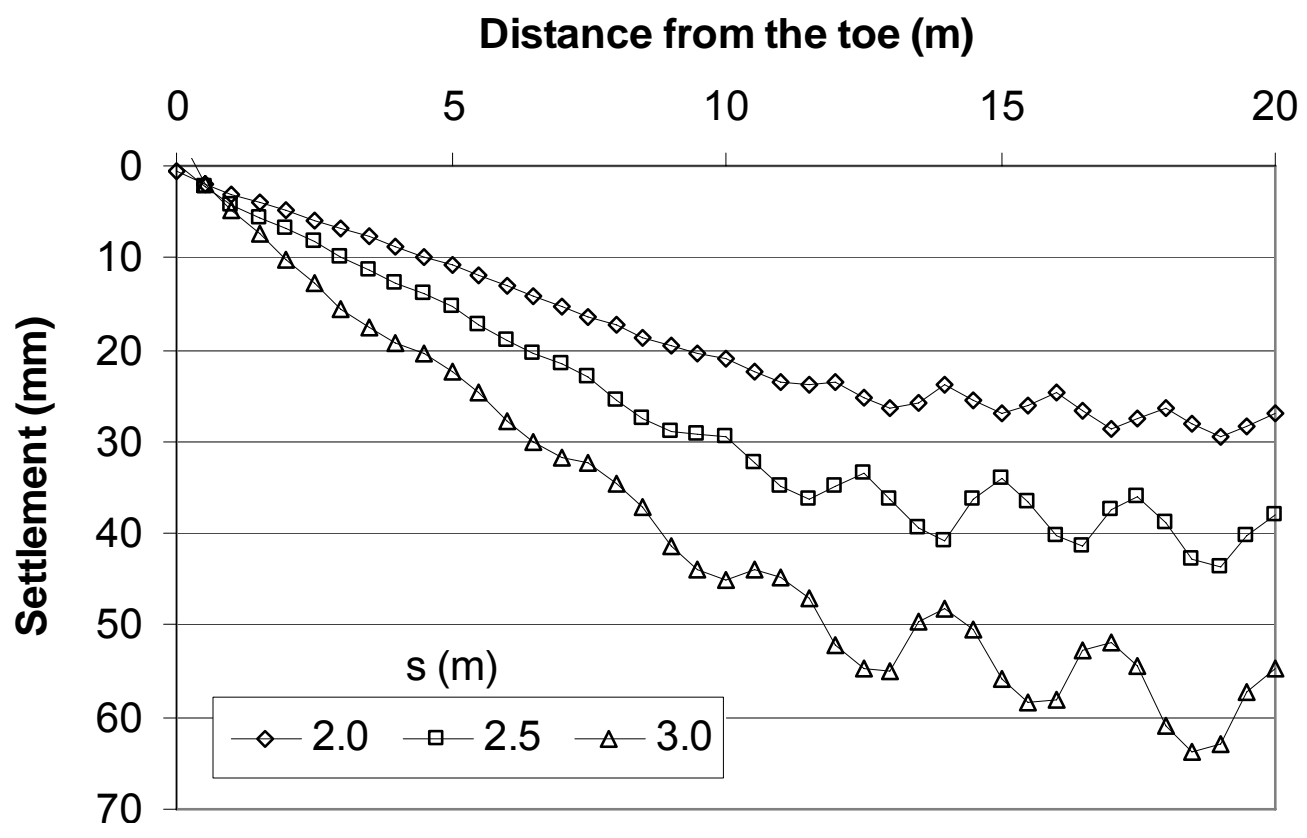

(d) At the base through Section II-II

Fig. 5-39. Settlement Profiles for Various Column Spacing on at 4.5 Years after Service (3D) (continued) 
The influences of the column spacing on the maximum settlement and the maximum differential settlement are plotted in Figs. 5-40 and 5-41, respectively. Both the maximum settlement and the maximum differential settlement increased with the increase of the column spacing. It is also shown that the column spacing had more effect on the maximum settlement and the maximum differential settlement at the base than those on the crest. Figures 5-40 and 5-41 show that the effect of the consolidation on the maximum settlement and maximum differential settlement when the column spacing increased.

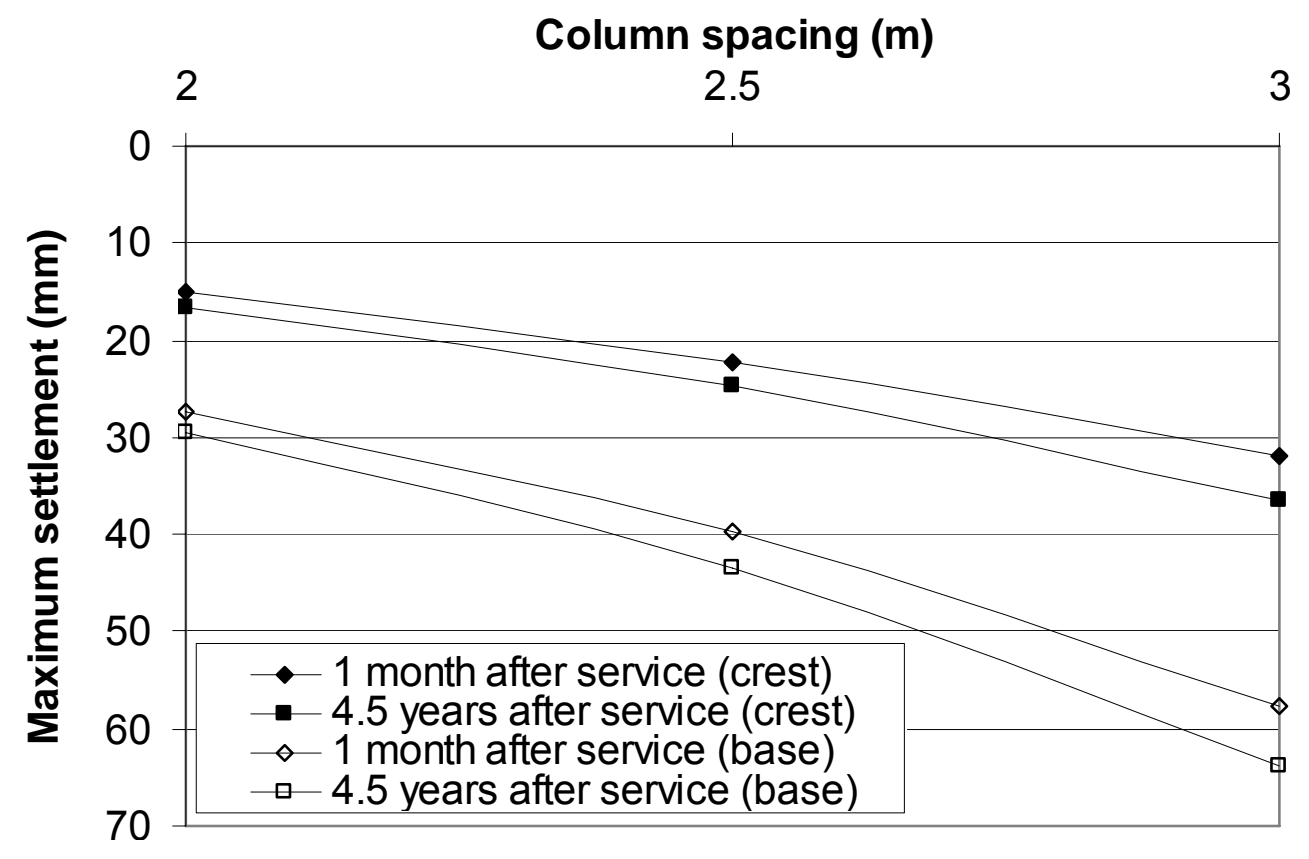

Fig. 5-40. Maximum Settlement versus Column Spacing (3D) 


\section{Column spacing (m)}

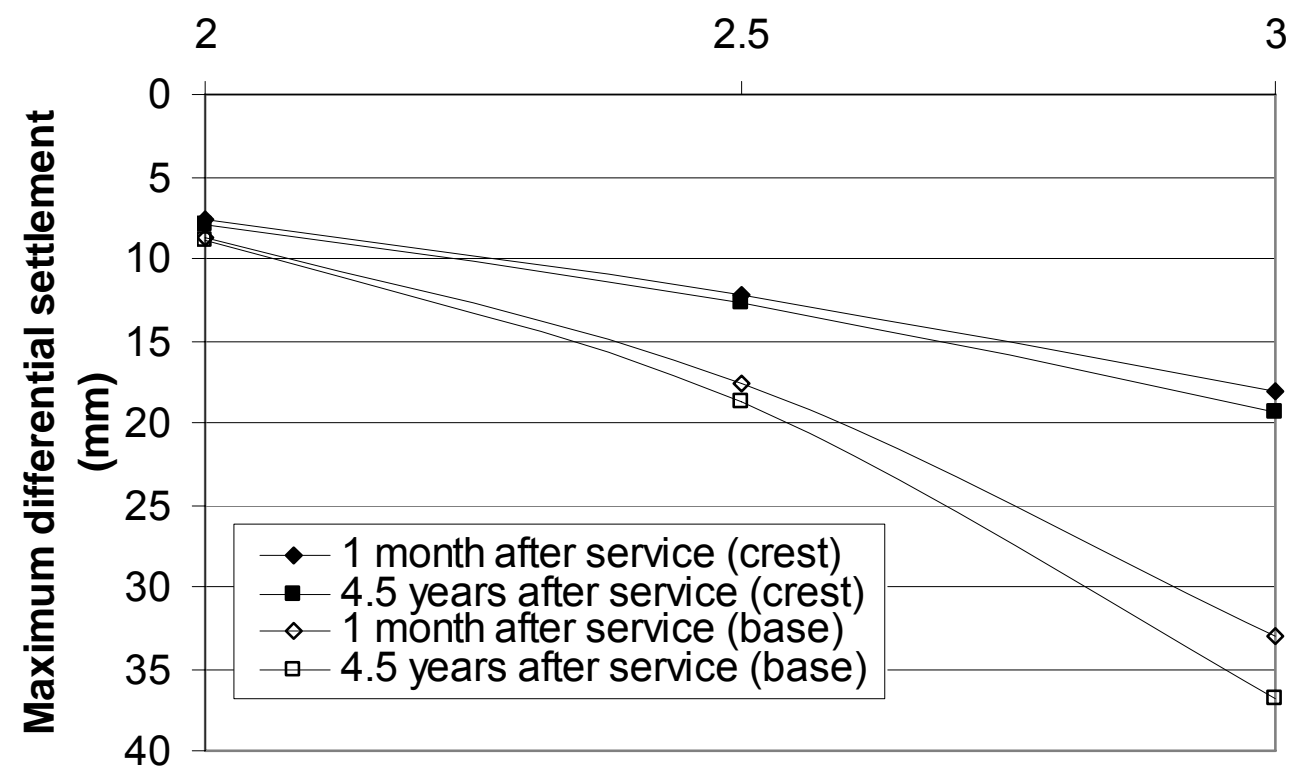

Fig. 5-41. Maximum Differential Settlement versus Column Spacing (3D)

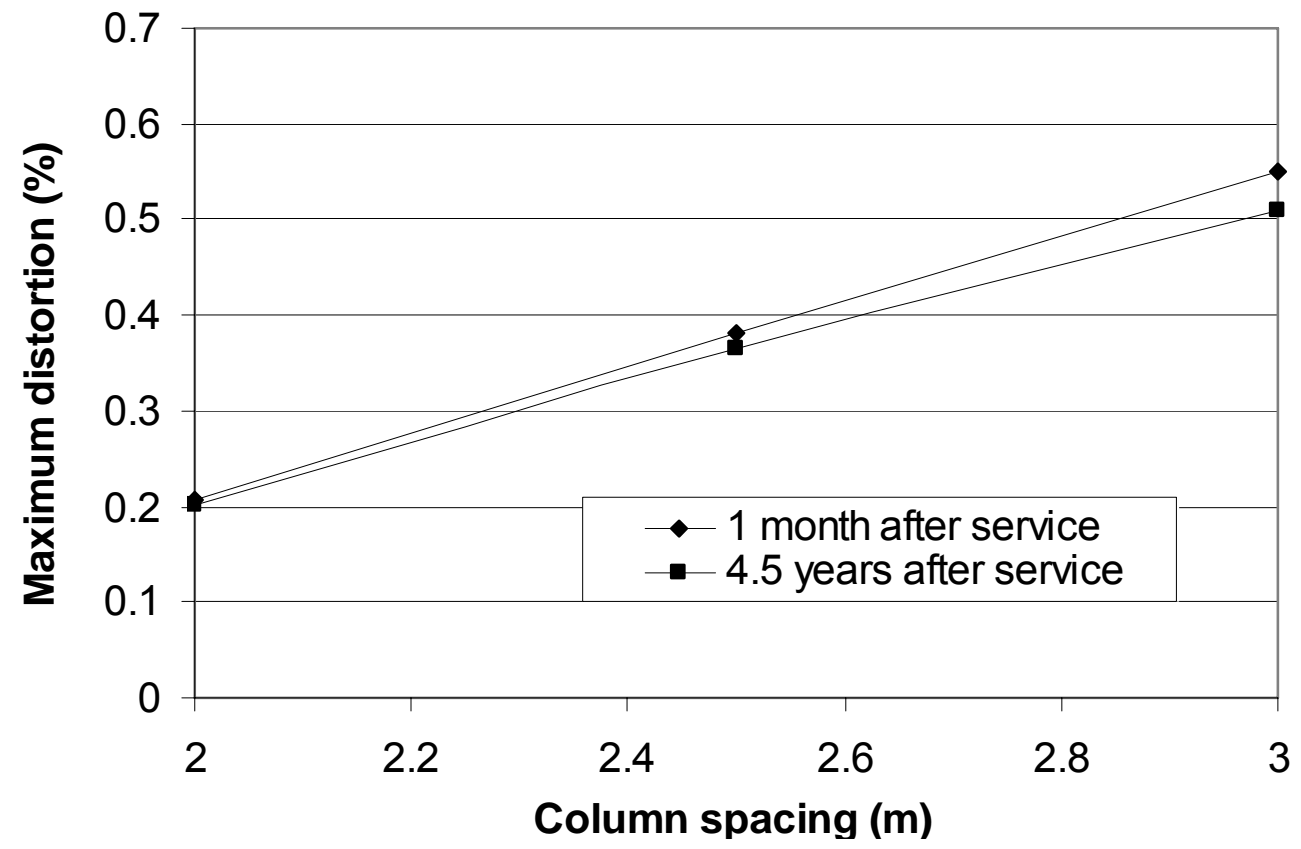

Fig. 5-42. Maximum Distortion on the Crest versus Column Spacing (3D) 
The influence of the column spacing on the maximum distortion is presented in Fig. 5-42. Obviously, the column spacing had a significant influence on the maximum distortion, i.e., the maximum distortion almost increased linearly with the column spacing within the range investigated. However, the maximum distortion decreased with the consolidation, especially for larger spacing.

\section{Influence of Geosynthetic Tensile Stiffness}

Different from the 2D parametric study, the geosynthetic reinforcement in the $3 \mathrm{D}$ analysis was modeled as plane triangular elements, connected through nodes. In addition, the geosynthetic was assumed to be an isotropic material. The influences of the tensile stiffness on the settlement profiles are presented in Fig. 5-43 and 5-44. Zero tensile stiffness represents the case without any geosynthetic reinforcement. The settlement profiles show that the use of the reinforcement with higher tensile stiffness yielded less maximum and differential settlements. The maximum reduction in the settlement for the tensile stiffness varying from 0 to $10000 \mathrm{kN} / \mathrm{m}$ tensile was approximately $6 \mathrm{~mm}$, which is equivalent to $26 \%$ reduction. The maximum settlement and the settlement reduction on the crest occurred in the middle of the half crest. 


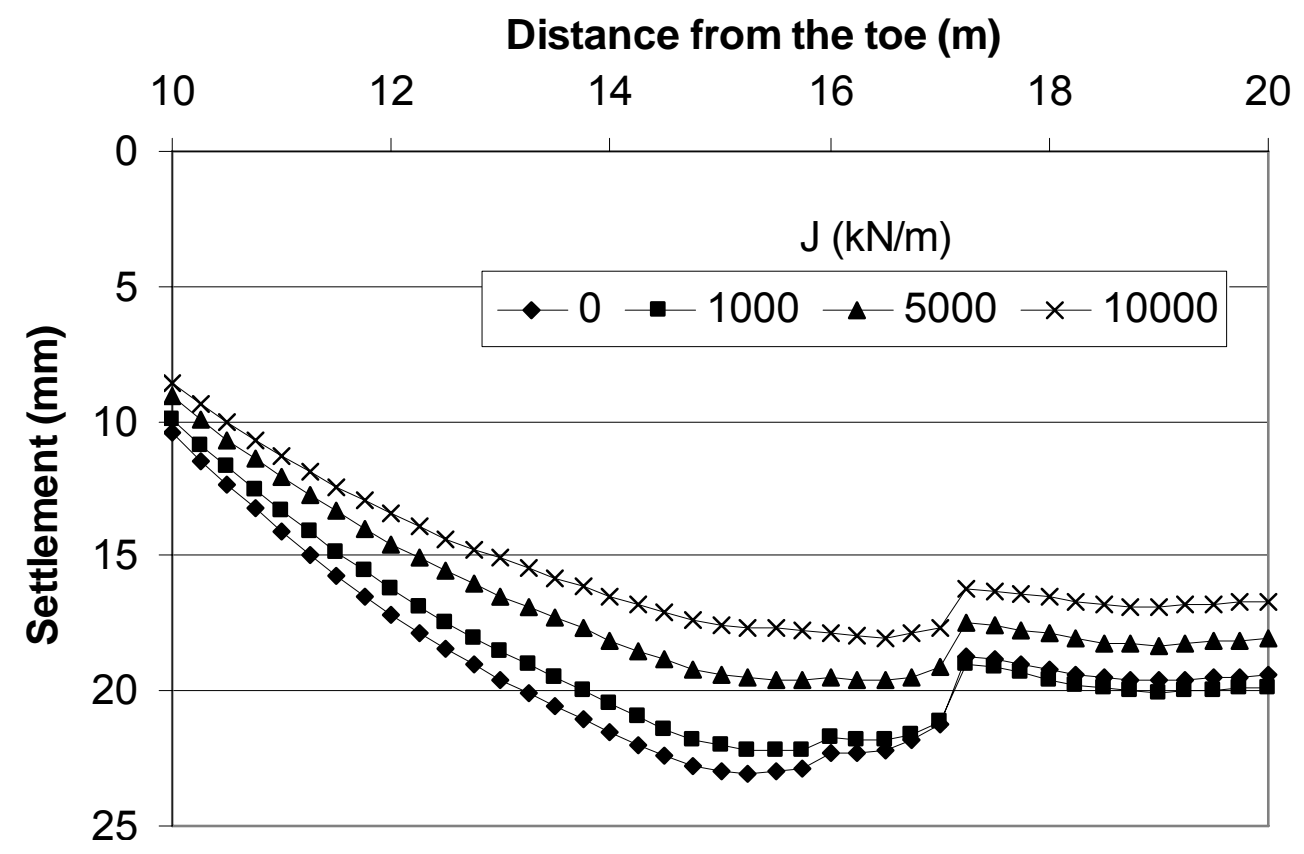

(a) On the crest through Section I-I

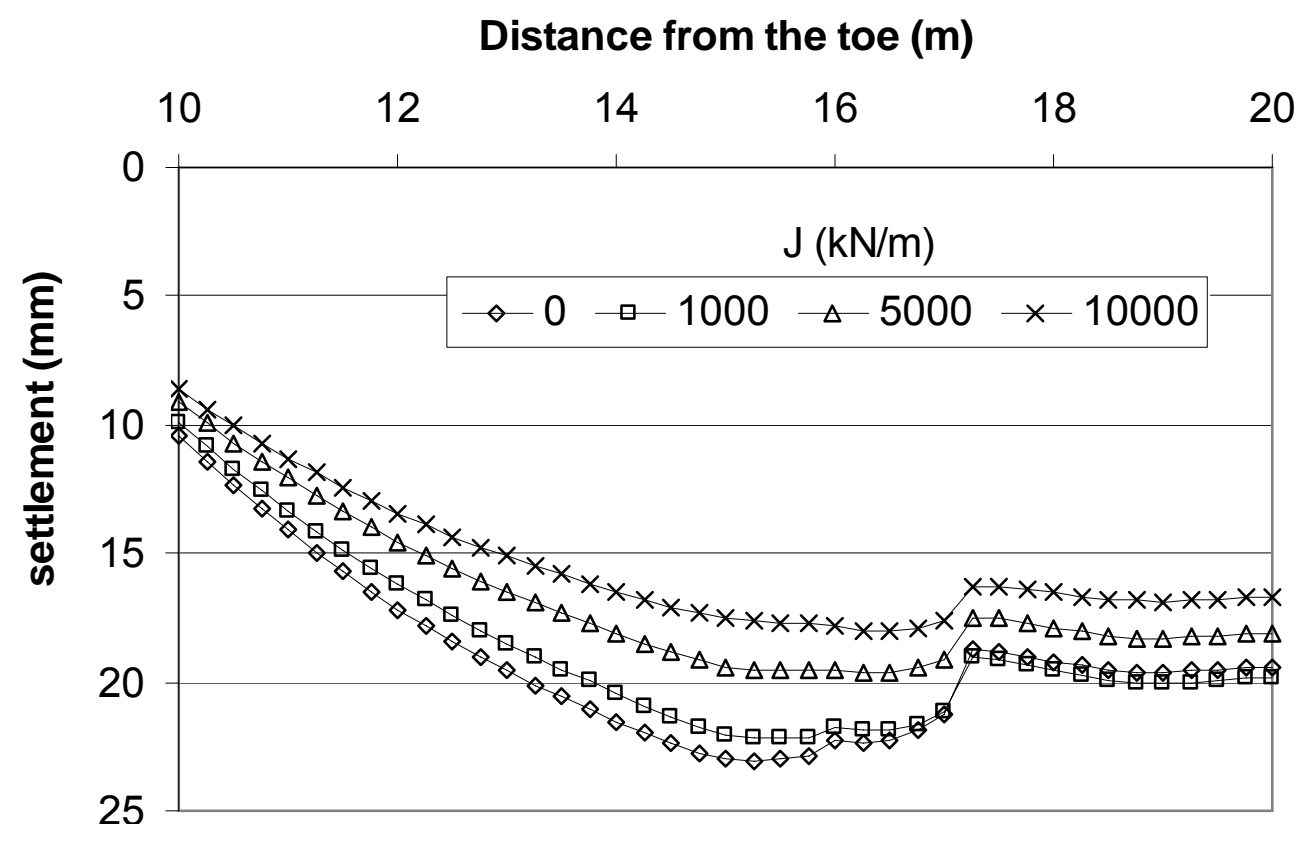

(b) On the crest through Section II-II

Fig. 5-43. Settlement Profiles for Various Tensile Stiffness at 1 Month after Service (3D) 


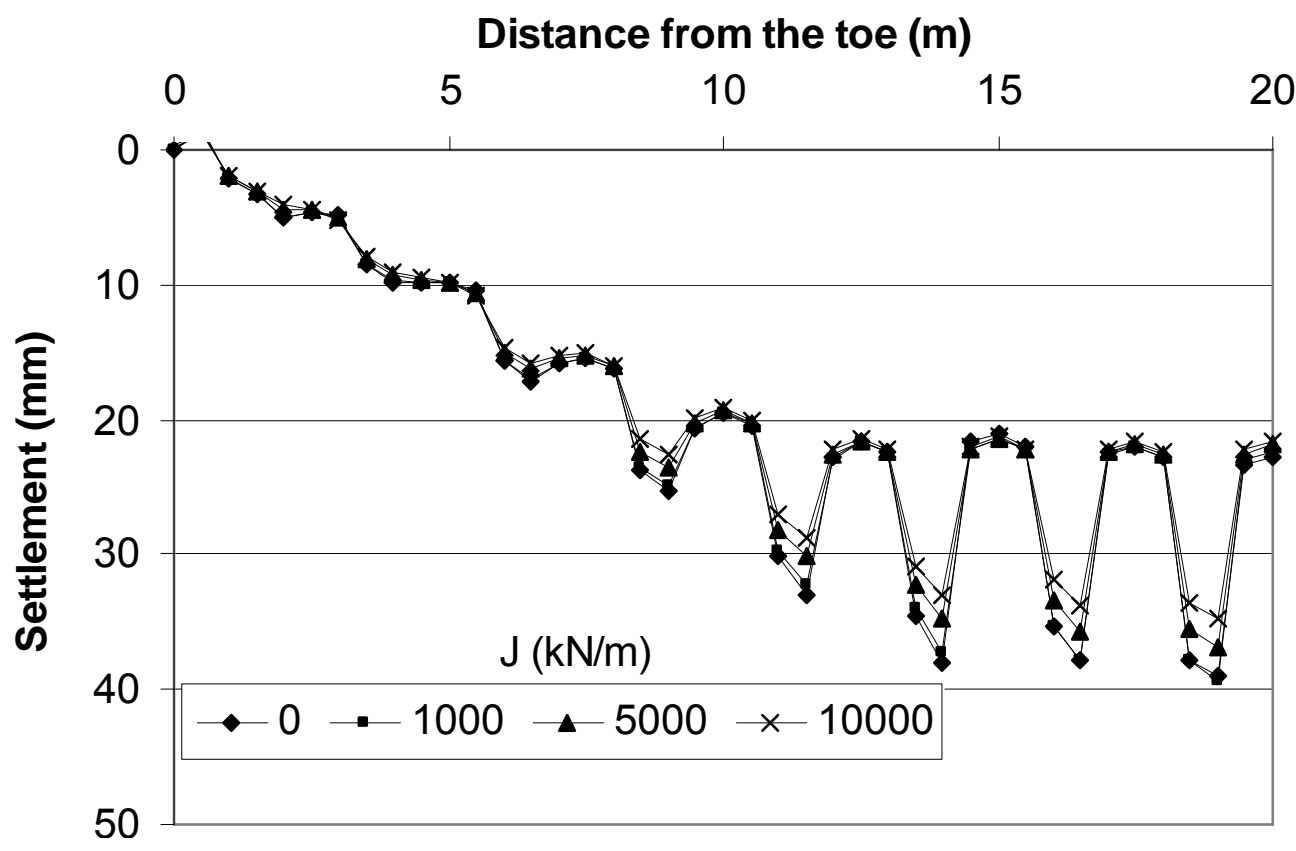

(c) At the base through Section I-I

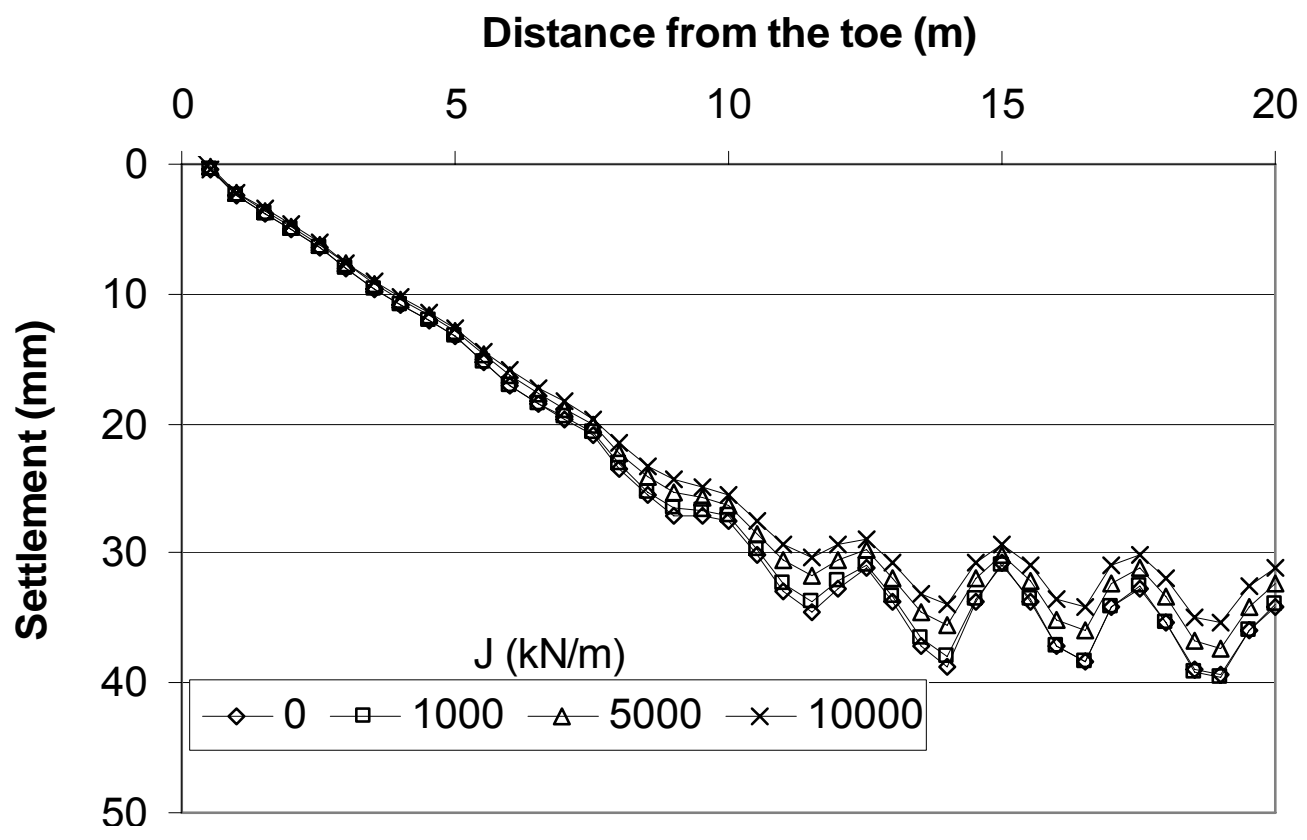

(d) At the Base through Section II-II

Fig. 5-43. Settlement Profiles for Various Tensile Stiffness at 1 Month after Service (3D) (continued) 


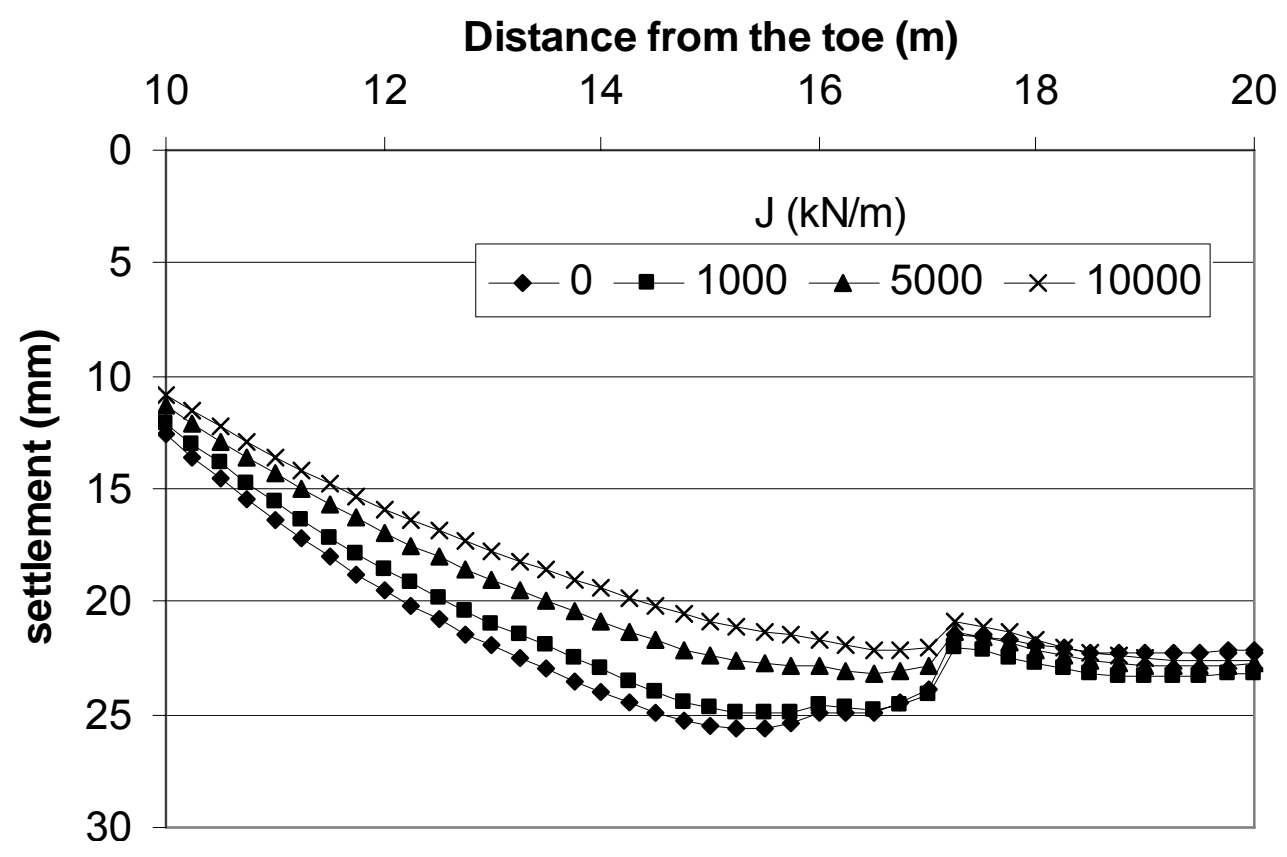

(a) On the crest through Section I-I

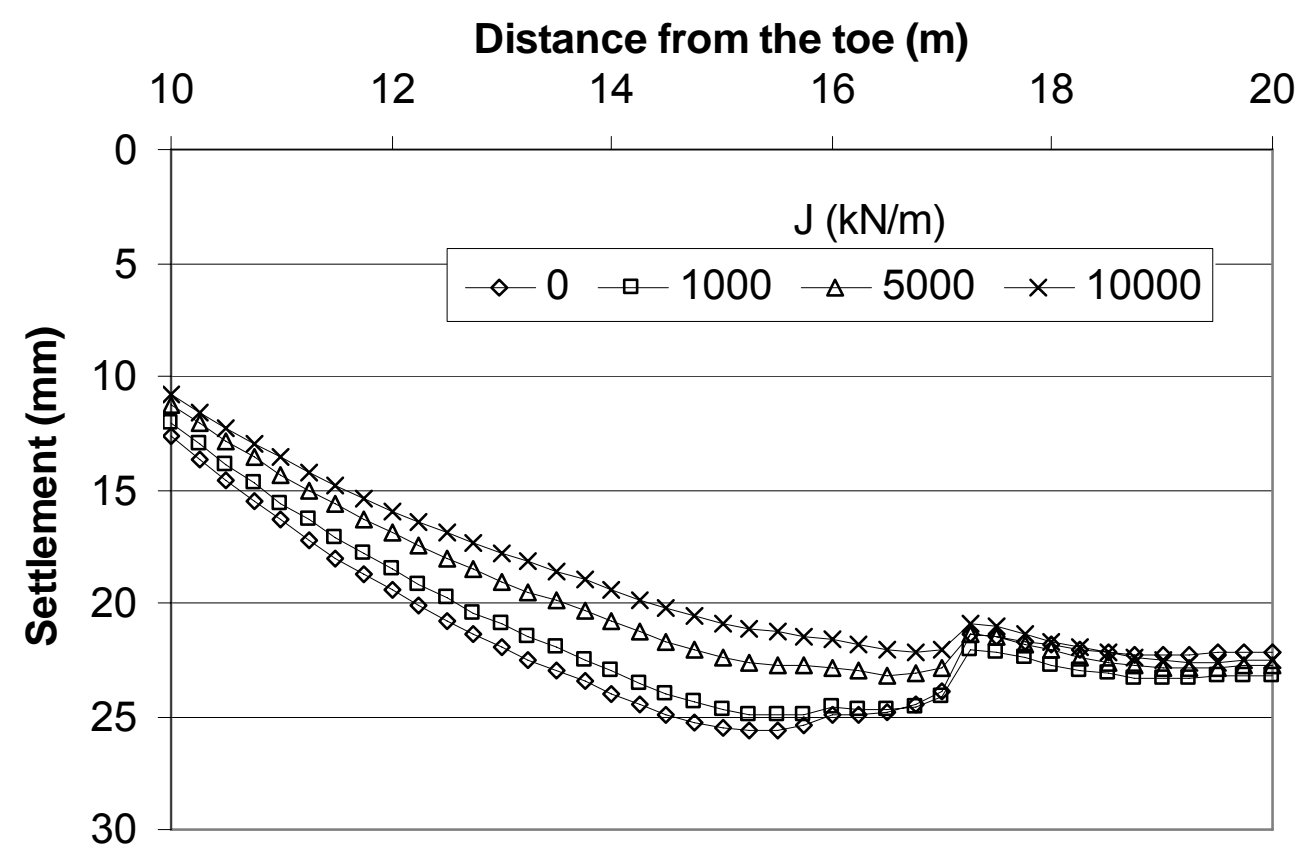

(b) On the crest through Section II-II

Fig. 5-44. Settlement Profiles for Various Tensile Stiffness at 4.5 Years after Service (3D) 


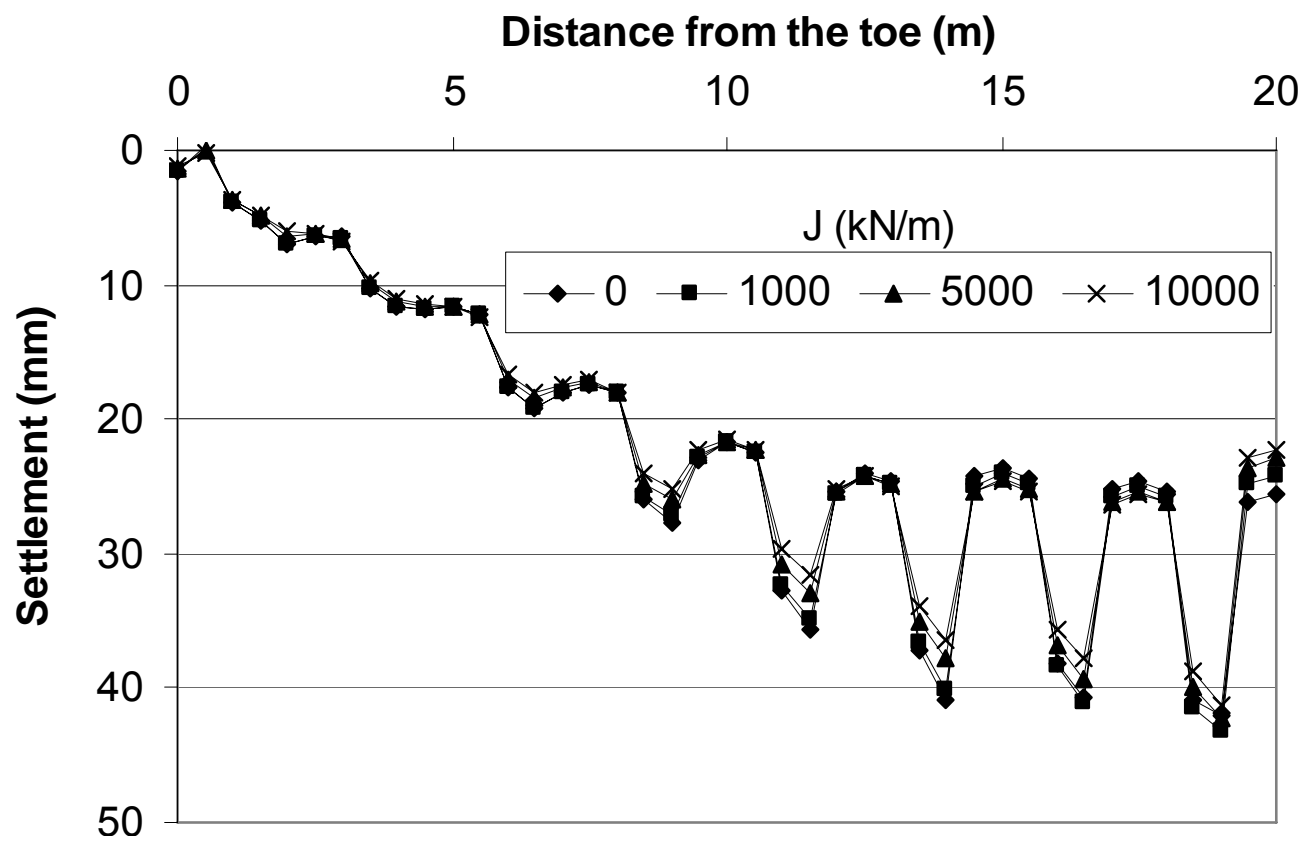

(c) At the base through Section I-I

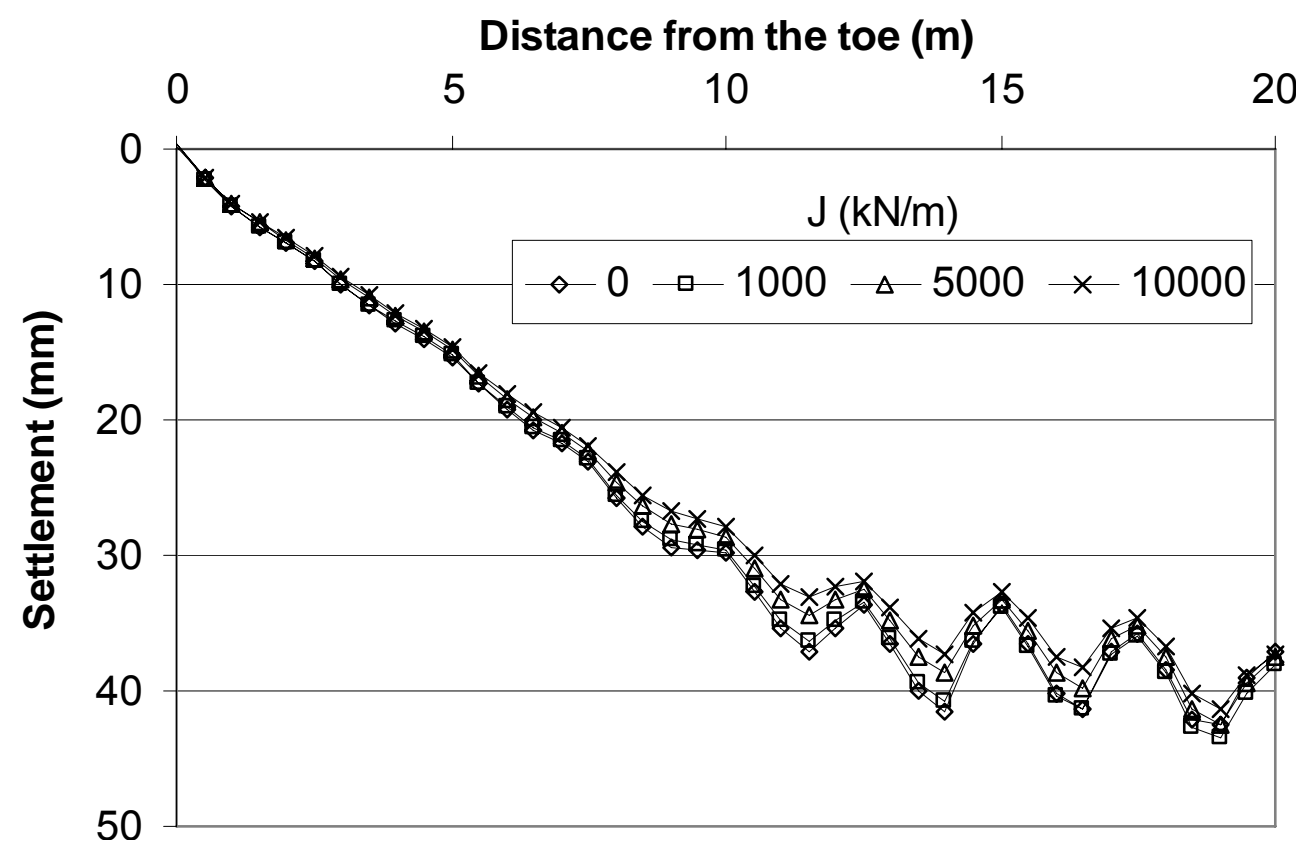

(d) At the base through Section II-II

Fig. 5-44. Settlement Profiles for Various Tensile Stiffness at 4.5 Years after Service (3D) (continued) 
The maximum settlement and differential settlements are plotted against the reinforcement tensile stiffness in Figs. 5-45 and 5-46, respectively. It is shown that the geosynthetic reinforcement reduced the maximum settlement and differential settlements but the reduction was limited.

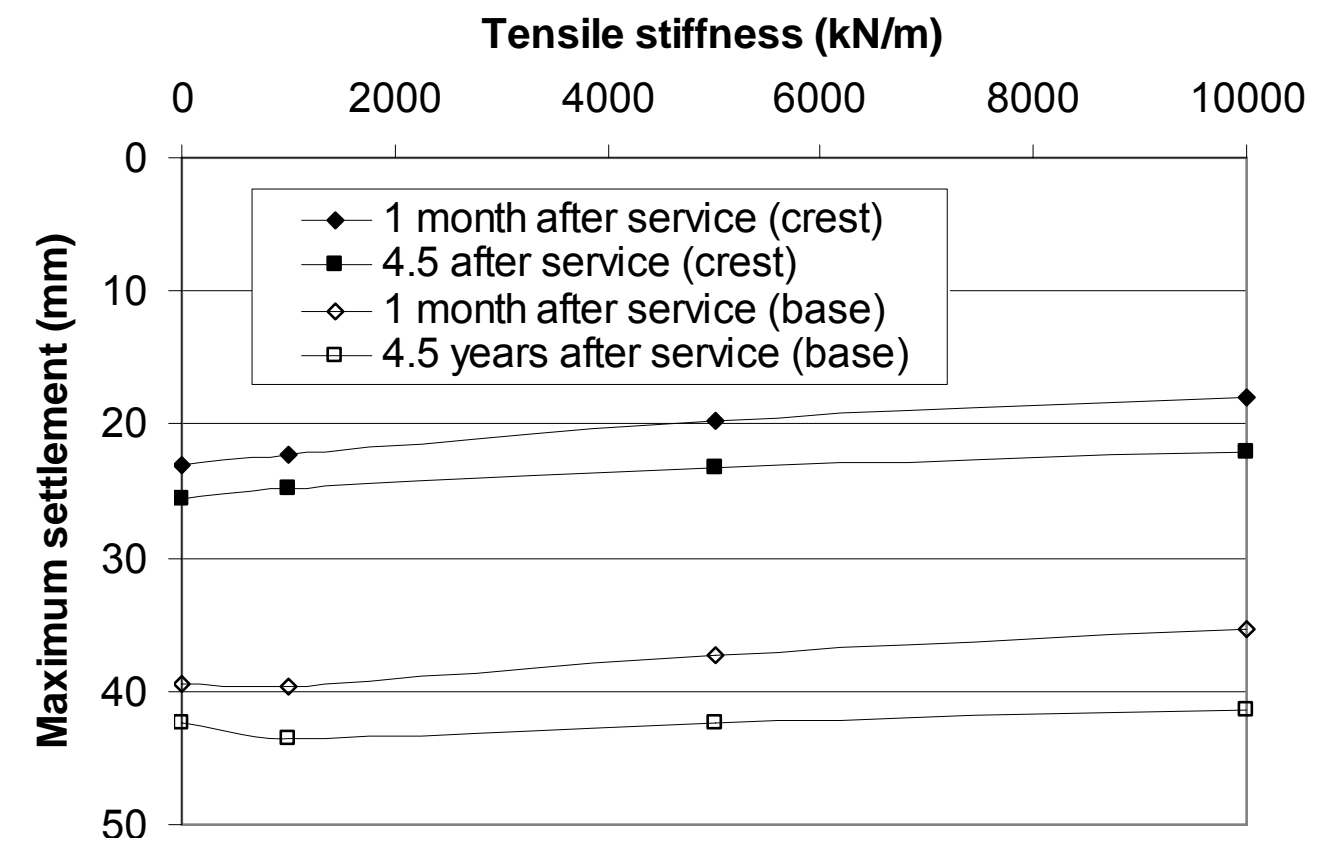

Fig. 5-45. Maximum Settlement versus Tensile Stiffness (3D) 


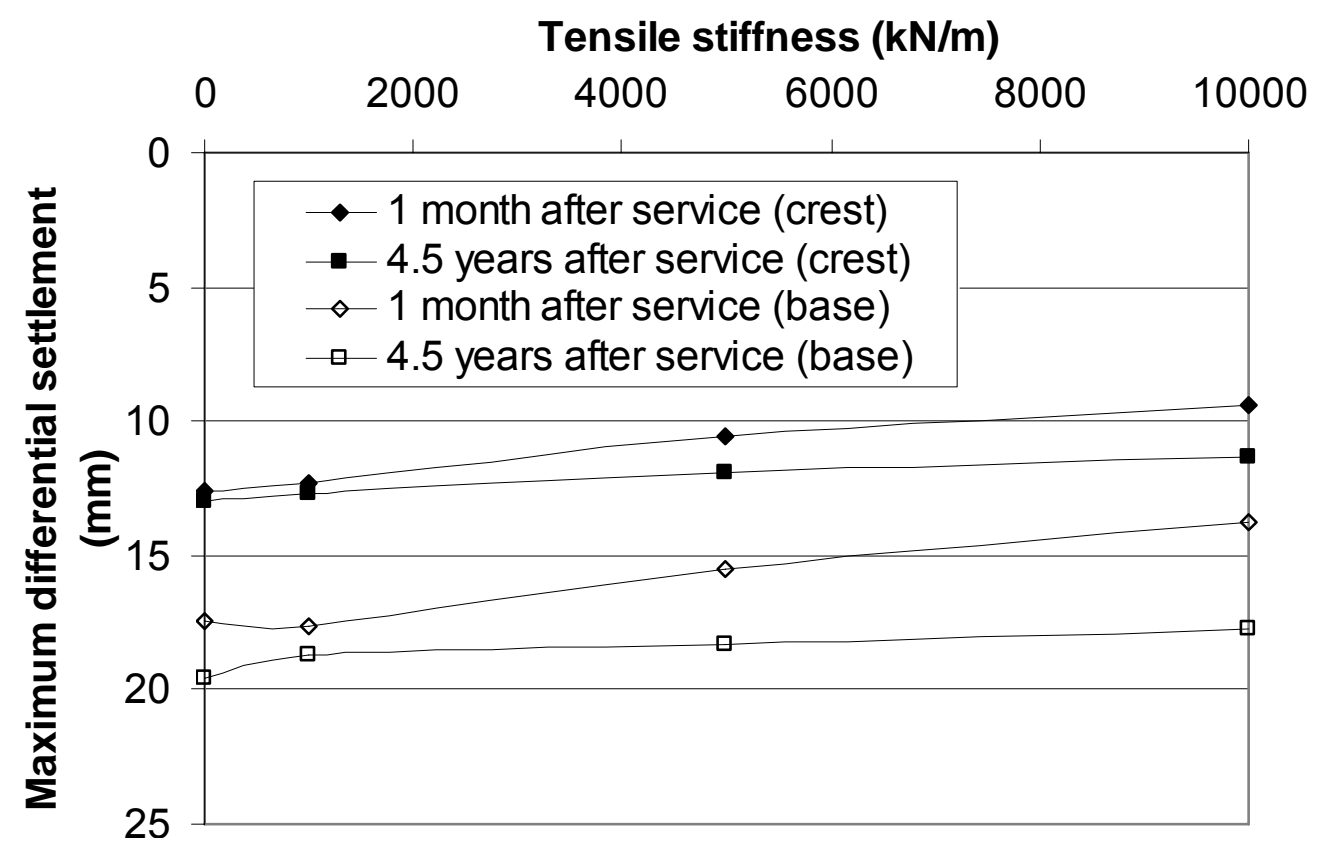

Fig. 5-46. Maximum Differential Settlement versus Tensile Stiffness (3D)

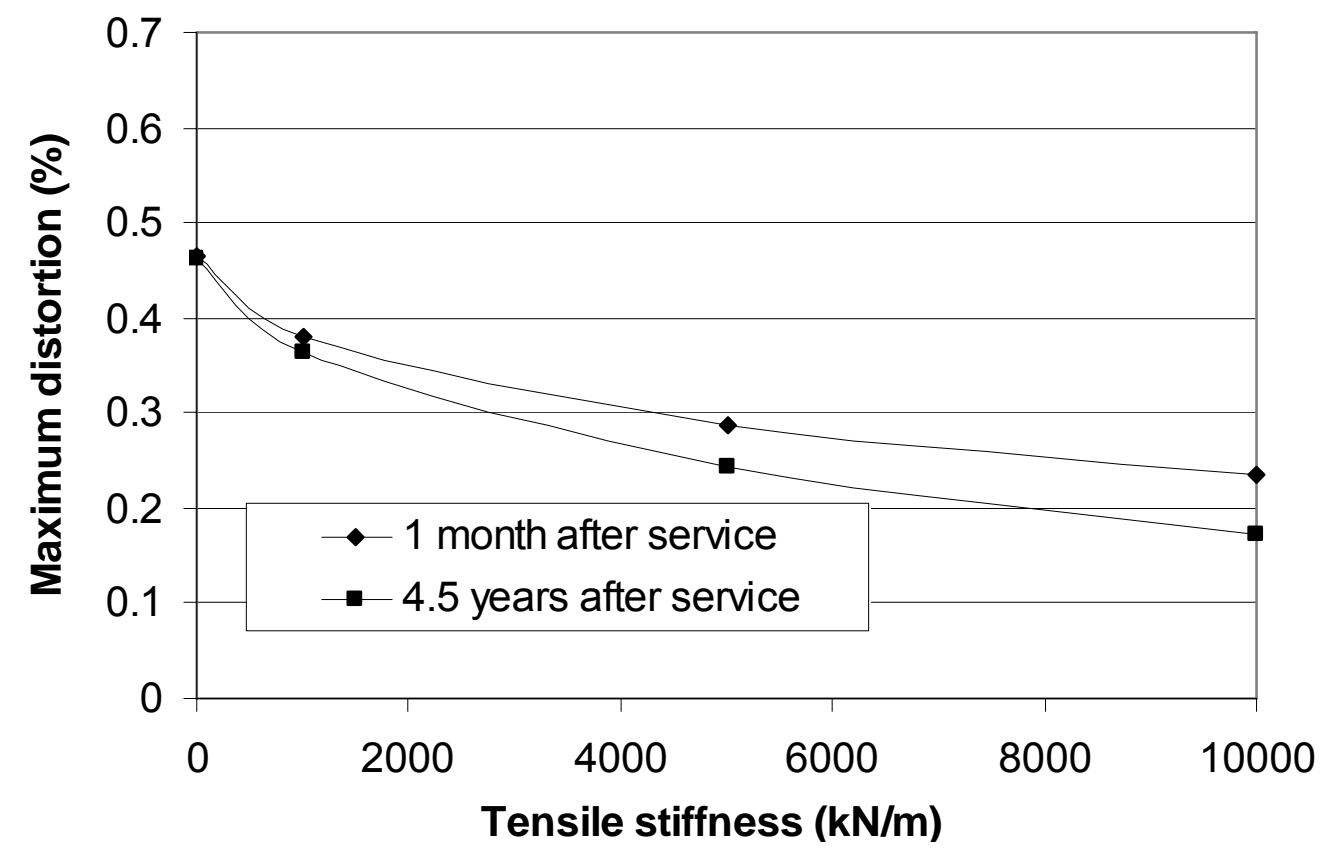

Fig. 5-47. Maximum Distortion on the Crest versus Tensile Stiffness (3D) 
The influence of the reinforcement tensile stiffness on the maximum distortion on the crest is shown in Fig. 5-47. The reduction of the maximum distortion by the reinforcement with higher stiffness was obvious. The consolidation of the foundation led to a further reduction on the maximum distortion.

\section{Influence of Construction Rate}

The average construction rate was changed in this study to evaluate its influence on the settlement. The settlement profiles developed under different construction rates are shown in Figs. 5-48 and 5-49. As expected, the higher construction rate caused a greater settlement on the crest. At the base, however, the higher construction rate led to a larger settlement on the soil but a smaller settlement on the columns. This result is consistent with that found in the $2 \mathrm{D}$ parametric study. In addition, the higher average construction rate led to a greater settlement increase from one month to 4.5

years after service due to higher accumulation of excess pore water pressure. The detailed discussion on the excess pore water pressure will be presented in the pore water pressure section. 


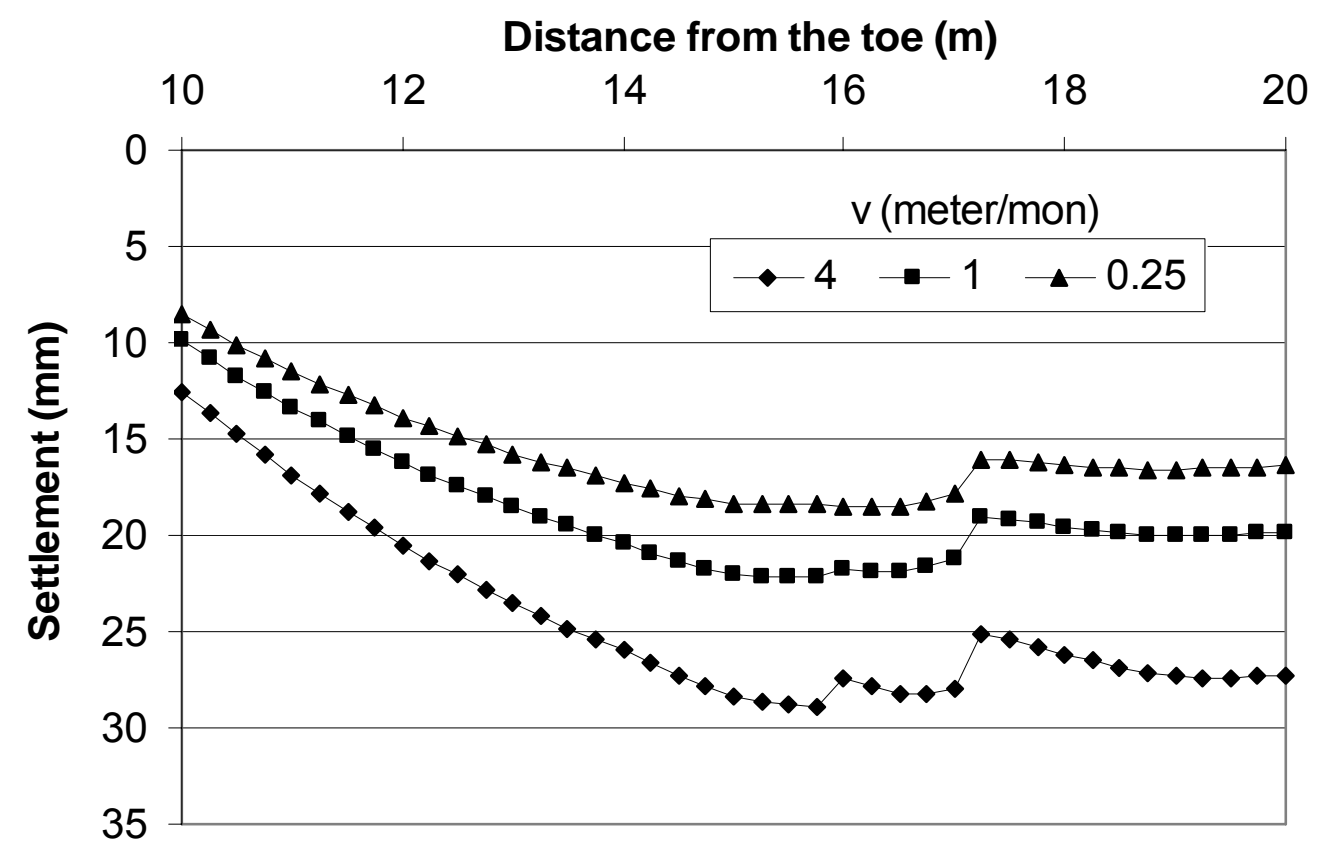

(a) On the crest through Section I-I

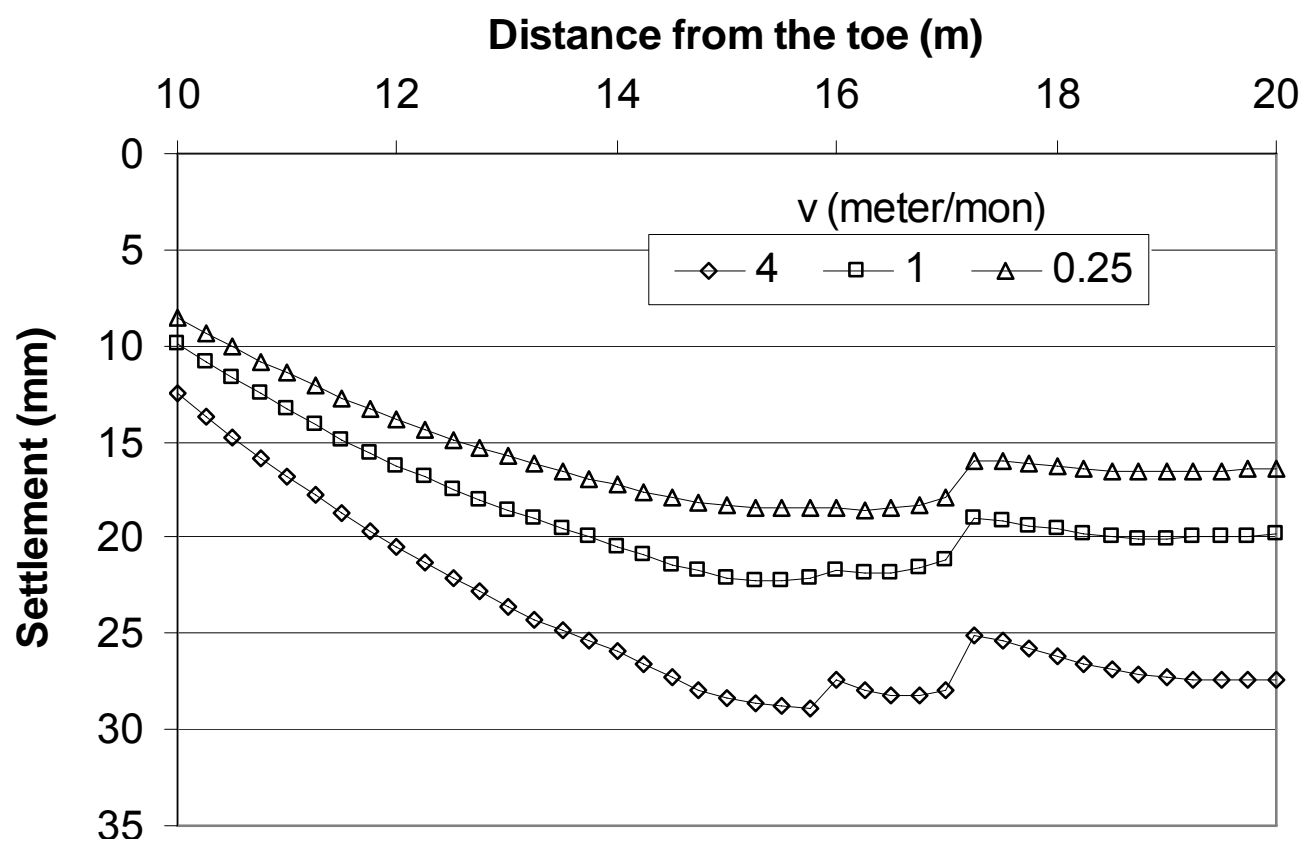

(b) On the crest through Section II-II

Fig. 5-48. Settlement Profiles for Various Average Construction Rates at 1 Month after Service (3D) 


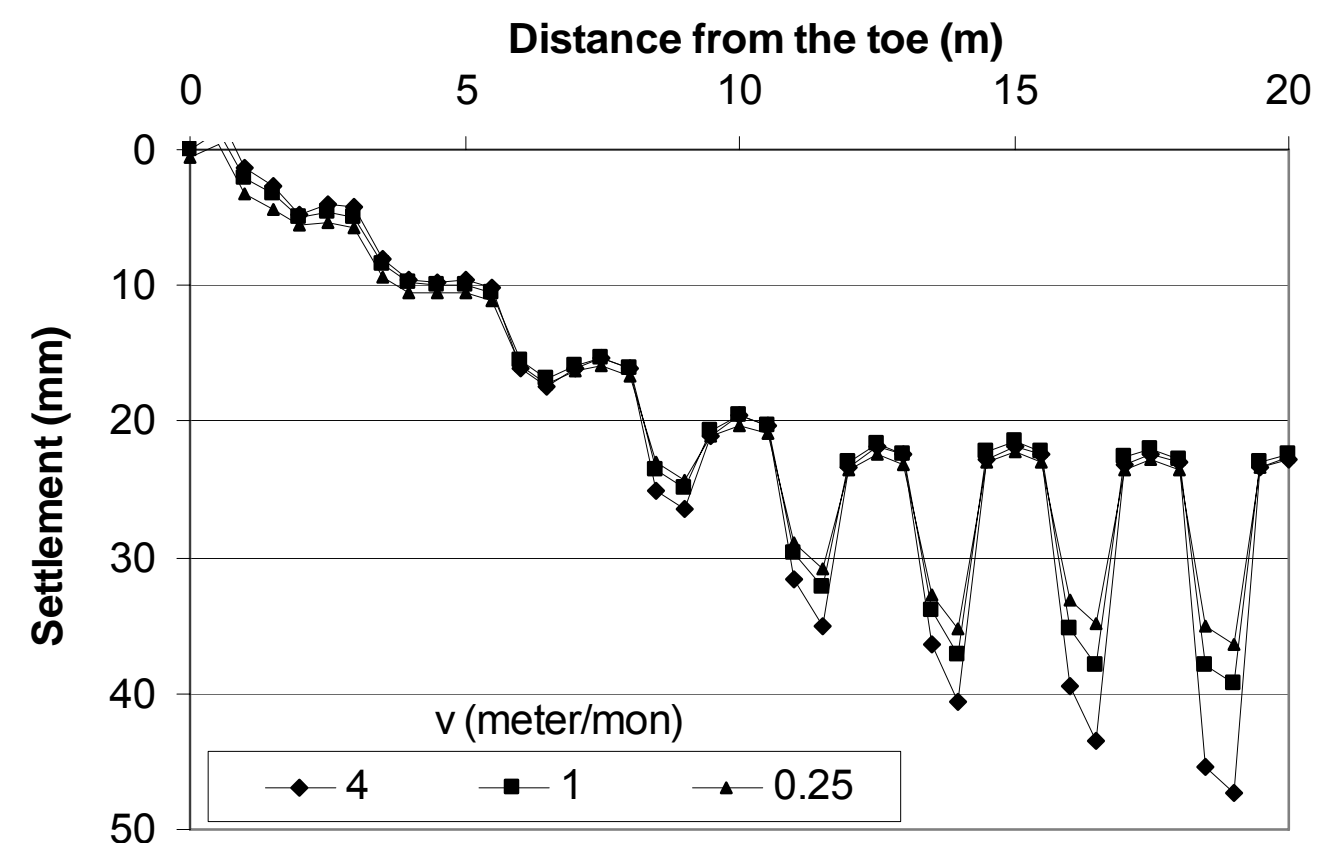

(c) At the base through Section I-I

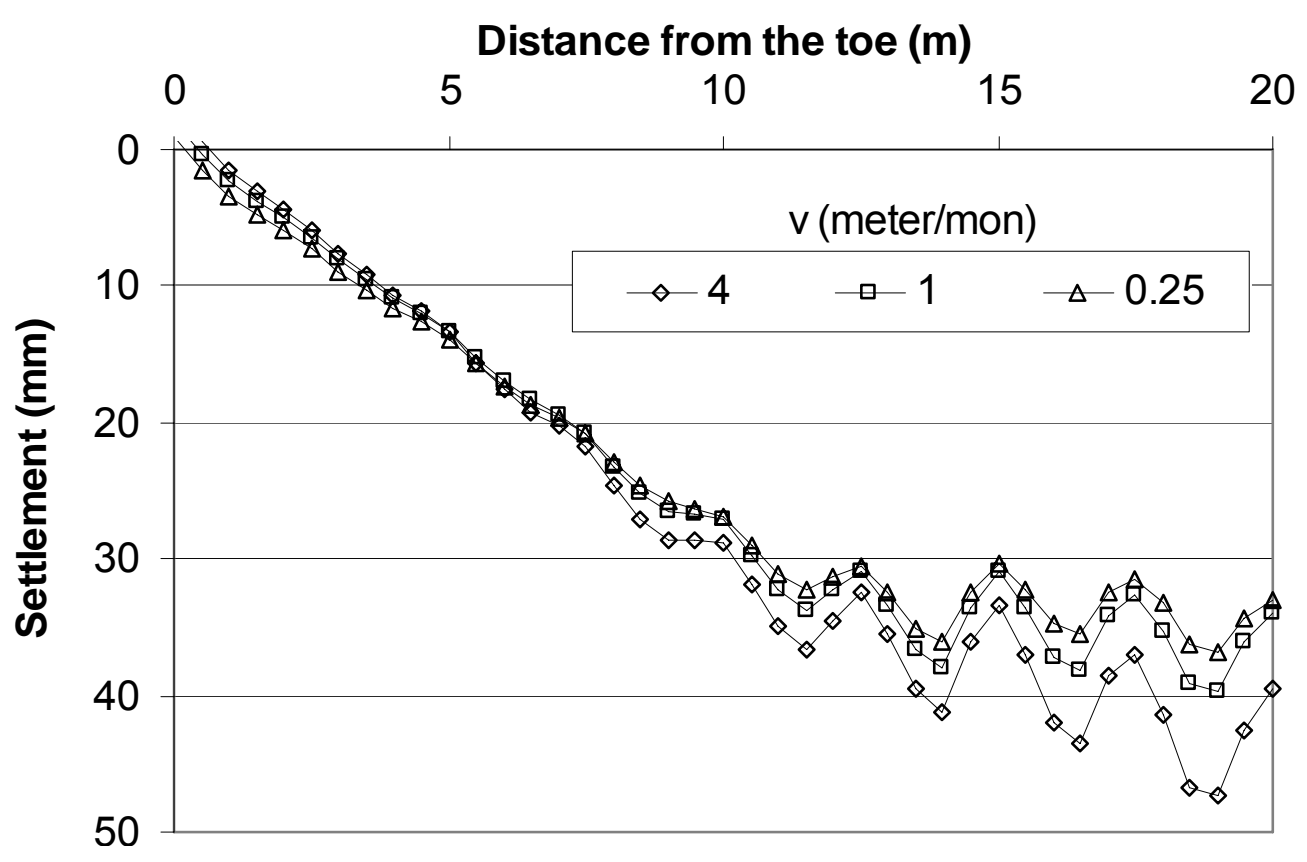

(d) At the base through Section II-II

Fig. 5-48. Settlement Profiles for Various Average Construction Rates at 1 Month after Service (3D) (continued) 
Distance from the toe (m)

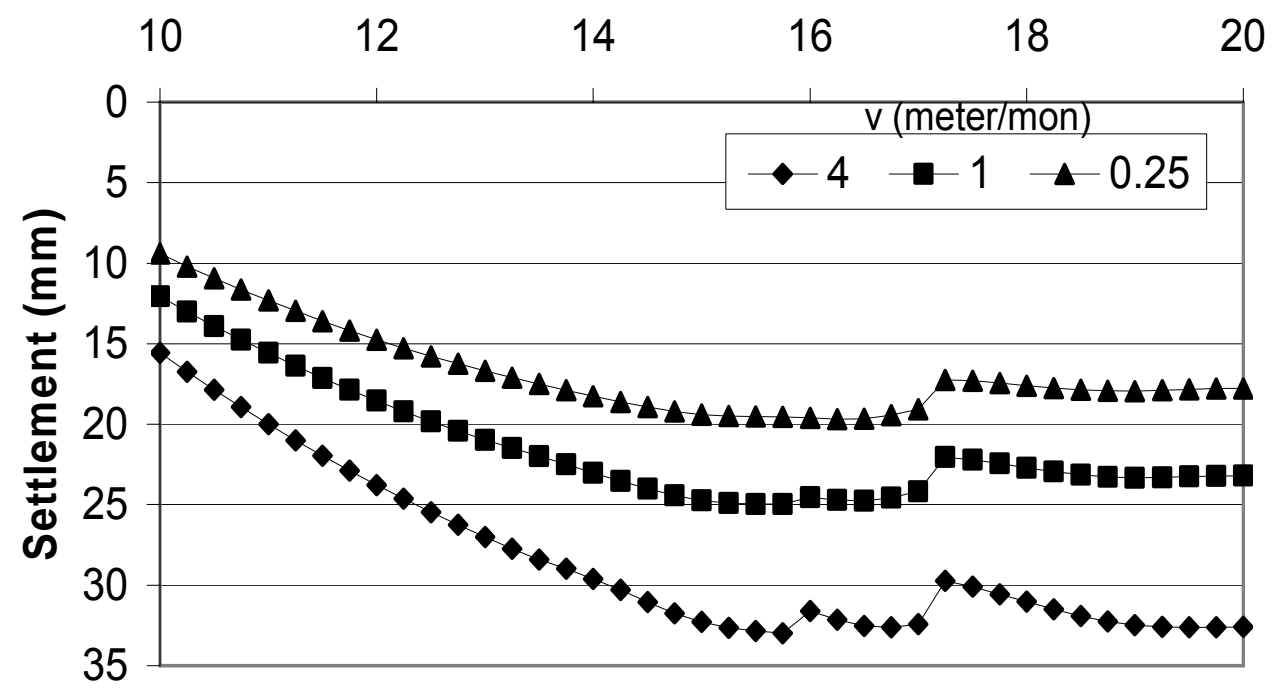

(a) On the crest through Section I-I

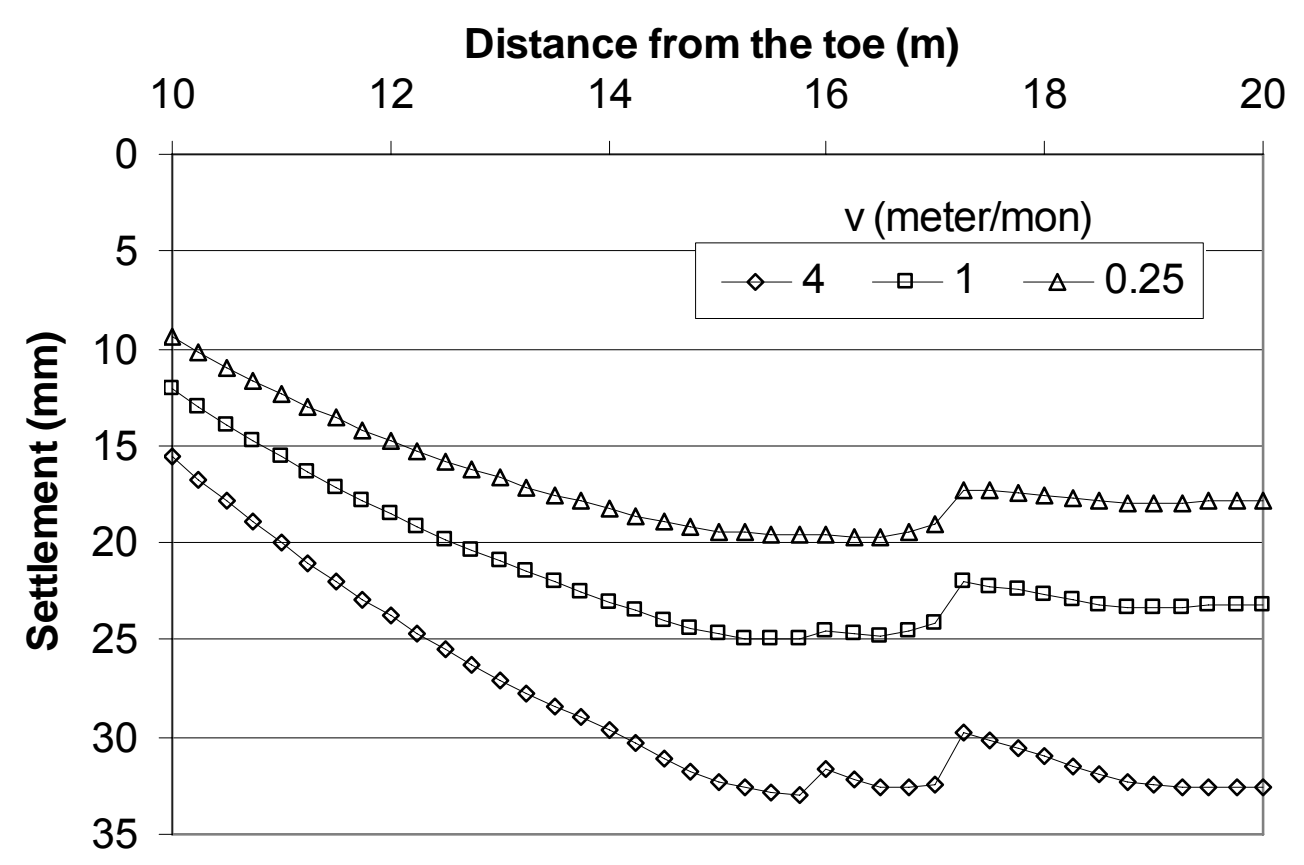

(b) On the crest through Section II-II

Fig. 5-49. Settlement Profiles for Various Average Construction Rates at 4.5 Years after Service (3D) 


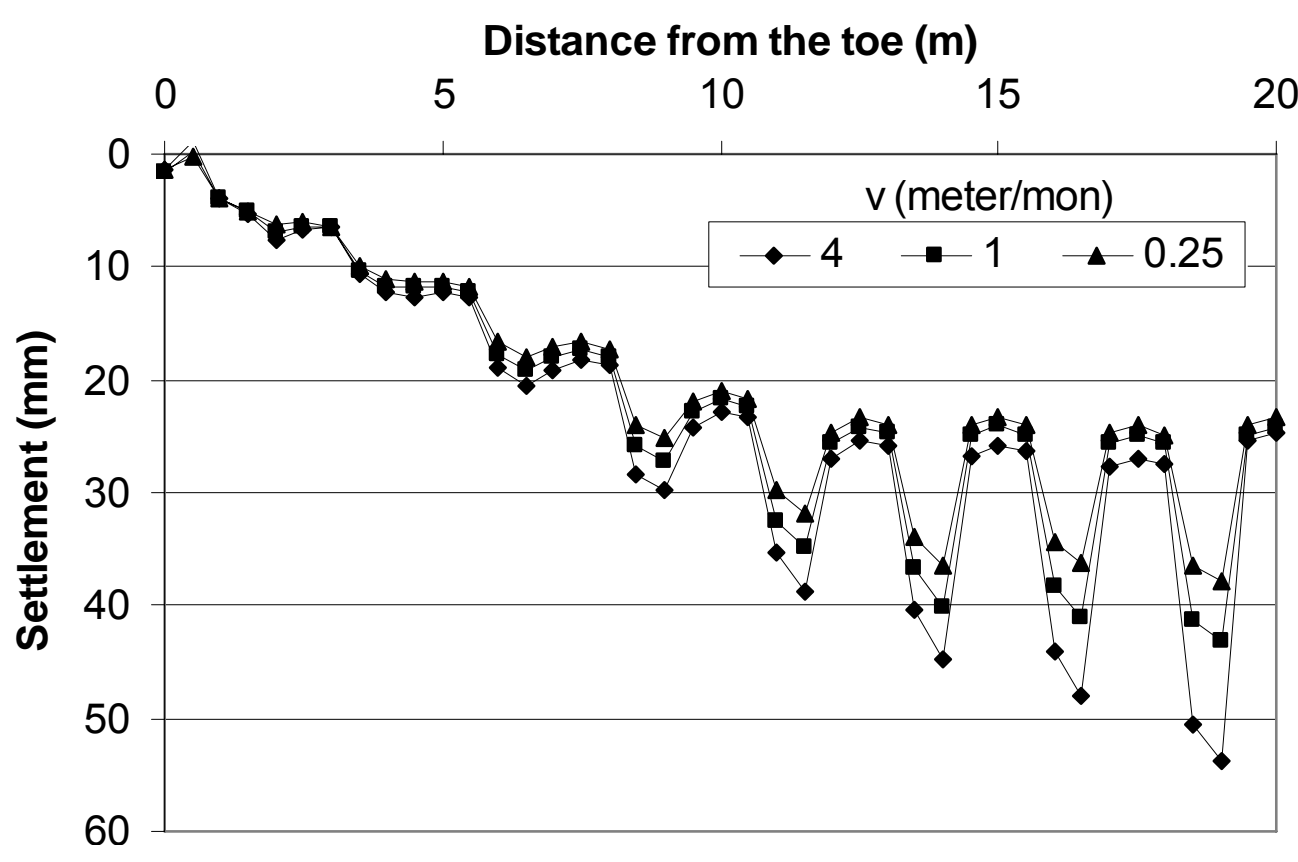

(c) At the base through Section I-I

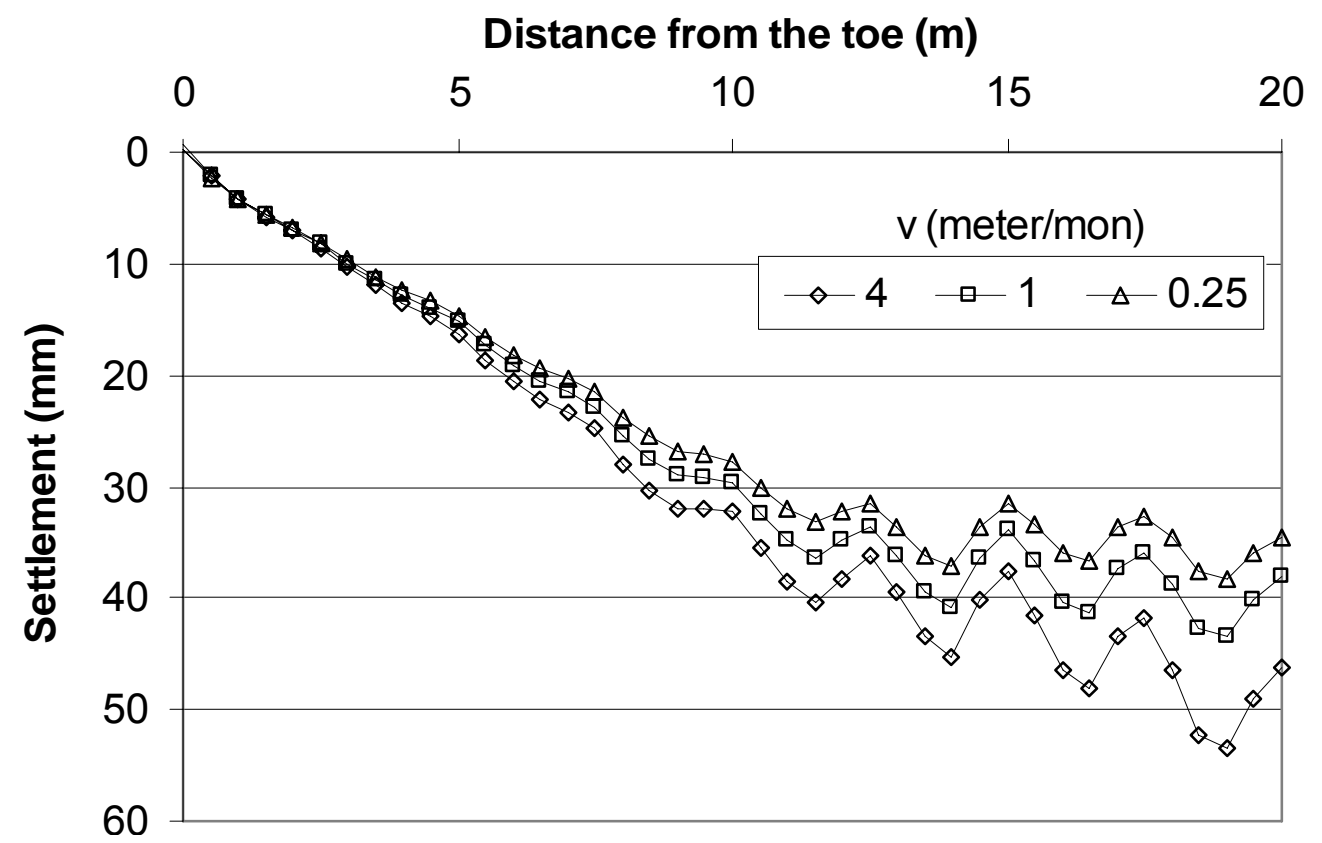

(d) At the base through Section II-II

Fig. 5-49. Settlement Profiles for Various Average Construction Rates at 4.5 Years after Service (3D) (continued) 
The maximum settlement and differential settlements against the average construction rate are plotted in Figs. 5-50 and 5-51. The decrease of the average construction rate led to smaller maximum settlement and differential settlements. The efficiency of the reduction in the maximum settlement and differential settlements by decreasing the average construction rate was almost linearly from $4 \mathrm{mter} / \mathrm{mon}$ to $1 \mathrm{~meter} / \mathrm{mon}$ and also from $1 \mathrm{~meter} / \mathrm{mon}$ to $0.25 \mathrm{~meter} / \mathrm{mon}$.

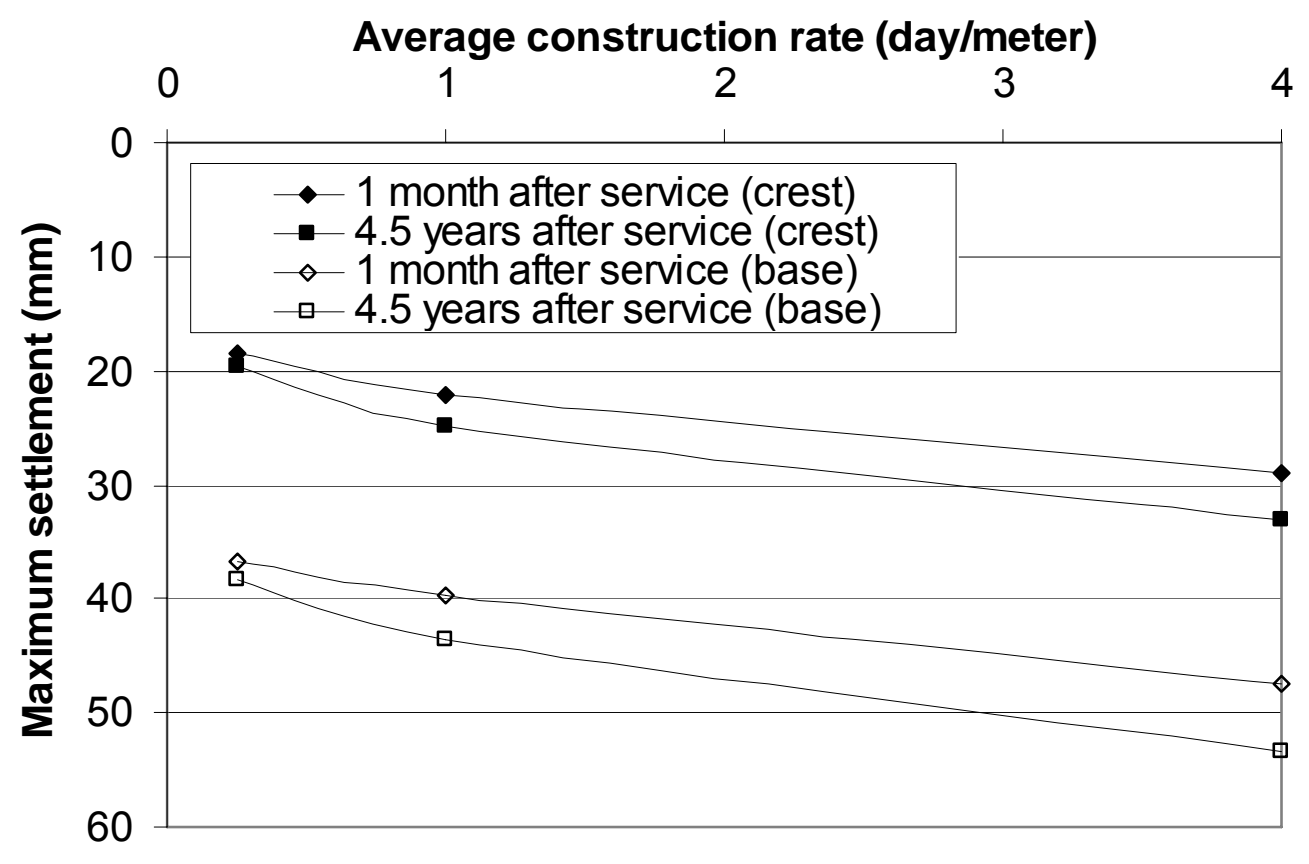

Fig. 5-50. Maximum Settlement versus Average Construction Rate (3D) 


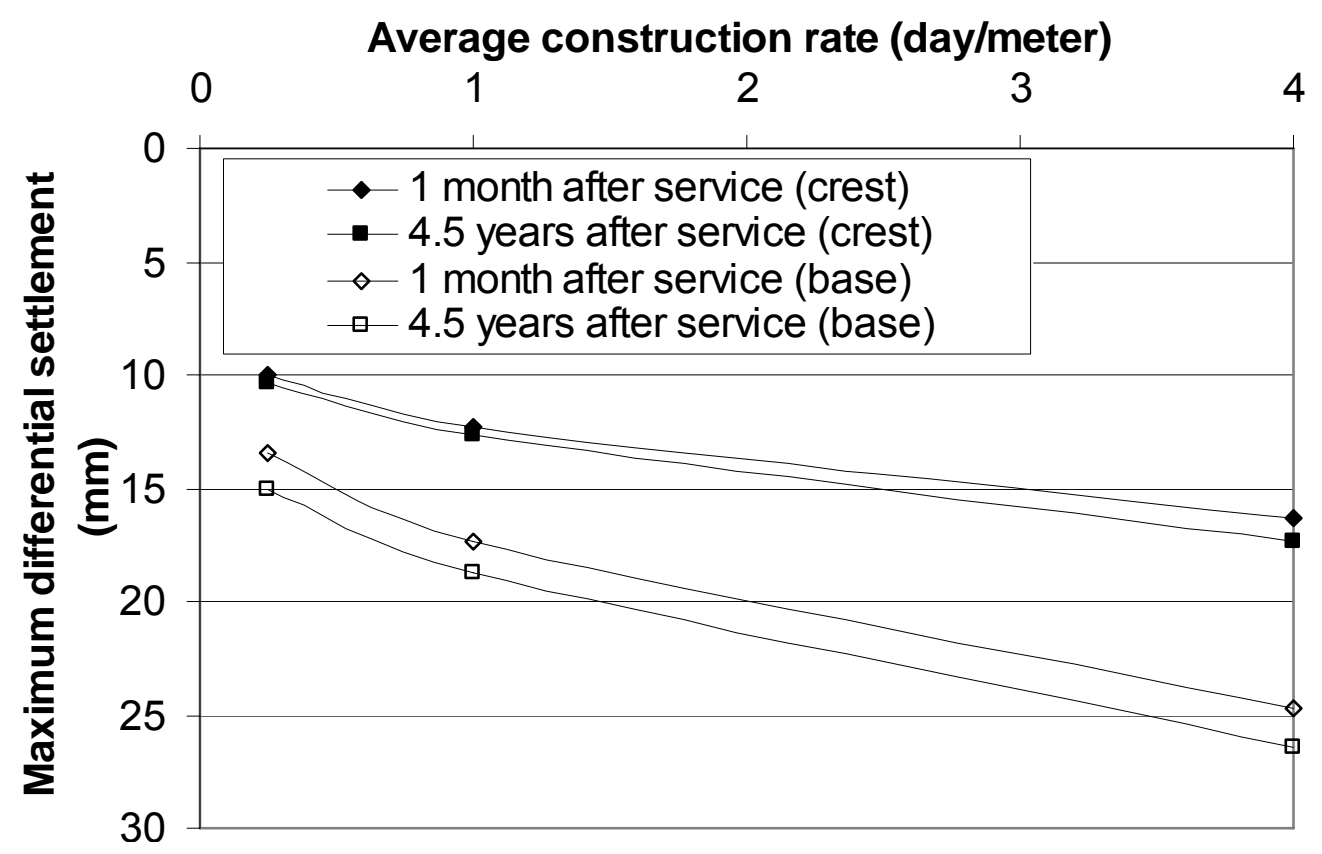

Fig. 5-51. Maximum Differential Settlement versus Average Construction Rate (3D)

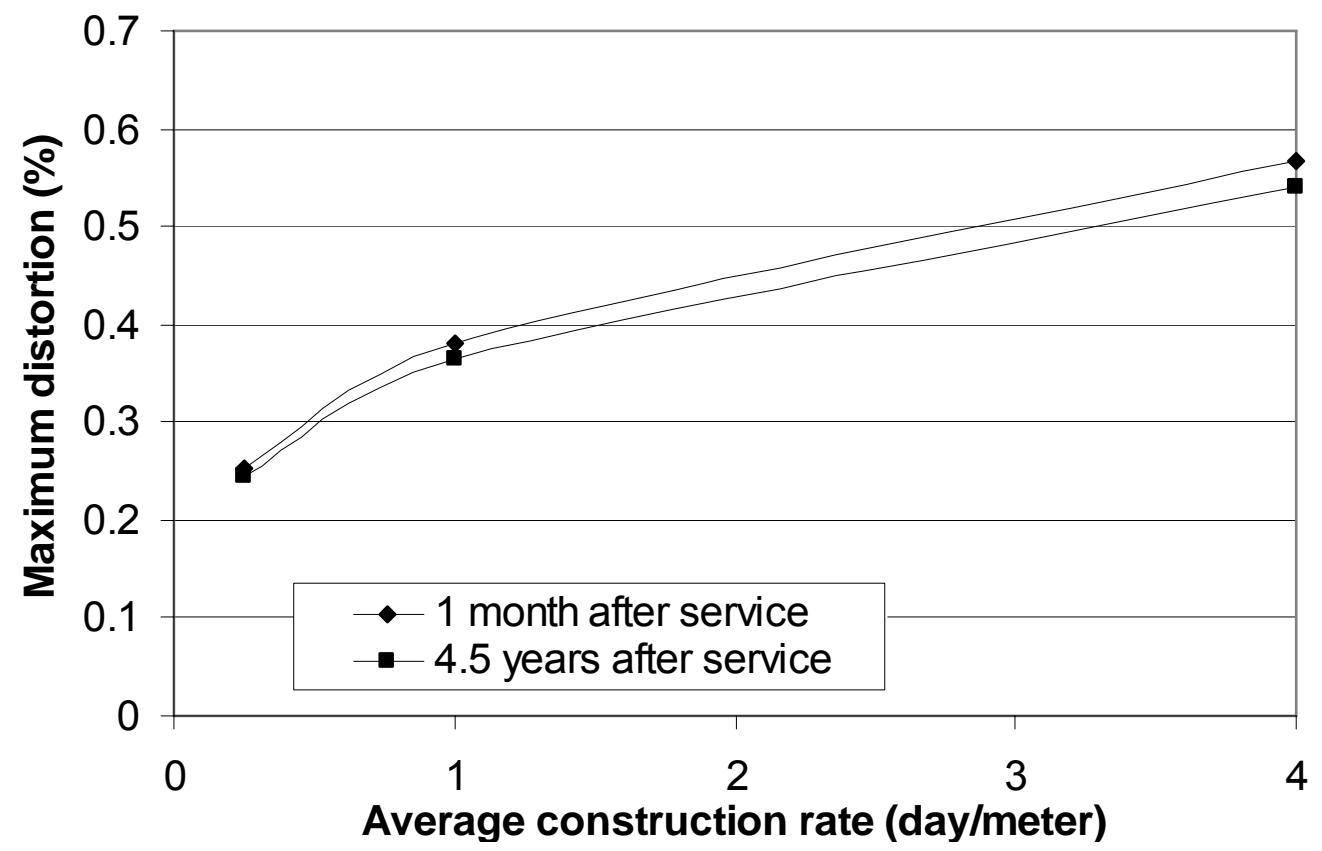

Fig. 5-52. Maximum Distortion on the Crest versus Average Construction Rate (3D) 
The influence of the average construction rate on the maximum distortion is presented in Fig. 5-52. The higher average construction rate resulted in a greater maximum distortion. The consolidation after the construction did not have much influence on the maximum distortion.

\subsubsection{Tension Developed in Geosynthetics}

As discussed previously, the tension in the geosynthetic reinforcement is induced by the differential settlement between columns and soft soil and the lateral spreading of the embankment. The influence of various factors on the tension in the geosynthetic reinforcement was investigated in this study and some of the results are presented herein.

\section{Influence of Soft Soil Elastic Modulus}

Since the geosynthetic reinforcement was simulated as plane elements, the tension developed in two perpendicular $\mathrm{x}$ and $\mathrm{y}$ directions can be calculated. The influence of soil modulus on the maximum tension developed in these two directions is presented in Fig. 5-53. The x-direction was perpendicular to the traffic direction and the ydirection was parallel to the traffic direction. Within the range of the soil modulus investigated in this study, the maximum tension in the $\mathrm{x}$-direction was always higher 
than that in the y direction. It can be seen that the soil modulus had a considerable influence on the tension in both directions. The increase of the soil modulus reduced the maximum tension. Since the increase of the soil modulus reduced the maximum differential settlement, the geosynthetic sheet was less deformed and stretched so that the maximum tension was reduced. However, the consolidation of the foundation soil had an insignificant influence on the maximum tension in both $\mathrm{x}$ and $\mathrm{y}$ directions as shown in Fig. 5-53.

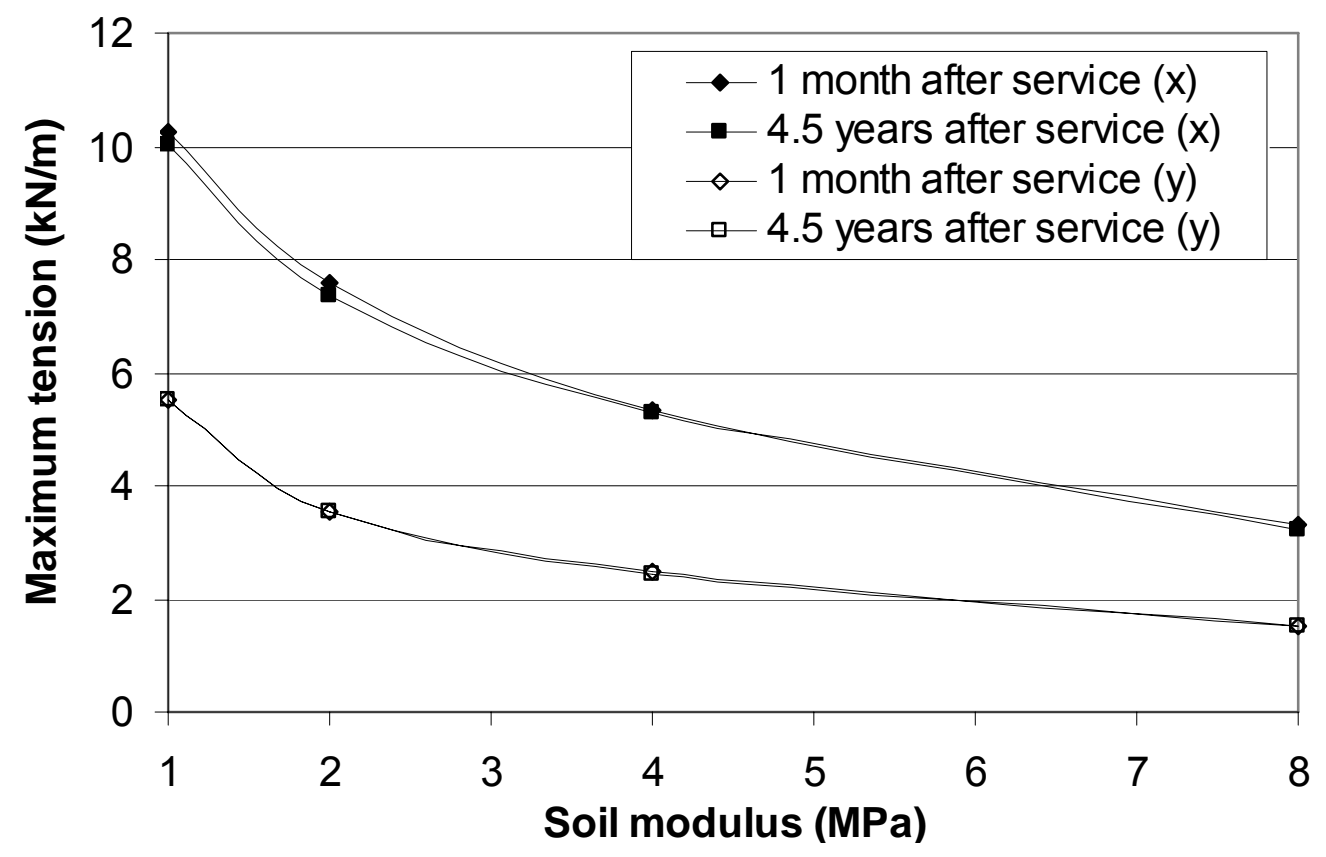

Fig. 5-53. Maximum Tension versus Soil Modulus (3D)

\section{Influence of Soft Soil Friction Angle}

The influence of the soft soil friction angle on the maximum tension in the reinforcement is shown in Fig. 5-54. The maximum tension in the $\mathrm{x}$ direction was 
higher than that in the y direction. An increase of the soil friction angle reduced the maximum tension in both directions. The consolidation of the foundation had an insignificant effect on the maximum tension in both directions.

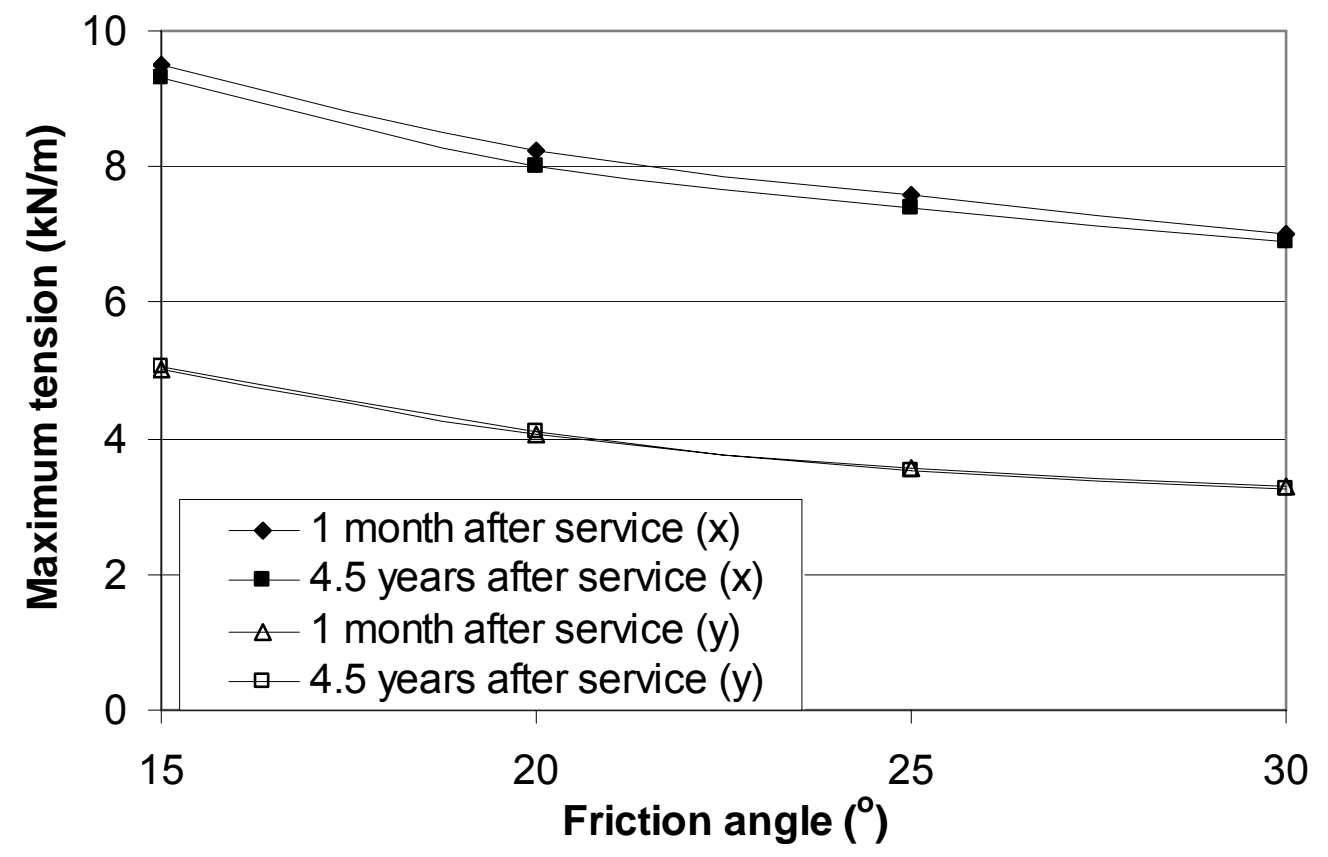

Fig. 5-54. Maximum Tension versus Friction Angle (3D)

\section{Influence of Soft Soil Permeability}

The influence of the soft soil permeability on the maximum tension in the geosynthetic reinforcement is shown in Fig. 5-55. The lower soil permeability yielded higher maximum tension because the lower soil permeability produced higher maximum differential settlement at the base. 


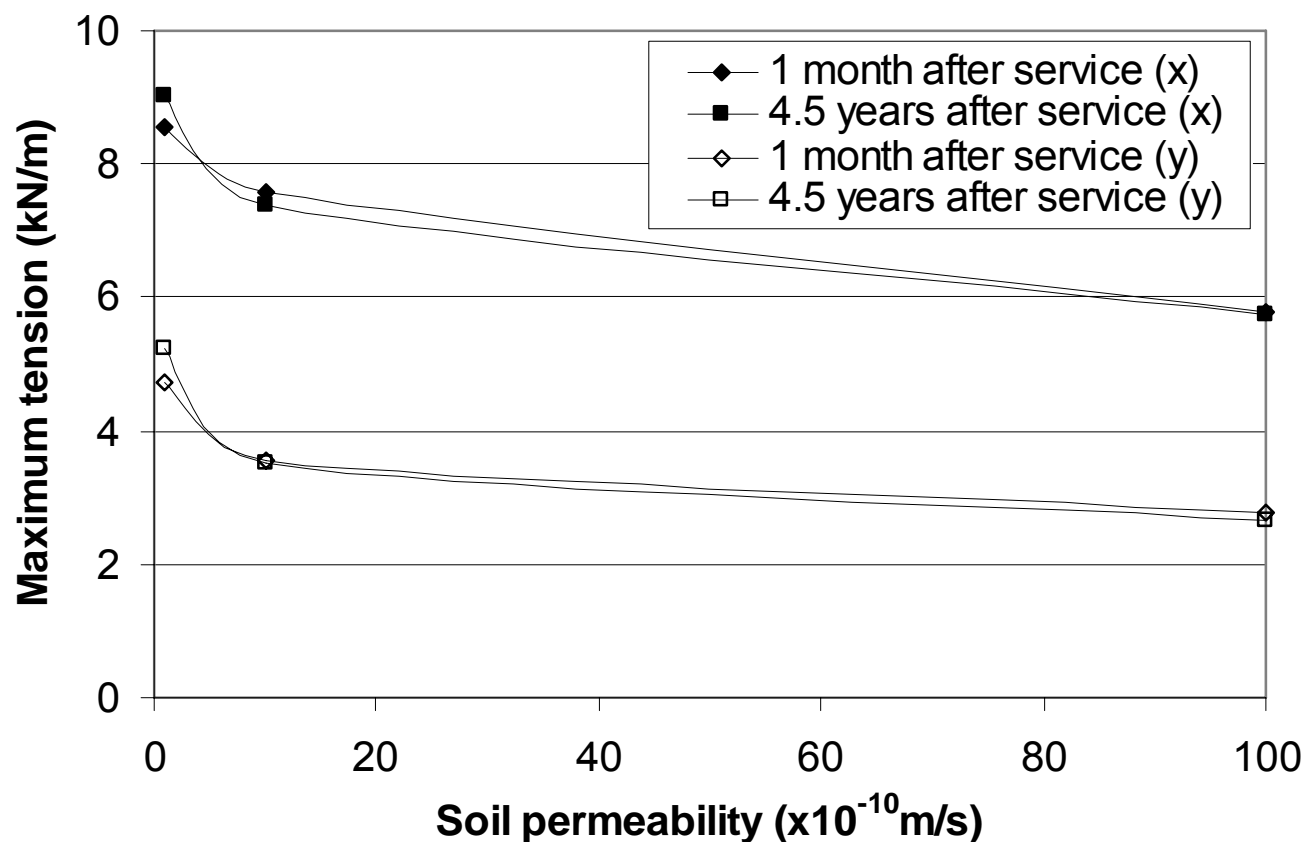

Fig. 5-55. Maximum Tension versus Soil Permeability (3D)

\section{Influence of Column Elastic Modulus}

The influence of the column modulus on the maximum tension is presented in Fig. 556. Apparently, the maximum tension in the $\mathrm{x}$ direction was higher than that in the $\mathrm{y}$ direction. The increase of the column modulus reduced the tension in the geosynthetic because the increase of the column modulus reduced the maximum differential settlement. However, the effect of the column modulus on the maximum tension was smaller in the $\mathrm{y}$ direction than that in the $\mathrm{x}$ direction. The consolidation of the foundation had an insignificant effect on the maximum tension in the geosynthetic. 


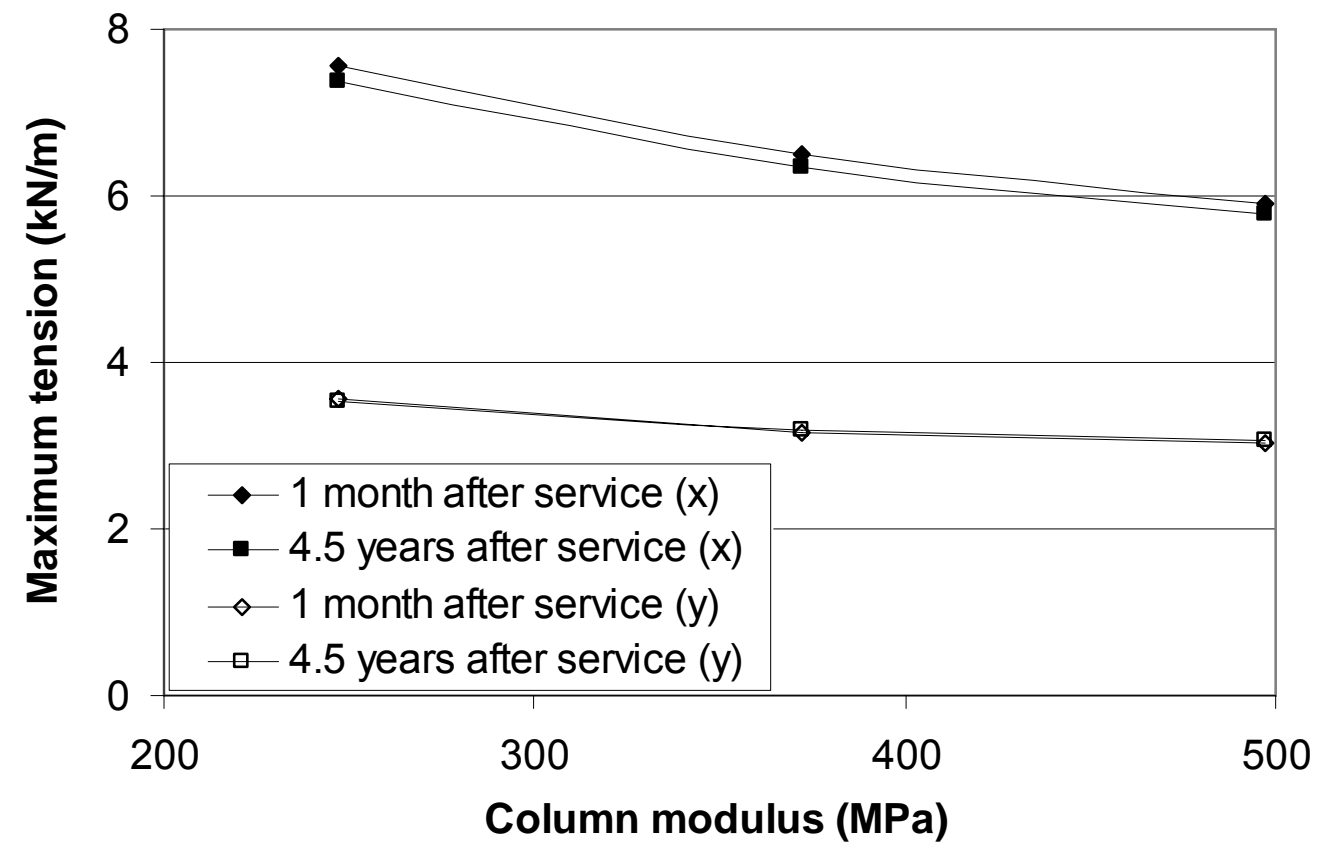

Fig. 5-56. Maximum Tension versus Column Modulus (3D)

\section{Influence of Column Spacing}

The influence of the column spacing on the maximum tension in the geosynthetic is presented in Fig. 5-57, which shows that the maximum tension in the y direction was lower than that in the $\mathrm{x}$ direction and larger spacing led to higher maximum tension in both $\mathrm{x}$ and $\mathrm{y}$ directions. The higher maximum tension at larger column spacing resulted from the larger maximum differential settlement. Figure 5-57 shows that the time effect on the maximum tension was minimal. 


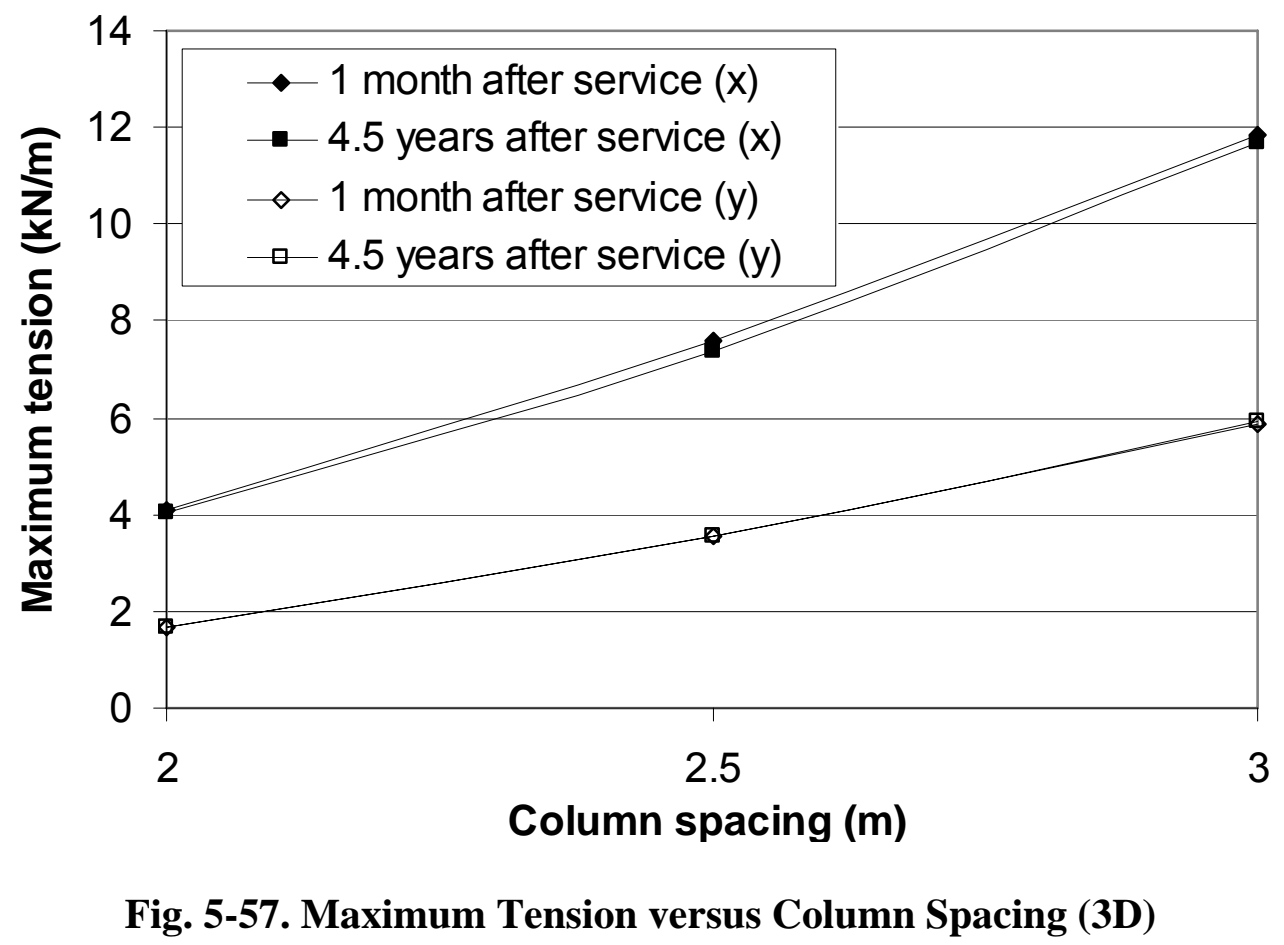

\section{Influence of Geosynthetic Tensile Stiffness}

The influence of the geosynthetic tensile stiffness on the maximum tension in both $\mathrm{x}$ and y directions is presented in Fig. 5-58. Since the geosynthetic was modeled as an isotropic material in this study, the tensile stiffness in both direction was equal. An increase of the tensile stiffness led to an increase in the maximum tension in both $\mathrm{x}$ and $\mathrm{y}$ directions, which is consistent with the phenomenon identified in the $2 \mathrm{D}$ parametric study. However, the increase of the maximum tension in the $\mathrm{x}$ direction was greater than that in the y direction. In addition, the time effect on the maximum tension was not significant. 


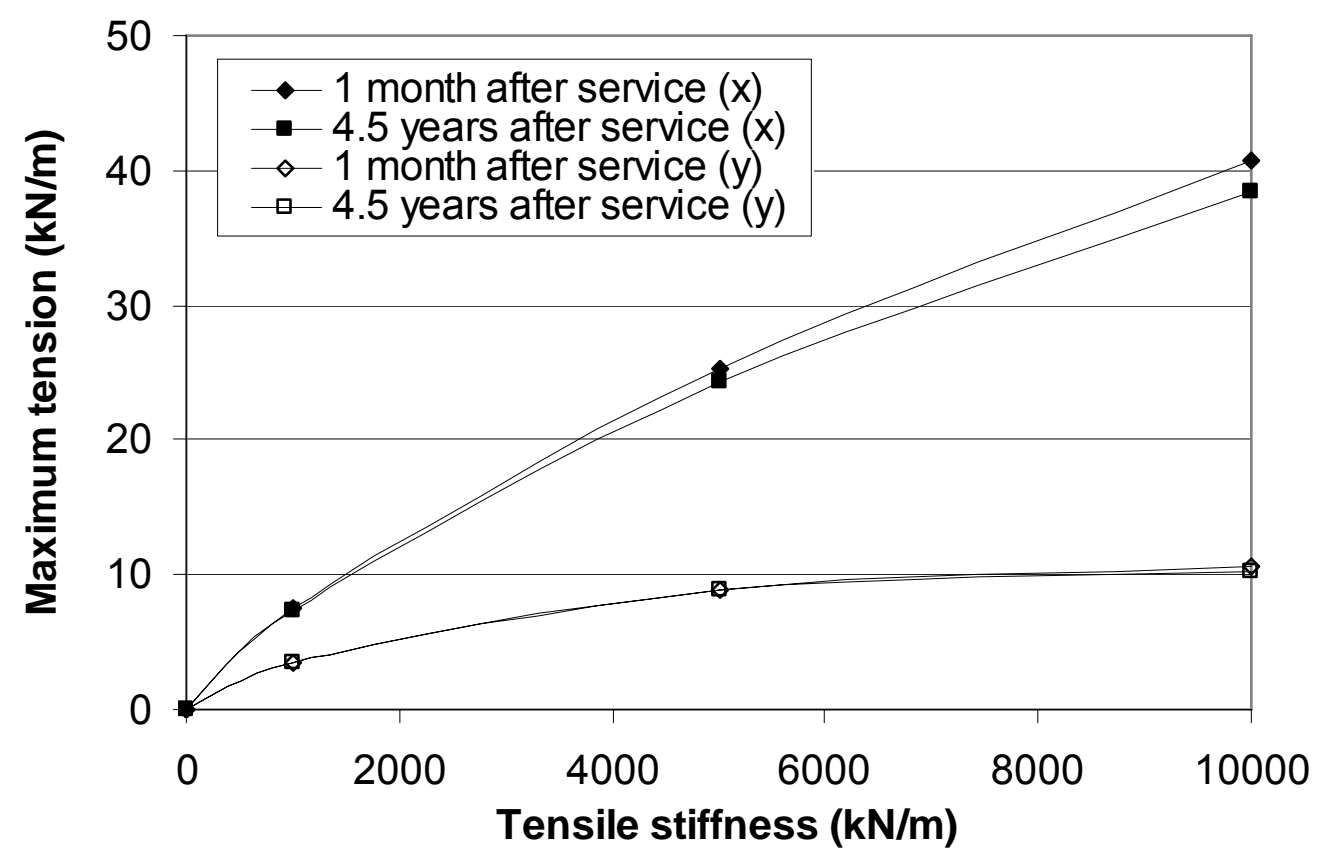

Fig. 5-58. Maximum Tension versus Tensile Stiffness (3D)

\section{Influence of Construction Rate}

The influence of the average construction rate on thee maximum tension is presented in Fig. 5-59, which shows the increase of the maximum tension in both $\mathrm{x}$ and $\mathrm{y}$ directions with an increase of the average construction rate. In other words, the lower construction rate yielded the lower maximum tension. 


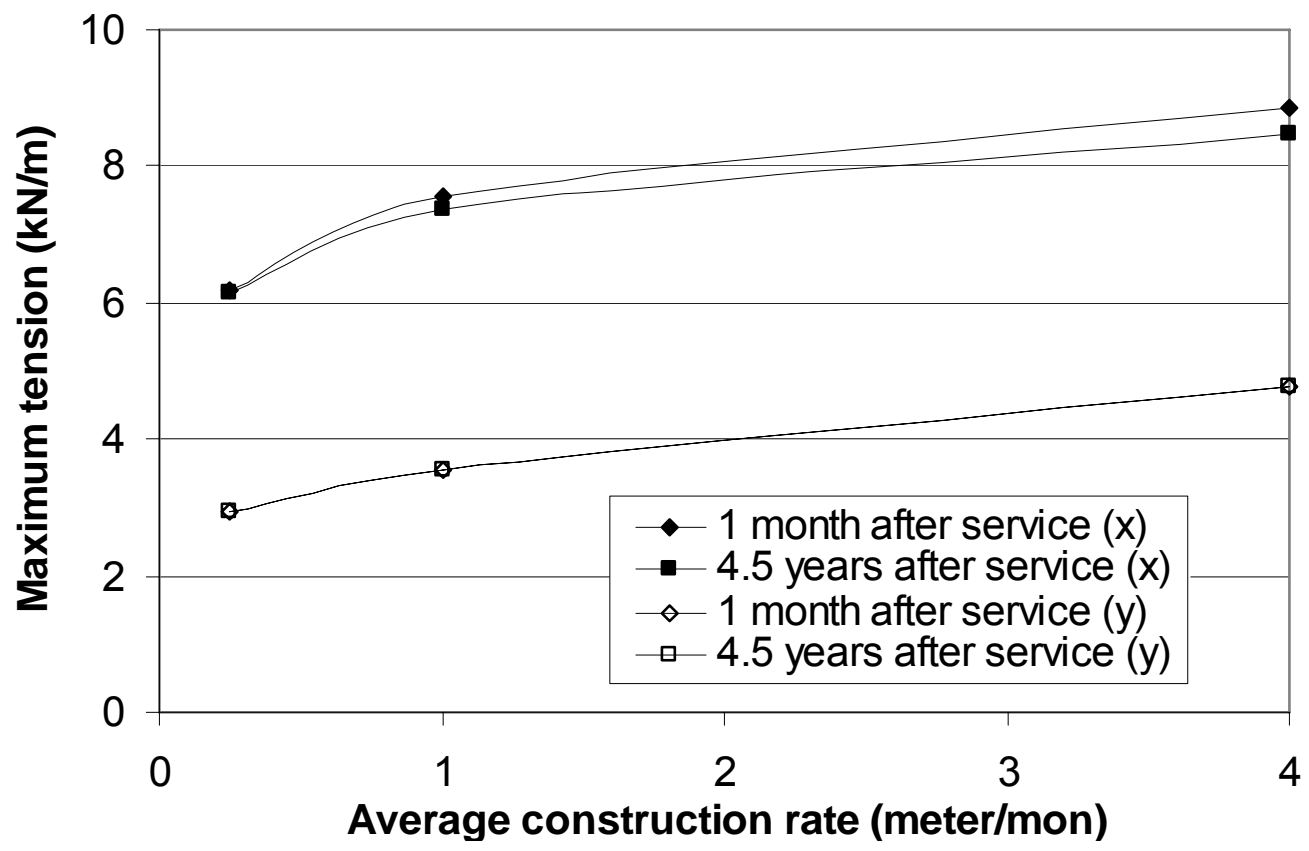

Fig. 5-59. Maximum Tension versus Average Construction Rate (3D)

\subsubsection{Vertical Stress and Stress Concentration Ratio}

Similar to the $2 \mathrm{D}$ study, the stress concentration ratio, $\mathrm{n}$, was used as an index to evaluate the efficiency of load transfer from the soft soil to the columns. In the $3 \mathrm{D}$ analysis, the average additional vertical effective stresses on the column and the soft soil within the influence area were used to calculate the stress concentration ratio. 


\section{Influence of Soft Soil Elastic Modulus}

The influence of the soil modulus on the additional vertical effective stress profiles along Sections I-I and II-II are presented in Fig. 5-60 and 5-61. The maximum additional vertical effective stress in Section I-I is much higher than that in Section IIII, since the DM columns are located at Section I-I. The increase of the soft soil modulus reduced the additional vertical effective stress on the columns, which is shown in Fig. 5-60 (a), but increased the additional vertical effective stress in the soft soil, which is more clearly shown in Fig 5-60 (b).

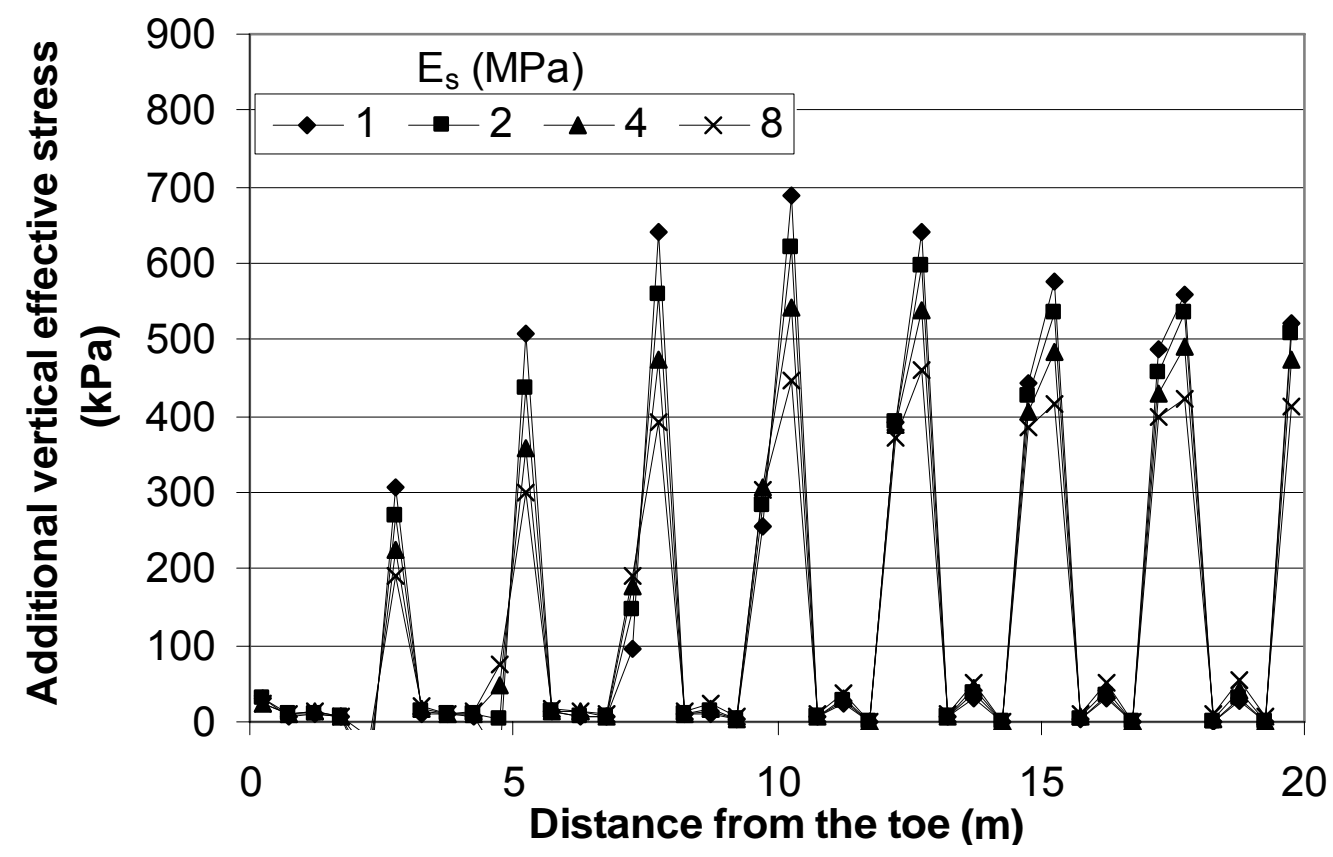

(a) Through Section I-I

Fig. 5-60. Additional Vertical Effective Stress Profiles for Various Soil Moduli at 1 Month after Service (3D) 


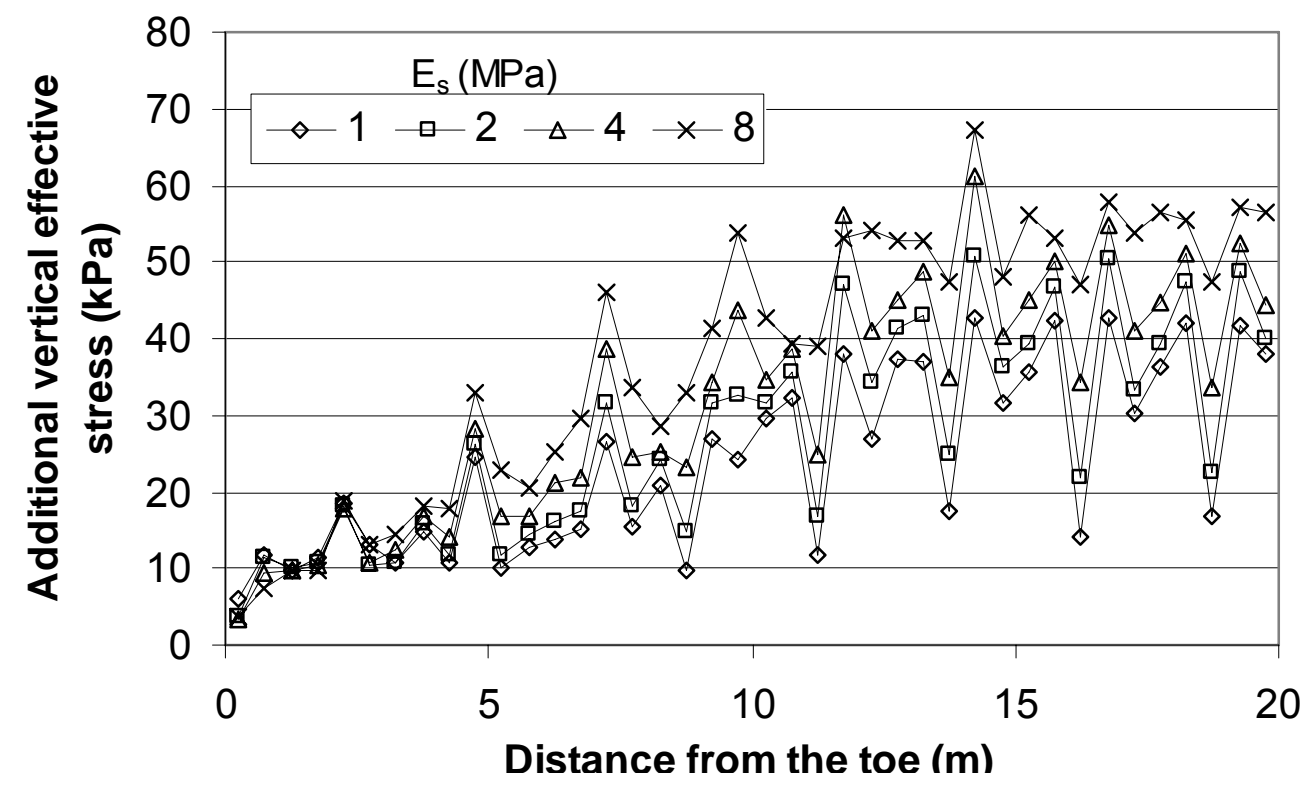

(b) Through Section II-II

Fig. 5-60. Additional Vertical Effective Stress Profiles for Various Soil Moduli at 1 Month after Service (3D) (continued)

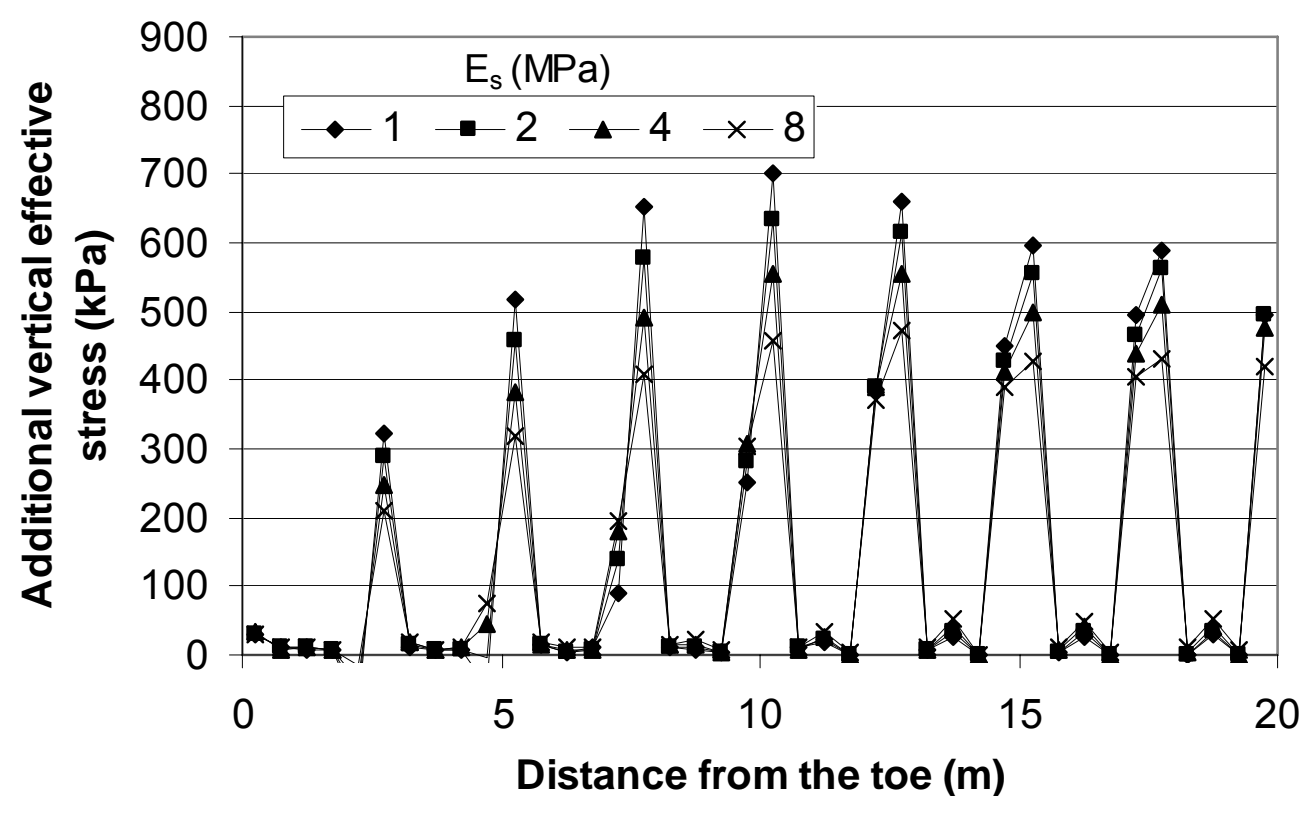

(a) Through Section I-I

Fig. 5-61. Additional Vertical Effective Stress Profiles for Various Soil Moduli at 4.5 Years after Service (3D) 


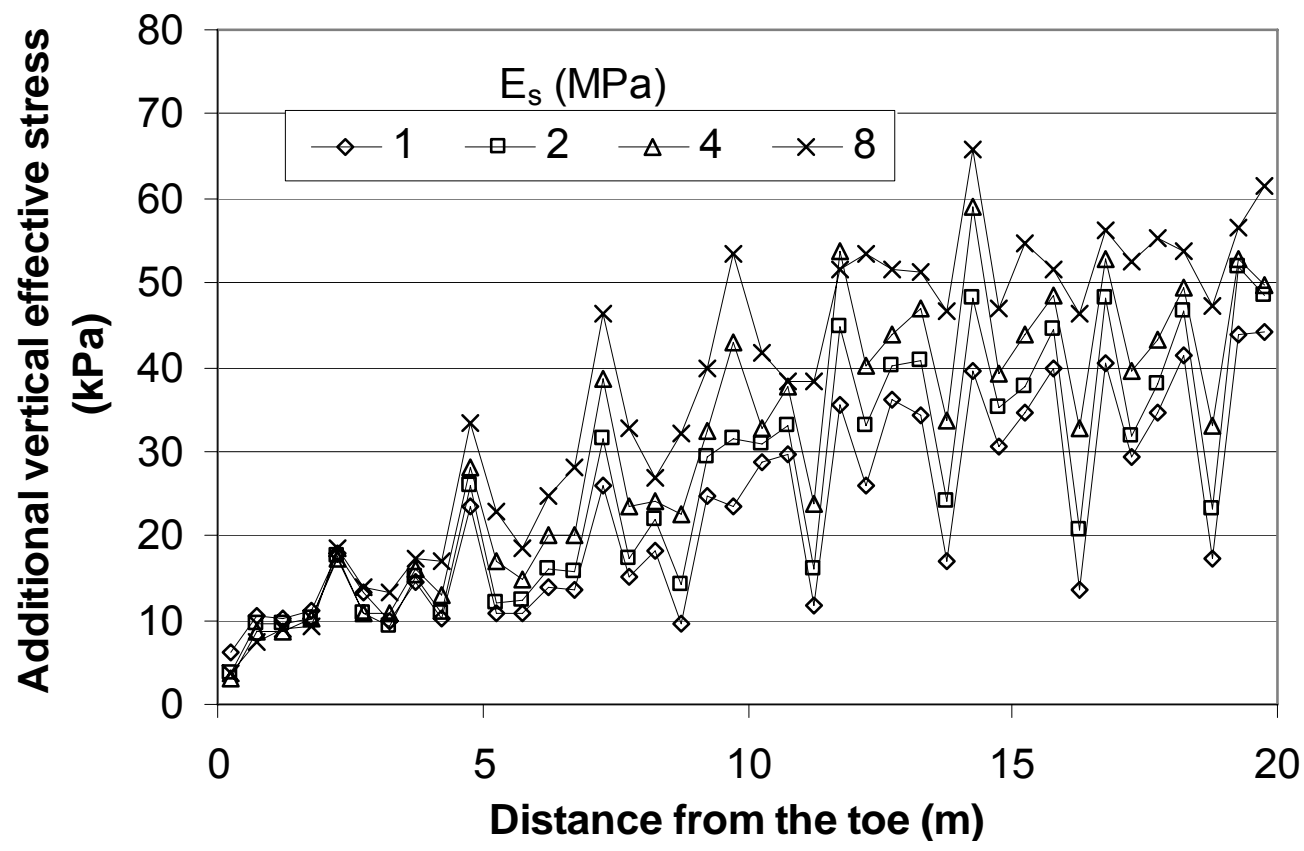

(b) Through Section II-II

Fig. 5-61. Additional Vertical Effective Stress Profiles for Various Soil Moduli at 4.5 Years after Service (3D) (continued)

For a clearer demonstration, the stress concentration ratio is plotted against the distance from the toe of the embankment in Fig. 5-62. The higher soft soil modulus led to a lower stress concentration ratio. The consolidation of the foundation slightly increased the stress concentration ratio. 


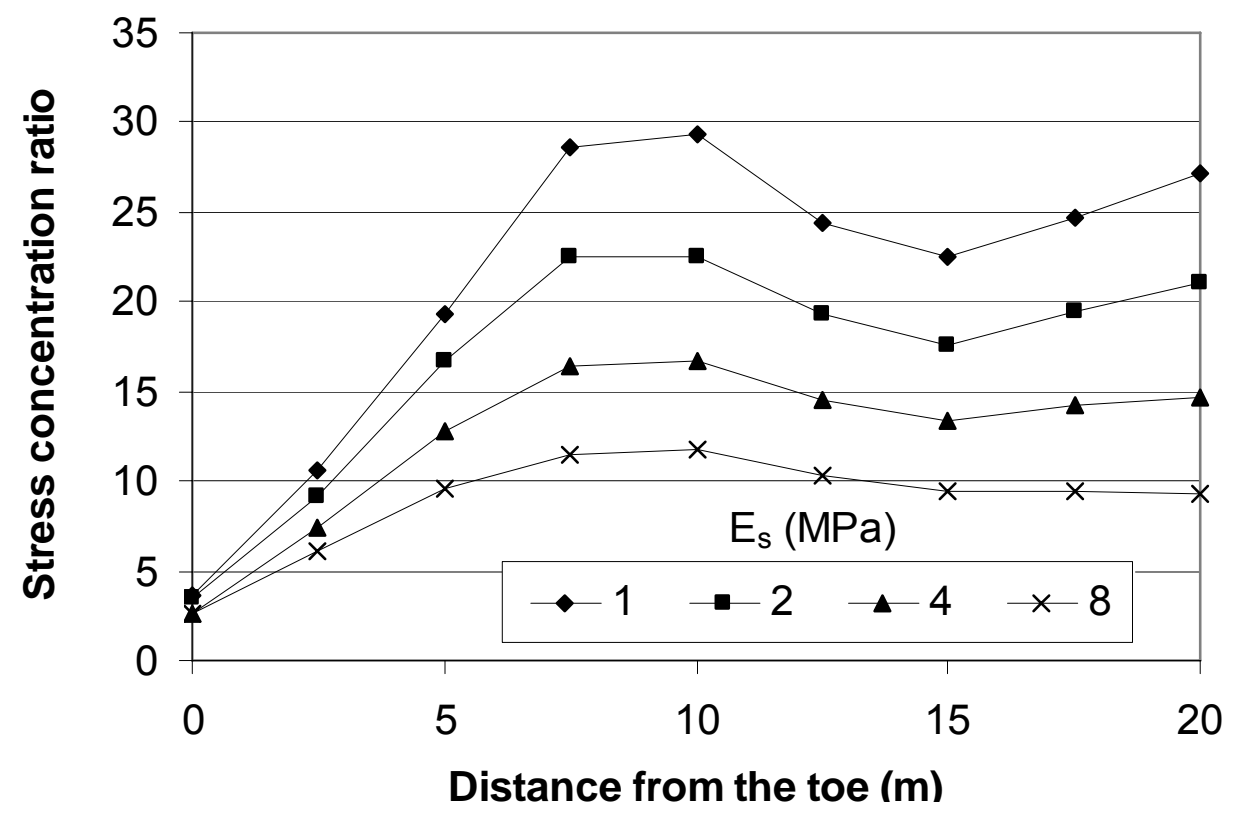

(a) 1 month after service

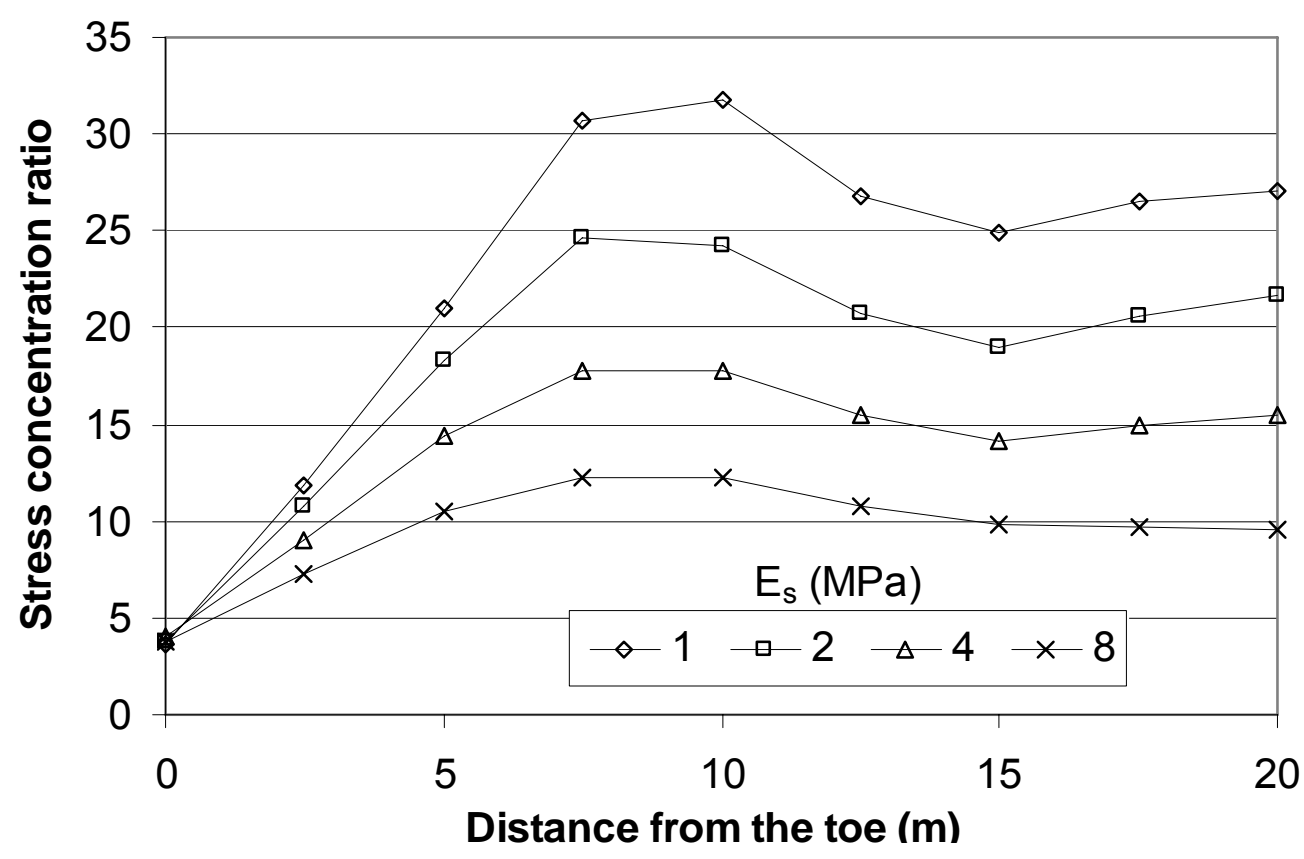

(b) 4.5 years after service

Fig. 5-62. Stress Concentration Ratio Profiles for Various Soil Moduli (3D) 


\section{Influence of Soft Soil Friction Angle}

The influence of the soil friction angle on the additional vertical effective stress is presented in Fig. 5-63. An increase of the soil friction angle reduced the additional vertical effective stress on the columns but increased the additional vertical effective stress in the soil. This finding is in agreement with that in the 2D parametric study in Chapter Four. The comparison of the profiles at one month after service with those at 4.5 years after service shows negligible change in the additional vertical effective stress.

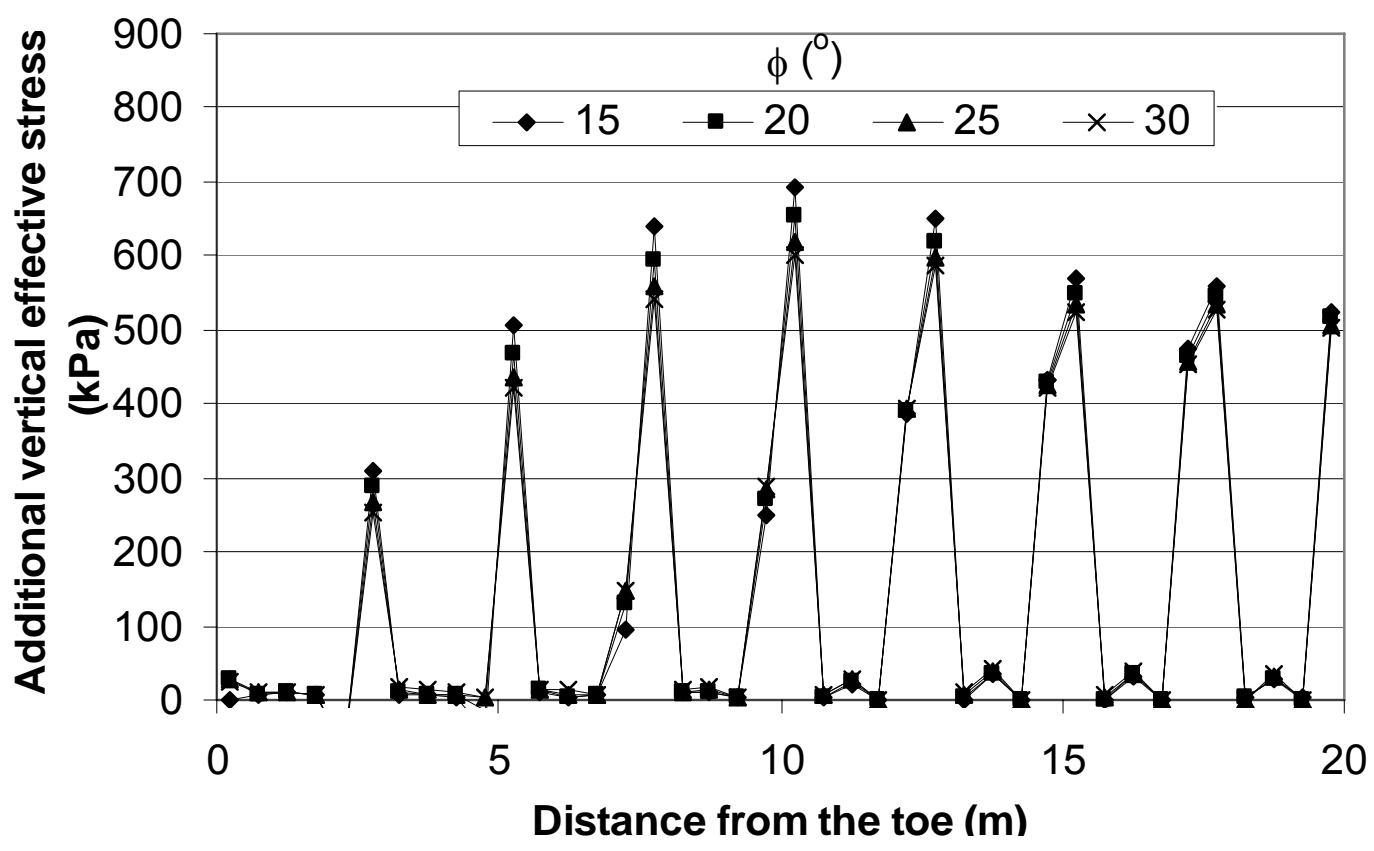

(a) Through Section I-I

Fig. 5-63. Additional Vertical Effective Stress Profiles of Various Friction Angles at 1 Month after Service (3D) 


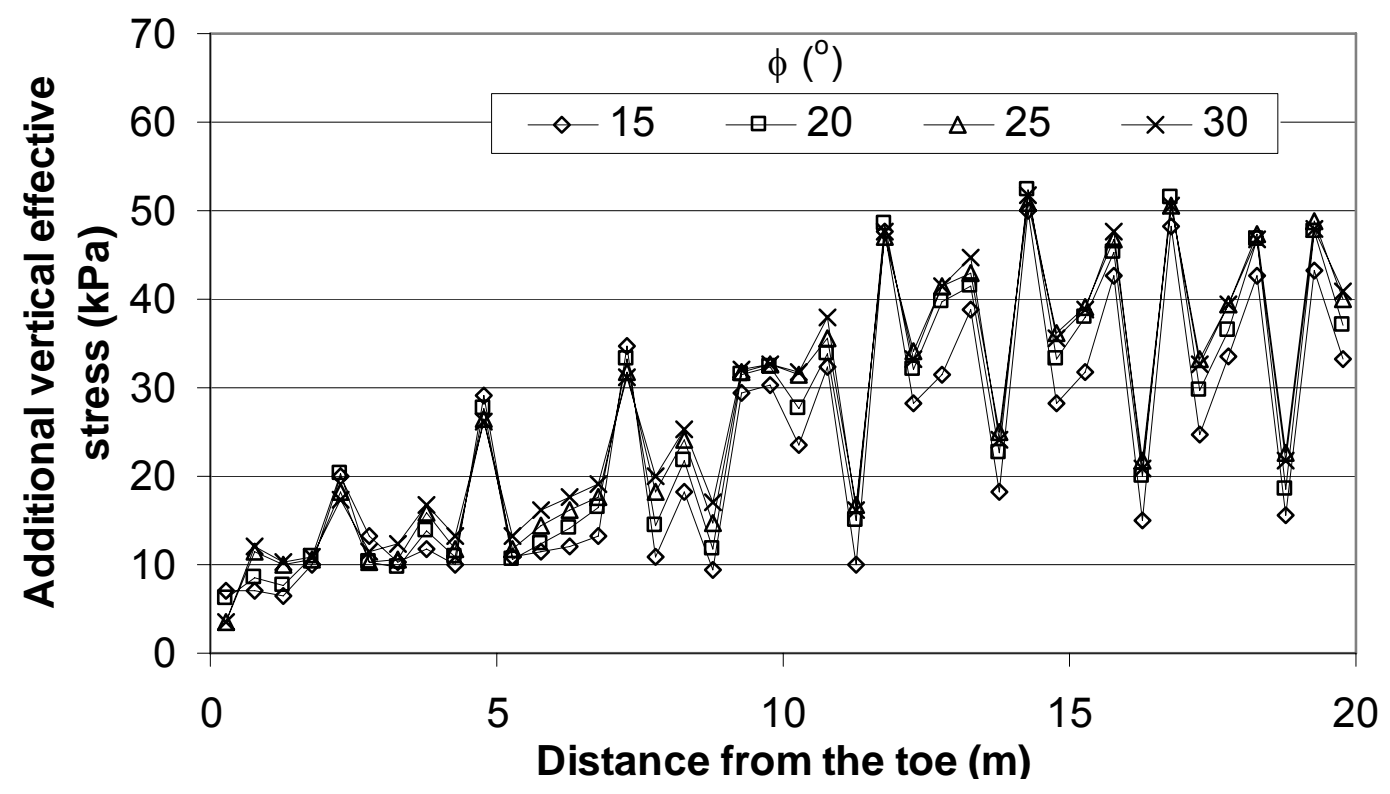

(b) Through Section II-II

Fig. 5-63. Additional Vertical Effective Stress Profiles of Various Friction Angles at 1 Month after Service (3D) (continued)

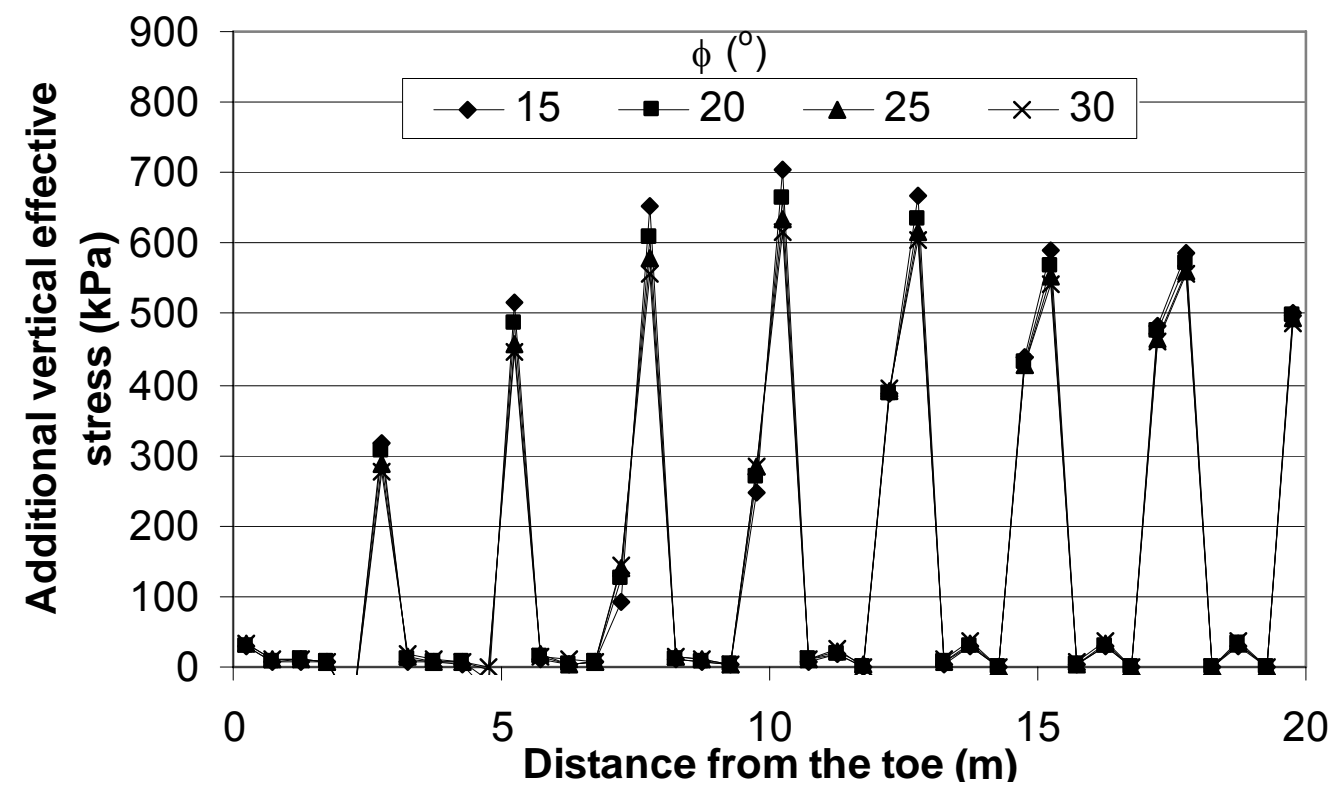

(a) Through Section I-I

Fig. 5-64. Additional Vertical Effective Stress Profiles for Various Friction Angles at 4.5 Years after Service (3D) 


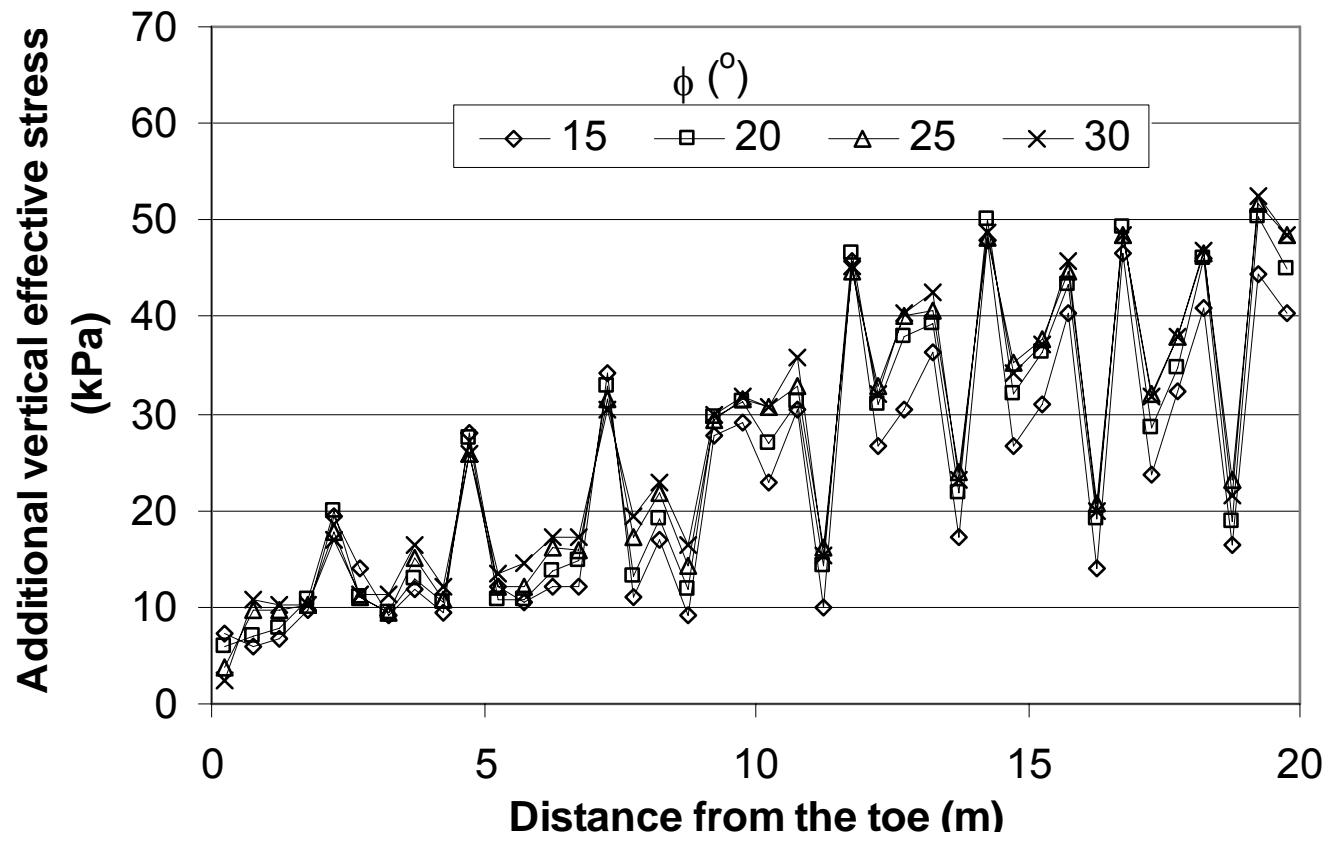

(b) Through Section II-II

Fig. 5-64. Additional Vertical Effective Stress Profiles for Various Friction Angles at 4.5 Years after Service (3D) (continued)

The influence of the soft soil friction angle on the stress concentration ratio is shown in Fig. 5-65. The higher stress concentration ratio was reached by a lower friction angle. This phenomenon is consistent with the change of the addition vertical effective stress with the soil friction angle. The comparison of Fig. 5-65 (a) and (b) shows a slight increase in the stress concentration ratio. 


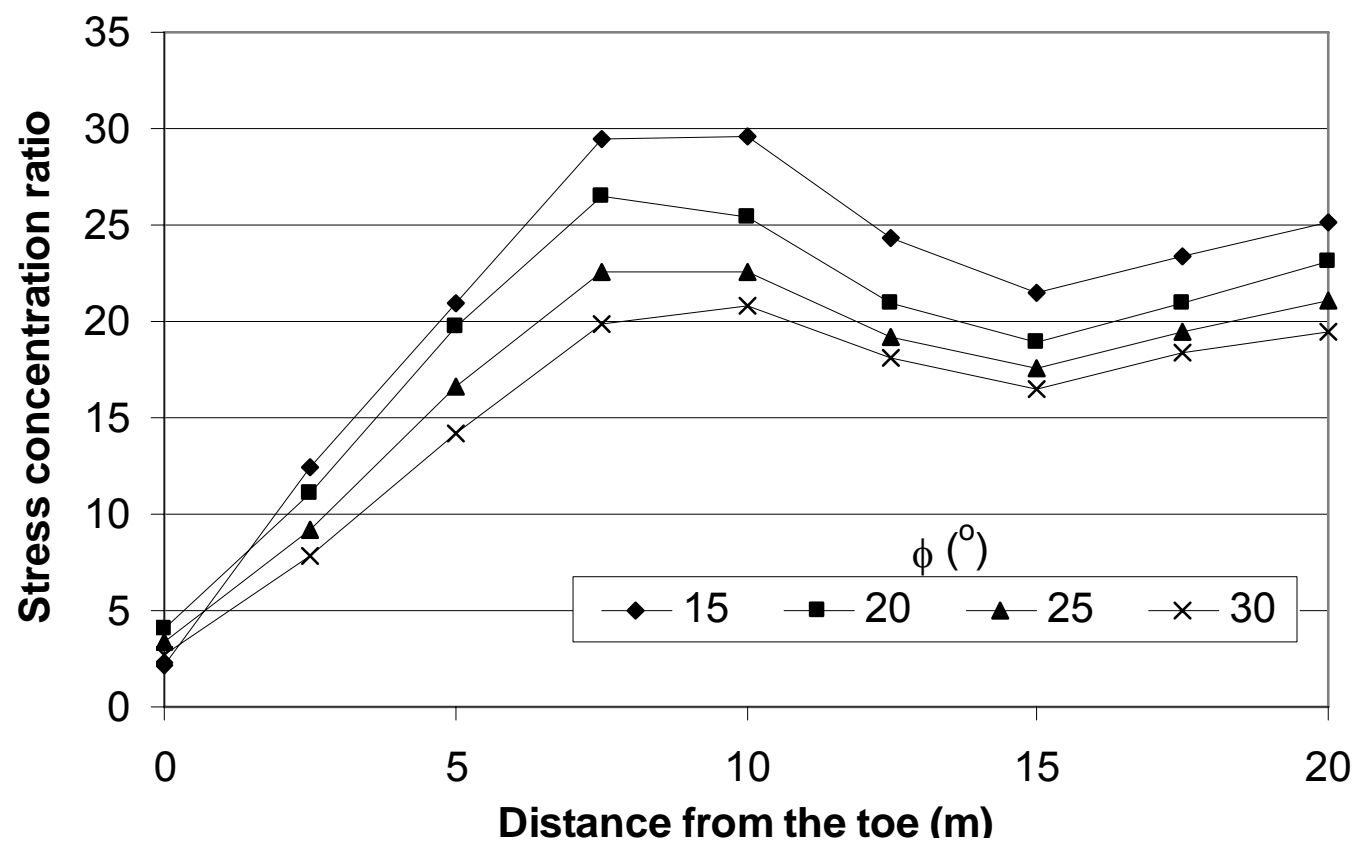

(a) 1 month after service

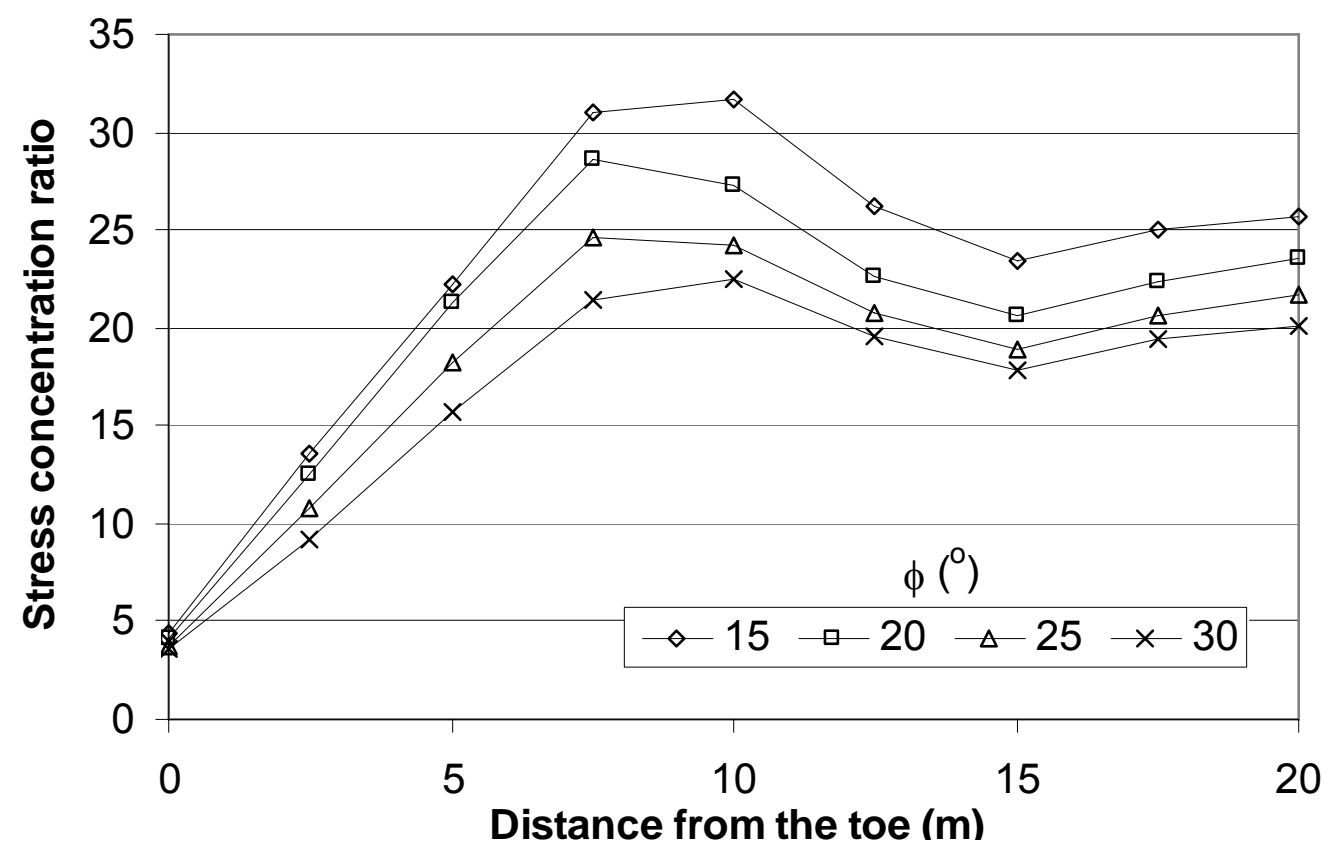

(b) 4.5 years after service

Fig. 5-65. Stress Concentration Ratio Profiles for Various Soil Friction Angles (3D) 


\section{Influence of Soft Soil Permeability}

The profiles of additional vertical effective stresses at different soil permeability are presented in Fig. 5-66. The lower soil permeability leads increased the additional vertical effective stress in the columns.

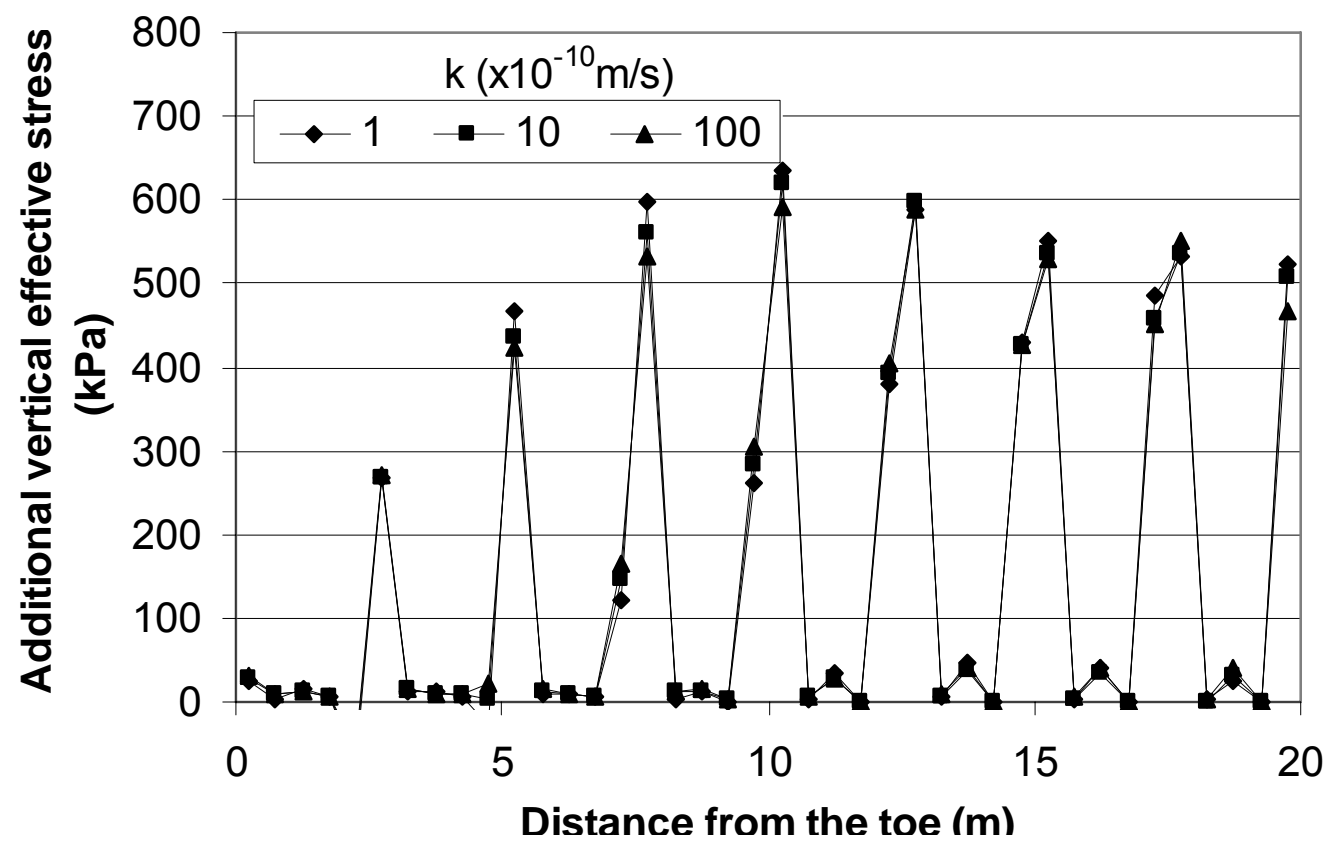

(a) Through Section I-I

Fig. 5-66. Additional Effective Stress Profiles for Various Soil Permeability at 1 Month after Service (3D) 


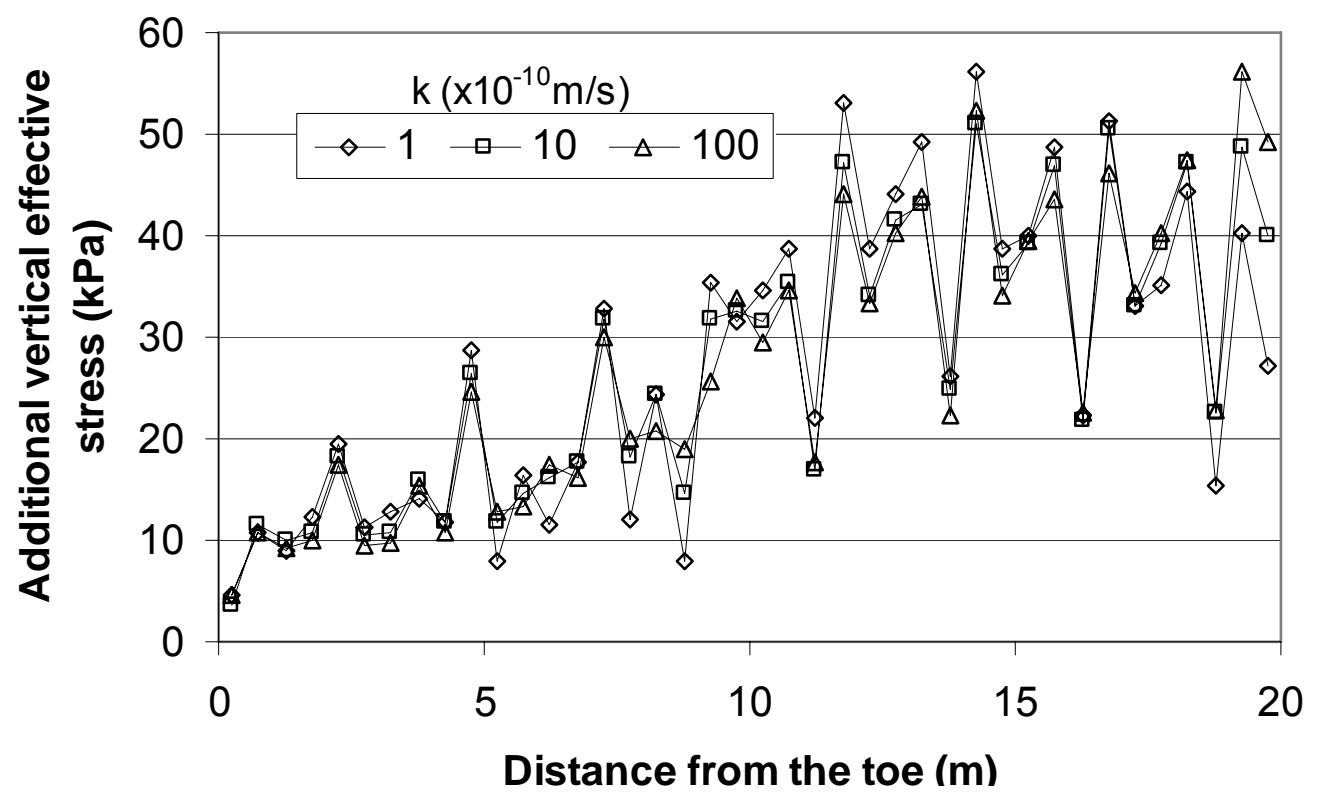

(b) Through Section II-II

Fig. 5-66. Additional Effective Stress Profiles for Various Soil Permeability at 1 Month after Service (3D) (continued)

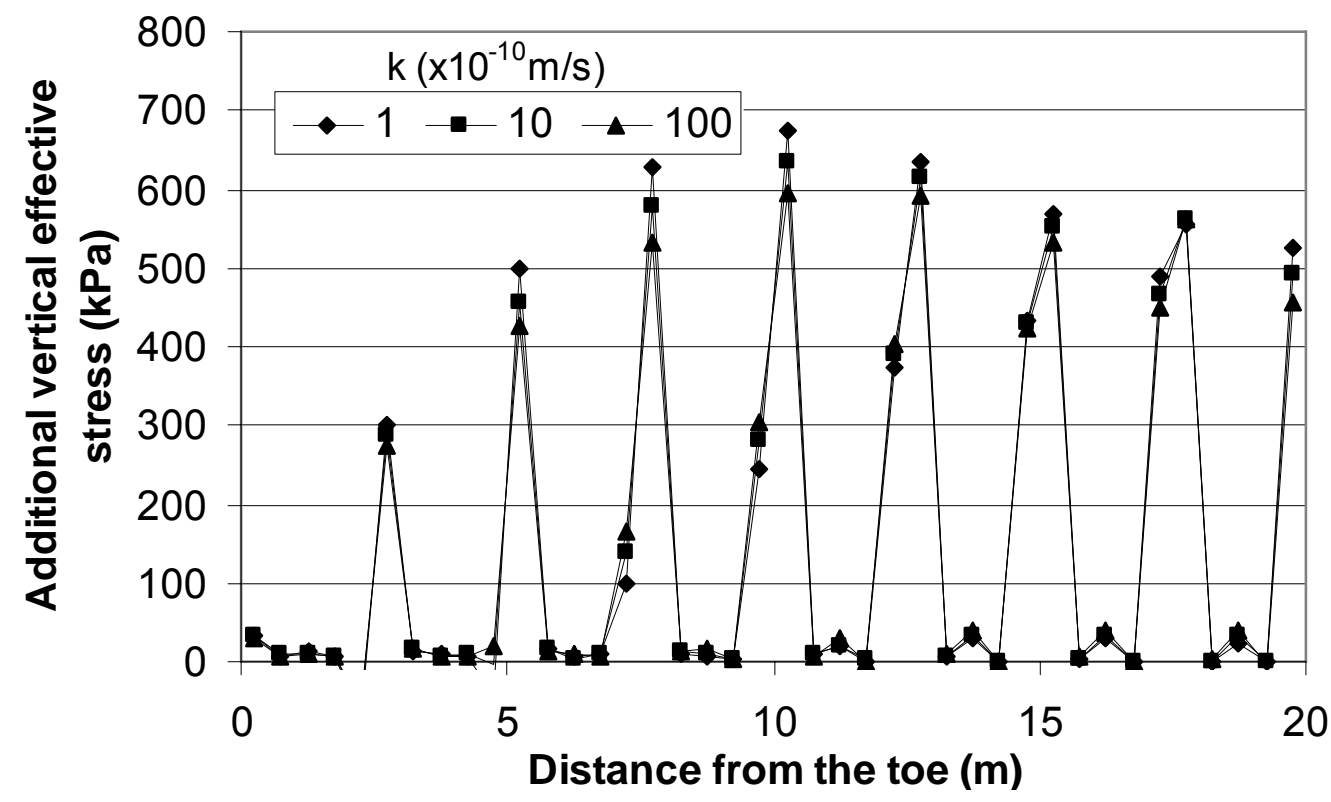

(a) Through Section I-I

Fig. 5-67. Additional Effective Stress Profiles for Various Soil Permeability at 4.5 Years after Service (3D) 


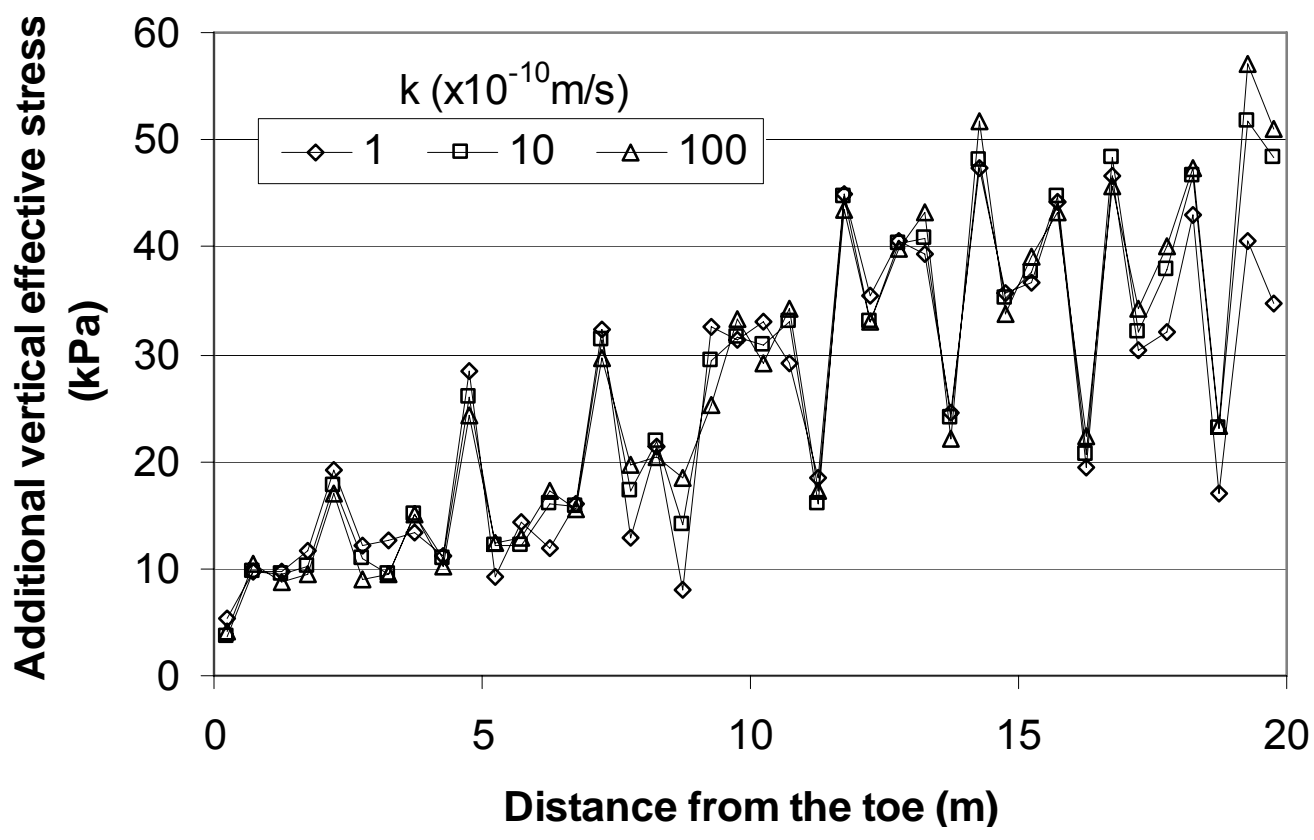

(b) Through Section II-II

Fig. 5-67. Additional Effective Stress Profiles for Various Soil Permeability at 4.5 Years after Service (3D) (continued)

The stress concentration ratio profiles at different time are presented in Fig. 5-68. At the low permeability $\left(\mathrm{k}=10^{-10} \mathrm{~m} / \mathrm{s}\right)$, the stress concentration ratio profile at one month after service was different from others. When the soil permeability was $10^{-9}$ to $10^{-}$ ${ }^{8} \mathrm{~m} / \mathrm{s}$, an increase of the soil permeability reduced the stress concentration ratio. As permeability equal to $10^{-10} \mathrm{~m} / \mathrm{s}$, high excess pore water pressure is induced and a large portion of embankment load is taken by pore water in soil. Hence, additional vertical effective stress in columns is low, which leads to a low stress concentration ratio at some locations. At 4.5 years after service, however, the trend became the same as others, because as consolidation proceeded, the load taken by pore water was 
transferred to columns. In addition, the stress concentration ratio at 4.5 years after service was higher than that at one month after service.

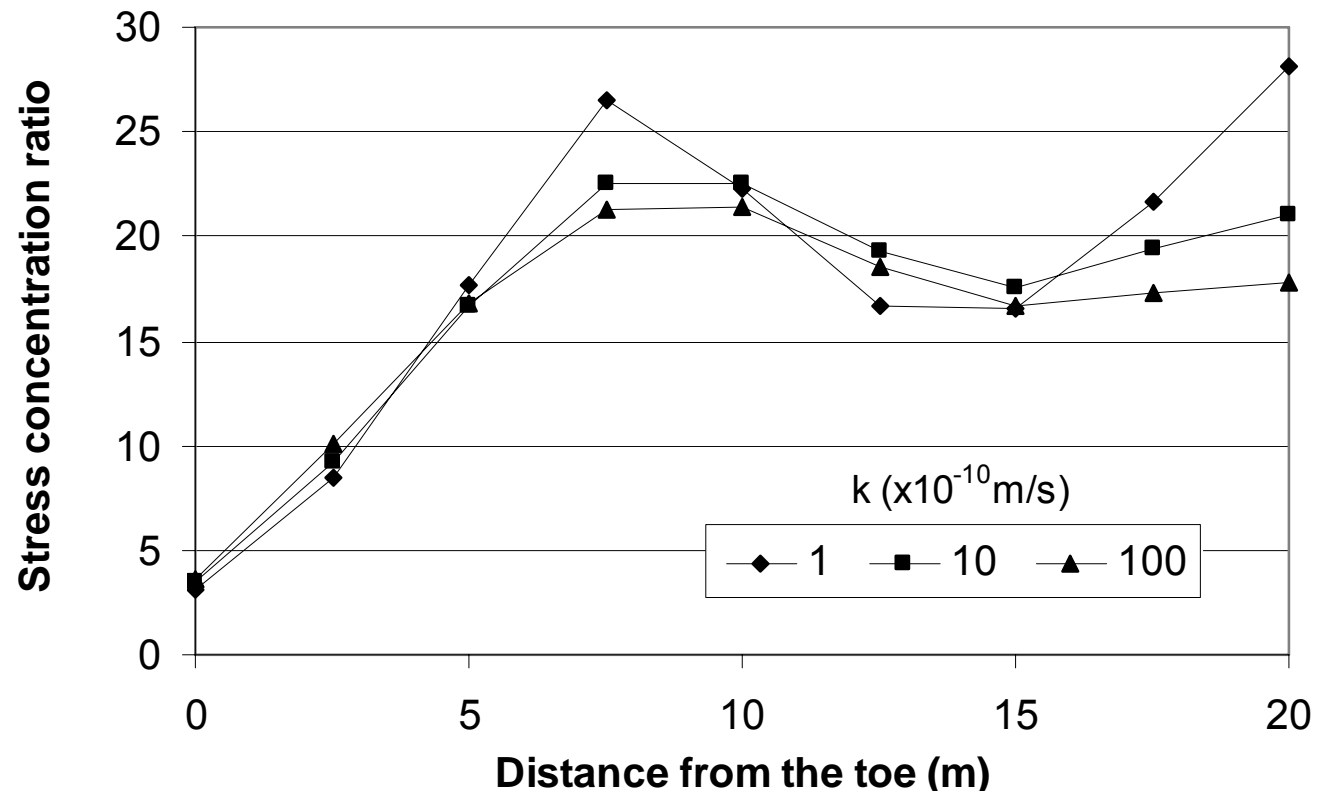

(a) At 1 month after service

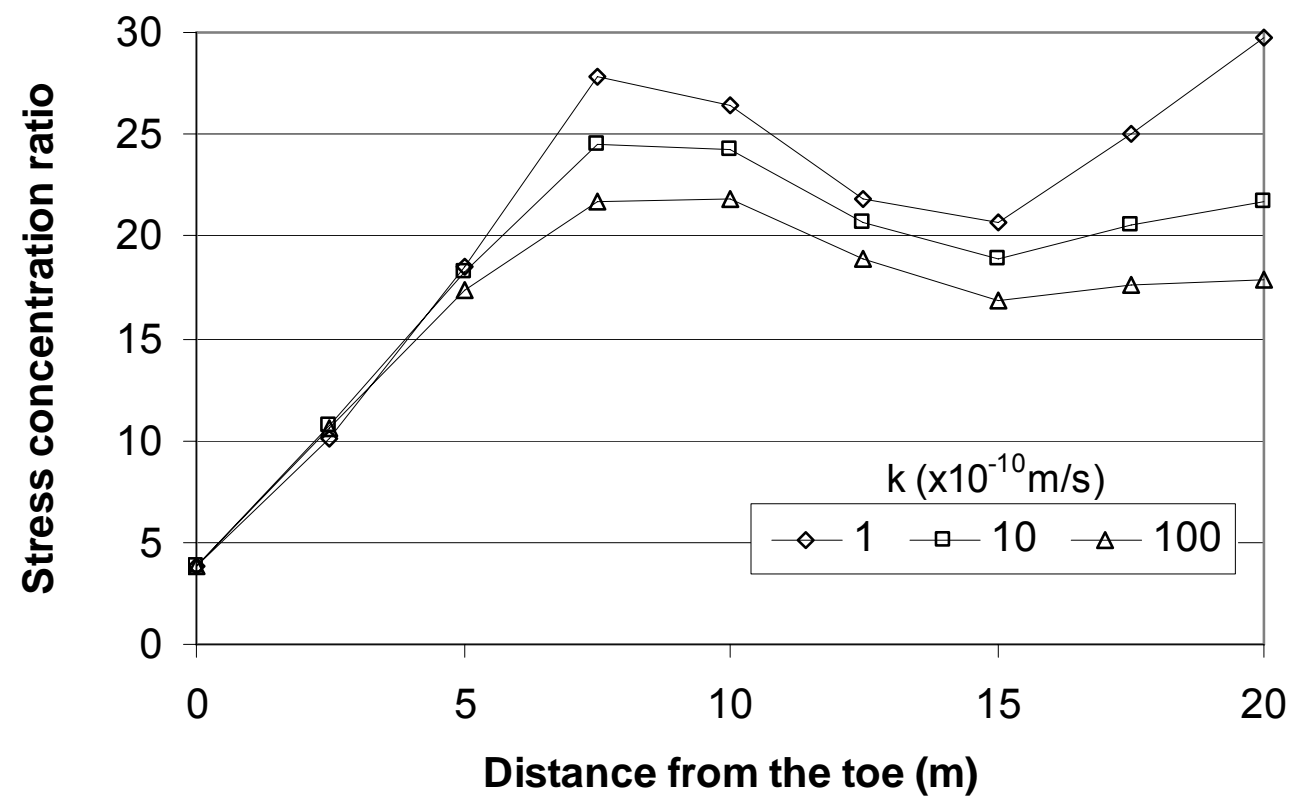

(b) At 4.5 years after service

Fig. 5-68. Stress Concentration Ratio Profiles for Various Soil Permeability (3D) 


\section{Influence of Column Elastic Modulus}

The influence of the column modulus on the additional vertical effective stress profiles is presented in Fig. 5-69 and 5-70, which show that, the higher column modulus produced higher additional vertical effective stresses on the columns and lower additional vertical effective stresses in the soft soil. However, since the column modulus was much higher than the soft soil modulus, the increase of the column modulus did not have any significant influence on the load transfer. Consequently, the additional vertical effective stress on the columns and in the soil did not change much.

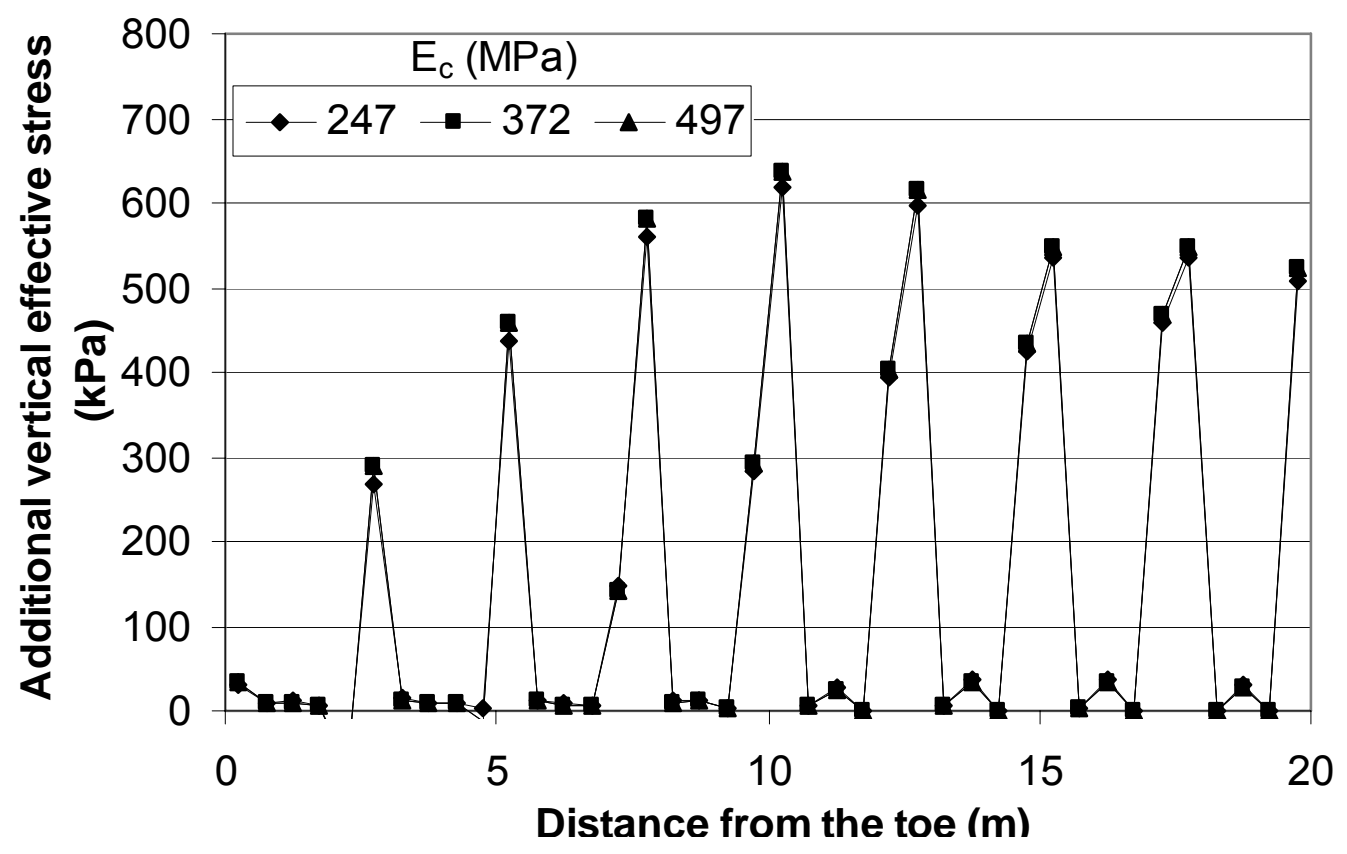

(a) Through Section I-I

Fig. 5-69. Additional Vertical Effective Stress Profiles for Various Column Moduli at 1 Month after Service (3D) 


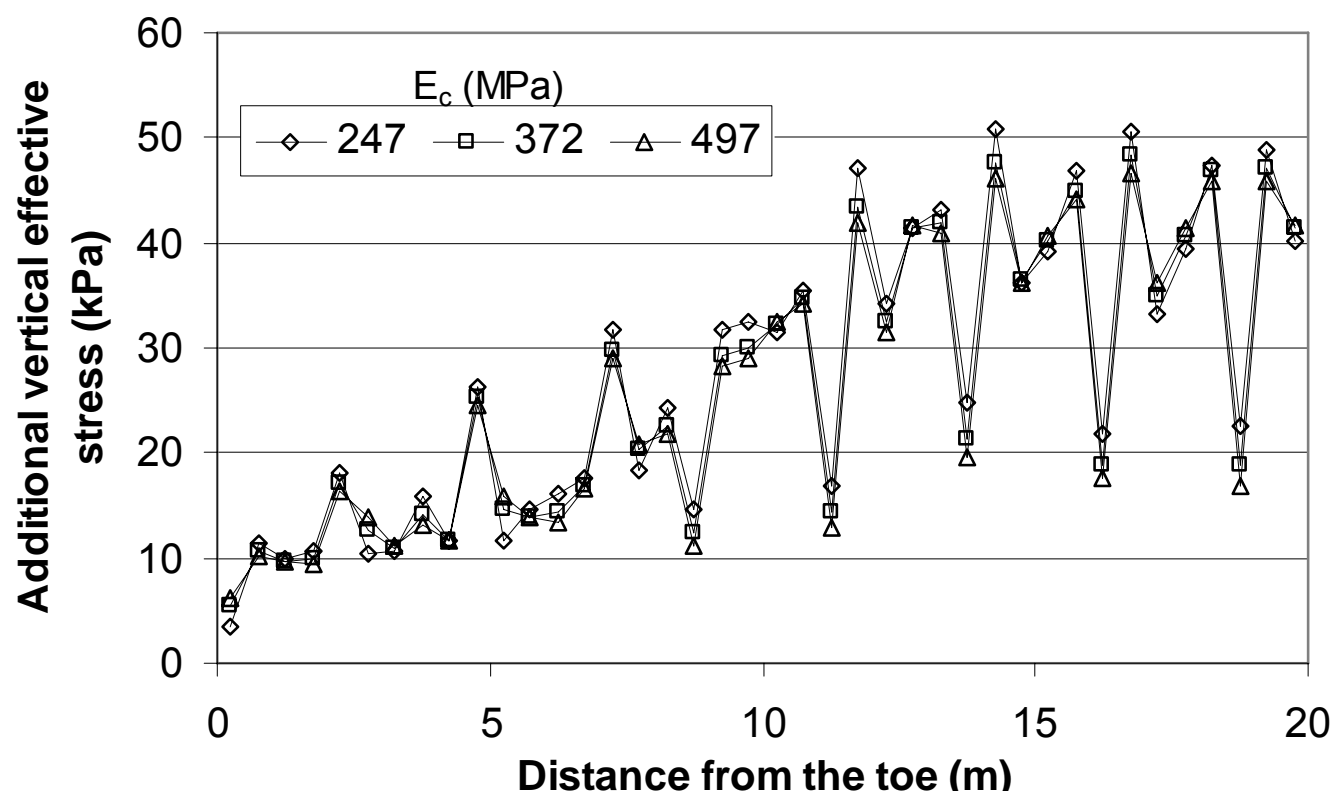

(b) Through Section II-II

Fig. 5-69. Additional Vertical Effective Stress Profiles for Various Column Moduli at 1 Month after Service (3D) (continued)

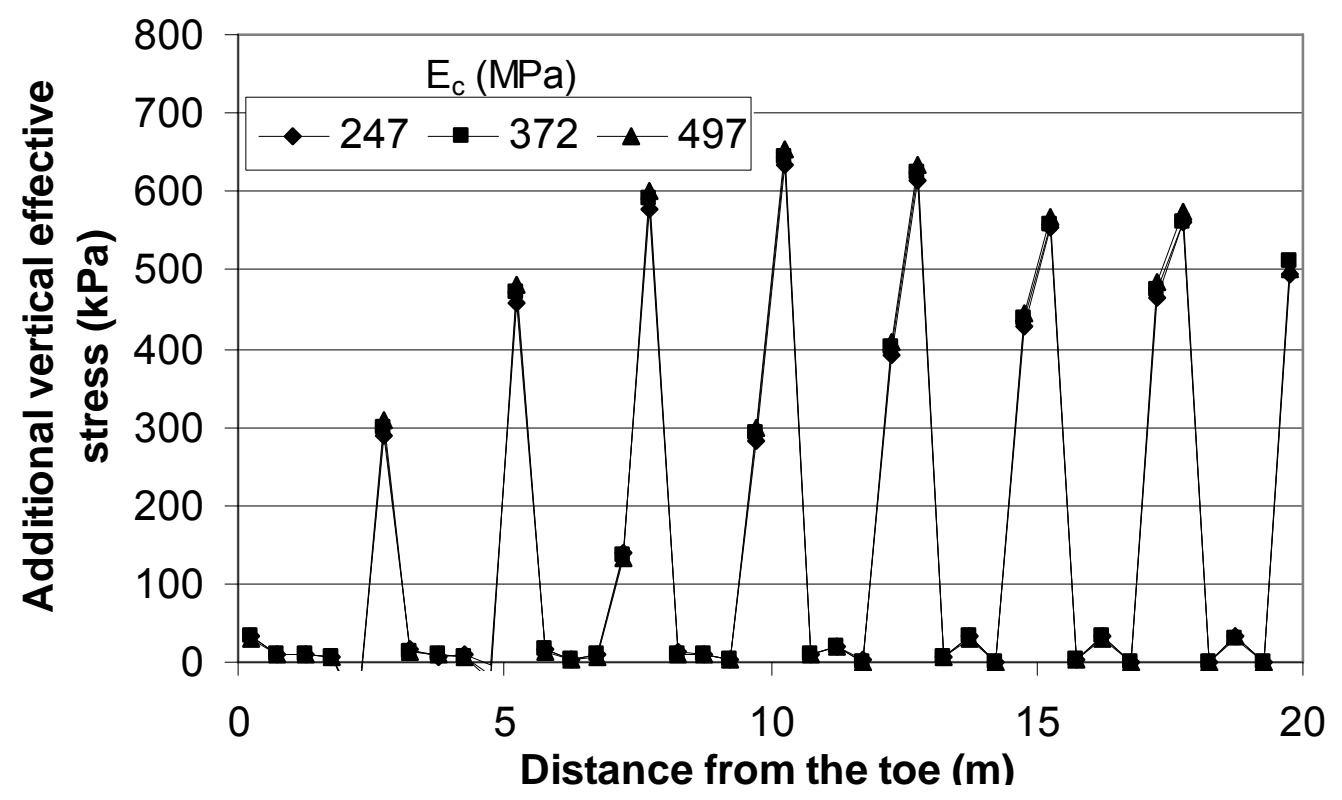

(a) Through Section I-I

Fig. 5-70. Additional Vertical Effective Stress Profiles for Various Column Moduli at 4.5 Years after Service (3D) 


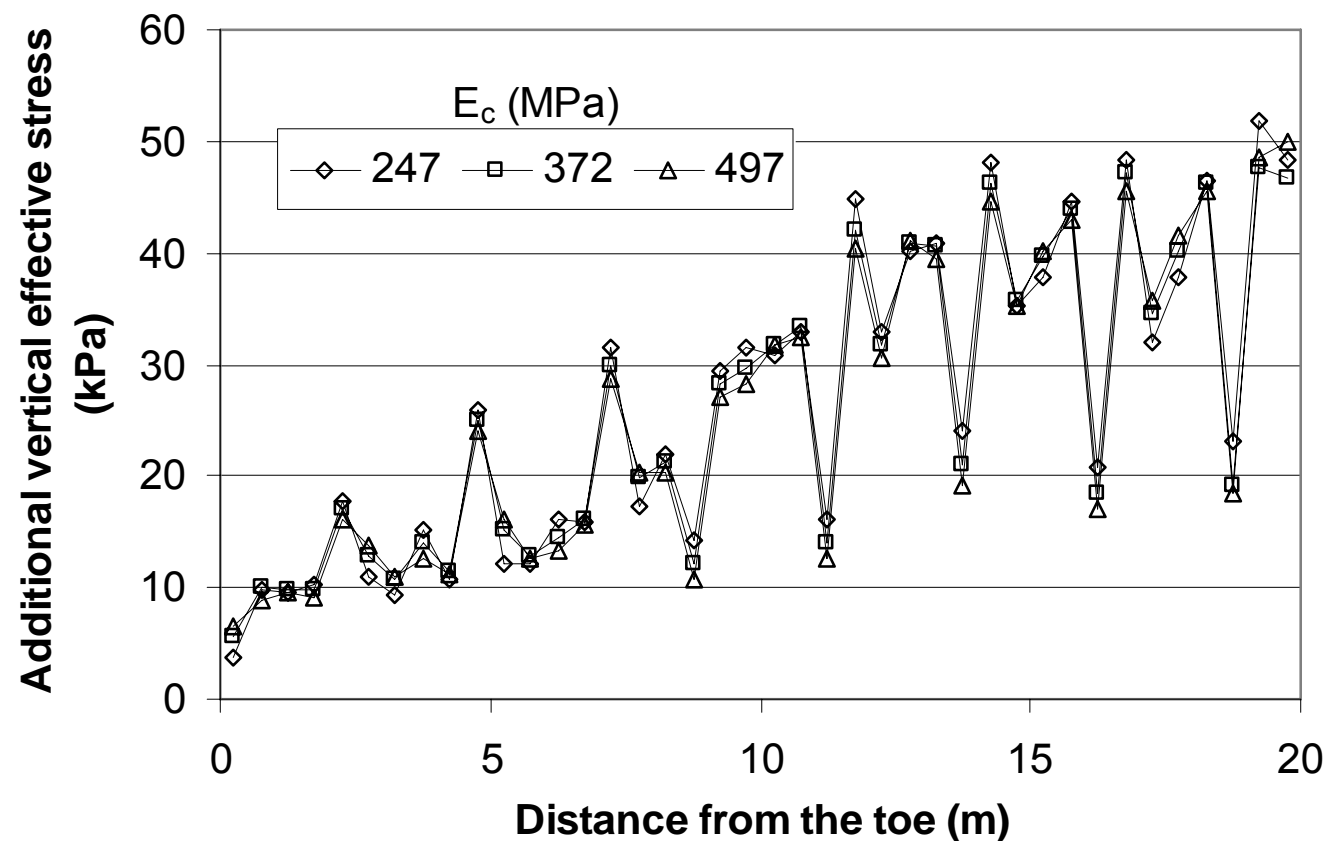

(b) Through Section II-II

\section{Fig. 5-70. Additional Vertical Effective Stress Profiles for Various Column Moduli at 4.5 Years after Service (3D) (continued)}

The influence of the column modulus on the stress concentration ratio profiles is presented in Fig. 5-71. The increase of the column modulus yielded a higher stress concentration ratio. The increase of the column modulus did not increase the stress concentration ratio significantly. This result is consistent with the influence of the column modulus on the additional vertical effective stress. In addition, the stress concentration ratio increased slightly from one month to 4.5 years after service. 


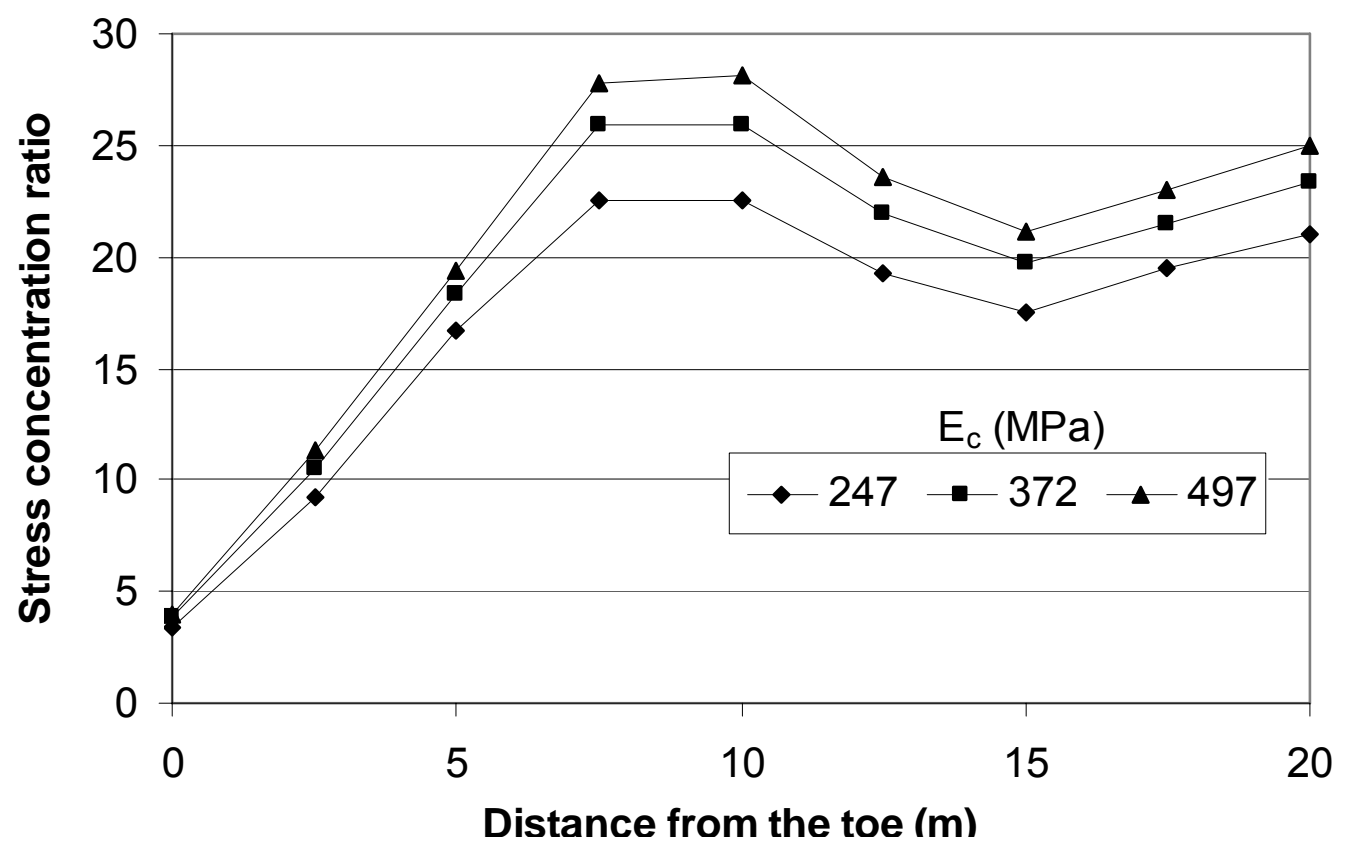

(a) 1 month after service

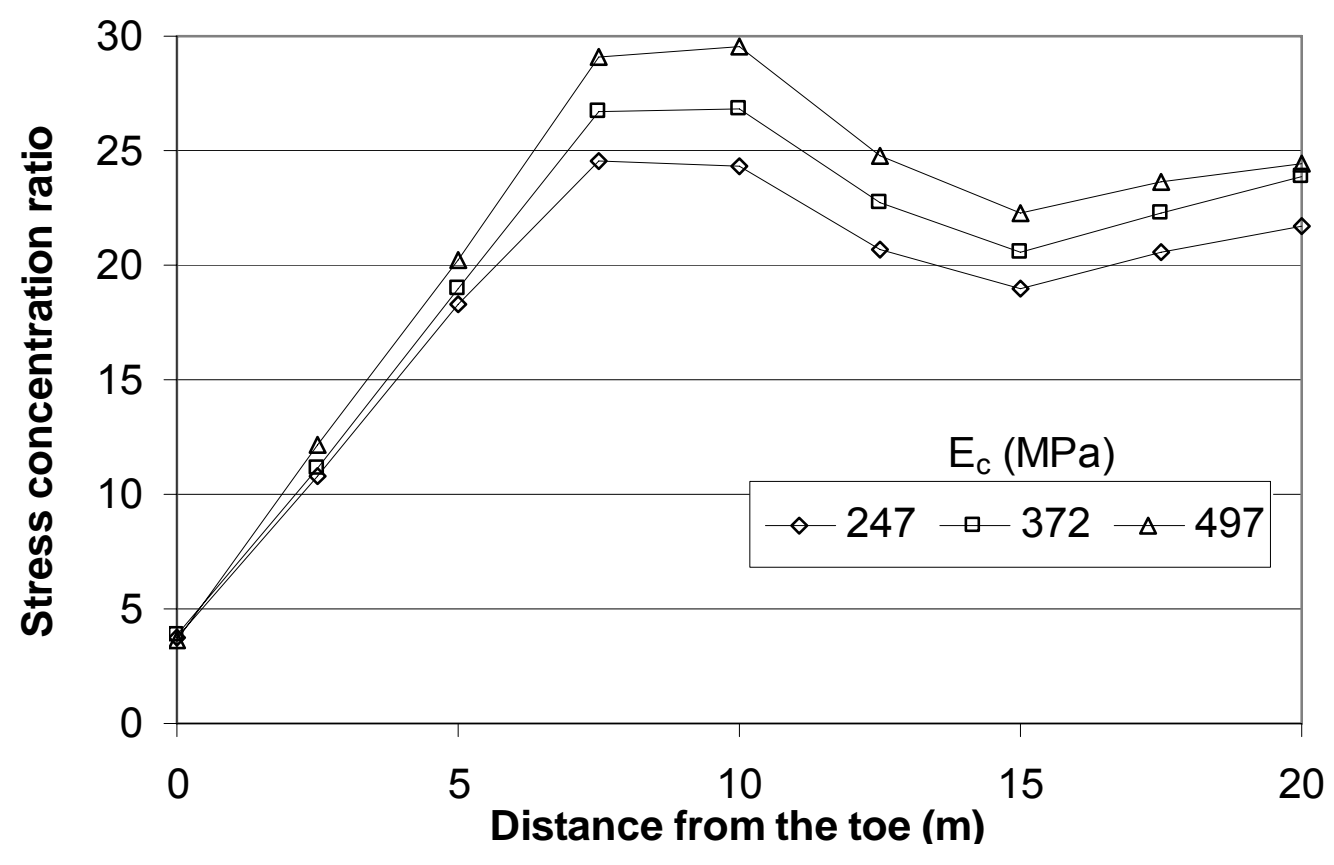

(b) 4.5 years after service

Fig. 5-71. Stress Concentration Ratio Profiles for Various Column Moduli (3D) 


\section{Influence of Column Spacing}

The influence of the column spacing on the additional vertical effective stress profiles is shown in Fig. 5-72. As discussed in the 2D parametric study, the change of the column spacing made it difficult to compare the additional vertical effective stresses in the columns and in the soil at the same location. As a result, the maximum additional vertical effective stresses on the columns and in the soil were used for the comparison. The increase of the column spacing yielded an increase of the additional vertical effective stresses both on the columns and in the soil.

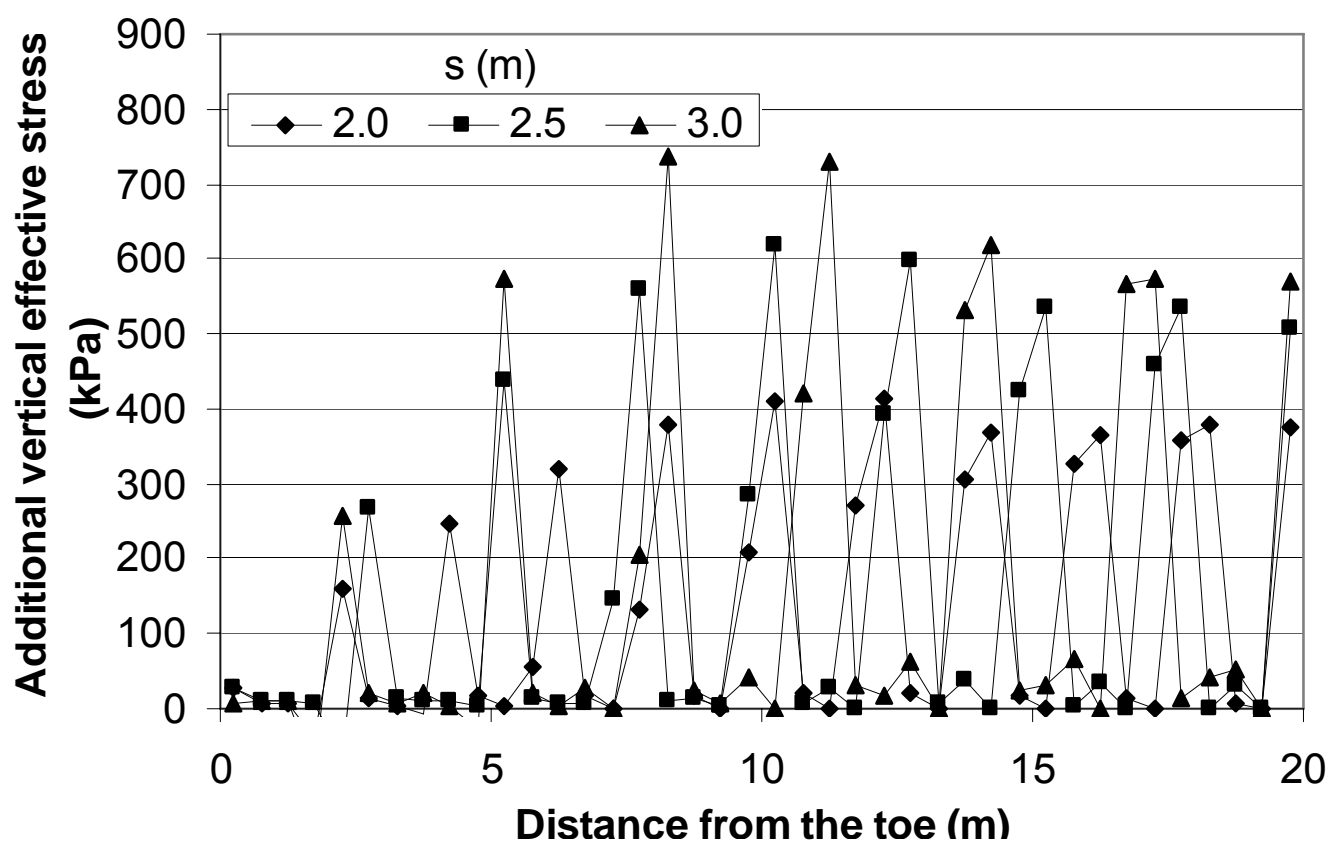

(a) Through Section I-I

Fig. 5-72. Additional Vertical Effective Stress Profiles of Various Column Spacing at 1 Month after Service (3D) 


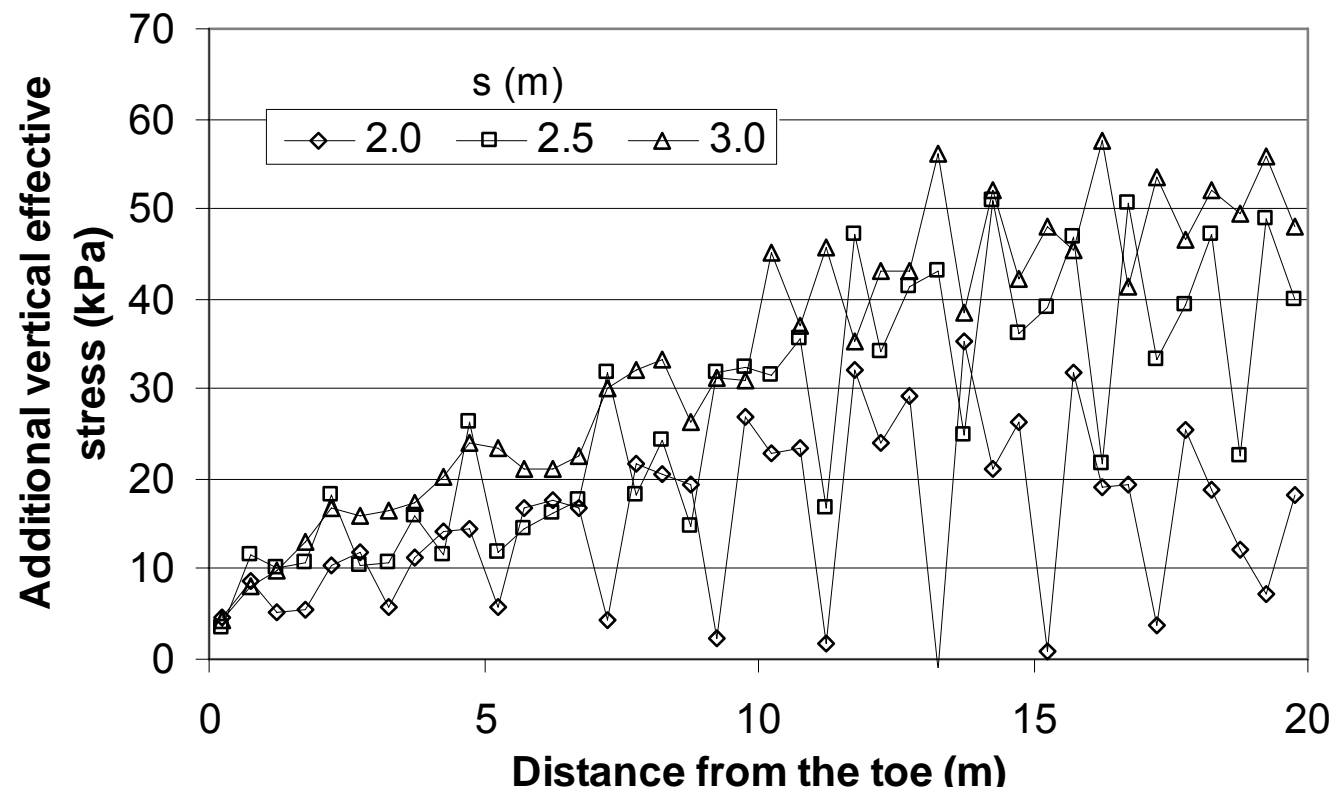

(b) Through Section II-II

Fig. 5-72. Additional Vertical Effective Stress Profiles of Various Column Spacing at 1 Month after Service (3D) (continued)

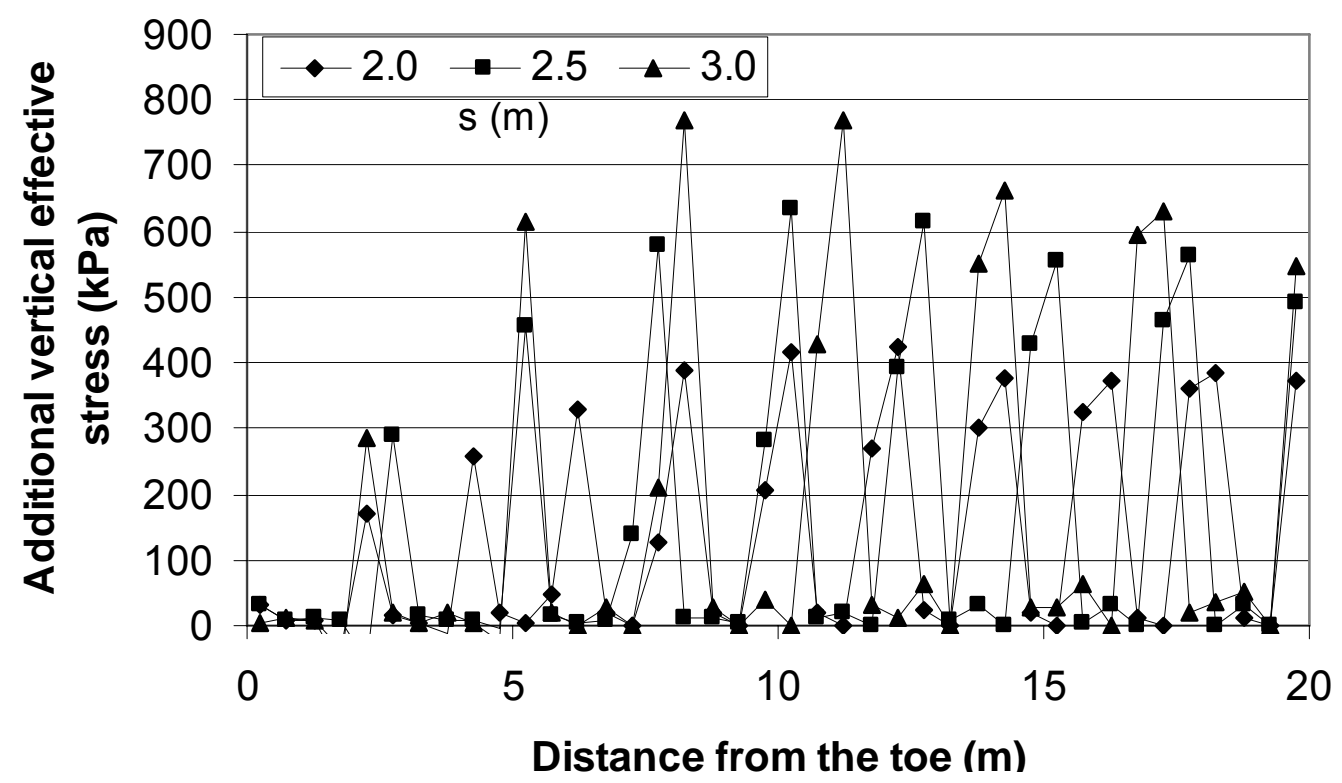

(a) Through Section I-I

Fig. 5-73. Additional Vertical Effective Stress Profiles of Various Column Spacing at 4.5 Years after Service (3D) 


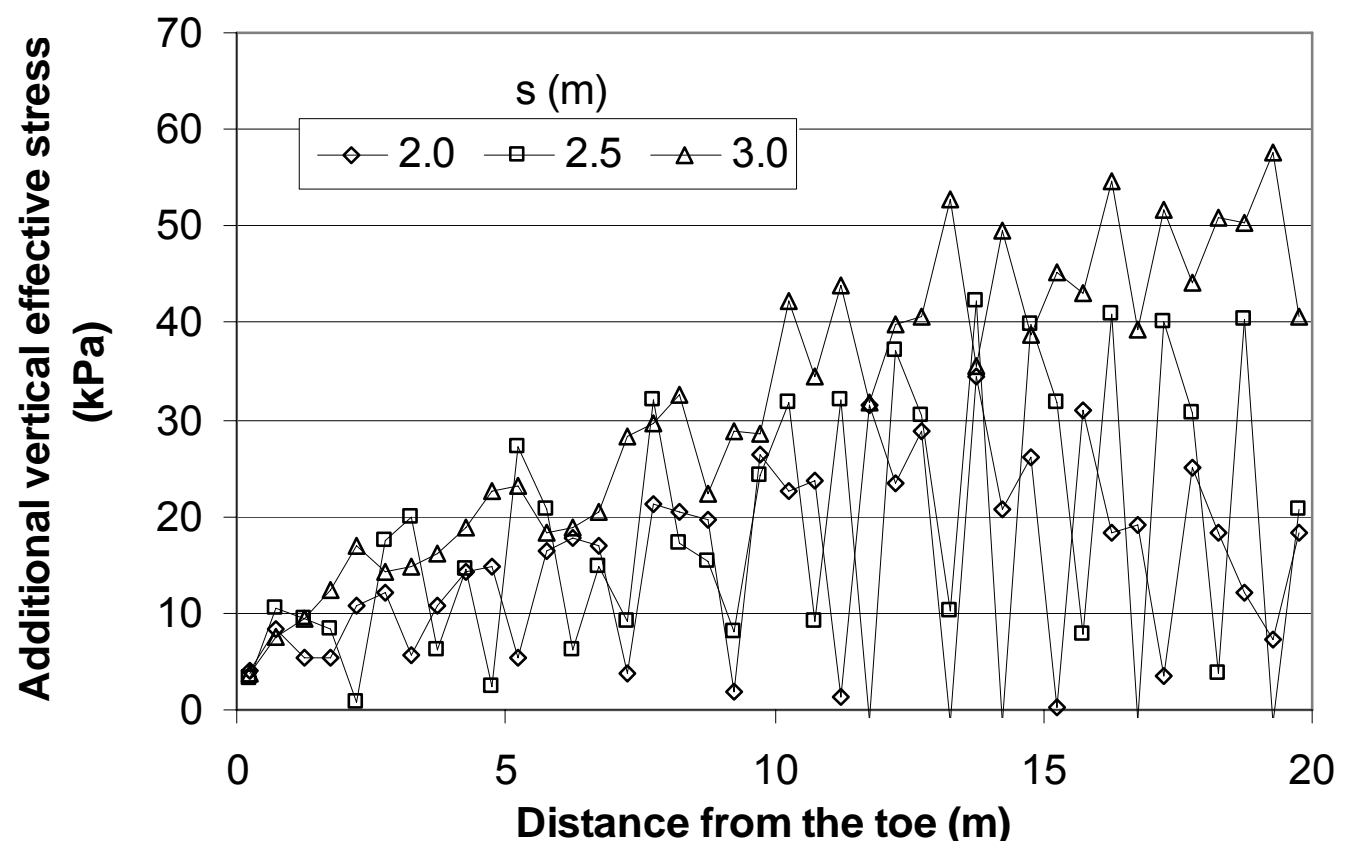

(b) Through Section II-II

Fig. 5-73. Additional Vertical Effective Stress Profiles of Various Column Spacing at 4.5 Years after Service (3D) (continued)

The stress concentration ratio profiles of different column spacing are presented in Fig. 5-74. It can be seen that the change of the spacing even changed the stress concentration ratio distribution pattern at the spacing of $2.0 \mathrm{~m}$. Since the tendency of the lateral movement at a smaller column spacing was less, the maximum stress concentration ratio occurred at the center of the embankment, which was also the distribution pattern found in the 2D parametric study. 


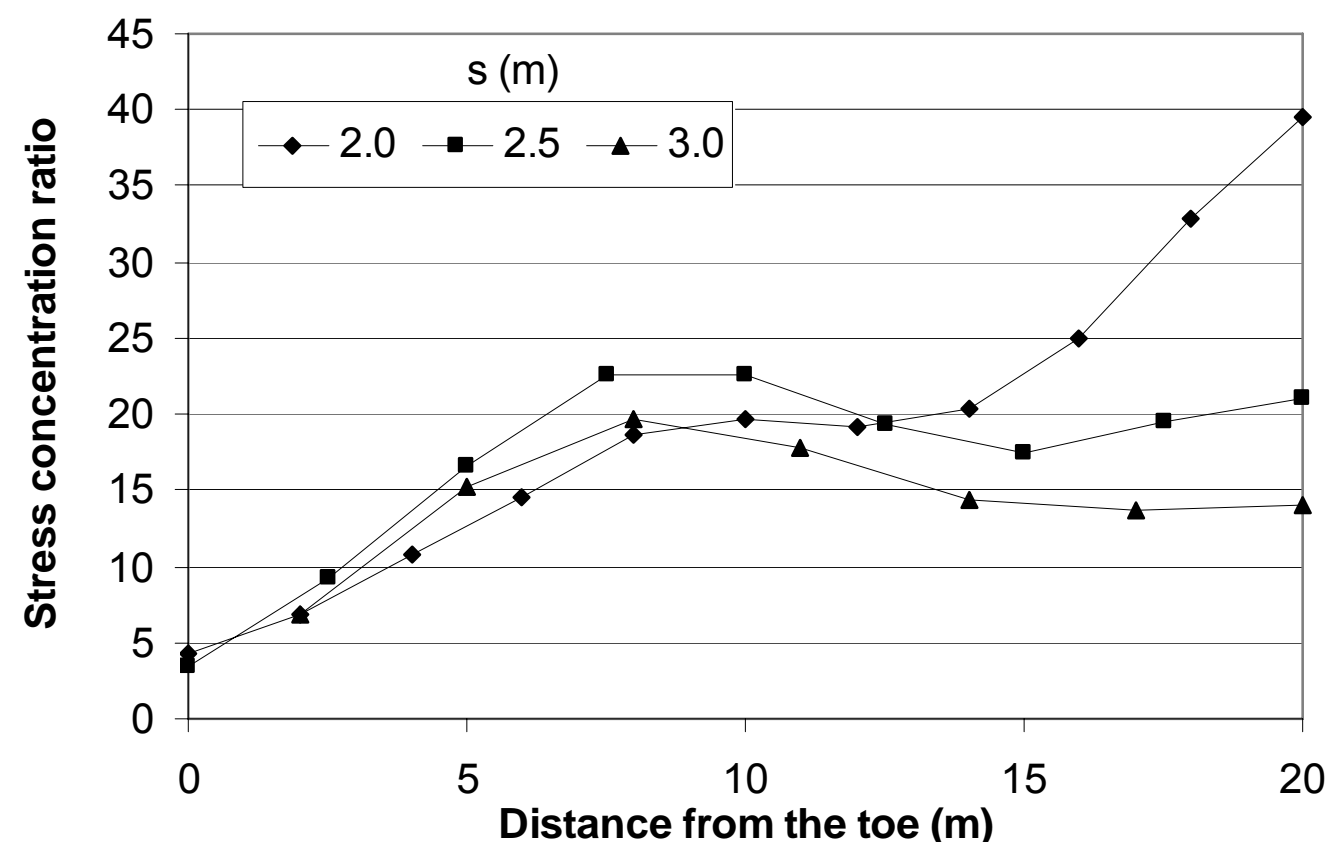

(a) 1 month after service

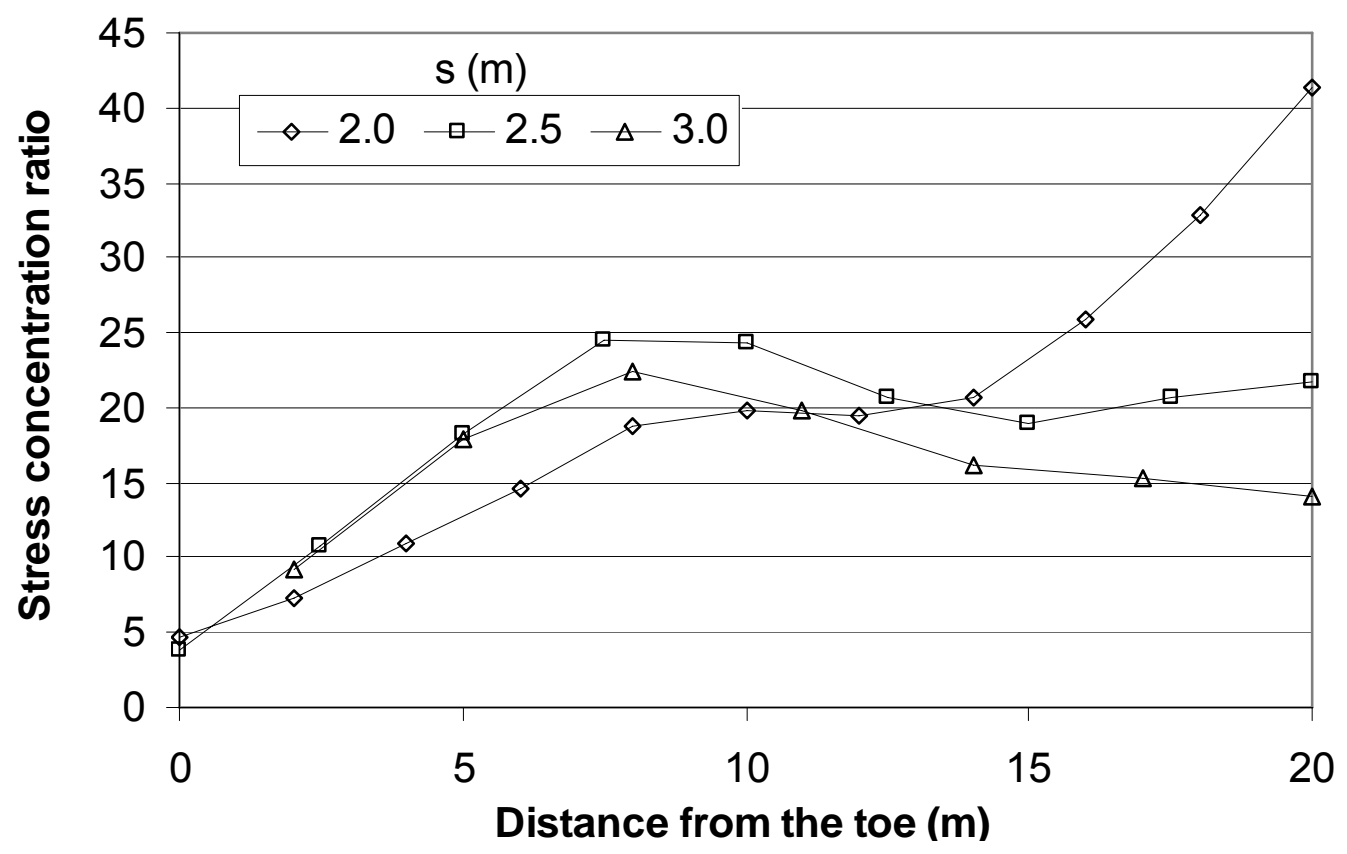

(b) 4.5 years after service

Fig. 5-74. Stress Concentration Ratio Profiles for Various Column Spacing (3D) 


\section{Influence of Geosynthetic Tensile Stiffness}

The influence of the geosynthetic tensile stiffness on the additional vertical effective stress profiles is presented in Fig. 4-75 and 4-76. Overall, the higher tensile stiffness led to lower additional vertical effective stresses both on the columns and in the soil.

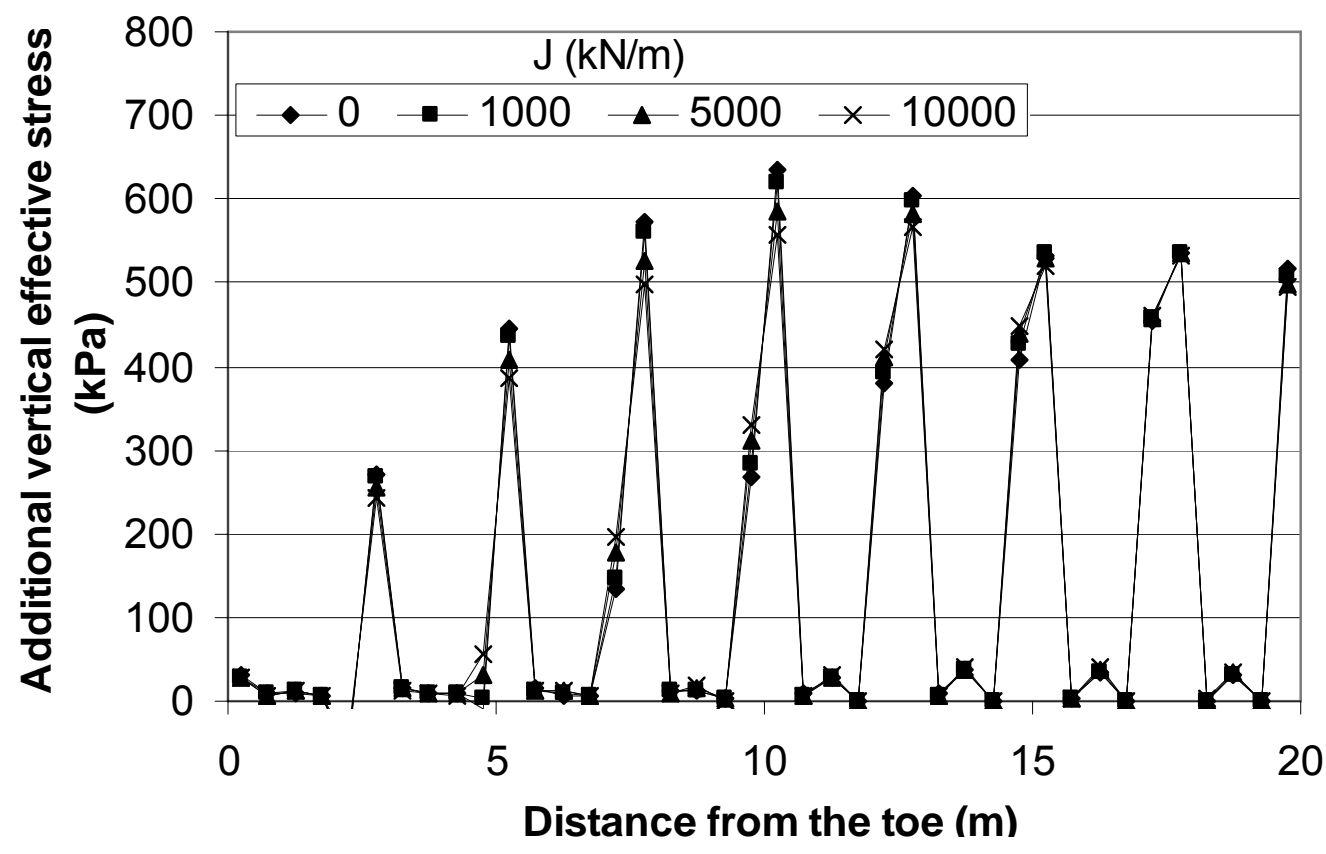

(a) Through Section I-I

Fig. 5-75. Additional Vertical Effective Stress Profiles for Various Tensile Stiffness at 1 Month after Service (3D) 


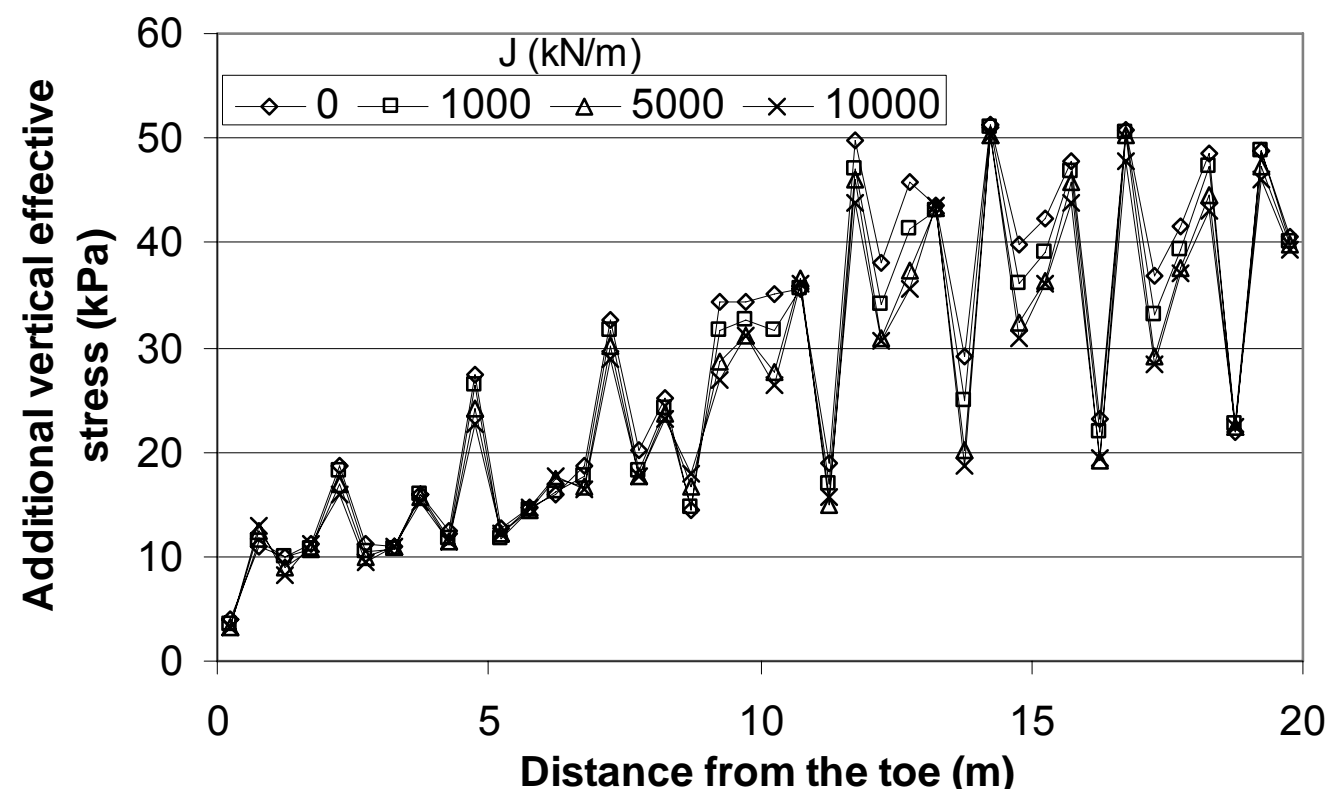

(b) Through Section II-II

Fig. 5-75. Additional Vertical Effective Stress Profiles for Various Tensile Stiffness at 1 Month after Service (3D) (continued)

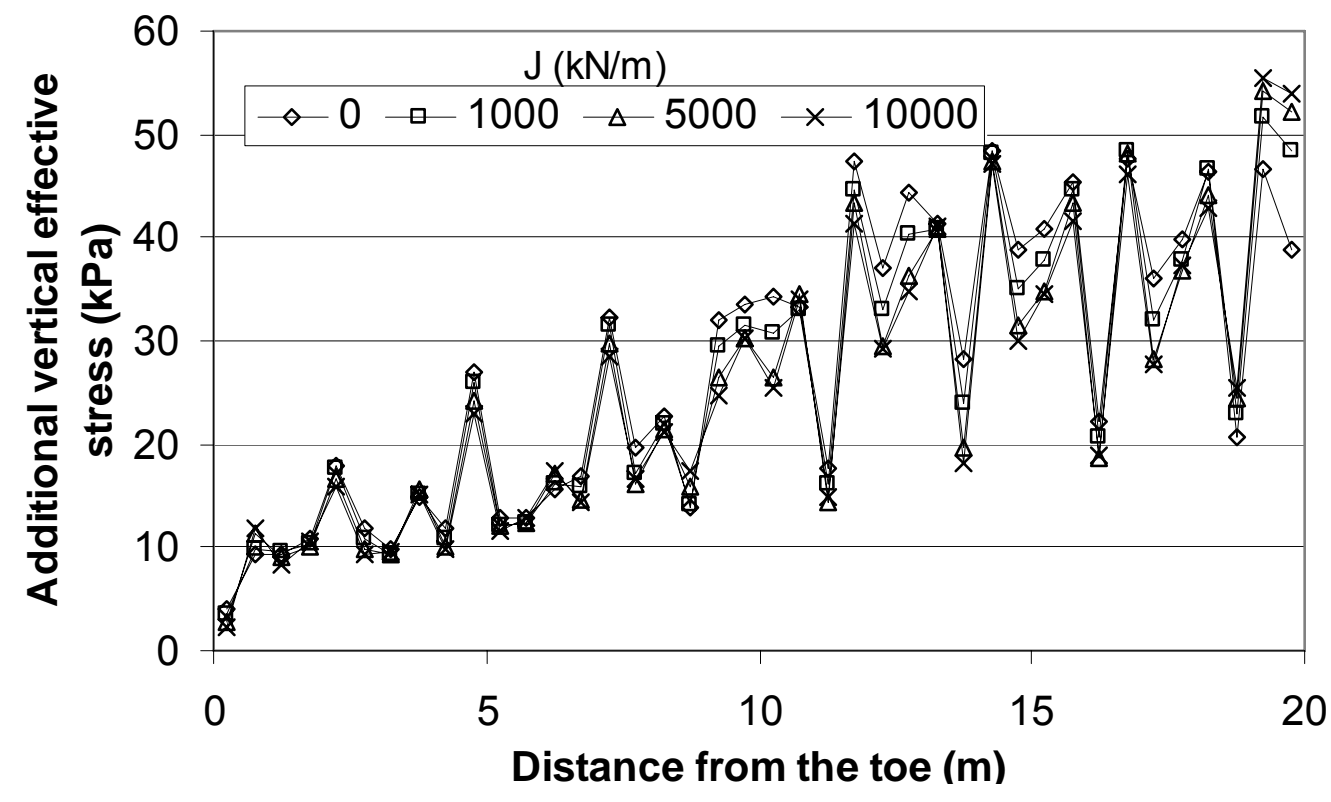

(a) Through Section I-I

Fig. 5-76. Additional Vertical Effective Stress Profiles for Various Tensile Stiffness at 4.5 Years after Service (3D) 


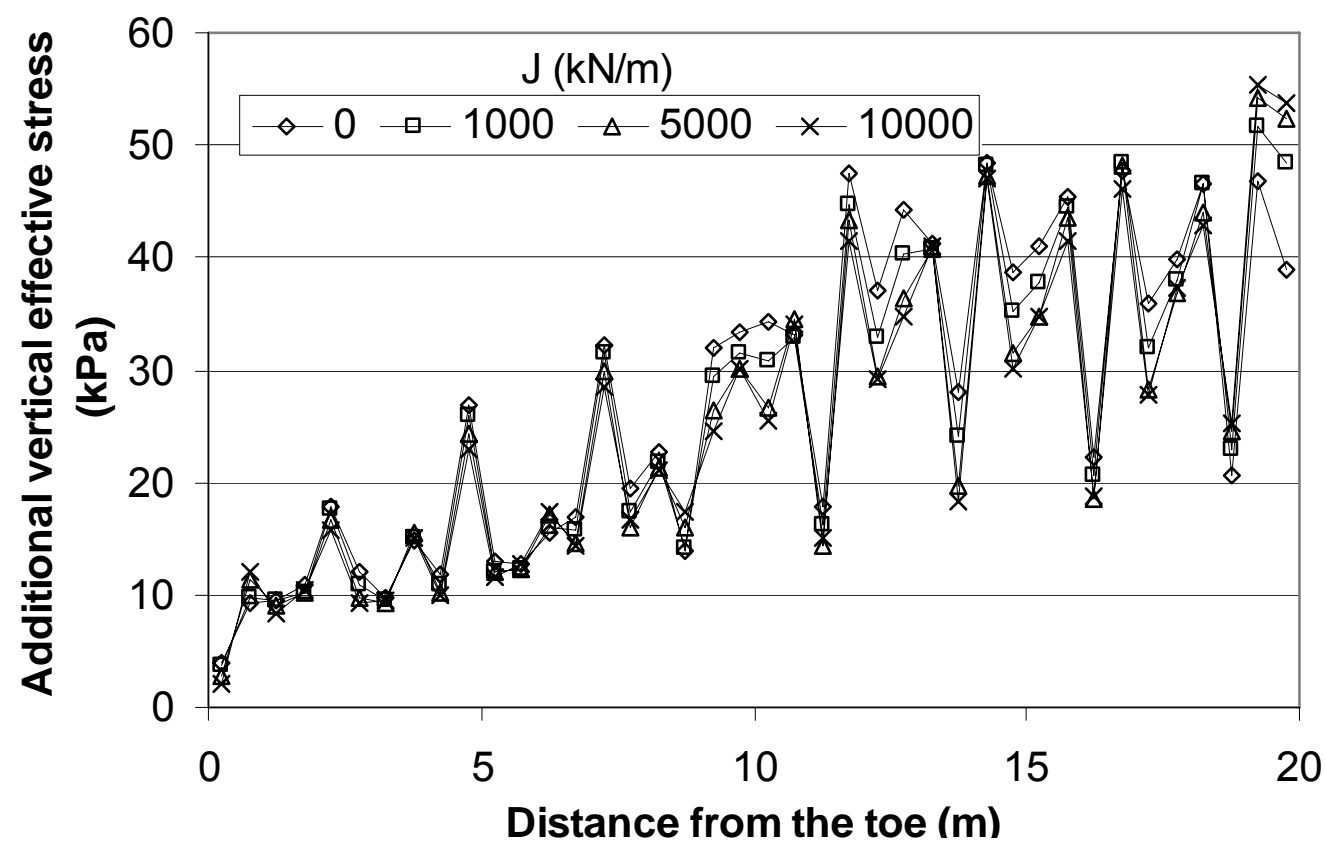

(b) Through Section II-II

\section{Fig. 5-76. Additional Vertical Effective Stress Profiles for Various Tensile Stiffness at 4.5 Years after Service (3D) (continued)}

The influence of the geosynthetic tensile stiffness on the stress concentration ratio profiles is shown in Fig. 5-77. The tensile stiffness of the geosynthetic did not have any significant influence on the stress concentration ratio in Fig. 5-77. Overall, the stress concentration ratio decreased with an increase of the tensile stiffness. 


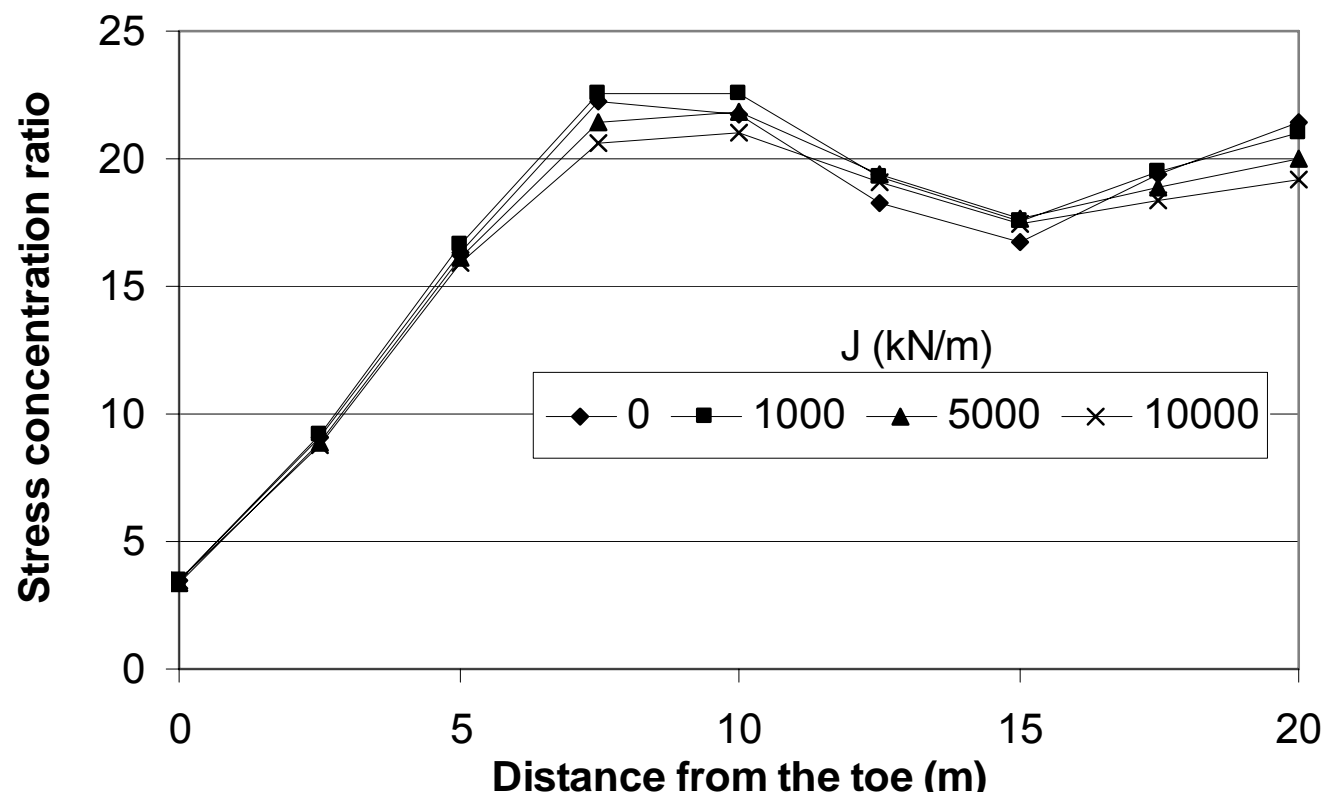

(a) 1 month after service

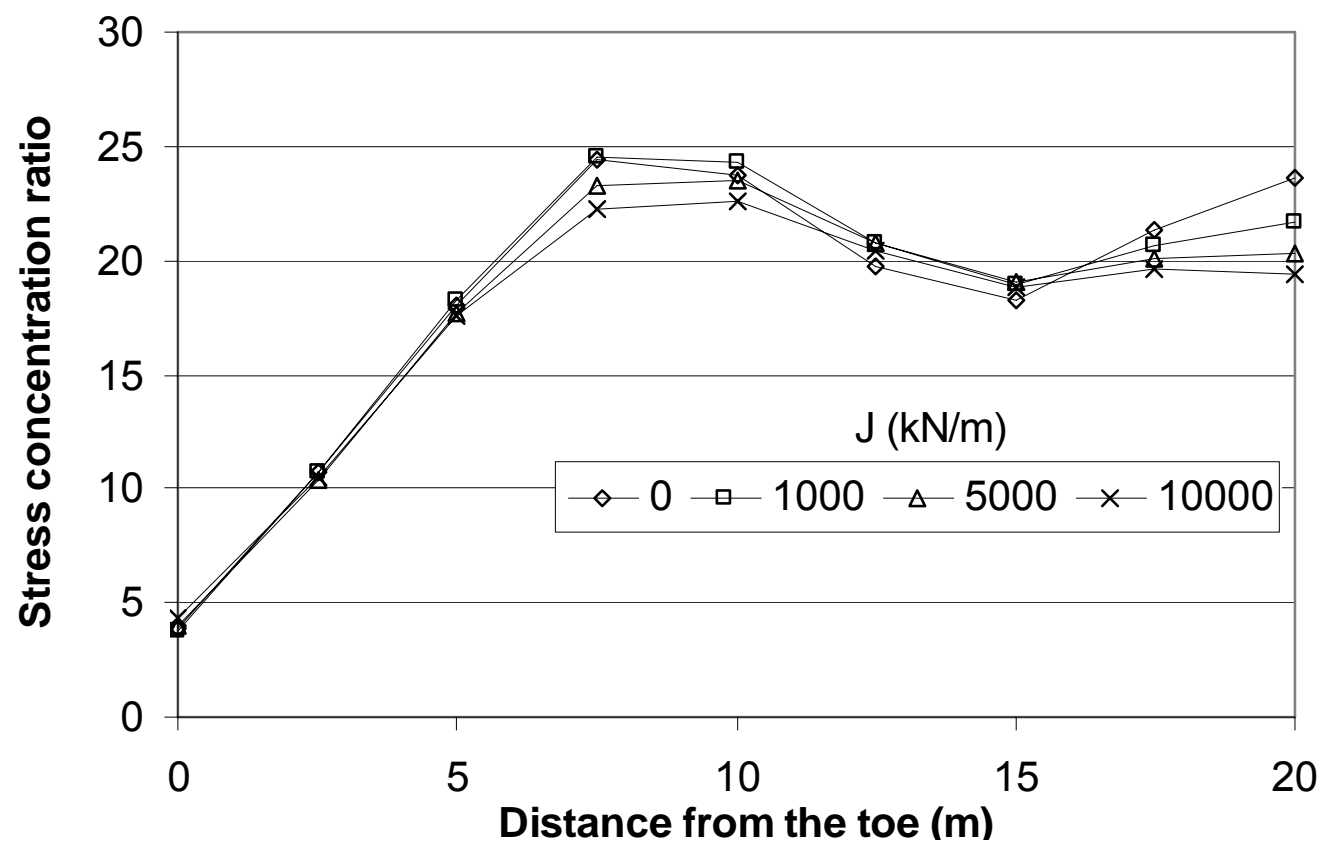

(b) 4.5 years after service

Fig. 5-77. Stress Concentration Ratio Profiles for Various Tensile Stiffness (3D) 


\section{Influence of Construction Rate}

The influences of the average construction rates on the additional vertical effective stress profiles are presented Fig. 5-78 and 5-79. The lower average construction rate reduced the additional vertical effective stresses on the columns but increased the additional vertical effective stresses in the soil. As discussed in the 2D parametric study in Chapter Four, a low average construction rate had a similar effect as the high soil permeability.

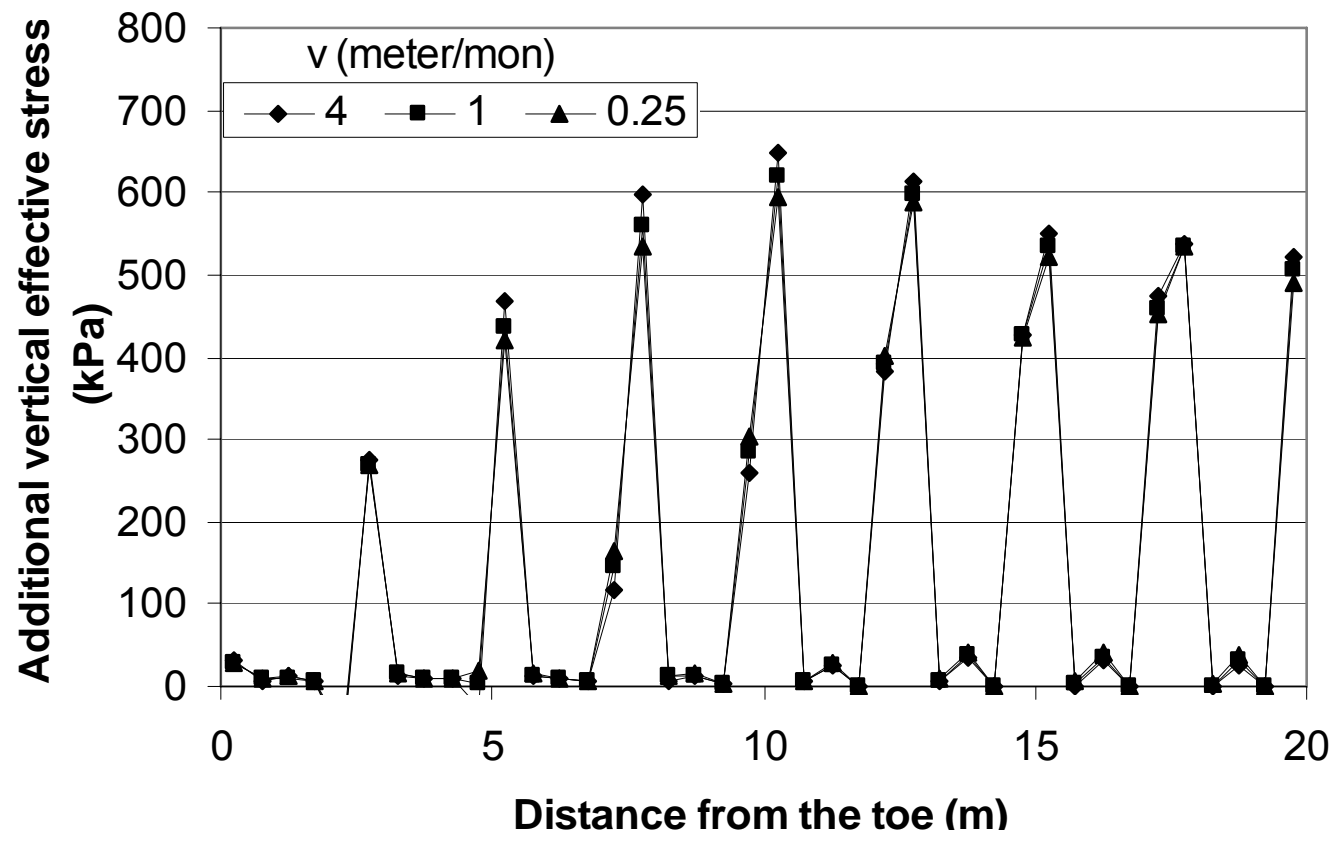

(a) Through Section I-I

Fig. 5-78. Additional Vertical Effective Stress Profiles for Various Average Construction Rates at 1 Month after Service (3D) 


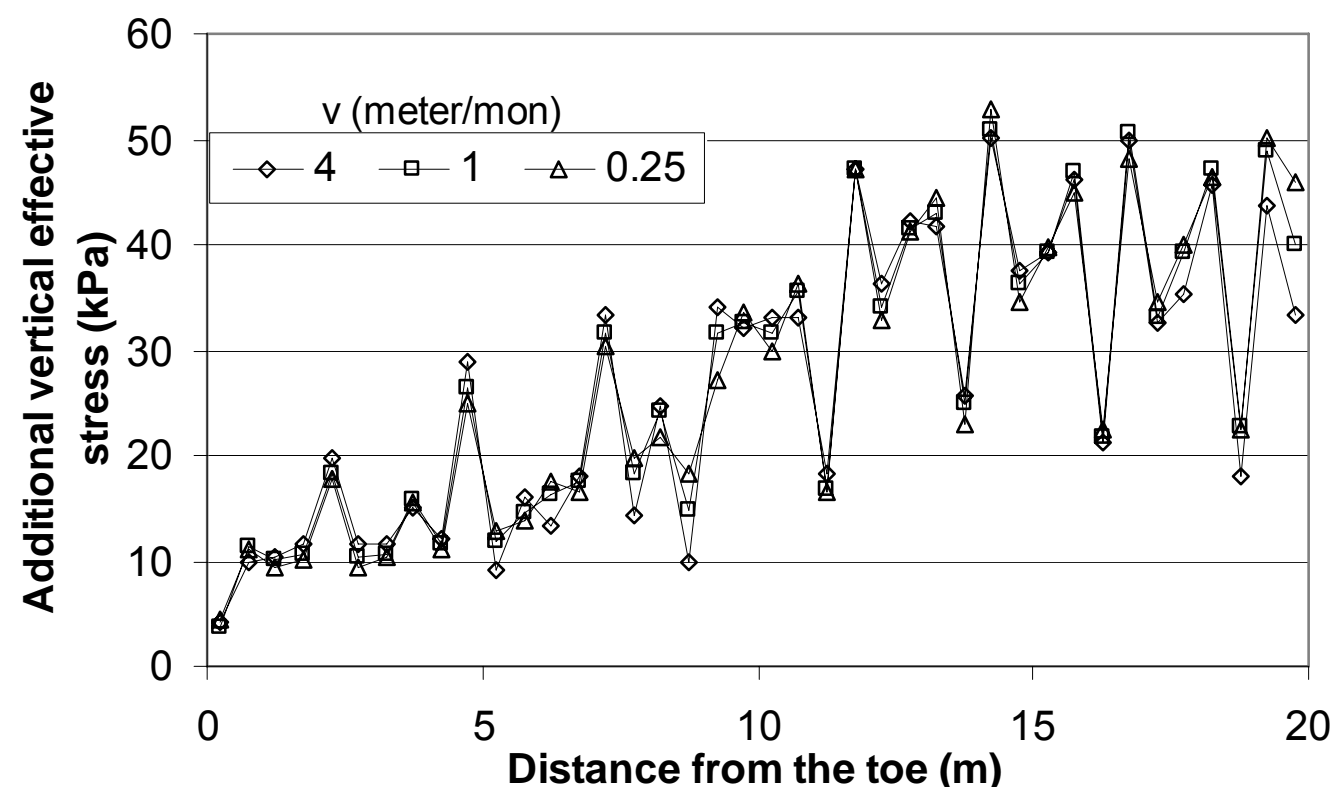

(b) Through Section II-II

Fig. 5-78. Additional Vertical Effective Stress Profiles for Various Average Construction Rates at 1 Month after Service (3D) (continued)

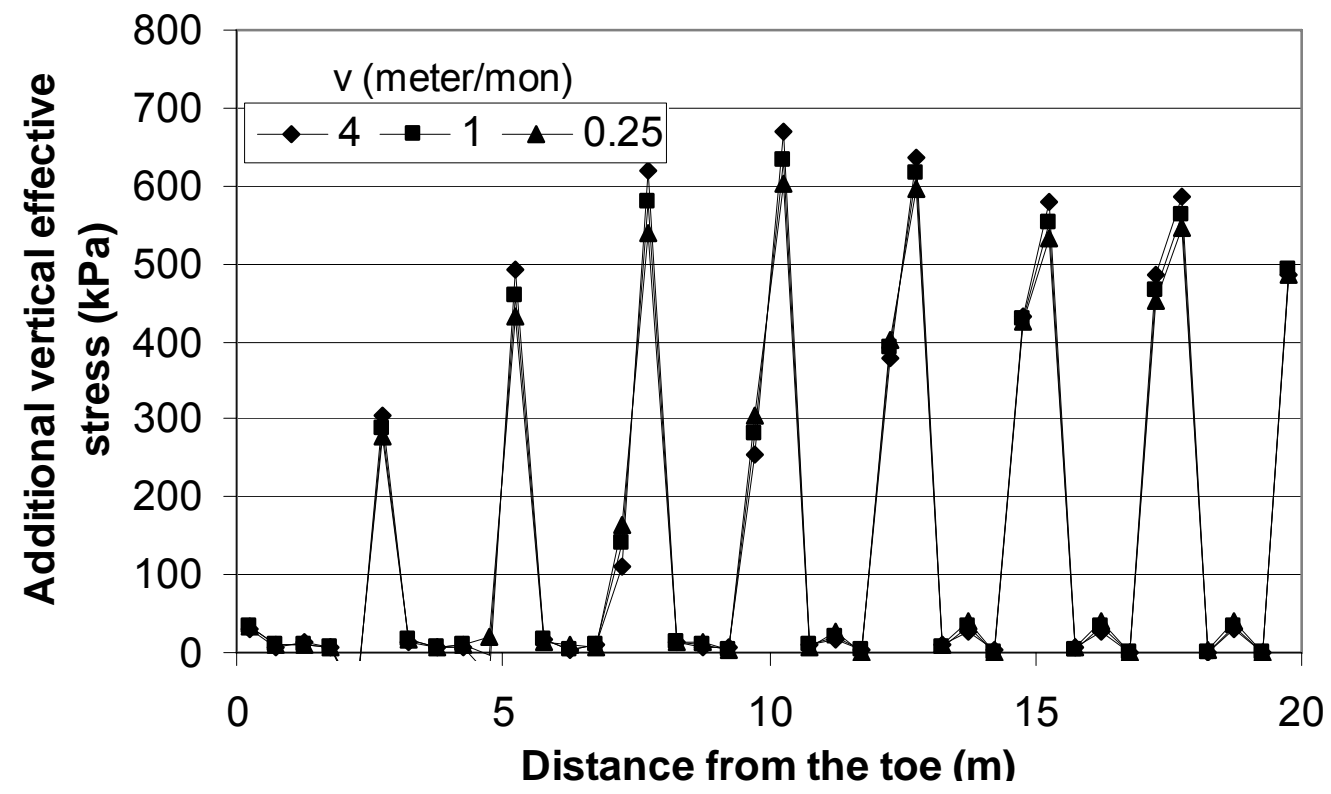

(a) Through Section I-I

Fig. 5-79. Additional Vertical Effective Stress Profiles for Various Average Construction Rates at 4.5 Years after Service (3D) 


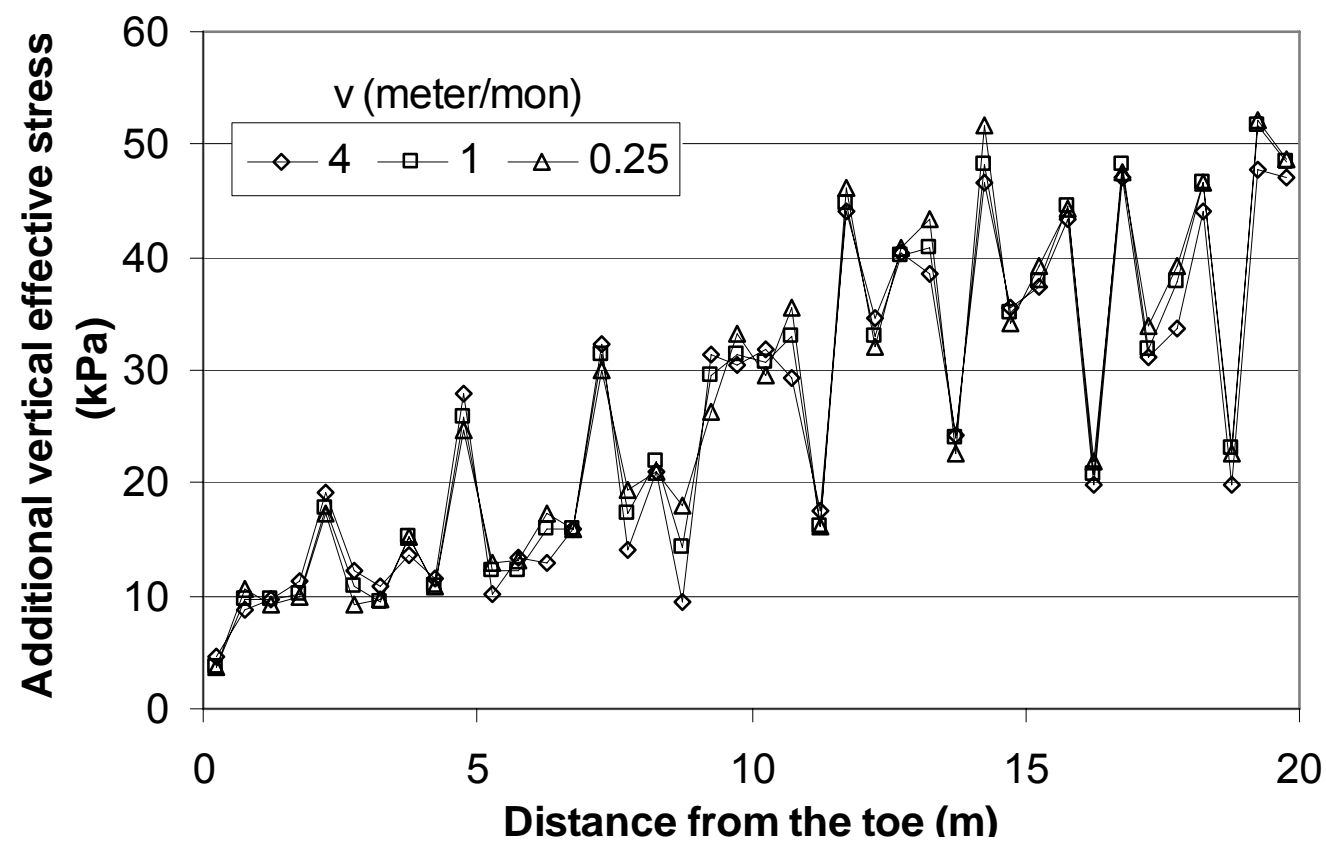

(b) Through Section II-II

Fig. 5-79. Additional Vertical Effective Stress Profiles for Various Average Construction Rates at 4.5 Years after Service (3D) (continued)

The influence of the average construction rate on the stress concentration ratio profiles is shown in Fig. 5-80. The increase of the average construction rate led to a higher stress concentration ratio, which was similar to what had been discussed in $2 \mathrm{D}$ parametric study. 


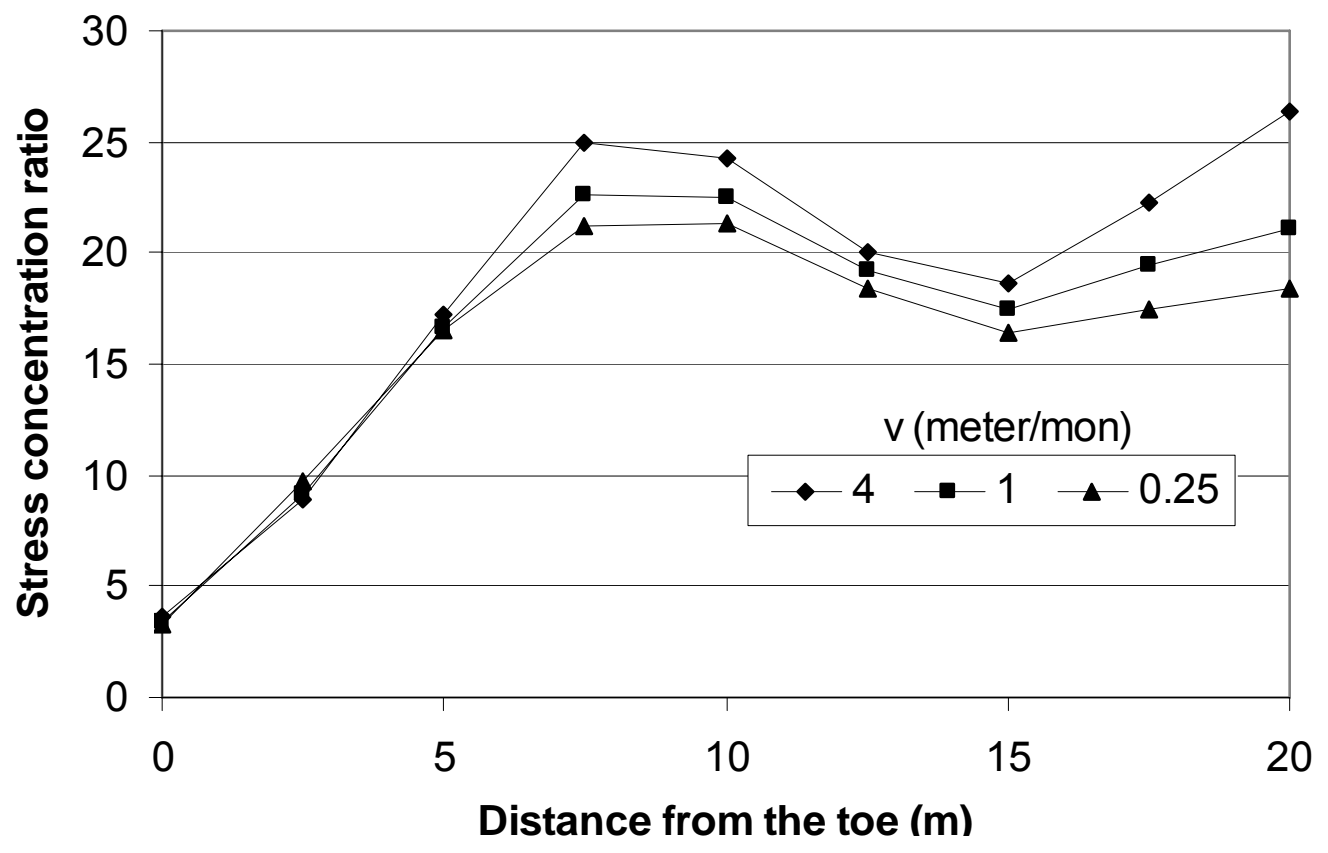

(a) 1 month after service

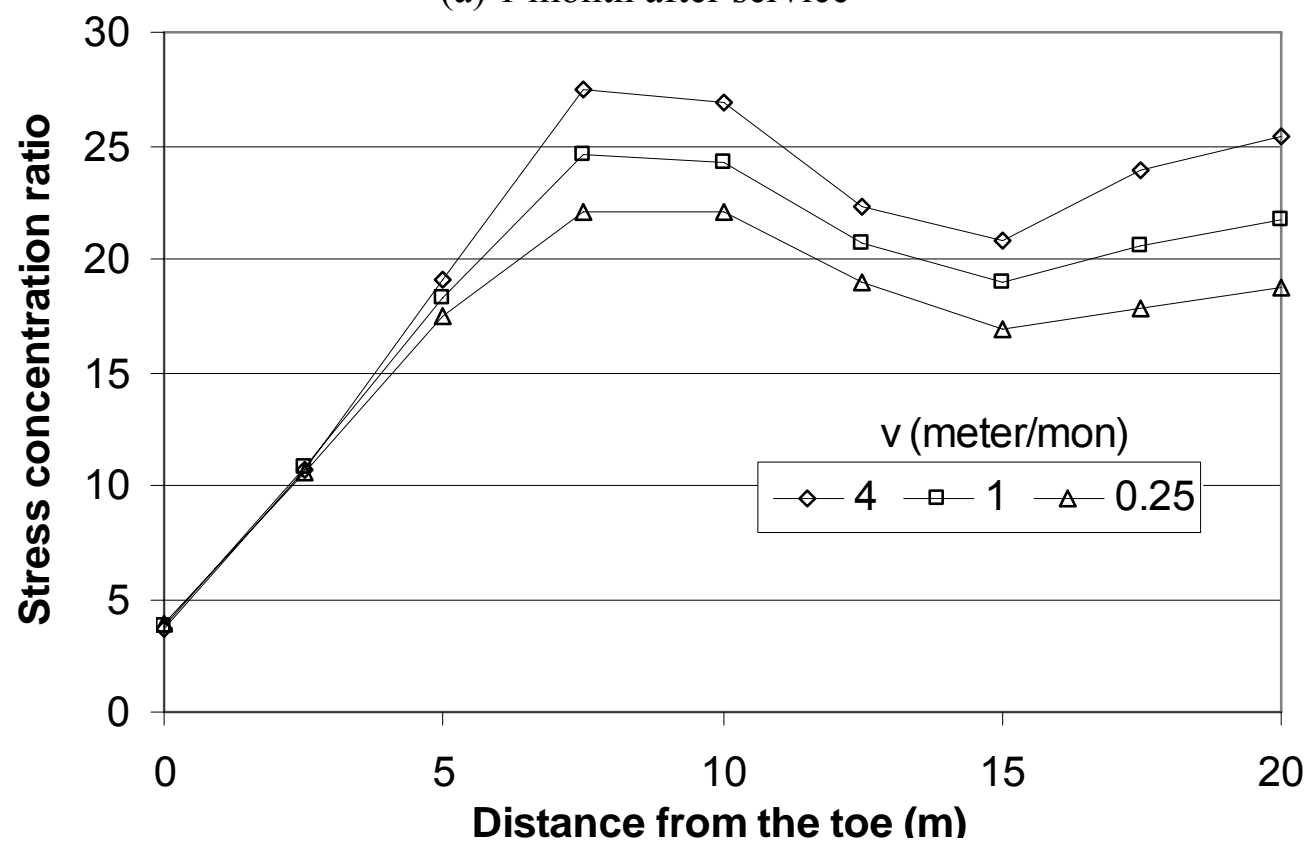

(b) 4.5 years after service

Fig. 5-80. Stress Concentration Ratio Profiles for Various Average Construction Rates (3D) 


\subsubsection{Excess Pore Water Pressure}

As discussed in Chapter Four, under a GRCS embankment, the excess pore water pressure dissipates hydraulically and mechanically, i.e., through drainage and load transfer. Therefore, the consolidation process depends on a number of factors in addition to the soil permeability. The major influence factors were investigated. The excess pore water pressure distribution within the soft soil along the depth (Section III-III shown in Fig. 5-1) and the degree of consolidation of the section are used as representatives.

\section{Influence of Soft Soil Elastic Modulus}

The excess pore water pressure distribution along Section III-III (refer to Fig. 5-1) at one month after service is presented in Fig. 5-81. Since the excess pore water pressure at 4.5 years after service approached zero, it is not presented in this section. Figure 581 shows that the excess pore water pressure at one month after service increased with the increase of the soft soil modulus. This phenomenon was identified and explained in details in the 2D parametric study. 


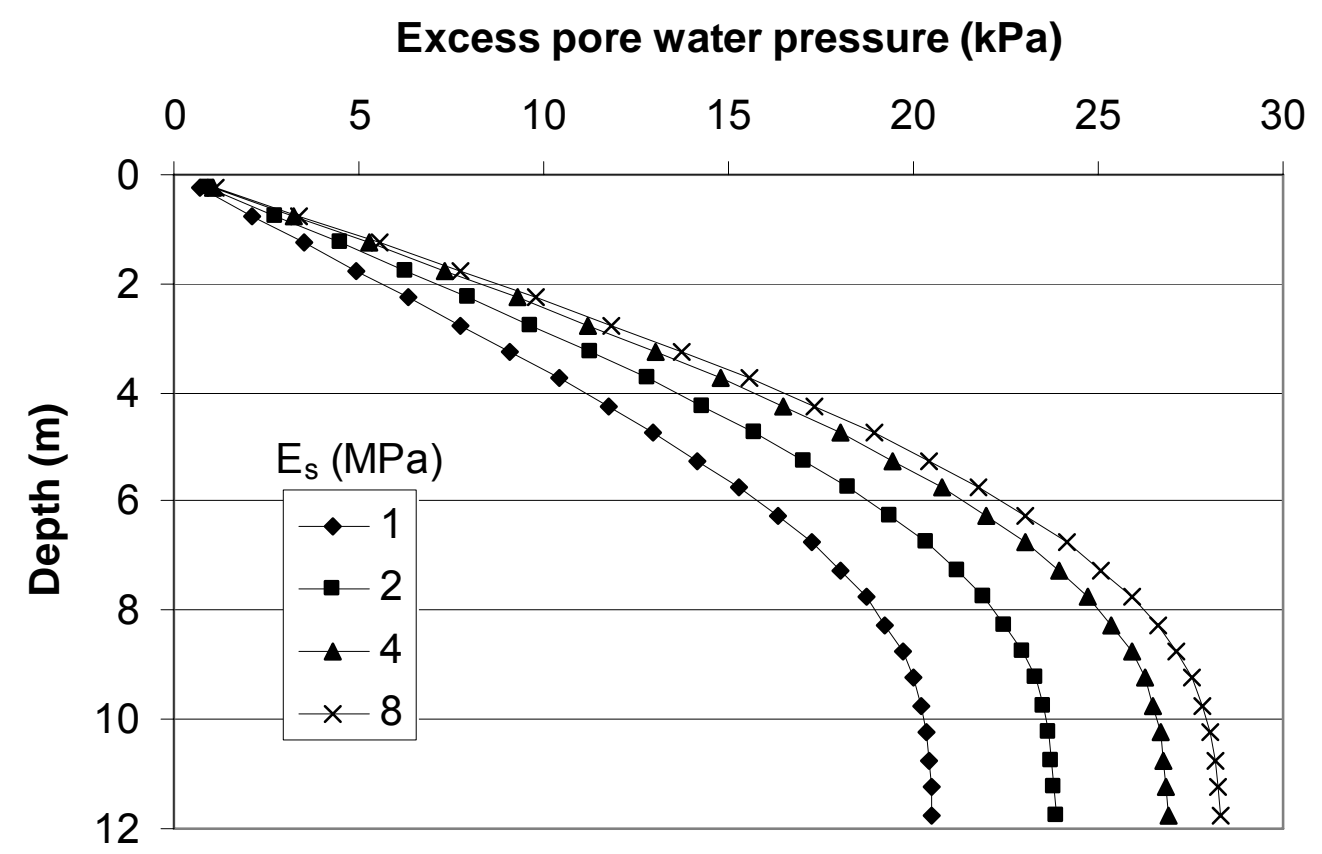

Fig. 5-81. Excess Pore Water Pressure Distributions for Various Soil Moduli (3D)

Following the same approach used in Chapter Four, the degree of consolidation at one month after service was calculated and plotted against the soil modulus as shown in Fig. 5-82. It can be concluded that higher soil modulus led to a lower degree of consolidation. Within the investigated range of the soft soil modulus, the degree of consolidation varied approximately $6 \%$, which implies that the soft soil modulus had a limited influence on the degree of consolidation. Furthermore, the influence of the soil modulus on the degree of consolidation became less as the soil modulus increased. 


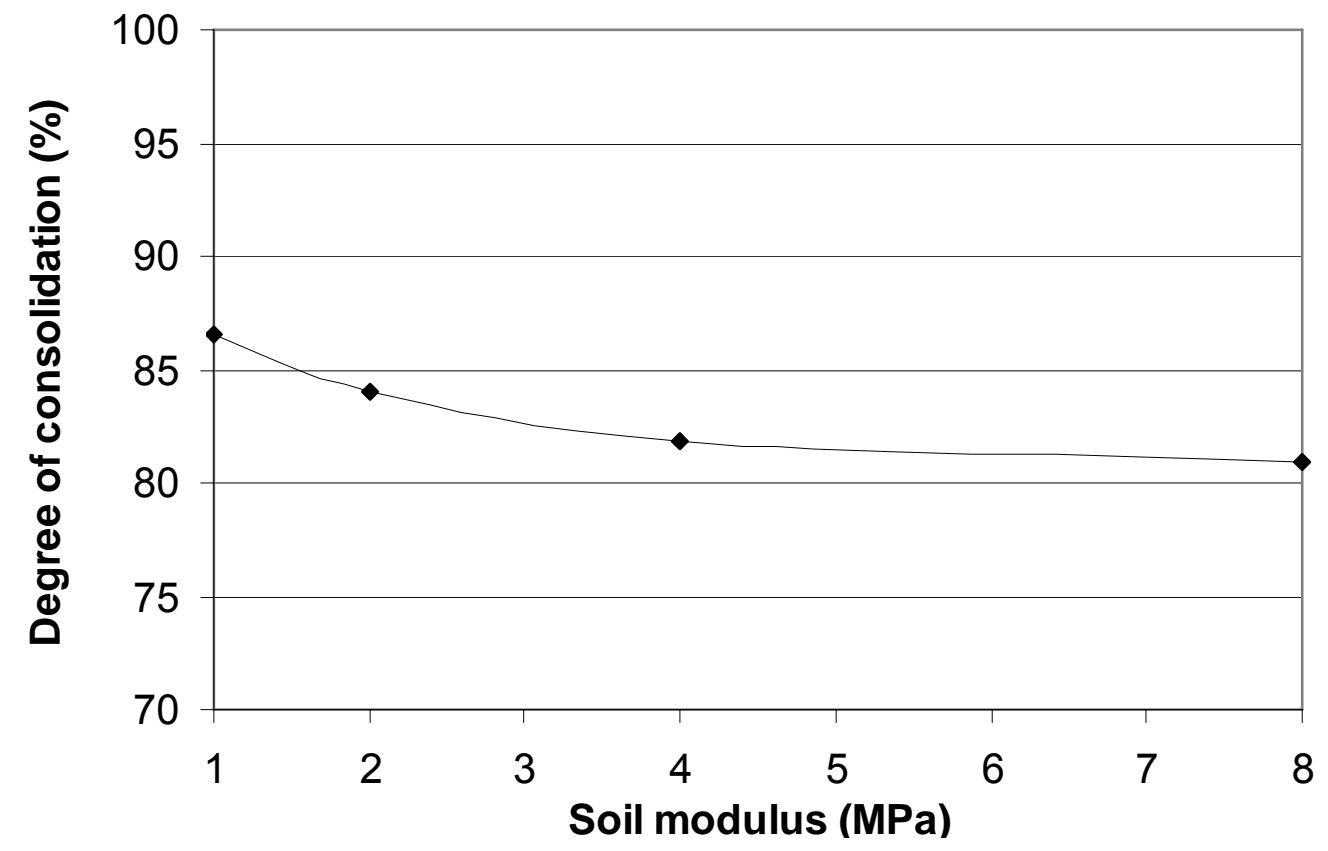

Fig. 5-82. Degree of Consolidation versus Soil Modulus (3D)

\section{Influence of Soft Soil Friction Angle}

The excess pore water pressure distribution along Section III-III is presented in Fig. 5-83. The smaller friction angle resulted in less excess pore water pressure at one month after service. This phenomenon is also consistent with that found in the $2 \mathrm{D}$ parametric study in Chapter Four. The difference in the excess pore water pressures at different friction angles was too small to make any practical significance. 


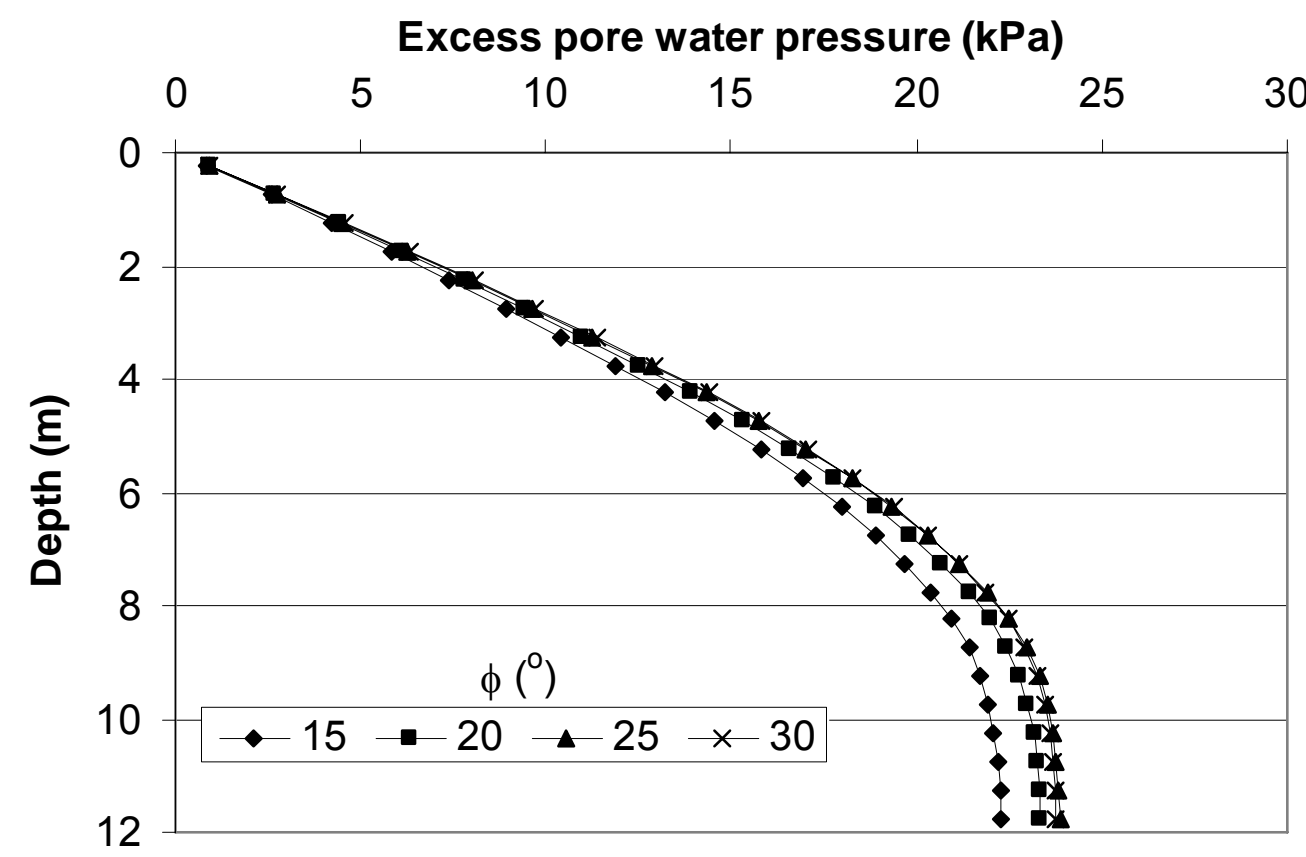

Fig. 5-83. Excess Pore Water Pressure Distributions for Various Friction Angles (3D)

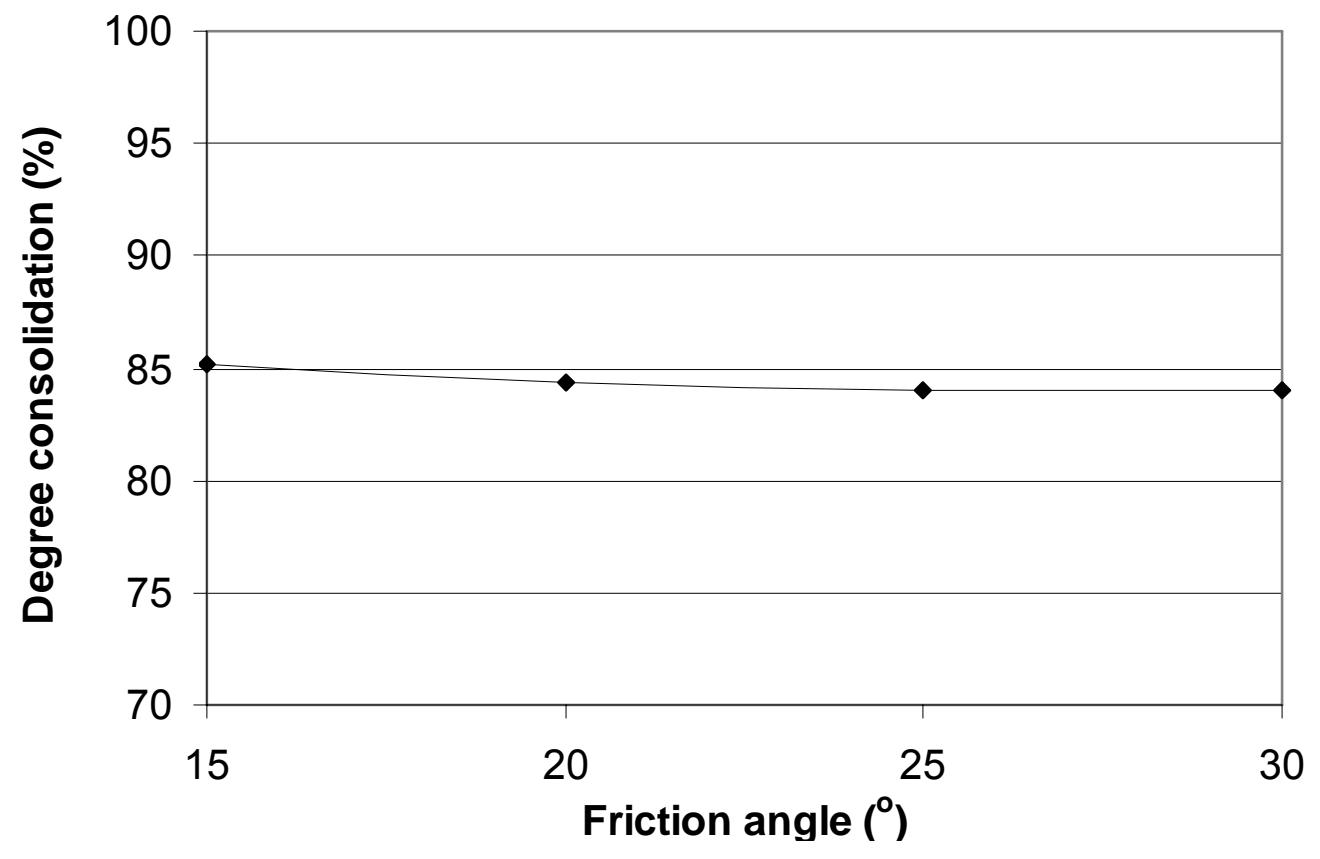

Fig. 5-84. Degree of Consolidation versus Friction Angle (3D) 
The degree of consolidation is plotted in Fig. 5-84 for a clearer illustration of the influence of the soil friction angle on the excess pore water pressure. The smaller soil friction angle led to a slightly higher degree of consolidation.

\section{Influence of Soft Soil Permeability}

The influence of the soil permeability on the excess pore water pressure distribution along Section III-III is shown in Fig. 5-85. As expected, the higher soil permeability led to less pore water pressure. The excess pore water pressure at one month of service almost dissipated completely at the soil permeability of $10^{-8} \mathrm{~m} / \mathrm{s}$.

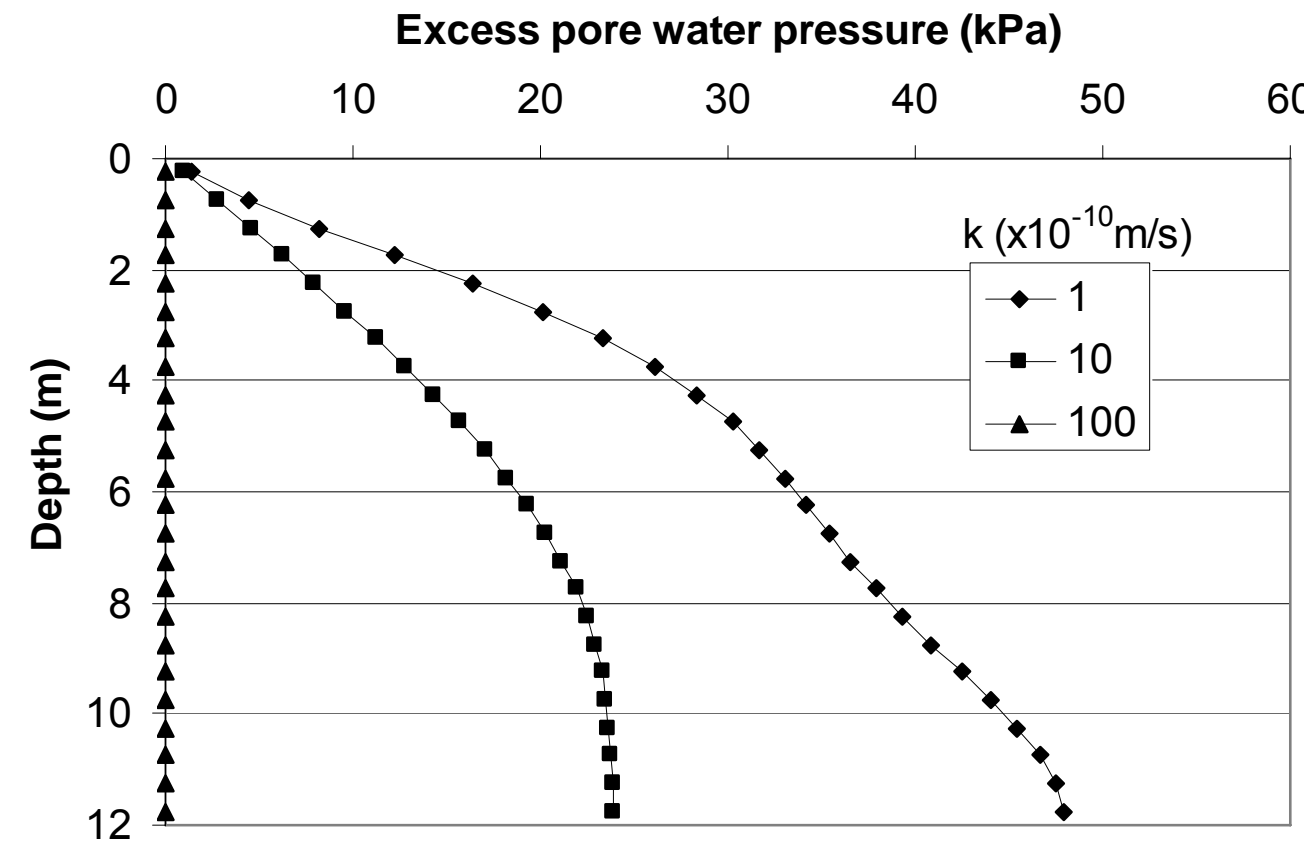

Fig. 5-85. Excess Pore Water Pressure Distributions for Various Soil Permeability (3D) 


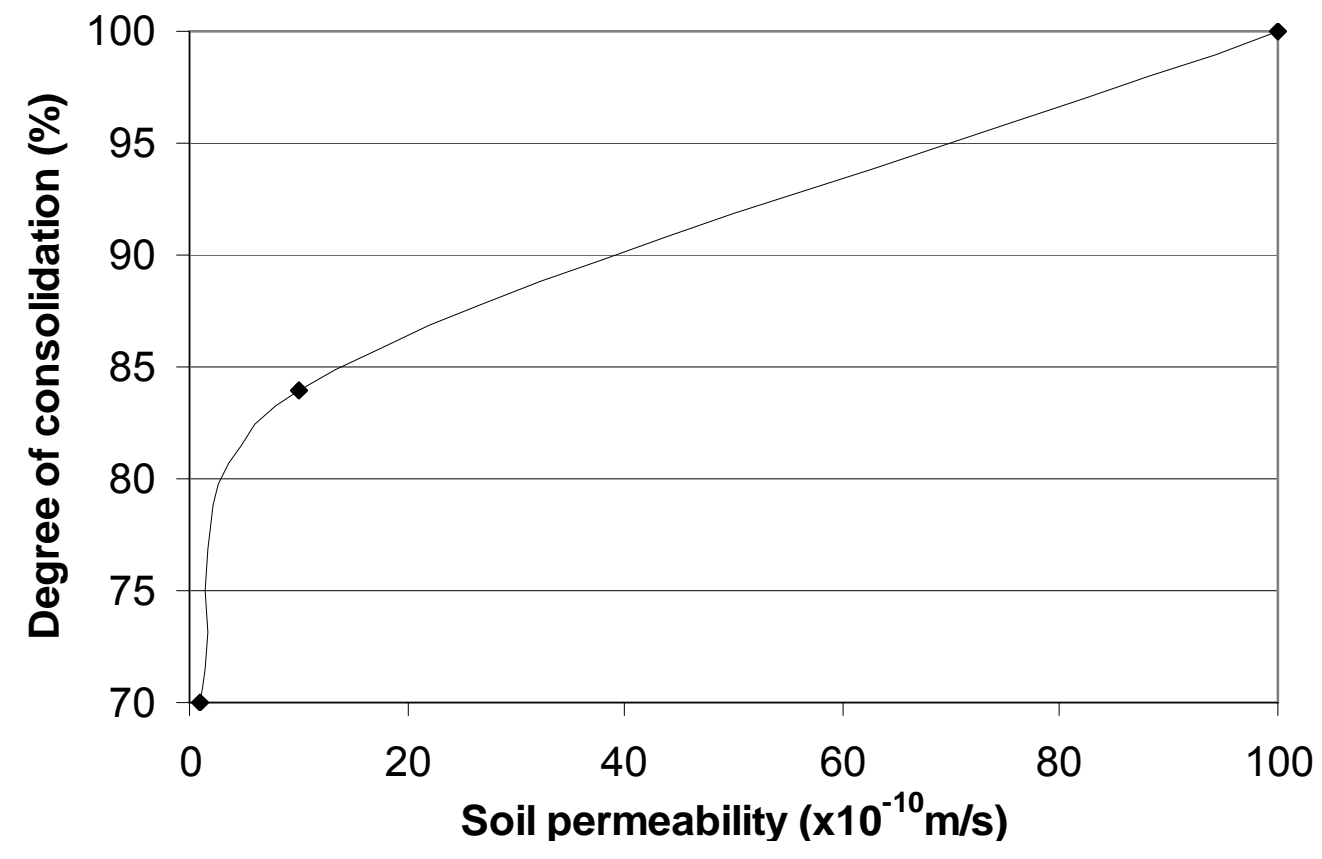

(a) Permeability in a normal scale

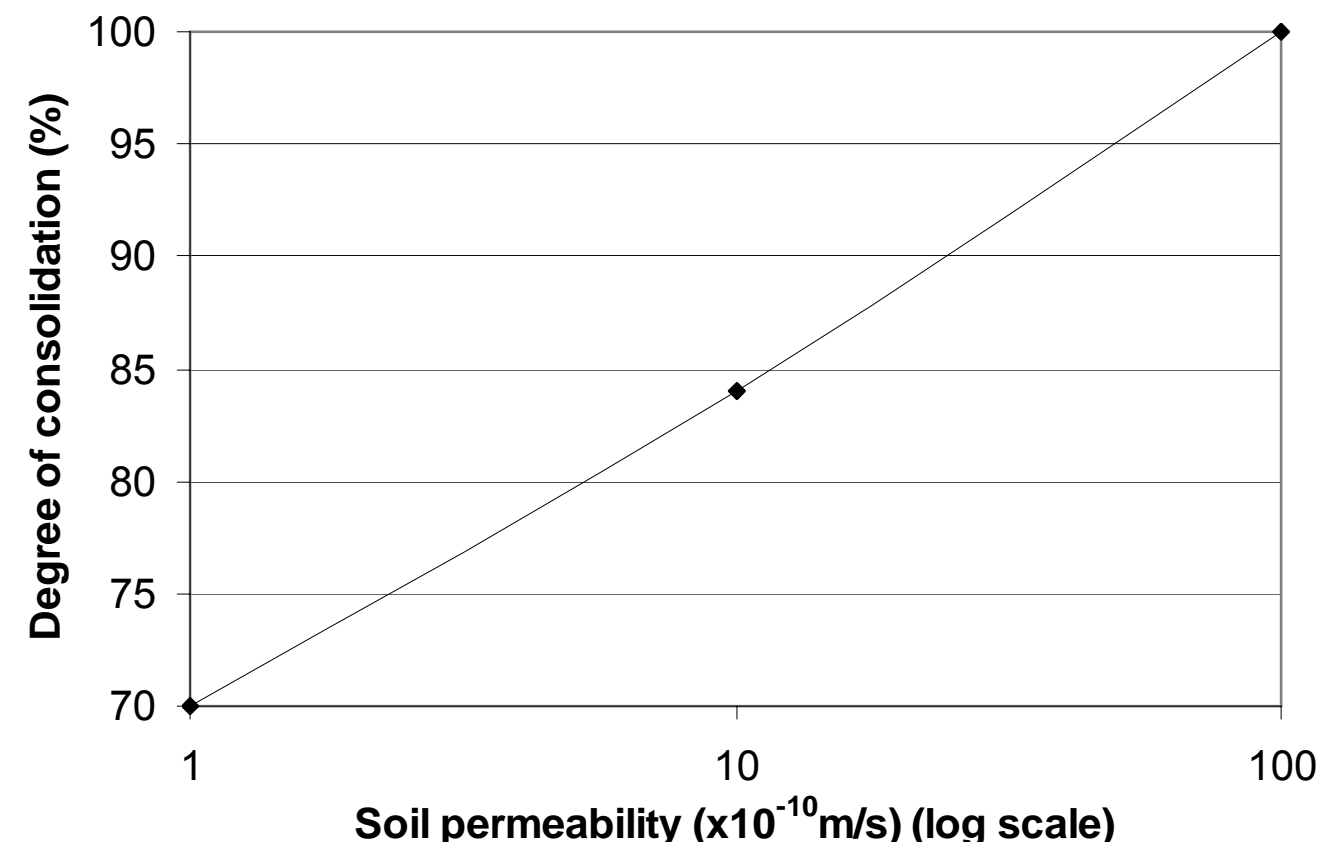

(b) Permeability in a $\log$ scale

Fig. 5-86. Degree of Consolidation versus Soil Permeability (3D) 
The degree of consolidation is plotted with respect to the soil permeability in Fig. 586. It can be seen that the soil permeability had a remarkable influence on the degree of consolidation. As shown in Fig. 5-86 (b), the degree of consolidation increased almost linearly with respect to the log scale of the soil permeability.

\section{Influence of Column Elastic Modulus}

The influence of the column modulus on the excess pore water pressure distribution along Section III-III is shown in Fig. 5-87. Apparently, the higher column modulus resulted in the lower the excess pore water pressure. This phenomenon can be explained that more excess pore water pressure dissipated by transferring the load from the soil to the columns when the column modulus was higher. Detailed discussion on this phenomenon can be found in Chapter Four.

The degree of consolidation is plotted against the column modulus in Fig. 5-88. The higher column modulus led to a higher degree of consolidation. 


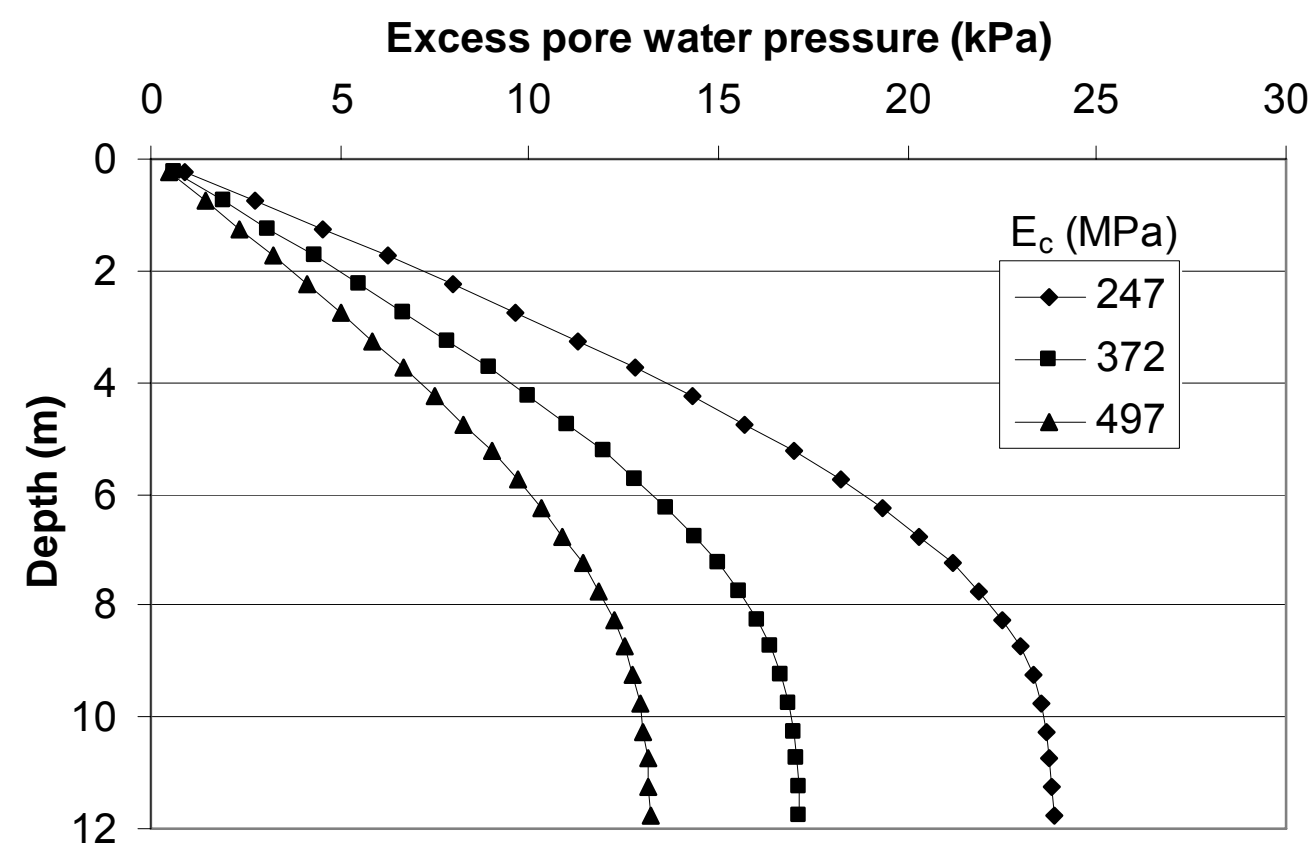

Fig. 5-87. Excess Pore Water Pressure Distributions for Various Column Moduli (3D)

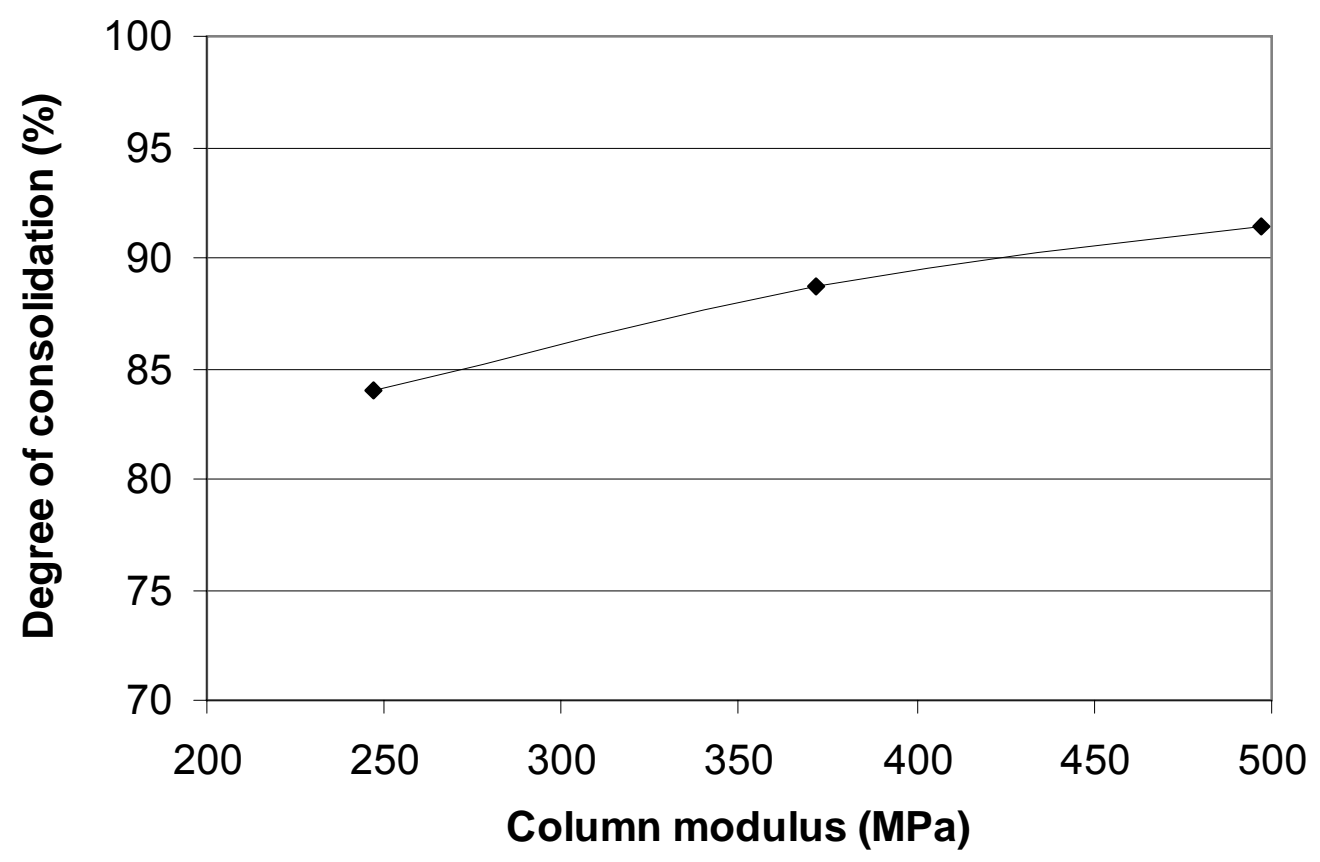

Fig. 5-88. Degree of Consolidation versus Various Column Moduli (3D) 


\section{Influence of Column Spacing}

The influence of the column spacing on the excess pore water pressure distribution along Section III-III is presented in Fig. 5-89. The larger column spacing led to a higher excess pore water pressure. This finding is consistent with that found in the 2D parametric study.

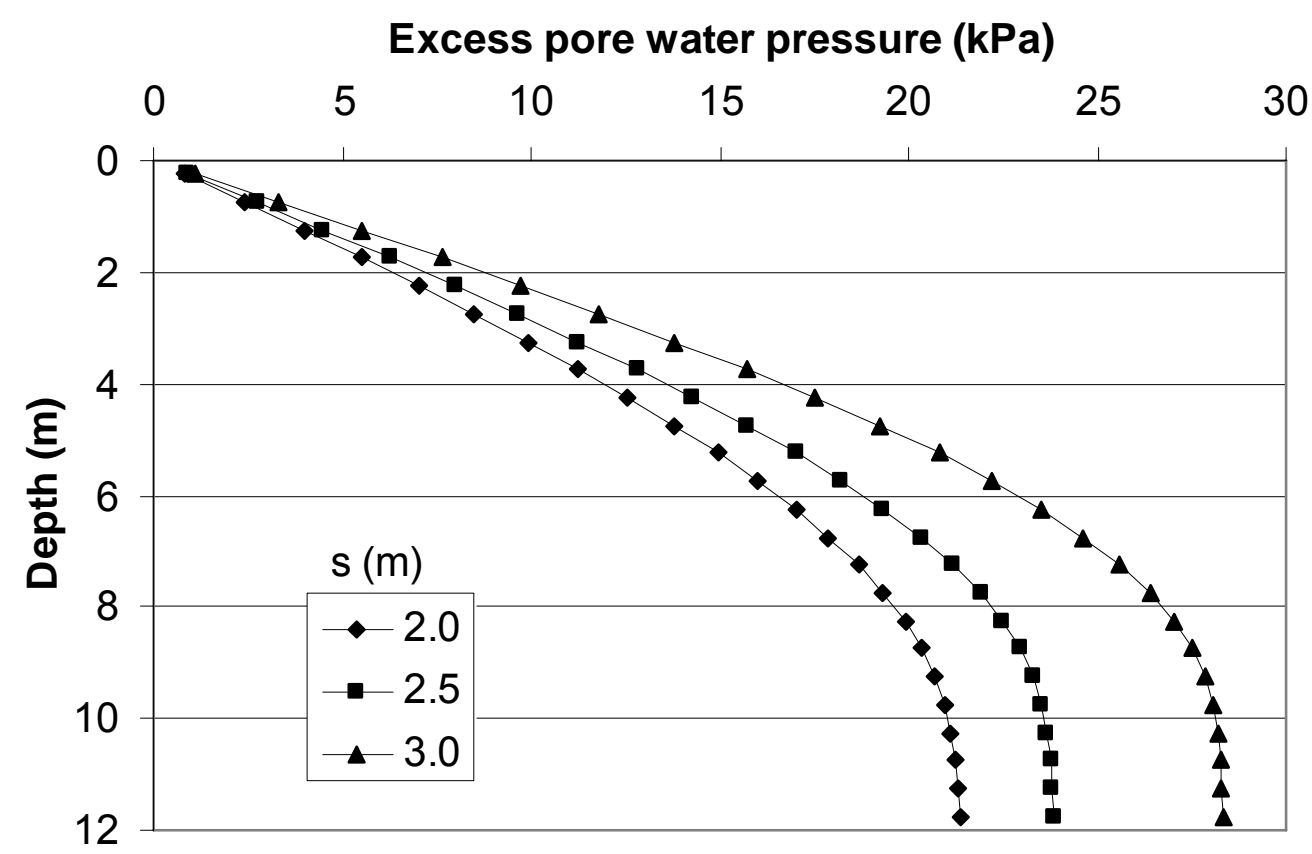

Fig. 5-89. Excess Pore Water Pressure Distributions for Various Column Spacing (3D)

The degree of consolidation is plotted against the column spacing in Fig. 5-90. Larger column spacing resulted in less degree of consolidation. 


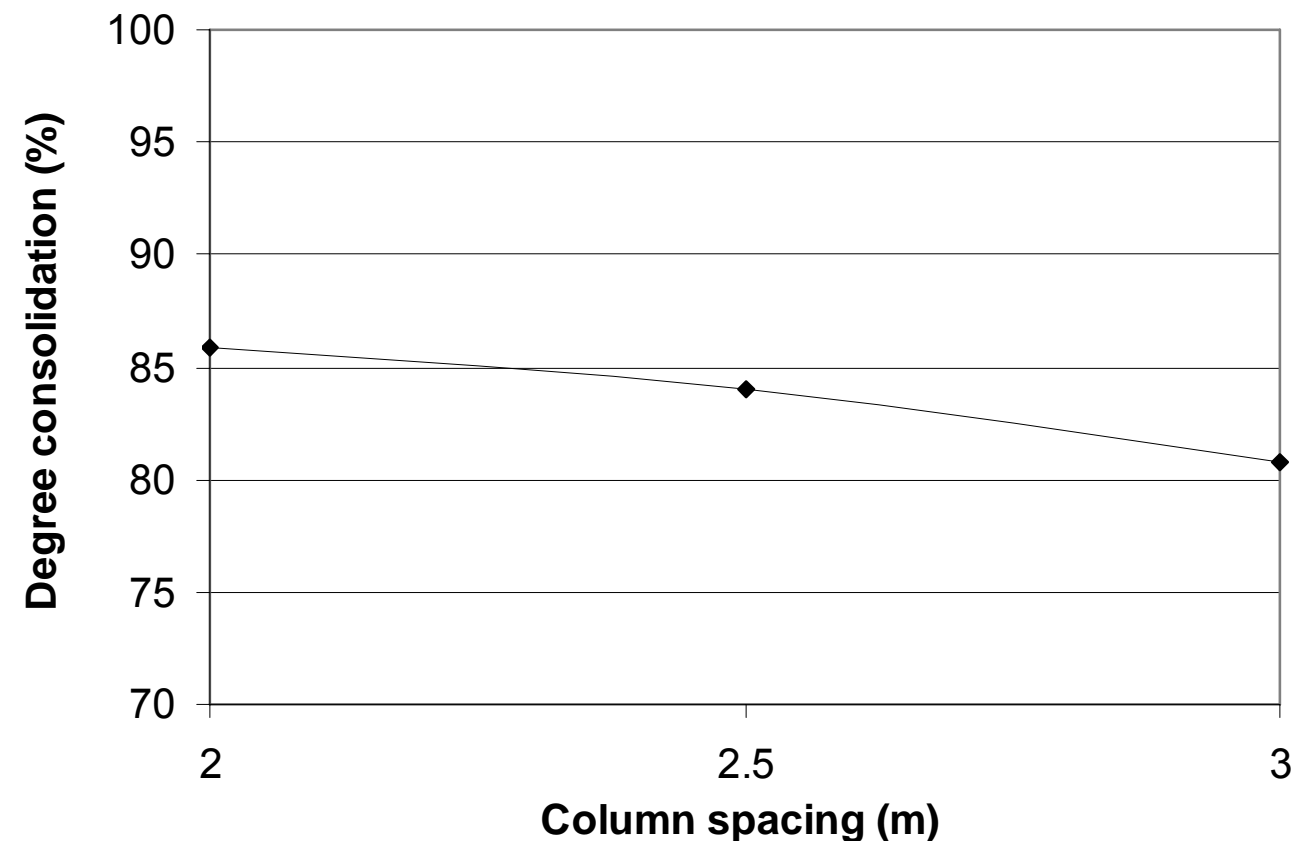

Fig. 5-90. Degree of Consolidation versus Column Spacing (3D)

\section{Influence of Geosynthetic Tensile Stiffness}

The influence of the geosynthetic tensile stiffness on the excess pore water pressure distribution along Section III-III is presented in Fig. 5-91. The increase of the tensile stiffness led to a slightly higher excess pore water pressure. The reason for the difference can be found in details in Chapter Four.

The degree of consolidation versus the geosynthetic tensile stiffness is presented in Fig. 5-92. The degree of consolidation decreases slightly with the increase of the geosynthetic tensile stiffness. 


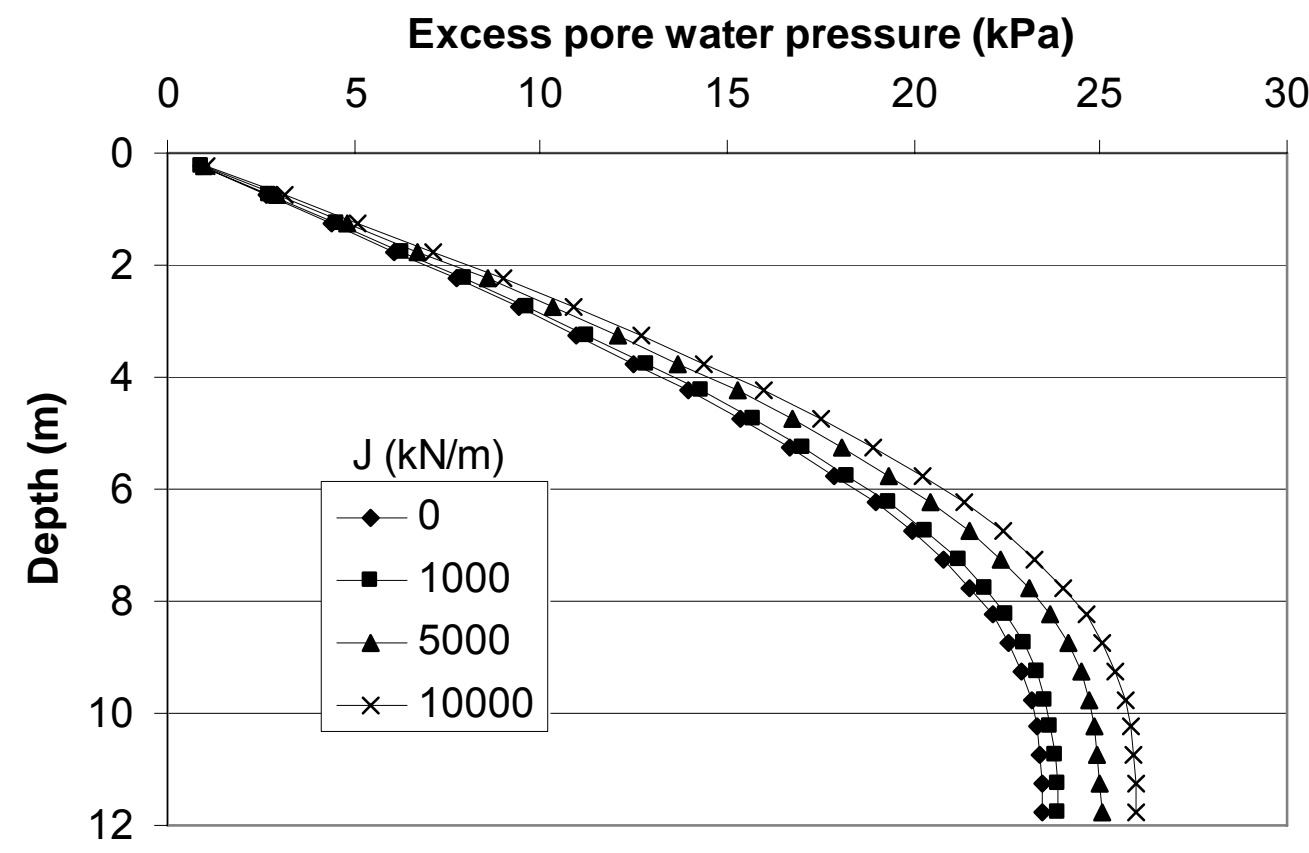

Fig. 5-91. Excess Pore Water Pressure Distributions for Various Tensile Stiffness (3D)

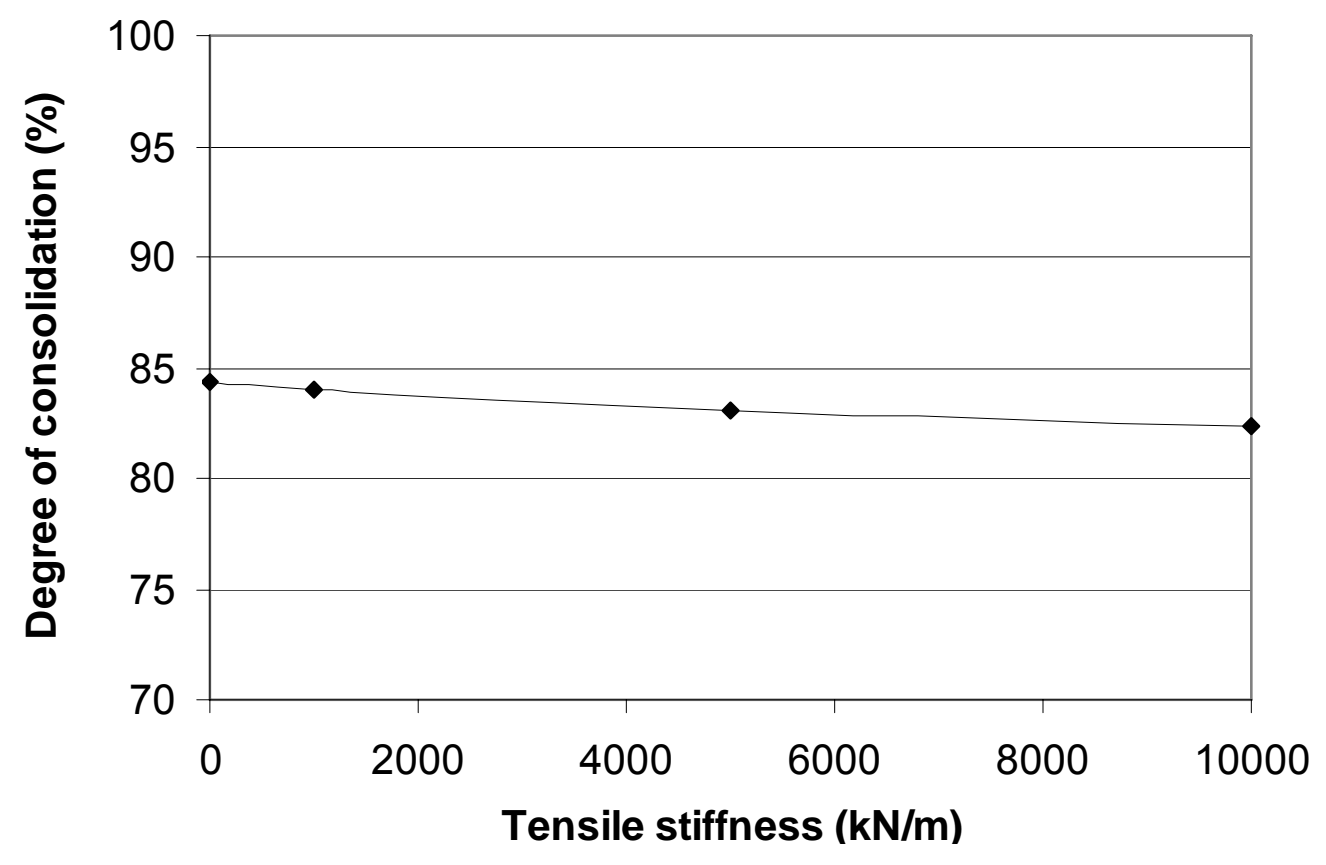

Fig. 5-92. Degree of Consolidation versus Tensile Stiffness (3D) 


\section{Influence of Construction Rate}

The influence of the excess pore water pressure distribution along Section III-III is presented in Fig. 5-93, which shows that the less excess pore water pressure accumulated at the lower average construction rate. As mentioned earlier, some of the excess pore water pressure dissipated during the construction. As the average construction rate was lower, more time was allowed for the excess pore pressure to dissipate during the construction.

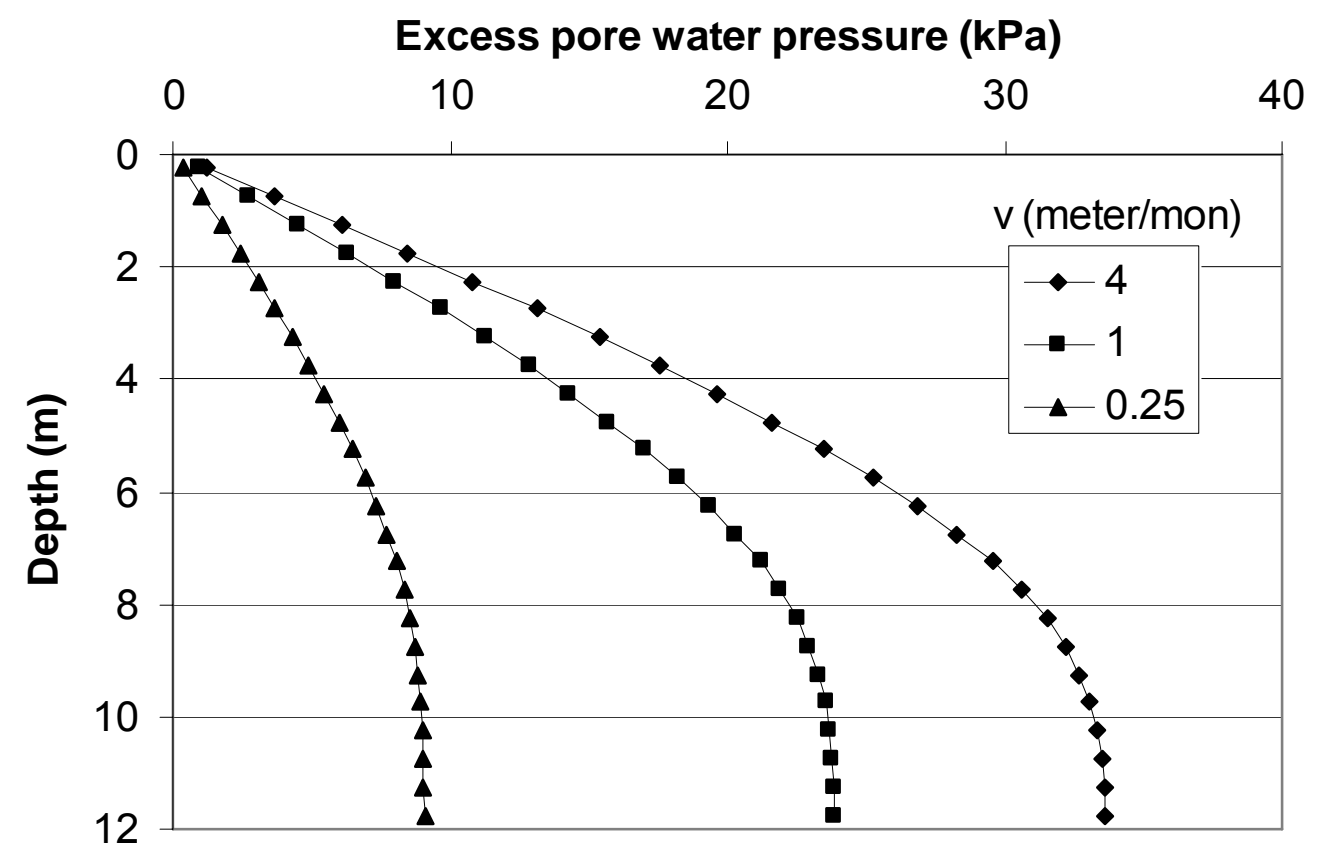

Fig. 5-93. Excess Pore Water Pressure Distributions for Various Average Construction Rates (3D)

The degree of consolidation is plotted with respect to the average construction rate in Fig. 5-94. The lower average construction rate yielded the higher degree of consolidation. 


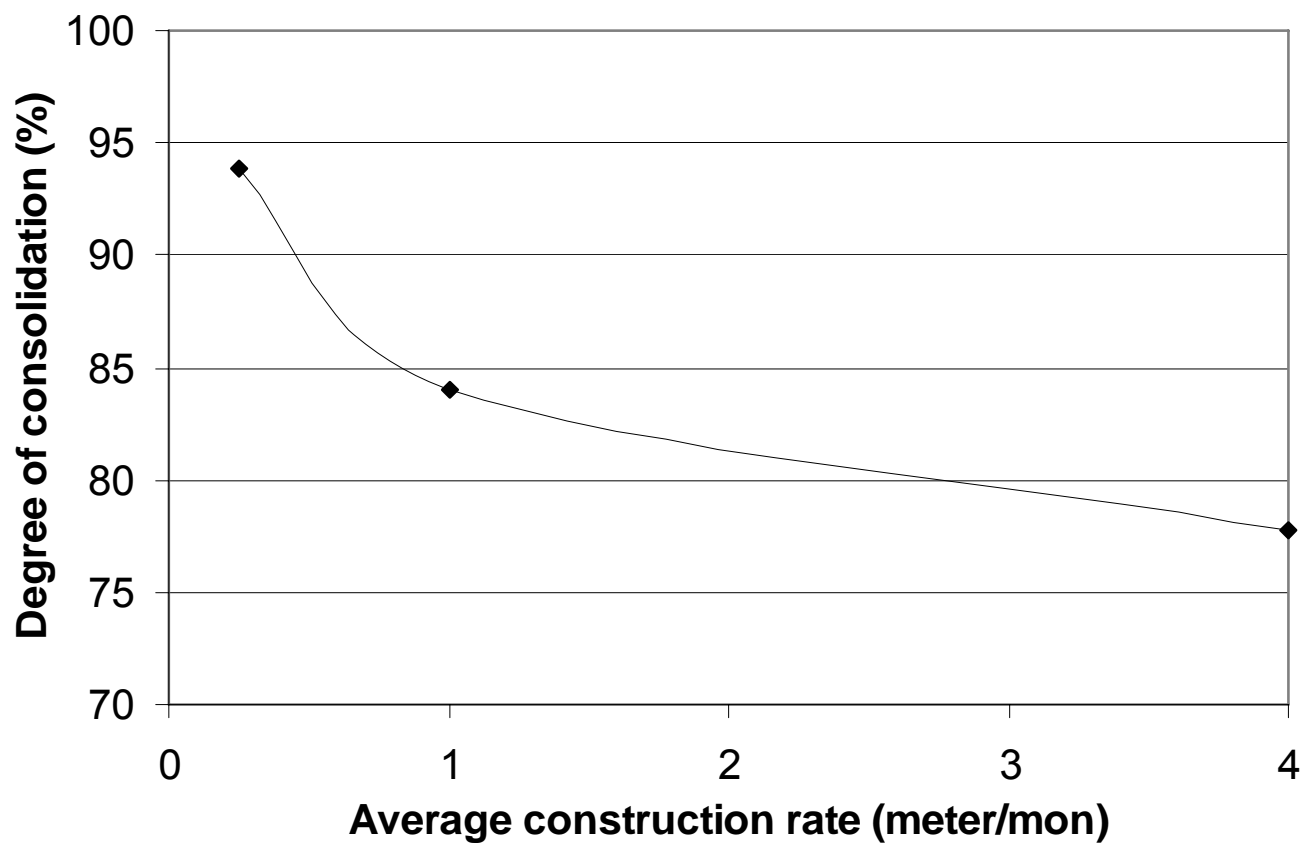

Fig. 5-94. Degree of Consolidation versus Average Construction Rate (3D) 


\section{CHAPTER SIX}

\section{COMPARISON OF TWO-DIMENSIONAL AND THREE DIMENSIONAL STUDIES}

Detailed 2D and 3D parametric study results have been presented in Chapters Four and Five, respectively. The results of the $2 \mathrm{D}$ and 3D parametric studies are summarized and compared in this chapter for two purposes. One is to evaluate the validity of the approach converting $3 \mathrm{D}$ cases into $2 \mathrm{D}$ cases based on their weighted areas. The column modulus in the 3D study was converted from the corresponding column modulus used in the 2D study and the other parameters were kept the same as those used in the $2 \mathrm{D}$ study. In practice, this weighted-area converting approach is commonly used to simplify columns installed in a square pattern to walls so that solutions or software for 2D problems can be used. To the author's best knowledge, however, this validity has been rarely verified. The second purpose of the comparison is to summarize and rate the influence of the investigated factors on the settlement, the tension, the stress concentration ratio, and the pore water pressure.

\subsection{Verification of Simplified Modeling}

Three-dimensional modeling is much more complicated and time-consuming than 2D modeling. Therefore, it is common practice to simplify a 3D case into a $2 \mathrm{D}$ case. One 
approach is to convert columns installed in a square pattern into walls based on a weighted area. Opposite to this procedure, walls can be converted to columns if the pattern of columns is known or assumed. As discussed in Chapter Five, the column moduli in the 3D parametric study were converted from those used in the $2 \mathrm{D}$ parametric study. For example, the column modulus of $247 \mathrm{MPa}$ under the $3 \mathrm{D}$ condition was converted from the wall modulus of $100 \mathrm{MPa}$ under the 2D condition.

The 2D modeling in this research terminated at 30 years after service, at which the degree of consolidation reached $100 \%$. The status at 30 years after service is considered as the final status of the 2D modeling. Even though the 3D modeling terminated at 4.5 years after service, most of the excess pore water pressures dissipated and the degrees of consolidation were more than $95 \%$. Therefore, the status at 4.5 years after service is approximately taken as the final status of the $3 \mathrm{D}$ modeling. The $2 \mathrm{D}$ and $3 \mathrm{D}$ results at one month after service and at the final status are both compared but an emphasis is on the results for the final status. The maximum settlements against the column moduli at one month after service and at the final status are presented in Fig. 6-1 (a) and (b), respectively. It is shown that the 2D results had the same maximum settlement trends on the crest and at the base with the increase of the modulus as the 3D results. However, the 2D results overestimated the maximum settlement both on the crest and at the base as compared with the $3 \mathrm{D}$ results. In addition, the maximum distortion is plotted against the column modulus in Fig. 6-2, which shows that the $2 \mathrm{D}$ results underestimated the maximum distortion at 
one month after service and the final status as compared with the $3 \mathrm{D}$ results. These comparisons show the differences in the maximum settlement and distortion between the converted 2D cases and the corresponding 3D ones.

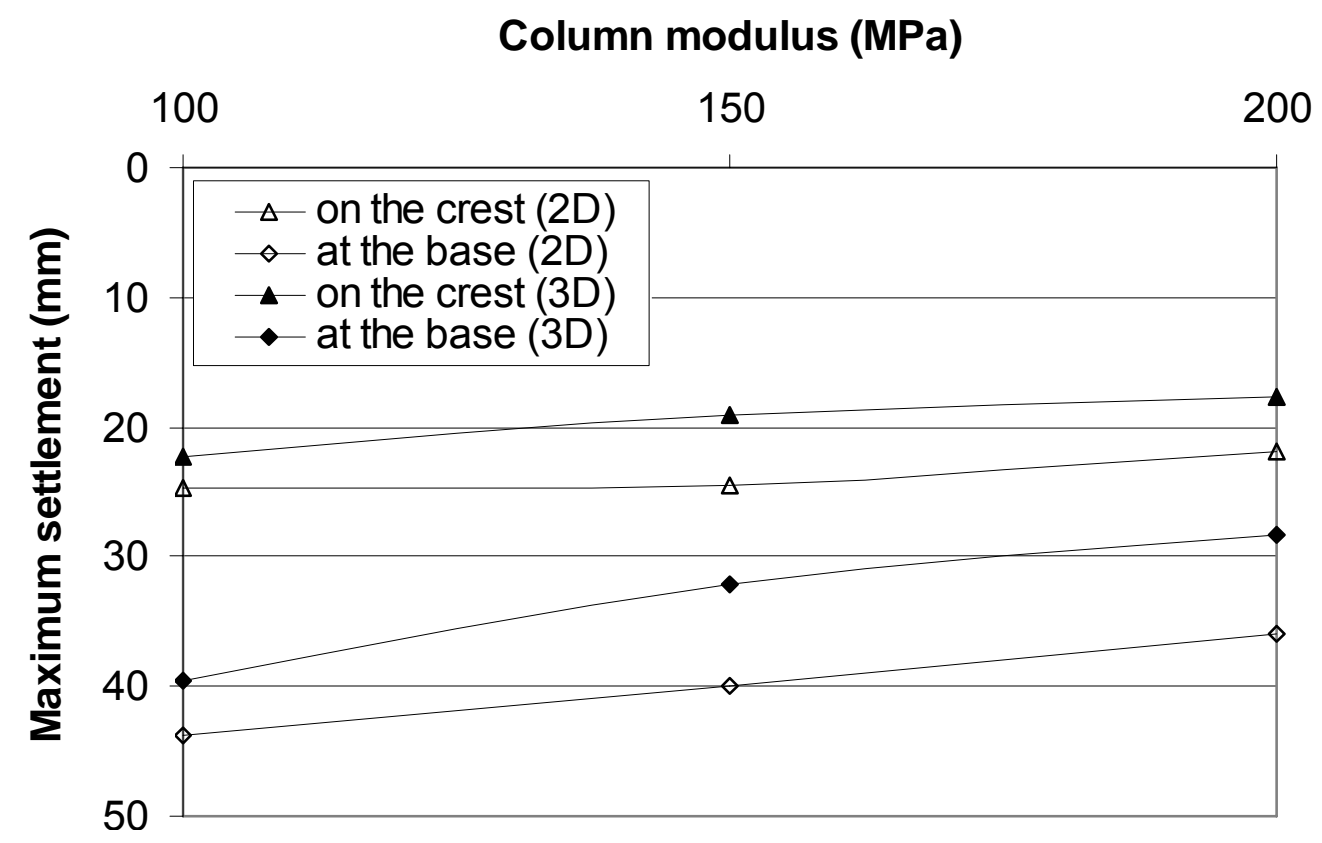

(a) 1 month after service

Fig. 6-1. Comparison of Maximum Settlement 


\section{Column modulus (MPa)}

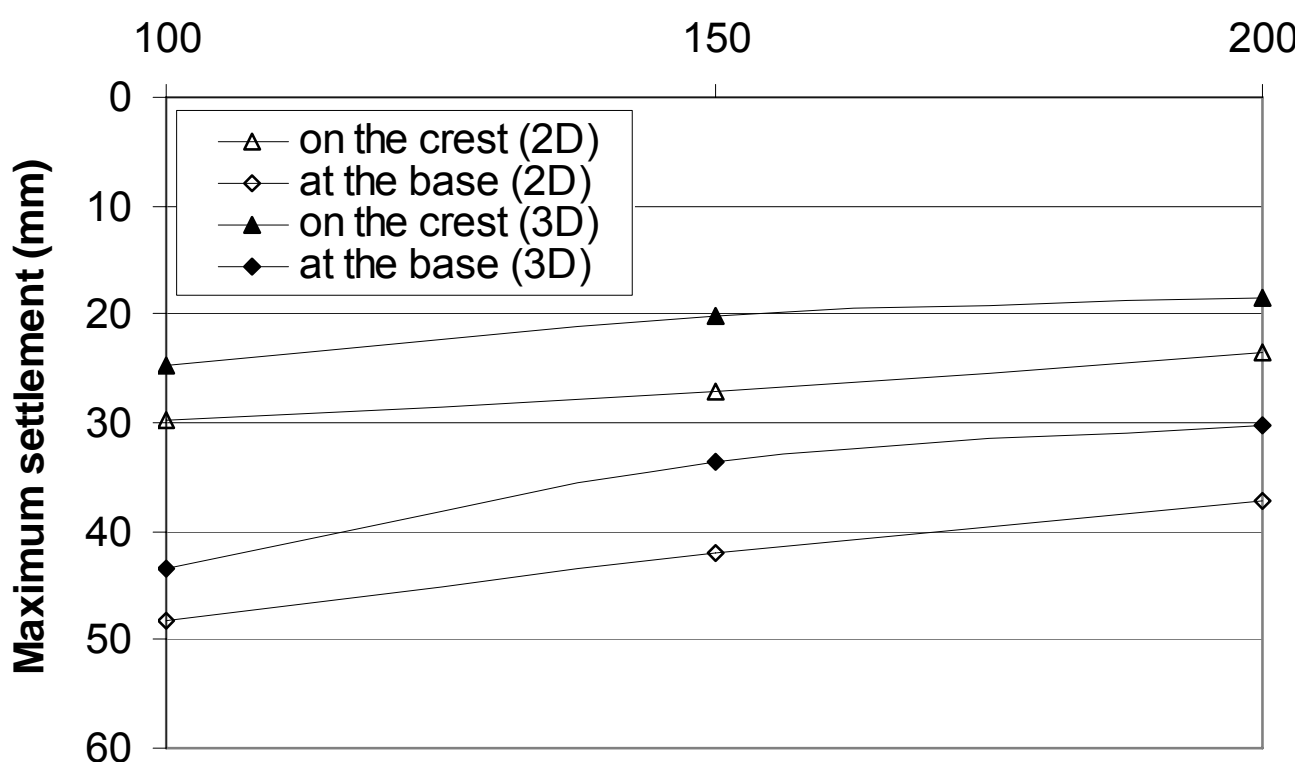

(b) Final status

Fig. 6-1. Comparison of Maximum Settlement (continued)

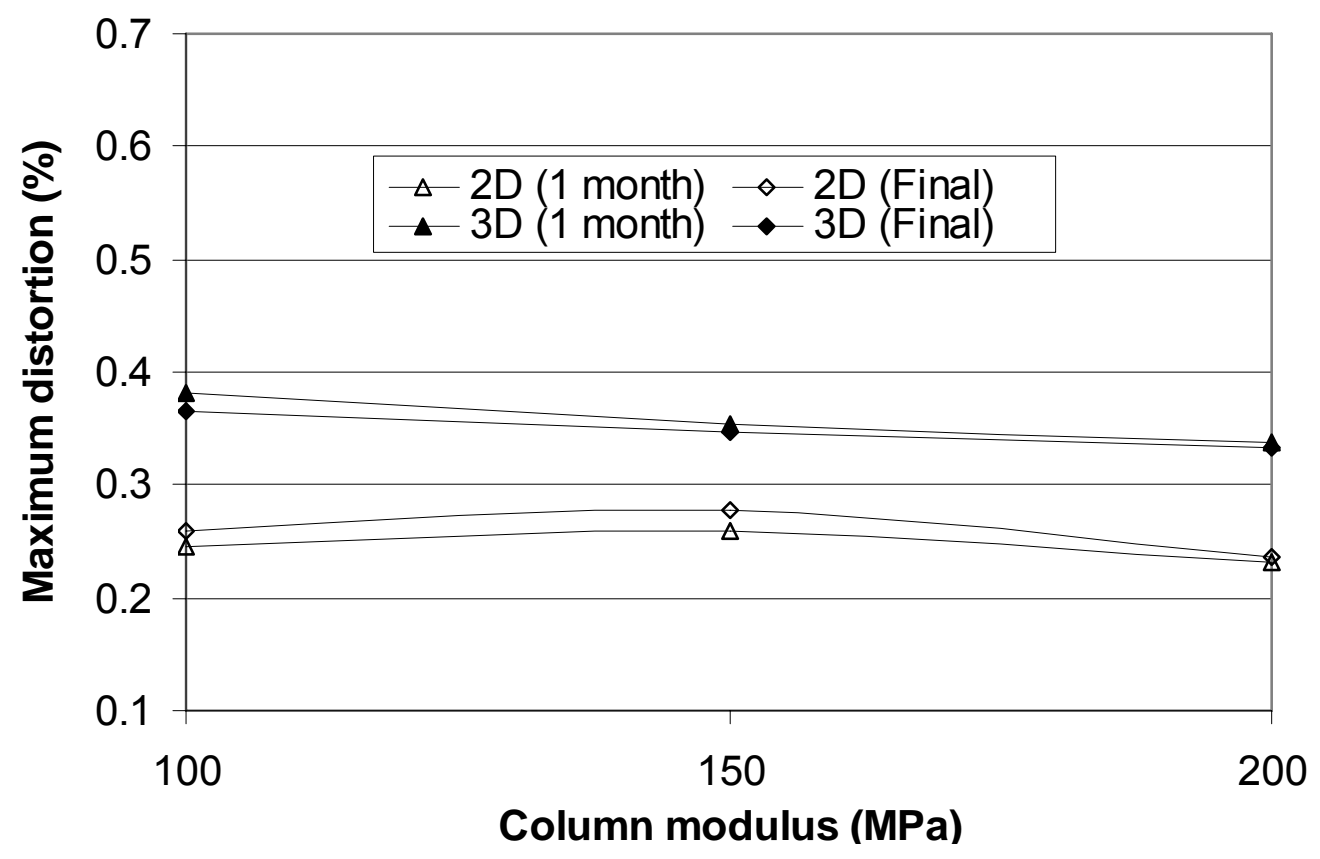

Fig. 6-2. Comparison of Maximum Distortion 
The maximum tension in the geosynthetic reinforcement against the column modulus is plotted in Fig. 6-3. The legends, "3D (X, one month)" and "3D (Y, one month)", represent the tension developed in the $\mathrm{x}$ and $\mathrm{y}$ directions, respectively at one month after service while "3D ( $\mathrm{X}$, final)" and "3D ( $\mathrm{Y}$, final)" represent the tension developed in the $\mathrm{x}$ and $\mathrm{y}$ directions, respectively at the final status. Figure 6-3 shows that the maximum tension obtained from the 2D modeling deviated from that from the 3D modeling except when the column modulus was close to 100MPa. It is also shown that the tension in the y direction was much lower than that in the $\mathrm{x}$ direction.

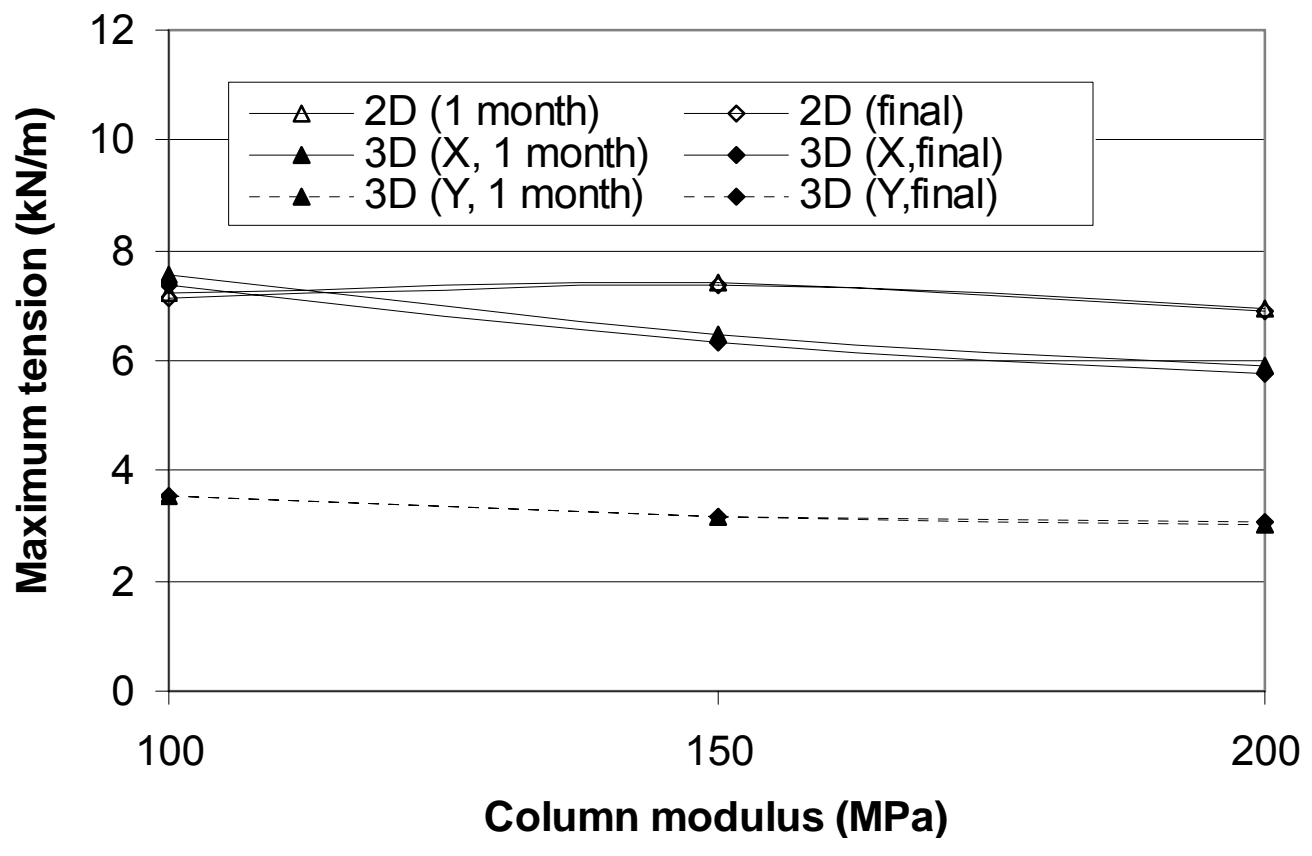

Fig. 6-3. Comparison of Maximum Tension

The maximum stress concentration ratio is plotted against the column modulus in Fig. 6-4. It is expected that the $2 \mathrm{D}$ cases underestimated the maximum stress 
concentration ratio as compared with the corresponding $3 \mathrm{D}$ cases since the column moduli in the $2 \mathrm{D}$ cases were lower than those in the corresponding $3 \mathrm{D}$ cases.

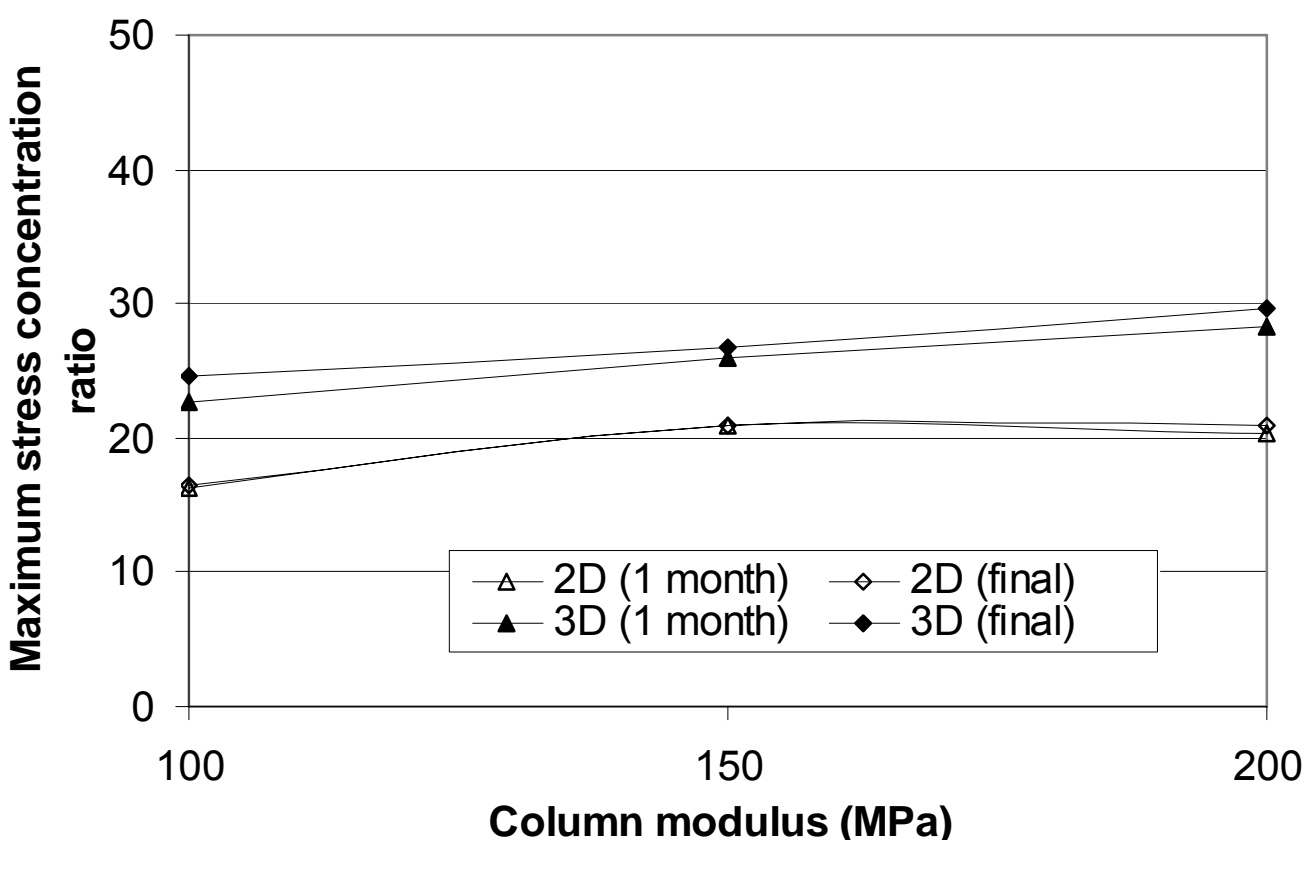

Fig. 6-4. Comparison of Maximum Stress Concentration Ratio

The degree of consolidation at one month after service is plotted against the column modulus in Fig. 6-5 to evaluate the difference in the excess pore water pressure. The 2D cases underestimated the degree of consolidation as compared with the corresponding 3D cases. 


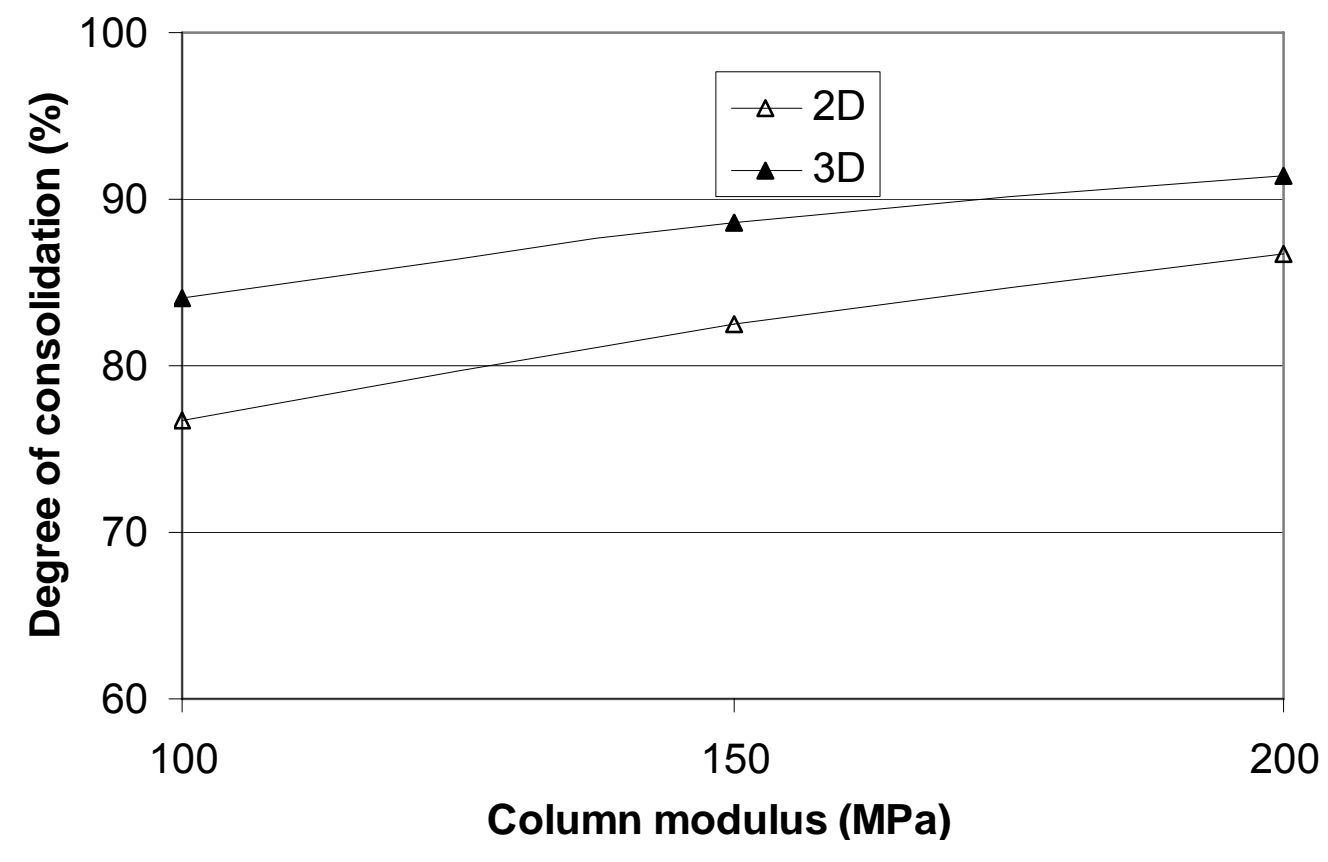

Fig. 6-5. Comparison of Degree of Consolidation

On the basis of the above comparisons, a general conclusion can be made: the simplified 2D model can not well compute the maximum settlement, the maximum distortion, the maximum tension, the maximum stress concentration ratio, and the degree of consolidation if the columns are actually arranged in a 3D pattern, such as the square pattern in this study.

\subsection{D and 3D Comparisons}

Even though the influence of each factor on the performance of GRCS embankments has been discussed in Chapter Four for the 2D modeling and Chapter Five for the 3D 
modeling, they have not been summarized and well compared. Hence, the 2D and 3D results would be summarized, compared, and rated herein. In this section, both the results at one month after service and at the final status are presented, however, the results at the final status are used as the bases for the comparisons.

\subsubsection{Maximum Settlement and Distortion}

The settlement is the key issue for the performance of the GRCS embankments, especially the maximum and differential settlements on the crest. To evaluate the influence of each factor on the maximum and differential settlements, the maximum settlement and distortion on the crest of the embankment are used.

\section{Influence of Soft Soil Elastic Modulus}

The maximum settlement and distortion under 2D and 3D conditions are plotted against the soil modulus in Fig. 6-6 and Fig. 6-7, respectively. Figure 6-6 shows that although the maximum settlement under the 3D condition was smaller than that under the $2 \mathrm{D}$ condition, the degrees of influence under these two conditions were almost the same. The maximum settlement was reduced by about $20 \mathrm{~mm}$ under both conditions when the soil modulus increased from 1 to $8 \mathrm{MPa}$. 


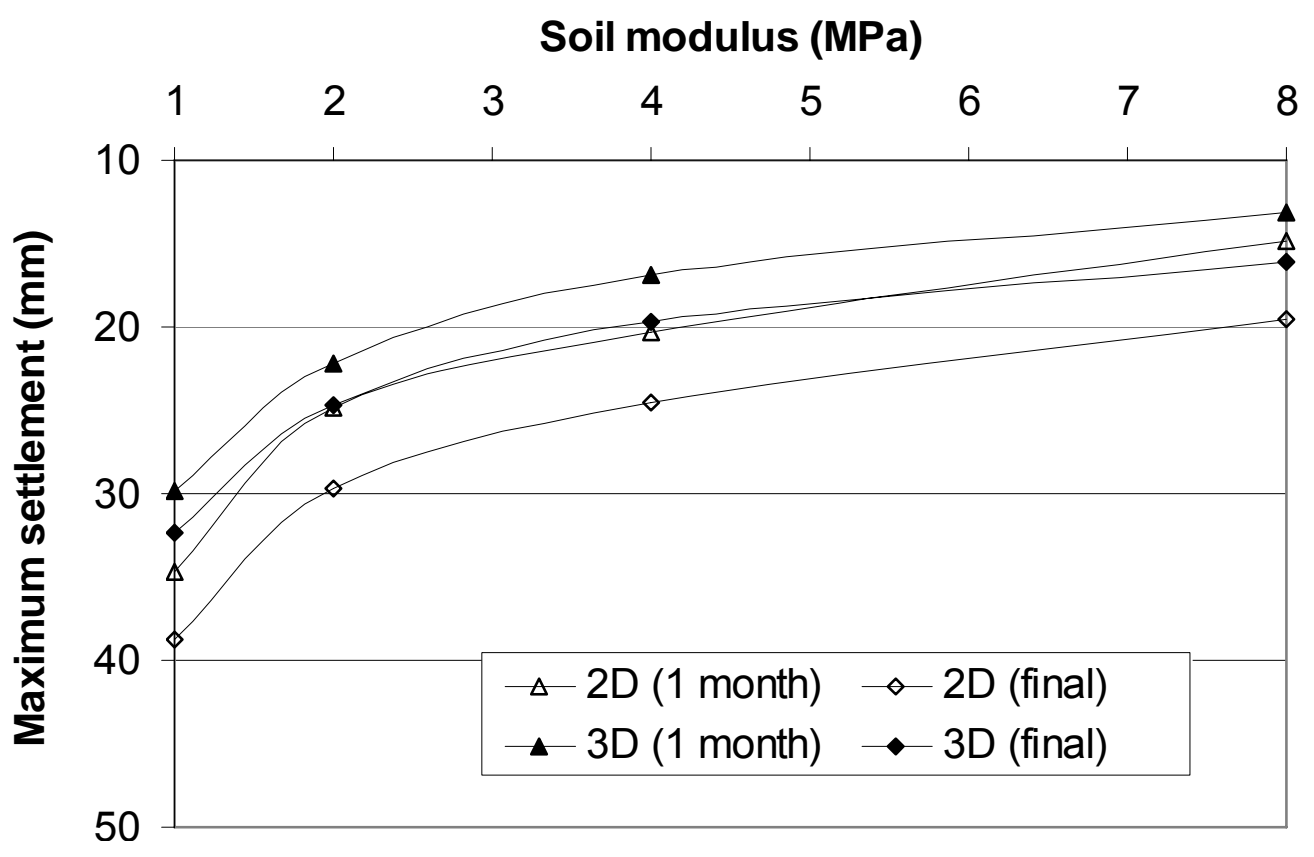

Fig. 6-6. Maximum Settlement versus Soil Modulus under 2D and 3D Conditions

The maximum distortion at the crest is presented against the soil modulus in Fig. 6-7. Apparently, the increase of the soil modulus had more effect on the reduction of the maximum distortion under the $3 \mathrm{D}$ condition than that under the $2 \mathrm{D}$ condition. When the soil modulus increased from 1 to $8 \mathrm{MPa}$, the maximum distortion under the $3 \mathrm{D}$ condition decreased by about $0.4 \%$, while the maximum distortion under the $2 \mathrm{D}$ condition decreased by about $0.3 \%$. 


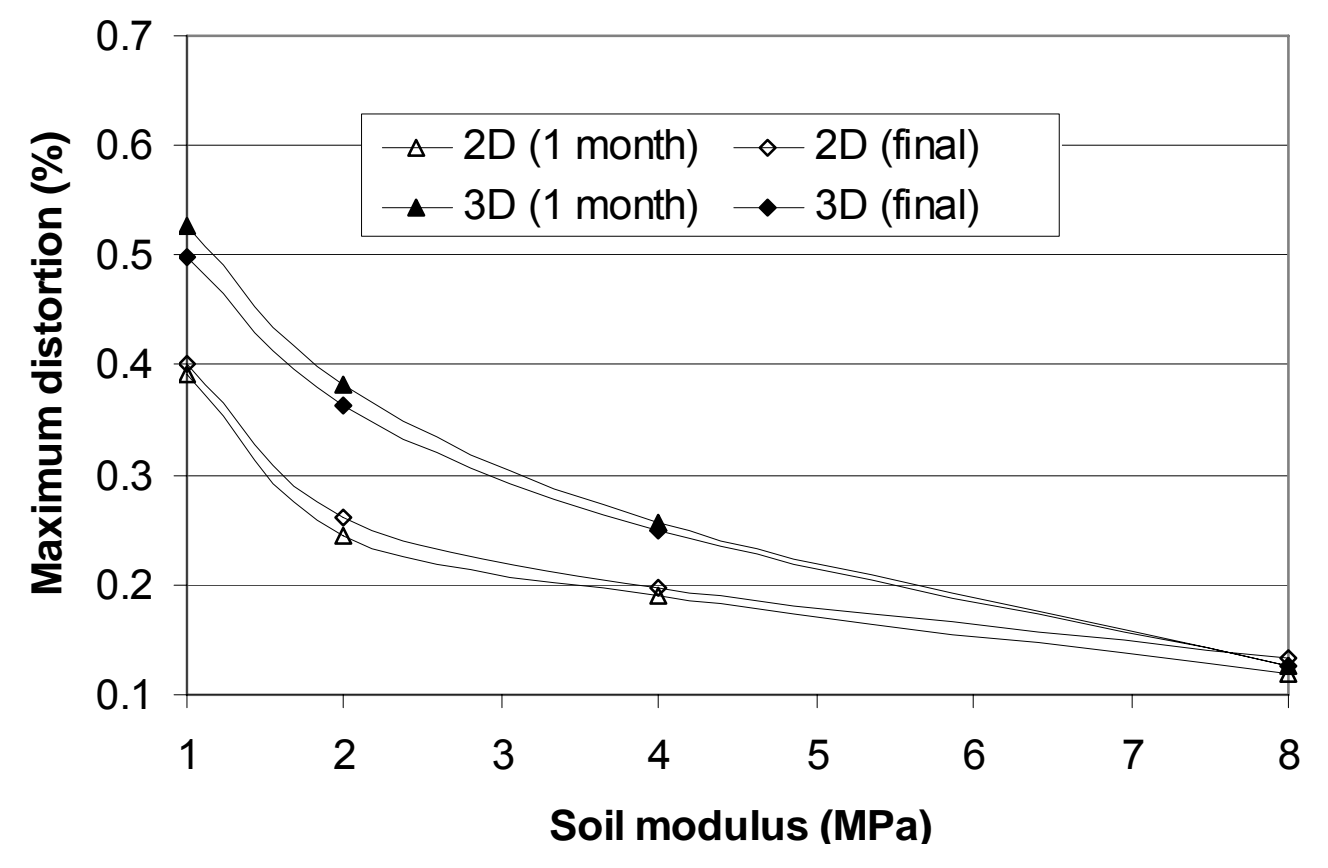

Fig. 6-7. Maximum Distortion versus Soil Modulus under 2D and 3D Conditions

\section{Influence of Soft Soil Friction Angle}

The maximum settlement and distortion against the soil friction angle are presented in Figs. 6-8 and 6-9, respectively. Apparently, the increase of the soil friction angle had a greater effect on the reduction in the maximum settlement and especially the maximum distortion under the $3 \mathrm{D}$ condition than those under the $2 \mathrm{D}$ condition. When the soil friction angle increased from $15^{\circ}$ to $30^{\circ}$, the maximum settlement under the $3 \mathrm{D}$ condition was reduced by $15 \mathrm{~mm}$ and the maximum distortion was reduced by $0.4 \%$, while the maximum settlement under the $2 \mathrm{D}$ condition was reduced by $10 \mathrm{~mm}$ and the maximum distortion was reduced by $0.1 \%$. These differences are attributed to the sliding of the embankment fill. The embankment constructed above the columns 
installed in a square pattern had a higher tendency of sliding than that above the walls. Unlike the $2 \mathrm{D}$ condition, the columns in a square pattern were isolated by the soft soil. The sliding surface extending into the foundation could cut through the soft soil without intersecting with any DM columns. Local failure was more likely to occur. The increase of the soil strength would minimize the local failure; therefore, it had a remarkable influence on both the maximum settlement and the maximum distortion.

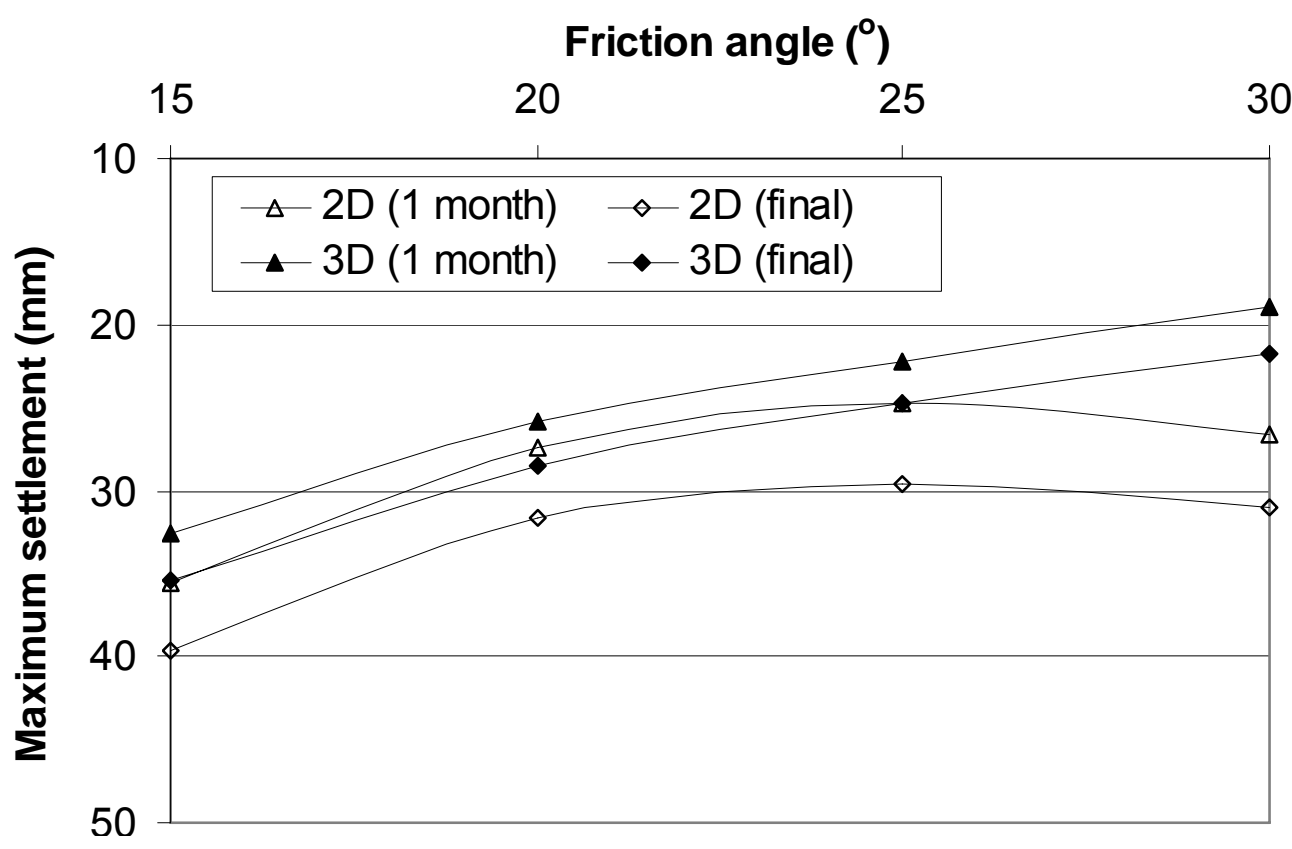

Fig. 6-8. Maximum Settlement versus Friction Angle under 2D and 3D Conditions 


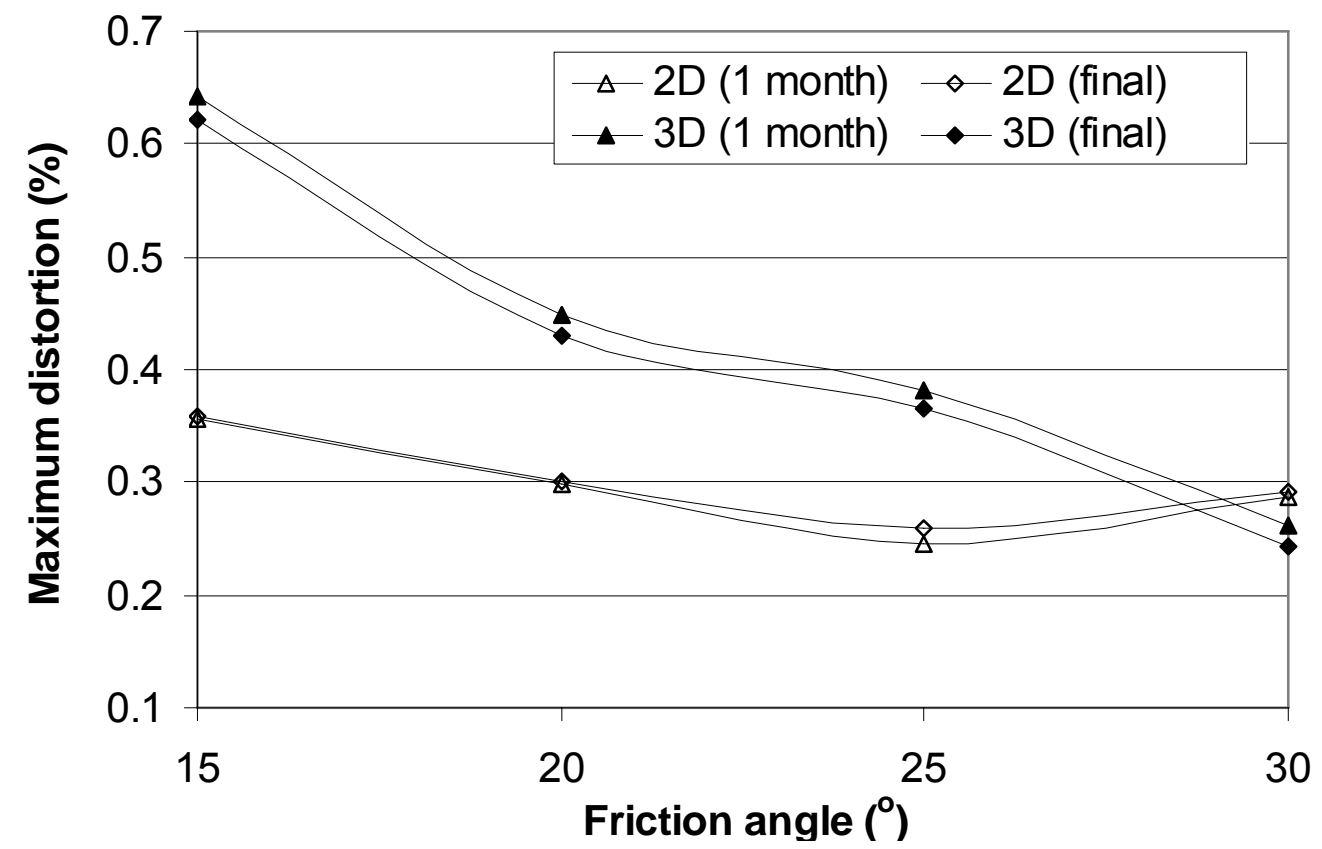

Fig. 6-9. Maximum Distortion versus Friction Angle under 2D and 3D Conditions

\section{Influence of Soft Soil Permeability}

The influences of the soil permeability on the maximum settlement and the maximum distortion are presented in Fig. 6-10 and 6-11, respectively, which show that the increase of the soil permeability had a significant effect on the reduction of the maximum settlement and the maximum distortion under both 3D and 2D conditions. As the soil permeability increased from $10^{-10} \mathrm{~m} / \mathrm{s}$ to $10^{-8} \mathrm{~m} / \mathrm{s}$, the maximum settlement decreased by approximately $17 \mathrm{~mm}$ and the maximum distortion decreased by $0.4 \%$ under the 3D condition, while the maximum settlement and the maximum distortion decreased by about $22 \mathrm{~mm}$ and $0.2 \%$ under the $2 \mathrm{D}$ condition, respectively. 


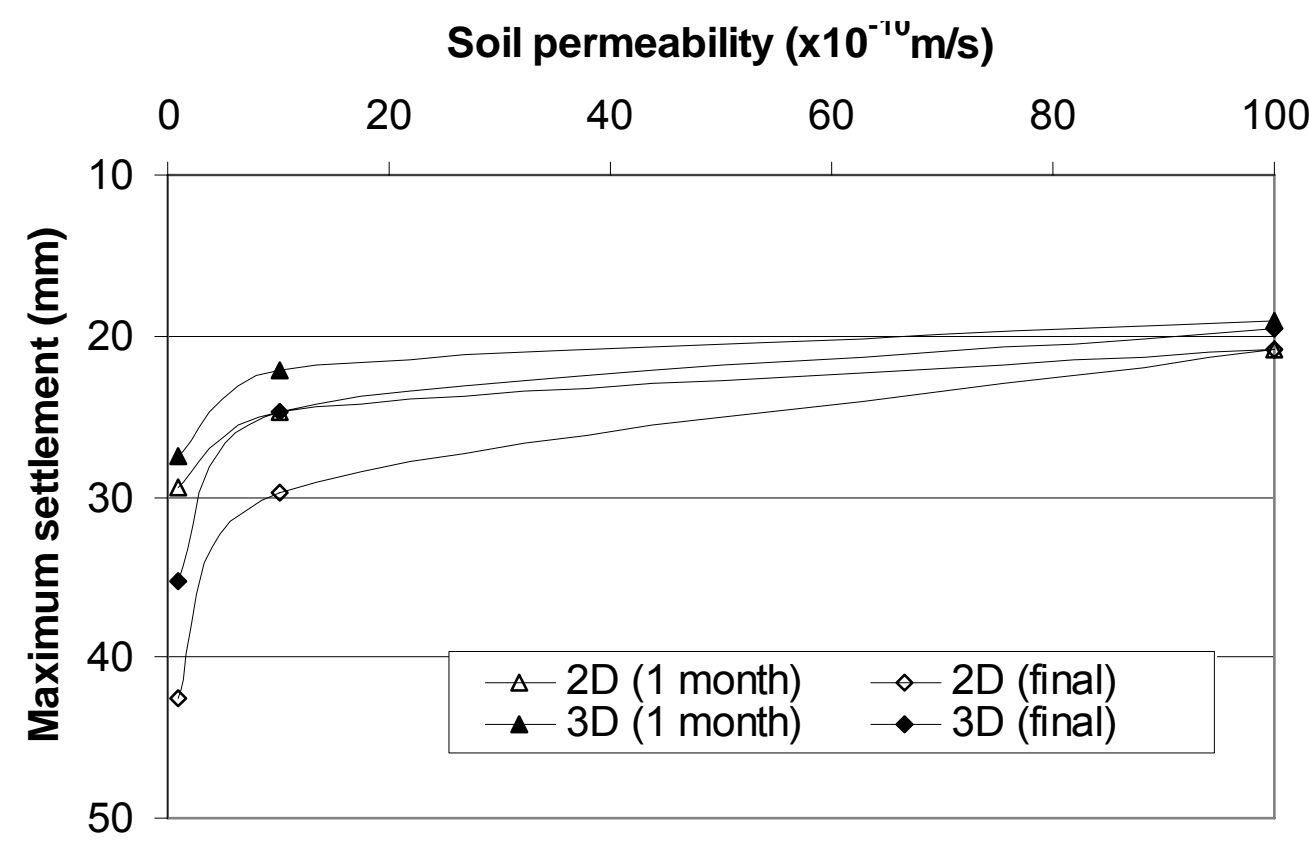

Fig. 6-10. Maximum Settlement versus Soil Permeability under 2D and 3D Conditions

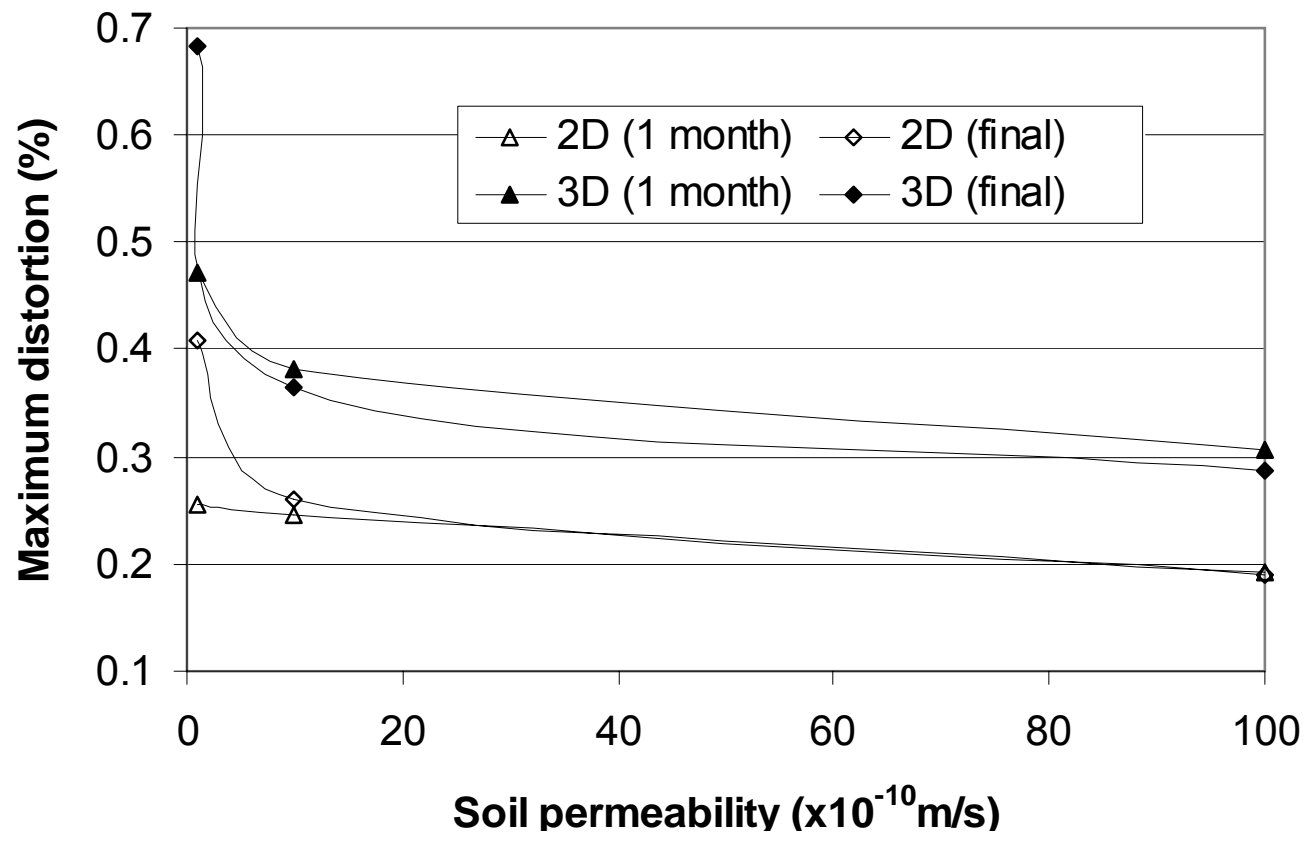

Fig. 6-11. Maximum Distortion versus Soil Permeability under 2D and 3D Conditions 


\section{Influence of Column Elastic Modulus}

The influences of the column modulus on the maximum settlement and the maximum distortion under both 3D and 2D conditions are shown in Fig. 6-12 and 6-13, respectively. The increase of the column modulus had an effect on the reduction in the maximum settlement and the maximum distortion. However, this effect was limited under both 3D and 2D conditions. An increase of the column modulus from $100 \mathrm{MPa}$ to $200 \mathrm{MPa}$ reduced the maximum settlement and the maximum distortion by about $8 \mathrm{~mm}$ and $0.03 \%$, respectively under the 3D condition, and by $6 \mathrm{~mm}$ and $0.01 \%$, respectively under the $2 \mathrm{D}$ condition.

\section{Column modulus (MPa)}

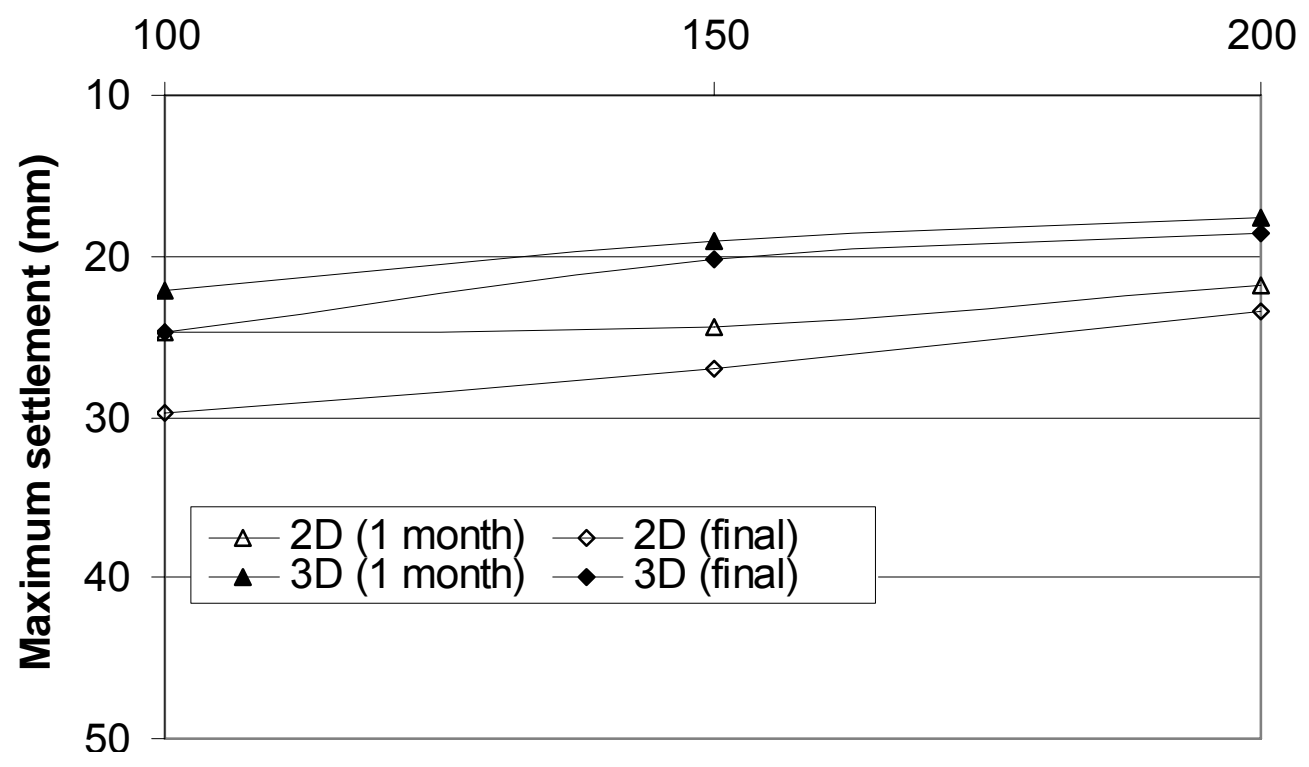

Fig. 6-12. Maximum Settlement versus Column Modulus under 2D and 3D Conditions 


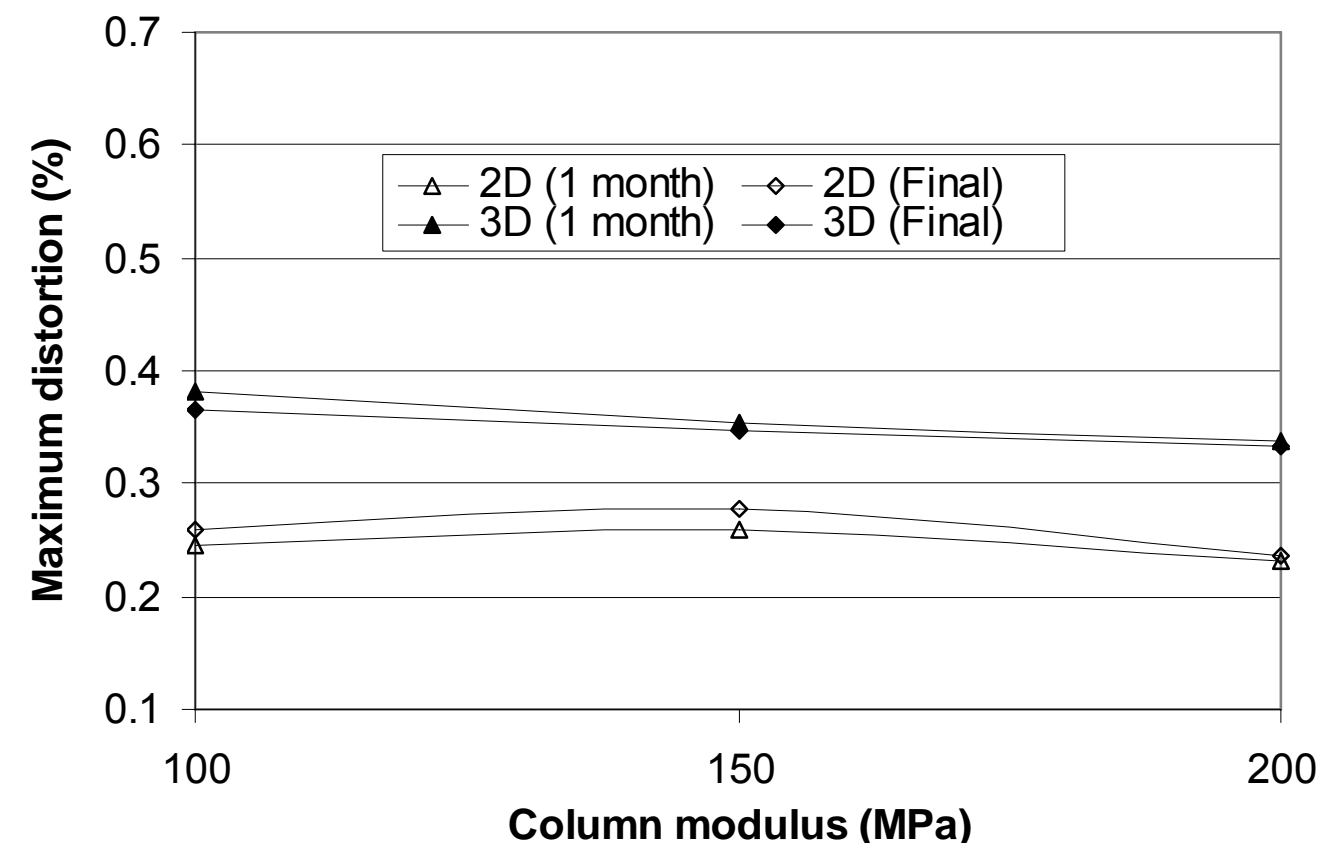

Fig. 6-13. Maximum Distortion versus Column Modulus under 2D and 3D Conditions

\section{Influence of Column Spacing}

The maximum settlement and the maximum distortion against the column spacing are presented in Fig. 6-14 and 6-15, respectively. As the column spacing increased from $2 \mathrm{~m}$ to $3 \mathrm{~m}$, the maximum settlement increased about $20 \mathrm{~mm}$ and $17 \mathrm{~mm}$ under the $3 \mathrm{D}$ and $2 \mathrm{D}$ conditions, respectively while the maximum distortion increased about $0.35 \%$ and $0.19 \%$ under the 3D and 2D conditions, respectively. 


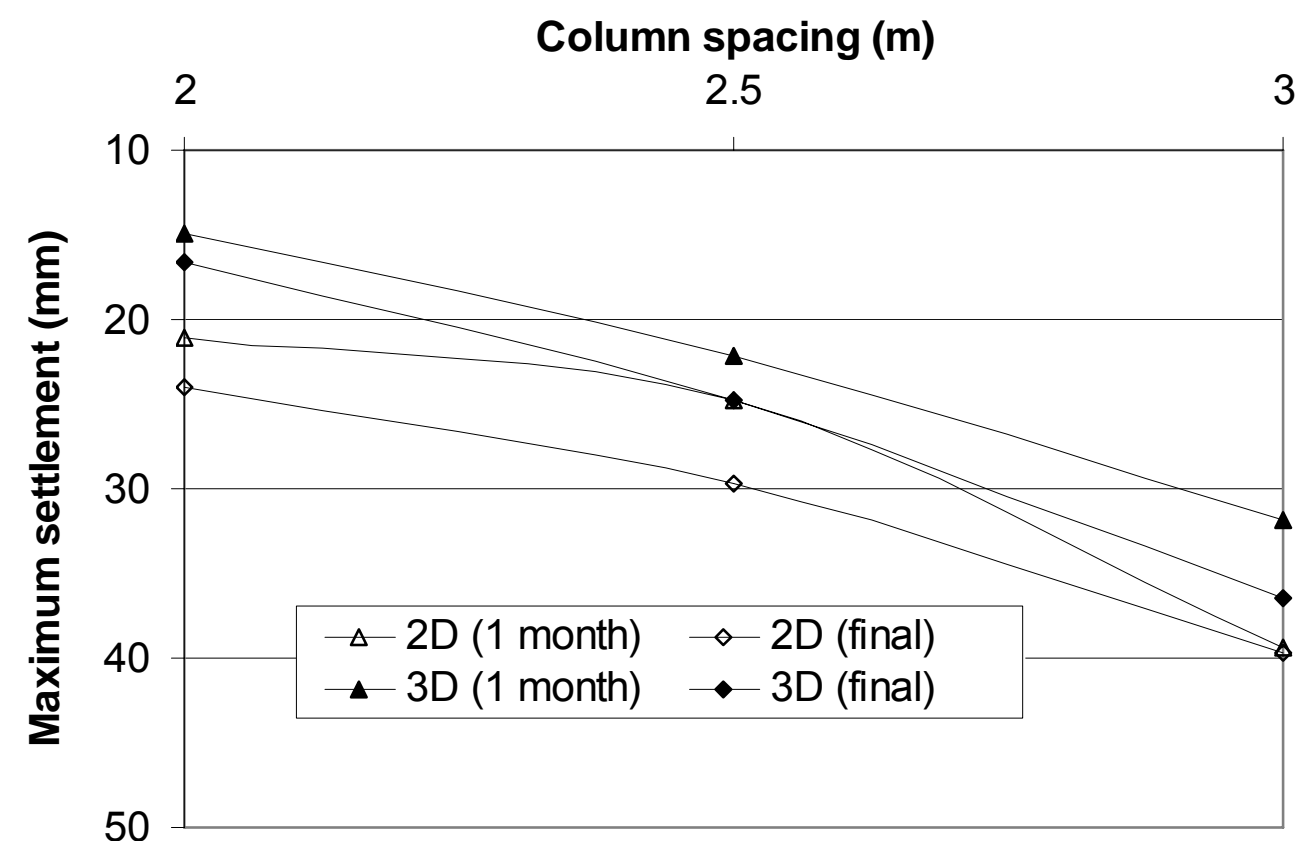

Fig. 6-14. Maximum Settlement versus Column Spacing under 2D and 3D Conditions

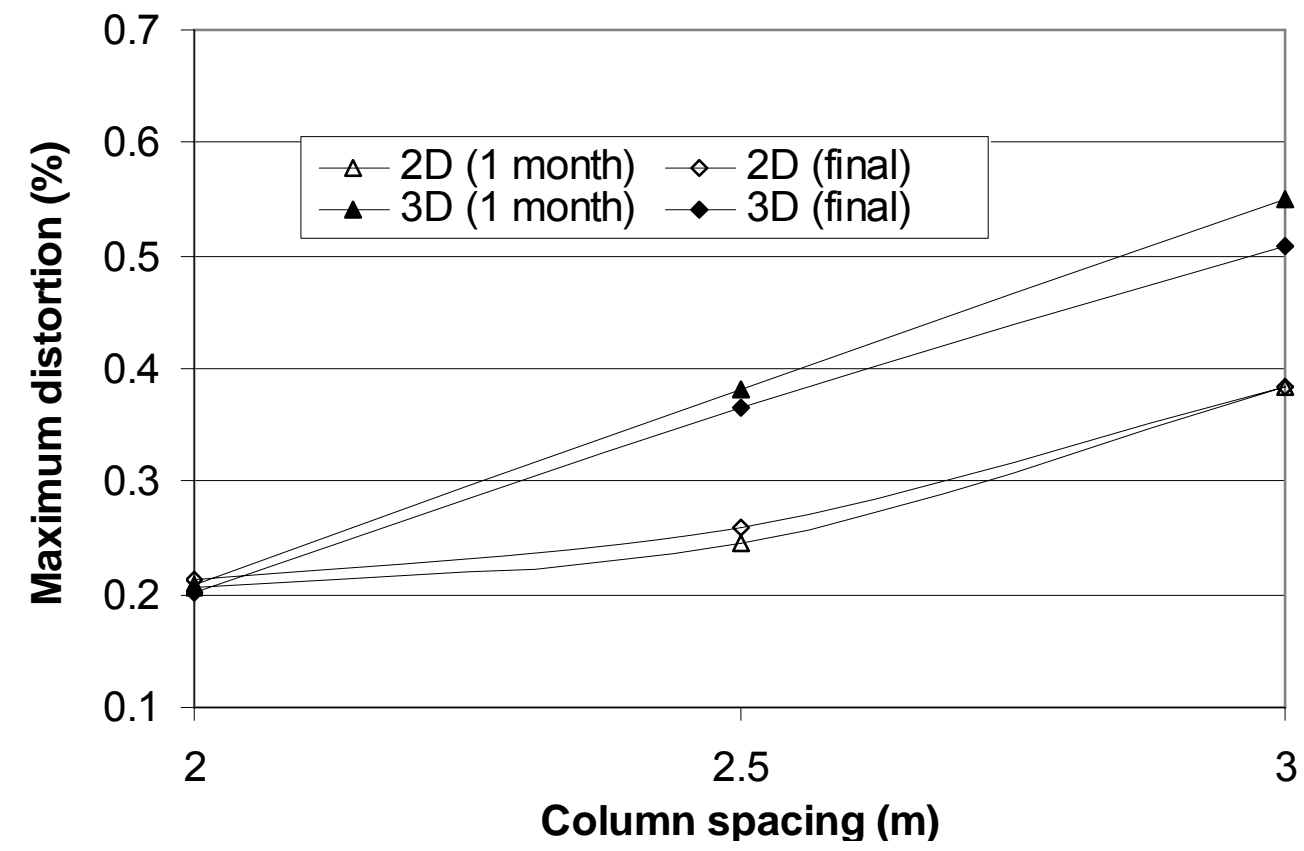

Fig. 6-15. Maximum Distortion versus Column Spacing under 2D and 3D Conditions 


\section{Influence of Geosynthetic Tensile Stiffness}

The maximum settlement and the maximum distortion are plotted against the geosynthetic tensile stiffness in Figs. 6-16 and 6-17, respectively, which show that the geosynthetic tensile stiffness had an limited effect on the maximum settlements under both 3D and 2D conditions. The maximum settlements decreased by approximately $2 \mathrm{~mm}$ under $3 \mathrm{D}$ and $2 \mathrm{D}$ conditions as the tensile stiffness increased from 0 to $10,000 \mathrm{kN} / \mathrm{m}$. However, the geosynthetic tensile stiffness had a significant influence on the maximum distortion under the 3D condition but an insignificant influence on the maximum distortion under the $2 \mathrm{D}$ condition. When the geosynthetic tensile stiffness varied from 0 to $10,000 \mathrm{kN} / \mathrm{m}$, the maximum distortion decreased by $0.3 \%$ under the $3 \mathrm{D}$ condition but only by $0.02 \%$ under the $2 \mathrm{D}$ condition. This discrepancy is also attributed to the local deformation between individual columns or walls. Hence, the tendency of the local deformation can be mitigated by the geosynthetic reinforcement. The geosynthetic with the higher tensile stiffness had more effect on the mitigation. 


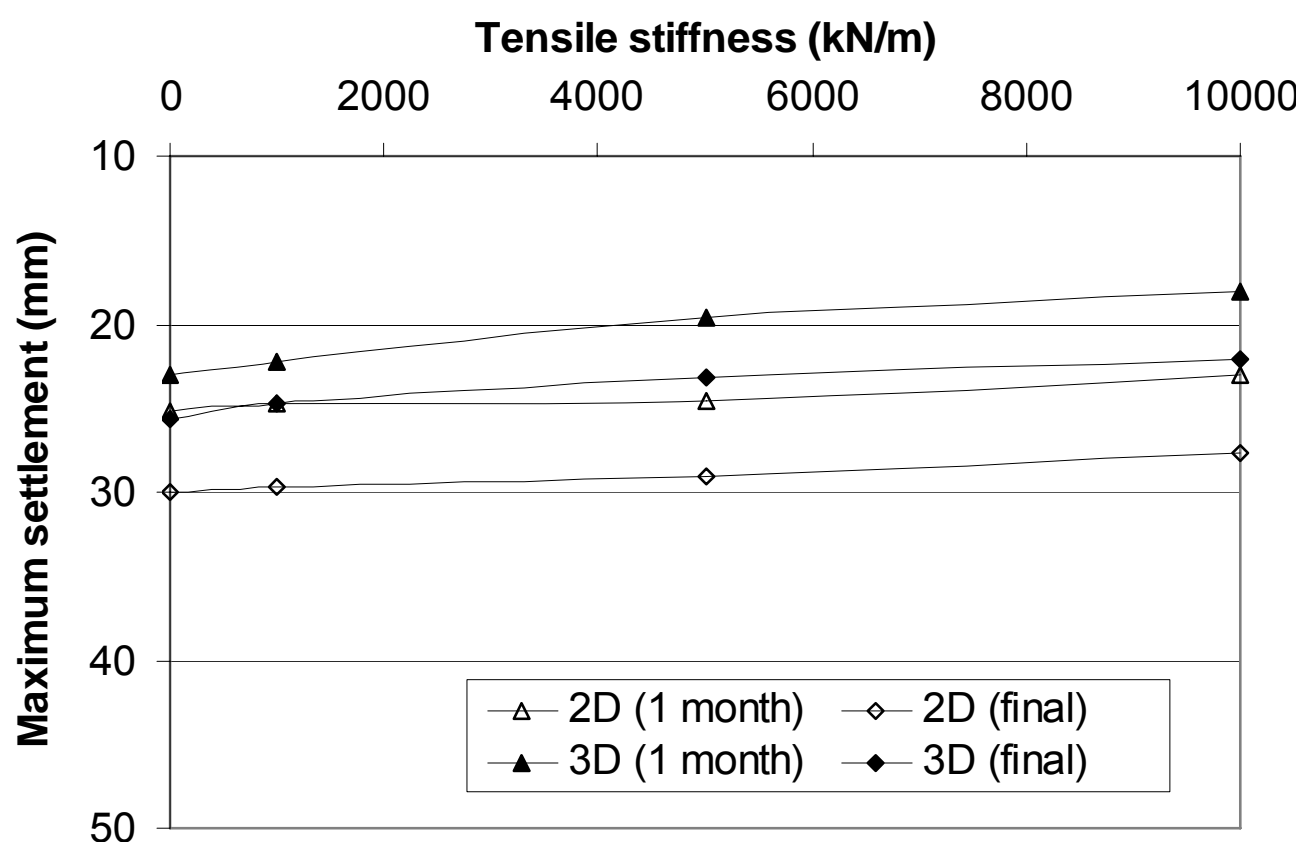

Fig. 6-16. Maximum Settlement versus Tensile Stiffness under 2D and 3D Conditions

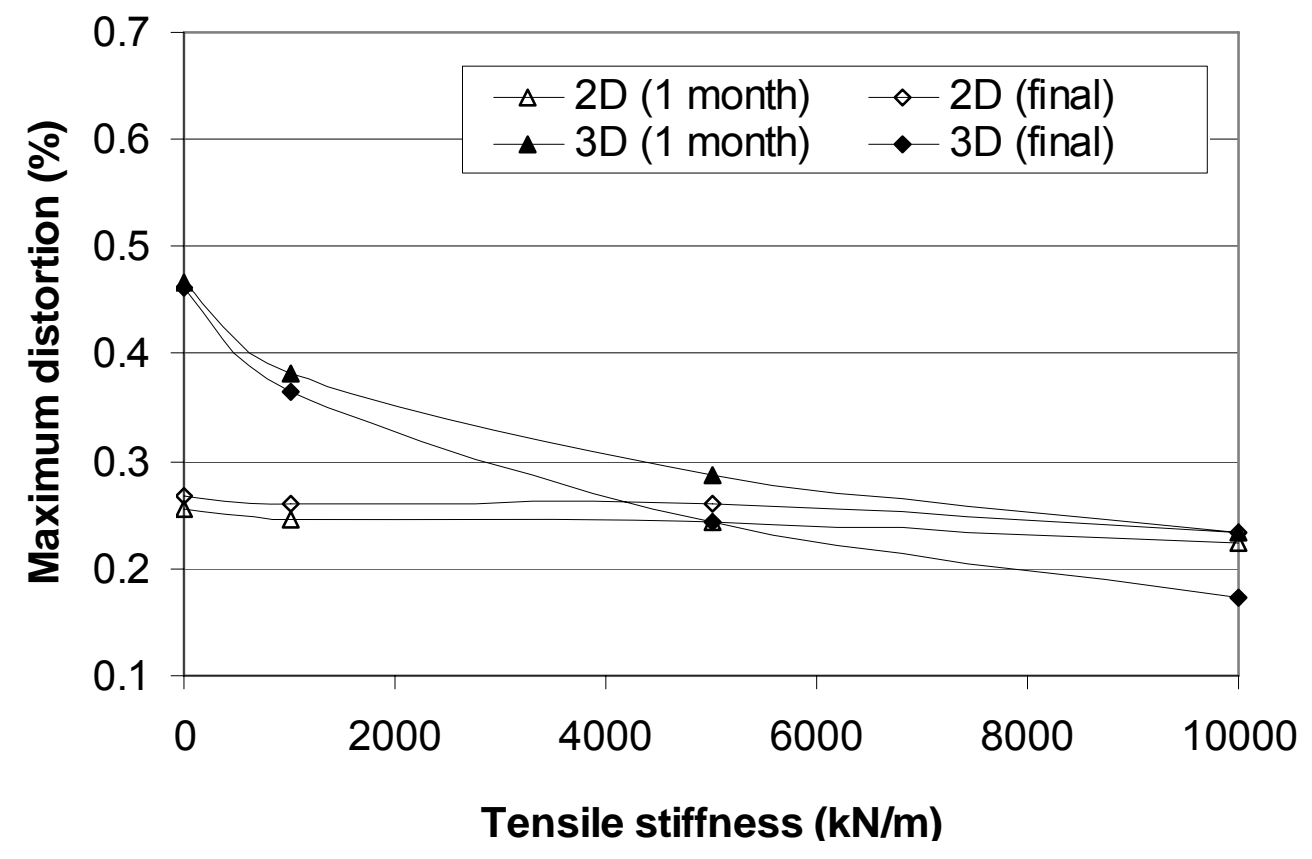

Fig. 6-17. Maximum Distortion versus Tensile Stiffness under 2D and 3D Conditions 


\section{Influence of Construction Rate}

The influences of the average construction rate on the maximum settlement and the maximum distortion are presented in Figs. 6-18 and 6-19, respectively. As the average construction rate decreased from 4 to $0.25 \mathrm{~meter} / \mathrm{mon}$, the maximum settlement decreased by $12 \mathrm{~mm}$ under the $3 \mathrm{D}$ condition and by $15 \mathrm{~mm}$ under the $2 \mathrm{D}$ condition while the maximum distortion decreased by $0.32 \%$ under the $3 \mathrm{D}$ condition and $0.1 \%$ under the $2 \mathrm{D}$ condition, respectively.

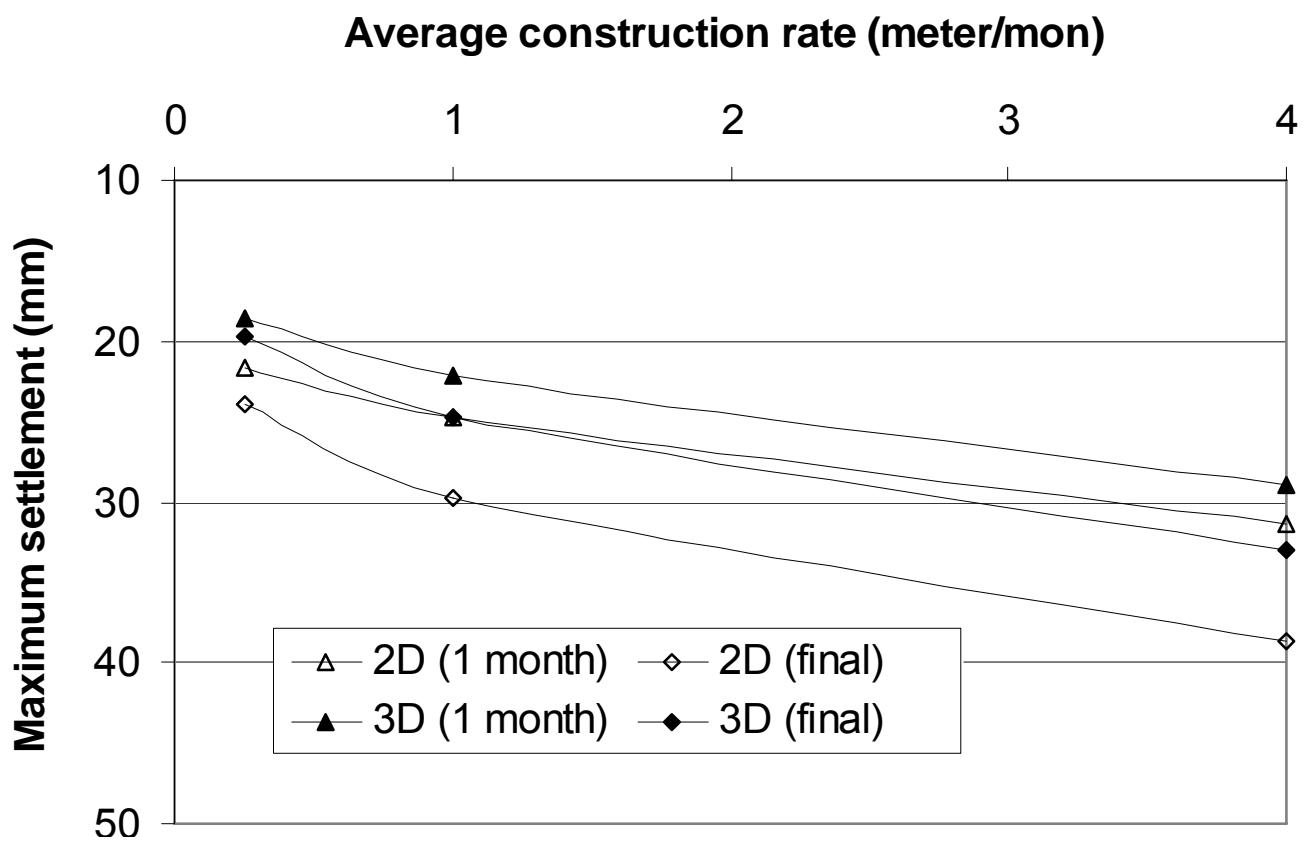

Fig. 6-18. Maximum Settlement versus Average Construction Rate under 2D and 3D Conditions 


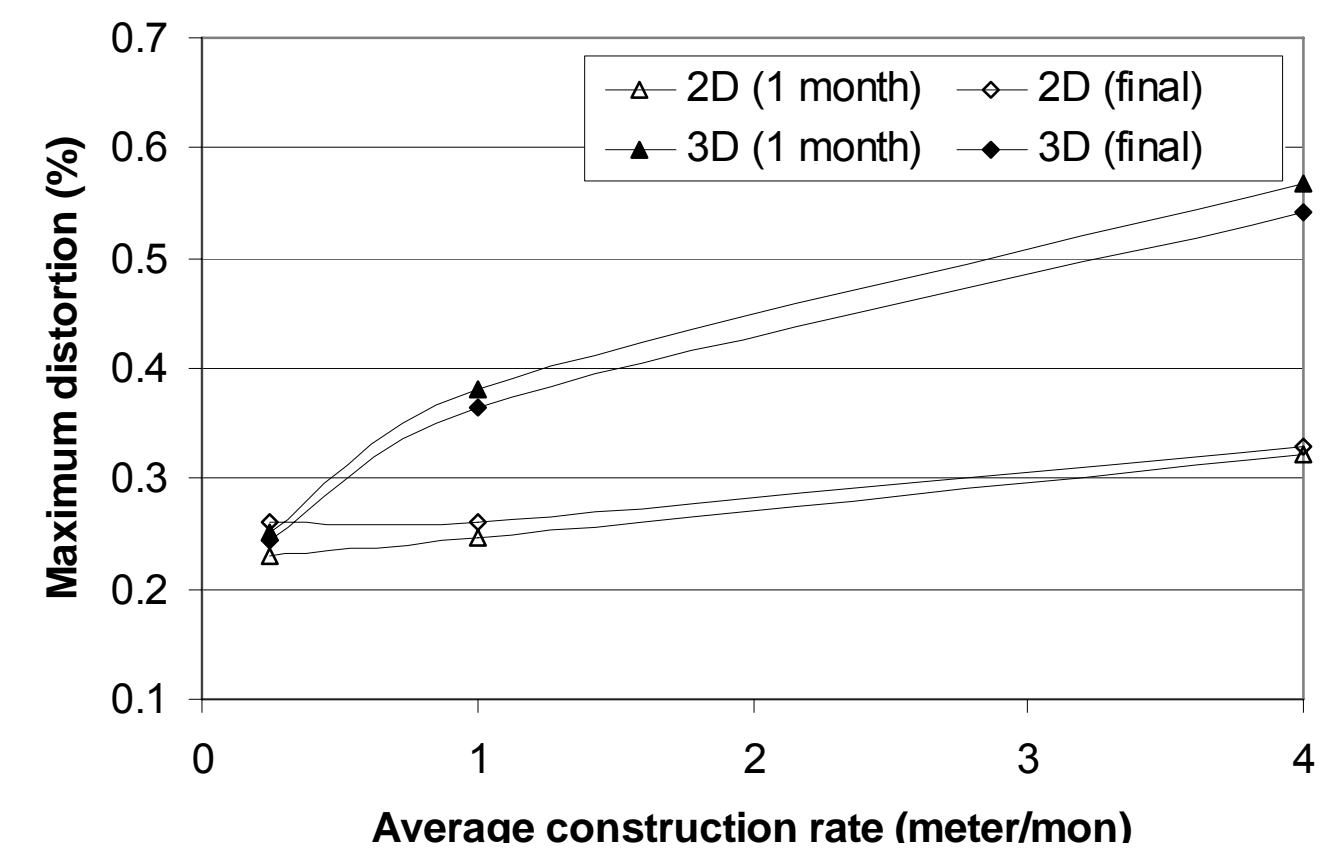

Fig. 6-19. Maximum Distortion versus Average Construction Rate under 2D and 3D Conditions

\subsubsection{Maximum Tension Developed in Geosynthetics}

The tension calculated under the 2D condition was that developed along the direction perpendicular to the traffic direction. Under the $3 \mathrm{D}$ condition, the tension developed in the direction along the traffic (i.e., the y direction) and perpendicular to the traffic (i.e., the $\mathrm{x}$ direction) can be calculated. Since the maximum tension in $\mathrm{x}$ direction under the $3 \mathrm{D}$ condition is corresponding to that in the $2 \mathrm{D}$ condition, the maximum tension in the $\mathrm{x}$ direction under the $3 \mathrm{D}$ condition was used for comparison with that under the 2D condition. 


\section{Influence of Soft Soil Elastic Modulus}

The influence of the soil modulus on the maximum geosynthetic tension is presented in Fig. 6-20, which shows that for the soil modulus from 1 to $8 \mathrm{MPa}$, the maximum tension in the $\mathrm{x}$ and y directions decreased by $7 \mathrm{kN} / \mathrm{m}$ and $4 \mathrm{kN} / \mathrm{m}$, respectively under $3 \mathrm{D}$ condition instead of $8 \mathrm{kN} / \mathrm{m}$ under the $2 \mathrm{D}$ condition.

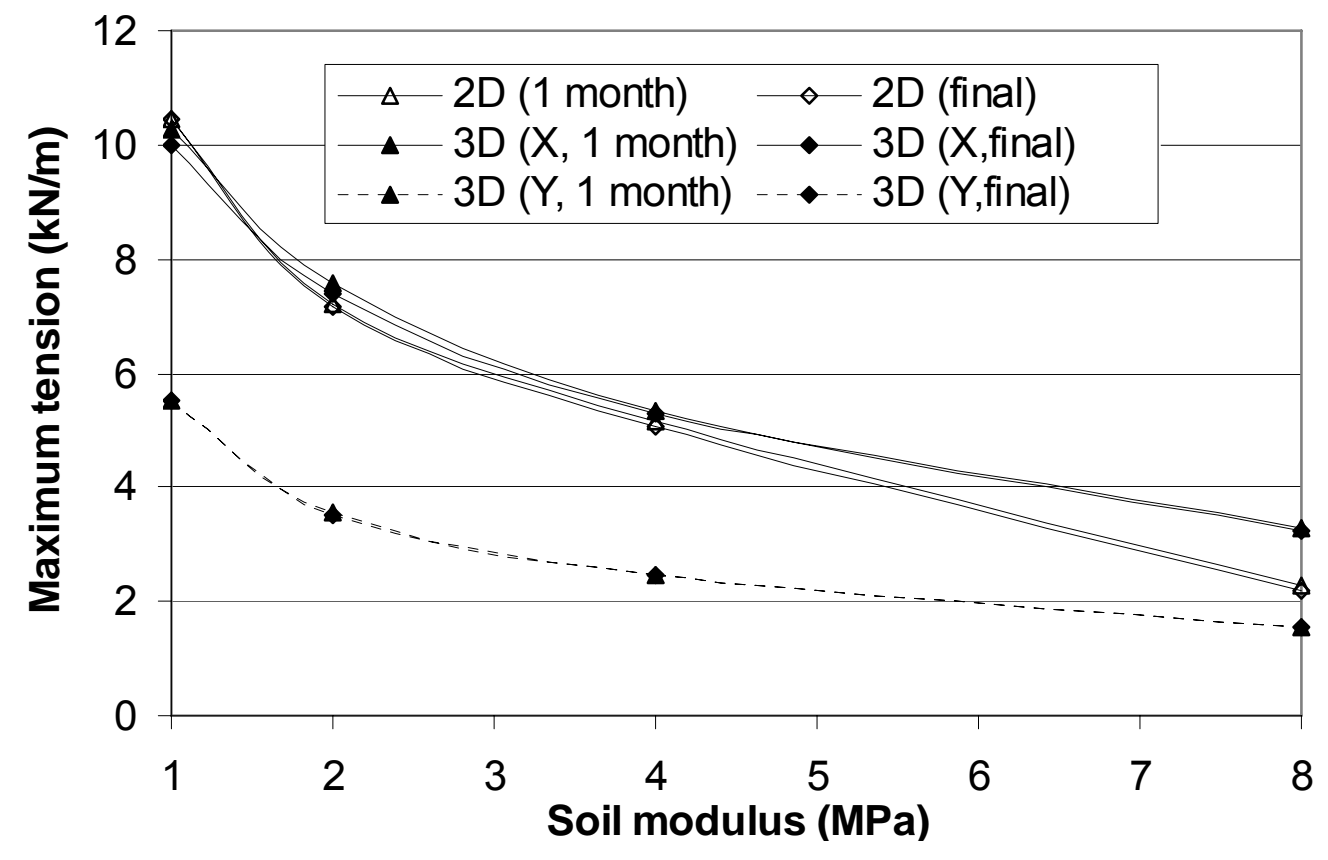

Fig. 6-20. Maximum Tension versus Soil Modulus under 2D and 3D Conditions

\section{Influence of Soft Soil Friction Angle}

The maximum geosynthetic tension is plotted against the soft soil friction angle in

Fig. 6-21. For the soil friction angle from $15^{\circ}$ to $30^{\circ}$, the maximum tension in the $\mathrm{x}$ 
and y directions decreased by $4 \mathrm{kN} / \mathrm{m}$ and $2 \mathrm{kN} / \mathrm{m}$, respectively, under the $3 \mathrm{D}$ condition instead of slightly more than $2 \mathrm{kN} / \mathrm{m}$ under the $2 \mathrm{D}$ condition.

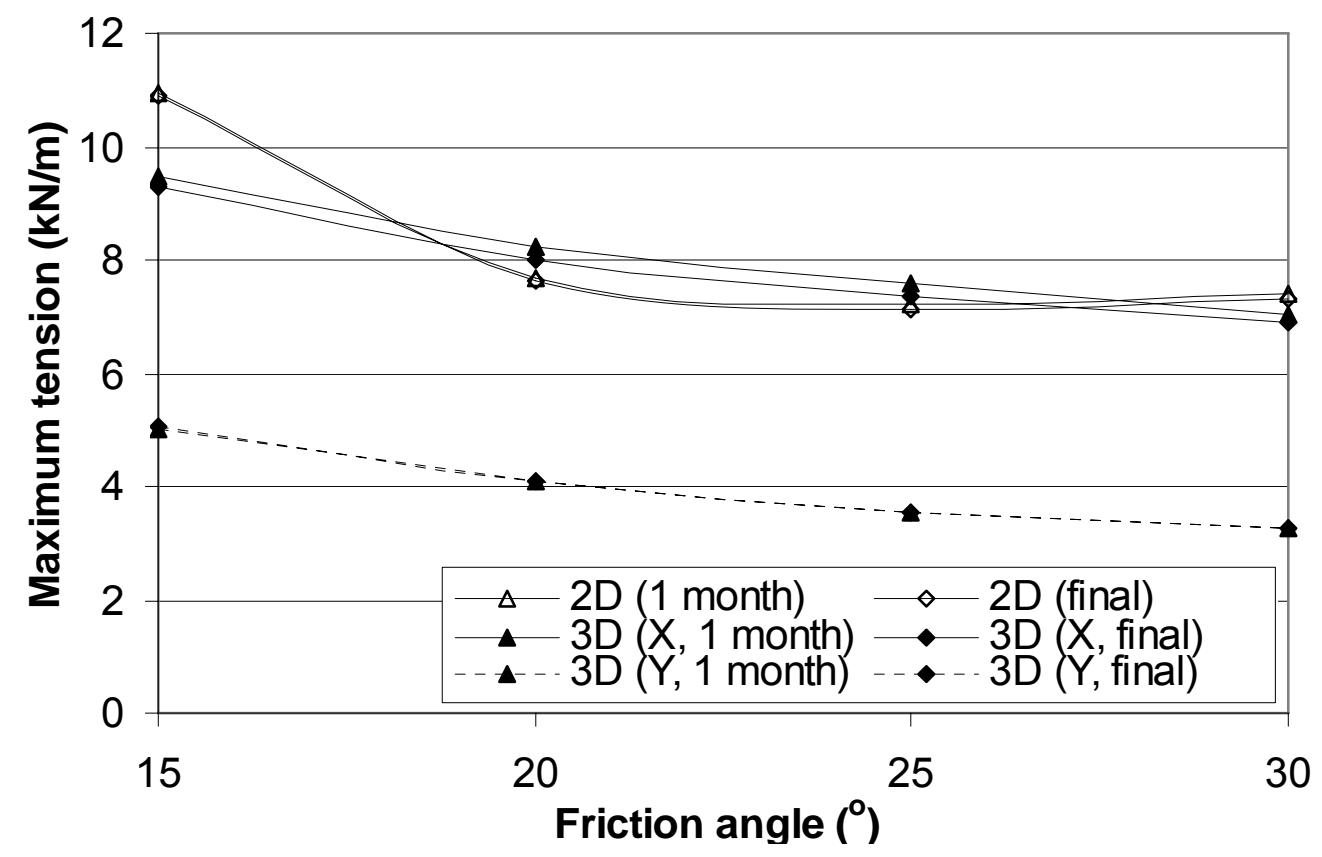

Fig. 6-21. Maximum Tension versus Friction Angle under 2D and 3D Conditions

\section{Influence of Soft Soil Permeability}

The influence of the soil permeability on the maximum geosynthetic tension is presented in Fig. 6-22. As the soil permeability increased from $10^{-10}$ to $10^{-8} \mathrm{~m} / \mathrm{s}$, the maximum tension in the $\mathrm{x}$ and $\mathrm{y}$ directions both decreased by about $3 \mathrm{kN} / \mathrm{m}$ under the $3 \mathrm{D}$ condition instead of about $4 \mathrm{kN} / \mathrm{m}$ under the $2 \mathrm{D}$ condition. 


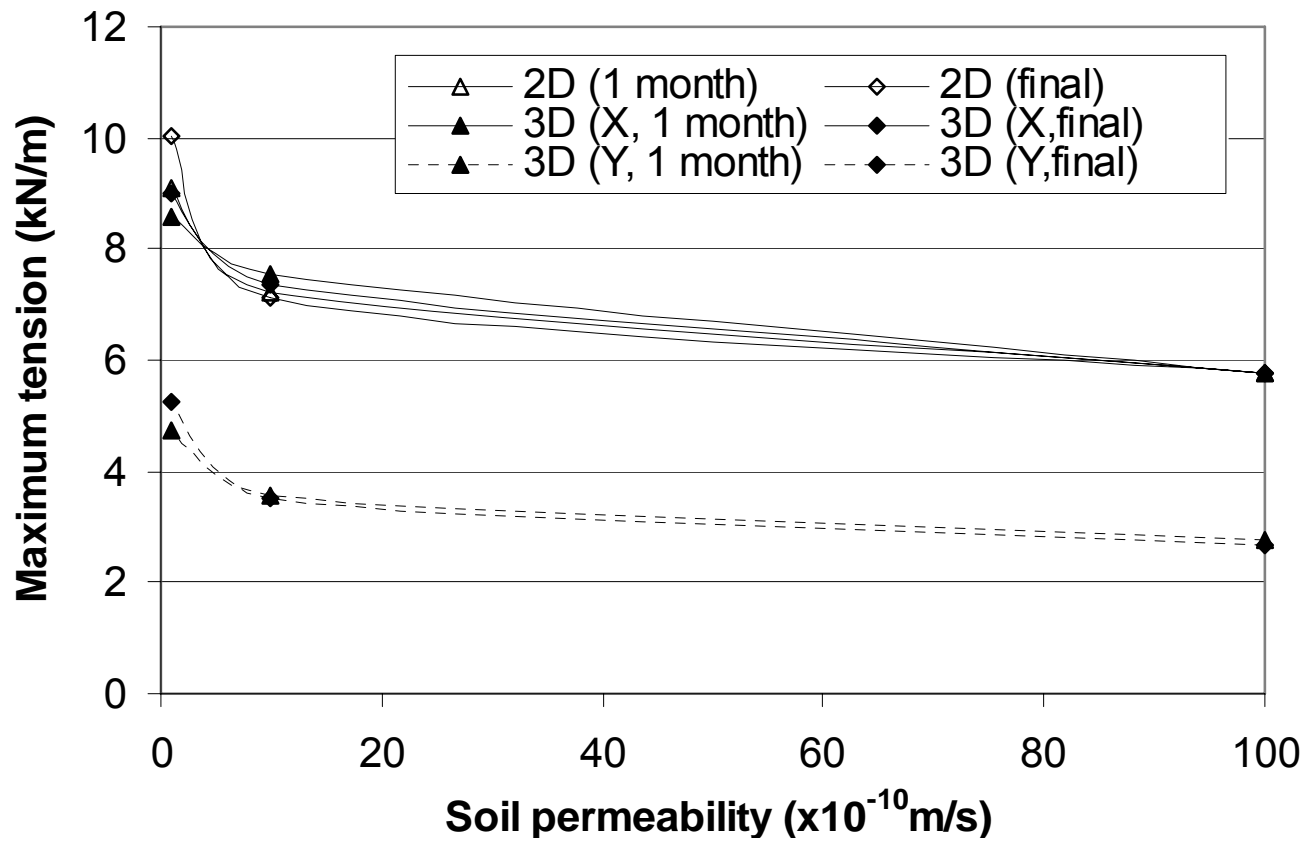

Fig. 6-22. Maximum Tension versus Soil Permeability under 2D and 3D Conditions

\section{Influence of Column Elastic Modulus}

Figure 6-23 presents the relationship between the maximum tension and the column modulus, which shows that the column modulus had limited influence on the maximum tension. However, the influence of the column modulus on the maximum tension in the $\mathrm{x}$ direction under the $3 \mathrm{D}$ condition was more significant than those under other conditions. 


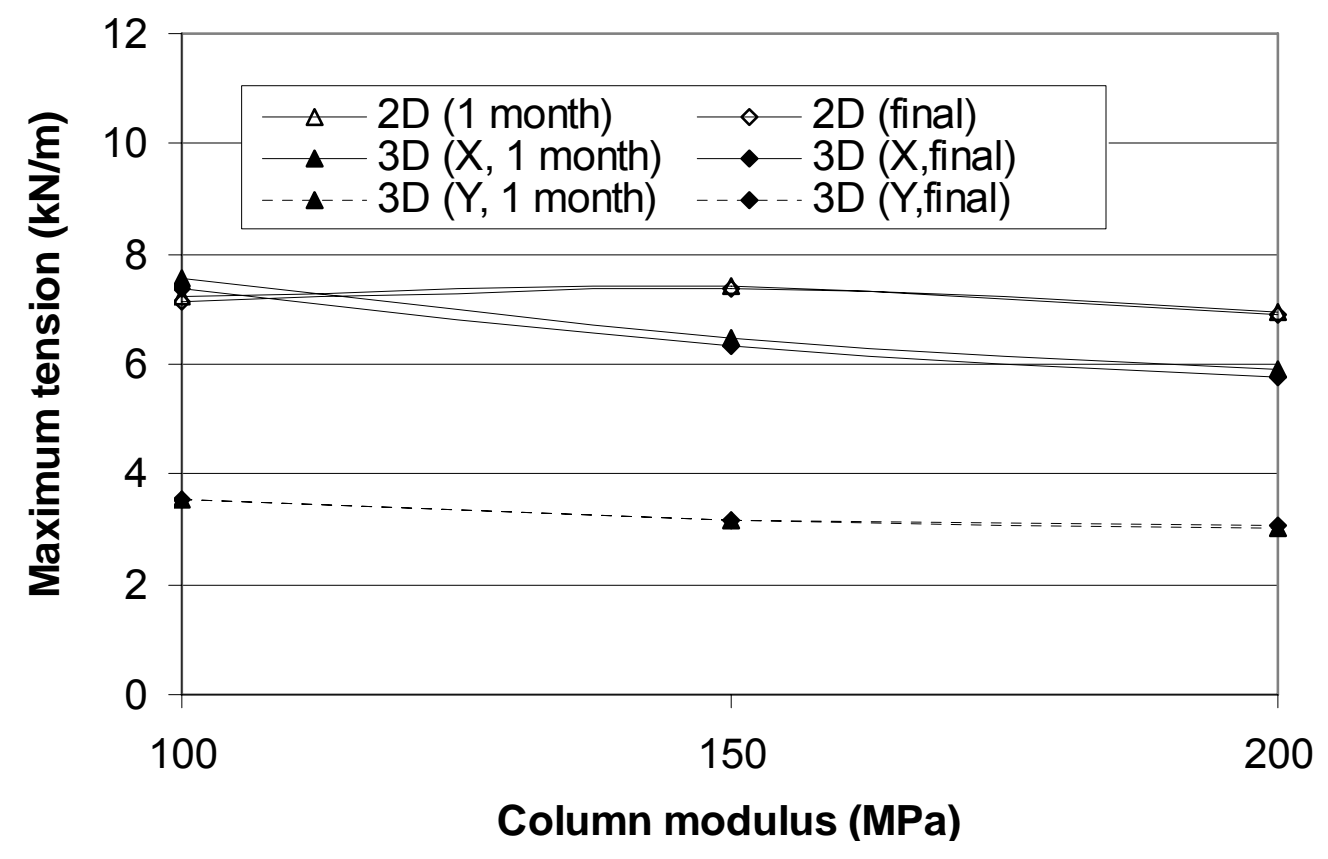

Fig. 6-23. Maximum Tension versus Column Modulus under 2D and 3D Conditions

\section{Influence of Column Spacing}

The influence of the column spacing on the maximum tension is presented in Fig. 624. As the column spacing increased from 2 to $3 \mathrm{~m}$, the maximum tension in the $\mathrm{x}$ and y directions decreased by approximately $8 \mathrm{kN} / \mathrm{m}$ and $4 \mathrm{kN} / \mathrm{m}$, respectively, under the $3 \mathrm{D}$ condition instead of approximately $5 \mathrm{kN} / \mathrm{m}$ under the $2 \mathrm{D}$ condition. 


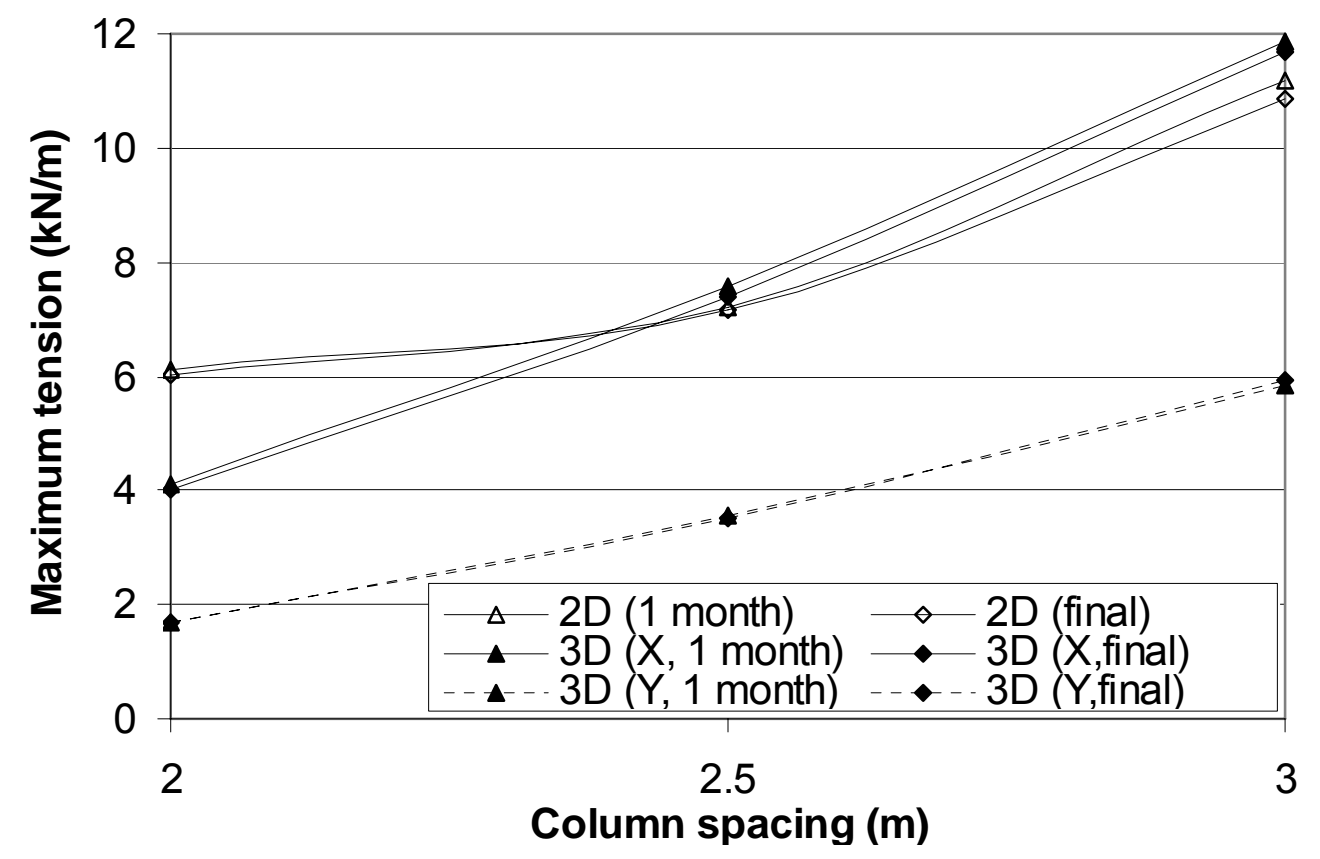

Fig. 6-24. Maximum Tension versus Column Spacing under 2D and 3D Conditions

\section{Influence of Geosynthetic Tensile Stiffness}

The geosynthetic tensile stiffness on the maximum tension is presented in Fig. 6-25. The tensile stiffness had a significant influence on the maximum tension. As the tensile stiffness increased from 0 to $10,000 \mathrm{kN} / \mathrm{m}$, the maximum tension in $\mathrm{x}$ direction and y directions increased by $48 \mathrm{kN} / \mathrm{m}$ and $10 \mathrm{kN} / \mathrm{m}$, respectively under the $3 \mathrm{D}$ condition instead of $40 \mathrm{kN} / \mathrm{m}$ under the $2 \mathrm{D}$ condition. 


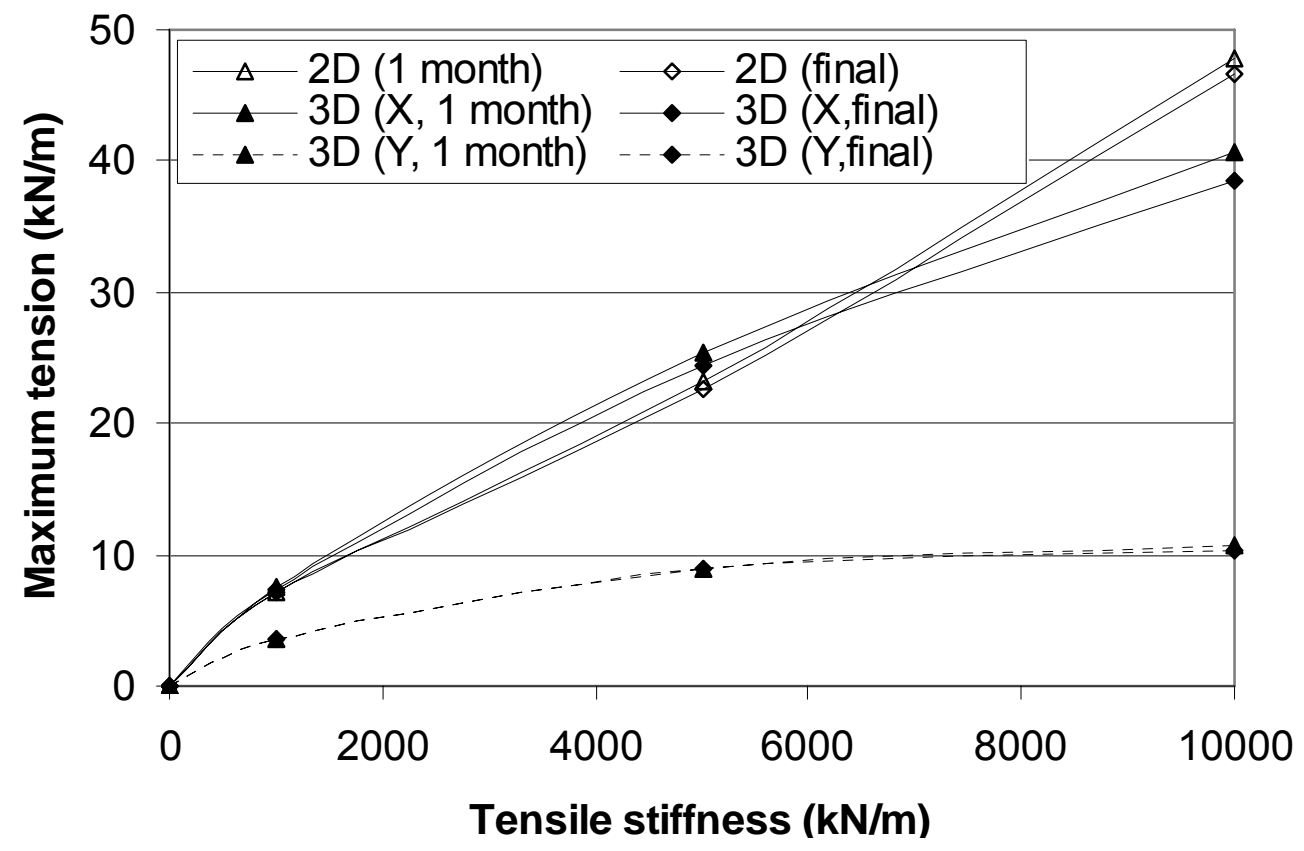

Fig. 6-25. Maximum Tension versus Tensile Stiffness under 2D and 3D Conditions

\section{Influence of Construction Rate}

The maximum geosynthetic tension against the average construction rate is shown in Fig. 6-26. The maximum tension in the $\mathrm{x}$ and $\mathrm{y}$ directions decreased by approximately $3 \mathrm{kN} / \mathrm{m}$ and $2 \mathrm{kN} / \mathrm{m}$, respectively under the $3 \mathrm{D}$ condition when the average construction rate was decreased from 4 to $0.25 \mathrm{~meter} / \mathrm{mon}$. The maximum tension decreased by about $3 \mathrm{kN} / \mathrm{m}$ in the same range of the average construction rate under the 2D condition. 


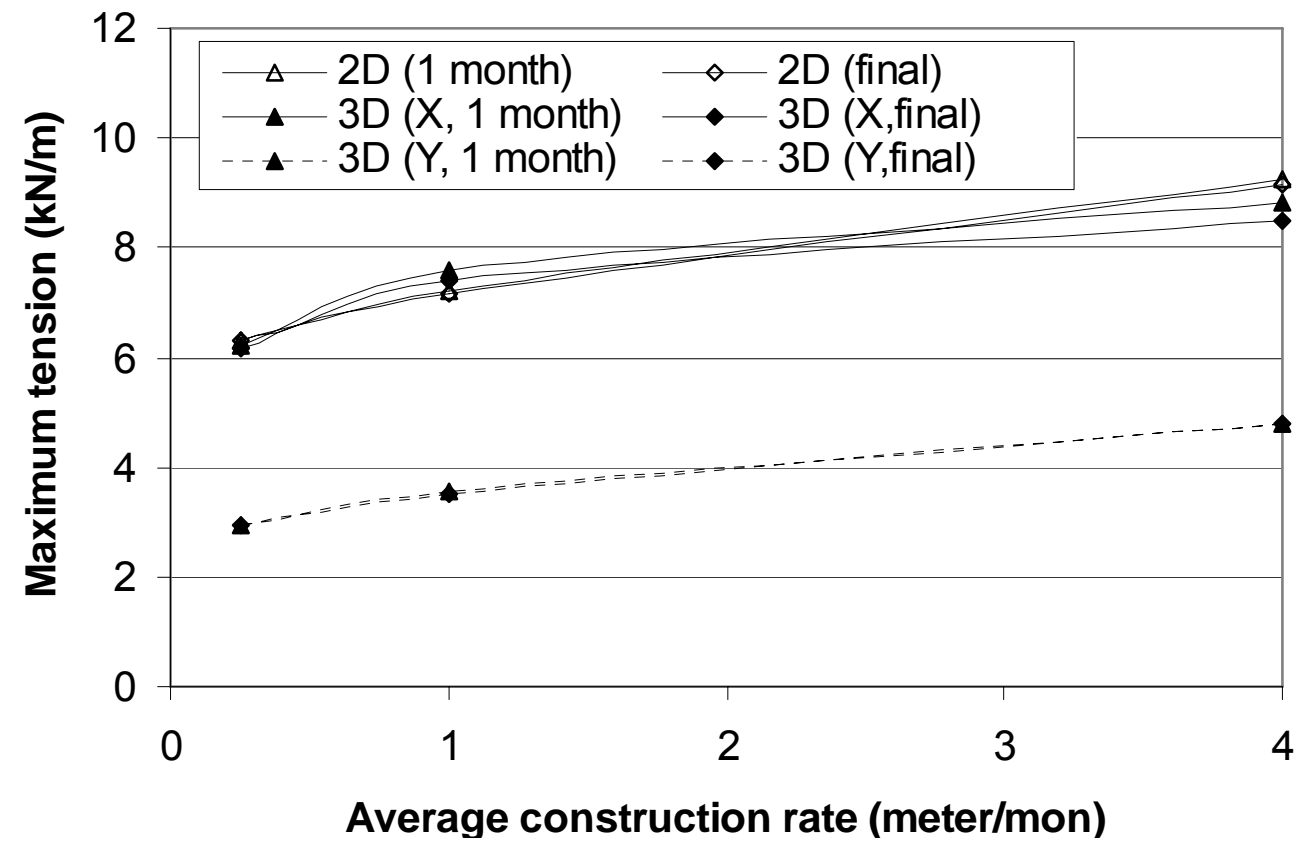

Fig. 6-26. Maximum Tension versus Average Construction Rate under $2 D$ and 3D Conditions

\subsubsection{Maximum Stress Concentration ratio}

The stress concentration ratio was adopted in this study to evaluate the load transfer efficiency. The stress concentration ratios under 2D and 3D conditions have been discussed in Chapter Four and Chapter Five, respectively. They are presented here together for the purpose of comparison. 


\section{Influence of Soft Soil Elastic Modulus}

The maximum stress concentration ratio against the soil modulus is presented in Fig. 6-27, which shows that the soil modulus had a remarkable influence on the maximum stress concentration under both 3D and 2D conditions. For the soil modulus varying from 1 to $8 \mathrm{MPa}$, the maximum stress concentration ratio decreased by 20 and 25 under 3D and 2D conditions, respectively.

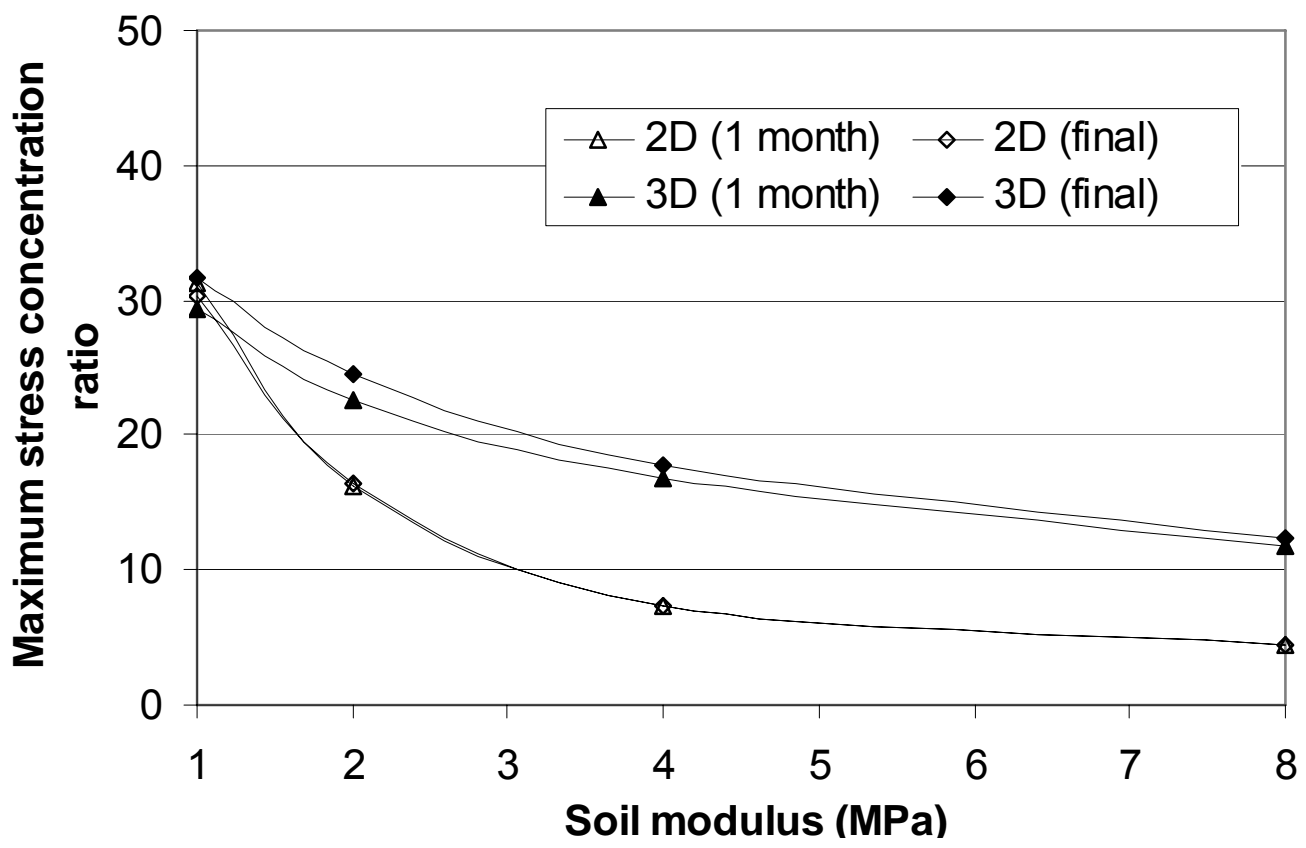

Fig. 6-27. Maximum Stress Concentration Ratio versus Soil Modulus under 2D and 3D Conditions 


\section{Influence of Soft Soil Friction Angle}

The maximum stress concentration ratios developed at different soil friction angles under 2D and 3D conditions are presented in Fig. 6-28. For the soil friction angle ranging from $15^{\circ}$ to $30^{\circ}$, the maximum stress concentration ratio decreased by 10 under the 3D condition and by 6 under the 2D condition.

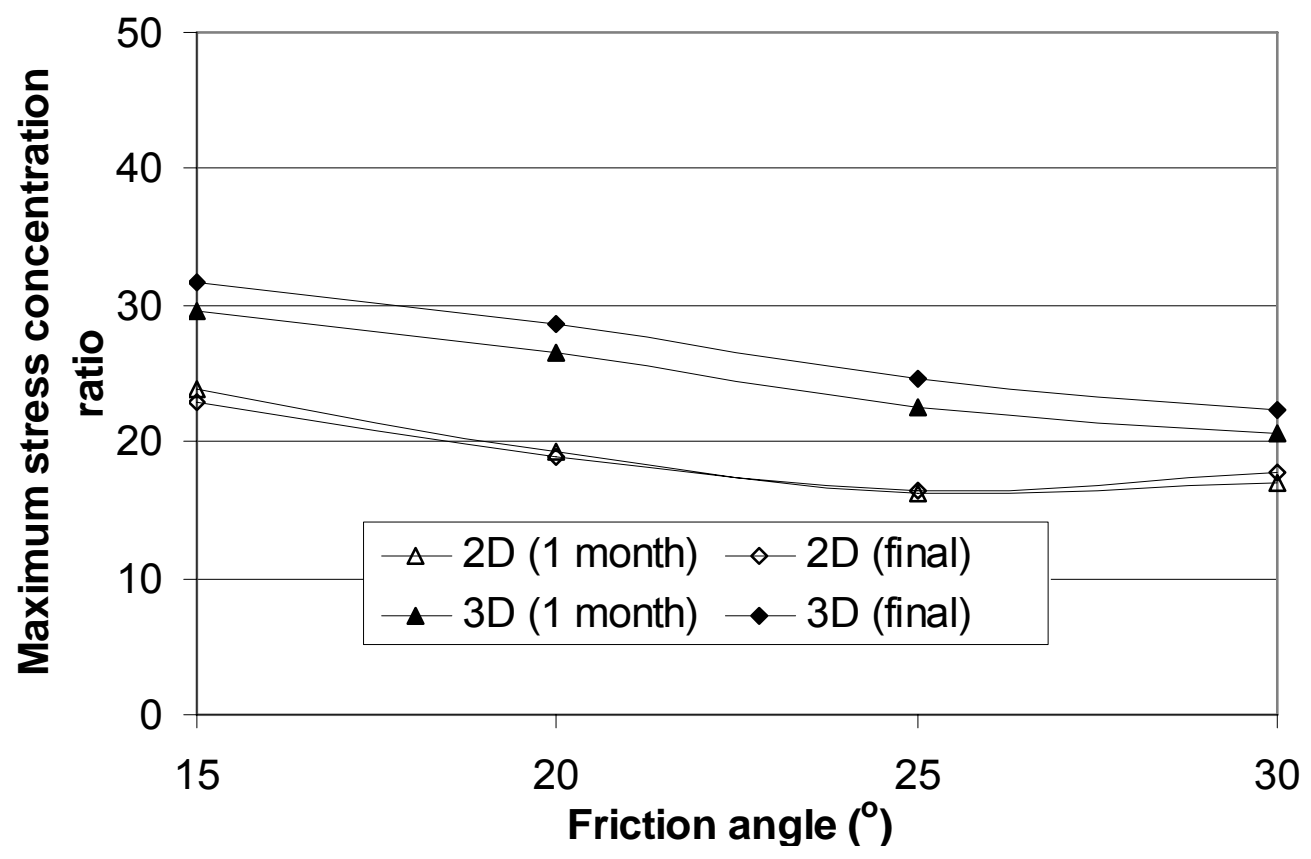

Fig. 6-28. Maximum Stress Concentration Ratio versus Friction Angle under 2D and 3D Conditions

\section{Influence of Soft Soil Permeability}

The maximum stress concentration ratio is plotted against the soft soil permeability in

Fig. 6-29. The increase of the soil permeability from $10^{-10}$ to $10^{-8} \mathrm{~m} / \mathrm{s}$ led to a decrease 
of the maximum stress concentration ratio by 9 under the 3D condition and by 15 under the $2 \mathrm{D}$ condition.

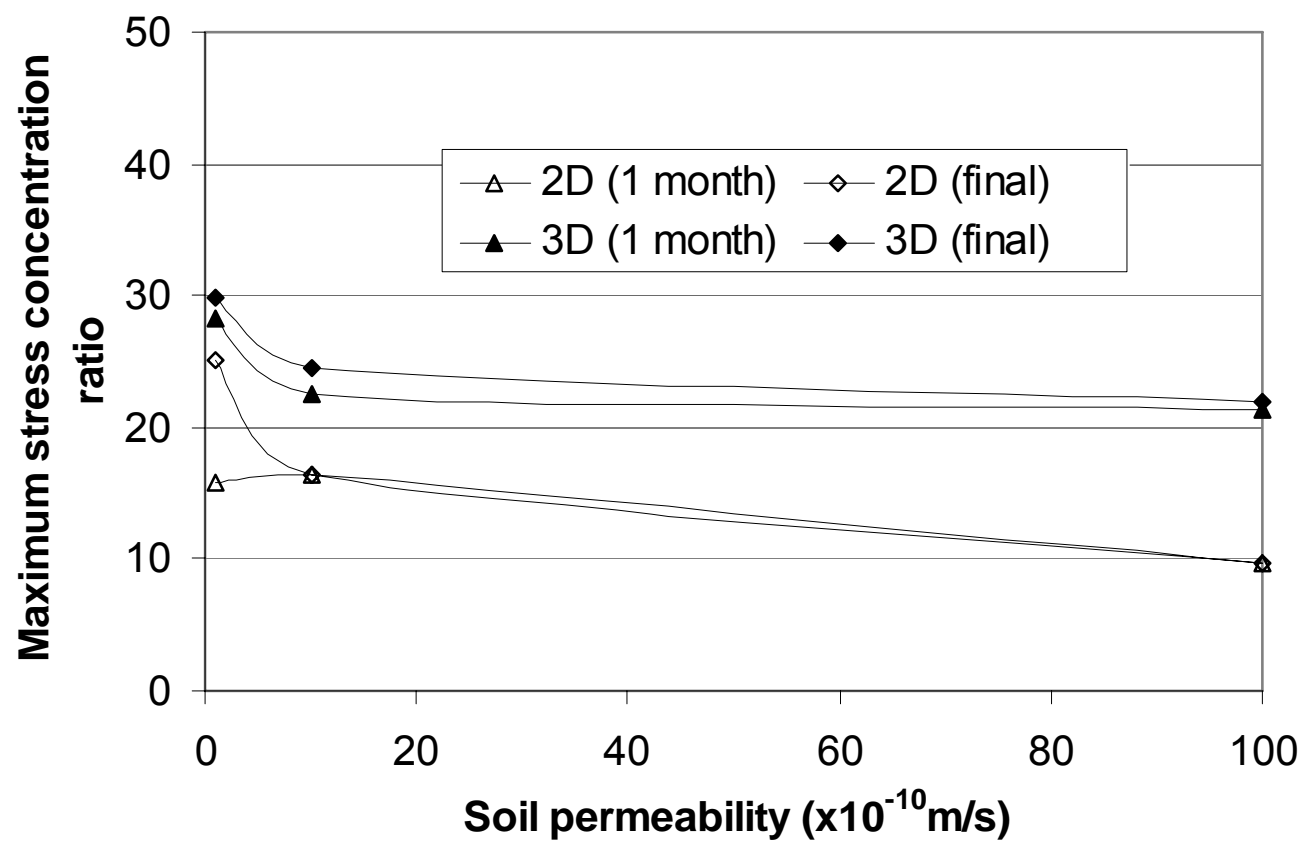

Fig. 6-29. Maximum Stress Concentration Ratio versus Soil Permeability under 2D and 3D Conditions

\section{Influence of Column Elastic Modulus}

The maximum stress concentration ratio versus the column modulus is presented in Fig. 6-30. The increase of the column modulus from 100 to $200 \mathrm{MPa}$ led to an in crease in the maximum stress concentration ratio of 4 and 5 under $3 \mathrm{D}$ and $2 \mathrm{D}$ conditions, respectively. 


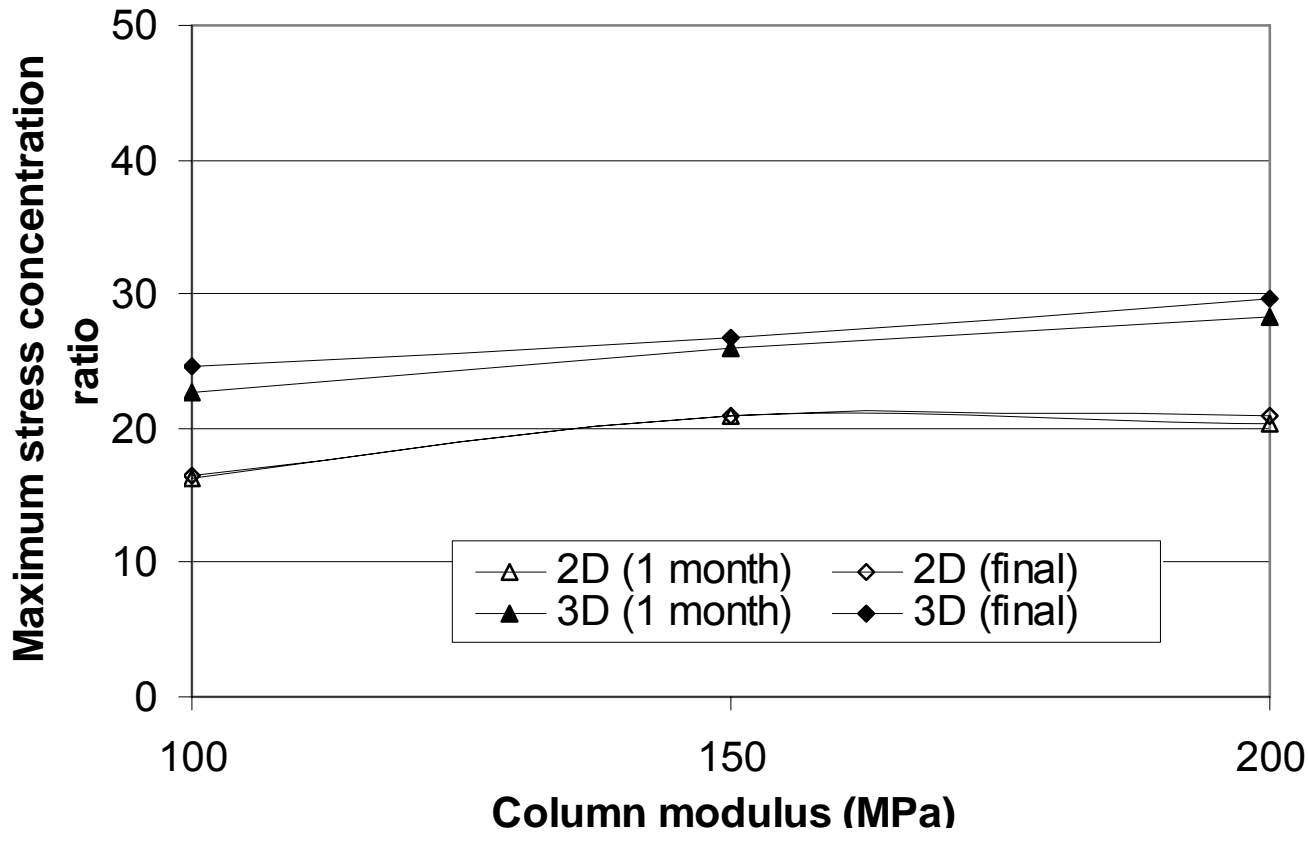

Fig. 6-30. Maximum Stress Concentration Ratio versus Column Modulus under 2D and 3D Conditions

\section{Influence of Column Spacing}

The curves of the maximum stress concentration ratio versus the column spacing are shown in Fig. 6-31. When the column spacing was increased from $2 \mathrm{~m}$ to $3 \mathrm{~m}$, the maximum stress concentration ratio decreased by approximately 20 and 17 under 3D and 2D conditions, respectively. 


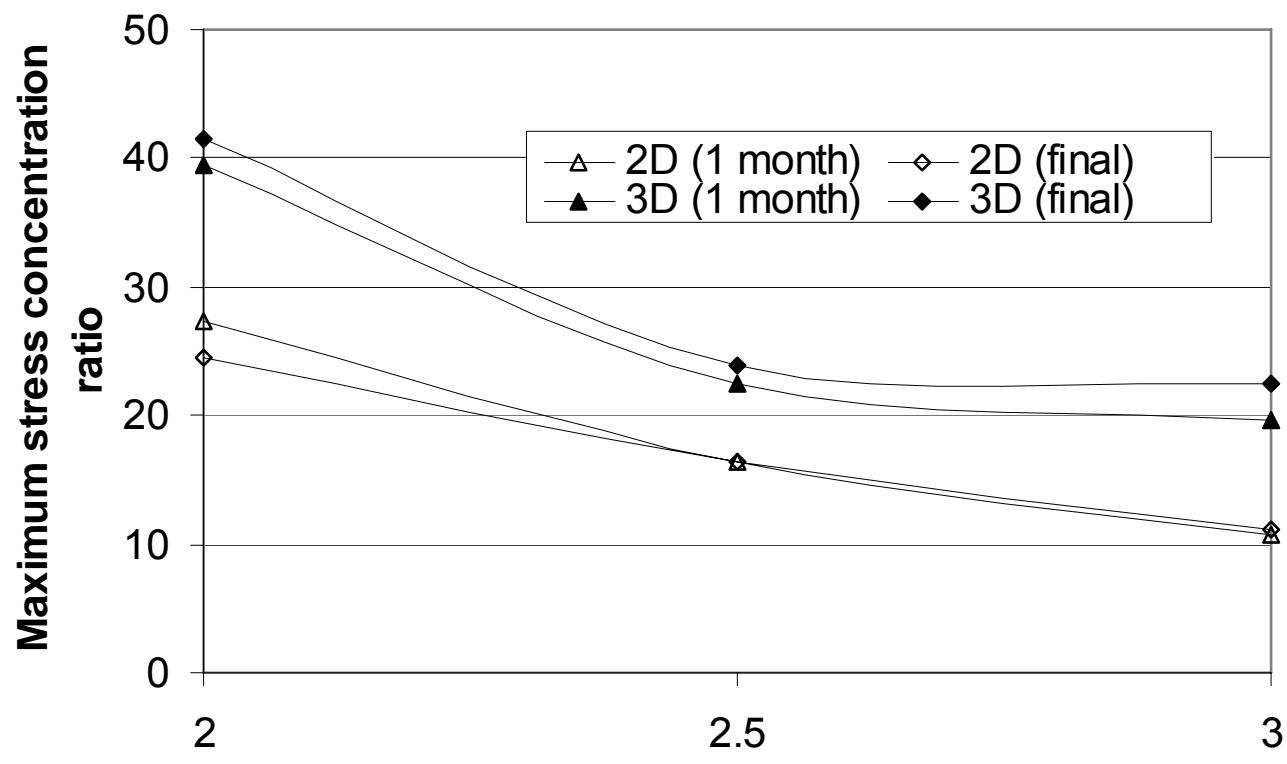

Column spacing $(\mathrm{m})$

Fig. 6-31. Maximum Stress Concentration Ratio versus Column Spacing under 2D and 3D Conditions

\section{Influence of Geosynthetic Tensile Stiffness}

The maximum stress concentration ratio is plotted against the tensile stiffness in Fig. 6-32. Clearly, the tensile stiffness had a slight influence on the stress concentration ratio. For the tensile stiffness varying from 0 to $10000 \mathrm{kN} / \mathrm{m}$, the maximum stress concentration ratio only decreased by approximately 1 and 3 under $3 \mathrm{D}$ and $2 \mathrm{D}$ conditions, respectively. 


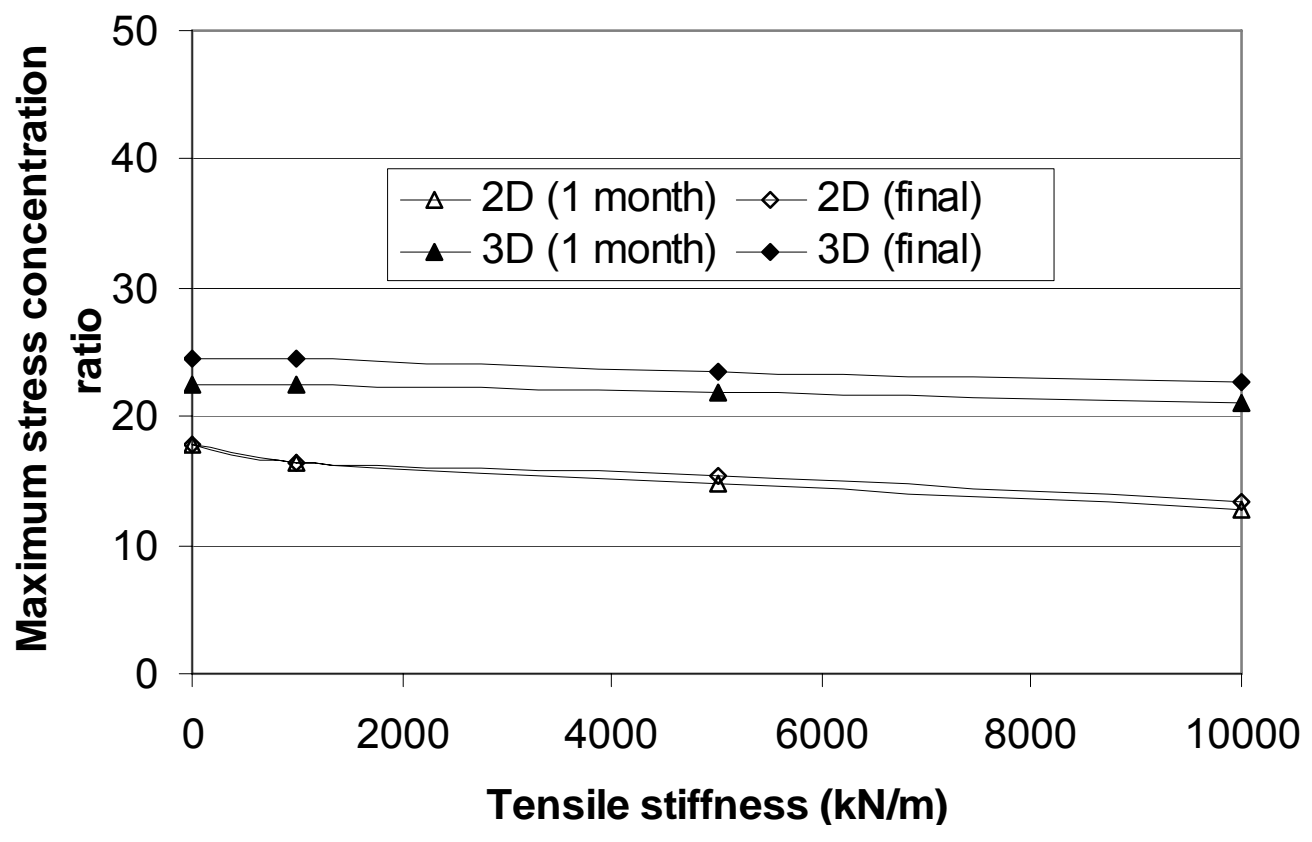

Fig. 6-32. Maximum Stress Concentration Ratio versus Tensile Stiffness under 2D and 3D Conditions

\section{Influence of Construction Rate}

The influence of the average construction rate on the maximum stress concentration ratio is presented in Fig. 6-33. As the average construction rate decreased from 4 to $0.25 \mathrm{~meter} / \mathrm{mon}$, the maximum stress concentration ratio decreased by approximately 6 and 7 under 3D and 2D conditions, respectively. 


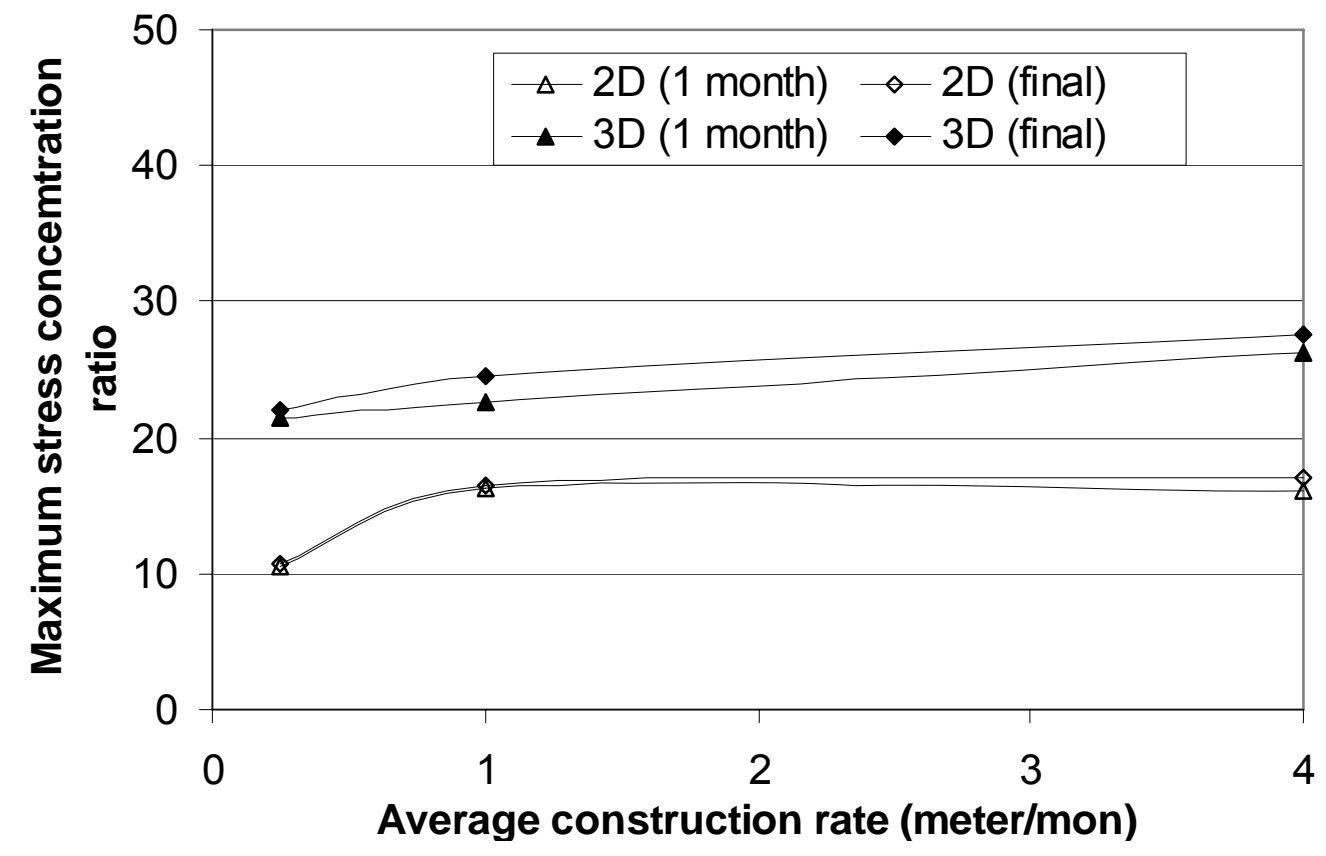

Fig. 6-33. Maximum Stress Concentration Ratio versus Average Construction Rate under 2D and 3D Conditions

\subsubsection{Excess Pore Water Pressure}

The comparisons conduced on the maximum settlement, the maximum distortion, the maximum tension, and the maximum stress concentration ratio were based on the results at one month of service and the final status. However, the comparison of the excess pore water pressure is based on the results at one month after service because the excess pore water pressure at the final status completely dissipated under the $2 \mathrm{D}$ condition and almost completely dissipated under the 3D condition. 


\section{Influence of Soft Soil Elastic Modulus}

The influence of the soil modulus on the degree of consolidation is presented in Fig. 6-34. The increase of the soil modulus from 1 to $8 \mathrm{MPa}$ resulted in the decrease in the degree of consolidation by approximately $6 \%$ and $5 \%$ under $3 \mathrm{D}$ and $2 \mathrm{D}$ conditions, respectively.

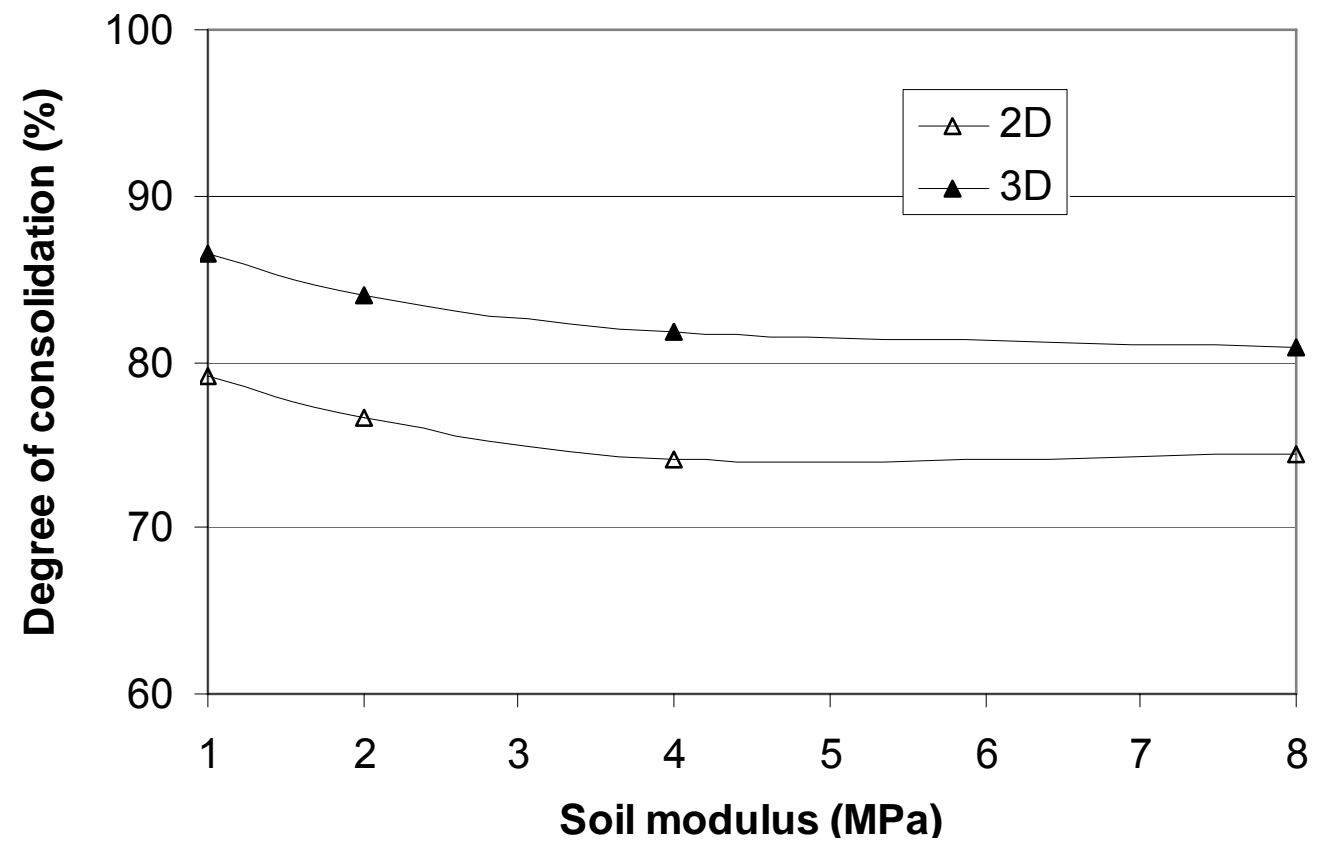

Fig. 6-34. Degree of Consolidation versus Soil Modulus under 2D and 3D Conditions

\section{Influence of Soft Soil Friction Angle}

The degree of consolidation is plotted against the soil friction angle in Fig. 6-35. The increase of the soil friction angle yielded a slight decrease in the degree of consolidation. 


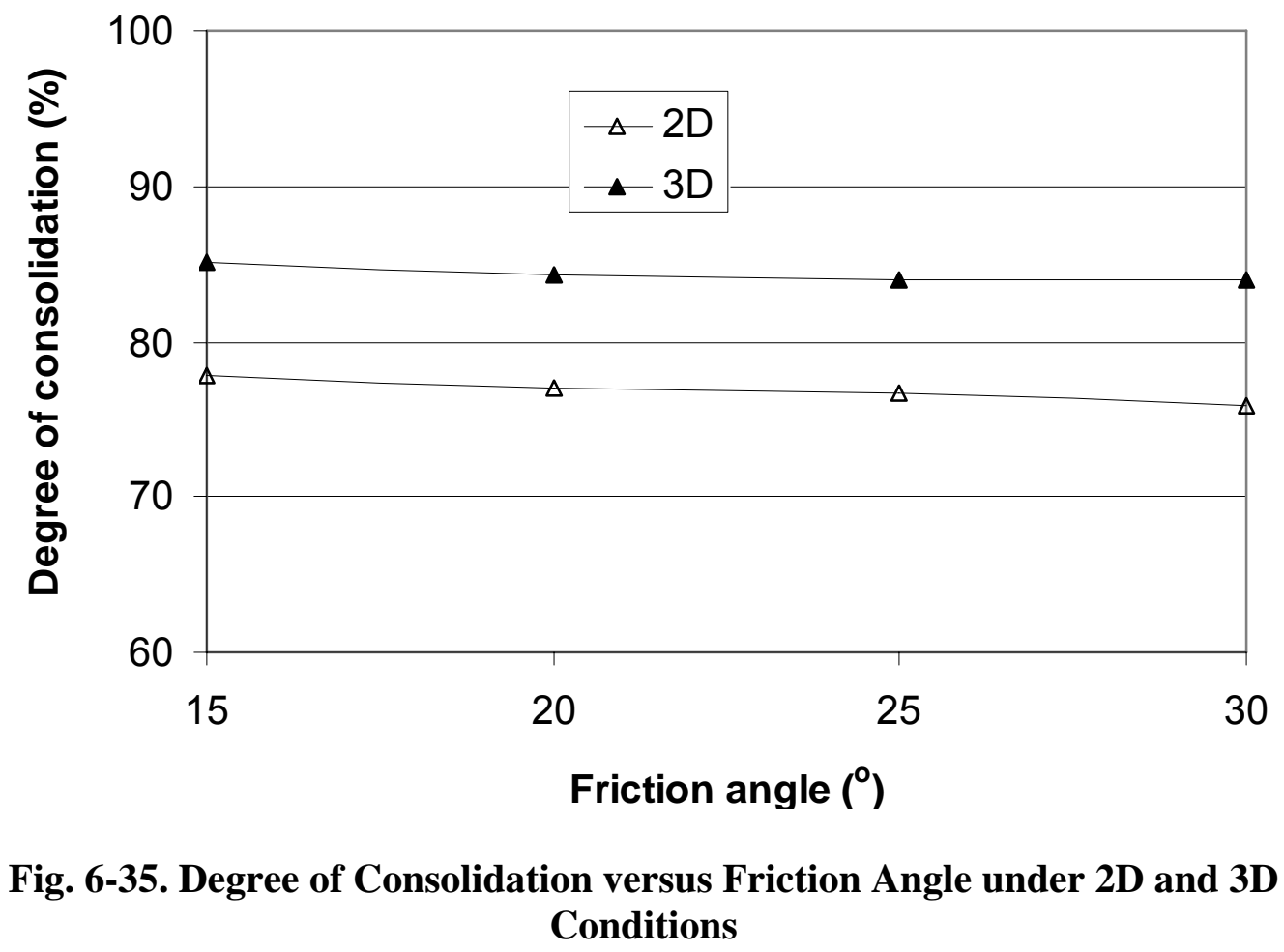

\section{Influence of Soft Soil Permeability}

The influence of the soil permeability on the degree of consolidation is presented in Fig. 6-36. The increase of the soil permeability had a dramatic influence on the degree of consolidation. As the soil permeability increased from $10^{-10}$ to $10^{-8} \mathrm{~m} / \mathrm{s}$, the degree of consolidation increased by approximately $30 \%$ and $38 \%$ under $3 \mathrm{D}$ and $2 \mathrm{D}$ conditions. For the soft soil at the permeability of $10^{-8} \mathrm{~m} / \mathrm{s}$, the degree of consolidation at one month of service was nearly $100 \%$ at both $2 \mathrm{D}$ and $3 \mathrm{D}$ conditions. 


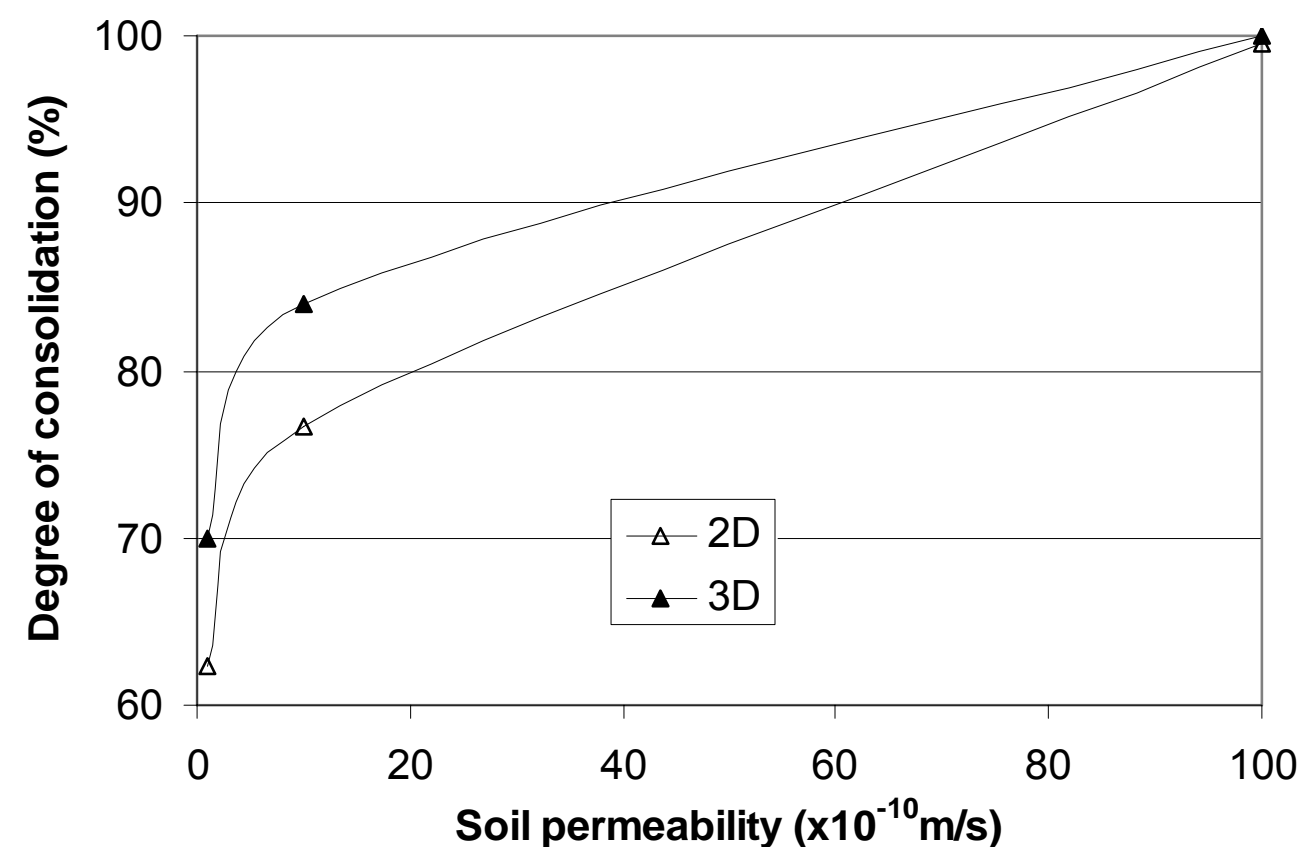

Fig. 6-36. Degree of Consolidation versus Soil Permeability under 2D and 3D Conditions

\section{Influence of Column Elastic Modulus}

The influence of the column modulus on the degree of consolidation versus is shown in Fig. 6-37. The increase of the column modulus from 100 to 200MPa resulted in an increase of the degree of consolidation by $8 \%$ and $10 \%$ under 3D and $2 \mathrm{D}$ conditions, respectively. 


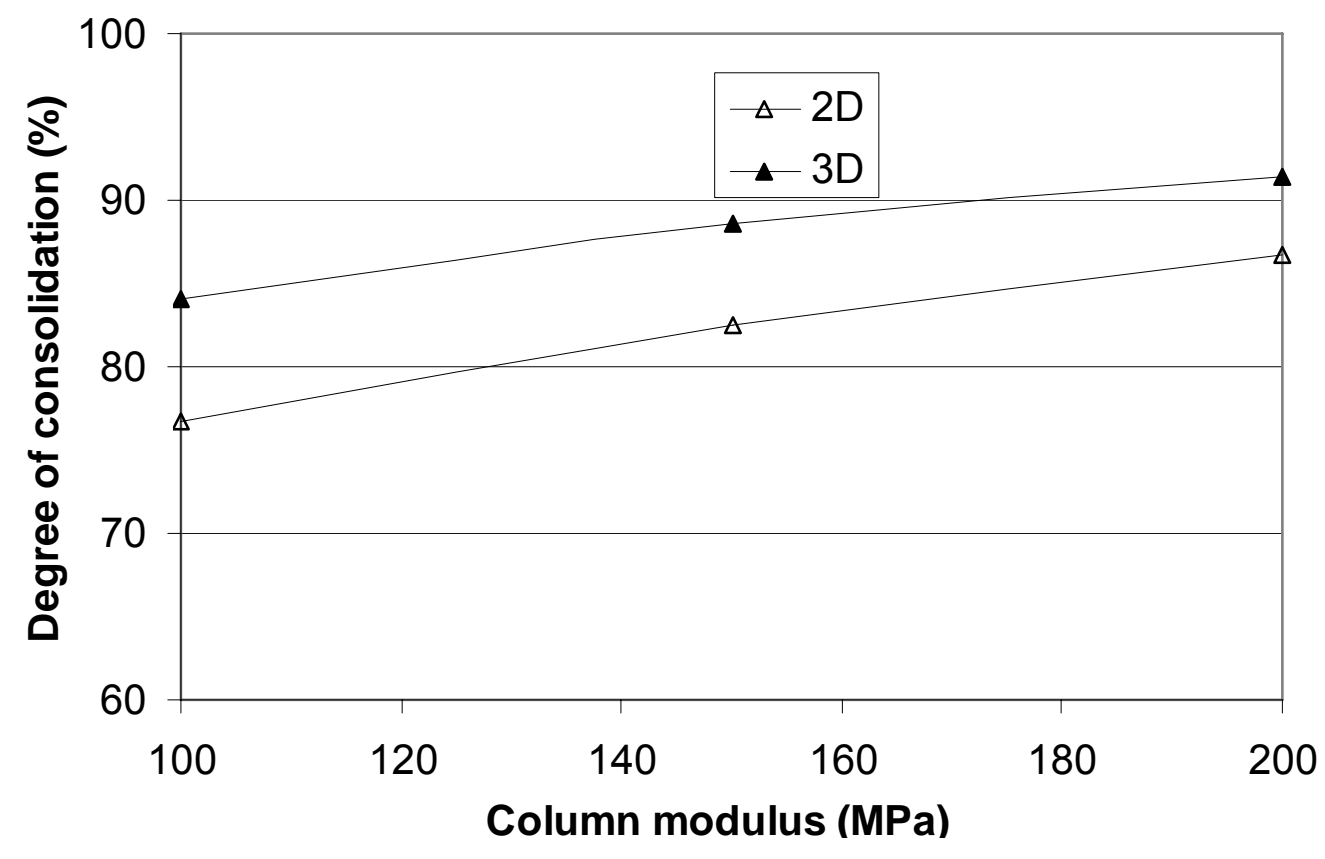

Fig. 6-37. Degree of Consolidation versus Column Modulus under 2D and 3D Conditions

\section{Influence of Column Spacing}

The influence of the column spacing on the degree of consolidation is presented in Fig. 6-38. The increase of the column spacing from 2 to $3 \mathrm{~m}$ led to a decrease in the degree of consolidation by $6 \%$ and $5 \%$ under $3 \mathrm{D}$ and $2 \mathrm{D}$ conditions, respectively. 


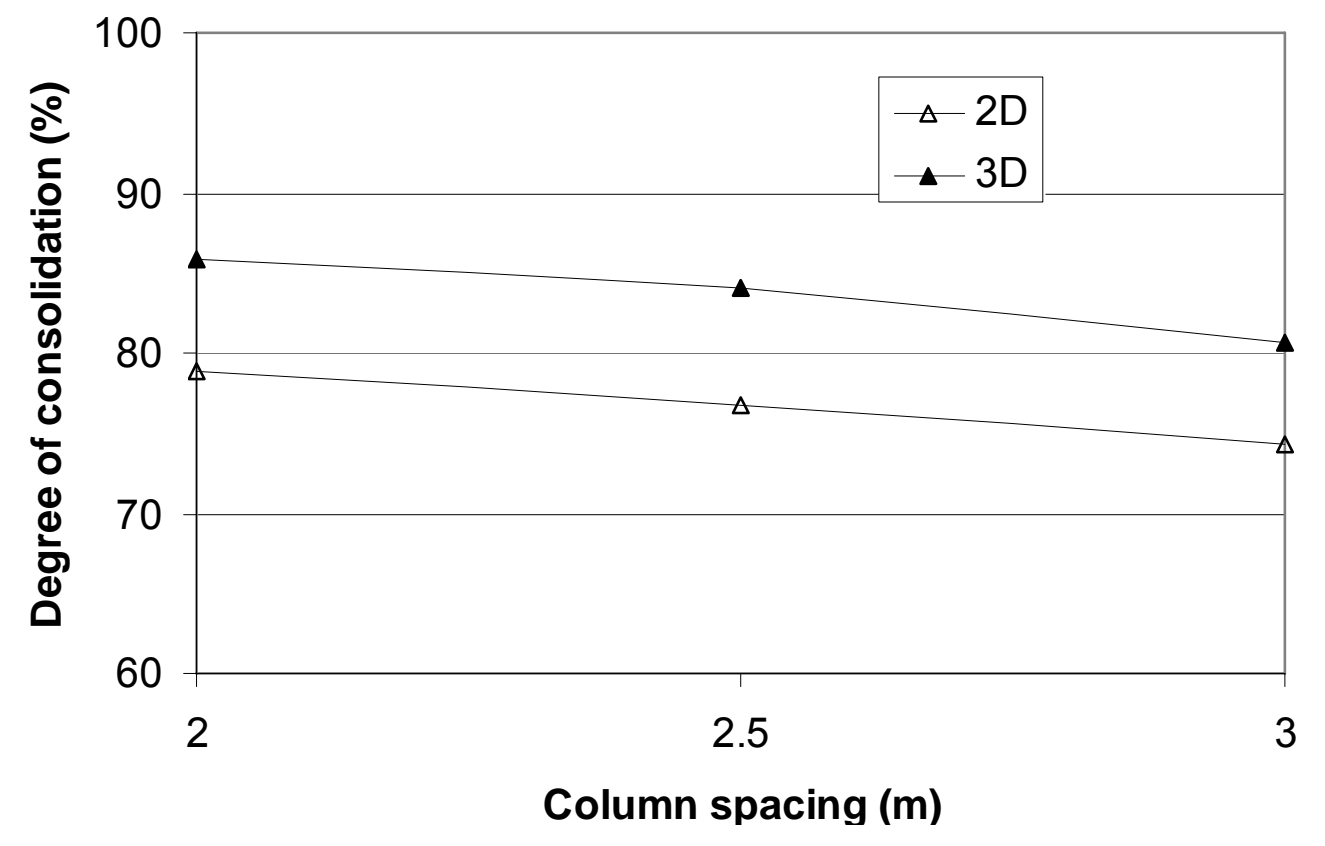

Fig. 6-38. Degree of Consolidation versus Column Spacing under 2D and 3D Conditions

\section{Influence of Geosynthetic Tensile Stiffness}

The degree of consolidation is presented against the geosynthetic tensile stiffness in Fig. 6-39. The increase of the tensile stiffness from 0 to $10,000 \mathrm{kN} / \mathrm{m}$ only led to a decrease in the degree of consolidation by about $1 \%$ under the 3D condition and about $2 \%$ under the $2 \mathrm{D}$ condition. 


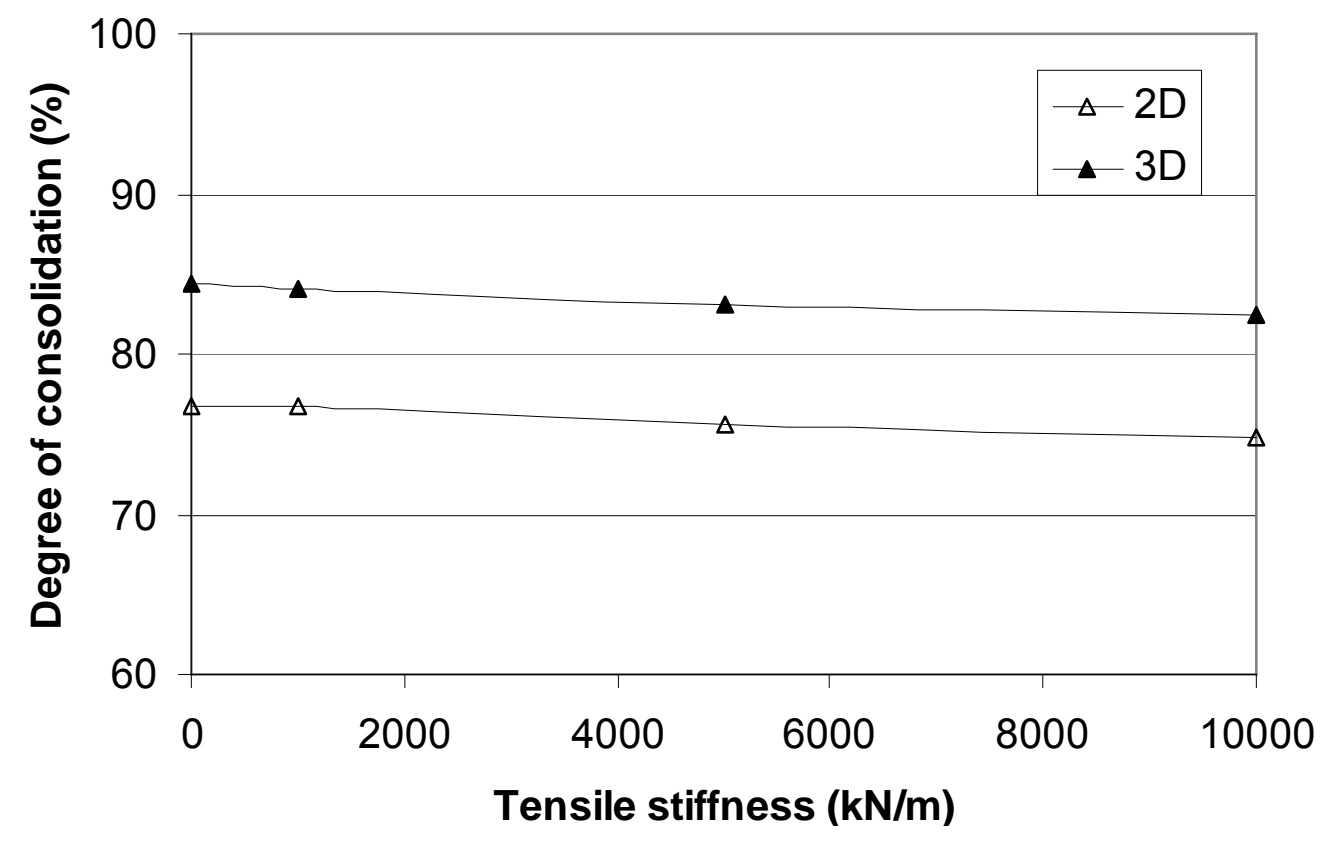

Fig. 6-39. Degree of Consolidation versus Tensile Stiffness under 2D and 3D Conditions

\section{Influence of Construction Rate}

The degree of consolidation is plotted against the average construction rate in Fig. 640. As the average construction rate decreased from 4 to $0.25 \mathrm{~meter} / \mathrm{mon}$, the degree of consolidation increased by approximately $15 \%$ under the $3 \mathrm{D}$ condition and by $23 \%$ under the 2D condition. 


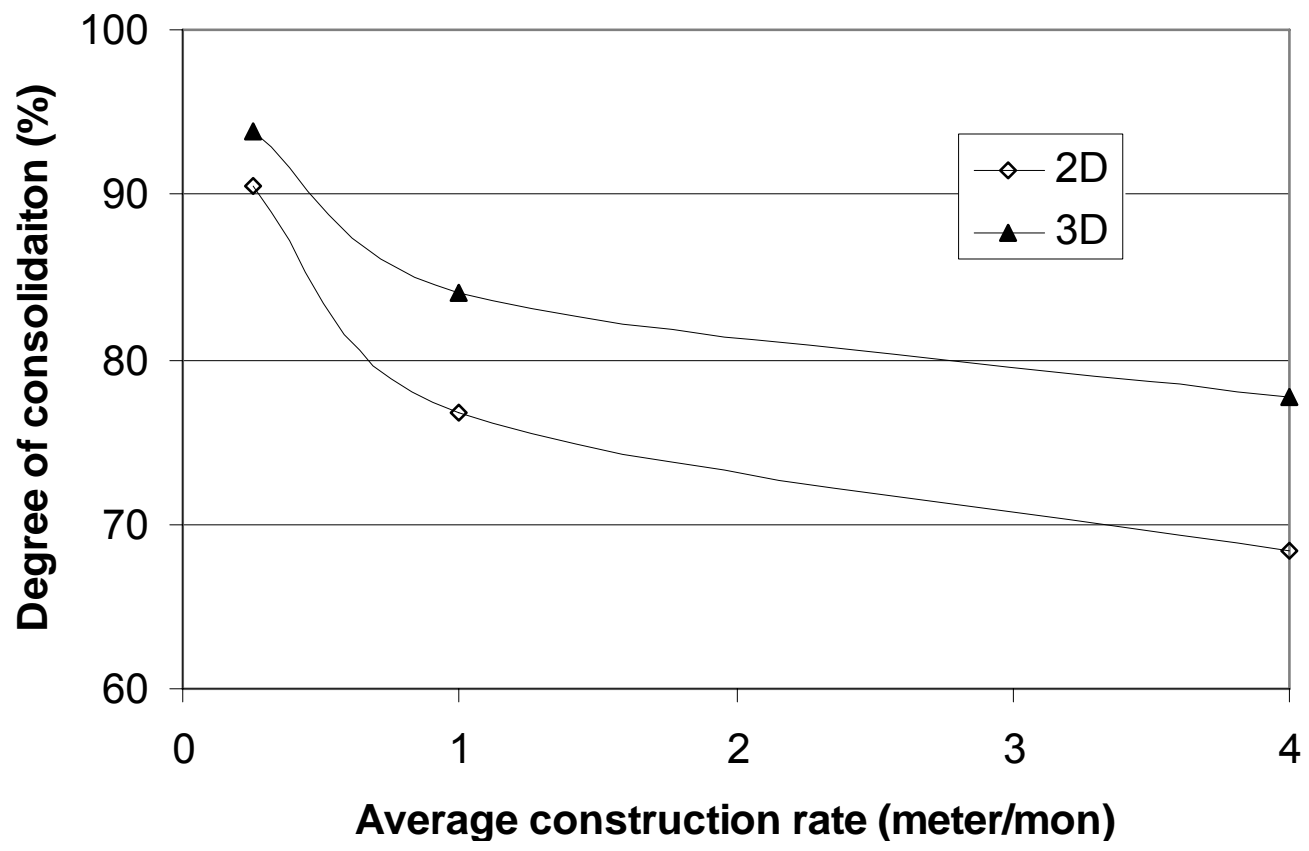

Fig. 6-40. Degree of Consolidation versus Average Construction Rate under 2D and 3D Conditions

\subsubsection{Summary}

The influences of various factors on the maximum settlement, the maximum distortion, the maximum tension, the maximum stress concentration ratio, and the degree of consolidation under 3D and 2D conditions have been compared above. To help the design of GRCS embankments, the influences of the factors are summarized and rated below.

The influence of a factor on the behavioral parameters related to the performance of the GRCS embankment (including the maximum settlement, the maximum distortion, 
the maximum tension, the maximum stress concentration ratio, and the degree of consolidation) is considered positive or negative according to its influence on the serviceability of the GRCS embankment. If the increase of the factor leads to a decrease in the maximum settlement, the maximum distortion or maximum tension, this factor is considered having a positive effect on any of these behavioral parameters; otherwise, this factor is considered having a negative effect on the behavioral parameter. On the other hand, if the increase of the factor leads to an increase in the maximum stress concentration ratio or degree of consolidation, this factor is considered having a positive effect on any of these behavioral parameters; otherwise, this factor is considered having a negative effect on the behavioral parameters. For example, by increasing the soil modulus the maximum settlement decreases, and maximum stress concentration ratio decreases, then the soil modulus is defined to have a positive influence on maximum settlement but a negative influence on maximum stress concentration ratio. The degree of influence of each influence factor on any of the behavioral parameters is defined as ratio of the variation of the behavioral parameter to the mean of the behavioral parameter. For example, under 2D conditions, the maximum settlements at soft soil modulus equal to $1,2,4$, and $8 \mathrm{MPa}$ are $34.69,24.79,20.25$, and $14.87 \mathrm{~mm}$, respectively. The variation of the maximum settlement within the soft soil modulus range investigated is $|34.69-14.87|=19.82$ and the mean of the maximum settlement is $\frac{34.69+14.87}{2}=24.78$. Consequently, the degree of influence of soft soil modulus on the maximum settlement is calculated as 
$\frac{19.82}{24.78} \times 100 \%=80 \%$. The degree of influence on the behavioral parameters is listed in Table 6-1 and 6-2.

Table 6-1. The Degree of Influence under a 3D Condition (\%)

\begin{tabular}{|c|c|c|c|c|c|}
\hline Factors & $\mathrm{S}_{\max }$ & $\mathrm{I}_{\max }$ & $\mathrm{T}_{\max }$ & $\mathrm{n}_{\max }$ & $\mathrm{U}_{\max }$ \\
\hline $\mathrm{E}_{\mathrm{s}}$ & 68 & 120 & 102 & 176 & 7 \\
\hline$\phi$ & 47 & 87 & 30 & 34 & 1 \\
\hline $\mathrm{k}$ & 58 & 81 & 44 & 31 & 35 \\
\hline $\mathrm{E}_{\mathrm{c}}$ & 14 & 9 & 24 & 18 & 8 \\
\hline $\mathrm{s}$ & 75 & 86 & 97 & 60 & 6 \\
\hline $\mathrm{J}$ & 14 & 92 & 168 & 8 & 2 \\
\hline $\mathrm{v}$ & 51 & 76 & 32 & 22 & 19 \\
\hline
\end{tabular}

Table 6-2. The Degree of Influence under a 2D Condition (\%)

\begin{tabular}{|c|c|c|c|c|c|}
\hline Factors & $\mathrm{S}_{\max }$ & $\mathrm{I}_{\max }$ & $\mathrm{T}_{\max }$ & $\mathrm{n}_{\max }$ & $\mathrm{U}_{\max }$ \\
\hline $\mathrm{E}_{\mathrm{s}}$ & 66 & 100 & 131 & 299 & 6 \\
\hline$\phi$ & 25 & 21 & 39 & 25 & 3 \\
\hline $\mathrm{k}$ & 68 & 73 & 54 & 88 & 46 \\
\hline $\mathrm{E}_{\mathrm{c}}$ & 24 & 9 & 3 & 24 & 12 \\
\hline $\mathrm{s}$ & 49 & 57 & 57 & 74 & 6 \\
\hline $\mathrm{J}$ & 8 & 13 & 173 & 29 & 3 \\
\hline $\mathrm{v}$ & 47 & 23 & 37 & 45 & 28 \\
\hline
\end{tabular}

The degree of the influence on any of the behavioral parameters is divided into three levels: high, medium, and low. Since there is no standard to distinguish those levels, the common concept of the significance in geotechnical engineering is adopted, i.e., the degree of influence less than $30 \%$ is considered low; the degree of influence between $30 \%$ and $60 \%$ is considered medium and the degree of influence greater than $60 \%$ is considered high. 
The influence of each factor on each behavioral parameter is presented in Table 6-3 and 6-4. The negative sign (-) indicates negative influence and the positive sign $(+)$ indicates positive influence. The number of negative or positive sign indicates the degree of influence. One sign indicates low influence; two signs indicates medium influence; three signs indicates high influence. For example, one positive sign, i.e., “+”, indicates low positive influence; two negative signs, i.e., "- - -, indicates medium negative influence.

Table 6-3. The Influence of Factors under the 3D Condition

\begin{tabular}{|c|c|c|c|c|c|}
\hline Factors & $\mathrm{S}_{\max }$ & $\mathrm{I}_{\max }$ & $\mathrm{T}_{\max }$ & $\mathrm{n}_{\max }$ & $\mathrm{U}_{\max }$ \\
\hline $\mathrm{E}_{\mathrm{s}}$ & +++ & +++ & +++ & --- & - \\
\hline$\phi$ & ++ & +++ & ++ & -- & - \\
\hline $\mathrm{k}$ & ++ & +++ & ++ & -- & ++ \\
\hline $\mathrm{E}_{\mathrm{c}}$ & + & + & + & + & + \\
\hline $\mathrm{s}$ & --- & --- & --- & --- & - \\
\hline $\mathrm{J}$ & + & +++ & --- & - & - \\
\hline $\mathrm{v}$ & -- & --- & -- & + & - \\
\hline
\end{tabular}

Note: $\mathrm{s}_{\max }-$ maximum settlement, $\mathrm{I}_{\max }-$ maximum distortion, $\mathrm{T}_{\max }-$ maximum tension, $\mathrm{n}_{\max }-$ maximum stress concentration ratio, $\mathrm{U}_{\max }-$ maximum degree of consolidation.

Table 6-4. The Influence of Factors under the 2D Condition

\begin{tabular}{|c|c|c|c|c|c|}
\hline Factors & $\mathrm{S}_{\max }$ & $\mathrm{I}_{\max }$ & $\mathrm{T}_{\max }$ & $\mathrm{n}_{\max }$ & $\mathrm{U}_{\max }$ \\
\hline $\mathrm{E}_{\mathrm{s}}$ & +++ & +++ & +++ & --- & - \\
\hline$\phi$ & + & + & ++ & - & - \\
\hline $\mathrm{k}$ & +++ & +++ & ++ & --- & ++ \\
\hline $\mathrm{E}_{\mathrm{c}}$ & + & + & + & + & + \\
\hline $\mathrm{s}$ & -- & -- & -- & --- & - \\
\hline $\mathrm{J}$ & + & + & --- & - & - \\
\hline $\mathrm{v}$ & -- & - & -- & ++ & - \\
\hline
\end{tabular}




\section{CHAPTER SEVEN}

\section{CONCLUSIONS AND RECOMMENDATIONS}

In the past twenty years, especially in the last few years, various studies have been completed on GRCS embankments, which have greatly improved the understanding of this technology. This study is expected to provide additional knowledge into this topic. The major findings from this study are summarized in this chapter and recommendations for practical applications are made. In addition, possible future studies on this topic are presented at the end of this chapter.

\subsection{Conclusions}

This research was the first comprehensive study that coupled mechanical and hydraulic modeling of GRCS embankments. The behavior and performance of the embankments were investigated in a time domain. This study provided important and useful information on the post-construction settlement and the generation and dissipation of excess pore water pressure. The findings from this study are summarized below.

- The total settlement, the differential settlement, and the distortion at the base of the embankment were much larger than those on the crest for both $2 \mathrm{D}$ and $3 \mathrm{D}$ cases. It is 
misleading to use the base values as the reference to evaluate the serviceability of the GRCS embankment.

- When columns were installed in a square pattern, the differential settlement developed along the direction perpendicular to the traffic direction was much larger than that along the traffic direction. Therefore, more attention should be paid to the differential settlement developed in the direction perpendicular to the traffic direction in practice.

- Obvious difference existed in the maximum settlement, the maximum distortion, the maximum tension, and the degree of consolidation from the $3 \mathrm{D}$ and the converted $2 \mathrm{D}$ analyses. The simplification of a $3 \mathrm{D}$ case into a $2 \mathrm{D}$ case based on the area weighted average approach may not result in a good representation of the 3D case.

- The time-dependent settlement on the crest (i.e., post-construction settlement) was influenced by a number of factors. A coupled mechanical and hydraulic modeling is preferred to accurately estimate the settlement on the crest.

- The consolidation process of the foundation under the GRCS embankment was much faster than that estimated using Terzaghi's one-dimensional consolidation theory because the excess pore water pressure dissipated through drainage and load transfer. 
- According to the results of 2D and 3D parametric study, all the investigated factors had some effect on the maximum settlement on the crest. The type of influence by each factor on the maximum settlement under the 3D condition was the same as that under the $2 \mathrm{D}$ condition. The soft soil modulus had a high positive influence on the maximum settlement under both $2 \mathrm{D}$ and $3 \mathrm{D}$ conditions. The soil permeability had a medium positive influence under $3 \mathrm{D}$ condition but a high positive influence under $2 \mathrm{D}$ condition. The soft soil friction angle had a medium positive influence under 3D condition and had a low positive influence under 2D condition. The column modulus had a low positive influence under 3D and 2D conditions. The column spacing had a high and medium negative influence under 3D and 2D conditions, respectively. The geosynthetic tensile stiffness had a low positive influence under both $3 \mathrm{D}$ and $2 \mathrm{D}$ conditions and the average construction rate had a medium negative influence under both $3 \mathrm{D}$ and $2 \mathrm{D}$ conditions.

- The maximum distortion on the crest is the most important index used to describe the smoothness of the embankment surface. The influence type of each investigated factor on the maximum distortion under the 3D condition was same as that under the 2D condition. However, the degree of influence under the 3D condition might differ from that under the $2 \mathrm{D}$ condition. The soft soil modulus and the soft soil permeability had a high positive effect under both 2D and 3D conditions. The soft soil friction angle had a high and a low positive influence under 3D and $2 \mathrm{D}$ conditions, 
respectively. The column modulus had a low positive influence under both $2 \mathrm{D}$ and 3D conditions. The column spacing had a high negative influence under 3D condition and a medium negative influence under 2D condition. The geosynthetic tensile stiffness had a high and low positive influence under 3D and 2D conditions, respectively. The average construction rate had a high and a low negative influence under $3 \mathrm{D}$ and $2 \mathrm{D}$ conditions, respectively.

- The maximum tension developed in the geosynthetic reinforcement is an important parameter in the material selection. Under the $3 \mathrm{D}$ condition, the maximum tension was always developed along the direction that was perpendicular to the traffic direction. This result was attributed to the lateral movement of the embankment fill. The investigated factors had the same type of influence on the maximum tension under both 2D and 3D conditions. All of the investigated factors had the same degree of influence under 3D conditions as under 2D conditions. The soft soil modulus had a high positive influence under both $2 \mathrm{D}$ and $3 \mathrm{D}$ conditions. The soft soil friction angle and the soft soil permeability had a medium positive influence under both $2 \mathrm{D}$ and 3D conditions. The column modulus had a low positive influence under 2D and 3D conditions. The column spacing had a high and a medium negative influence under $3 \mathrm{D}$ and $2 \mathrm{D}$ conditions, respectively. The geosynthetic tensile stiffness had a high negative influence under both $2 \mathrm{D}$ and $3 \mathrm{D}$ conditions. And the average construction rate had a medium negative influence under both $2 \mathrm{D}$ and $3 \mathrm{D}$ conditions. 
- The stress concentration ratio is used to evaluate the load transfer efficiency. All the factors had the same type of influence on the maximum stress concentration ratio under the $3 \mathrm{D}$ condition as that under the $2 \mathrm{D}$ condition. The soft soil modulus and column spacing had a high negative influence under both 2D and 3D conditions. The column modulus had a low positive influence and the geosynthetic tensile stiffness had a low negative influence under both 2D and 3D conditions. The soft soil friction angle had a medium negative influence under the $3 \mathrm{D}$ condition and a low negative influence under the $2 \mathrm{D}$ condition. The soft soil permeability had a medium negative influence under the 3D condition but a high negative influence under the $2 \mathrm{D}$ condition. The average construction rate had a low positive influence under the 3D condition and a medium positive influence under the 2D condition.

- The degree of consolidation is used to reflect the magnitude of remaining excess pore water pressure after service. The influence type of each factor on the degree of consolidation under the $3 \mathrm{D}$ condition was the same as that under the $2 \mathrm{D}$ condition. The degree of consolidation of each influence factor under the 3D condition was the same as that under the 2D condition. The soft soil modulus, the soft soil friction angle, the column spacing, the geosynthetic tensile stiffness, and the average construction rate had low negative influence. The column modulus had low positive influence and the soft soil permeability had medium positive influence. 
- Among all the factors investigated, the soft soil modulus had a high positive influence on the maximum settlement, the maximum distortion, and the maximum tension, while it had a high negative influence on the maximum stress concentration ratio. It indicates that an increase of soft soil modulus could reduce not only the maximum settlement, the maximum distortion, and the maximum tension but also the required strength of DM columns.

- The geosynthetic tensile stiffness only had a high influence on the maximum tension but had a low influence on the other behavioral parameters under the $2 \mathrm{D}$ condition. This fact indicated that the use of a stiffer geosynthetic reinforcement was not an effective approach to improve the serviceability of the GRCS embankments under the $2 \mathrm{D}$ condition.

- The soft soil permeability had a medium to high influence on the performance indices under both 2D and 3D conditions. The increase of the soft soil permeability could reduce the maximum settlement, the maximum distortion, and the maximum tension but increase the degree of consolidation. In addition, the increase of the soft soil permeability led to a decrease in the maximum stress concentration ratio. In a word, the increase of soil permeability could improve the performance of the GRCS embankments and reduce the required strength of columns. 
- The column modulus had a low influence on all of the behavioral parameters concerned under both 2D and 3D conditions. On the other hand, the column spacing had a medium to high influence on the maximum settlement, the maximum distortion, the maximum tension, and the maximum stress concentration ratio under $2 \mathrm{D}$ and $3 \mathrm{D}$ conditions. It implies that the use of a larger area replacement ratio would be more effective than the use of stronger columns to improve the serviceability of GRCS embankments.

- The soft soil permeability and the average construction rate showed significant influence on the increase in the maximum settlement after construction. However, the maximum differential settlement and the maximum distortion did not consistently increase with consolidation. The variations of the maximum differential settlement and the maximum distortion were insignificant for the cases analyzed in this study except for the cases with low permeability $\left(\leq 10^{-10} \mathrm{~m} / \mathrm{s}\right)$ or a high construction rate ( $>4$ meter/mon).

- The tension in the geosynthetic reinforcement did not vary significantly with the consolidation after the construction based on the cases investigated in this study except for the case having low soil permeability $\left(\leq 10^{-10} \mathrm{~m} / \mathrm{s}\right)$ or a high construction rate $(\geq 4 \mathrm{~m} / \mathrm{mon})$. 
- Lower soil permeability and/or higher construction rate led to an increased immediate settlement due to induced local failure.

- GRCS embankments over columns in a square pattern showed higher tendency of lateral movement than those over walls.

\subsection{Recommendations}

The following recommendations can be made from this study:

1. Three-dimensional analyses are recommended when columns are installed in a square pattern since a converted 2D model may yield inaccurate results.

2. The settlements on the crest of the embankment should be used to evaluate its serviceability instead of those at the base.

3. It is important to minimize excess pore water pressure developed during the construction of the embankment since high excess pore water pressure increases not only the post-construction settlements but also the immediate settlements. A low construction rate may be adopted to reduce the accumulation of excess pore water pressure for foundation soils having low permeability. 
4. Geosynthetic reinforcement should be used when columns are installed in a square pattern in a large spacing.

\subsection{Future Work}

The following issues may be considered for future work:

1. Most studies including the study in this dissertation have assumed a pseudo-static load to simulate the traffic load. It is more realistic to model the traffic load as cyclic loading, which is expected to have influences on the generation and dissipation of the excess pore water pressure and the settlement.

2. In addition to the wall and square patterns of columns, the triangular, rectangular, and wall patterns along the direction perpendicular to the traffic direction are used in practice. It would be useful to evaluate the effectiveness of these patterns.

3. GRCS embankments may be used with other ground improvement technologies, such as wick drains. The use of wick drains can accelerate the consolidation process. This combined technology should be further investigated. 
4. The installation of columns may lead to disturbance on foundation soil and generate excess pore water pressure. The generated pore water pressure is expected to affect the behavior of GRCS embankments. The influence of installation should be studied in 2D and 3D numerical modeling in the future.

5. In this study, the embankment fill was modeled as a linearly elastic perfectly plastic material. However, the mechanical properties of the embankment fill are typically stress-dependent. This effect should be investigated in the future study.

6. In this study, the soft soil was modeled as a linearly elastic perfectly plastic material. In a future study, Cam-Clay model may be used to investigate the influence of other factors, such as over consolidation ratio (OCR), ground water table depth and so on, on GRCS embankment performance. 


\section{REFERENCES}

Agaiby, S. W. and Jones, C. J. F. P. (1995). "Design of reinforced fill systems over voids" Canadian Geotechnical Journal, 32(6), p 939-945.

Alamgir, M., Miura, N., Poorooshasb, H. B. and Madhav, M. R. (1996). "Deformation analysis of soft ground reinforced by columnar inclusions." Computers and Geotechnics, 18(4), p 267-290.

Alexiew, D. and Gartung, E. (1999). “Geogrid reinforced railway embankment on piles-performance monitoring 1994-1998.” Proc. of Geossinteticos’99, Rio de Janeiro, Brazil, p 403-411.

Alzamora, D. Wayne, M. H. and Han, J. (2000). "Performance of SRW supported by geogrids and jet grout columns." Proceedings of ASCE Specialty Conference on Performance Confirmation of Constructed Geotechnical Facilities, Geotechnical Special Publication No. 94, ASCE, p 456-466.

Barksdale, R. D. and Dobson, T. (1983). "Improvement of marginal urban sites using stone columns and rigid concrete columns." The $34^{\text {th }}$ Annual Highway Geology Symposium and Field Trip at Stone Mountain, GA, 16p.

Bedesem, W. B. (1964). A Continuum Theory of Soil-Structure Interaction in Granular Media. Ph.D. Thesis, University of Illinois-Urbana Champaign.

Bell, A. L., Jenner, C., Maddison, J. D. and Vignoles, J. (1994). "Embankment support using geogrids with vibro concrete columns." Proceedings, 5th 
International Conference on Geotextiles, Geomembranes, and Related Products, p 335-338.

Biot, M. A. (1956) "General solutions of the equations of elasticity and Cconsolidation for a porous material." J. Appl. Mech., Trans. ASME, 78, p 91-96.

Blumel, W., Heinemann, M., Werth, K. and Muller, K. D. (2004). "Road construction on a landfill with vibro concrete columns and geogrids." Proc. Euro Geo3, Geosynthetic Conference, March 1-3, Munich, Germany, p 273-278.

Bonaparte, R. and Christoper, B. (1987). "Design and construction of reinforced embankments over weak foundations." Transportation Research Record, n 1153, p 26-39.

Bonaparte, R., Holtz, R. D. and Giroud, J. P. (1985). "Soil reinforcement design using geotextiles and geogrids." ASTM Symposium Geotextile Testing and the Design Engineering, Los Angeles, Calif., July.

Borges, J. L. and Cardoso, A. S. (2001). "Structural behavior and parametric study of reinforced embankment on soft clays." Computer and Geotechnics, 28(3), p 209233.

Brandl, H., Gartung, E., Verspohl, J. and Alexiew, D. (1997). "Performance of a geogrid-reinforced railway embankment on piles." Proc. of the $14^{\text {th }}$ ICSMFE, Hamburg, 3, p 1731-1736.

British Standard Institution. (1995). BS8006 Code of Practice for Strengthened/ Reinforced Soils and Other Fills. London, U.K.. 
Broms, B. B. and Wong, I. H. (1985). "Embankment piles." Third International Geotechnical Seminar-Soil Improvement Methods, Singapore, Nov. p 27-29.

Bruce, D. A. (2001). An Introduction to the Deep Mixing Methods as Used in Geotechnical Applications - Volumne III: The Verification and Properties of Treated Ground. FHWA-RD-99-167, 455p.

Budhu, M. (2000). Soil Mechanics and Foundations. New York: John Wiley, 586p.

Card, G. B. and Carter, G.R. (1995). "Case history of a piled embankment in London's Docklands." Engineering Geology of Construction, Geological Society Engineering Geology Special Publication No. 10, p 79-84.

Carlsson, B. (1987). Reinforced soil, principles for calculation. Terratema AB, LinkÖping.

Chelapati, C. V. (1964). "Arching in soil due to the deflection of a rigid horizontal strip." Technical Note N-591, U.S. Naval Civil Engineering Laboratory, Port Hueneme, Calif., October.

Chen, R.P., Chen, Y.M., Han, J. and Xu, Z.Z. (2006). “A theoretical solution for pilesupported embankments on soft soil." Submitted for possible publication in Canadian Geotechnical Journal.

Chen, R. P., Chen, Y. M. and Xu, Z. Z. (2006). "Interaction of rigid pile-supported embankment on soft soil." Geotechnical Special Publication, n 151, Proceedings of GeoShanghai Conference, p 231-238. 
Chen, R. P., Jia, N. and Chen, R. P. (2004). "Soil arching analysis of pile-supported embankment." China Journal of Highway and Transportation, 17(4), p 1-6. (in Chinese)

Chen, Sheng-Li, Zhang, Bing-Yin, Zhang, Jian-Min and Yin, Kun-Ting (2005). "Centrifugal modeling of reinforced embankment on soft clay." Yanshilixue Yu Gongcheng Xuebao/Chinese Journal of Rock Mechanics and Engineering, 24(15), Aug. 1, p 2751-2756. (in Chinese)

Chew, S. H., Phoon, H. L., Loke, K. H. and Lim, L. K. (2004). "Geotextile reinforced piled embankment for highway bridges." $8^{\text {th }}$ International Conference on Advanced Technology on Transportation Engineering, Beijing, China, May 26$28, \mathrm{p} 438-443$.

Chow, Y. K. (1996). "Settlement analysis of vertical loaded stone columns in soft ground." Soil and Foundation, 36(1), p 111-113.

Cochrane, S. R. and Bell, A. L. (1981). "Settlement behaviour of a test foundation slab founded on soft clay." Ground Movements and Structures, Proceedings of the 2nd International Conference, p 638-654.

Collin, J. G. (2003). Column Supported Embankments Technical Summary \# 10, 65p.

Collin, J. G. (2004). "Column supported embankment design consideration." Proc. of the 52 Annual Geotechnical Engineering Conference, J.F. Labuz and J.G. Bentler (eds.) p 51-78. 
Crowe, R. E., Bathurst, R. J. and Alston, C. (1999). "Design and construction of a road embankment using geosynthetics." Canadian Geotechnical Conference, Oct 23-25, Winnipeg, Manit, Canada, p 266-271.

Das, B. M. (2001). Principles of Geotechnical Engineering, fifth edition, Brooks/Cole, Pacific Grove, CA, 589p.

Demerdash, M. A. (1996). An Experimental Study of Piled Embankments Incorporating Geosynthetic Basal Reinforcement. Ph.D. Dissertation, University of Newcastle-Upon-Type, 158p.

Dubois, D. D. and Bell, A. L. (1982). "Fabric reinforced trial embankment." Quarterly Journal of Engineering Geology, 15(3), p 217-225.

Dunnicliff, J. (1988). Geotechnical Instrumentation for Monitoring Field Performance, Wiley, 608p.

EPRI (1990). Manual on Estimating Soil Properties for Foundation Design, Cornell University, Ithaca, 327p.

Fei, K., Liu, H.-L. and Gao, Y.-F. (2004). "Settlement differential analysis of PCC rigid pile composite ground under road embankment loading." Yantu Lixue/Rock and Soil Mechanics, 25(8), Aug., p 1244-1248. (in Chinese)

Filz, G. M. and Smith, M. E. (2005). Design of Bridging Layers in GeosyntheticReinforced, Column-Supported Embankments, Final Contract Report, 40p.

Finn, W. D. L. (1960). Stresses in Soil Masses under Various Boundary Conditions. Ph.D. Dissertation, Seattle, the University of Washington. 
Finn, W. D. L. (1963). "Boundary value problems of soil mechanics." Journal of the Soil Mechanics and Foundation Division, ASCE, 89(SM5), p 39-72.

Fluet, J.E., Christopher, B.R. and Slater, A.R. (1986). "Geosynthetic stress-strain response under embankment loading condition." Proc. 3rd Int. Conf. on Geotextiles, Vienna, Vol. 1, p 175-180.

Forsman, J. (2001). Geovahvistetutkimus, Helsinki, 122p (in Finnish).

Forsman, J., Honkala, A. and Smura, M. (1999). "Hertsby case: A column stabilized and geotextile reinforced road embankment on soft subsoil." Dry Mix Method for Deep Soil Stabilization, Bredenberg, Holm, and Broms (eds), Balkema, Rotterdam, p 263-268.

Gabr, M., Dodson, R. and Collin, J. (1998). "A study of stress distribution in geogrid reinforced sand." Geotechnical Special Publication, p 62-76.

Gabr, M. and Han, J. (2005). "Geosynthetic reinforcement for soft foundations: US perspectives." Geotechnical Special Publication, Geo-Frontiers, n 130-142, p 3095-3114.

Getzler, Z., Komornik, A. and Mazurik, A. (1968). "Model study on arching above buried structures." Journal of the Soil Mechanics and Foundation Division, ASCE, 94(SM5), p 1123-1141.

Giroud, J. P., Bonaparte, R., Beech, J. F. and Gross, B. A. (1990). "Design of soil layer-geosynthetic systems overlying voids." Geotextile and Geomembrane, Elsevier, 9(1), p 11-50. 
Goh, A. T. C., Teh, C. I. and Wong, K. S. (1997). "Analysis of piles subjected to embankment induced lateral soil movements." Journal of Geotechnical and Geoenvironmental Engineering, 123(9), p 792-801.

Goughnour, R. R. (1983). "Settlement of vertical loaded stone columns in soft ground." Proceedings of the Europe Conference on Soil Mechanics and Foundation Engineering $8^{\text {th }}$, Helsinki, Finland, p 235-240.

Gourc, J. P. and Villard, P. (2000). "Reinforcement by membrane effect: application to embankment on soil liable to subsidence." Keynote lectures, NGM-2000 and $4^{\text {th }}$ GIGS Helsinki 2000, H. Rathmayer (ed.), Building Information Ltd, Helsinki, p 25-42.

Guido, V.A., Knueppel, J. D. and Sweeny, M.A. (1987). "Plate loading test on geogrid-reinforced earth slab." Geosynthetic 87 Conference New Orleans, p 216-225.

Habib, H.A.A., Brugman, M.H.A. and Uijting, BG.J. (2002). "Widening of Road and pile-supported mattress on piles." Proceedings, Geosynthetic-7th ICG, Delmas, Gourc, \& Girard (eds), Lisse: Swets \& Zeitlinger, p 369-72.

Han, J. (1999). "Design and construction of embankments on geosynthetic reinforced platforms supported by piles." Proceedings of 1999 ASCE/PaDOT Geotechnical Seminar, Central Pennsylvania Section, ASCE and Pennsylvania Department of Transportation, Hershey, PA.

Han, J. (2003) Development of Design Charts for Geosynthetic Reinforced Embankment on Deep Mixed Columns. Interim. Report I., 118p. 
Han, J. and Akins, K. (2002). "Case studies of geogrid-reinforcement and pilesupported earth structure on weak foundation soils." Proc. of International Deep Foundation Congress, Geotechnical Special Publication, No. 116-Deep Foundation 2002, edited by O'Neill and Towsend, ASCE, Orlando, p 668-679.

Han, J. and Akins, K. (2002). "Use of geogrid-reinforced and pile supported earth structure.” Geotechnical Special Publication, n 1161, Feb 14-16, Orlando, FL.

Han, J. and Collin, J. G. (2005). "Geosynthetic support systems over pile foundations." Geotechnical Special Publication, Geo-Frontiers, n130-142, 2005, p 3939-3953.

Han, J. and Gabr, M. A. (2002). "Numerical analysis of geosynthetic-reinforced and pile-supported earth platform over soft soil." Journal of Geotechnical and Geoenvironmental Engineering, 128(1), Jan, p 44-53.

Han, J., Huang, J. and Porbaha, A. (2005). "2D numerical modeling of a constructed geosynthetic-reinforced embankment over deep mixed columns." Geotechnical Special Publications, n 130-142, Geo-Frontiers 2005, p 511-521.

Han, J. and Shelth, A. R. (2003). Development of Design Charts for Geosynthetic Reinforced Embankment on Deep Mixed Columns. Interim. Report II., 96p.

Han, J. and Ye, S. L. (2001). "Simplified method of consolidation rate of stone column reinforced foundation." Journal of Geotechnical and Geoenvironmental Engineering, 127(7), Jun, p 597-603.

Handy, R. L. (1985) 'The arch in soil arching.' Journal of Geotechnical Engineering, ASCE, Vol. 111, p 302-318. 
Harrop-Williams, K. (1989). “Arch in soil arching.” Journal of Geotechnical Engineering, Mar, 115(3), p 415-419.

Haza, E., Gotteland, P. and Gourc, J. P. (2000). "Design method for local load on a geosynthetic reinforced soil structure." Geotechnical and Geological Engineering, 18(4), 2000, p 243-267.

Hewlett, W. J. and Randolph, M. F. (1988). "Analysis of piled embankments." Ground Engineering, 21(3), p 12-18.

Hinchberger, S. D. and Rowe, R. K. (2003). "Geosynthetic reinforced embankments on soft clay foundation: predicting reinforcement strain at failure." Geotextiles and Geomembranes, 21(3), p 151-175.

Horgan, G. J. and Sarsby, R.W. (2002). "The arching effect of soils over voids and piles incorporating geosynthetic reinforcement." Proceedings, Geosynthetic- $7^{\text {th }}$ ICG, Delmas, Gourc, \& Girard (eds), Lisse: Swets \& Zeitlinger, p 373-78.

Hu, H. R., Chen, S. -L. and Shen, Z. -J. (2003). "Centrifugal and numerical modeling of geosynthetic reinforced embankment on soft clay." Yantu Lixue/Rock and Soil Mechanics, 24( 3), Jun, p 389-394. (in Chinese)

Huang, W. X. (1983). Engineering Properties of Soil, China WaterPower Press, Beijing, China, p 481.

Huang, J., Han, J. and Collin, J. G. (2005). "Geogrid-reinforced piled supported railway embankment-three dimensional numerical analysis." Transportation Research Record, No. 1936, p 221-229.

Itasca (2002). Fluid-mechanical Interation. 161p. 
Jacky, J. (1944). "The coefficient of earth pressure at rest." Journal for Society of Hungarian Architects and Engineers, Budapest, Oct. P 355-358. (in Hungarian)

Janssen, H. A. (1895). "Versuche uber getreidedruck in silozellen." Z. Ver. Deut. Ingr., vol 39, 1895, p. 1045 (partial English translation in Proceedings of the Institute of Civil Engineers, London, England, 1896, 553p).

Jenner, C. G., Austin, R.A. and Buckland, D. (1998). "Embankment support over piles using geogrids." Proceedings of 6th International Conference on Geosynthetics Vol. 1, p 763-66.

Jia, N. (2004). Research on Settlement Behavior of Highway Widening on Soft Soil and Improvement Method. Ph.D. Dissertation, Zhejiang Universty. (in Chinese)

John, N. W. M. (1987). Geotextiles. Blackie, Glasgow and London

Jones, C. J. F. P., Lawson, C. R. and Ayres, D. J. (1990). “Geotextile reinforced piles embankment." Proceedings, 5th International Conference on Geotextiles, Geomembrane, and Related Products, 1990, p 155-160.

Kempfert, H.-G., Göbel, C., Alexiew, D. and Heitz, C. (2004). "German recommendation for reinforced embankments on pile-similar elements." EuroGeo3-Third European Geosynthetic Conference, Geotechnical Engineering with geosynthetics, p 279-284.

Kempfert, H.-G., Stadel, M. and Zaeske, D. (1997). "Design of geosyntheticreinforced bearing layers over piles." Bautechnik 74, Heft 12, p 818-825. 
Kempton, G., Russell, D., Pierpoint, N.D. and Jones, C. J. F. P. (1998). "Two- and three-dimensional numerical analysis of the performance of piled embankments." Proceedings, 6th International Conference on Geosynthetics, p 767-772.

Kezdi, A. (1975). “Lateral earth pressure.” In Foundation Engineering Handbook, ed. H.F. Winterkorn \& H. Y. Fang. Van Nostrand Reinhold, New York, p 197-220.

Koerner, G. R., Koerner, R. M. and Elias, V. (1993). "Geosynthetic installation damage under two different backfill conditions.” ASTM Special Technical Publication, n 1190, p 163-183.

Koerner, R. M. (2005). Designing with Geosynthetics, $5^{\text {th }}$, Prentice Hall, 796p.

Krynine, D. P. (1945). Discussion of "Stability and stiffness of cellular cofferdams." by Karl Terzaghi, Transactions, ASCE, vol. 110, p 1175-1178.

Lawson, C. R. (1992). "Soil reinforcement with geosynthetics." Applied Ground Improvement Techniques,Southeast Asian Geotechnical Society (SEAGS), p 5574.

Love, J. and Milligan, G. (2003). "Design methods for basally reinforced pilesupported embankments over soft ground." Ground Engineering, March, p 3943.

Low, B. K. and Duncan, J. M. (1985). "Analysis of the behavior of reinforced embankments on weak foundations." Report VPI/CE-GT-85-11, Virginia Polytechnic Institute, Blacksburg, Oct.

Low, B. K., Tang, S. K. and Choa, V. (1994). "Arching in piled embankment." Journal of Geotechnical Engineering, ASCE, 120(11), p 1917-1938. 
Magnan, J. (1994). "Methods to reduce the settlement of embankments on soil clay: a review." Foundations and Embankment Deformations, ASCE, Geotechnical Special Publication No. 40, p 77-90.

Mandal, J. N. and Joshi, A. A. (1996) "Design of geosynthetic reinforcements on soft soil." Geotextiles and Geomembranes, 14(2), Feb, p 137-145.

Marston, A. and Anderson, A. O. (1913). "The theory of loads on pipes in ditches and tests of cement and clay drain tile and sewer pipe" Bulletin No. 31, Iowa Engineering Experiment Station, Ames, Iowa.

Marston, A. (1929). "The theory of external loads on closed conduits in the light of the latest experiments." Highway Research Board - Proceedings, Dec 12-13, p138-170.

Marston, A. (1930). "The theory of external loads on closed conduits in the light of latest experiments.” Bulletin No. 96, Iowa Engineering Experiment Station, Ames, Iowa.

McKelvey III, J. A. (1994) "The anatomy of soil arching." Geotextiles and Geomembranes, Vol. 13, p 317-329.

McNulty, J. W. (1965). “An experimental study of arching sand.” Technical Report No. I-674, U.S. Army Engineer Waterways Experiment Station, Corp of Engineers, Vicksburg, Mississippi, 170p.

Miura, N. and Madhav, M. R. (1994) "Engineering of ground on lowlands." Proc. of the Symposium on Developments in Geotechnical Engineering: from Harvard to New Delhi, Thailand, Jan 12-16, p 6-51—6-62. 
Naughton, P. J. and Kempton, G. T. (2005). "Comparison of analytical and numerical analysis design methods for piles embankment." Geotechnical Special Publication, Geo-Frontiers 2005, p 487-496.

Ohkubo, T., Asada, S. and Karube, D. (1996). "A study on the reinforcing effects of geogrids over laid on piling group for the embankment foundations." Earth Reinforcement, Ochiai, Yasufuku, and Omine (eds.), Balkema, Rotterdam, p 641646.

Othman, M. Z. and Pyrah, I C. (1996). "Experimental and computer simulation of piled embankment behavior." Proc. of the 1996 1st International Conference on Computational Methods and Testing for Engineering Integrity, Mar 19-21, p 247.

Palmeira, E. M., Pereira, J. H. F. and da Silva, A. R. L. (1998). "Backanalyses of geosynthetic reinforced embankments on soft soils." Geotextiles and Geomembranes, Elsevier Science, 16(5), Oct., p 273-293.

Poorooshasb, H. B. (1991). "Load settlement response of a compacted fill layer supported by a geosynthetic overlying a void." Geotextiles and Geomembranes, Elsevier Science 10 (3), p 179-201.

Poorooshasb, H. B. (2002). "Subsidence evaluation of geotextile-reinforced gravel mats bridging a sinkhole." Geosynthetics International, 9(3), p 259-282.

Poorooshasb, H. B., Alamgir, M. and Miura, N. (1996). "Application of an integrodifferential equation to the analysis of geotechnical problems." Structural Engineering and Mechanics, 4(3), p 227-242. 
Rathmayer, H. (1975). "Piled embankment supported by single pile caps." Proc., Conf. on Soil Mechanics and Foundation Engineering, Istanbul, Mar. 31-Arpil 4, p 283-290.

Rehnman, S.E., Eriksson, U.B. and Jendeby, L. (1999). "Embankment on soft soil, interaction between embankment, reinforcement and piles. Long term measurement at Urvalla, Sweden.” Geotechnical Engineering for Transportation Infrastructure, Barends el al. (eds), Balkema, Rotterdam, p 1-6.

Reid, W. M. and Buchanan, N. W. (1984). "Bridge approach support piling.” Proc. of Conf. on Piling and Ground Treatment. Paper 21, Thomas Telford, London, p 267-274.

Rogbeck, Y., Gustavsson, S., Södergren, I. and Lindquist, D. (1998). "Reinforced piled embankments in Sweden-design aspects.” Proc. 1998 Sixth International Conference on Geosynthetics, p 755-762.

Rowe, R. K. (1984). "Reinforced embankment: Analysis and design.” Journal of Geotechnical Engineering Division, ASCE, 110(GT2), p 231-246.

Rowe, R. K. and Soderman, K. L. (2001). "Comparison of predicted and observed behavior of two test embankment." Geotextiles and Geomembanes, 1(2), p 143160.

Russell, D. and Pierpoint, N. (1997) “An assessment of design methods for piled embankments." Ground Engineering, 30(11), 1997, p 39-44. 
Russell, D., Naughton, P.J. and G. Kempton, G. (2003). “A new design procedure for piled embankments." Proceedings of the 56th Canadian Geotechnical Conference and the NAGS Conference, $\mathrm{p}$ 858-865.

Schmertmann, J. H. (1991). A new, empirically based, arching theory and method for the design loading of a geogrid supporting overburden and spanning a void. Schmertmann \& Crapps, Inc., October.

Spangler, M. G. and Handy, R. L. (1982). Soil Engineering, Happer \& Row, Publishers, New York, p 727-763.

Steward, M. E. Navin, M. P., and Filz, G. M. (2004). "Analysis of a columnsupported test embankment at the I-95/Route 1 interchange." Proceedings of GeoTrans 2004, Geotechnical Engineering for Transportation Projects, ASCE, 2004, p 1337-1346.

Svanø, G., Ilstad, T., Eiksund, G. and Want, A. (2000). "Alternative calculation principle for design of piled embankments with base reinforcement." Proc. 4th International Conference on Ground Improvement Geosystems, Helsinki, June, p 541-548.

Terzaghi, K. (1936). "Stress distribution in dry and in saturated sand above a yielding trap door." Proc. of the First International Congress on Soil Mechanics and Foundation Engineering, Cambridge, Mass., June, 1, p 307-311.

Terzaghi, K. (1943). Theoretical Soil Mechanics, John Wiley \& Sons, New York, $510 \mathrm{p}$. 
van Eekelen, S. J. M., Bezuijen, A. and Oung, O. (2003). "Arching in piled embankments: experiments and design calculations." BGA International Conference on Foundations, Innovations, Observations, Design and Practice, Dundee, United Kingdom, Sep. 2-5, p 885-894.

Topolnicki, M. (1996). "Case history of a geogrid-reinforced embankment supported on vibro concrete columns." Proceedings, Geosynthetics: Applications, Design and Construction, De Groot, De Hoedt, and Termaat (eds), p 333-340.

Vega-Meyer, R. and Shao, Y. (2005). "Geogrid-reinforced and pile supported roadway embankment." Geotechnical Special Publication, Geo-Frontiers 2005, Jan 24-26, p 461-473.

Villard, P., Gourc, J. P. and Giraud, H. (2000). "Geosynthetic reinforcement solution to prevent the formation of localized sinkholes." Canadian Geotechnical Journal, 37(5), p 987-999.

Weng, S. and Ma, D. S. (2001). "Effect of the geotextile-reinforced sand cushion on the deformation and stability under an embankment." Rock and Soil Mechanics, 122 (1), p 42-46. (in Chinese)

Whitman, R. V., Getzler, Z. and Hoeg, K. (1963). "Tests upon thin domes buried sand.” Boston Society of Civil Engineers - Journal, 50(1), Jan. p 1-22.

White, D. (2005). "The overriding aspects of the design of geosynthetic-reinforced pile supported embankments." Geotechnical Special Publication, Geo-Frontier 2005, n 130-142, p 475-486. 
Willibey, G. and van't Hoog, L. S. (1987). “Design optimization of geosynthetic reinforced embankment over soft foundations." Geotextiles and Geomembranes, 6(1-3), p 185-195.

Wood, H., Horgan, G. and Pedley, M. (2004). “A63 Selby bypass - Design and construction of a 1.6kM geosynthetic reinforced piled embankment." Proc. Euro Geo3, Geosynthetic Conference, March 1-3, Munich, Germany, p 299-304.

Wu, J. T. H., Siel, B. D., Chou, N. N. S. and Helwany, H. B. (1992). "Effectiveness of geosynthetic reinforced embankments constructed over weak foundations." Geotextiles and Geomembranes, 11(2), p 133-150.

Yankelevsky, D. Z. (1983). “Analysis of Arching in granular medium above a buried strip." Proceedings of the Seventh Asian Regional Conference on Soil Mechanics and Foundation Engineering, v 1, p 393-397.

Yan, L., Yang, J. S. and Han, J. (2005). “Geosynthetic-reinforced pile-supported earth platform composite foundation.” Yantu Lixue/Rock and Soil Mechanics, 26(2),, p 265-269. (in Chinese)

Yan, S. W., Zhou, H. J., Cui, W. and Feng, S. Z. (2005). "Study on geogridreinforced and pile-supported embankment over gulch weak subsoil." Yantu Lixue/Rock and Soil Mechanics, 26(4), April, p 633-637. (in Chinese)

Young, L. W., Milton, M. N., Collin, J. G. and Drooff, E. (2003). "Vibro-concrete columns and geosynthetic reinforced load transfer platform solve difficult foundation problem." Proceedings for 22nd World Road Congress, South Africa. 
Zeng, K. H., Yu, J. L. and Gong, X. N. (2004). “Analysis of performance of LSC pile composite ground under the load from embankment." Zhejiang Daxue Xyebao/Journal of Zhejiang University (Engineering Science), 38(2), Feb, p $185-$ 190. (in Chinese) 